Steffen Meyer

Zwischenstaatliche

Finanzzuweisungen im

zusammenwachsenden

Europa 


\section{Zwischenstaatliche Finanzzuweisungen im zusammenwachsenden Europa}

Das Erkenntnisinteresse dieser Arbeit gilt der Notwendigkeit und Geeignetheit der Vergabe von Finanzzuweisungen zwischen den Mitgliedstaaten der Europäischen Union. Es wird der Frage nachgegangen, welche Wohlfahrtseffekte durch ein europäisches Finanzausgleichsystem ausgelöst werden. Da der europäische Integrationsprozeß vielgestaltigen Einfluß auf die sozio-ökonomischen Lebenslagen der Bevölkerung nimmt, wird ein Referenzrahmen entworfen, der es erlaubt, über ökonomische Kriterien hinaus auch sozio-kulturelle, rechtliche und politische Abwägungskalküle zur Bewertung der Finanzzuweisungen heranzuziehen. Die Untersuchung verdeutlicht, daß es berechtigte Argumente für einen europäischen Finanzausgleich gibt. Es zeigt sich aber auch, daß Fehlentwicklungen nicht auszuschließen sind. Ein Urteil über die Wohlfahrtseffekte der Finanzzuweisungen erfordert daher eine differenzierte (Einzelfall-)Analyse.

Steffen Meyer, geboren 1968 in Nürnberg, studierte von 1988 bis 1994 Volkswirtschaftslehre in Milledgeville, USA (Georgia College \& State University), und an der Universität Würzburg. Anschließend war er Wissenschaftlicher Mitarbeiter am Lehrstuhl für Finanzwissenschaft der Universität Würzburg. 1999 schloß er an der dortigen Wirtschaftswissenschaftlichen Fakultät das Promotionsverfahren ab. Der Autor ist Referent in der Abteilung für Grundsatzfragen der Wirtschafts- und Finanzpolitik des Bundesministeriums der Finanzen. 


\section{Zwischenstaatliche Finanzzuweisungen im zusammenwachsenden Europa}




\section{FINANZWISSENSCHAFTLICHE SCHRIFTEN}

Herausgegeben von den Professoren

Albers, Krause-Junk, Littmann, Oberhauser, Pohmer, Schmidt

Band 97

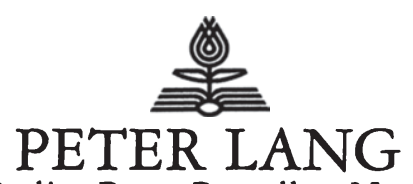

Frankfurt am Main - Berlin · Bern - Bruxelles - New York · Oxford - Wien 


\section{Steffen Meyer}

\section{Zwischenstaatliche Finanzzuweisungen im zusammenwachsenden Europa}

Zur Gestaltung eines Finanzausgleichs für die Europäische Union

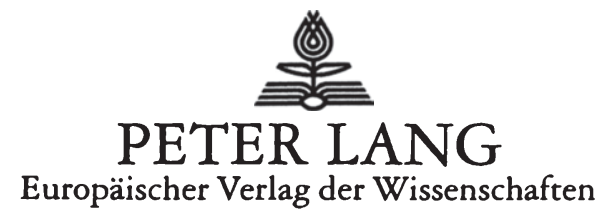


Die Deutsche Bibliothek - CIP-Einheitsaufnahme

Meyer, Steffen:

Zwischenstaatliche Finanzzuweisungen im zusammenwachsenden Europa : zur Gestaltung eines

Finanzausgleichs für die Europäische Union / Steffen Meyer. Frankfurt am Main ; Berlin ; Bern ; Bruxelles ; New York ;

Oxford ; Wien : Lang, 2000

(Finanzwissenschaftliche Schriften ; Bd. 97)

Zugl.: Würzburg, Univ., Diss., 1999

ISBN 3-631-36077-0

Open Access: The online version of this publication is published on www.peterlang.com and www.econstor.eu under the international Creative Commons License CC-BY 4.0. Learn more on how you can use and share this work: http://creativecommons. org/licenses/by/4.0.

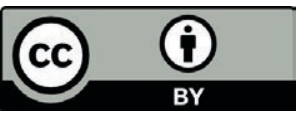

This book is available Open Access thanks to the kind support of ZBW - Leibniz-Informationszentrum Wirtschaft.

Gedruckt auf alterungsbeständigem, säurefreiem Papier.

\author{
D 20 \\ ISSN 0170-8252 \\ ISBN 3-631-36077-0 \\ ISBN 978-3-631-75269-2 (eBook) \\ (C) Peter Lang GmbH \\ Europäischer Verlag der Wissenschaften \\ Frankfurt am Main 2000 \\ Alle Rechte vorbehalten.
}

Das Werk einschließlich aller seiner Teile ist urheberrechtlich geschützt. Jede Verwertung außerhalb der engen Grenzen des

Urheberrechtsgesetzes ist ohne Zustimmung des Verlages unzulässig und strafbar. Das gilt insbesondere für

Vervielfältigungen, Übersetzungen, Mikroverfilmungen und die Einspeicherung und Verarbeitung in elektronischen Systemen.

Printed in Germany 1234567 
meinen Eltern

Steffen Meyer - 978-3-631-75269-2

Downloaded from PubFactory at 01/11/2019 06:28:10AM

via free access 
Steffen Meyer - 978-3-631-75269-2

Downloaded from PubFactory at 01/11/2019 06:28:10AM

via free access 


\section{Inhaltsverzeichnis}

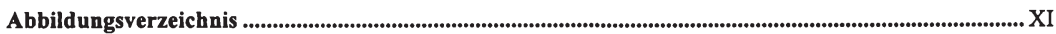

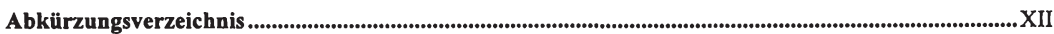

I EINFÜHRUNG

1 Problemstellung ................................................................................................................................................................ 1

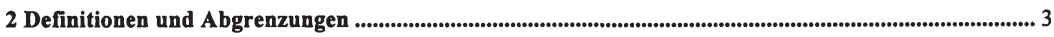

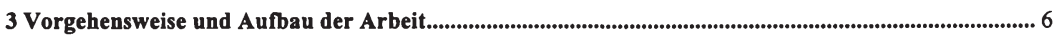

\section{DER NORMATIVE REFERENZRAHMEN - DIE ERWEITERTE ÖKONOMISCHE THEORIE DES FÖDERALISMUS .

1 Die Grundzüge eines erweiterten föderativen Referenzsystems..................................................... 9

2 Die Teilprinzipien des erweiterten foderativen Referenzsystems........................................................ 16

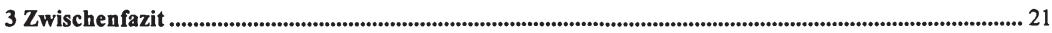

\section{ZWISCHENSTAATLICHE FINANZZUWEISUNGEN - THEORETISCHE GRUNDLEGUNG EINES RATIONALEN FINANZAUSGLEICHSYSTEMS .........23}

1 Formen zwischenstaatlicher Finanzzuweisungen ................................................................................ 24

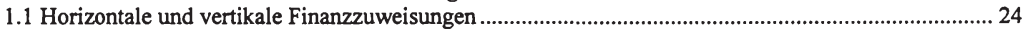

1.2 Auflagengebundene und allgemeine Finanzzuweisungen ............................................................ 25

1.2.1 Finanzzuweisungen mit und ohne Verwendungsauflagen ...................................................... 25

1.2.2 Finanzzuweisungen mit und ohne Empfangsauflagen .......................................................... 26

1.2.3 Finanzzuweisungen mit und ohne Eigenleistung ................................................................ 27

1.3 Betragsmäßig begrenzte und unbegrenzte Finanzzuweisungen ......................................................2 29

1.4 Die Formen unterschiedlicher Finanzzuweisungen im Überblick ................................................. 30

2 Wirkungsanalyse alternativer Formen zwischenstaatlicher Finanzzuweisungen................................... 31

2.1 Modelltheoretische Vorüberlegungen.......................................................................................... 31

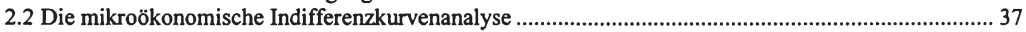

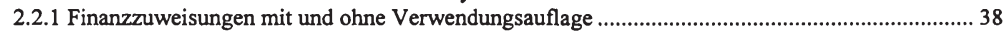

2.2.2 Finanzzuweisungen mit und ohne Empfangsauflage ................................................................. 42

2.2.3 Finanzzuweisungen mit und ohne Eigenbeteiligung.............................................................. 44

2.2.4 Betragsmäßig begrenzte und betragsmäßig offene Finanzzuweisungen ..................................... 48

2.2.5 Zwischenfazit zur Indifferenzkurvenanalyse ...................................................................... 52

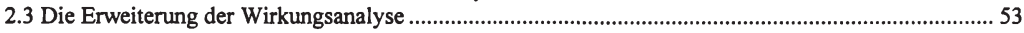

2.3.1 Der politische Entscheidungsprozeß und seine Akteure - Intrakollektiv .................................. 54

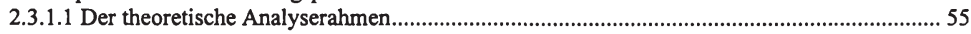

2.3.1.2 Das Verhalten der Politiker (und Parteien) ....................................................................... 57

2.3.1.3 Das Verhalten der Bürokraten ........................................................................................ 58

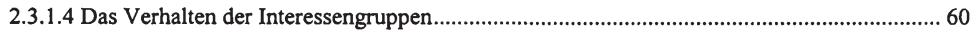

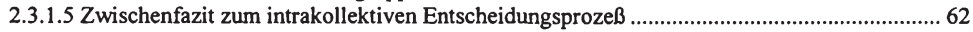

2.3.2 Der politische Entscheidungsprozeß und seine Akteure - Interkollektiv ...................................65

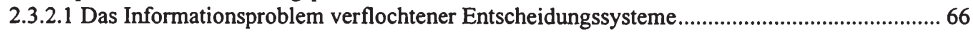

2.3.2.2 Das Konsensfindungsproblem verflochtener Entscheidungssysteme................................... 70

2.3.2.2.1 Die allgemeine Koordinations- und Konfliktregelungsproblematik.............................. 70

2.3.2.2.2 Der Konsensbedarf der Verhandlungssituation ......................................................... 74

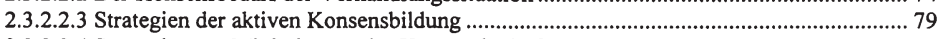

2.3.2.2.4 Strategien zur Minimierung des Konsensbedarfs ......................................................... 83

2.3.2.2.5 Schlußfolgerungen zur Konsensfindungsproblematik .............................................. 87 
2.3.2.3 Zwischenfazit zum interkollektiven Entscheidungsprozeß ..............................................90

2.4 Zwischenfazit und Exkurs zur Wirkungsanalyse: die Diskussion meritorischer Güter als Rechtfertigung eines Eingriffs in die Präferenzen der Transferempfänger.

3 Die Ausgestaltung der Finanzzuweisungen im Hinblick auf ihre Funktionen ................................... 101

3.1 Die Ausgestaltung der Finanzzuweisungen im Hinblick auf ökonomische Funktionen.................... 101

3.1.1 Allokationsfunktion ....................................................................................................... 101

3.1.1.1 Die Kompensation räumlicher externer Effekte ............................................................... 101

3.1.1.2 Die Beeinflussung regionaler Wirtschaftsstrukturen..................................................... 104

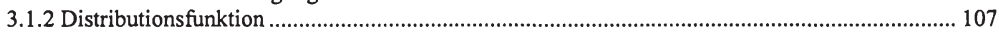

3.1.2.1 Vertikale fiskalische Ungleichgewichte ........................................................................... 107

3.1.2.2 Horizontale fiskalische Ungleichgewichte ..................................................................... 109

3.1.2.2.1 Von der fiskalischen Gleichheit zwischen Individuen zur fiskalischen Gleichheit zwischen Gebietskörperschaften.

3.1.2.2.2 Zum Konzept der fiskalischen Gleichheit zwischen Gebietskörperschaften................ 111

3.1.2.2.3 Zur Bestimmung der Finanzkraft............................................................................ 111

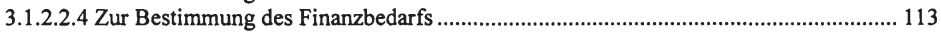

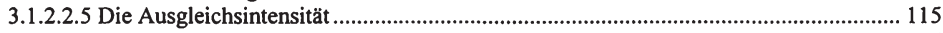

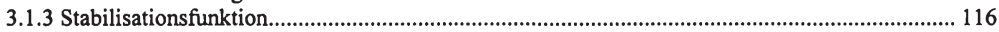

3.1.3.1 Ausgleich konjunktureller Schwankungen.................................................................. 116

3.1.3.2 Die Beeinflussung des Wirtschaftswachstums .............................................................. 119

3.2 Die Ausgestaltung der Finanzzuweisungen im Hinblick auf nicht-ökonomische Funktionen............. 122

3.2.1 Die Aufrechterhaltung der dezentralen Organisation des Staates .......................................... 122

3.2.2 Die Beeinflussung des Verhaltens der Wähler...................................................................... 123

3.2.3 Die Beeinflussung des Verhaltens der politischen Entscheidungsträger.................................. 124

3.3 Zusammenfassung - Funktionen der Finanzzuweisungen ........................................................... 124

4 Anforderungen an das (Gesamt-)System zwischenstaatlicher Finanzzuweisungen ............................ 125

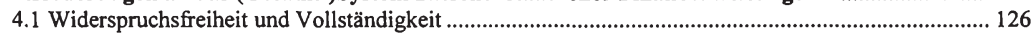

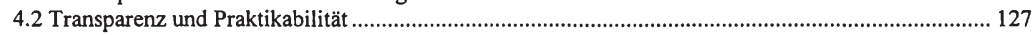

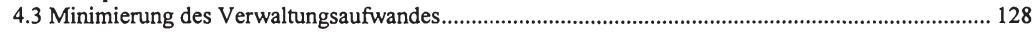

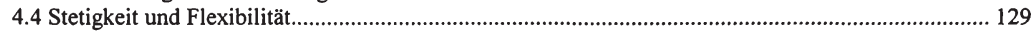

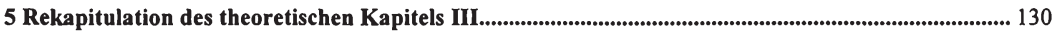

\section{ZIELSYSTEM UND RAHMENBEDINGUNGEN EINES RATIONALEN FINANZAUSGLEICHSYSTEMS IN DER ZUSAMMENWACHSENDEN EU}

1 Das Zielsystem der EU im Spiegel der rechtlichen Grundlagen der Integration................................. 133

1.1 Die Struktur des Vertrags über die Europäische Union (EUV) ....................................................... 136

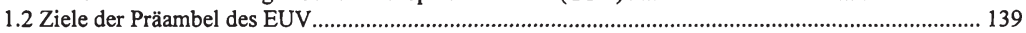

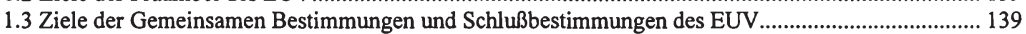

1.4 Ziele des Vertrags über die Europäische Gemeinschaft (EGV) ........................................................ 140

1.5 Zusammenfassende Betrachtung und Schlußfolgerungen ........................................................... 143

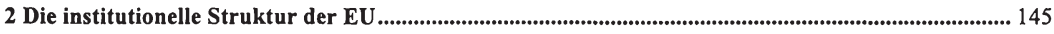

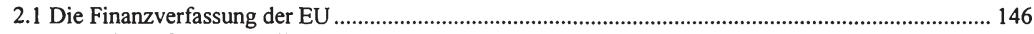

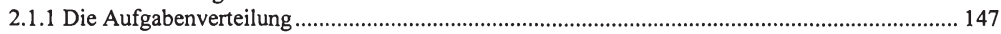

2.1.1.1 Grundsatzregelung - das Prinzip der begrenzten Einzelermächtigung ................................. 147

2.1.1.2 Die dynamische Entwicklung der Aufgabenverteilung .................................................. 148

2.1.1.3 Die Formen der Rechtssetzung................................................................................ 153

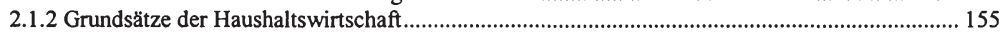

2.1.3 Die Ausgabenseite der Finanzverfassung........................................................................... 158

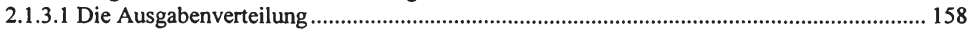

2.1.3.2 Das Volumen und die Struktur der Ausgabentätigkeit ....................................................... 159

2.1.4 Die Einnahmenseite der Finanzverfassung ........................................................................... 163

2.1.4.1 Die Besonderheit des Einnahmensystems der EU........................................................ 164

2.1.4.2 Das Volumen und die Struktur der Einnahmen............................................................... 170

2.2 Die Organe und Entscheidungsverfahren der EU .......................................................................... 171

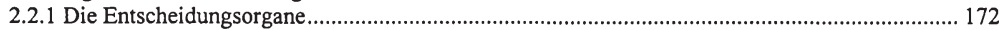

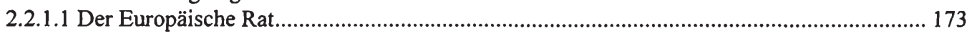

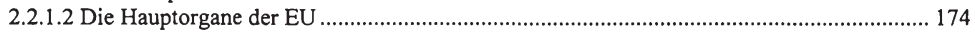

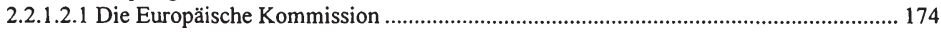


2.2.1.2.2 Der Rat der Europäischen Union (Ministerrat)..................................................... 176

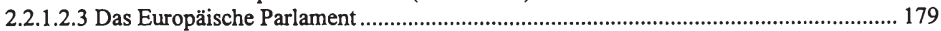

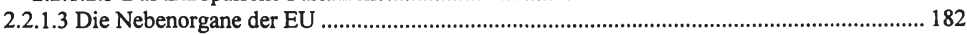

2.2.2 Das Zusammenwirken der Organe in den Entscheidungsprozessen der EU ............................. 185

2.3 Der europäische Integrationsprozeß ................................................................................................ 190

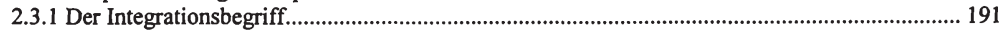

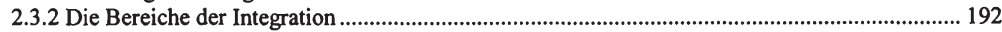

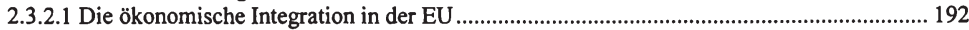

2.3.2.2 Die politische Integration in der EU.......................................................................... 194

2.3.3 Der Zusammenhang zwischen ökonomischer und politischer Integration................................ 197

2.4 Schlußfolgerungen für den weiteren Gang der Untersuchung ....................................................... 199

\section{FUNKTIONEN DER FINANZZUWEISUNGEN IM EUROPÄISCHEN} INTEGRATIONSPROZEß.

1 Räumliche externe Effekte zwischen den Mitgliedstaaten..............................................................204

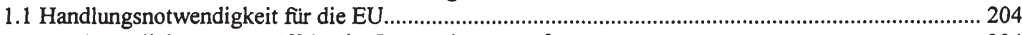

1.1.1 Räumliche externe Effekte im Integrationsprozeß ................................................................ 204

1.1.2 Räumliche externe Effekte im Infrastrukturbereich ............................................................... 206

1.1.3 Räumliche externe Effekte im Bereich Forschung und Entwicklung ........................................208

1.1.4 Räumliche externe Effekte im Umweltbereich ....................................................................... 210

1.1.5 Räumliche externe Effekte im Bildungsbereich......................................................................... 211

1.1.6 Die Bedeutung der FZ zur Internalisierung räumlicher externer Effekte ................................... 212

1.2 Bestehende Aktivitäten der EU zur Internalisierung räumlicher externer Effekte.............................. 213

1.3 Die Internalisierung räumlicher externer Effekte durch FZ .........................................................2 214

1.3.1 Zur Ausgestaltung der FZ aus rein ökonomischer Sicht ........................................................... 215

1.3.2 Die Umsetzung der effizienten Problemlösung im politischen Entscheidungsprozeß ................ 216

1.3.2.1 Die Gewinnung der entscheidungsrelevanten Informationen............................................ 217

1.3.2.2 Die Fragen der Konfliktregelung und Konsensfindung................................................... 219

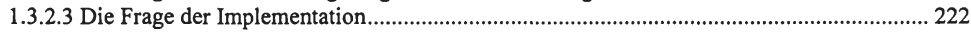

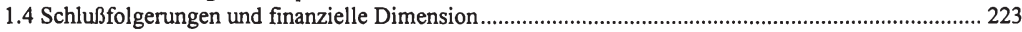

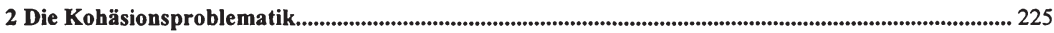

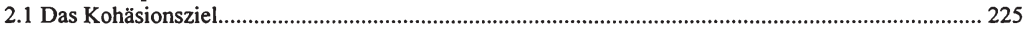

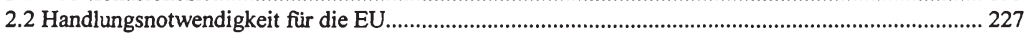

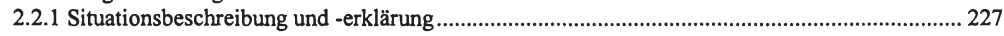

2.2.2 Prognose der zukünftigen Entwicklung ............................................................................. 231

2.3 Bestehende Aktivitäten der EU - die Regionalpolitik der EU ..................................................... 238

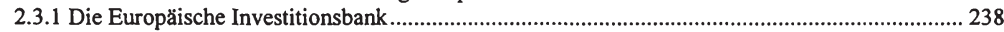

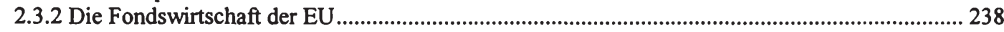

2.3.3 Problemfelder der bestehenden Regionalpolitik ................................................................... 244

2.4 Die Erfüllung der Kohäsionsfunktion durch FZ ....................................................................... 250

2.4.1 Zur Ausgestaltung der FZ aus rein ökonomischer Sicht ....................................................... 250

2.4.2 Die Umsetzung der effizienten Problemlösung im politischen Entscheidungsprozeß ................. 256

2.4.2.1 Die Gewinnung der entscheidungsrelevanten Informationen............................................. 257

2.4.2.2 Die Fragen der Konfliktregelung und Konsensfindung................................................... 258

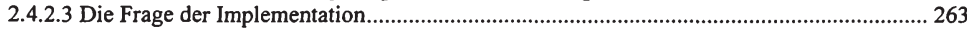

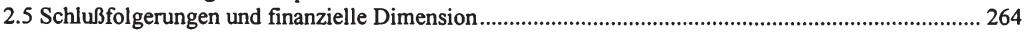

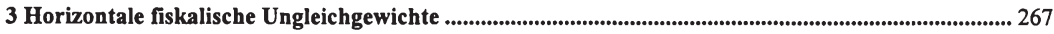

3.1 Handlungsnotwendigkeit für die EU - zum Begriff der Solidarität ................................................ 267

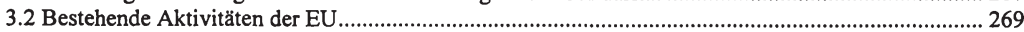

3.3 Der Ausgleich horizontaler fiskalischer Ungleichgewichte durch FZ .................................................. 269

3.3.1 Zur Ausgestaltung der FZ aus rein ökonomischer Sicht ........................................................ 269

3.3.2 Die finanzielle Dimension............................................................................................... 272

3.3.3 Die Umsetzung der effizienten Problemlösung im politischen Entscheidungsprozeß .................. 279

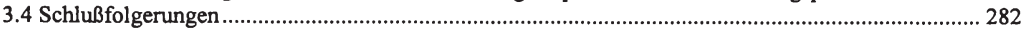

4 Das Problem asymmetrischer Schocks zwischen den Mitgliedstaaten ...........................................286

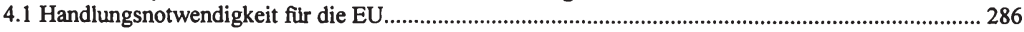

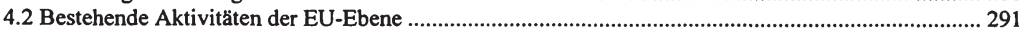

4.3 Der Ausgleich asymmetrischer Schocks durch FZ ................................................................... 292

4.3.1 Zur Ausgestaltung der FZ aus rein ökonomischer Sicht ........................................................ 292 
4.3.2 Die Umsetzung der effizienten Problemlösung im politischen Entscheidungsprozeß ................ 299

4.3.2.1 Die Gewinnung der entscheidungsrelevanten Informationen.............................................2299

4.3.2.2 Die Fragen der Konfliktregelung und Konsensfindung.................................................. 300

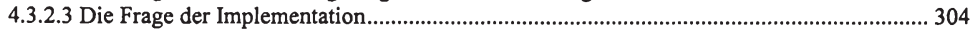

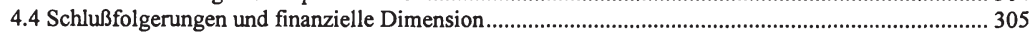

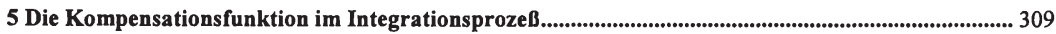

5.1 Handlungsnotwendigkeit für die EU............................................................................................ 309

5.2 Bestehende Aktivitäten der EU zur Kompensation einzelner Mitgliedstaaten .................................. 314

5.3 Die Kompensation einzelner Mitgliedstaaten durch FZ ............................................................. 315

5.4 Die Umsetzung der effizienten Problemlösung im politischen Entscheidungsprozeß............................. 315

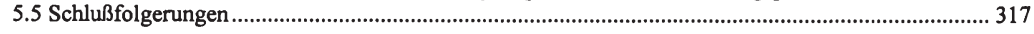

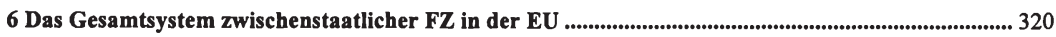

6.1 Zum Status-Quo der zwischenstaatlichen FZ in der EU ................................................................ 3220

6.2 Reformvorschlag - ein funktionales System zwischenstaatlicher FZ............................................ 323

6.2.1 Zur Widerspruchsfreiheit und Vollständigkeit eines funktionalen Gesamtsystems........................ 324

6.2.2 Zur Transparenz und Praktikabilität eines funktionalen Gesamtsystems..................................... 328

6.2.3 Zum Verwaltungsaufwand eines funktionalen Gesamtsystems ............................................... 329

6.2.4 Zur Stetigkeit und Flexibilität eines funktionalen Gesamtsystems .......................................... 330

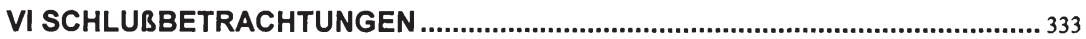

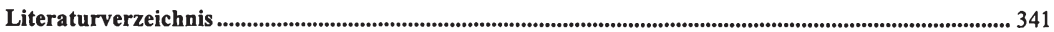




\section{Abbildungsverzeichnis}

Abb. II-1: Ressourcen- und Präferenzkosten im politischen Entscheidungsprozeß

Abb. III-1: Ausgestaltungsformen zwischenstaatlicher Finanzzuweisungen ....................................................... 31

Abb. III-2: Finanzzuweisung ohne Verwendungsauflage .............................................................................. 38

Abb. III-3: Finanzzuweisung mit Verwendungsauflage .................................................................................... 42

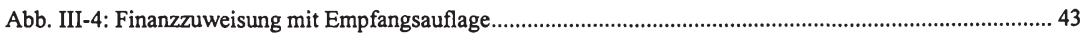

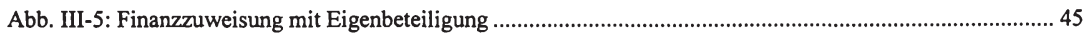

Abb. III-6: Vergleich von Finanzzuweisungen mit und ohne Eigenbeteiligung .................................................. 47

Abb. III-7: Die Finanzzuweisung mit Eigenleistung und betragsmaßiger Begrenzung ......................................... 49

Abb. III-8: Die Finanzzuweisung mit Eigenleistung und betragsmäßiger Begrenzung im

Wirkungsvergleich mit alternativen Ausgestaltungsformen.............................................................. 50

Abb. III-9: Problemstrukturen in verflochtenen Entscheidungssystemen .......................................................... 72

Abb. III-10: Interessenkonstellationen in verflochtenen Entscheidungssystemen ............................................. 77

Abb. III-11: Kompensationszahlungen im Verhandlungssystem ...................................................................... 82

Abb. III-12: Koppelgeschäfte im Verhandlungssystem ................................................................................ 83

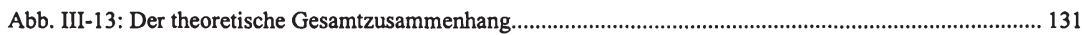

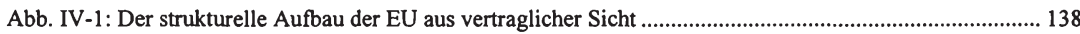

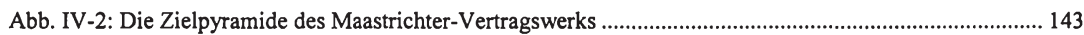

Abb. IV-3: Die Finanzielle Vorausschau der EU von 1993-1999 in Mrd. ECU .................................................. 161

Abb. IV-4: Die Entwicklung der Ausgabenstruktur der EU, ausgewählte Jahre 1970-98 ................................... 162

Abb. IV-5: Die Eigenmittel-Obergrenze der EU..................................................................................... 169

Abb. IV-6: Die Entwicklung der Einnahmen der EU, ausgewählte Jahre 1971-98............................................ 170

Abb. IV-7: Die Entwicklung der Einnahmestruktur der EU, ausgewählte Jahre 1971-98 .................................. 171

Abb. IV-8: Die Beschlußfassung mit qualifizierter Mehrheit im Ministerrat...................................................... 177

Abb. V-1: BIP pro Kopf, KKS, 1997, in Prozent, EUR 15=100

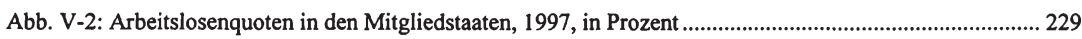

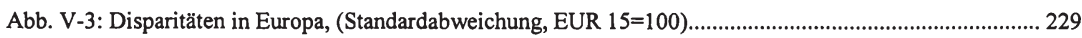

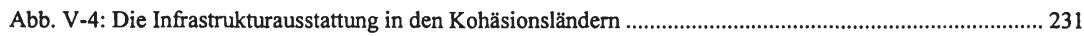

Abb. V-5: BIP pro Kopf in den Kohäsionsländern, KKS, in Prozent, EUR 15=100 ………............................. 236

Abb. V-6: Disparitäten beim BIP pro Kopf in KKS (Standardabweichung, EUR 15=100)................................ 237

Abb. V-7: Die Basisdaten zum Ausgleich horizontaler fiskalischer Ungleichgewichte im Jahr 1997................ 274

Abb. V-8: Fünf Varianten zum Ausgleich horizontaler fiskalischer Ungleichgewichte im Jahr 1997;

Transfervolumen in Mrd. ECU..................................................................................................... 275

Abb. V-9: Die Entwicklung des Transfervolumens in Mrd. ECU, ausgewählte Jahre 1975-97;

Preise des Jahres 1997 .................................................................................................................... 284 


\section{Abkürzungsverzeichnis}

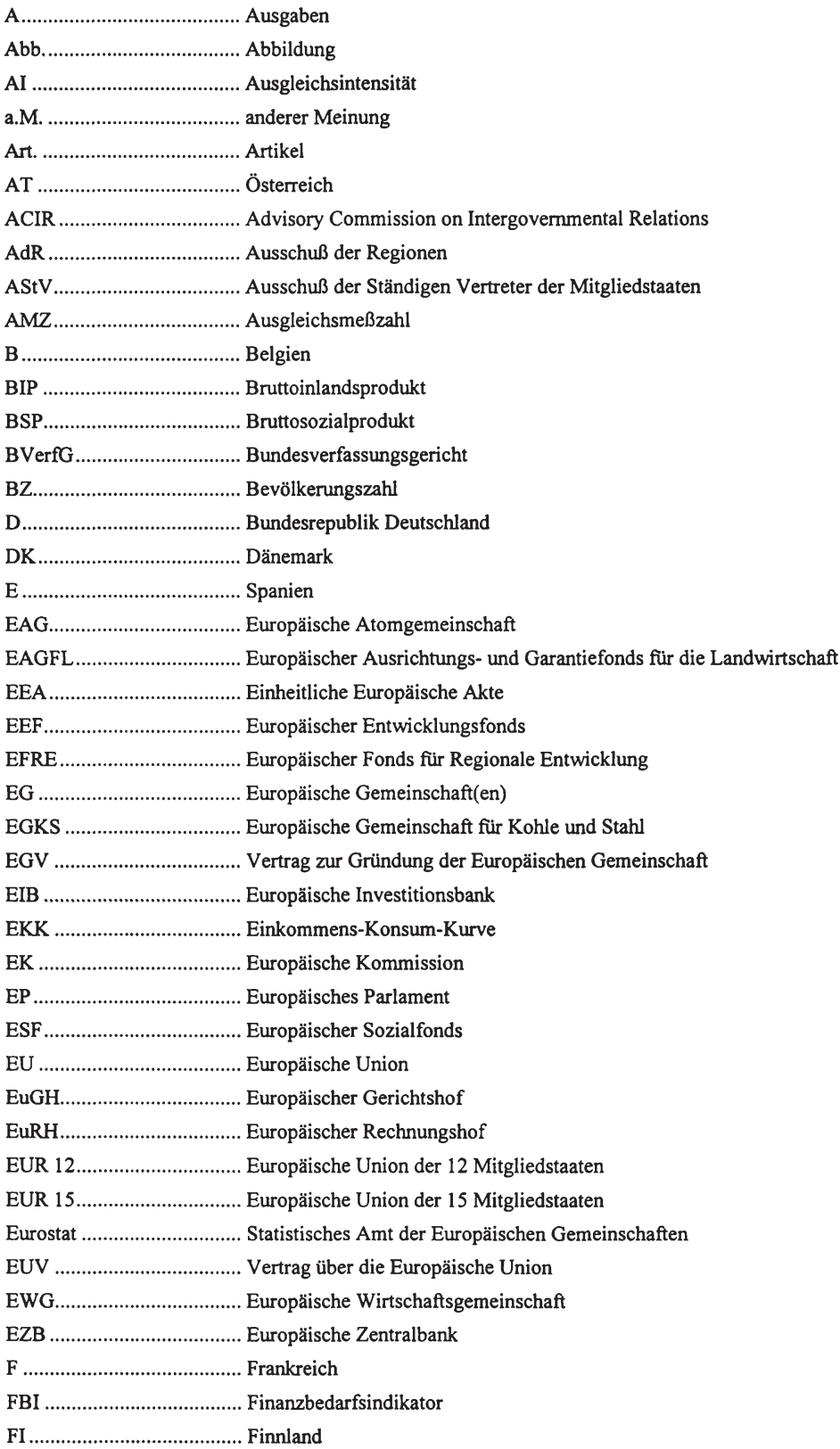


FIAF Finanzinstrument für die Ausrichtung der Fischerei

FK. Finanzkraft

FKM Finanzkraftmeßzahl

Fn Fußnote

FZ.. Finanzzuweisung(en)

GAP. Gemeinsame Agrarpolitik

GASP Gemeinsame Außen- und Sicherheitspolitik

GATT General Agreement on Trade and Tariffs

GK. Gesamtkosten

GKS. Gebietskörperschaft(en)

GR Griechenland

HO. Haushaltsordnung

I... Italien

insb. insbesondere

IRL Irland

KKS. Kaufkraftstandard

L Luxemburg

LE Leistungseinheit

M. Einkommen

m.E. mit Einschränkung

m.w..N mit weiteren Nachweisen

MwSt. Mehrwertsteuer

NI Niederlande

NOA. Nicht-obligatorische Ausgaben

NUTS Niveaux d'Unités Territoriales Statistiques

OA Obligatorische Ausgaben

P. Portugal

p.. Preis

PK.. Präferenzkosten

PKK. Preis-Konsum-Kurve

RK Ressourcenkosten

S. Seite

SE. Schweden

TP Teilprinzip

UK. Vereinigtes Königreich

WSA Wirtschafts- und Sozialausschuß

WWU Wirtschafts- und Währungsunion

ZJIP Zusammenarbeit in der Justiz- und Innenpolitik 
Steffen Meyer - 978-3-631-75269-2

Downloaded from PubFactory at 01/11/2019 06:28:10AM

via free access 


\section{Einführung}

\section{I-1 Problemstellung}

„Die souveränen Nationen der Vergangenheit sind nicht mehr der Rahmen, in dem sich die Probleme der Gegenwart lösen lassen. Und die Gemeinschaft selbst ist nur eine Etappe auf dem Weg zu Organisationsformen der Welt von morgen."1

Die Europäische Union (EU) befindet sich in einem Integrationsprozeß in Richtung einer wirtschaftlichen, sozialen und politischen Gemeinschaft. Die EU kann in dieser Hinsicht als ein System dynamischer Institutionen charakterisiert werden. Es entsteht ein neuartiges staatliches Gebilde sui-generis, ${ }^{2}$ das bereits heute über eine europäische Föderation (Staatenbund) hinausgeht und sich längerfristig zu einem föderativen Staat (Bundesstaat) entwickeln könnte. Dieser Prozeß wurde im Anschluß an den Zweiten Weltkrieg durch eine bewußte politische Entscheidung der verantwortlichen Entscheidungsträger ausgelöst. Der zukünftige Verlauf dieses Integrationsprozesses kann jedoch nur sehr eingeschränkt vorhergesagt werden, da er von einer Reihe politischer, historischer, sozio-kultureller und ökonomischer Faktoren abhängt, die sich einer zielgerichteten Gestaltung mittels der vorhandenen staatlichen Handlungsparameter in unterschiedlich starkem Maße entziehen. ${ }^{3}$ Zudem sind die wesentlichen Ziele der europäischen Integration keineswegs eindeutig und endgültig bestimmt, sondern weiterhin Gegenstand kontroverser Diskussionen innerhalb der und zwischen den Mitgliedstaaten der EU. ${ }^{4}$ Die Auswahl der (wirtschafts)politischen Instrumente ist regelmäßig von lebhaften Auseinandersetzungen bezüglich der Geeignetheit alternativer Maßnahmen zwischen politisch Verantwortlichen und Wissenschaftlern geprägt. ${ }^{5}$

Zur gleichen Zeit bestehen beträchtliche räumliche Disparitäten innerhalb der EU. Die Gemeinschaft stellt kein homogenes Gebiet dar. Es existieren bedeutende Unterschiede im Hinblick auf globale und strukturelle Indikatoren, die die sozio-ökonomischen Lebensbedingungen der einzelnen Mitgliedstaaten bestimmen. Hierzu gehören bspw. reales Einkommen, reales Sozialprodukt, Arbeitslosenrate, Sozialleistungen, sektorale Produktionsstruktur und öffentliche Infrastruktur. Diese Heterogenität „der räumlichen Verteilung von Lebenslagen"6

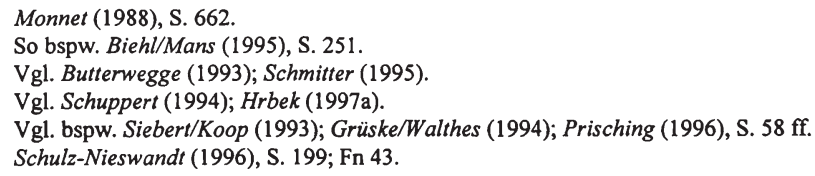


steht in einer engen wechselseitigen Verbindung zur Fortentwicklung der europäischen Einigung, da sie das Ausmaß der im Integrationsprozeß auftretenden Probleme immens erhöht und deren konsensorientierte Lösung wesentlich erschwert. ${ }^{\text {? }}$

Vor diesem Hintergrund beschäftigt sich die vorliegende Untersuchung mit der Gewährung zwischenstaatlicher Finanzzuweisungen (FZ) innerhalb der EU. Die Redistribution finanzieller Ressourcen zwischen Gebietskörperschaften (GKS) als Ausdruck eines Finanzausgleichs im engen Sinne ${ }^{8}$ ist ein zentraler Forschungsgegenstand der Finanzwissenschaft. Die ökonomische Theorie des Föderalismus stellt den traditionellen wohlfahrtstheoretischen Ausgangspunkt normativer Überlegungen zu einer optimalen Gestaltung zwischenstaatlicher FZ aus (rein) ökonomischer Sicht dar. ${ }^{9}$ Bereits die Beschreibung des europäischen Integrationsprozesses läßt jedoch die „Komplexität und strukturelle Unbestimmtheit” ${ }^{10}$ des Untersuchungsgegenstandes erkennen, der die traditionelle Föderalismusanalyse nur sehr eingeschränkt gerecht werden kann. Der rein ökonomische Ansatzpunkt führt zu einer Begrenzung des Gegenstandsbereichs, da er eine Reihe problemrelevanter Größen nicht abbildet. ${ }^{11}$ Eine integrierende Theorie des Finanzausgleichs, die in systemischer Sichtweise sowohl ökonomische als auch politische, historische und sozio-kulturelle Aspekte des Analyseobjektes berücksichtigt und den dynamischen, prozeßhaften Charakter des Problembereiches in geeigneter Weise abbildet, existiert jedoch nicht. Den Anspruch, eine solche umfassende Theorie entwickeln zu können erhebt auch diese Arbeit nicht. Allerdings wird der Versuch unternommen, den traditionellen wohlfahrtstheoretischen Theorieansatz um- bzw. auszubauen und durch weitere eigenständige Theorieansätze so zu ergänzen, daß zusätzliche erklärende Variablen in der Untersuchung Berücksichtigung finden. Diese Vorgehensweise soll einen Beitrag zu einer integrierenden (interdisziplinären) Sichtweise des ausgewählten Themenbereiches leisten, in der sowohl den außerökonomischen Aspekten als auch den Akteuren und rechtlich-organisatorischen Rahmenbedingungen diejenige Beachtung geschenkt wird, die sie in der Realität für den Prozeß der Vergabe von FZ besitzen. Im Rahmen dieser Arbeit ist diese Schwerpunktsetzung elementar, da jederzeit der Bezug zur konkreten Situation innerhalb der EU erhalten bleiben soll. Entsprechend dieses Untersuchungszieles wird eine Synthese von theoretischer und empirischer Analyse angestrebt. Konkret will die Arbeit einen wissenschaftlichen Beitrag zur Beantwortung zweier Fragen leisten:

7 Vgl. Schulz-Nieswandt (1996), S. $199 \mathrm{ff}$.

8 Vgl. zu diesem Begriff Abschnitt I-2 dieser Arbeit.

9 Vgl. hierzu die grundlegenden Standardwerke von Musgrave (1959) und Oates (1972).

10 Abromeit (1997), S. 208.

11 Vgl. bspw. die sehr viel stärkere Kritik bei Reuter (1994), S. 29 ff. 
- Welche Notwendigkeit besteht innerhalb der EU zur Einrichtung eines Finanzausgleichsystems (im engen Sinne) zwischen den Mitgliedstaaten?

- Welche Ausgestaltung sollen die einzelnen zwischenstaatlichen FZ haben, um dem Integrationsprozeß sowie den relevanten Zielen der EU bestmöglich zu entsprechen und die Einrichtung eines rationalen Gesamtsystems der FZ zu ermöglichen?

Die Arbeit versteht sich damit als ein Beitrag zu einer Theorie des zwischenstaatlichen Finanzausgleiches unter besonderer Berücksichtigung des europäischen Einigungsprozesses.

\section{I-2 Definitionen und Abgrenzungen}

Der Begriff „Finanzausgleich” ${ }^{12}$ kann in unterschiedlich weiter Fassung abgegrenzt werden. Der „Finanzausgleich im weiten Sinne” bezieht sich auf die Gesamtheit der Finanzbeziehungen zwischen den GKS eines Staates. Die Regelungen umfassen dann die Verteilung sowohl der Aufgaben als auch der zur Aufgabenerfüllung erforderlichen Ausgaben und Einnahmen auf die vorhandenen Jurisdiktionen des föderativen oder konföderalen Staates. ${ }^{13}$ Unter dem „Finanzausgleich im engen Sinne” versteht man die Gestaltung der Ausgleichszahlungen zwischen den GKS im Anschluß an die vorgegebene, originäre Aufgaben- und Einnahmenverteilung. Diese Ausgleichszahlungen stellen einseitige Geldströme zwischen den GKS dar, die als zwischenstaatliche Finanzzuweisungen bezeichnet werden. ${ }^{14}$ Es erfolgt eine Analyse der sekundären Verteilung der staatlichen Einnahmen. Die Gesamtheit dieser ergänzenden Maßnahmen bildet das Finanzausgleichsystem im engen Sinne, das eingerichtet wird, um „Unzulänglichkeiten der Aufgabenverteilung oder der originären Einnahmenverteilung zu beseitigen." ${ }^{\text {15 }}$ Dieses System steht im Mittelpunkt der vorliegenden Arbeit. Folglich beziehen sich die weiteren Ausfuihrungen stets auf den Finanzausgleich im engen Sinne, sofern nicht gesondert auf die weite Begriffsfassung hingewiesen wird. ${ }^{16}$

12 Vgl. zu den folgenden Abgrenzungen Keller (1961); Noll (1979), S. 193 ff.; Peffekoven (1983), S. 250 ff. u. (1988), S. 608 ff.; Andel (1983), S. 316 ff. u. (1992), S. 455 ff. u. 485 ff.; Zimmermann (1983); Biehl (1988a), S. $689 \mathrm{ff}$.

13 Diese Aspekte stellen die konstitutierenden Elemente der Finanzverfassung eines Staates dar, vgl. bspw. Zimmermann (1983), S. 4 ff. oder Kops (1997), S. 23 ff.

14 Die Leistung monetärer FZ (Transfers und Subventionen) vom öffentlichen Sektor an den privaten Sektor sind folglich nicht Gegenstand dieser Arbeit. Ebensowenig wird die Vergabe realer Transfers zwischen den GKS berücksichtigt, wie sie bspw. in Form der unentgeltlichen Bereitstellung öffentlicher Güter erfolgen kann. Es bestehen aber enge Interdependenzen zu diesen beiden Aspekten, die nicht unberücksichtigt bleiben dürfen.

15 Kops (1989), S. 39.

16 Um Mißverständnisse zu vermeiden, wird aber zumeist der Begriff „zwischenstaatliche FZ” verwendet. Nur aus sprachlichen Gründen wird als Synonym auch von Transfers oder Übertragungen gesprochen. 
Diese Begrenzung des Untersuchungsfeldes stellt eine Einschränkung der vorliegenden Arbeit dar. Selbstverständlich bestehen weitgehende Interdependenzen zwischen der Aufgaben-, Ausgaben- und Einnahmenverteilung innerhalb eines Staates. Es besteht die Gefahr, diesen wechselseitigen Abhängigkeiten nur ungenügend Rechnung zu tragen, wenn die Analyse auf einen Teilaspekt der Finanzverfassung beschränkt bleibt. Deshalb wird stets auf den Bezug zwischen europaweiter Aufgaben-, Ausgaben- und Einnahmenverteilung aufmerksam gemacht, wo dies zur Diskussion des Finanzausgleichs im engen Sinne von wesentlicher Bedeutung ist. Dieses Vorgehen besitzt eine besondere Relevanz auf europäischer Ebene, da deren institutionelle Struktur eine „Wandelverfassung”"17 ist, die im Laufe des voranschreitenden Integrationsprozesses einer ständigen Veränderung unterliegt. Damit entwickelt sich auch die Aufgaben- und Einnahmenverteilung der EU-Ebene fortwährend weiter, mit entsprechenden Aus- und Rückwirkungen auf die FZ zwischen den Mitgliedstaaten.

Der Finanzausgleich im engen Sinne besitzt eine vertikale und eine horizontale Dimension. In vertikaler Hinsicht erfolgt eine Korrektur der originären Einnahmenverteilung zwischen den verschiedenen Ebenen des betrachteten Staates (vertikaler Finanzausgleich). In horizontaler Hinsicht werden Ausgleichszahlungen zwischen GKS gleicher nachgelagerter Ebenen festgelegt (horizontaler Finanzausgleich). Dabei können die Ziele des horizontalen Finanzausgleichs auch durch vertikale zwischenstaatliche Transfers verwirklicht werden. Man spricht dann von vertikalen Finanzzuweisungen mit horizontalem Wirkungskreis.

Da die Notwendigkeit eines Finanzausgleichs zwischen den Mitgliedstaaten den Untersuchungsgegenstand dieser Arbeit bildet, stehen nachfolgend die horizontalen FZ sowie die vertikalen FZ mit horizontaler Wirkung im Mittelpunkt. Auch in diesem Zusammenhang wird die weitreichende Interdependenz der einzelnen Teilelemente des Finanzausgleichs deutlich. So hat bspw. die vertikale (originäre) Einnahmenverteilung zwischen den Ebenen entscheidenden Einfluß auf die finanziellen Spielräume der zentralen EU-Ebene, durch die Vergabe vertikaler zwischenstaatlicher Transfers horizontale Verteilungswirkungen auszulösen.

Für die Untersuchung des besonderen Staatsgebildes der EU ist die Abgrenzung der Begriffe „nationaler (bundesstaatlicher), internationaler, supranationaler (überstaatlicher) und zwischenstaatlicher Finanzausgleich" sinnvoll. ${ }^{18}$ Erörterungen zum Finanzausgleich nehmen in der Regel Bezug auf die GKS eines abgeschlossenen Staatswesens. Es wird dann der nationale (bundesstaatliche) Finanzausgleich analysiert. Treffen hingegen ,souveräne Staaten

\footnotetext{
17 Ipsen (1972), S. 201.

18 Die hier getroffene Abgrenzung geht vor allem auf Keller (1961), S. 546 f. zurück.
} 
Maßnahmen zur Abgrenzung ihrer Finanzhoheit und zur Ordnung ihrer gegenseitigen finanziellen Beziehungen", ${ }^{19}$ ohne durch die Abtretung von Souveränitätsrechten ihre Selbständigkeit einzuschränken, so spricht man vom zwischenstaatlichen Finanzausgleich. Führt ein fortschreitender politischer oder ökonomischer Integrationsprozeß jedoch zur Einrichtung supranationaler Institutionen, an die Souveränitätsrechte von den einzelnen Staaten übertragen werden, so ergibt sich die Frage des supranationalen Finanzausgleichs zwischen den übergeordneten Institutionen und den nachgelagerten GKS auf nationaler und regionaler Ebene. Die beiden letztgenannten Formen des Finanzausgleichs werden unter dem Oberbegriff ,internationaler Finanzausgleich" zusammengefaßt.

Die Einordnung eines europäischen Finanzausgleichs in dieses Abgrenzungsschema gestaltet sich problematisch. Die Mitgliedstaaten haben bestimmte Souveränitätsrechte an die (neukonstituierte) EU-Ebene abgetreten, womit diese die Kompetenz zur Aufgabenerfüllung in begrenzten Bereichen erhalten hat. Eine umfassende staatliche Gewalt mit autonomer „Entscheidungsbefugnis über das öffentliche Leistungsangebot und unmittelbarer Verantwortlichkeit der Entscheidenden gegenüber dem ... Wähler", ${ }^{20}$ wie es für ein Teilsystem eines föderativen Staat konstituierend wäre, besteht jedoch noch nicht. ${ }^{21}$ Daher ist zum gegenwärtigen Zeitpunkt von einem supranationalen Finanzausgleich zu sprechen. Allerdings befindet sich die EU in einem evolutorischen Integrationsprozeß, in dessen weiterer Entwicklung der $\mathrm{Zu}$ sammenschluß der Mitgliedstaaten vermehrt Konturen eines europäischen Bundesstaates gewinnt. In dem Maße, wie sich diese Entwicklung vollzieht, ist ein europäischer Finanzausgleich zunehmend als nationaler (bundesstaatlicher) Finanzausgleich zu interpretieren.

Im Hinblick auf die Fragestellungen dieser Arbeit ergeben sich aus dieser begrifflichen Unbestimmtheit des europäischen Finanzausgleichs keine konzeptionellen Schwierigkeiten. Denn der Untersuchung ist die wichtige Einsicht voranzustellen, daß es sich beim supranationalen Finanzausgleich ,im Prinzip ... um die gleichen Probleme [handelt], die auch innerhalb jedes einzelnen Staates, speziell föderalistischer Struktur, auftauchen und zu lösen sind."22 Allerdings werden jene Probleme aufgrund der im allgemeinen zu erwartenden größeren Heterogenität zwischen den einzelnen am supranationalen Finanzausgleich teilhabenden Staaten schwieriger zu lösen sein als auf nationaler Ebene.

Um begriffliche Mißverständnisse zu vermeiden, kann deshalb im Folgenden auf die differenzierte Abgrenzung verzichtet werden. Es wird stets von einem „zwischenstaatlichen Finanz-

\footnotetext{
$\operatorname{Keller}(1961)$, S. 546.

Noll (1979), S. 193.

Vgl. hierzu auch Abschnitt IV-2.

Andel (1983), S. 316.
} 
ausgleich" gesprochen, der sich je nach Stand des Integrationsprozesses auf einen supranationalen oder nationalen Finanzausgleich auf europäischer Ebene bezieht.

\section{I-3 Vorgehensweise und Aufbau der Arbeit}

Der Aufbau der Arbeit und damit die systematische Vorgehensweise stellt sich im einzelnen wie folgt dar:

Im zweiten Kapitel wird ein theoretischer Referenzrahmen entwickelt, der als normative Diskussionsgrundlage für die Beurteilung der Analyseergebnisse in den weiteren Abschnitten dieser Arbeit herangezogen wird. Der Referenzrahmen basiert auf einer erweiterten ökonomischen Theorie des Föderalismus, die es erlaubt, ökonomische, politische und sozio-kulturelle Aspekte der Gestaltung rechtlich-organisatorischer Strukturen eines Mehrebenen-Staates zu berücksichtigen. Damit wird es möglich, bei der konkreten Analyse der zwischenstaatlichen FZ unterschiedliche Theorieansätze heranzuziehen und deren Ergebnisse unter Bezugnahme auf die Beurteilungskriterien des umfassenden Referenzrahmens miteinander zu verknüpfen. Kapitel II weist deutlich darauf hin, daß es eine differenzierte Betrachtungsweise unmöglich macht, (vordergründig) einfache und eindeutige Schlußfolgerungen zur Problemstellung dieser Arbeit abzuleiten. Konkrete Handlungsempfehlungen zur Gestaltung der FZ-Vergabe in der EU unterliegen stets fundamentalen Zielkonflikten und erheblichen Unsicherheiten, die politische Bewertungen durch die staatlichen Entscheidungsträger notwendig machen. Dies gilt schon im Rahmen einer rein ökonomischen Betrachtung und um so mehr unter Berücksichtigung zusätzlicher außerökonomischer Abwägungskalküle.

In Kapitel III werden die zwischenstaatlichen FZ und damit die Frage der sekundären Verteilung der staatlichen Einnahmen als besonderer Teilaspekt aus dem umfassenden normativen Referenzrahmen herausgegriffen und einer intensiven theoretischen Untersuchung unterzogen. Es wird ermittelt, welche Funktionen die FZ grundsätzlich erfüllen können und wie deren zweckmäßigste Ausgestaltungsform je nach Zielsetzung aussehen muß. Insgesamt vermittelt Kapitel III das theoretische Rüstzeug zur Analyse des Finanzausgleich im engen Sinne auf der europäischen Ebene.

$\mathrm{Zu}$ diesem Zweck wird eine ausführliche Wirkungsanalyse alternativer Ausgestaltungen der FZ vorgenommen. Dabei stützt sich die Analyse auf drei Theorieansätze, die jeweils unterschiedliche empirisch relevante Teilaspekte der Gesamtproblematik aufgreifen. So werden partialanalytische Schlußfolgerungen zu den zu erwartenden Wirkungen einer Vergabe zwischenstaatlicher FZ in der EU abgeleitet. 
Die neoklassische mikroökonomische Indifferenzkurvenanalyse verdeutlicht die Wirkungen von FZ in einer Modellwelt, die von Akteuren und Institutionen vollständig abstrahiert. Sie ist als die für diese Arbeit grundlegende (rein) ökonomische Betrachtung aufzufassen.

Die ökonomische Theorie der Politik erlaubt es, die am politischen Entscheidungsprozeß beteiligten Akteure zu integrieren und eigenständig zu modellieren. Das neoklassische Verhaltenskalkül wird auf die Politik angewendet zur Erklärung der (subjektiven) Interaktionsorientierung der relevanten Entscheidungs- und Einflußträger.

Die Theorie der Politikverflechtung hingegen erweitert das Analysefeld um die institutionellen Rahmenbedingungen. Hierdurch wird der Einfluß verdeutlicht, den die Organisation des staatlichen Willensbildungs- und Entscheidungsprozesses auf die Vergabe der FZ besitzt. ${ }^{23}$

Die durch die Wirkungsanalyse gewonnenen Erkenntnisse ermöglichen eine systematische Diskussion der mit den FZ zu verfolgenden Ziele (Funktionen). Es werden normative Schlußfolgerungen zur aufgabenadäquaten Ausgestaltung der FZ abgeleitet.

In Kapitel IV erfolgt eine empirisch-deskriptive Analyse des Zielsystems sowie der rechtlichorganisatorischen, ökonomischen und politischen Rahmenbedingungen, in die ein europäischer Finanzausgleich im engen Sinne eingeordnet werden muß. Es wird das institutionelle Rüstzeug bereitgestellt, um empirisch gehaltvolle Aussagen zu einer rationalen Gestaltung der FZ auf der EU-Ebene treffen zu können. Es zeigt sich, daß die Ziele und die unterschiedlichen Rahmenbedingungen aufs engste mit dem Stand des europäischen Integrationsprozesses verbunden und dynamischen Veränderungen unterworfen sind. Dennoch können unwiderrufliche vertragliche Vorgaben sowie empirisch bedeutsame institutionelle Problembereiche und Konfliktfelder abgeleitet werden, die bei der Gestaltung eines europäischen Finanzausgleichs eine besondere Beachtung erfahren müssen.

Erst diese umfassenden Vorarbeiten erlauben es im Kapitel V, Gestaltungsmöglichkeiten für ein rationales Finanzausgleichsystem der EU zu bestimmen. Ein rationales Finanzausgleichsystem zeichnet sich dadurch aus, daß die unterschiedlichen Ausgestaltungsformen der FZ systematisch zur Erreichung eines vorgegebenen Zielbündels eingesetzt werden. Daher wird die Notwendigkeit und Geeignetheit zwischenstaatlicher FZ als finanzpolitisches Instrument zur Verwirklichung der dem europäischen Einigungsprozeß zugrundeliegenden wirtschaftsund gesellschaftspolitischen Ziele untersucht.

${ }^{23}$ Die Auswahl der Theorieansätze verdeutlicht, daß das Spektrum der wohlfahrtstheoretischen Ansätze in dieser Arbeit nicht verlassen wird. Hier besteht ein zusätzlicher Forschungsbedarf, der im Rahmen der vorliegenden Abhandlung nicht aufgegriffen wird (vgl. hierzu näher die Schlußbetrachtungen in Kapitel VI). 
Dabei werden zwei Schwerpunkte gesetzt. Zum einen werden die möglichen Ansatzpunkte, die für die Vergabe zwischenstaatlicher FZ in der EU bestehen, systematisch herausgearbeitet. Hierbei zeigt sich ein enges interdependentes Verhältnis zwischen den verschiedenen $\mathrm{FZ}$ und dem dynamischen Integrationsprozeß. Die Vergabe der FZ nimmt einen entscheidenden Einfluß auf den Ablauf des Integrationsprozesses und im Wechselspiel determiniert der Stand des Integrationsprozesses die Relevanz der zwischenstaatlichen FZ.

Zum anderen wird der Prozeß der politischen Entscheidungsfindung und -durchführung einer differenzierten Betrachtung unterzogen. Es steht hierbei die Frage im Mittelpunkt, ob es im europäischen Politikverflechtungssystem zwischen Mitgliedstaaten und EU-Ebene möglich ist, ein rationales Finanzausgleichsystem zu entwickeln oder ob systematisch Fehlentwicklungen zu erwarten sind. Deshalb wird analysiert, mit welcher Wahrscheinlichkeit in den einzelnen Politikbereichen effektive FZ-Maßnahmen beschlossen und durchgeführt werden können. Hieraus können abschließend Schlußfolgerungen zu einem rationalen Gesamtsystem der FZ in einem zusammenwachsenden Europa gezogen werden. 


\section{Der normative Referenzrahmen - die erweiterte ökonomische Theorie des Föderalismus}

Im einleitenden Kapitel wurde bereits darauf verwiesen, daß es sinnvoll ist, die EU im Hinblick auf die Probleme eines Staates mit entwickelter föderativer Struktur zu betrachten. Diese Ansicht wird durch die Analyse des Zielsystems und der rechtlich-organisatorischen Rahmenbedingungen der EU bestärkt. ${ }^{24}$ Wenngleich Uneinigkeit über die konkrete Ausgestaltung besteht, ist ein Fortschritt des europäischen Integrationsprozesses ,nicht anders zu verwirklichen denn als Föderation." ${ }^{25}$ Daher besteht die Notwendigkeit, dieser Arbeit zum europäischen Finanzausgleich einen föderalismusbezogenen theoretischen Referenzrahmen zugrundezulegen. Zugleich soll die politisch-institutionelle Dimension eine besondere Betonung erfahren. Einen idealtypischen Anknüpfungspunkt zur Berücksichtigung beider Aspekte hat Biehl entwickelt. Sein erweitertes föderatives Referenzsystem stellt die theoretische Grundlage der Untersuchungen in den folgenden Kapiteln dar. ${ }^{26}$

Dieser Referenzrahmen umfaßt den Finanzausgleich im weiten Sinne. Er entspricht einer „Art 'Konstruktionszeichnung' oder 'Bauplan'”, 27 mit dessen Hilfe die für einen Finanzausgleich „konstituiven Elemente identifiziert und so von anderen Problemzusammenhängen getrennt werden können, daß dabei keine wesentlichen Interdependenzen zerschnitten werden." ${ }^{, 28} \mathrm{Zu}$ gleich werden Bewertungskriterien eingeführt. Der Referenzrahmen ermöglicht es, spezielle Einzelaspekte der Gesamtheit der Finanzbeziehungen zwischen den Jurisdiktionen eines Staates $\mathrm{zu}$ isolieren, eingehend $\mathrm{zu}$ untersuchen und sie kritisch in das systematische Ganze einzuordnen. Dieser Vorgehensweise wird in den weiteren Kapiteln gefolgt, um die FZ zwischen den EU-Mitgliedstaaten (Finanzausgleich im engen Sinne) detailliert zu analysieren.

\section{II-1 Die Grundzüge eines erweiterten föderativen Referenzsystems}

Gedankliche Grundlage des Modells ist ein marktwirtschaftlich orientiertes Mischsystem mit einem privaten und einem öffentlichen Sektor. In diesem System erfüllt der öffentliche Sektor eine Doppelfunktion. Er nimmt die Funktion zur Bereitstellung öffentlicher Güter wahr. ${ }^{29}$

24 Vgl. hierzu Kapitel IV.

25 Abromeit (1993), S. 208.

26 Biehl stellte das föderative Referenzsystem erstmals 1983 vor. Anschließend wendete er die Überlegungen auf bestehende Finanzsysteme - insb. Deutschland und die $E U$ - an. Vgl. mit Bezug zu Deutschland Biehl (1983), (1989), (1994b); mit Bezug zur EU Biehl (1988b), (1991a), (1991b), (1994a), (1994c), (1995a).

27 Biehl (1988b), S. 65.

28 Biehl (1983); S. $71 \mathrm{f}$.

29 In dieser Arbeit werden alle Güter, die vom Staat angeboten werden, als öffentliche Güter bezeichnet. Sowohl Kollektivgüter, die sich durch die Eigenschaften des nichtkonkurrierenden Konsums und/oder der Nichtaus- 
Dabei ist er Bestandteil der allgemeingültigen Verfassung, in der institutionelle Regeln vorgegeben sind, anhand derer über die öffentliche Güterbereitstellung entschieden wird. Gleichzeitig wird durch den öffentlichen Sektor die übergeordnete Verfassungsfunktion erfüllt. In dieser Funktion bestimmt er die Einrichtung und Weiterentwicklung der rechtlichorganisatorischen Struktur des Staates, die den Ordnungsrahmen für die Aktivitäten des öffentlichen wie des privaten Sektors konstituiert. ${ }^{30}$

Sowohl die Erfüllung der Verfassungs- als auch der Bereitstellungsfunktion beansprucht Ressourcen. Die Institutionalisierung einer bestimmten rechtlich-organisatorischen Struktur des öffentlichen Sektors kann daher als „das Ergebnis eines Suchprozesses” interpretiert werden, „durch den unter zahlreichen möglichen Problemlösungen bei gegebenen raumzeitlichen (Anfangs-)Rahmenbedingungen die jeweils kostengünstigeren identifiziert und anschließend (in unregelmäßigen) Zeitabständen festgeschrieben werden." ${ }^{31}$ Es wird davon ausgegangen, daß verschiedene Wege zur sachlichen Problemlösung mit gleicher Effektivität (Zielerreichungsgrad) des Handelns existieren, die sich aber im Hinblick auf die zur Problemlösungsimplementation aufzuwendenden Kosten unterscheiden.

Die Suche nach einer effizienten Struktur des öffentlichen Sektors rückt die ökonomische Theorie des Föderalismus in das Blickfeld, in der normative Aussagen zur ,effizienten” Verteilung der öffentlichen Aufgaben zwischen den Ebenen des Staates, sowie der Regelung der Kompetenzen bei der Einnahmeerzielung und Ausgabetätigkeit getroffen werden. ${ }^{32}$ Aufbauend auf die von Musgrave eingefuihrte Dreiteilung der staatlichen Funktionen in Allokation, Distribution und Stabilisierung steht das (Organisations-)Problem eines föderativen Staates im Mittelpunkt, „to determine the respective roles of different levels of government in the implementation of economic policy." ${ }^{33}$ Allerdings folgt die traditionelle Föderalismustheorie einer engen, rein ökonomischen Betrachtungsweise. ${ }^{34}$ Die konventionelle Föderalismustheorie wird der Integration außerökonomischer Aspekte mit politischen und sozio-kulturellen Abwägungskalkülen geöffnet, indem über die üblichen ökonomischen Kategorien hinausgehend ein weit gefaßter Kostenbegriff eingeführt wird. Die Aufgabenverteilung zwischen den Ebenen des föderativen Staates wird dann als eine Kosten-Nutzen-Analyse im erweiterten Sinne inter-

schließbarkeit auszeichnen, als auch meritorische Güter (vgl. hierzu näher Abschnitt III-2.4) sind eine Teilgruppe der öffentlichen Güter (vgl. zu dieser Abgrenzung Noll (1979), S. 78 ff.).

Biehl (1995a), S. $110 \mathrm{f}$.

Vgl. grundlegend Oates (1972) sowie Musgrave/Musgrave (1973), S. 595 ff.; auch Forte (1977).

Oates (1968), S. 38.

34 Es wird davon ausgegangen, daß die Bürger keine Kosten aufwenden müssen, um ihre Präferenzen zu signalisieren. Es bestehen keine Mobilitätskosten. Darüber hinaus bleiben Verwaltungs- und Verhandlungskosten im öffentlichen Sektor unberücksichtigt. Vgl. hierzu Breton/Scott (1978), S. 34 ff.; auch Thöni (1986), S. 35 ff. 
pretiert. Dabei werden die Nutzen als vermiedene Kosten aufgefaßt, so daß die optimale Aufgabenverteilung im gedanklichen Referenzsystem als ein Kostenminimum ermittelt werden kann. Um die Dichotomie zwischen ökonomischen und nicht-ökonomischen Bewertungskalkülen aufzubrechen, wird in Anlehnung an Buchanan und Tullock ${ }^{35}$ sowie Pennock $^{36}$ zusätzlich zur ökonomischen Ressourcenkostenkategorie die Präferenzkostenkategorie ${ }^{37}$ eingeführt: ${ }^{38}$

- Die Ressourcenkosten umfassen „tangible und quantifizierbare Größen”, ${ }^{99}$ die zumeist den Produktionsfaktoren Arbeit, Boden und Kapital zugerechnet werden können. Diese (knappen) Faktoren werden im öffentlichen Sektor zur Erfüllung seiner Doppelfunktion aufgewendet. Entsprechend dem Opportunitätskostenkonzept sind sie für alternative angebotsseitige Verwendungen nicht mehr verfügbar. Bei der Verfassungsfunktion handelt es sich speziell um Ressourcen zur „Errichtung, Aufrechterhaltung und Veränderung von Institutionen sowie für die 'Produktion' von Eigentums- und Verfügungsrechten," ${ }^{40}$ wohingegen bei der Bereitstellungsfunktion Ressourcen zur „Erzeugung, Finanzierung und Verteilung"41 öffentlicher Güter eingesetzt werden. ${ }^{42}$

- Die Präferenzkosten beziehen sich auf die Wünsche und Wertvorstellungen der Bürger. Dies verdeutlicht, daß beim Konzept der Präferenzkosten nicht angebotsseitige, sondern nachfrageseitige Wohlfahrtsverluste erfaßt werden. Sie entstehen immer dann, wenn das öffentliche Leistungsangebot nicht den variierenden Präferenzen der Bürger entspricht. Ihren Anschlußpunkt findet diese Kostenkategorie in dem Allokationsmechanismus der demokratischen Mehrheitsentscheidungen. Es verbleibt stets eine „frustrierte Minderheit”43 an Wählern, deren Präferenzen in Hinblick auf Umfang und Struktur der öffentlichen Leistungen keine oder nur ungenügende Berücksichtigung finden. Die entstehenden Nutzeneinbußen stellen Präferenzkosten bzw. Frustrationskosten dar. Sie können außerdem

35 Vgl. Buchanan/Tullock (1962), insb. S. 43 ff. u. $63 \mathrm{ff}$.

36 Vgl. Pennock (1959).

37 Pennock (1959), S. 147 bezeichnet diese Kategorie als Frustrationskosten; Buchanan/Tullock (1962), S. 63 sprechen von externen Kosten. Die unterschiedlichen Begriffe werden auch in der aktuellen Literatur synonym verwendet (vgl. bspw. Leipold (1994a), S. 1; Frey, B./Kirchgässner (1994), S. 48 f.). Vgl. hierzu bspw. Biehl (1983), S. 74 f.; (1988b), S. 68 ff.; (1991a), S. 359 f.; (1994b), S. 154 f.

39 Walthes (1996), S. 107.

40 Biehl (1991a), S. 359. Hierzu zählen insb. politische Transaktionskosten (vgl. hierzu näher Abschnitt III2.3.2.2.5).

41 Walthes (1996), S. 107.

42 Diese Anknüpfungspunkte des Ressourcenverzehrs können in bestimmte Kostenkategorien übersetzt werden, die jeweils in einem strukturellen Zusammenhang zur föderativen Organisation des öffentlichen Sektors stehen. Neben den Ressourcenkosten im engsten Sinne für die konkrete Produktion der öffentlichen Güter lassen sich Kosten der Information, der Verhandlung bzw. Konsensfindung, der Entscheidung, der Verwaltung und der Kontrolle in diese differenziertere Abgrenzung aufnehmen (vgl. hierzu bspw. Frey, $R$. (1977), S. $31 \mathrm{ff}$;; Thöni (1986), S. 42 f. u. 46 ff.).

43 Noll (1979), S. 197; vgl. auch Forte (1977), S. 361. 
auftreten, wenn bei der Bereitstellung meritorischer Güter, ein wohlbeabsichtigter Eingriff in die Präferenzordnung der Bürger durch die staatlichen Entscheidungsträger vorgenommen wird. ${ }^{44}$

Es ist zu betonen, daß sich im Aggregat der Präferenzkosten neben der bloßen Anzahl der

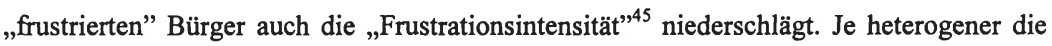
Wertvorstellungen zwischen den Bürgern eines Gemeinwesens ausfallen und je wichtiger die zu treffenden Entscheidungen von den Bürgern eingeschätzt werden, desto höher sind ceteris paribus die Nutzeneinbußen, die jeder Einzelne im Rahmen der Oktroyierung fremder Wertvorstellungen aufgrund von Majorisierung oder Meritorisierung hinzunehmen hat. $^{46}$

Die erweiterte Kostenanalyse legt es nahe, die übliche Dreiteilung der Aufgabenbereiche des öffentlichen Sektors in einer erweiterten Fassung zu begreifen. Die Anwendung des Musgraveschen Begriffstrias wird nicht nur auf die Bereitstellung öffentlicher Güter bezogen, sondern auch auf die öffentliche Verfassungsfunktion: ${ }^{47}$

- Der Allokationsbegriff ist nicht auf die Frage der effizienten Verteilung knapper Ressourcen zur Erzeugung privater und öffentlicher Güter beschränkt. Die Zuteilung von Ressourcen zur Schaffung und Aufrechterhaltung des rechtlich-organisatorischen Rahmens sowie privater und öffentlicher Handlungs- und Verfügungsrechte wird zusätzlich thematisiert.

- Die Distributionsfunktion bleibt nicht auf die am Gerechtigkeitsziel orientierte Korrektur der personellen oder regionalen Einkommens- und Vermögensverteilung im privaten Sektor beschränkt. Es wird die gerechte Ver- und Aufteilung der politischen Macht in die Analyse einbezogen (horizontale und vertikale Gewaltenteilung).

- Die erweiterte Stabilisierungsfunktion bezieht sich neben der traditionellen Ausrichtung auf die Glättung von Konjunkturzyklen innerhalb des makro-ökonomischen Systems auch auf die (andauernde) Sicherung der Stabilität des gesellschaftlichen, politischen und institutionellen Systems. Unter dieser Zielsetzung sind destabilisierende „politische Extreme”,48 zu verhindern und ist ein langfristiger Ausgleich zwischen ,zentrifugalen und zentripetalen politischen Kräften" ${ }^{\text {49 }}$ anzustreben.

44 Vgl. zur Frage der Berechtigung meritorischer Maßnahmen Abschnitt III-2.4.

45 Noll (1979), S. 197.

46 Vgl. hierzu auch Noll (1979), S. 197; Biehl (1983), S. 77.

47 Vgl. hierzu insb. Biehl (1983), S. 75 f.; (1994a), S. 103; (1994b), S. 156.

48 Biehl (1988b), S. 68.

49 Biehl (1983), S. 76. 
Gemäß der erweiterten Kostenanalyse wird eine Aggregation der einzelnen Elemente der Ressourcenkosten (RK) und Präferenzkosten (PK) vorgenommen ${ }^{50}$ und $\mathrm{zu}$ einem graphischen Grundmodell zusammengefaßt, das sowohl zu Fragestellungen bezüglich der Verfassungs- als auch der Bereitstellungsfunktion angewendet werden kann:

1. Zunächst wird reflektiert, welche Eigenschaften einen Verfassungsrahmen auszeichnen, der gewährleistet, daß die politische Entscheidungsfindung, auf deren Basis die Bereitstellung öffentlicher Güter erfolgt, entsprechend des erweiterten Musgraveschen Begriffstrias und der erweiterten Kostenanalyse als „optimal” bezeichnet werden kann. Es steht die Frage der optimalen Abstimmungsregel und des optimalen Grads der Repräsentanz im Zentrum des Interesses. Die Existenz unterschiedlicher gebietskörperschaftlicher Ebenen wird an dieser Stelle noch nicht thematisiert.

Die Kosten, die bei der politischen Entscheidungsfindung entstehen, werden in Abhängigkeit von der Anzahl N der an den Entscheidungsprozessen beteiligten Mitglieder der Gemeinschaft abgebildet (vgl. hierzu Abb. II- $1^{51}$ ). Die RK-Kurve weist ihr absolutes Minimum auf, wenn nur eine Person $(\mathrm{N}=1)$ im Gemeinwesen entscheidungsberechtigt ist. In diesem Fall muß ausschließlich dieser Alleinentscheider Ressourcen aufwenden, um zu einer Entscheidungsfindung über das Angebot öffentlicher Güter zu gelangen. Alle anderen Individuen sind am politischen Prozeß nicht beteiligt und können die ihnen zur Verfügung stehenden Ressourcen uneingeschränkt für private ökonomische Aktivitäten nutzen. Zugleich ist es plausibel, daß die PK in dieser Situation ein Maximum erreichen. Die Bürger werden vollständig aus dem politischen Entscheidungsprozeß ausgeschlossen. Die „Frustration” erreicht ein Maximum, da zu befürchten ist, „daß der Alleinentscheider i.S. eines 'Diktators' seine Macht auch zur Unterdrückung und Ausbeutung der Mitglieder der betrachteten Gesellschaft einsetzen könnte” und sich folglich ein „Maximum an negativen Auswirkungen auf das Wertesystem des beurteilenden Individuums ergeben kann." ${ }^{~} 2$ Mit

50 Es wird also davon ausgegangen, daß die einzelnen Kostenkategorien in aggregierbaren Einheiten ausgedrückt werden können, was die Durchführbarkeit einer kardinalen Nutzenmessung erfordert. Da hierbei die Nutzen einer Vielzahl an Individuen zusammengefaßt werden, wird zudem die Möglichkeit interpersoneller Nutzenvergleiche angenommen. Um dies realisieren zu können, müssen die Nutzendifferenzen zwischen den einzelnen Individuen mit einem einheitlichen Maßstab meßbar sein (vgl. hierzu näher Biehl (1988b), Fn 4, m.w.N. u. grundsätzlicher Arnold (1992), S. 27 f., m.w.N.).

51 Die Abb. II-1 bildet partialanalytisch die Frage des optimalen Grads der Repräsentanz ab. Wird die Frage der optimalen Abstimmungsregel dargestellt, so verlaufen die Kurven analog. Allerdings wird dann auf der Abszisse nicht die Anzahl der am Entscheidungsprozeß Beteiligten abgebildet, sondern der Prozentanteil der Entscheidungsberechtigten, der zur Beschlußfassung notwendig ist.

52 Biehl (1995a), S. 113. Für die Existenz des Maximums an PK ist es letztlich unerheblich, ob der Diktator seine Macht tatsächlich zur Ausbeutung der Bürger mißbraucht oder im Sinne eines „weisen” oder ,wohlwollenden" Alleinherrschers die von allen Bürgern gewünschte Lösung herbeiführt. „In einer offenen und freien Gesellschaft [verursacht] die Ausschaltung der Bürger vom politischen Entscheidungsprozeß unabhängig vom Ergebnis dieses Prozesses maximale 'Frustration'." (Biehl, (1988b), S. 70) Vgl. hierzu aber auch die 
zunehmender Zahl der Entscheidungsberechtigten sinken die PK. Bei uneingeschränkter politischer Partizipation aller Bürger $(\mathrm{N}=$ alle), also in einer plebiszitären Situation mit Einstimmigkeit als Entscheidungsregel, erreichen die PK ihr Minimum. Nun können alle Individuen des Gemeinwesens ihre Präferenzen in das Entscheidungsverfahren einbringen und jede Majorisierung ist ausgeschlossen. Jedoch steigt mit zunehmender Zahl der am Abstimmungsproze $ß$ Beteiligten und zunehmenden Anforderungen an die Abstimmungsregel die RK-Kurve (überproportional) an. Im Rahmen der politischen Partizipation muß jeder einzelne Bürger nun einen erheblichen Teil der ihm zur Verfügung stehenden Ressourcen zur Entscheidungsvorbereitung (Kosten der Informationsfindung und -verarbeitung), Entscheidungsfindung (Verhandlungskosten, Kompensationszahlungen) und Entscheidungskontrolle (Kontrollkosten) aufwenden.

Abb. II-1: Ressourcen- und Präferenzkosten im politischen Entscheidungsprozeß

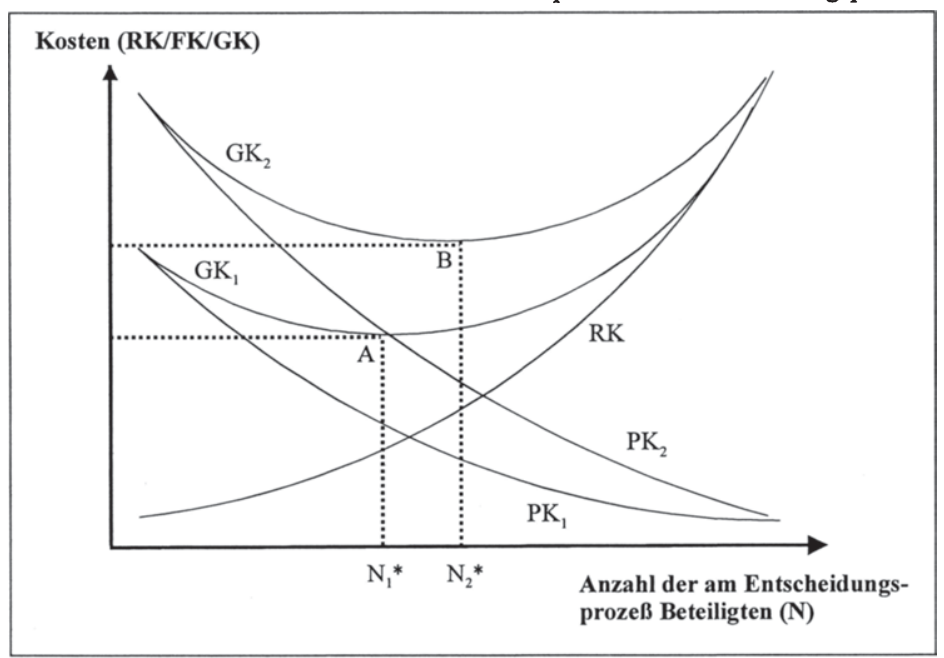

Quelle: Darstellung in Anlehnung an Biehl (1995a), S. 112.

Bei Gültigkeit dieser Ausführungen ergibt sich zwingend, daß die PK mit steigender Anzahl der Entscheidungsbeteiligten und zunehmender Anforderung an die Abstimmungsregel monoton fallen (dabei werden in der Abbildung zwei unterschiedliche Niveaus der Präferenzkosten $\mathrm{PK}_{1}$ und $\mathrm{PK}_{2}$ angenommen), wohingegen die $\mathrm{RK}$ monoton steigen. Die Aggregation der beiden Kostenkurven ergibt deshalb einen u-förmigen Gesamtkostenverlauf 
$\left(\mathrm{GK}_{1}\right.$ bei Präferenzkostenniveau $\mathrm{PK}_{1}$ bzw. $\mathrm{GK}_{2}$ beim Präferenzkostenniveau $\mathrm{PK}_{2}$ ). Im Minimum der Gesamtkosten (Punkt A bzw. B) liegt die „optimale” rechtlich-organisatorische Struktur des öffentlichen Sektors $\left(\mathrm{N}_{1} *\right.$ bzw. $\left.\mathrm{N}_{2}{ }^{*}\right)$.

Bei der Optimierung der Entscheidungsstrukturen unter Kostenaspekten stellt daher weder der Fall des Alleinentscheiders noch der Fall des Plebiszits (direkte Demokratie) eine kostenminimale Lösung dar. Das Kostenminimum der GK-Kurven liegt zwischen diesen beiden Extremen (repräsentative Demokratie). Der kostenminimale Grad der Repräsentanz wird bestimmt durch das Verhältnis $\mathrm{N}_{1}{ }^{*}$ bzw. $\mathrm{N}_{2}{ }^{*}$ zu N. In analoger Weise läßt sich ermitteln, daß als „optimale” Abstimmungsregel nicht die Einstimmigkeitsregel, sondern eine Form der Mehrheitswahlregel institutionalisiert werden muß, um die Gesamtkosten bei der Erfüllung der öffentlichen Funktionen zu minimieren. ${ }^{53}$

2. Das Grundmodell läßt sich in geeigneter Weise auf die Bereitstellungsfunktion des öffentlichen Sektors übertragen. Es kann dann die Frage beantwortet werden, welche gebietskörperschaftliche Ebene des föderativen Staates eine bestimmte öffentliche Aufgabe unter Beachtung des erweiterten Analyserahmens erfüllen sollte. Die Anzahl der am Entscheidungsprozeß Beteiligten N in Abbildung $\Pi 1-1$ ist nun als Anzahl der GKS zu interpretieren, die die Kompetenz zur Aufgabenerfüllung besitzt. Wiederum läßt sich aus den RK und den PK eine u-förmige Gesamtkostenkurve ableiten, aus der sich ein „optimaler” Dezentralisierungsgrad für die Bereitstellung eines öffentlichen Gutes bestimmen läßt.

Abschließend wird nochmals auf die Frustrationsintensität eingegangen, da hierdurch ein zusätzlicher Aspekt in das Modell integriert wird, der die Vorgehensweise der erweiterten Kostenanalyse veranschaulicht. ${ }^{54}$ Ausgehend von der Überlegung, daß die Bürger Verfassungsänderungen eine größere Bedeutung beimessen als laufenden Entscheidungen innerhalb der bestehenden Verfassung, wird die Majorisierung einer Minderheit im Rahmen der Verfassungsfunktion eine größere „Frustration” auslösen als im Rahmen der Bereitstellungsfunktion. Die (absolute) Höhe der PK der überstimmten Minderheit fällt bei Verfassungsentscheidungen höher aus als bei Bereitstellungsentscheidungen. In der graphischen Darstellung drückt sich dies dadurch aus, daß die PK-Kurve für die Bereitstellungsfunktion $\left(\mathrm{PK}_{1}\right)$ flacher verläuft als für die Verfassungsfunktion $\left(\mathrm{PK}_{2}\right)$. Unter der Annahme eines für beide Funktionen gleichen

53 Das Modell läßt nur eine sehr begrenzte Aussage zu. Solange der genaue Verlauf der beiden Kurven nicht bekannt ist, kann lediglich geschlußfolgert werden, daß die Extremlösungen nicht optimal sind. Dieses Ergebnis weicht von jenem der traditionellen Wohlfahrtstheorie ab. Da dort keine Transaktionskosten berücksichtigt werden, stellt es die optimale Entscheidungsregel dar, alle Betroffenen an der Allokationsentscheidung zu beteiligen und nur eine einstimmige Beschlußfassung zuzulassen (vgl. Buchanan/Tullock (1962), S. 92 ff.; Feldman (1980), S. 106 ff.).

54 Vgl. hierzu insb. Biehl (1994a), S. 102; (1995a), S. 115 f. 
Verlaufs der RK-Kurve rückt das Minimum der Gesamtkostenkurve bei Verfassungsentscheidungen weiter vom Ursprung fort (von $\mathrm{N}_{1}{ }^{*} \mathrm{zu} \mathrm{N}_{2}{ }^{*}$ ). Bei Verfassungsentscheidungen ist daher ceteris paribus ein höherer Grad der Repräsentanz zu gewährleisten und eine höhere Anforderung an die Abstimmungsregel zu stellen, als bei Entscheidungen zur Bereitstellung öffentlicher Güter.

Der analoge Gedankengang kann im Hinblick auf die Heterogenität der Präferenzen und Wertvorstellungen der Bürger angestellt werden. Je heterogener diese Präferenzen und Wertvorstellungen ausfallen, desto höher sind die Nutzeneinbußen der überstimmten Bürger. Im graphischen Modell resultiert in einer ,heterogenen” Gemeinschaft ein steilerer Verlauf der PK-Kurve (also $\mathrm{PK}_{2}$ ) als in einem Gemeinwesen mit homogeneren Präferenzen und Wertvorstellungen $\left(\mathrm{PK}_{1}\right)$. Daher ist in einer heterogenen Gemeinschaft bei allen Entscheidungen ein höherer Grad der Repräsentanz zu gewährleisten und eine restriktivere Abstimmungsregel zu institutionalisieren, als innerhalb einer homogenen Gemeinschaft. ${ }^{55}$

\section{II-2 Die Teilprinzipien des erweiterten foderativen Referenzsystems}

In den bisherigen Ausführungen wurde ein umfassendes „Kostenminimierungskriterium” Analyseinstrument eingeführt. Die beiden Kostenkategorien des Grundmodells beinhalten eine Reihe unterschiedlicher Einzelfaktoren. Das Grundmodell ist daher für konkrete Anwendungen nur schwer handhabbar. Aus diesem Grund werden nachfolgend föderalistische Teilprinzipien als Beurteilungskriterien formuliert, die sich nach Möglichkeit stets nur auf einzelne Kostenelemente beziehen und hierdurch eine anwendungsorientierte Operationalisierung der Kostenminimierungshypothese ermöglichen. ${ }^{57}$ Die Gesamtkosten bei der Erfüllung der öffentlichen Aufgaben werden als eine additive Funktion der einzelnen Teilprinzipien aufgefaßt. ${ }^{58}$ Die Teilprinzipien erlauben partialanalytische Schlußfolgerungen zu isolierten Kostenelementen. Im Folgenden werden acht Prinzipien unterschieden: ${ }^{59}$

55 Allerdings sei darauf hingewiesen, daß die Annahme eines unveränderten Ressourcenkostenverlaufs eine möglicherweise unzulässige Vereinfachung darstellt. Sowohl bei Verfassungsänderungen als auch bei der Entscheidungsfindung in sehr heterogenen Gemeinwesen sind außergewöhnlich hohe Verhandlungskosten denkbar, die so auch einen steileren Verlauf der RK-Kurve auslösen würden. Der Optimalpunkt $\mathrm{N}^{*}$ würde sich dann wieder in Richtung Ursprung zurückverschieben (vgl. auch Biehl (1995a), Fn 11).

56 Biehl (1995a), S. 137.

57 Vgl. Biehl (1995a), S. 124. Diese Disaggregation bringt es mit sich, daß bestimmte Teilprinzipien genannt werden, die auch Gegenstand der traditionellen ökonomischen Föderalismustheorie sind, wie bspw. das Kongruenzprinzip. Andere Teilprinzipien, wie das Prinzip horizontaler und vertikaler Gewaltenteilung, gehen hingegen deutlich über den traditionellen Ansatz hinaus. Zudem zeigt sich, daß auch die Teilprinzipien nicht immer so abgegrenzt werden können, daß nur ein Kostenelement thematisiert wird.

$58 \mathrm{GK}=\mathrm{f}\left(\mathrm{TP}_{1}, \mathrm{TP}_{2}, \ldots, \mathrm{Tp}_{\mathrm{i}}\right)$; mit $\mathrm{i}=$ Anzahl der bestehenden Teilprinzipien (TP). Dies impliziert auch, daß die Reihenfolge der Teilprinzipien, an deren Anfang entsprechend der konventionellen ökonomischen Theorie des Föderalismus die allokativen Aspekten stehen, nichts über die Bedeutung der Teilprinzipien als Beurtei- 
1. Das Kongruenzprinzip: Es stellt sicher, daß der räumliche Wirkungsbereich eines öffentlichen Gutes mit der territorialen Ausdehnung der GKS übereinstimmt, die das Gut bereitstellt. Das Kongruenzprinzip besitzt einen räumlichen Bezug. Es entsteht eine Struktur monofunktionaler Bereitstellungseinheiten, die im Extremfall eine ebenso große Zahl an Einzelorganisationen aufweist wie es öffentliche Güter mit unterschiedlichem Wirkungskreis gibt. Bleibt das Kongruenzprinzip unbeachtet, so geht die Wirkung eines öffentlichen Gutes entweder über die Grenzen der GKS hinaus oder erreicht nur einen Teilbereich der GKS. Im ersten Fall entstehen räumliche externe Effekte (spillouts, externalities), im letzteren Fall interne Effekte (spillins, internalities). ${ }^{60}$ Beide Situationen können eine räumliche Über- bzw. Unterversorgung mit dem betrachteten öffentlichen Gut zur Folge haben, die Präferenzkosten auslösen. Es besteht ein Internalisierungsproblem: durch den Einsatz staatlicher Instrumente ist das „suboptimale” Angebot des öffentlichen Guts in den betroffenen GKS zu korrigieren.

2. Das Korrespondenzprinzip: Es gewährleistet die Übereinstimmung von Nutzern, Zahlern und Entscheidungsberechtigten eines öffentlichen Gutes. ${ }^{61}$ Es bezieht sich auf den Entscheidungsproze $ß$ des Gemeinwesens. Selbst bei Verwirklichung des Kongruenzprinzips muß dafür Sorge getragen werden, daß unter den im Rahmen einer repräsentativen Demokratie gewählten Entscheidungsträgern sowohl die Nutzer als auch die Zahler eines öffentlichen Gutes angemessen vertreten sind. Ist dies der Fall, so ist eine Voraussetzung furr rationale Budgetentscheidungen gewahrt. Besitzen hingegen die Nutzer ein Übergewicht unter den Entscheidungsträgern, ist mit einem Überangebot an öffentlichen Gütern zu rechnen; besitzen die Zahler ein Übergewicht, ist mit einem Unterangebot zu rechnen.

3. Das Fusionsprinzip: Würde man die Untersuchung an dieser Stelle abbrechen, wäre jeder Bürger Mitglied einer Vielzahl monofunktionaler Bereitstellungseinheiten unterschiedlichster Größe. Dies wäre mit unüberwindbaren Koordinationsproblemen und prohibitiv hohen Kosten zur Entscheidungsfindung und -durchführung in den zahlreichen Einzelfällen verbunden. Diese Belastung kann verringert werden, indem monofunktionale Organisationen, die den gleichen räumlichen Wirkungskreis besitzen, zu multifunktionalen GKS fusionie-

lungskriterium aussagt. Die Wertung der einzelnen Teilprinzipien hängt von der subjektiven Einschätzung des jeweiligen Betrachters ab.

59 Vgl. hierzu Biehl (1988b), S. 70 ff.; (1991a), S. 363 ff.; (1994a), S. 104 ff.; (1994b), S. 157 ff.; (1994c), S. 145 ff.; (1995a), S. 124 ff. Je nach Zweckmäßigkeit und Untersuchungsschwerpunkt unterscheidet er dabei jeweils eine größere oder kleinere Anzahl an Teilprinzipien.

60 Vgl. hierzu Olson (1969).

61 Das Korrespondenzprinzip entspricht weitgehend dem von Olson (1969) eingeführten Postulat der fiskalischen Äquivalenz (,fiscal equivalence”). 
ren. Auf diese Weise können bestehende Skalenerträge in allen Phasen des Entscheidungsund Bereitstellungsprozesses ausgenutzt werden.

4. Das Prinzip optimaler Kompetenzausstattung: Einer bestehenden territorialen Bereitstellungseinheit können so lange weitere Kompetenzbereiche zugewiesen werden, wie die Grenzkosten für die Aufgabenwahrnehmung niedriger sind als die Gesamtkosten bei getrennter monofunktionaler Organisation. Das Prinzip optimaler Kompetenzausstattung geht insofern über das Fusionsprinzip hinaus, als es die Einsparung weiterer Ressourcenkosten ermöglicht, „wenn die sich aus der Aufgabe des Kongruenzprinzips ergebenden Inkongruenzkosten niedriger sind als die Kosteneinsparungen, die aus der besseren Nutzung des gegebenen gewaltenteiligen Entscheidungssystems folgen." ${ }^{, 62}$ Diejenigen GKS, deren Entscheidungskapazität unterausgelastet ist, übernehmen Kompetenzen von denjenigen GKS, die überlastet sind, um die Entscheidungskapazitäten insgesamt besser zu nutzen.

5. Das Prinzip horizontaler und vertikaler Gewaltenteilung: Die Gewaltenteilung ist eines der grundlegenden Prinzipien einer freiheitlich-demokratischen Gesellschaft. Die horizontale Gewaltenteilung in Judikative, Exekutive und Legislative und die vertikale Gewaltenteilung zwischen den einzelnen Ebenen des föderativen Staates sollen den einzelnen Bürger „vor einer zu starken Konzentration staatlicher Macht in einer einzigen Institution .. schützen". 63

Das Prinzip bezieht sich auf die Präferenzkosten, die bei der staatlichen Entscheidungsfindung (Verfassungsfunktion) entstehen. Der Verletzung des horizontalen Systems der „checks and balances” zur Kontrolle staatlicher Macht wird prohibitive Präferenzkosten beigemessen, so daß die Gewaltenteilung uneingeschränkt aufrechterhalten bleibt, obwohl die öffentlichen Güter ohne Gewaltenteilung ressourcenkostengünstiger bereitgestellt werden könnten. Die vertikale Gewaltenteilung stellt eine zweite, ergänzende Machtkontrolle im föderativen Staat dar. Die gerechte politische Machtverteilung wird in diesem Fall noch stärker gewichtet als bei einer ausschließlich horizontalen Gewaltenteilung. Daher werden zusätzliche Ressourcenkosten toleriert, die entstehen, wenn eine öffentliche Aufgabe in einer Organisationseinheit zu minimalen Ressourcenkosten erfüllt werden könnte, aus distributiven Überlegungen zur Verhinderung politischer Machtkonzentration diese allokativ effiziente Aufgabenzuweisung jedoch unterbleibt.

${ }^{62}$ Biehl (1991a), S. 368; vgl. auch Biehl (1995a), S. 129.

${ }^{63}$ Vgl. Biehl (1994a), S. 103. 
6. Das Subsidiaritätsprinzip: Es stellt ein gesellschaftliches Ordnungs- und Gliederungsprinzip dar. ${ }^{64}$ Seine Bedeutung für die Aktivitäten des öffentlichen Sektors läßt sich durch zwei Versionen, die zunächst ,geradezu entgegengesetzt erscheinen”65 aber tatsächlich systematisch miteinander verknüpft sind, veranschaulichen. In seiner negativen Interpretation bestimmt das Subsidiaritätsprinzip, daß die jeweils kleinere Einheit - beginnend bei lokalen, regionalen und schließlich nationalen GKS - das Recht aber auch die Verpflichtung besitzt, die von ihr zu erfüllenden Aufgaben eigenverantwortlich wahrzunehmen. „Erst wo ihre Leistungsfähigkeit überfordert wäre, darf die Gemeinschaft helfend beispringen und ihnen die Leistung abnehmen, sie teilweise oder ganz übernehmen." ${ }^{66}$ In seiner positiven Interpretation leitet sich die ausdrückliche Verpflichtung für die jeweils nächstgrößere Einheit der Staatsorganisation ab, der kleineren Einheit Beistand in Form einer aktiven Hilfe zur Selbsthilfe zu leisten, wann immer letztere eine ihr zukommende Aufgabe nicht autonom erfüllen kann. ${ }^{67}$

Legitimiert ist das Eingreifen der größeren Einheit solange, bis die kleinere Einheit in die Lage versetzt wurde, die Aufgabe wieder eigenverantwortlich zu erfüllen. Das Subsidiaritätsprinzip beinhaltet folglich die Aufforderung zur subsidiären Rückverlagerung von Aufgaben. Zudem hat die größere Einheit bei der Ausübung ihrer Aufgabenwahrnehmung den Grundsatz der Verhältnismäßigkeit der Mittel zu beachten. Die Intensität und der Umfang der ergriffenen Maßnahmen dürfen das zur Aufgabenerfüllung notwendige Maß nicht überschreiten, um den kleineren Einheiten einen möglichst weiten Gestaltungsspielraum zu belassen. $^{68}$

Das Subsidiaritätsprinzip ist ein Kompetenz- bzw. Zuständigkeitsprinzip, das normativ bestimmt „wie die Menschen und die von ihr getragenen Institutionen im Gesamtgefuige des Staates und der Gesellschaft einander zugeordnet sind". ${ }^{69}$ In einer Normalsituation rechtfertigt es eine Kompetenzdezentralisierung, die über die aus dem Blickwinkel der Ressourcenkosten optimalen Grad hinausgeht. Es wird den durch größere Bürgernähe erreichbaren Präferenzkostensenkungen eine besonders starke Gewichtung im Vergleich zu den Ressourcenkosteneinsparungen, die sich durch eine Zentralisierung realisieren ließen, zugesprochen. ${ }^{70}$ Ist die Leistungsfähigkeit der dezentralen GKS hingegen überlastet (Sondersi-

64 Vgl. zum Subsidiaritätsprinzip grundlegend Nell-Breuning (1962).

Nell-Breuning (1962), S. 827.

Nell-Breuning (1962), S. 827.

Vgl. Nell-Breuning (1962), S. 827 ff. u. 832; Döring (1994) und Homann/Kirchner (1995), S. 48 f.

68 Vgl. Europäische Kommission (1992a), S. 5 u. (1993b), S. 379 f.; auch Döring (1994) und Wissenschaftlicher Beirat (1994), S. 24 f.

69 Dams/Heide (1995), S. 938.

70 Vgl. Döring (1994), S. 243; auch Europäische Kommission(1992a), S. 1. 
tuation), begründet das Subsidiaritätsprinzip eine besondere gesamtstaatliche Verantwortung der übergeordneten Ebene, die eine Zentralisierung von Kompetenzen nicht nur rechtfertigt, sondern uneingeschränkt fordert.

7. Das Prinzip der Kompetenzdifferenzierung: Gemäß der konventionellen Föderalismustheorie wird eine öffentliche Aufgabe stets vollständig an eine bestimmte GKS übertragen (Vollkompetenz). Es besteht die Vorstellung, daß die autonom agierende GKS eigene Problemlösungen realisiert, die den Präferenzen ihrer Bürger entsprechen. Diese föderative Organisationsstruktur wird als kompetitiver Föderalismus bezeichnet. Jedoch haben die bisherigen Erörterungen verdeutlicht, daß weitreichende Interdependenzen zwischen den Funktionen des öffentlichen Sektors bestehen und zwar sowohl in räumlicher als auch in sachlicher Hinsicht. ${ }^{71}$ Die Nichtbeachtung dieser Interdependenzen fuihrt zu Ressourcenund Präferenzkosten. Aus dieser Sicht muß die Vollkompetenz eines bestimmten Aufgabenbereichs in einzelne Teilkompetenzen zerlegt werden, die durch verschiedene GKS des föderativen Staates wahrgenommen werden. ${ }^{72}$ In diesem System der vertikalen bzw. horizontalen Politikverflechtung (kooperativer Föderalismus) müssen allerdings Ressourcen zur Koordinierung der einzelnen Teilkompetenzen aufgewendet werden. Daher kann die (schwache) Schlußfolgerung gezogen werden, daß eine optimale Kompetenzdifferenzierung stets „Zwischen dem Polarfall ausschließlicher Zuteilung von Vollkompetenzen und vollständiger Zerlegung in Teilkompetenzen mit Verteilung auf sehr viele unterschiedliche Einheiten"73 liegt.

8. Das Prinzip gerechter Lastenverteilung: Es knüpft an die Wertvorstellungen über die Lösung von Verteilungsproblemen an. Das Äquivalenzprinzip und das Leistungsfähigkeitsprinzip sind die beiden Fundamentalprinzipien, auf deren Basis über die gerechte Verteilung der Finanzierungslasten öffentlicher Güterbereitstellung entschieden wird. In traditioneller Abgrenzung wird das Prinzip der gerechten Lastenverteilung auf Personen angewen-

71 In räumlicher Hinsicht sei auf die Existenz externer Effekte zwischen den GKS verwiesen. In sachlicher Hinsicht sei in Anknüpfung an die übliche Aufgabenverteilung gemäß der ökonomischen Föderalismustheorie exemplarisch der „globale” Zusammenhang zwischen Allokations-, Distributions- und Stabilisierungsfunktion im traditionellen (engen) Sinne angesprochen. Es ist im Extrem denkbar, „daß aufgrund der Übertragung der Allokationsfunktion an regionale Regierungen der nationenweiten Regierungsebene nur in geringem Umfange Handlungsparameter zur Verfügung stehen, um aktive Redistributions- und Stabilisierungspolitik betreiben zu können." (Noll (1979), S. 202) Aus diesem Blickwinkel ist es sinnvoll, der zentralen Ebene auch einen größeren Teilbereich der Allokationsfunktion bzw. zusätzliche Einnahmekompetenzen zuzuordnen.

72 So kann eine Vollkompetenz bspw. in die Teilkompetenzen der Gesetzgebungshoheit, der Durchführungshoheit, der Verwaltungshoheit und der Finanzierungshoheit zerlegt werden (vgl. Biehl (1995a), S. 132). In anderer Abgrenzung könnten die Phasen des Handlungsablaufs Planung, Entscheidung, Durchführung und Kontrolle unterschieden werden (vgl. Noll (1979), S. 202). Schließlich kann eine Vollkompetenz auch in eine Rahmenkompetenz für die übergeordnete gebietskörperschaftliche Ebene und eine Durchführungskompetenz für die nachgeordnete gebietskörperschaftliche Ebene aufgeteilt werden (vgl. Biehl (1988b), S. 75).

73 Biehl (1995a), S. 132 f. 
det. ${ }^{74}$ Die Überlegungen zum Äquivalenz- und Leistungsfähigkeitsprinzip lassen sich aber auch auf die Frage der Lastenverteilung zwischen GKS übertragen. ${ }^{75}$ Verfügen einzelne GKS nicht über ausreichende Einnahmen, um ein angemessenes Angebot öffentlicher Güter bereitzustellen, so können aus Gerechtigkeitsüberlegungen heraus Ausgleichszahlungen zwischen den GKS beschlossen werden. Die Forderung nach interkollektiver gerechter Lastenverteilung geht dann über in das Prinzip des Finanzausgleichs im engeren Sinne. ${ }^{76}$

\section{II-3 Zwischenfazit}

Die ökonomische Theorie des Föderalismus wurde in den voranstehenden Teilabschnitten durch die Erweiterung des ökonomischen Kostenbegriffs der Aufnahme außerökonomischer Fragen zum politischen Entscheidungsprozeß und zu sozio-kulturellen Merkmalen (Wertordnungs- und Präferenzstrukturen) der betrachteten Gemeinwesen geöffnet. Der Analyse liegt ein graphisches Grundmodell zur Abbildung der Kosten bei der Erfüllung öffentlicher Aufgaben zugrunde. Die beiden Kostenkategorien der Ressourcenkosten und der Präferenzkosten beinhalten jedoch zu viele Einzelelemente, um aus dem Grundmodell heraus konkrete Sachverhalte untersuchen zu können. Deshalb wurde mit den föderativen Teilprinzipien eine Anzahl an Beurteilungskriterien definiert, die jeweils partialanalytische Schlußfolgerungen zu einzelnen (Kosten-)Elementen ermöglichen. Theoretisch erlaubt die zeitgleiche Berücksichtigung aller aufgeführten Teilprinzipien die Ableitung optimaler Regelungen zur Erfüllung der staatlichen Funktionen.

Die idealisierte Vorstellung besitzt allerdings lediglich einen didaktischen Wert. Die Gesamtheit der normativen Kriterien kann nur im gedanklichen Referenzmodell simultan beachtet werden, nicht aber in der (komplexen) Realität. ${ }^{77}$ Darüber hinaus wurden eine Reihe zusätzlich vereinfachender Annahmen getroffen, die die theoretische Analyse ermöglichen, aber die Umsetzung der Modellergebnisse in der Realität immens erschweren. ${ }^{78}$ V.a. ist zu betonen,

74 Vgl. hierzu Haller (1981), S. 13 ff.; aktuell Brümmerhoff (1996), S. 238 ff. Die Steuerfinanzierung öffentlicher Ausgaben kann als eine Kombination aus (gruppenmäßigem) Äquvalenzprinzip und Leistungsfähigkeitsprinzip aufgefaßt werden. Unter Beachtung des Kongruenzprinzips werden die Finanzierungslasten gemäß des Äquivalenzprinzips der GKS zugerechnet, in deren Grenzen das öffentliche Gut seinen Wirkungskreis besitzt. Innerhalb dieser GKS werden die öffentlichen Ausgaben jedoch nach dem Leistungsfähigkeitsprinzip zwischen den einzelnen Gruppenmitgliedern (Bewohner) aufgeteilt.

75 So bspw. Hackenbroch (1983), S. $112 \mathrm{ff}$.

76 Vgl. hierzu die weitergehenden Ausführungen zur ,fiskalischen Gleichheit” in Abschnitt III-3.1.2.

77 Dieses Vorhaben scheitert bereits an kognitiven Beschränkungen der politischen Entscheidungsträger.

78 Insbesondere die im Folgenden genannten Problemfelder wurden durch vereinfachende Modellannahmen aus der Analyse ausgeschlossen:

- Die angeführten Präferenzkosten sind Ausdruck des Nutzens öffentlicher Güter; die Messung dieses Nutzens ist in der Realität mit beinahe unüberwindbaren Schwierigkeiten verbunden. 
daß die einzelnen (Kosten-)Elemente nicht wirklich objektivierbar sind. In einer realen Entscheidungssituation werden die „optimalen” Regelungen deshalb unabdingbar von den subjektiven Wertvorstellungen des Betrachters bestimmt. Dennoch bietet das erweiterte föderative Referenzsystem eine wertvolle Diskussionsgrundlage zur partialanalytischen Untersuchung konkreter Problembereiche in einem Mehrebenen-Staat. Zwar können keine quantifizierbaren Ergebnisse „errechnet” werden, doch lassen sich qualitative Aussagen ableiten. Es können Tendenzaussagen zur Weiterentwicklung einer bestehenden oder Konzipierung einer neu zu schaffenden rechtlich-organisatorischen Struktur eines föderativen Staates getroffen werden. ${ }^{79}$ Die Beschränkung des Realitätsgehalts des Referenzmodells muß aber bewußt bleiben, wenn es zur Analyse und/oder Bewertung der Fragestellungen in den folgenden Abschnitten dieser Arbeit herangezogen wird.

Der erweiterte föderative Referenzrahmen verdeutlicht darüber hinaus, daß bei der Gestaltung der rechtlich-organisatorischen Struktur eines föderativen Staates eine Vielzahl an ökonomischen, politischen und sozio-kulturellen Interdependenzen und Zielkonflikten beachtet werden muß ${ }^{80}$ Die Aufspaltung der komplexen Problemzusammenhänge in Teilprinzipien bzw. die Partialanalyse einzelner staatlicher Funktionen darf nicht dazu führen, daß die Wechselwirkungen unbeachtet bleiben. ${ }^{81}$ Bei allen Aussagen müssen eine Reihe miteinander verknüpfter Einzelaspekte abgewogen werden. Im föderativen Staat verbleibt damit stets ein Koordinationsbedarf zwischen den einzelnen Bereitstellungseinheiten öffentlicher Güter. ${ }^{82}$

Aufbauend auf diese grundsätzlichen Überlegungen zum Finanzausgleich im weitesten Sinne kann nun in Kapitel III zum Schwerpunkt des theoretischen Teils dieser Arbeit übergegangen werden. Die zwischenstaatlichen FZ werden als besonderer Teilaspekt aus dem allgemeinen Referenzrahmen herausgegriffen und eingehend untersucht.

- In der Realität ist der dargestellte Vergleich der verschiedenen Kostenkategorien deshalb kaum möglich. Die Präferenz- und Ressourcenkosten müßten in aggregierbaren Einheiten ausgedrückt werden können. Dies erforderte eine kardinale Nutzenmessung und folglich die Möglichkeit interpersoneller Nutzenvergleiche.

- Die Messung von Skalenerträgen und der durch externe Effekte entstehenden Kosten ist in der Realität äußerst problematisch.

- Das Grundmodell ist statischer Natur. Es werden Aussagen mit einem ganz spezifischen Raum- und Zeitbezug abgeleitet. Jedoch besitzt eine dynamische Sichtweise der „Optimalität” der Verfassungsregeln und der Aufgabenverteilung eine entscheidende Bedeutung.

79 Vgl. auch Scharpf (1997a), S. 65.

80 Diese Aussage besitzt bereits im Rahmen einer statischen Betrachtungsweise uneingeschränkte Gültigkeit, wie insb. die Erläuterung der einzelnen Teilprinzipien zeigte. Wird zusätzlich die dynamische Fortentwicklung der Einzelaspekte im Zeitablauf in die Überlegungen einbezogen, so erhöht sich die Komplexität der Fragestellung nochmals.

81 So auch schon Oates (1972), S. XV im Hinblick auf die rein ökonomische Betrachtungsweise.

82 Vgl. hierzu Breton/Scott (1978), S. 142 f.; Noll (1979), S. 202 f. und jüngst Hesse, J.J. (1997), S. 116 f. 


\section{Zwischenstaatliche Finanzzuweisungen - theoretische Grundlegung eines rationalen Finanzausgleichsystems}

Intention dieses Kapitels III ist es, die theoretischen Grundlagen der Vergabe zwischenstaatlicher FZ zur Einrichtung eines rationalen Finanzausgleichsystems ${ }^{83} \mathrm{zu}$ analysieren. Grundlegendes Element eines rationalen Finanzausgleichsystems ist die Definition eines widerspruchsfreien und vollständigen Zielsystems, dessen Realisierung durch den systematischen Einsatz des vorhandenen Instrumentariums zwischenstaatlicher FZ angestrebt wird. ${ }^{84}$ Daher wird nachfolgend ermittelt, welche Funktionen die FZ erfüllen können und wie deren zweckmäßigste Form je nach zu verfolgender Zielsetzung aussehen muß. Die Ergebnisse dieses Kapitels stellen das „theoretische Rüstzeug” dar, das in Kapitel V auf die spezifische Dimension der europäischen Ebene angewendet wird. Es erlaubt, die Geeignetheit ${ }^{85}$ zwischenstaatlicher FZ als Instrument zur Erreichung verschiedener Ziele der EU zu analysieren.

Die Untersuchung erfolgt in vier Schritten. Zum ersten werden die Formen, die FZ annehmen können, vorgestellt (Beschreibung des Instrumentariums; Abschnitt III-1). Zum zweiten wird eine ausführliche Analyse der Wirkungen alternativer Ausgestaltungen der FZ vorgenommen (Wirkungsanalyse; Abschnitt III-2). Die mikroökonomische Indifferenzkurvenanalyse veranschaulicht die zentralen Wirkungen unterschiedlicher FZ auf den Umfang und die Struktur des öffentlichen Leistungsangebots in den transferempfangenden GKS. Dieses Ausgangsmodell wird anschließend zielgerichtet erweitert, um den politischen Entscheidungsprozeß in die Untersuchung zu integrieren. Die Wirkungsanalyse wird hierdurch auf die Grundlage alternativer Modellüberlegungen gestellt, die sich sinnvoll ergänzen. Dies ermöglicht es in einem dritten Schritt, die mit den FZ zu verfolgenden Ziele (Funktionen) zu diskutieren und Schlußfolgerungen für ihre aufgabenadäquate Ausgestaltung abzuleiten (Zielbestimmung in Verbindung mit einer aufgabenorientierten Auswahl des Instrumentariums; Abschnitt III-3). Ein schlüssiges Gesamtsystem ist jedoch nur zu realisieren, wenn die wechselseitigen Wirkungszusammenhänge zwischen den einzelnen Funktionen beachtet werden. Daher werden im vierten Schritt Anforderungen an das Gesamtsystem der FZ formuliert (Abschnitt III-4).

${ }^{83}$ Hierunter ist entsprechend der Abgrenzung im einleitenden Kapitel dieser Arbeit (Abschnitt I-2) ein Finanzausgleichsystem im engen Sinne zu verstehen.

84 Vgl. hierzu Spiess (1973), S. 8 ff.; auch Fischer-Menshausen (1988), S. 655 f.

${ }_{85}$ Diese Geeignetheit bezieht sich auch auf den Vergleich zu alternativen staatlichen Handlungsparametern; vgl. hierzu auch Break (1980), S. 76. 


\section{III-1 Formen zwischenstaatlicher Finanzzuweisungen}

\section{III-1.1 Horizontale und vertikale Finanzzuweisungen}

Je nachdem, welche GKS an der Vergabe der FZ beteiligt sind, kann zwischen horizontalen und vertikalen FZ unterschieden werden. Horizontale FZ erfolgen zwischen GKS der gleichen Ebene des föderativen Staates. Bei vertikalen FZ hingegen gehören Empfänger und Geber der FZ unterschiedlichen Regierungsstufen an. ${ }^{86}$ Im Mittelpunkt dieser Arbeit stehen die Beziehungen zwischen den EU-Mitgliedstaaten. Die FZ werden als direkte „Maßnahmen zur Linderung von Spannungen zwischen Aufgaben und Einnahmen" ${ }^{\text {} 87}$ auf der Ebene der Mitgliedstaaten betrachtet. Daher liegt das Augenmerk auf solchen FZ, durch die horizontale Wirkungen ausgelöst werden. Diese Wirkungen können durch horizontale FZ zwischen den Mitgliedstaaten und durch vertikaler FZ zwischen der zentralen EU-Ebene und den Mitgliedstaaen (vertikale FZ mit horizontalem Wirkungskreis) ausgelöst werden. ${ }^{88}$

Die Entscheidung für vertikale oder horizontale FZ ist in die Struktur der Finanzverfassung des betrachteten Gesamtstaates einzubetten. ${ }^{89}$ Weist die Finanzverfassung die ergiebigsten Steuerarten der zentralen Ebene zu, spricht dies für vertikale FZ. Demgegenüber sind direkte horizontale Ausgleichszahlungen geeignet, sofern die GKS der betroffenen Ebene des Gesamtstaates über eine weitgehende Einnahmenautonomie verfügen oder im Rahmen eines Steuerverbundes am Aufkommen der einnahmeergiebigen Steuerarten partizipieren. Diese Verfahrensweise stellt sicher, daß die transfergewährende gebietskörperschaftliche Ebene über das notwendige Mittelvolumen verfügt, die FZ in zieladäquater Höhe leisten zu können. ${ }^{90}$

In einem System vertikaler FZ ist zu berücksichtigen, daß die transferempfangenden GKS stets in einem bestimmten Umfang selbst zur Finanzierung der erhaltenden FZ beitragen. Sei es direkt, weil jede untergeordnetete GKS allgemeine Finanzierungsbeiträge an die zentrale Ebene zu leisten hat oder indirekt, weil die Bewohner der transferempfangenden GKS zugleich Steuerzahler der zentralen Ebene sind. Damit werden die mit der FZ-Vergabe angestrebten Wirkungen (teilweise) konterkariert. Diese Situation kann bei horizontalen FZ nicht entstehen, da die transferleistenden und transferempfangenden GKS bei dieser Organisationsform strikt voneinander abgegrenzt sind. ${ }^{91}$

86 Vgl. hierzu bspw. Noll/Hildebrandt (1996), S. 113; Kops (1989), S. 158 ff.

87 Grossekettler (1996), S. 16.

88 Vgl. hierzu bspw. Peffekoven (1988), S. 626.

89 Vgl. zum Folgenden v.a. Mathews (1977), S. 436 f. u. Peffekoven (1988), S. 626.

90 Vgl. hierzu auch Hackenbroch (1983), S. $133 \mathrm{f}$.

91 Vgl. hierzu Hilber (1974), S. 12 f. Auf die Möglichkeit, daß es den transferzahlenden GKS gelingen könnte, Steuerlasten auf transfererhaltende GKS durch Steuerüberwälzung zu verlagern und auf diese Weise auch bei 


\section{III-1.2 Auflagengebundene und allgemeine Finanzzuweisungen}

Die zweite grundlegende Klassifizierung der FZ ist die Abgrenzung von FZ, die an bestimmte Auflagen gebunden sind, von allgemeinen FZ (Pauschalzuweisungen). Die Auflagen werden in Verwendungsauflagen und Empfangsauflagen eingeteilt. ${ }^{92}$

\section{III-1.2.1 Finanzzuweisungen mit und ohne Verwendungsauflagen}

FZ ohne Verwendungsauflagen sind mit keinerlei Restriktionen für den Gebrauch der zugewiesenen Mittel behaftet. Hingegen ist die Übertragung der Mittel bei FZ mit Verwendungsauflagen (zweckgebundenen FZ) an die Verausgabung in vom Zuweisungsgeber abgegrenzten Bereichen geknüpft.

Diese Auflagenbindung soll sicherstellen, daß die Mittel nur für die vom Zuweisungsgeber gewünschten Zwecke eingesetzt werden. Dabei kommt der jeweiligen Ausgestaltung der Verwendungsauflagen eine große Bedeutung zu. Durch eine sehr spezifische, restriktive Formulierung der Auflagen wird der bei der Mittelverwendung verbleibende Handlungsspielraum der transferempfangenden GKS stark eingeschränkt. Der Zuweisungsempfänger wird dann weitgehend „zu einem Verwaltungsagenten des Transfergebers denaturiert”. ${ }^{93}$ Andererseits kann den Zuweisungsempfängern ein erheblicher diskretionärer Entscheidungs- und damit Verausgabungsspielraum bewahrt bleiben, wenn durch die Verwendungsauflagen nur (recht) allgemeine Zielbereiche bestimmt werden. ${ }^{94}$

Eine effektive Kontrolle der auflagengerechten Mittelverwendung wird umso schwieriger, je unspezifischer die Zweckbindung der Zuweisungen erfolgt. Dann steigt die Wahrscheinlichkeit umfangreicher „Sickerverluste" ${ }^{\text {95 }}$ durch die Verwendung der Zuweisungen für Zwecke, die nicht der Zielsetzung der Zuweisungsgeber entsprechen. ${ }^{96}$ Die Sickerverluste können zudem durch die budgetinterne Substitution eigener Mittel der transferempfangenden GKS durch erhaltene FZ ausgelöst werden. ${ }^{97}$ Da die Zweckbindung der FZ keinen Einfluß auf die komplementäre Bereitstellung eigener Finanzmittel für den durch die FZ unterstützten Bereich nimmt, können die freigewordenen eigenen Mittel zur Bereitstellung alternativer öffentlicher

horizontalen FZ eine Vermischung der Finanzierungslasten entstehen könnte, soll an dieser Stelle nur hingewiesen werden; vgl. hierzu bspw. Groenewegen (1988), S. 19 f.

92 Vgl. hierzu Waldauer (1973), S. 213; Smekal (1980), S. 172 ff.; Zimmermann (1983), S. 43 f. u. Fischer (1988), S. $25 \mathrm{ff}$.

93 Smekal (1980), S. 173.

94 Z.B. verbleibt der transferempfangenden GKS ein erheblicher Handlungsspielraum, wenn als Verwendungszweck nur ein bestimmter Aufgabenbereich, z.B. Bildung, angegeben wird. Vgl. Zimmermann (1983), S. 44.

95 Musgrave/Musgrave/Kullmer (1992), S. 33.

96 Das Problem der Fungibilität. Vgl. Smekal (1980), S. 173; aktuell Costello (1993a), S. 108 ff.

97 Das Problem der Additionalität. 
Güter verwendet oder in Form von Steuersenkungen an die Bürger der GKS weitergegeben werden. ${ }^{98}$ Um derartige Zielverfehlungen zu vermeiden, können die Zuweisungsgeber die Vergabe der FZ an die Erfüllung bestimmter Empfangskriterien binden.

\section{III-1.2.2 Finanzzuweisungen mit und ohne Empfangsauflagen ${ }^{99}$}

FZ mit Empfangsauflagen knüpfen die Vergabe der Mittel an bestimmte Eigenschaften, die innerhalb der zuweisungsempfangenden GKS erfüllt sein müssen. Die Empfangsauflagen führen zu einer Eingrenzung des Empfängerkreises der FZ.

FZ ohne Empfangsauflagen werden stets in einem vom Transfergeber zuvor festgelegtem Umfang gewährt. Der Transferempfänger besitzt keine Möglichkeit, die Höhe der Mittelzuweisung durch gezielte Veränderung von Eigenschaften der eigenen GKS zu beeinflussen. Bestehen hingegen Empfangsauflagen, wird das Verhalten der Empfänger zu einer Determinante der konkreten Mittelvergabe. Die staatlichen Entscheidungsträger besitzen nun grundsätzlich die Möglichkeit durch gezielte Verhaltensreaktionen, die Eigenschaften der eigenen GKS so zu verändern, daß die Empfangsauflagen erfüllt werden. Damit kann sich eine GKS, die ursprünglich nicht an der Vergabe der Transfers partizipiert hätte, für FZ qualifizieren. ${ }^{100}$

Wie bei den Verwendungsauflagen kommt der konkreten Ausgestaltung der Empfangsauflagen eine wesentliche Bedeutung zu. Erfolgt eine sehr restriktive Formulierung verbleiben kaum Möglichkeiten durch Verhaltensänderungen die Auflagen - quasi nachträglich - zu erfüllen, so daß die FZ auf einen detailliert festgelegten Empfängerkreis begrenzt wird. Allerdings ist die Art der Empfangsauflage zu beachten: ${ }^{101}$

- Empfangsauflagen demographischer (bspw. die Altersstruktur der Einwohner oder Bevölkerungsdichte) und geographischer (bspw. die topographische Lage in Küsten- oder Gebirgsnähe) Art lösen kaum Reaktionen aus, da es weitgehend ausgeschlossen ist, daß die GKS durch Variation interner Handlungsparameter die Erfüllung jener Empfangsauflagen gewährleisten. ${ }^{102}$

98 Vgl. hierzu Oates (1977), S. 77, der vom „leakage”-Effekt spricht. Ähnlich Wilde (1968), S. 341 u. (1971), S. 145 f. Diese Sickerverluste sind nur dann ausgeschlossen, wenn die transferempfangende GKS in der Ausgangssituation ohne FZ keine eigenen Mittel im Zielbereich der FZ bereitstellt. Vgl. zum Folgenden Wilde (1971), S. 147 ff.; Smekal (1980), S.172 ff. u. Fischer (1988), S. 25 ff.

100 Vgl. King (1984), S. 87 u. 88.

101 Vgl. zum Folgenden auch Hilber (1974), S. $16 \mathrm{f}$.

102 Allenfalls im Bereich demographischer Empfangsauflagen ist es in begrenztem Umfang möglich, die Bemessungsgrundlage für die FZ zu beeinflussen; so können Altersstruktur der Bevölkerung oder Einwohnerzahl bspw. durch die Zusammenlegung dezentraler GKS oder durch eine aktive Zuwanderungspolitik verändert werden. Diese Anpassungsreaktionen sind dann als unerwünscht zu bezeichnen, wenn ihnen aus gesamtwirtschaftlicher Sicht keine ,wirtschaftlichen und verwaltungsmäßigen Vorteile” (Smekal (1980), S.173) zukommen und sie stattdessen Ausdruck eines nicht-kooperativen Nullsummenspiels zwischen dezentralen GKS 
- Im Gegensatz hierzu besteht im Fall funktionaler (bspw. das bestehende Bereitstellungsniveau des geförderten Guts) oder ökonomischer (bspw. das Verhältnis zwischen Finanzkraft und Finanzbedarf) Empfangsauflagen die Möglichkeit strategischer Anpassungsreaktionen. Wird die FZ an die Existenz einer unzureichenden Finanzkraft einer GKS gebunden, so werden der GKS (ceteris paribus) Anreize genommen, die interne wirtschaftliche Leistungsfähigkeit durch eine effiziente und wachstumsfördernde Politik nachhaltig zu verbessern, da die damit verbundene Steigerung der eigenen Finanzkraft zu einem Verlust von FZ führen würde. ${ }^{103}$ Zudem besteht die Gefahr, daß die betroffene GKS ihre eigene Steueranstrengung reduziert, um die Zuteilung zusätzlicher Transfers auszulösen. ${ }^{104}$ Wird in Reaktion hierauf eine zusätzliche Empfangsauflage in Form einer MindestSteueranstrengung eingeführt, sind unerwünschte Verteilungswirkungen für wirtschaftliche weniger leistungsfähige GKS denkbar, „da die Nutzeneinbuße durch die Besteuerung dort größer angenommen werden muß als in einer 'reichen 'Gemeinde." ${ }^{105}$ Beziehen sich Mindestanforderungen auf das Bereitstellungsniveau spezifischer öffentlicher Güter, so werden die Verhaltensreaktionen der transferempfangenden GKS, um an der Vergabe der FZ partizipieren zu können, weitgehend durch den Transfergeber vorherbestimmt.

- Ausdrücklich erwünscht sind Anpassungsreaktionen, die aufgrund von Empfangsauflagen im politisch-administrativen Bereich erfolgen. Solche Auflagen besitzen zumeist die Aufgabe, die verwaltungsbezogenen Voraussetzungen einer effizienten Verwendung der FZ auf dezentraler Ebene zu gewährleisten, indem die Existenz einer effizienten Finanzverwaltung und/oder einer effektiven und unabhängigen Kontrollinstanz der Mittelverausgabung gefordert wird.

\section{III-1.2.3 Finanzzuweisungen mit und ohne Eigenleistung}

Eine besondere Form der Empfangsauflage stellt die Verknüpfung der FZ-Vergabe mit einer finanziellen Eigenleistung der transferempfangenden GKS dar („matching grant”). ${ }^{106}$ Der Zuweisungsempfänger erhält die FZ nur, wenn er sich selbst an der Finanzierung der öffentlichen Leistung beteiligt. Die Höhe der FZ wird als eine Funktion der finanziellen Eigenlei-

sind, die im (ruinösen) horizontalen Wettbewerb um FZ eine Verschwendung öffentlicher Ressourcen betreiben. Vgl. hierzu auch die Überlegungen zum interkollektiven Entscheidungsprozeß in Abschnitt III-2.3.2; zur Problematik des Fiskalwettbewerbs zwischen GKS vgl. Sinn (1995); (1997a).

103 Vgl. hierzu näher Abschnitt III-3.1.2.2.5 zur Bestimmung der Ausgleichsintensität im Fall horizontaler fiskalischer Ungleichgewichte.

104 Es besteht eine, ,moral-hazard"-Problematik.

${ }^{105}$ Smekal (1980), S. 172.

106 Vgl. hierzu bspw. Wilde (1968), S. 340 u. (1971), S. 144 ff.; Peffekoven (1988), S. 624. 
stung spezifiziert (,matching ratio”). Diese bezeichnet zumeist einen prozentualen Anteil der FZ am Umfang der in Eigenleistung bereitgestellten Mittel. ${ }^{107}$

Die Vergabe einer FZ mit Eigenleistung erfolgt notwendigerweise in Verbindung mit bestimmten Verwendungsauflagen. Da eine Pauschalzuweisung der transferempfangenden GKS nicht nur die Wahlmöglichkeit zur Erhöhung des Angebots öffentlicher Güter überläßt, sondern alternativ auch Steuersenkungen gewährt werden können, besteht sonst die Gefahr, daß der Umfang nicht-zweckgebundener FZ mit Eigenleistung ausufert, weil der Kofinanzierung durch die Transferempfänger keine Grenzen gesetzt sind. ${ }^{108}$

Das Ziel der Transfergeber ist es, den Bereitstellungsumfang einer bestimmten öffentlichen Leistung auf ein gewünschtes Niveau anzuheben. ${ }^{109}$ Der entscheidende Parameter zur Zielerreichung ist die Festlegung eines adäquaten Finanzierungsanteils der Transferempfänger. Wird der Finanzierungsanteil willkürlich oder aufgrund unzureichender Information festgesetzt, ist mit großer Wahrscheinlichkeit ein suboptimales Bereitstellungsniveau die Folge. Eine zu niedrige Eigenbeteiligung kann exzessive Ausgaben im unterstützen Bereich auslösen; wird der Finanzierungsanteil zu hoch festgelegt, bleibt das Ausgabevolumen möglicherweise zu gering. Allerdings muß die Finanzkraft der zuweisungsempfangenden GKS beachtet werden. Je geringer die Finanzkraft ist, desto größer wird die Wahrscheinlichkeit, daß FZ aufgrund mangelnder eigener Kofinanzierungsmittel nicht in Anspruch genommen werden kön-

${ }^{107}$ Ein 50-Prozent-FZ (,50 percent matching grant”) bedeutet, daß die transferempfangende GKS eine FZ in Höhe von 50 Pfennigen für jede Mark erhält, die sie aus eigenen Mitteln bereitstellt. Vgl. King (1984), S. 88.

${ }^{108} \mathrm{Die}$ folgende $\mathrm{Abb}$. verdeutlicht den Zusammenhang an einem Zahlenbeispiel. Es wird von einer FZ mit Eigenleistung (50-Prozent-FZ ohne Verwendungsauflage) ausgegangen. Unter der „ceteris-paribus"-Annahme sonst unveränderter öffentlicher Leistungen der transferempfangenden GKS führt die FZ zunächst zu einer Steuererhöhung in doppelter Höhe der erhaltenen FZ, um die verlangte Kofinanzierung sicherzustellen. In einem zweiten - in der Modellwelt allerdings zeitgleichen - Schritt erfolgt ein Transfer an die privaten Wirtschaftssubjekte, der äquivalent zu einer Steuersenkung ist, in Höhe des addierten Betrages aus FZ und Kofinanzierung, wobei letztere genau der originären Steuererhöhung entspricht. Es ergibt sich folgender Nettoeffekt: das öffentliche Leistungsniveau der transferempfangenden GKS bleibt unverändert, bei einer eigenen Steueranstrengung (effektive Steuerbelastung der privaten Wirtschaftssubjekte), die sich um den gesamten Betrag der (an die Eigenleistung gebundenen) FZ verringert hat. Die transferempfangenden GKS hat somit einen Anreiz, die eigene Kofinanzierung beständig auzuweiten. Als theoretische Extremsituation erfolgt die gesamte Finanzierung der angebotenen öffentlichen Leistungen durch die FZ der transfergewährenden GKS (vgl. hierzu auch Wilde (1968), S. 340):

\begin{tabular}{|c|c|c|c|c|c|c|}
\hline $50 \%$ FZ & $\begin{array}{c}\text { Steuer- } \\
\text { aufkommen }\end{array}$ & $\begin{array}{c}\Delta \text { Steuerauf- } \\
\text { 'kommen } \\
\text { (Steuererhöhung) }\end{array}$ & $\begin{array}{c}\text { öffentliches } \\
\text { Leistungs- } \\
\text { angebot }\end{array}$ & $\begin{array}{c}\text { Transfer } \\
\text { (Steuer- } \\
\text { senkung) }\end{array}$ & $\begin{array}{c}\text { effektive Steuer } \\
\text { belastung }\end{array}$ & $\begin{array}{c}\text { Nettoeffekt: } \\
\Delta \text { Steuer- } \\
\text { belastung }\end{array}$ \\
\hline- & 5000 & - & 5000 & - & 5000 & - \\
\hline 500 & 6000 & 1000 & 5000 & 1500 & 4500 & -500 \\
\hline 1000 & 7000 & 2000 & 5000 & 3000 & 4000 & -1000 \\
\hline$\ldots$ & $\ldots$ & $\ldots$ & $\ldots$ & $\ldots$ & $\ldots$ & $\ldots$ \\
\hline 5000 & 15000 & 10000 & 5000 & 15000 & 0 & -5000 \\
\hline
\end{tabular}

109 Vgl. hierzu Musgrave/Musgrave (1973), S. 637 f; Costello (1993a), S. 107 f; Walsh (1993), S. 41. 
nen und das gewünschte Bereitstellungsniveau deshalb verfehlt wird. Dies spricht für eine Staffelung der Eigenbeteiligung in einem zur Finanzkraft umgekehrten Verhältnis. ${ }^{110}$

Zudem ist zu berücksichtigen, daß jede Finanzierungsbeteiligung durch den Transfergeber die Anreize der Transferempfänger, die effiziente Verwendung der Ressourcen zu überwachen, abschwächt, da nunmehr nur ein Anteil der eingesetzten Mittel eigenen Einnahmequellen entspringt. Es resultieren Ineffizienzen bei der Bereitstellung der öffentlichen Leistungen. ${ }^{11}$ Mit zunehmenden Finanzierungsanteil muß daher die transferleistenden GKS ihre Kontrollaktivitäten erhöhen. Selbst wenn durch diese Kontrolle die Ineffizienzen bei der Bereitstellung erfolgreich unterbunden werden, bleibt aber die Summe aus Kontrollkosten und Ineffizienzkosten positiv. Einen Lösungsansatz stellt ein Bemessungsgrundlagenwechsel bei der Bestimmung der Finanzierungsbeteiligung der Transfergeber dar. Werden als Basis der FZ nicht die Ausgaben, die zur Güterbereitstellung aufgewendet werden, herangezogen, sondern Indikatoren der Leistungsqualität der Mittelverwendung („output performance”112), so erhalten die transferempfangenden GKS finanzielle Anreize zum effizienten Einsatz der gesamten Ausgaben. ${ }^{113}$

\section{III-1.3 Betragsmäßig begrenzte und unbegrenzte Finanzzuweisungen}

Als drittes Kriterium ist die Abgrenzung von betragsmäßig begrenzten („closed-end grant”) zu betragsmäßig unbegrenzten FZ (,open-end grant”) zu beachten. ${ }^{114}$ Im ersten Fall bestimmen die transfergebenden Entscheidungsträger vor Beginn des Zuweisungsverfahrens einen Gesamtbetrag, der den transferberechtigten GKS gemäß eines festgelegten Verteilungsschlüssels zugewiesen wird (Repartitionsprinzip). Erhöht sich die Zahl der transferberechtigten GKS oder erweitert sich die Bemessungsgrundlage der FZ innerhalb einzelner GKS, so erfolgt eine Kürzung des Zuweisungsbetrages je Einheit der Bemessungsgrundlage. Im zweiten Fall legen die Transfergeber in einem ersten Schritt einen bestimmten Zuweisungsbetrag pro Einheit der Bemessungsgrundlage der FZ fest (Quotitätsprinzip). Das Gesamtvolumen der FZ ergibt sich

${ }^{110}$ Diese Staffelung „kann theoretisch proportional, progressiv oder auch regressiv gestaltet sein.” (Smekal (1980), S. 174) Vgl. auch Hilber (1974), S. 12; Oates (1977), S. $326 \mathrm{ff}$.

111 Es besteht eine ,moral hazard"-Problematik. Vgl. Walsh (1993), S. 41; auch schon Wilde (1968), S. 345 f. Eine andere Meinung äußert Peffekoven, der daraufhinweist, daß bei konstanter Aufgabenerfullung einer GKS jede ineffiziente Verausgabung von Finanzmitteln entweder eine Erhöhung der eigenen Einnahmen oder eine Reduzierung der eigenen Ausgaben nachsichziehen muß, so daß nicht einzusehen sei, „warum bei der Einnahmeverwendung für eigene oder zugewiesene Mittel unterschiedliche Effizienzkriterien gelten sollen.” (Peffekoven (1988), S. 623.)

112 Walsh (1993), S. 41.

${ }^{113}$ Vgl. Costello (1993a), S. 110; Walsh (1993), S. 41.

${ }^{114}$ Vgl. Smekal (1980), S. 175; King (1984), S. 88; Fischer (1988), S. 29 f. u. Peffekoven (1988), S. 624. 
dann erst ex-post, da die Transferempfänger nun durch gezielte Verhaltensreaktionen ihren Zuweisungsbetrag erhöhen können.

Der Vorteil der betragsmäßig begrenzten FZ liegt für die transfergebende GKS in der finanzpolitischen Planungssicherheit. Dafür können sich unerwünschte Verteilungseffekte ergeben, wenn das Transfervolumen erschöpft ist, bevor das gewünschte Bereitstellungsniveau der geförderten öffentlichen Leistung in den transferempfangenden GKS erreicht wird. Bei betragsmäßig unbegrenzter FZ besteht hingegen die Gefahr, „daß die Empfänger exzessiv Gebrauch von solchen Zuwendungen machen werden." 115 Zudem ist das Transfervolumen für die FZGeber nicht mehr planbar.

Die Nachteile der beiden (isolierten) Ausgestaltungsformen lassen sich durch eine Kombination aus betragsmäßig begrenzten und unbegrenzten FZ verringern. ${ }^{116}$ Zum einen besteht die Option, zwar grundsätzlich einen bestimmten Zuweisungsbetrag pro Einheit der Bemessungsgrundlage festzulegen (Repartitionsprinzip), aber zusätzlich ein verbindliches Maximalvolumen der FZ zu bestimmen. Ein besonders relevanter Fall sind FZ mit Eigenbeteiligung und betragsmäßiger Begrenzung (,,closed-end matching-grant”). Es werden (deutliche) Überkapazitäten vermieden und die finanzielle Belastungen des Geberhaushalts abschätzbar, obwohl die Transferempfänger die Möglichkeit besitzen, durch eigene Anpassungsreaktionen die Bemessungsgrundlage zu erweitern. Zum anderen kann grundsätzlich eine explizite Höhe der FZ diktiert werden (Quotitätsprinzip), aber zusätzlich eine verbindliche Koppelung des Zuweisungsbetrages an adäquate Indikatoren erfolgen. Als Indikator kann bspw. die Aufkommensentwicklung einer bestimmten Steuer oder die Preissteigerungsrate im Bereich der geförderten öffentlichen Leistungen herangezogen werden. Im ersten Fall wird der Umfang der Zuweisungen an der allgemeinen Entwicklung der öffentlichen Einnahmen beteiligt. Im zweiten Fall wird verhindert, daß sich der reale Wert der FZ im Zeitablauf durch Preissteigerungen verringert und daraufhin eine zielinadäquate Einschränkung des Bereitstellungsniveau im geförderten öffentlichen Leistungsbereich durch die Transferempfänger vorgenommen wird. Der zu gewährende FZ-Betrag ergibt sich nun allerdings aus der Entwicklung des gewählten Indikators, so daß die finanzielle Belastung für die Transfergeber nicht länger genau abschätzbar ist.

\section{III-1.4 Die Formen unterschiedlicher Finanzzuweisungen im Überblick}

Abbildung III-1 zeigt die Formen der FZ im Überblick. Entscheidendes Unterscheidungskriterium ist die Auflagenbindung, wobei zwischen Verwendungs- und Empfangsauflagen abzu-

${ }^{115}$ Peffekoven (1988), S. 624. Die FZ können ,ein Eigenleben beginnen”. (Hansmeyer (1977), S. 974)

116 Vgl. zum Folgenden v.a. Smekal (1980), S. 175 u. Fischer (1988), S. 29 f. 
grenzen ist. Eine besonders wichtige Empfangsauflage bildet die Eigenbeteiligung. Dabei ist zwischen betragsmäßig begrenzten und unbegrenzten $\mathrm{FZ}$ zu unterscheiden:

Abb. III-1: Ausgestaltungsformen zwischenstaatlicher Finanzzuweisungen

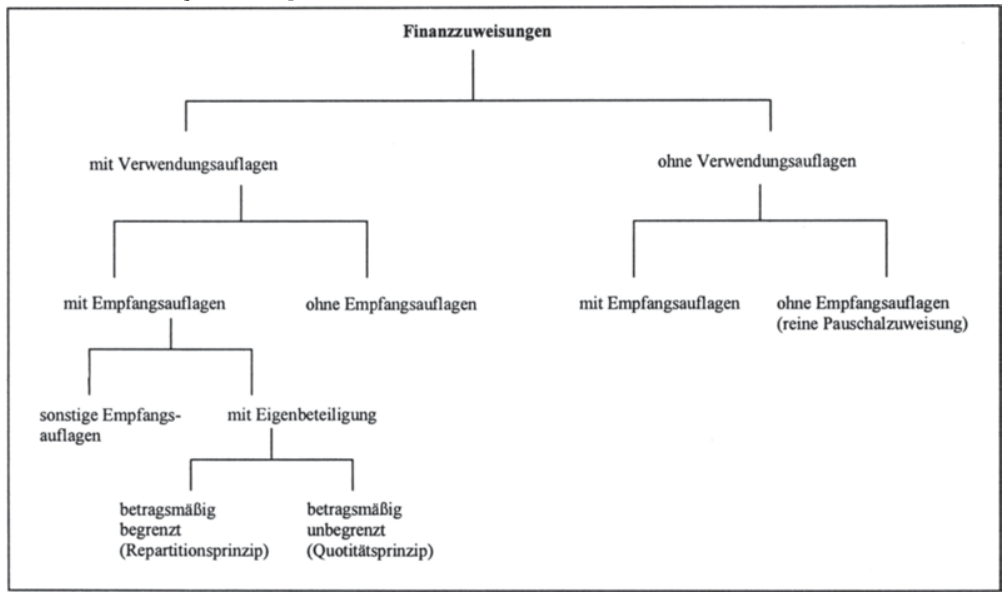

Quelle: eigene Darstellung in Anlehnung an King (1984), S. 87.

\section{III-2 Wirkungsanalyse alternativer Formen zwischenstaatlicher Finanzzuweisungen}

Um Schlußfolgerungen zur aufgabenadäquaten Ausgestaltung der FZ ziehen zu können, ist es notwendig, die relevanten Wirkungszusammenhänge zwischen den alternativen Ausgestaltungsformen der FZ und dem sich hieraus in der transferempfangenden GKS ergebenden Angebot öffentlicher Güter zu untersuchen. Die zu analysierenden Wirkungen beziehen sich auf den Umfang und die Struktur des bereitgestellten Bündels öffentlicher Leistungen. ${ }^{117}$

\section{III-2.1 Modelltheoretische Vorüberlegungen}

Idealerweise müßte die Wirkungsanalyse das Verhalten aller beteiligten Akteure ${ }^{118}$ in einer längerfristigen, dynamischen Perspektive unter Berücksichtigung aller direkten und indirekten Effekte der Mittelvergabe auf allen betroffenen Teilmärkten abbilden. Eine solch leistungsfähige Theorie, die diese komplexen Wirkungszusammenhänge innerhalb eines konsistenten Analyserahmens erfaßt, existiert jedoch nicht. ${ }^{119}$ Um konkrete Aussagen ableiten zu können,

\footnotetext{
117 So auch schon Osman (1966), S. 362.

118 Also insb. Berücksichtigung des Verhaltens der Transferempfänger und der Transfergeber.

119 Vgl. King (1984), S. 89; auch Bock (1985), S. 40.
} 
müssen deshalb Einzelaspekte der vielschichtigen Zusammenhänge modelltheoretisch erfaßbar gemacht werden, denen eine zentrale Bedeutung zukommt. ${ }^{120}$

In diesem Zusammenhang erfolgt in der Literatur üblicherweise eine Indifferenzkurvenanalyse in Analogie zur mikroökonomischen Theorie des privaten Haushalts. ${ }^{121}$ Die transfererhaltende GKS wird zu einem einzelnen nutzenmaximierenden Konsumenten zusammengefaßt, der einer bestimmten Budgetrestriktion unterliegt. Die FZ stellen eine Veränderung dieser Budgetrestriktion dar, die bei vorgegebener Präferenzordnung (Indifferenzkurvenschar) zu einer Anpassungsreaktion der transfererhaltenden GKS führt, die die Maximierung der Bewertungsfunktion (Nutzenfunktion) der GKS unter Berücksichtigung der veränderten Budgetrestriktion garantiert. Der Wirkungsanalyse werden folgende Annahmen zugrundegelegt, die eine graphische Darstellung im Rahmen der Indifferenzkurvenanalyse ermöglichen: ${ }^{122}$

- die abgebildeten gesellschaftlichen Indifferenzkurven verlaufen konvex;

- es existieren keine Randlösungen entlang der Achsen des Koordinatensystems;

- die Kosten der öffentlichen Güterbereitstellung pro Leistungseinheit innerhalb transferempfangenden GKS sind unabhängig vom Umfang der Leistungsbereitstellung;

- die öffentlichen Güter sind beliebig teilbar, so daß jede (marginale) Anpassungsreaktion der transferempfangenden GKS auf die FZ-Vergabe möglich ist;

- die transferempfangenden GKS besitzt keine Möglichkeit, Steuerlasten von der eigenen auf andere GKS zu verlagern (keine Steuerüberwälzung) - Steuererhöhungen müssen folglich ausschließlich von den Bewohnern der eigenen GKS getragen werden;

- die Anpassungsreaktionen der transferempfangenden GKS auf die FZ-Vergabe lösen keine externen Effekte für anderer GKS aus, so daß kein Internalisierungsproblem zu lösen ist;

- die transferempfangenden GKS stellen ausschließlich Waren und Dienstleistungen bereit, nicht aber Transferzahlungen an private Wirtschaftssubjekte - damit schränken Steuererhöhungen in der transferempfangenden GKS die verbleibenden finanziellen Ressourcen der Bewohner zur Nachfrage privater Güter ein; ${ }^{123}$

\footnotetext{
${ }^{120}$ Vgl. Tinbergen (1972), S. 69 ff.; auch Kleinewerfers/Jans (1983), S. 9 ff.

121 Dieses Untersuchungsschema wurde erstmals von Scott (1952), S. 377 ff. u. Wilde (1968), S. $340 \mathrm{ff} . \mathrm{u}$. (1971), S. 143 ff. angewendet. Hierauf aufbauend vgl. bspw. Oates (1972), S. 65 ff.; Waldauer (1973), S. 212 ff.; Gramlich (1977), S. 219 ff.; Romer/Rosenthal (1980), S. 451 ff; Smekal (1980), 176 ff.; King (1984), S. 86 ff.; Fischer (1988), S. 31 ff.; Costello (1993a), S. 104 ff.

122 Diese Annahmen beziehen sich v.a. auf King (1984), S. 90 u. Wilde (1971), S. 143 f., aber auch Smekal (1980), S. $176 \mathrm{f}$.

123 Damit wird der Kofinanzierung der Transferempfänger eine Grenze gesetzt (vgl. Abschnitt III-1.2.3).
} 
- ein Wandel der gesellschaftlichen Präferenzenstruktur infolge der FZ-Vergabe ist ausgeschlossen, so daß der Verlauf der abgebildeten gesellschaftlichen Indifferenzkurven von der FZ-Vergabe unberührt bleibt; ${ }^{124}$ und schließlich

- die Bewohner der transferempfangenden GKS werden nicht durch Steuerzahlungen zur Finanzierung der FZ an die eigene GKS herangezogen. ${ }^{125}$

Auch die nachfolgende Wirkungsanalyse geht von dieser Modellwelt aus, die ihren Fokus auf einen Ausschnitt der Wirklichkeit richtet. Es werden partialanalytische Ergebnisse abgeleitet, „deren vorläufige Gültigkeit von Fall zu Fall in der Praxis nachzuprüfen ist." ${ }^{126}$ Dabei sind die engen Grenzen des Aussagewertes der betriebenen Modellanalyse zu beachten. Über die restriktiven Annahmen des beschriebenen Analyseschemas hinaus, sind zwei Problembereiche von großer Wichtigkeit. Zum einen grundlegende Einwände gegenüber der mikroökonomischen Indifferenzkurvenanalyse, die eine erhebliche Relevanz für die FZ-Analyse besitzen. Zum anderen besondere Schwierigkeiten, die sich bei der Übertragung der Theorie des privaten Haushalts auf die Analyse des Verhaltens von GKS ergeben.

(1) Grundsätzliche Beschränkungen der mikroökonomische Indifferenzkurvenanalyse: ${ }^{127}$

- Die mikroökonomische Indifferenzkurvenanalyse bleibt stets auf eine gegebene Periode begrenzt (statische Analyse). Dynamische Prozesse werden aus dem Untersuchungsbereich ausgegrenzt, obwohl sich die Finanzbeziehungen zwischen GKS in aller Regel auf eine Mehrzahl an Perioden beziehen. ${ }^{128}$

- Es findet eine isolierte Analyse der Akteure der transferempfangenden GKS statt (Partialanalyse). Das Reaktionsverhalten der Entscheidungsträger der transferleistenden GKS sowie weiterer an der FZ-Vergabe indirekt beteiligter Akteure wird exogenisiert, obwohl es eine ebenso große Bedeutung für die Wirkungen der FZ besitzen kann wie das Verhalten der Entscheidungsträger der transferempfangenden GKS. ${ }^{129}$

${ }^{124}$ Diese Aussage impliziert, daß die FZ keine Umverteilungswirkungen innerhalb der GKS auslösen und mögliche zuweisungsabhängige Demonstrationseffekte unwirksam bleiben, die jeweils zu einer Veränderung der Präferenzen innerhalb der GKS führen würden.

${ }_{125}$ Diese Steuerzahlungen würden die Wirkungen der FZ teilweise konterkarieren (vgl. Abschnitt III-1.1).

126 Smekal (1980), S. 180. Dies hat notwendigerweise in Kapitel V bei der Übertragung der Ergebnisse auf den europäischen Integrationsprozeß zu erfolgen.

127 Vgl. zur grundlegenden Kritik der mikroökonomischen Indifferenzkurvenanalyse insb. Külp (1988) aber auch Rothschild (1992), S. 38 ff. Vgl. auch die deutliche Kritik von Spiess (1973), S. 24 ff., der den Ansatz als tautologisch bezeichnet, weil man als Ergebnisse nur das erhält, „was vorher in Form eines IndifferenzKurvensystems in das Modell hineingesteckt wurde." (Spiess (1973), S. 28)

$128 \mathrm{Vgl}$. Levaggi/Smith (1994), S. 72 f.; allgemein Külp (1988), S. 481.

129 Vgl. Levaggi/Smith (1994), S. 72 f. 
- Es werden ausschließlich direkte Auswirkungen der FZ im öffentlich-ökonomischen Sektor betrachtet (Primäreffekte). In der Realität sind jedoch auch vielschichtige indirekte Effekte der Mittelvergabe auf andere Bereiche der öffentlichen Leistungsbereitstellung und Einnahmenerzielung (komplementäre oder substitutionale Beziehungen), auf andere Regierungseinheiten und auf den privaten Sektor von Bedeutung (Sekundäreffekte). ${ }^{130}$

(2) Schwierigkeiten bei der Übertragung der Theorie des privaten Haushalts auf den öffentlichen Sektor:

- Während die Theorie des privaten Haushalts von einem Einpersonenhaushalt oder einem Haushaltsvorstand ausgeht, der die subjektiven Wünsche und Wertungen des privaten Haushalts zum Ausdruck bringt, gibt es in einer GKS eine Vielzahl staatlicher Entscheidungsträger und privater Wirtschaftssubjekte mit divergierenden Präferenzen. Damit stellt sich die Frage, wessen Präferenzstruktur durch die Indifferenzkurvenschar abgebildet wird und so über die Aufteilung des insgesamt verfügbaren Einkommens auf die alternativen Güter entscheidet. In der Regel wird angenommen, daß die Präferenzen aller Akteure identisch sind. ${ }^{131}$ Die abgebildeten Indifferenzkurven stellen dann die Präferenzen der gesamten Gesellschaft der GKS als „community indifference curves”132 dar.

Diese Vorstellung liegt auch der nachfolgenden Wirkungsanalyse zugrunde. Daher führt eine FZ-Vergabe an die transferempfangende GKS und eine Steuersenkung an die Bürger stets zu äquivalenten Ergebnissen: Beide Maßnahmen bewirken eine übereinstimmende Erhöhung des verfügbaren Einkommens innerhalb der GKS, die gemäß der gemeinschaftsweit einheitlichen Präferenzen auf den Konsum privater und öffenlicher Güter aufgeteilt wird. ${ }^{133}$ Wird allerdings die Annahme der „,community indifference curves” aufgehoben, so kann nicht mehr davon ausgegangen werden, daß eine FZ-Vergabe im Hinblick auf das hieraus resultierende Bereitstellungsniveau öffentlicher Güter äquivalent zu einer Steuersenkung ist. Die Verwendungsentscheidung der staatlichen Entscheidungsträger über einen an die GKS zugewiesenen FZ-Betrag kann von derjenigen der privaten Wirtschaftssubjekte über eine (direkt) erhaltene Steuersenkung abweichen. Empirische Untersuchungen $^{134}$ bekräftigen die Bedeutung dieser Aussage, da sie zu dem Schluß gelangen, daß die GKS zugewiesenen Mittel „tendenziell an der budgetären Verwendung 'kleben bleiben`

$130 \mathrm{Vgl.} \mathrm{Break}$ (1980), S. $94 \mathrm{f}$.

131 So bspw. Smekal (1980), S. 176 f; Benkert (1984a), S. 45; King (1984), S. 89 oder Fischer (1988), S. 32 f.

132 King (1984), S. 89.

133 Vgl. hierzu Scott (1952) sowie auch Bradford/Oates (1971a).

134 Vgl. hierzu v.a. Gramlich (1977), S. 227 ff. Für einen Überblick über jüngere u. ăltere empirische Untersuchungen vgl. Hines/Thaler (1995), S. 217 ff. 
und damit zu einem höheren Niveau an öffentlichen Leistungen führen als das der Fall wäre, wenn die Zuweisungen unmittelbar den Individuen zuflössen." 135

Daher stellt es einen wichtigen Schritt zu einer realitätsnäheren Betrachtungsweise dar, wenn ,zugelassen” wird, daß zwischen den beiden Gruppen der privaten Wirtschaftssubjekte und staatlichen Entscheidungsträger keine einheitlichen Nutzenvorstellungen existieren und sich auch die Präferenzen der einzelnen privaten Wirtschaftssubjekte sowie staatlichen Entscheidungsträger unterscheiden. Diese Annahme rückt die konkreten Entscheidungsstrukturen des politisch-administrativen Systems ins Blickfeld, da diese maßgeblich bestimmen, welche Wünsche und Wertvorstellungen zur Verwendung der FZ sich im politischen Willensbildungsprozeß durchsetzen. Das Ergebnis drückt zum einen die bestehenden Machtverhältnisse und Interessenkonstellationen innerhalb des Entscheidungsgremiums aus, zum anderen den diskretionären Handlungsspielraum, der den staatlichen Akteuren bei der vorherrschenden Entscheidungsstruktur verbleibt. ${ }^{136}$ Unter der Annahme, daß sich den politischen Entscheidungsträgern keine autonomen Handlungsspielräume bieten und deren (ausschließliches) Handlungsmotiv die Wiederwahl nach Ablauf der Legislaturperiode darstellt, werden sie ihre Entscheidungen an den Präferenzen desjenigen Wählers (Medianwähler) orientieren, dessen Stimmabgabe bei den nächsten Wahlen eine Minderheit in eine Mehrheit verwandeln wird. ${ }^{137}$ Geht man allerdings davon aus, daß weitgehende Informations- und Machtasymmetrien zwischen den privaten und öffentlichen Akteuren bestehen, die zu autonomen Handlungsspielräumen der Entscheidungsverantwortlichen führen, so können die Mitglieder des Entscheidungsgremiums der transferempfangenden GKS (zum Teil) ihre (persönlichen) Präferenzen durchsetzen. ${ }^{138}$

${ }^{135}$ Musgrave/Musgrave/Kullmer (1992), S. 34. Dieses Phänomen wird als „Fliegenfänger-Effekt” bezeichnet (vgl. bspw. Gramlich (1977), S. 226).

136 Vgl. hierzu Benkert (1984a), S. 45 u. 48. Vgl. hierzu ausführlich die Überlegungen zum politischen Entscheidungsprozeß und seinen Akteuren in Abschnitt III-2.3.1.

137 So bspw. Romer/Rosenthal (1980), S. 451 ff. Vgl. zum Medianwählermodell allg. Brümmerhoff (1996), S. $101 \mathrm{ff}$. Es wird angenommen, daß sich die staatlichen Entscheidungsprozesse in einem demokratischen Staat mit Mehrheitswahlrecht vollziehen. Diese Annahme trifft für die Mitgliedstaaten der EU zu. Der Realitătsgehalt des Medianwählermodells wird jedoch dadurch eingeschränkt, daß die Medianwählerposition zumeist unbestimmbar bleibt. In den Wahlen wird über eine Vielzahl öffentlicher Leistungsangebote unterschiedlicher Dimensionen entschieden, so daß es unmöglich wird, ,alle Alternativen in einem Präferenzkontinuum zu erfassen." (Brümmerhoff(1996), S. 113)

138 So bspw. Wilde (1968), S. 340 ff. Dies stellt einen wesentlichen Ansatzpunkt zur Erklärung des Fliegenfänger-Effektes dar. Der Erhalt von FZ-Mitteln und eine Steuersenkung werden von den Bürgern möglicherweise unterschiedlich wahrgenommen. Die Bürger unterliegen einer Fiskalillusion, wenn sie den tatsächlichen Steuerpreis von öffentlichen Gütern, die mit FZ finanziert werden, im Vergleich zu öffentlichen Gütern, die direkt mit Steuermitteln der eigenen GKS finanziert werden, systematisch unterschätzen. Vergibt die zentrale Ebene in dieser Situation eine FZ an die GKS, so verbleibt den dezentralen Entscheidungsträger ein Handlungsspielraum zur Ausweitung des Bereitstellungsniveaus öffentlicher Güter (vgl. Musgrave/Musgrave/Kullmer (1992), S. 34 f.). 
- In der Theorie des privaten Haushalts fällen die Wirtschaftssubjekte (eindimensionale) Konsumentscheidungen zwischen alternativen privaten Gütern. Die Übertragung des Ansatzes auf den öffentlichen Sektor führt zu einer differenzierteren (zweidimensionalen) Entscheidungssituation, da in der transferempfangenden GKS nicht nur die gewünschte Aufteilung der zugewiesenen Finanzmittel auf alternative öffentliche Leistungen bestimmt werden muß, sondern zudem festzulegen ist, ob ein Anteil der empfangenen Mittel durch Steuersenkungen zum Konsum zusätzlicher privater Güter zur Verfügung gestellt werden soll. $^{139}$

Um die Auswirkungen der FZ-Vergabe auf die Besteuerung mitzuberücksichtigen, muß diese zweidimensionale Entscheidungssituation als Grundlage der Indifferenzkurvenanalyse gewählt werden. In der graphischen Darstellung werden deshalb auf der Ordinate stets die vorhandenen Ressourcen ${ }^{140}$ der GKS abgebildet, die zum Erwerb aller vom Transfergeber nicht geförderten Güter verwendet werden können. Hierunter ist der Konsum privater Güter und die Bereitstellung der nicht als unterstützungswürdig eingestuften öffentlichen Güter zu subsumieren. Auf der Abszisse wird der Bereitstellungsumfang der vom Transfergeber geförderten öffentlichen Güter dargestellt. ${ }^{141}$ Allerdings ist diese Darstellungsweise aus zwei Gründen eine Fiktion. Sie impliziert zum einen, daß zeitgleich über privaten und öffentlichen Konsum entschieden werden kann. „Realiter liegen [aber] zwei ganz unterschiedliche Koordiantionsmechanismen vor - ein ökonomischer Markt für private Güter und ein politischer Prozeß für öffentliche Güter. Diese beiden Mechanismen lassen sich nicht in einem Diagramm darstellen." ${ }^{142}$ Zum anderen unterstellt sie die Vergleichbarkeit der Preise öffentlicher und privater Güter. Da aber bei öffentlichen Gütern das Marktausschlußprinzip nicht anwendbar ist, werden sie nicht über Märkte angeboten, sondern unentgeltlich bereitgestellt. Damit können keine Marktpreise bestimmt werden. Öffentliche Güter werden vielmehr zu den Kosten bewertet, die zu ihrer Bereitstellung aufgewendet werden müssen. Der Preisvergleich zu privaten Gütern wird hierdurch erschwert. ${ }^{143}$

Die Übertragung der Theorie des privaten Haushalts auf den öffentlichen Sektor ist aus dieser Sicht nur unproblematisch, wenn die institutionelle Gestaltung der Finanzverfassung die Einnahmeautonomie der transferempfangenden GKS soweit einschränkt, daß diese auf die FZ-Vergabe nicht mit Steuervariationen reagieren können. In diesem Fall reduziert sich

\footnotetext{
139 Vgl. hierzu bspw. Bös (1978), S. 102 ff; Smekal (1980), S. 177 u. 179 oder Fischer (1988), S. 33 f.

140 "These resources include all its citizens' incomes, less taxes paid to authorities other than the grantee, together with receipts of grants." (King (1984), S. 90)

141 Diese Art der graphischen Darstellung wählen bspw. Wilde (1968), S. 341 ff. u. King (1984), S. 90 ff.

142 Noll (1992), S. 9; vgl. auch Fischer (1988), S. 33.

143 Vgl. Fischer (1988), S. 33; allgemein zu dieser Problematik Brümmerhoff(1996), S. 14 f.
} 
die Wahlmöglichkeit der Transferempfänger auf die Bereitstellung alternativer öffentlicher Güter. Wie bei der Theorie des öffentlichen Haushalts wird im Diagramm dann eine eindimensionalen Entscheidungssituation abgebildet. ${ }^{144}$

\section{III-2.2 Die mikroökonomische Indifferenzkurvenanalyse ${ }^{145}$}

Das „Effizienzkonzept”"146 der nachfolgenden Indifferenzkurvenanalyse stellt die Ziele der Transfergeber in den Mittelpunkt. Eine FZ ist dann effizient, wenn die zugewiesenen Finanzmittel der von den Transfergebern bestimmten Verwendung (tatsächlich) zufließen. Jede Verwendung der FZ für andere Zwecke, unerheblich ob zum Konsum privater Güter (Steuersenkung) oder alternativer, nicht unterstützter öffentlicher Güter, wird als Sickerverlust angesehen und wirkt effizienzmindernd. ${ }^{147}$ Unabhängig von der Ausgestaltung der FZ sind die folgenden Konstellationen denkbar: ${ }^{148}$

- (Fall 1) es werden zusätzlich zur FZ eigene Finanzmittel der transferempfangenden GKS im geförderten öffentlichen Leistungsbereich gebunden $(\mathrm{dA} / \mathrm{dFZ}>1){ }^{149}$

- (Fall 2) das Ausgabevolumen wird exakt um den Zuweisungsbetrag erhöht (dA/dFZ=1);

- (Fall 3) die Gesamtausgaben im geförderten Leistungsbereich werden erhöht, aber in geringerem Umfang als es dem Volumen der FZ-Vergabe entspricht $(0<\mathrm{dA} / \mathrm{dFZ}<1)$; $^{150}$

- (Fall 4) das ursprüngliche Ausgabevolumen bleibt trotz der FZ unverändert aufrechterhal$\operatorname{ten}(\mathrm{dA} / \mathrm{dFZ}=0) ;^{151}$

- (Fall 5) es resultiert infolge der FZ ein absolut sinkendes Ausgabevolumen im Vergleich zur ursprünglichen Situation $(\mathrm{dA} / \mathrm{dFZ}<0)$.

144 So verfährt bspw. Fischer (1988). In der vorliegenden Arbeit bleibt die Darstellung der Entscheidungssituation jedoch problematisch, da die Mitgliedstaaten der $E U$ praktisch über eine völlige Einnahmenautonomie verfügen, wie die Analyse der Finanzverfassung der $E U$ in Abschnitt IV-2.1.4 verdeutlicht.

${ }^{145}$ In dem beschriebenen Modell ist es nicht notwendig, eine Unterscheidung zwischen vertikalen und horizontalen Transfers zu treffen. Die betrachteten intrakollektiven Entscheidungen der Transferempfänger sind von diesem Ausgestaltungsaspekt unabhängig (vgl. Fischer (1988), S. 30). Die Abgrenzung erlangt jedoch in den weiteren Abschnitten dieser Arbeit eine Bedeutung.

${ }_{146}$ Musgrave/Musgrave/Kullmer (1992), S. 33.

147 Dieses Effizienzkonzept unterscheidet sich daher deutlich von jenem, daß zur Ableitung des föderativen Referenzrahmens in Kapitel II zugrundegelegt wurde. Sowohl Präferenzkosten, die auftreten, wenn die FZ nicht den Wünschen und Wertvorstellungen der Transferempfänger entsprechen, als auch Ressourcenkosten zur Durchfuihrung und Kontrolle der FZ-Vergabe bleiben ausgeklammert. Das Effizienzkonzept spiegelt lediglich den absoluten Wirkungszusammenhang zwischen einer Einkommensänderung $(\mathrm{dM}=\mathrm{dFZ})$ und der hieraus resultierenden Änderung des Ausgabenvolumens der geförderten öffentlichen Leistung (dA) wider.

148 Vgl. zum folgenden Waldauer (1973), S. 214 u. Smekal (1980), S. 177.

149 Dies impliziert, daß entweder eine Steuererhöhung vollzogen wird oder Finanzmittel aus anderen Bereichen der öffentlichen Leistungsbereitstellung umgeschichtet werden. Wilde (1968), S. 342 spricht in Abgrenzung zu ,leakage"-Effekten von ,seepage"-Effekten.

${ }^{150}$ In diesem Fall treten folglich Sickerverluste auf.

151 Die geförderten öffentlichen Güter werden in dieser Situation als Sättigungsgüter bezeichnet. 


\section{III-2.2.1 Finanzzuweisungen mit und ohne Verwendungsauflage}

Abbildung III-2 verdeutlicht die Wirkungsweise einer FZ ohne Verwendungsauflage. Der Transfergeber beabsichtigt die Förderung des öffentlichen Leistungsangebots ganz allgemein. Der Bereitstellungsumfang des geförderten öffentlichen Güterangebots wird auf der Abszisse abgebildet. Auf der Ordinate werden die Ressourcen ausgewiesen, die innerhalb der GKS zum Erwerb aller nicht geförderten Güter verwendet werden können, in diesem Fall folglich alle privaten Güter. AB verkörpert die Budgetgerade der GKS in der Ausgangssituation, deren Abstand vom Koordinatenursprung das Gesamteinkommen der GKS und deren Steigung das Preisverhältnis zwischen privaten und öffentlichen Gütern signalisiert. Die Budgetgerade bringt die verschiedenen realisierbaren Konsumpläne der GKS bei der Wahl zwischen privaten und öffentlichen Gütern zum Ausdruck. Die gemeinschaftlichen Präferenzen der GKS werden durch die Indifferenzkurven ( $i_{0}$ und $i_{1}$ ) aufgezeigt. Das Gleichgewicht (Nutzenmaximum) liegt in der beschriebenen Ausgangssituation bei $\mathrm{E}_{0}$. Es werden OF Einheiten privater Güter und OG Einheiten öffentlicher Güter nachgefragt.

Abb. III-2: Finanzzuweisung ohne Verwendungsauflage

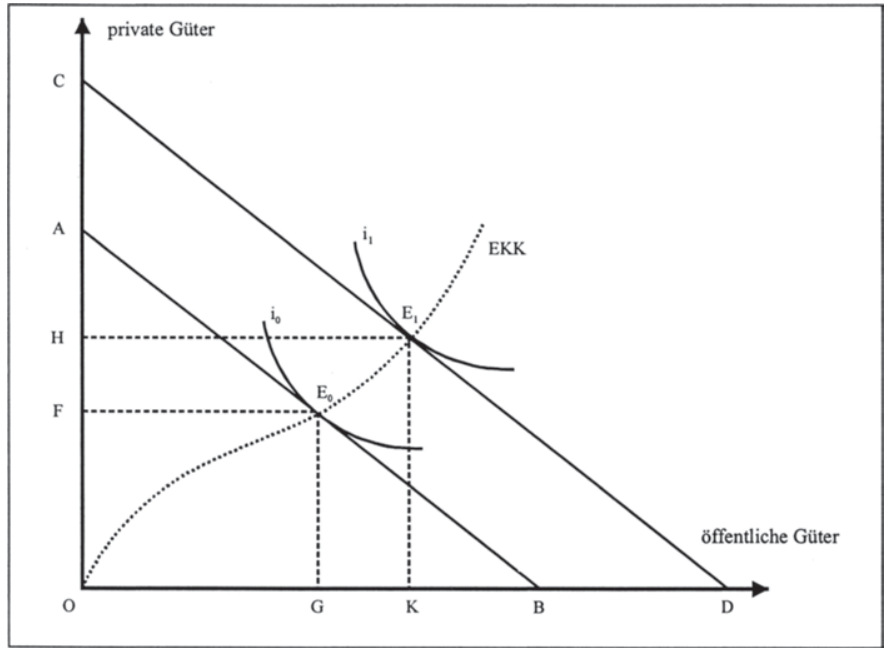

Quelle: Darstellung in Anlehnung an King (1984), S. 91.

Nun erfolgt die Vergabe einer Pauschalzuweisung in Höhe von AC - ausgedrückt in Einheiten privater Güter - an die GKS. Da die FZ an keinerlei Auflagen gebunden ist, bewirkt sie einen allgemeinen Einkommenszufluß in die GKS, der sich graphisch durch eine Parallelverschiebung der urspünglichen Budgetgeraden von $\mathrm{AB}$ nach $\mathrm{CD}$ ausdrückt. Die Pauschalzuweisung 
löst ausschließlich einen Einkommenseffekt aus, da das relative Preisverhältnis zwischen öffentlichen und privaten Gütern annahmegemäß vom Bereitstellungsvolumen unabhängig ist. Das neue Gleichgewicht ergibt sich bei $\mathrm{E}_{1}$. Es werden jetzt $\mathrm{OH}$ Einheiten der privaten Güter und OK Einheiten der öffentlichen Güter konsumiert. Beim dargestellten Verlauf der gemeinschaftlichen Indifferenzkurven der GKS erhöht sich sowohl der Konsum öffentlicher Güter (um GK Einheiten) als auch der privater Güter (um HF Einheiten). Dies verdeutlicht, daß ein bestimmter Anteil (HF/AC) der FZ an die privaten Wirtschaftssubjekte in Form einer Steuersenkung zur Ermöglichung privaten Konsums weitergeleitet wurde.

Welche relative Änderung der nachgefragten Mengen geförderter und nicht-geförderter Güter in Reaktion auf die Vergabe einer Pauschalzuweisung resultiert, ist abhängig von der bestehenden Relation der Einkommens-Elastizität der Nachfrage $(\eta)$ der alternativen Güter, die sich im konkreten Verlauf der Indifferenzkurven widerspiegelt. ${ }^{152}$ Aus der Verbindung aller Tangentialpunkte zwischen Indifferenzkurven unterschiedlichen Nutzenniveaus und alternativen Budgetgeraden läßt sich die Einkommens-Konsum-Kurve (EKK) als geometrischer Ort aller Nutzenmaxima im Güterraum ableiten, die sich bei Variation der $\mathrm{FZ}^{153}$ und konstanten Preisen der privaten und öffentlichen Güter ergibt. Im Hinblick auf den Zusammenhang zwischen nachgefragten Gütermengen und Einkommens-Elastizität bestehen die folgende Konstellationen, die jeweils zum Effizienzkonzept der Wirkungsanalyse in bezug gesetzt werden können:

- Sind die geförderten öffentlichen und die privaten Güter - wie im Beispiel der Abb. III-2 superiore Güter $(\eta>0)$, steigt die Nachfrage nach beiden Güterarten aufgrund der Transferzahlung an. Die EKK besitzt in diesem Fall eine positive Steigung, die umso größer ist, je höher die Einkommens-Elastizität der privaten Güter im Verhältnis zur EinkommensElastizität der öffentlichen Güter ausfällt (Fall 3 des Effizienzkonzepts: $0<\mathrm{dA} / \mathrm{dFZ}<1$ ).

- Besitzt eine der beiden alternativen Güterarten eine Einkommens-Elastizität von 1 entspricht die Veränderungsrate der nachgefragten Menge des betreffenden Gutes $(\Delta x / x)$ genau der Veränderungsrate des Einkommens der GKS (FZ/M $=\Delta \mathrm{M} / \mathrm{M})$. Der Anteil der Ausgaben dieses Gutes an den Gesamtausgaben bleibt konstant. Dies verdeutlicht, „daß die Einkommenselastizitäten der einzelnen Güter nicht gänzlich unabhängig voneinander sein

152 Die nachfolgenden Überlegungen könnten ansich sehr knapp gefaßt werden. Jedoch erfolgen in der wissenschaftlichen Literatur zur Indifferenzkurvenanalyse bei der Interpretation der Einkommens-Elastizität häufig unpräzise (vgl. bspw. Benkert (1984a), S. 46) oder schlichtweg unrichtige Aussagen (vgl. bspw. Waldauer (1973), S. 215 ff.; Smekal (1980), S. 180 f. u. Fischer (1988), S. 37 ff.). Aus diesem Grund wird der Zusammenhang zwischen der Höhe der Einkommens-Elastizität eines Gutes und den hieraus ableitbaren Schlußfolgerungen zur Variation der nachgefragten Menge des Gutes ausführlicher erläutert.

153 Dies entspricht der Variation des Einkommens der GKS. 
können." ${ }^{154} \mathrm{Da}$ die Indifferenzkurvenanalyse lediglich zwei Güterarten unterscheidet, muß zur Erfüllung der Budgetrestriktion auch der Ausgabenanteil des zweiten Gutes konstant bleiben $(\eta=1)$, wenn der Ausgabenanteil des ersten Gutes an den Gesamtausgaben unverändert bleibt. ${ }^{155}$ Für die EKK gilt in diesem Fall ein linearer Verlauf mit positiver Steigung. Die Nachfragemenge beider Güter erhöht sich in Anschluß an die FZ-Vergabe, jedoch jeweils in geringerem Umfang als dem Volumen der FZ (Fall 3 des Effizienzkonzepts).

- Der analoge Gedankengang gilt für die Fälle, in denen die nachgefragte Menge eines der beiden Güterarten überproportional zur Veränderungsrate des Einkommens der GKS ansteigt $(\eta>1)$, so daß sich dessen Ausgabenanteil erhöht. ${ }^{156}$ Zur Einhaltung der Budgetrestriktion muß der relative Ausgabenanteil des anderen Gutes sinken, womit eine Einkommens-Elastizität kleiner als $1(\eta<1)$ verbunden ist. Ist die Einkommens-Elastizität des letzteren Gutes positiv $(0<\eta<1)$, ${ }^{157}$ erhöht sich dessen Ausbringungsmenge infolge der Transferzahlung trotz des sinkenden Ausgabenanteils (Fall 3 des Effizienzkonzepts).

- Ein Grenzfall liegt vor, wenn die gesamte FZ ausschließlich zur Bereitstellung des einen Gutes verausgabt wird (Fall 2 bzw. Fall 4 des Effizienzkonzepts). Das Ausbringungsniveau des jeweils anderen Gutes bleibt dann unverändert $(\eta=0)$ und sein Anteil an den Gesamtausgaben sinkt. Entsprechend muß der Ausgabenanteil des anderen Gutes ansteigen $(\eta>1)$, um zu gewährleisten, daß die Gesamtausgaben der Budgetsumme entsprechen. Die EKK verläuft in diesem Fall entweder parallel zur Abszisse, wenn die FZ ausschließlich für die geförderten öffentlichen Güter verwendet wird, oder parallel zur Ordinate, wenn die $\mathrm{FZ}$ ausschließlich für die privaten Güter verwendet wird.

- Schließlich kann sich das Ausgabevolumen eines (Luxus-)Gutes $(\eta>1)$ um einen Betrag erhöhen, der über den Umfang der FZ hinausgeht (Fall 1 bzw. Fall 5). Die nachgefragte Menge des anderen Guts muß nun nicht nur relativ sondern auch absolut zurückgehen (inferiores Gut; $\eta<0$ ). Die EKK weist eine negative Steigung auf und krümmt sich in Richtung der Abszisse (die privaten Güter sind inferior; Fall 1) bzw. der Ordinate (die geförderten öffentlichen Güter sind inferior; Fall 5). ${ }^{158}$

154 Böventer/Illing (1995), S. 104.

${ }^{155}$ Diese Überlegung kann anhand der Engelschen Aggregationsbedingung $\left(a_{x} * \eta_{x M}+a_{y} * \eta_{y M}=1\right)$ verdeutlicht werden. Bleiben die relativen Ausgabenanteile $a_{x} u$. $a_{y}$ der Güter $x$ bzw. y konstant $u$. beträgt die Einkommens-Elastizität des einen Gutes 1, so muß auch die Einkommens-Elastizität des anderen Gutes 1 betragen, um die Erfullung der Aggregationsbedingung zu gewährleisten.

156 Das betreffende Gut ist ein Luxus-Gut.

${ }^{157}$ Das betreffende Gut ist ein Standard-Gut.

158 An dieser Stelle soll nochmals kritisch auf die Interpretation der Einkommens-Elastizität eingegangen werden (vgl. Fn 152 in diesem Abschnitt). Beispielhaft sei auf Fischer (1988), S. 38 verwiesen, der im Hinblick auf eine FZ, die ausschließlich zur Bereitstellung des Gutes y der beiden alternativen Güterarten x u. y verausgabt wird, feststellt: „Die Einkommenselastizitäten betragen in diesem Fall für y Eins und für x Null.” Diese Aus- 
Welche Wirkungen besitzen nun FZ mit Verwendungsauflagen (vgl. Abb. III-3)? Ausgehend von der ursprünglichen Budgetgeraden $A B$ erhält die GKS erneut eine $\mathrm{FZ}$ in Höhe von $\mathrm{AC}$, allerdings zweckgebunden: Um den Transfer zu erhalten, muß die begünstigte GKS gewährleisten, daß die gesamten zugewiesenen Mittel AC im geförderten Leistungsbereich verausgabt werden. Eine Zweckbindung der eigenen Finanzmittel der GKS ist hiermit jedoch nicht verbunden. Damit erhält die GKS die FZ auch dann, wenn die eigenen Mittel ausschließlich zur Finanzierung nicht geförderter Güter verwendet werden. Da das relative Preisverhältnis zwischen den geförderten und den nicht-geförderten Gütern wie im Fall der Pauschalzuweisung unverändert bleibt, beschreibt der Teilabschnitt FD der neuen Budgetgeraden CD die Menge der realisierbaren Konsumpläne.

Das neue Gleichgewicht liegt bei $E_{1}$. Die Graphik verdeutlicht, daß sich der gleiche Optimalpunkt auch bei der Gewährung einer Pauschalzuweisung einstellt. ${ }^{159}$ Die gleiche Aussage gilt für eine $\mathrm{FZ}$ in Höhe von $\mathrm{AG}$ (Optimalpunkt $\mathrm{E}_{2}$ ). Eine $\mathrm{FZ}$ dieses Volumens stellt jedoch einen Grenzfall dar. Die gesamten eigenen Ressourcen der GKS (OA) werden nun für den Konsum der nicht-geförderten Güter aufgewendet und ausschließlich die FZ-Mittel in Höhe AG werden zur Bereitstellung des geförderten öffentlichen Gutes verausgabt. Es treten bis zu diesem Punkt auch bei der Vergabe zweckgebundener FZ Sickerverluste auf. ${ }^{160} \mathrm{Da}$ sich die Verwendungsauflage nur auf die zugewiesenen Transfers bezieht, kann der Abfluß der eigenen Finanzmittel der Transferempfänger aus dem Bereich der geförderten öffentlichen Leistung von den Transfergebern nicht unterbunden werden.

Geht das Volumen der FZ allerdings über AG hinaus, resultiert ein abweichendes Bereitstellungsniveau zwischen den beiden Zuweisungsarten. ${ }^{161}$ Die Situation wird in der Abbildung. III-3 durch eine FZ in Höhe von AJ wiedergegeben. Im Fall einer Pauschalzuweisung ist JK die neue Budgetrestriktion der GKS. Es resultiert der Gleichgewichtspunkt $\mathrm{E}_{4}$. Wird die FZ

sage ist jedoch unrichtig. Offensichtlich legt $F$ ischer seiner Aussage das Effizienzkonzept zugrunde, das auch der Wirkungsanalyse dieser Arbeit vorangestellt wurde. Dieses Effizienzkonzept nimmt ausschließlich Bezug auf die zusätzlichen Ausgaben (dA), die im geförderten Bereich infolge einer FZ-Vergabe (dFZ) getätigt werden. Interpretiert man die Schlußfolgerungen Fischers in diesem Sinne, so erweisen sich die zitierten Ergebnisse als stimmig: in bezug auf das Gut $\mathrm{x}$, für das keine zusätzlichen Ausgaben getătigt werden, ergibt sich der Quotient $(\mathrm{dA} / \mathrm{dFZ}=0 / \mathrm{dFZ}=0)$. Für das Gut $\mathrm{y}$, für das zusätzliche Ausgaben in Höhe des gesamten FZVolumens (d.h. $d A=d F Z)$ getätigt werden, errechnet sich der Quotient $(\mathrm{dA} / \mathrm{dFZ}=\mathrm{dFZ} / \mathrm{dFZ}=1)$. Während in diesem Fall ein Vergleich der absoluten Änderung von Ausgaben und Einkommen erfolgt, wird bei der Betrachtung der Einkommens-Elastizität ein Vergleich der relativen Änderung von nachgefragten Gütermengen und Einkommen $(\mathrm{dx} / \mathrm{x}: \mathrm{dM} / \mathrm{M}$ bzw. dy/y : dM/M) angestellt. In dieser Hinsicht - von der Fischer explizit ausgeht - sind seine Ergebnisse unrichtig. Die Einkommens-Elastizität für das Gut $\mathrm{x}$ ist zwar tatsächlich Null, hingegen ergibt sich für das Gut y notwendigerweise eine Einkommens-Elastizität von größer als Eins (vgl. hierzu weiter oben in Abschnitt III.2.2). In analogen Gedankengängen lassen sich Unstimmigkeiten bspw. bei Waldauer (1973), S. 216 oder Smekal (1980), S. 181 nachweisen.

159 In diesem Fall beschreibt die Budgetgeraden CD die Menge der realisierbaren Konsumpläne.

${ }^{160}$ Die Höhe der Sickerverluste entspricht maximal dem Ausgabevolumen OT, das in der Ausgangssituation aus eigenen Finanzmitteln zur Bereitstellung des geförderten öffentlichen Gutes verwendet wurde.

161 Wilde (1968), S. 341 f. spricht in diesem Zusammenhang vom Auftreten eines ,deflective effect". 
jedoch zweckgebundenen vergeben, so stellt der Teilabschnitt NK der neuen Budgetgerade JK die realisierbaren Konsumpläne dar, weil $\mathrm{BK}(=\mathrm{AN}$; $=\mathrm{OP})$ Einheiten des geförderten öffentlichen Gutes bereitgestellt werden (müssen). Der neue Optimalpunkt $\mathrm{N}$ ist durch ein höheres Bereitstellungsvolumen der geförderten öffentlichen Leistung geprägt, als es für die Pauschalzuweisung gleicher Höhe der Fall war (OP > OQ). Der Grund hierfür liegt darin, daß ab dem FZ-Volumen von AG bei einer zweckgebundenen FZ im Unterschied zur Pauschalzuweisung keine zusätzlichen Sickerverluste auftreten können, da keine Substitution eigener Finanzmittel mehr möglich ist. Ab dem FZ-Volumen von AG werden diese bereits vollständig (also in Höhe 0A) zur Bereitstellung nicht-geförderter Güter eingesetzt. Zugleich ist aber festzustellen, daß die transferempfangende GKS auf eine niedrigere Indifferenzkurve gezwungen wird als im Fall der Pauschalzuweisung ( $i_{3}$ an Stelle von $i_{4}$ ), sobald das FZ-Volumen AG übertrifft.

Abb. III-3: Finanzzuweisung mit Verwendungsauflage

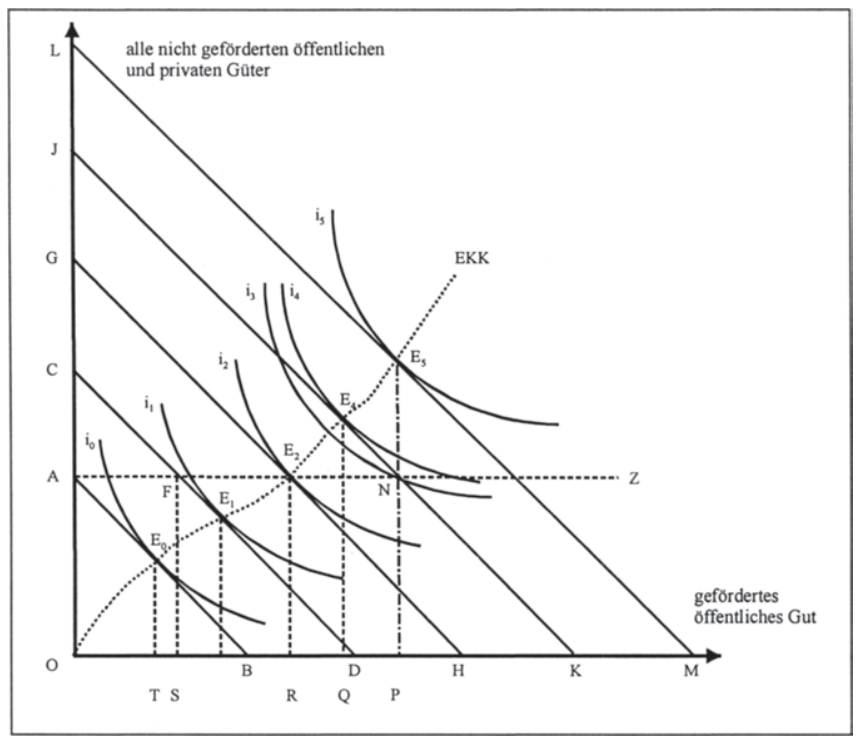

Quelle: Darstellung in Anlehnung an Musgrave/Musgrave/Kullmer (1992), S. 30 und Fischer (1988), S. 41.

\section{III-2.2.2 Finanzzuweisungen mit und ohne Empfangsauflage}

FZ mit Empfangsauflagen knüpfen die Mittelvergabe an bestimmte Eigenschaften, die innerhalb der zuweisungsempfangenden GKS erfüllt sein müssen. Nachfolgend werden die möglichen Wirkungen einer solchen Empfangsauflage am Beispiel einer funktionalen Empfangsauflage verdeutlicht: Die transfererhaltende GKS muß unabhängig von der FZ-Vergabe ein 
bestimmtes Mindestbereitstellungsniveau des geförderten öffentlichen Gutes aus eigenen Mitteln finanzieren (vgl. hierzu Abb. III-4). ${ }^{162}$

Die Empfangsauflage fordert ein Mindestbereitstellungsniveau in Höhe von OG. Wird diese Anforderung erfüllt, erhält die GKS ohne weitere Auflagen eine FZ des zuvor festgelegten Volumens AC, so daß das relative Preisniveau zwischen geförderten und nicht-geförderten Gütern unverändert bleibt. Daher führt die FZ-Vergabe zu einer Parallelverschiebung der ursprünglichen Budgetgerade von $\mathrm{AB}$ nach $\mathrm{CD}$. Unter Beachtung der Empfangsauflage bildet die „nichtstetige" ${ }^{\text {163 }}$ Budgetgerade AHFD die Menge der realisierbaren Konsumpläne der Transferempfänger. Zum Vergleich wird die Vergabe einer (reinen) Pauschalzuweisung dargestellt, in deren Folge die vollständige Budgetgerade CD die Wahlmöglichkeiten der GKS ausdrückt. Die beiden Fälle a und b in Abbildung III-4 demonstrieren, daß bei gegebenem Volumen der FZ (AC) und gegebenem Verlauf der EKK ${ }^{164}$ die Höhe der Empfangsauflage den entscheidenden Faktor für den Wirkungsvergleich einer Pauschalzuweisung und einer FZ mit Empfangsauflage darstellt:

Abb. III-4: Finanzzuweisung mit Empfangsauflage

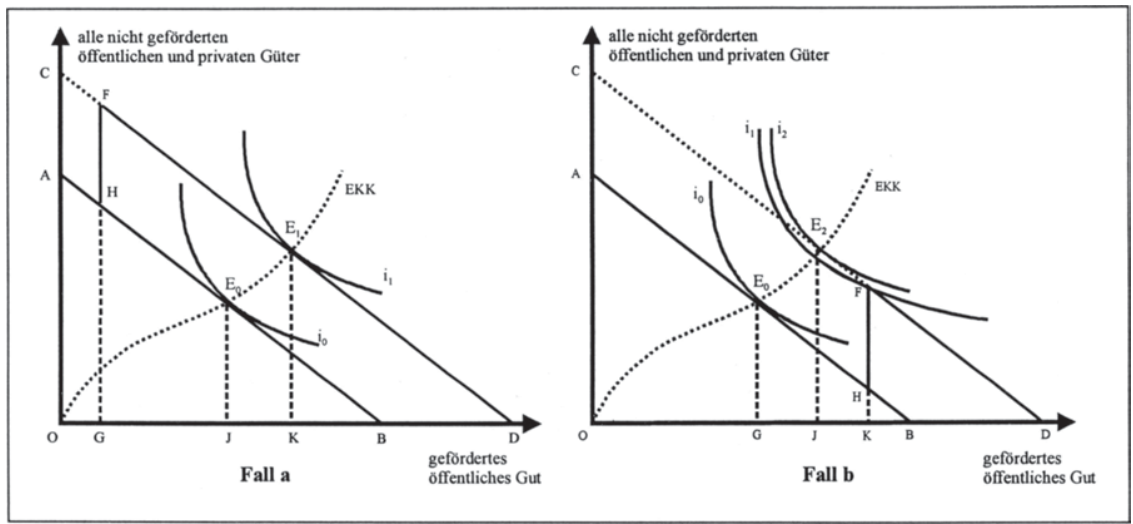

Quelle: Darstellungen in Anlehnung an Wilde (1971), S. 148 u. Waldauer (1973), S. 216.

162 Vgl. zum Folgenden v.a. Wilde (1968), S. 147 ff; Waldauer (1973), S. 216 f. u. Fischer (1988), S. 39 f. sowie auch Costello (1993a), S. 108 u. 110.

163 Hirte (1996), S. 78.

164 Es gelten die gleichen Schlußfolgerungen zur Bedeutung des Verlaufs der EKK für die Wirkungsanalyse, wie bei der Analyse der Verwendungsauflagen. Nachfolgend wird stets eine EKK positiver Steigung dargestellt, da dies als eine realitätsnahe Betrachtung bezeichnet wird, vgl. Böventer/Illing (1995), S. 99; auch Fischer (1988), S. 38. 
- Fall a: Wird das geforderte eigenfinanzierte Bereitstellungsniveau auf (relativ) niedrigerem Niveau OG festgesetzt, entfaltet die FZ mit Empfangsauflage im Vergleich zur Pauschalzuweisung keine zusätzliche Wirkung. ${ }^{165}$ In beiden Fällen ergibt die Bereitstellungsmenge OK (Gleichgewichtspunkt $E_{1}$ ). Die Bestimmung der Empfangsauflage ist eine überflüssige Determinierung.

- Fall b: Wird das geforderte eigenfinanzierte Bereitstellungsniveau hingegen auf (relativ) hohem Niveau OG festgesetzt, so besitzt die FZ mit Empfangsauflage einen Lenkungseffekt im Vergleich zur Pauschalzuweisung. ${ }^{166}$ Das Bereitstellungsniveau der geförderten öffentlichen Leistung erhöht sich von $\mathrm{OJ}$ auf $\mathrm{OK}$.

Gleichzeitig entstehen jedoch Wohlfahrtsverluste. Die Empfangsauflage stellt einen Eingriff in die Präferenzen der Transferempfänger dar, so daß die zuweisungsempfangende GKS nur das Nutzenniveau ( $\left.i_{1}\right)$ erreicht, wohingegen sich im Fall einer Pauschalzuweisung das Nutzenniveau ( $\left.i_{2}\right)$ einstellen würde. Erfolgt eine weitere Verschärfung der Empfangsauflage, so kann eine Situation eintreten, in welcher die Annahme der empfangsauflagengebundenen FZ das Nutzenniveau der transfererhaltenden GKS im Vergleich zur Ausgangssituation verringert. Die potentiellen Transferempfänger werden dann auf die Inanspruchnahme der FZ verzichten und das Ziel der Transfergeber, das Bereitstellungsniveau der als förderungswürdigen öffentlichen Leistung zu erhöhen, wird verfehlt.

\section{III-2.2.3 Finanzzuweisungen mit und ohne Eigenbeteiligung ${ }^{167}$}

Eine Sonderform der empfangsauflagengebundenen FZ ist die FZ mit Eigenbeteiligung. ${ }^{168}$ Der Transfergeber beteiligt sich bei dieser Form der FZ am Umfang der durch die transferempfangenden GKS im geförderten Leistungsbereich durch Eigenleistung aufgebrachten Mittel. Diese Ko-Finanzierung durch den Transfergeber bewirkt eine Reduktion des Preises des geförderten öffentlichen Gutes relativ zum Preis aller anderen nicht-geförderten Güter. Im Unterschied zu den zuvor betrachteten Ausgestaltungsformen der FZ verursacht die Gewährung einer FZ mit Eigenbeteiligung daher nicht eine Parallelverschiebung sondern eine Drehung der ursprünglichen Budgetgeraden (vgl. Abbildung III-5). Die FZ mit Eigenbeteiligung löst einen Einkommenseffekt und einen Substitutionseffekt aus. Der Einkommenseffekt ergibt

${ }^{165}$ Der Schnittpunkt zwischen der EKK und der jeweils relevanten Budgetgerade ist bei beiden Ausgestaltungsformen identisch.

${ }^{166}$ Es ergibt sich nun für die empfangsgebundene FZ kein Schnittpunkt mehr zwischen der EKK und der relevanten Budgetgeraden AHFD.

167 Vgl. Wilde (1968), S. 342 f. u. (1971), S. 144 f.; King (1984), S. 93 f. sowie Fischer (1988), S. 43 ff.

${ }^{168}$ Ihre Vergabe erfolgt stets zweckgebunden zur Förderung einer betimmten öffentlichen Leistung. Vgl. hierzu Abschnitt III-1.2.3. 
sich aus der Gewährung von FZ-Mitteln durch die Transfergeber. Der Substitutionseffekt wird durch die Preissenkung in bezug auf das geförderte öffentliche Gut ausgelöst.

Abb. III-5: Finanzzuweisung mit Eigenbeteiligung

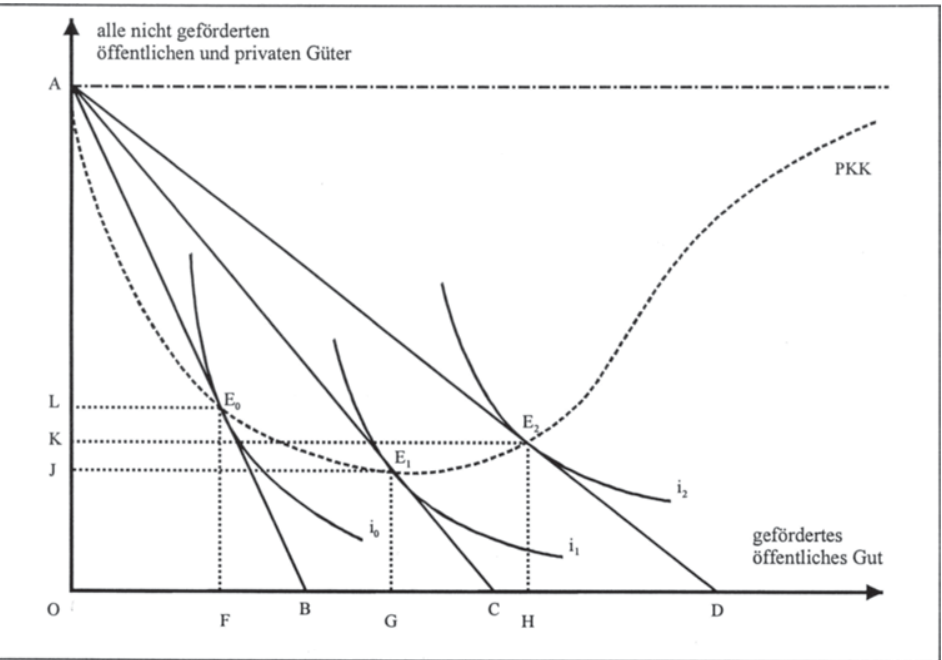

Quelle: Darstellung in Anlehnung an Wilde (1968), S. 343 u. King (1984), S. 93

Budgetgerade $\mathrm{AB}$ mit dem zugehörigen Gleichgewichtspunkt $\mathrm{E}_{0}$ gibt die Ausgangssituation wieder. Die Einführung einer Finanzierungsbeteiligung durch die transfergebende GKS, die dem Anteil BC/0C der gesamten Bereitstellungskosten der geförderten öffentlichen Leistung entspricht, führt zu einer Drehung der ursprünglichen Budgetgerade AB in Punkt A. Es resultiert die neue Budgetgerade $\mathrm{AC}$ mit dem Optimalpunkt $\mathrm{E}_{1}$. Eine Erhöhung des prozentualen Anteils der FZ an den gesamten Bereitstellungskosten auf den Anteil BD/OD drückt sich in einer weitergehenden Drehung der Budgetgerade nach $\mathrm{AD}$ mit dem Optimalpunkt $\mathrm{E}_{2}$ aus.

Die Veränderung der Gleichgewichtspunkte wird von der Preis-Elastizität der Nachfrage nach dem geförderten öffentlichen Gut bestimmt. Je elastischer die Preis-Elastizität, desto stärker ist die Wirkung einer FZ mit Eigenbeteiligung auf das Bereitstellungsniveau der geförderten Leistung. Besitzen die Transfergeber Kenntnis des Wertes der Preis-Elastizität, kann die finanzielle Eigenleistung der Transferempfänger so gewählt werden, daß ein von den Transfergebern gewünschtes Ausbringungsniveau des geförderten Guts genau erreicht wird. ${ }^{169}$

169 So muß die finanzielle Eigenleistung der Transferempfänger in der Graphik III-5 OB/OC betragen, um die Anhebung des Bereitstellungsniveaus des förderungswürdigen Gutes von OF auf OG zu gewährleisten. Jedoch unterliegen die Transfergeber dem bereits mehrfach angesprochenen Informationsproblem (vgl. v.a. Abschnitt III.2.1, insb. S. 34). In der Realität liegen nur sehr ungenaue Kenntnisse der Preiselastizitäten unter- 
Analytisch läßt sich die Preis-Elastizität aus dem Verlauf der Indifferenzkurven ableiten. Die Verbindung aller Tangentialpunkte zwischen Indifferenzkurven unterschiedlichen Nutzenniveaus und den Budgetgeraden alternativer Steigung ergibt die Preis-Konsum-Kurve (PKK) als geometrischen Ort aller Nutzenmaxima im Güterraum, die sich bei Variation des Finanzierungsanteils der Transfergeber aber konstantem Einkommen in der transfererhaltenden GKS und konstantem Preis der nicht-geförderten Güter ergibt. Die Steigung der PKK drückt die jeweilige Preis-Elastizität im betrachteten Punkt des Güterraumes aus.

Weist die PKK eine negative Steigung auf (Abszissenabschnitt OG), so ist die PreisElastizität in bezug auf das geförderte öffentliche Gut in diesem Bereich kleiner als (-1) und es werden nicht nur die gesamten Zuweisungsmittel im geförderten Bereich verausgabt, sondern zusätzlich die eigenfinanzierten Ausgaben für das geförderte öffentliche Gut erhöht (elastische Nachfrage). ${ }^{170}$ Dieser „Ausgaben-Anreizeffekt” ${ }^{\text {"171 }}$ beträgt LJ in dem durch die Bewegung von Optimalpunkt $\mathrm{E}_{0} \mathrm{zu}$ Optimalpunkt $\mathrm{E}_{1}$ dargestellten Fall.

In Punkt $E_{1}$ besitzt die PKK eine Steigung von Null. Die Preis-Elastizität ist in diesem Punkt exakt (-1). Dies impliziert eine Erhöhung der Ausgaben im geförderten Leistungsbereich, die genau dem Volumen der FZ entspricht. Es existieren bei dieser Konstellation keine Sickerverluste. Das eigenfinanzierte Ausgabenvolumen für nicht-geförderte Güter bleibt unverändert. Erhöht der Transfergeber den Finanzierungsanteil über $\mathrm{BC} / 0 \mathrm{C}$ hinaus, so nimmt die Preis-Elastizität einen Wert zwischen (-1) und Null an (unelastische Nachfrage). Nun treten im Vergleich zu der Konstellation mit der Finanzierungsbeteiligung BC/0C Sickerverluste in Höhe von $\mathrm{KJ}$ auf. ${ }^{172}$

Mit zunehmender Verringerung der Eigenbeteiligung der Transferempfänger nähert sich die PKK schließlich asymptotisch der Parallelen zur Abszisse durch den Punkt A. Denn selbst wenn der Preis des geförderten öffentlichen Gutes auf Null gesenkt wird, kann die unterstützte GKS nicht mehr als die gesamten eigenen Mittel OA für die nicht geförderten Güter aufwen-

schiedlicher öffentlicher Güter vor, wenngleich empirische Untersuchungen im „Normalfall” (Fischer (1988), S. 45) Preiselastizităten zwischen minus Eins und Null ermitteln (vgl. bspw. Gramlich (1977), S. 227 f.).

170 Besteht die Moglichkeit der vollständigen Substituierbarkeit des geforderten Gutes, so sinkt dessen nachgefragte Menge $a b$ einer bestimmten Höhe seines Preises auf Null. Es wird dann Punkt A realisiert mit einem Bereitstellungsniveau 0A der nicht-geförderten Güter. Löst nun eine FZ mit Eigenbeteiligung eine Preissenkung des geförderten Gutes aus, so wird ab einer bestimmten Höhe der Finanzierungsbeteiligung durch die Transfergeber auch das geförderte öffentliche Gut nachgefragt. Folglich muß nun ein bestimmter Anteil der eigenen Finanzmittel der Transferempfänger im Bereich der geförderten Leistung verwendet werden. Dies wiederum ist der Fall bei einer Preis-Elastizität kleiner als (-1), die in einer negativen Steigung der PKK ihren Ausdruck findet. Damit kann die Schlußfolgerung gezogen werden, daß die PKK stets einen Abschnitt mit negativer Steigung aufweisen muß (vgl. hierzu allgemein auch Böventer/Illing (1995), S. 108 f.).

171 Peffekoven (1988), S. 624. Wilde (1968), S. 342 spricht vom, ,seepage”-Effekt.

172 Im Vergleich zur Ausgangssituation ohne FZ ergibt sich jedoch nach wie vor ein geringeres Ausgabevolumen der transferempfangenden GKS für die nicht-geförderten Güter $(0 \mathrm{~K}<0 \mathrm{~L})$. Die Sickerverluste beziehen sich auf die Marginalbetrachtung der Erhöhung der Finanzierungsbeteiligung über BC/0C hinaus: „Leakage occurs at the margin." (Wilde (1968), S. 342) 
den. Das Ausmaß der Sickerverluste beträgt maximal OF, das dem eigenfinanzierten Bereitstellungsniveau des geförderten öffentlichen Gutes in der Ausgangssituation entspricht. ${ }^{173}$

Diese Feststellung leitet über zum Wirkungsvergleich zwischen einer FZ mit Eigenleistung und einer FZ ohne Eigenleistung, die entweder zweckgebunden oder als (reine) Pauschalzuweisung vergeben wird (Abbildung III-6). ${ }^{174}$

Abb. III-6: Vergleich von Finanzzuweisungen mit und ohne Eigenbeteiligung

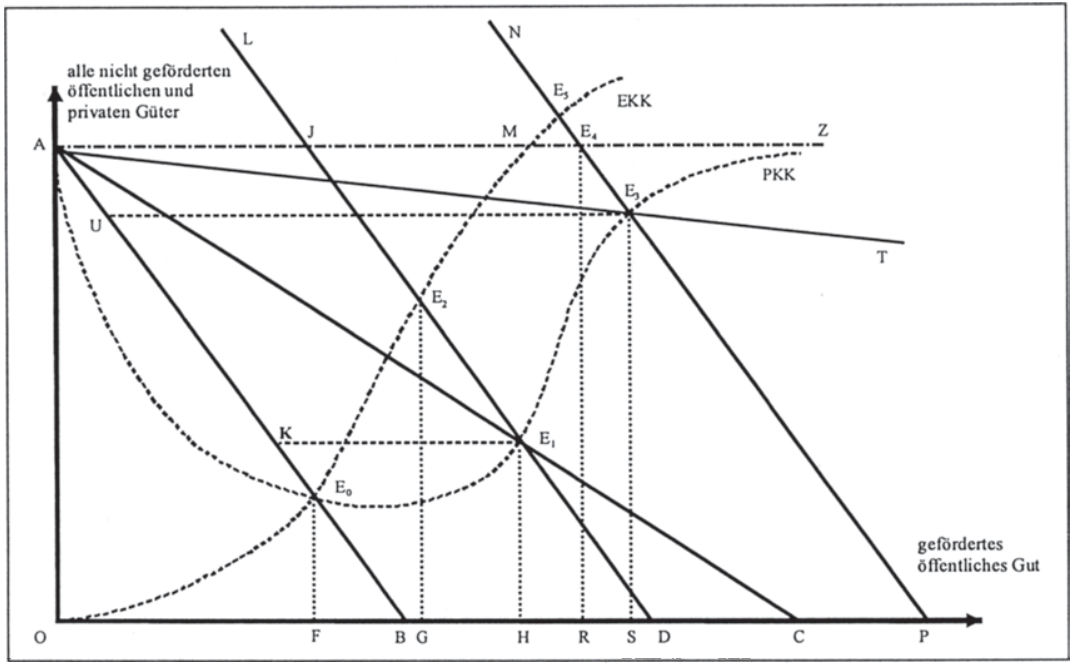

Quelle: Darstellung in Anlehnung an King (1984), S. 94 und Fischer (1988), S. 46.

Ausgehend von der Budgetgerade $\mathrm{AB}$ und dem Gleichgewichtspunkt $\mathrm{E}_{0}$ erhält die GKS eine FZ mit Eigenleistung, so daß die gedrehte Budgetgerade AC mit dem neuen Optimalpunkt $\mathrm{E}_{1}$ resultiert. Der Transfergeber gewährt eine $F Z$ in Höhe $E_{1} K$, die einem Finanzierungsanteil $\mathrm{BC} / \mathrm{OC}$ entspricht. Das Bereitstellungsniveau der geförderten öffentlichen Leistung wird von $\mathrm{OF}$ auf $\mathrm{OH}$ ausgedehnt. Zum Vergleich empfängt die GKS eine $\mathrm{FZ}$ identischer Höhe $\mathrm{E}_{1} \mathrm{~K}$ (=BD), jedoch als FZ ohne Eigenleistung. Die Graphik verdeutlicht, daß bei einer FZ dieser Höhe bei einer zweckgebundenen FZ (relevante Budgetgerade: JD) und bei einer Pauschalzuweisung (relevante Budgetgerade: LD) der Optimalpunkt $E_{2}$ gewählt wird. Das Bereitstellungniveau der geförderten öffentlichen Leistung (OG) ist bei dieser Konstellation niedriger,

\footnotetext{
${ }^{173}$ Vgl. Wilde (1968), S. $342 \mathrm{f}$.

${ }^{174}$ Um die Übersichtlichkeit der Darstellung zu erhalten, wird bei der Abb. III-6 auf die Darstellung der Indifferenzkurven verzichtet. Aus dem gleichen Grund sind die Budgetgerade AT, LD und NP nur in dem für die Wirkungsanalyse entscheidenden Bereich eingezeichnet.
} 
als bei Vergabe einer FZ mit Eigenbeteiligung $(\mathrm{OG}<\mathrm{OH})$. Die Begründung hierfür liegt darin, daß die Transfergeber bei der FZ mit Eigenbeteiligung nicht nur die Verwendungsentscheidung der Transferempfänger in bezug auf die zugewiesenen Mittel bestimmen, sondern zusätzlich Einfluß auf die Verausgabung der eigenen Finanzmittel der Transferempfänger nehmen. Daher treten bei einer FZ mit Eigenbeteiligung geringere Sickerverluste auf.

Erfolgt allerdings eine fortlaufende Steigerung des FZ-Volumens, so nähern sich die Wirkungen, die eine zweckgebundene FZ und eine FZ mit Eigenleistung auf das Bereitstellungsniveau des geförderten Gutes besitzen, immer stärker einander an. Denn die Steigerung des FZVolumens impliziert bei der FZ mit Eigenbeteiligung die Erhöhung der Finanzierungsbeteiligung der Transfergeber. Damit verringert sich jedoch der Einfluß, den diese auf die eigenen Finanzmittel der Transferempfänger nehmen können und es treten (zunehmend) die gleichen Sickerverluste wie bei zweckgebundenen FZ auf. Dieser Zusammenhang wird auch in der Abbildung III-6 veranschaulicht. Mit zunehmender Finanzierungsbeteiligung der Transfergeber nähert sich der Optimalpunkt einer FZ mit Eigenleistung der Geraden AZ und damit dem Optimalpunkt einer zweckgebundenen FZ. ${ }^{175}$ Der (hohe) Finanzierungsanteil BT/OT führt für die FZ mit Eigenbeteiligung zu einem Mittelvolumen von $\mathrm{E}_{3} \mathrm{U}\left(=\mathrm{AE}_{4}\right.$; $\left.=\mathrm{BP}\right)$ und dem Optimalpunkt $\mathrm{E}_{3}$ (relevante Budgetgerade: $\mathrm{AT}$ ). Für die zweckgebundene FZ des gleichen Volumens resultiert der Optimalpunkt $\mathrm{E}_{4}$ (relevante Budgetgerade: $\mathrm{E}_{4} \mathrm{P}$ ). Der Unterschied des Lenkungseffekts der beiden Zuweisungsarten auf das Bereitstellungsniveau des geförderten öffentlichen Gutes (OS bzw. OR) hat sich im Vergleich zum zuvor beschriebenen Fall mit einer geringeren Finanzierungsbeteiligung der Transfergeber deutlich verringert (OS - OR $<\mathrm{OH}$ OG). Es ist daher die Schlußfolgerung zu ziehen, „daß bei sehr großen Zweckzuweisungen ... die Forderung einer Eigenbeteiligung überflüssig sein kann". 176

\section{III-2.2.4 Betragsmäßig begrenzte und betragsmäßig offene Finanzzuweisungen ${ }^{177}$}

Abschließend wird die Wirkung betragsmäßig begrenzter und offener FZ verglichen. Die Analyse konzentriert sich auf den Fall der FZ mit Eigenbeteiligung und betragsmäßiger Begrenzung. ${ }^{178}$ Abbildung $\mathrm{III}-7$ verdeutlicht den grundlegenden Zusammenhang:

\footnotetext{
175 Alle Gleichgewichtspunkte zweckgebundener FZ befinden sich von einem FZ-Volumen AM an direkt auf der Geraden AZ. Denn sobald die Höhe der FZ AM übersteigt existiert kein Schnittpunkt zwischen der für die zweckgebundene FZ relevanten Budgetgerade (in der Darstellung bspw. $\mathrm{E}_{4} \mathrm{P}$ ) und der EKK. Die Verwendungsauflage besitzt nun einen Lenkungseffekt, so daß ab diesem Transfervolumen das Bereitstellungsniveau des geförderten Guts bei einer Pauschalzuweisung (Optimalpunkt $E_{5}$ auf der relevanten Budgetgerade NP) von dem bei einer zweckgebundenen FZ nach unten abweicht (vgl. hierzu näher Abschnitt 2.2.1).

176 Fischer (1988), S. 45.

177 Vgl. hierzu ausführlich King (1984), S. 94 ff. sowie knapper Wilde (1971), S. 144 f., Waldauer (1973), S. 220 f., Fischer (1988), S. 47 f. u. Costello (1993a), S. $108 \mathrm{ff}$.
} 
Abb. III-7: Finanzzuweisung mit Eigenbeteiligung und betragsmäßiger Begrenzung

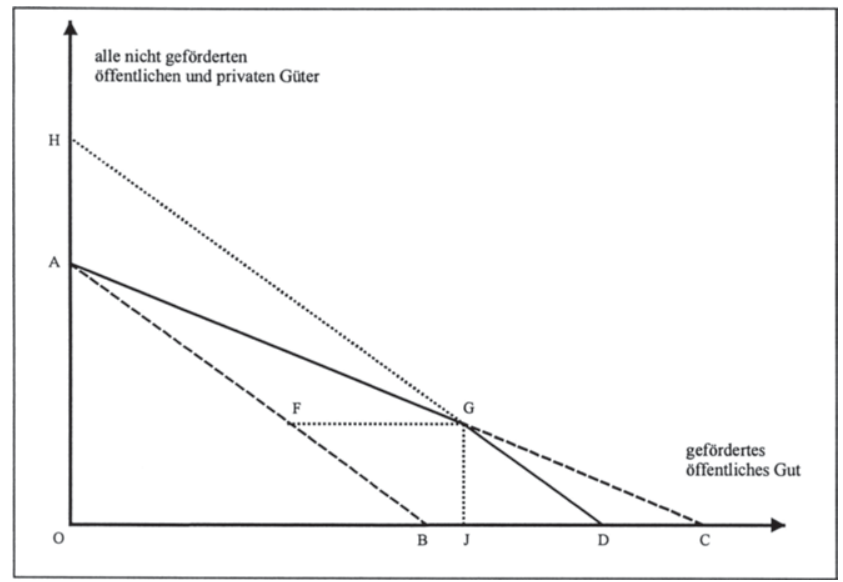

Quelle: Darstellung in Anlehnung an Fischer (1988), S. 47.

Ausgehend von der ursprünglichen Budgetgerade $\mathrm{AB}$ wird eine Finanzierungsbeteiligung $\mathrm{BC} / \mathrm{OC}$ durch die transfergebende GKS eingeführt, die eine Drehung der Budgetgeraden von $\mathrm{AB}$ nach $\mathrm{AC}$ nachsichzieht. Jedoch bestimmt der Transfergeber zusätzlich einen absoluten Höchstbetrag des zu gewährenden Transfervolumens. Diese Grenze entspricht in Abbildung III-8 einem Transfervolumen, mit dem BD (= FG) Einheiten des geförderten öffentlichen Guts bereitgestellt werden können. Die transfergebende GKS unterstützt daher jede bereitgestellte Einheit des geförderten öffentlichen Gutes nur solange gemäß der festgesetzten Finanzierungsbeteiligung bis der absolute Zuweisungshöchstbetrag $\mathrm{AH}$ - ausgedrückt in Einheiten nicht-geförderter Güter - ausgeschöpft ist. Wird die Bereitstellung des geförderten Guts in der transfererhaltenden GKS über das dieser Finanzierungsgrenze AH entsprechende Niveau OJ hinaus ausgedehnt, so gewährt der Transfergeber keine weiteren Unterstützungszahlungen. Für diese zusätzlichen Einheiten gilt erneut das ursprüngliche Preisniveau der Ausgangssituation und daher der Teilabschnitt GD der Budgetgeraden. Damit weist die relevante Budgetgerade AGD einen unstetigen Verlauf auf. An Punkt G ergibt sich eine Knickstelle.

${ }^{178}$ Diese Beschränkung erfolgt, weil im Hinblick auf Pauschalzuweisungen, FZ mit Verwendungsauflagen und FZ mit sonstigen Empfangsauflagen mit Fischer (1988), S. 47 argumentiert werden kann, daß „,die Unterscheidung zwischen betraglich offenen oder beschränkten FZ keine neuen Erkenntnisse [bringt]. Denn in allen drei Fällen wurde die Zahlung eines festgelegten (Pauschal-)Betrages analysiert, die sich in der Parallelverschiebung der Budgetgeraden auswirkt. Ob dieser Betrag vom Oberverband im vornhinein festgelegt wird (closed-end grant) oder ob er sich erst im nachhinein in Abhängigkeit von einer bestimmten Bemessungsgrundlage ergibt (open-end grant), spielt für die Wirkungsanalyse keine Rolle." Anders jedoch bei einer FZ mit Eigenbeteiligung, da die Höhe der FZ sich mit dem Bereitstellungsniveau des geförderten Guts (kontinuierlich) ändert. Daher können die Transfergeber hier erst nach der Allokation der gesamten Ressourcen auf die geförderten und nicht geförderten Güter bestimmen, in welcher Höhe FZ zu leisten sind. 
Die Auswirkungen der Integration einer betragsmäßigen Begrenzung in die Ausgestaltungsform der FZ mit Eigenbeteiligung auf das Bereitstellungsniveau der geförderten öffentlichen Leistung ist abhängig von der Lage dieser Knickstelle auf der Budgetgeraden - und damit dem maximalen Transfervolumen (Höchstgrenze) - im Verhältnis zum Verlauf der EKK-Kurve und der PKK-Kurve. Die nachfolgende Graphik zeigt die möglichen Konstellationen auf:

Abb. III-8: Finanzzuweisung mit Eigenbeteiligung und betragsmäßiger Begrenzung im Wirkungsvergleich mit alternativen Ausgestaltungsformen

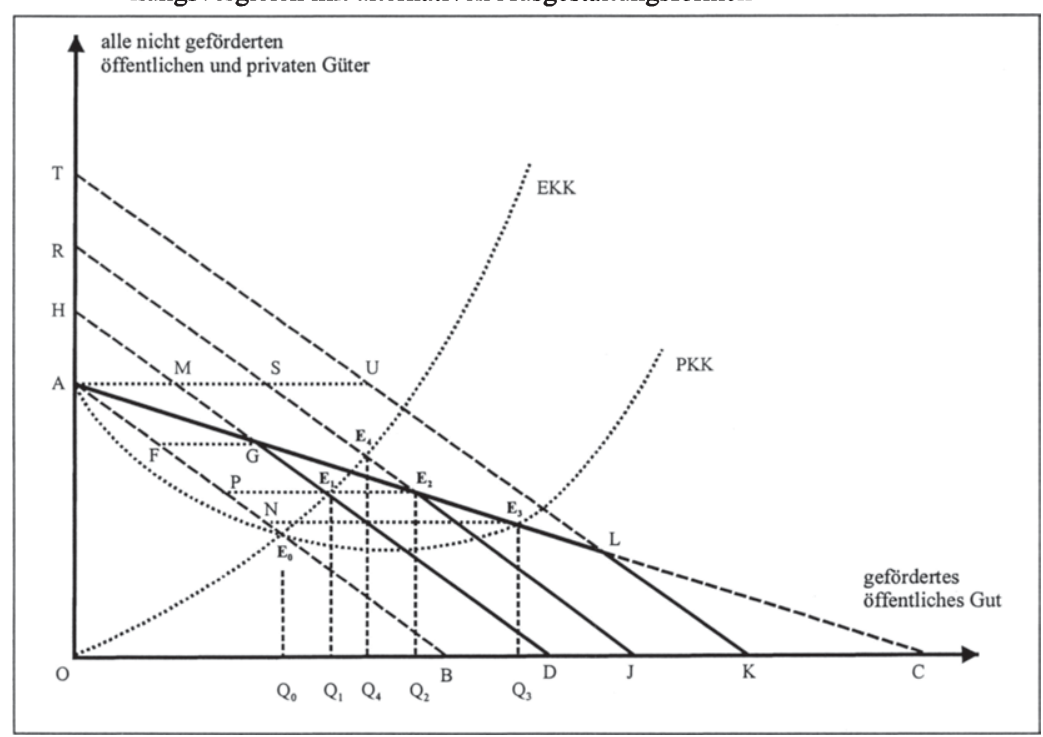

Quelle: Darstellung in Anlehnung an King (1984), S. 95 f. sowie Costello (1993a), S. 109.

Abbildung III-8 spiegelt erneut die Ausgangssituation der Abbildung III-7 wider. Zusätzlich werden die EKK und PKK dargestellt und es erfolgt eine Variation des Zuweisungshöchstbetrags. Neben der Höchstgrenze AH, die bereits in Abb. III-8 abgebildet wurde und eine Bereitstellung von $\mathrm{BD}(=\mathrm{FG}$; =AM) Einheiten des geförderten Guts zuläßt (relevante Budgetgerade AGD), sind zwei weitere Konstellationen dargestellt, deren Zuweisungshöchstbetrag eine Bereitstellung von $\mathrm{BJ}$ (relevante Budgetgerade $\mathrm{AE}_{2} \mathrm{~J}$ ) bzw. BK (relevante Budgetgerade $\mathrm{ALK}$ ) Einheiten der geförderten öffentlichen Leistung ermöglicht. Beim Wirkungsvergleich alternativer Ausgestaltungsformen der FZ sind drei Fälle zu unterscheiden:

- Bei dem - relativ niedrigen - maximalen Transfervolumen BD für das unterstützte öffentliche Gut befindet sich die Knickstelle G der unstetigen Budgetgerade AGD sowohl oberhalb der EKK als auch oberhalb der PKK. In dieser Situation entfaltet die Höchstbetragsregelung eine Wirkung. Der neue Optimalpunkt liegt auf dem Teilabschnitt GD der unsteti- 
gen Budgetgeraden AGD, der parallel zur ursprünglichen Budgetgeraden $\mathrm{AB}$ verläuft. In diesem Bereich besteht das der Ausgangssituation entsprechende relative Preisniveau, so daß für die Lage des neuen Optimalpunkts die Einkommens-Elastizität und damit die EKK ausschlaggebend ist. Es resultiert der Optimalpunkt $E_{1}$ mit dem Bereitstellungsumfang $\mathrm{OQ}_{1}$ des geförderten Guts.

Die Abbildung verdeutlicht, daß der gleiche Optimalpunkt $E_{1}$ auch bei der Vergabe einer Pauschalzuweisung (relevante Budgetgerade HD) und einer FZ mit Verwendungsauflage (relevante Budgetgerade MD) identischen Volumens realisiert wird. Die Gewährung einer betragsmäßig unbegrenzten FZ mit Eigenleistung (relevante Budgetgerade $\mathrm{AC}$ ), bei der die Lage des Optimalpunkts $\left(\mathrm{E}_{3}\right)$ nicht von der Einkommens-Elastizität sondern von der PreisElastizität - und somit von der abgebildeten PKK - abhängt, würde hingegen zu einer Ausdehnung des Ausbringungsvolumens auf $\mathrm{OQ}_{3}$ Einheiten des geförderten Gutes führen.

- Wird der Höchstbetrag der Transfervergabe auf das - relativ hohe - Volumen BK ausgedehnt, so ist die Knickstelle L auf der unstetigen Budgetgeraden ALK sowohl unterhalb der EKK als auch unterhalb der PKK positioniert. Die Höchstbetragsregelung kommt in dieser Situation gar nicht zur Geltung, da das zu gewährende Transfervolumen $\mathrm{NE}_{3}$ unterhalb des festgesetzten Höchstbetrages $\mathrm{BK}\left(\mathrm{NE}_{3}<\mathrm{BK}\right)$ verbleibt. Der Wirkungsvergleich einer betragsmäßig offenen (relevante Budgetgerade $\mathrm{AC}$ ) und einer betragsmäßig begrenzten (relevante Budgetgerade ALK) FZ mit Eigenleistung führt daher zu identischen Ergebnissen. In Abb. III-9 resultiert der Optimalpunkt $\mathrm{E}_{3}$ mit dem Bereitstellungsniveau $\mathrm{OQ}_{3}$ der geförderten Leistung. ${ }^{179}$

- Einen (theoretischen) Grenzfall stellt die Erhöhung des maximal zu gewährenden FZVolumens auf $\mathrm{BJ}$ dar. Die Knickstelle $\mathrm{E}_{2}$ der relevanten Budgetgerade $\mathrm{AE}_{2} \mathrm{~J}$ rückt nun zwischen die EKK und die PKK. Der Optimalpunkt muß in diesem Fall exakt der Knickstelle $\mathrm{E}_{2}$ mit dem Bereitstellungsniveau $\mathrm{OQ}_{2}$ des geförderten Guts entsprechen. Denn da ein Optimalpunkt weder als Schnittstelle zwischen der PKK und dem Teilabschnitt $\mathrm{AE}_{2}$ der Budgetgeraden, noch als Schnittpunkt zwischen der EKK und dem Teilabschnitt $E_{2} J$ der Budgetgeraden existiert, ergibt sich die Gleichgewichtslösung notwendigerweise als Ecklösung. Da zudem annahmegemäß keine Randlösungen entlang der Achsen des Koordinatensystems bestehen, verbleibt als Optimallösung ausschließlich der Punkt $E_{2}$.

Die Vergabe einer Pauschalzuweisung (relevante Budgetgerade RJ) und einer FZ mit Verwendungsauflage (relevante Budgetgerade SJ) des identischen Volumens BJ fuihren in die-

${ }^{179}$ Im Hinblick auf den Wirkungsvergleich zur Pauschalzuweisung und zur FZ mit Verwendungsauflage gelten die Ergebnisse des Abschnitts III-2.2.3. 
ser Situation zu einem niedrigeren Bereitstellungsniveau $\mathrm{OQ}_{4}$ des geförderten öffentlichen Guts $\left(\mathrm{OQ}_{4}<\mathrm{OQ}_{2} ;\right.$ Optimalpunkt $\left.\mathrm{E}_{2}\right)$. Die Gewährung einer betragsmäßig unbegrenzten $\mathrm{FZ}$ mit Eigenleistung (relevante Budgetgerade AC; Optimalpunkt $\mathrm{E}_{3}$ ) garantiert hingegen eine Ausdehnung des Bereitstellungsniveaus $\left(\mathrm{OQ}_{3}>\mathrm{OQ}_{2}\right)$.

\section{III-2.2.5 Zwischenfazit zur Indifferenzkurvenanalyse}

Die graphische Wirkungsanalyse liefert eine Reihe an Erkenntnissen für die Beurteilung der „Instrumentqualitäten"180 alternativer Ausgestaltungsformen zwischenstaatlicher FZ, die an dieser Stelle nochmals im Überblick aufgezeigt werden. ${ }^{181}$ Zunächst ist ein grundsätzliches, für jede Ausgestaltungsform gültiges Ergebnis voranzustellen:

- Die Geeignetheit einer konkreten Ausgestaltungsform als finanzpolitisches Instrument kann nur unter simultaner Berücksichtigung des Verlaufs der Einkommens- bzw. der PreisElastizität sowie der Höhe des FZ-Volumens beurteilt werden. Denn der Wirkungsvergleich alternativer Ausgestaltungsformen ist abhängig von der Relation zwischen der EKK bzw. PKK, der festgelegten Höhe des Transfervolumens (quantitativer Aspekt) und der durch die Ausgestaltung der FZ bestimmten Eingriffsintensität der FZ-Vergabe (qualitativer Aspekt).

Hierauf aufbauend können die folgenden Schlußfolgerungen getroffen werden:

- Die stimulierende Wirkung einer FZ-Vergabe auf das Bereitstellungsniveau einer geförderten öffentlichen Leistung ist umso stärker, je elastischer die Einkommens- und/oder die Preis-Elastizität innerhalb der transferempfangenden GKS in bezug auf die geförderte öffentliche Leistung im Vergleich zu allen nicht-geförderten Leistungen ausfällt.

- Sickerverluste entstehen bei jeder Ausgestaltungsform. Jedoch fallen diese „Effizienzverluste" bei FZ mit Eigenbeteiligung im Vergleich zu allen anderen Ausgestaltungsalternativen am geringsten aus; die höchsten Sickerverluste treten bei Pauschalzuweisungen auf.

- Diese Aussage muß allerdings in bezug zum Volumen der FZ gesetzt werden. Denn bei einem FZ-Volumen, das im Verhältnis zum Verlauf der EKK bzw. PKK relativ gering ist, besitzen Pauschalzuweisungen und FZ mit Verwendungsauflagen identische Lenkungseffekte. Hingegen nähern sich bei relativ hohem FZ-Volumen die Wirkungen von zweckge-

\footnotetext{
180 Zimmermann (1977), S. 172.

181 Vgl. hierzu auch Wilde (1968), S. 346 f; Waldauer (1973), S. 222 f. u. Fischer (1988), S. 49 ff.
} 
bundenen FZ und FZ mit Eigenleistung einander an, während Pauschalzuweisungen nun (deutlich) höhere Sickerverluste aufweisen.

- Sowohl Verwendungs- als auch Empfangsauflagen entfalten im Vergleich zu Pauschalzuweisungen nur dann eine zusätzlich stimulierende Wirkung auf das Bereitstellungsniveau der geförderten öffentlichen Leistung, sofern das Volumen der FZ bzw. die Höhe der Empfangsauflage eine kritische Grenze in Relation zur Einkommens-Elastizität überschreitet. Bei (relativ) niedrigem FZ-Volumen bzw. niedriger Empfangsauflagenhöhe führt die Auflagenfestsetzung deshalb zu unnötigen, wohlfahrtsmindernden Ressourcenkosten. ${ }^{182}$ Eine besonders starken Lenkungseffekt lösen Auflagen hingegen im Bereich solcher öffentlicher Leistungen aus, deren Bereitstellung von der transferempfangenden GKS bislang gar nicht oder nur in sehr geringem Umfang gewährleistet wurde. ${ }^{183}$

- Jede FZ, die von den Transfergebern nicht als reine Pauschalzuweisung vergeben wird, stellt eine (zielgerichtete) Beeinflussung des Ausgabeverhaltens und somit einen Eingriff in die Präferenzen der transferempfangenden GKS dar. Die hieraus entstehenden Wohlfahrtseffekte fallen umso stärker aus, je unelastischer die Einkommens- bzw. Preis-Elastizität in der unterstützten GKS im Hinblick auf das als föderungswürdig eingestufte öffentliche Gut ist. Bestimmt der Transfergeber durch die konkrete Ausgestaltung der FZ eine in Relation zur Einkommens- bzw. Preis-Elastizität der Transferempfänger „zu hohe” Eingriffsintensität, so würde die FZ-Annahme die Wohlfahrtposition der transferempfangenden GKS im Vergleich zur Ausgangssituation verschlechtern und die FZ wird abgelehnt.

\section{III-2.3 Die Erweiterung der Wirkungsanalyse}

Die Erkenntnisse der mikroökonomischen Indifferenzkurvenanalyse stellen Anhaltspunkte für die in der Realität zu erwartenden Wirkungen der Vergabe unterschiedlicher Formen der FZ dar. Jedoch demonstrieren die restriktiven Modellannahmen sowie die erläuterten grundlegenden und speziellen Einwände gegen das verwendete Analyseschema ${ }^{184}$ zugleich die Notwendigkeit weitergehender Untersuchungen. Im Hinblick auf den Untersuchungsschwerpunkt dieser Arbeit ist insb. zu kritisieren, daß die Ergebnisse ohne explizite Berücksichtigung

\footnotetext{
${ }^{182}$ Die Ausgestaltung der FZ mit Verwendungs- oder Empfangsauflagen löst im Vergleich zur Vergabe von Pauschalzuweisungen in jedem Fall zusätzliche Informations-, Verwaltungs- und Kontrollkosten aus. Insbesondere die Kontrollkosten zur (vollständigen) Durchsetzung beider Auflagenarten können möglicherweise prohibitiv hoch ausfallen. Daher sind diese Kostenkategorien bei einer „Gesamt”-Bewertung der FZ-Arten stets dem Nutzen der stimulierenden Wirkung auf das Bereitstellungsniveau der geförderten öffentlichen Leistung gegenüberzustellen. Vgl. hierzu auch Kops (1989), S. 165 u. 169; diese Vorgehensweise entspricht auch dem allgemeinen föderativen Referenzrahmen des Kapitels II.

${ }^{183}$ Fischer (1988), S. 51 spricht in diesem Zusammenhang von „Initiativ-FZ”. Vgl auch Wilde (1968), S. 347.

$184 \mathrm{Vgl}$. Abschnitt III-2.1.
} 
rechtlich-organisatorischer Rahmenbedingungen abgeleitet wurden. Den bisherigen Überlegungen lag implizit die Vorstellung einer idealen Hierachie zugrunde. Die Transfergeber wurden als allwissende und wohlmeinende Diktatoren aufgefaßt, die mittels Zwang für eine Vergabe der FZ im Sinne des Gemeinwohls Sorge tragen. ${ }^{185}$ Die Willensbildung der FZ-Vergabe wird im föderativen Staat jedoch in der Realität über Abstimmungs- und Verhandlungsprozesse koordiniert. Diese Steuerungsformen bedingen einen komplexen Entscheidungsfindungsprozeß, der dazu führt, daß die Ausgestaltung, die Verwendung und folglich auch die Wirkungen der FZ von jenen abweichen können, die sich in der idealen Hierachie der mikroökonomischen Indifferenzkurvenanalyse ergeben. ${ }^{186}$

Die folgenden weiterführenden Analysen umfassen deshalb einerseits das Verhalten der am Entscheidungsprozeß beteiligten Akteure bzw. Akteurgruppen innerhalb der betroffenen GKS (intrakollektiver Entscheidungsprozeß; Abschnitt III-2.3.1) und andererseits die Verhandlungen zur Willensbildungs- und Entscheidungsfindung bei der Vergabe der FZ zwischen den betroffenen GKS einer Ebene oder verschiedener Ebenen des föderativen Staates (interkollektiver Entscheidungsprozeß; Abschnitt III-2.3.2). Es wird dabei ermittelt, ob die bislang abgeleiteten Hypothesen über die Wirkungsweise verschiedener Formen zwischenstaatlicher FZ zugunsten alternativer Aussagen zu revidieren sind.

\section{III-2.3.1 Der politische Entscheidungsprozeß und seine Akteure - Intrakollektiv}

In der mikroökonomischen Indifferenzkurvenanalyse wird angenommen, daß die Präferenzen der privaten Wirtschaftssubjekte und der staatlichen Entscheidungsträger identisch sind. Konsequenterweise wird die Frage, ob die Verantwortlichen der verschiedenen Jurisdiktionen des föderativen Staates tatsächlich für eine präferenzadäquate Ausgestaltung und Verwendung der FZ Sorge tragen, aus der Untersuchung ausgeklammert. Die staatlichen Akteure werden als wohlwollende Agenten modelliert, die ihre Entscheidungen ausschließlich zur Maximierung der Wohlfahrt der Bürger ihres jeweiligen Hoheitsbereiches treffen. ${ }^{187}$

Diese Modellannahme trifft für beide an der Vergabe der FZ (direkt) beteiligten staatlichen Akteursgruppen zu, also für die Transfergeber und die Transfernehmer. Dabei wurden die Transfergeber vollständig aus der Untersuchung ausgeblendet. Ohne nähere Analyse wurde im Grundmodell davon ausgegangen, daß sie als ,weise Diktatoren” über vollständige Informationen zur zieladäquaten Ausgestaltung der FZ verfügen. Sie nutzen dieses Wissen, um die

\footnotetext{
${ }^{185} \mathrm{Vgl}$. Bohnet-Joschko (1996), S. $208 \mathrm{f}$.

186 Vgl. auch Oates (1972), S. 105. Analog auch schon zuvor Bradford/Oates (1971b), S. 440.

187 Vgl. Oates (1977), S. 317; auch Breton/Scott (1978), S. 90 ff.
} 
aggregierten Nutzen der Bürger des transfergebenden Hoheitsbereichs zu maximieren. ${ }^{188}$ Auf der Seite der Transferempfänger wurde angenommen, daß die Verwendung der FZ den Präferenzen der Bürger der transfererhaltenden GKS entspricht. Dieses Kalkül wurde graphisch erfaßt und ließ es zu, Aussagen zur Wirkung unterschiedlicher FZ abzuleiten.

Die Sichtweise der staatlichen Entscheidungsträger als wohlwollende Agenten ist jedoch „stark simplifizierend und versperrt den Blick für das Dilemma der Organisation im Staat." Sowohl auf der Transfergeber- als auch der Transfernehmerseite besteht eine Vielzahl an Akteuren, die direkt oder indirekt am staatlichen Entscheidungsprozeß beteiligt ist. Die einzelnen Akteure lassen sich zu verschiedenen Akteursgruppen zusammenfassen, die jeweils spezifische Eigeninteressen vertreten. Diese Akteursgruppen nehmen ihren Kompetenzspielräumen entsprechend Einfluß auf unterschiedliche Phasen des staatlichen Handlungsablaufs - Planung, Entscheidung, Durchführung und Kontrolle -, um die Ergebnisse der staatlichen Aktivitäten in Richtung der eigenen Interessenlage zu verändern. Es kann deshalb nicht davon ausgegangen werden, daß die staatlichen Akteure uneigennützig (ausschließlich) die Präferenzen der Mitglieder der eigenen GKS verfolgen. Den theoretischen Analyserahmen zur Untersuchung dieser Problemstellung bildet die ökonomische Theorie der Politik. ${ }^{190}$

\section{III-2.3.1.1 Der theoretische Analyserahmen}

In der ökonomischen Theorie der Politik wird das (traditionelle, neoklassische) ökonomische Verhaltensmodell ${ }^{191}$ auf die Politik angewandt. ${ }^{192}$ Es erfolgt eine ökonomische Analyse des politischen Prozesses. Diese berücksichtigt, daß in der Realität der individuelle Wähler nicht direkt am finanzpolitischen Entscheidungsprozeß beteiligt ist, sondern die Entscheidungsbefugnis an Parlamentarier delegiert, deren Auswahl durch Wahlen erfolgt (repräsentative Demokratie). Die ökonomische Theorie der Politik stellt nunmehr „eine Analogie zwischen dem Wettbewerb der Unternehmungen um die Konsumenten am Markt und dem Wettbewerb der Politiker um die Wähler in der politischen Arena her. Genau wie der Wettbewerb am Markt

\footnotetext{
${ }^{188}$ Dabei wird keine Aussage getroffen, ob der Hoheitsbereich der Transfergeber denjenigen der Transferempfänger miteinschließt - die FZ also vertikal von einer übergeordneten Ebene des föderativen Staates geleistet werden -, oder ob sich die Hoheitsbereiche gegenseitig ausschließen - die FZ also horizontal zwischen GKS einer föderativen Ebene geleistet werden.

189 Pitlik (1997), S. 151.

190 Vorläufer dieser Theorierichtung sind die Überlegungen von Wicksell (1896) u. Schumpeter (1950). Den Ausgangspunkt unterschiedlicher Forschungsrichtungen bilden die Werke von Arrow (1963), Downs (1968), Buchanan/Tullock (1962), Olson (1968) u. Niskanen (1971). Einen aktuellen Überblick über den Stand dieser Theorierichtung geben kurz Frey, B. (1988) sowie ausführlich Mueller (1989) u. Herder-Dorneich (1992).

191 Die grundlegenden Elemente des ökonomischen Verhaltensmodells sind der methodische Individualismus, die systematische Reaktion auf Anreize, die Trennung zwischen Präferenzen u. Restriktionen sowie die Eigennutzorientierung; vgl. Kirchgässner (1991), S. 12 ff.; Frey, B./Heggli (1993), S. 306 ff.

192 Vgl. Mueller (1989), S. 1 f.
} 
die Produzenten unter gewissen Annahmen veranlaßt, in Übereinstimmung mit den Präferenzen der Konsumenten zu produzieren, so veranlaßt der politische Wettbewerb die Repräsentanten unter bestimmten Annahmen, in Übereinstimmung mit den Interessen der Wähler zu handeln."193 Im Idealfall, bei vollständigem Wettbewerb zwischen den Politikern, wird der Handlungsspielraum der Entscheidungsträger völlig beseitigt, so daß ausschließlich der Wählerwillen zur Geltung kommt.

Entwickelt man über diese Grundlegung hinaus, ein realistischeres Abbild des politischen Entscheidungsprozesses, so wird deutlich, daß die Voraussetzungen eines vollständigen Wettbewerbs zwischen Politikern aus unterschiedlichen Gründen nicht erfüllbar sind: ${ }^{194}$

- Es bestehen Informationsdefizite, die die Wirksamkeit der politischen Konkurrenz reduzieren, da weder die Politiker noch die Wähler die kognitiven Fähigkeiten besitzen, alle entscheidungsrelevanten Informationen zu verarbeiten. Zudem ist zu berücksichtigen, daß die Informationssammlung Kosten verursacht, so daß es für alle Akteure ein „rationales” Kalkül darstellt, sich nicht alle theoretisch verfügbaren Informationen nutzbar zu machen. Schließlich bestehen Unsicherheiten, also ein „Mangel an sicherem Wissen über den Verlauf vergangener, gegenwärtiger, zukünftiger oder hypothetischer Ereignisse", ${ }^{195}$ die auch über die Beschaffung von Informationen nicht überwindbar sind. Liegen Informationsdefizite vor, so ist nicht zu erwarten, daß die Informationen zwischen den Akteuren symmetrisch verteilt sind und es entsteht ein Spielraum für strategische Verhaltensweisen.

- Der eigenständige Handlungsspielraum der Politiker auf dem „politischen Markt” wird „minimiert”, wenn über jeden einzelnen Politikvorschlag gemäß des Einstimmigkeitsprinzips abgestimmt wird und eine (möglichst) große Zahl an Politikern unterschiedliche Vorschläge ,anbietet”. ${ }^{196}$ In einer repräsentativen Demokratie finden Wahlen jedoch nur in größeren Zeitabständen statt, bei denen über ein ganzes Fragenpaket abgestimmt wird. Die Zahl der politischen Vertreter ist begrenzt. Zumeist gilt als Entscheidungsregel eine Form des Mehrheitswahlrechts. „Differenzierte Präferenzen kann der Bürger [daher] nicht zum Ausdruck bringen bzw. keine seinen Ansprüchen entsprechenden Leistungen einkaufen." 197 Diese Eigenschaften des politischen Marktes „have the effect of shielding politicians ... from the preferences and the pressure of citizens", ${ }^{198}$ so daß Handlungsspielräume für die Politiker entstehen.

\footnotetext{
193 Musgrave/Musgrave/Kullmer (1990), S. 127.

$194 \mathrm{Vgl}$. hierzu Hildebrandt (1995), S. $31 \mathrm{ff}$.

195 Downs (1968), S. 75.

196 Vgl. hierzu Breton (1974), S. 42 ff.

197 Hildebrandt (1995), S. 34.

198 Breton (1974), S. 43.
} 
- Neben den Wahlbürgern und den Politikern gibt es weitere Akteure bzw. Akteursgruppen. Auf der Angebotsseite sind insb. die Parteien und Bürokraten, auf der Nachfrageseite die Interessengemeinschaften zu berücksichtigen. Diese Akteursgruppen können die Unvollkommenheiten des politischen Wettbewerbs ausnutzen und so auf die Entscheidungen der Politiker (und Wähler) gemäß ihrer Vorstellungen Einfluß nehmen.

Diese Aufzählung stellt nur einen Ausschnitt der Argumente dar, die einen vollkommenen Wettbewerb zwischen den politischen Repräsentanten verhindern. Sie zeigt deutlich, daß der Idealfall, nach dem im politischen Entscheidungsprozeß ausschließlich der Wählerwille zur Geltung kommt, nur sehr bedingte Gültigkeit besitzt. Nachfolgend werden daher Annahmen über das zu erwartende Verhalten der wichtigsten Akteursgruppen getroffen, um zu verdeutlichen, wie sie (potentielle) Handlungspielräume ausnutzen werden, wenn sie eine Maximierung ihres Eigennutzens anstreben. So wird ein realitätsnäheres Abbild der politischen Willensbildung skizziert, als durch einen benevolenten Diktator, der allwissend gemäß den Präferenzen der Bürger entscheidet. ${ }^{199}$

\section{III-2.3.1.2 Das Verhalten der Politiker (und Parteien)}

Die Politiker beteiligen sich am politischen Prozeß nicht zur Maximierung des Gemeinwohls sondern zur Verfolgung privater Ziele wie Einkommen, Prestige, Macht oder auch zur Verwirklichung ideologischer Vorstellungen. Die Erreichung dieser Ziele ist entscheidend verbunden mit der Ausübung öffentlicher Ämter, die den Politikern zwischen den Wahlen quasi „eine monopolartige Position” ${ }^{200}$ und damit „einen weiten, nur durch die Verfassung eingeschränkten Handlungsspielraum"201 schafft. Die Politiker verfolgen deshalb ein strategisches Verhaltenskalkül, das insgesamt darauf ausgerichtet ist, bei den nächsten Wahlen eine Stimmenmehrheit zu erreichen, um in der kommenden Legislaturperiode eine öffentliche Position einnehmen zu können. Einzelne Politiker organisieren sich zu diesem Zweck in Parteien, aus deren Mitgliedern die Besetzung der politischen Ämter erfolgt. Die Regierungspartei und die oppositionellen Parteien bieten ihren Mitgliedern Unterstützungsleistungen an. Sie sind Ko-

199 Inwieweit die Ergebnisse der ökonomischen Theorie der Politik tatsächlich ein wirklichkeitsnahes Abbild des politischen Entscheidungsprozesses verkörpert ist jedoch umstritten. Die Kritik knüpft hier an den aus der Neoklassik übernommenen grundlegenden Elementen an. So ist z.B die Annahme des rationalen Verhaitens der Individuen (,homo oeconomicus") bereits innerhalb des rein ökonomischen Bereichs breiter Kritik ausgesetzt. Die Übertragung auf nicht-ökonomische Gebiete läßt die Zulässigkeit dieser Verhaltensannahme noch problematischer erscheinen (vgl. zur Kritik an der ökonomischen Theorie der Politik bspw. Hildebrandt (1995), S. 104 ff., m.w.N.).

200 Frey, B. (1988), S. 662.

201 Bohnet-Joschko (1996), S. 203. Frey, B. (1988), S. 662 weist jedoch richtigerweise darauf hin, daß tatsächlich ,administrative, legale, finanzielle ... und instrumentelle Nebenbedingungen” zu berücksichtigen sind. 
alitionen der Parteiangehörigen zur Erreichung individueller Ziele. Es werden politische Programme entwickelt, die einerseits die Parteiideologie widerspiegeln, andererseits jedoch eine Stimmenmaximierung bei Wahlen ermöglichen, um möglichst viele der bestehenden öffentlichen Ämter durch Mitglieder der eigenen Partei besetzen zu können. ${ }^{202}$

Das Vorgehen der regierenden Politiker im Laufe einer Legislaturperiode kann als eine Maximierung ihres Eigennutzens unter der Nebenbedingung der Wiederwahl charakterisiert werden. Dabei sind die Wünsche und Wertvorstellungen der Wahlbürger nicht notwendigerweise Bestandteil der Zielfunktion der Politiker. Allerdings stehen die Regierenden im „Konkurrenzkampf um Macht und Amt"203 zu oppositionellen Politikern. Es stellt daher eine Nebenbedingung des Verhaltens der Politiker dar, die Präferenzen der Bürger zumindest in jenem Umfang zu beachten, der nach Einschätzung der politisch Verantwortlichen zur Stimmenmehrheit bei den kommenden Wahlen genügt. Die Verfolgung der Wählerinteressen wird zum Nebenprodukt der Konkurrenz um die politische Führung. ${ }^{204}$

Diese Konkurrenz führt aber in aller Regel zu unerwünschten „politischen Konjunkturzyklen”. ${ }^{205}$ Geht man nämlich davon aus, daß der Zeithorizont der Wähler deutlich kürzer ausfällt als derjenige der Politiker, ${ }^{206}$ stellt es eine sinnvolle Strategie für die politisch Verantwortlichen dar, unabhängig von den Auswirkungen auf das Gemeinwohl, „Wahljahre (zumeist über eine expansive Politik) zu Aufschwungjahren zu machen und Wähler in Wahljahren mit Geschenken 'zu beglücken' ."207 Unpopuläre Maßnahmen hingegen werden unmittelbar nach Wahlen vorgenommen, da diese nach Ablauf (fast) einer ganzen Legislaturperiode kaum noch in die Entscheidung der Bürger zur Stimmabgabe einfließen. Daher besteht die Gefahr, daß die an der Wiederwahl interessierten Politiker langfristig ausgerichtete strategische Entscheidungen unterlassen und stattdessen eine Vielzahl kurzfristiger und inkonsistenter Maßnahmen ergreifen, um Wählerstimmen zu mobilisieren (,muddling through”). ${ }^{208}$

\section{III-2.3.1.3 Das Verhalten der Bürokraten}

Die bürokratischen Organisationsstrukturen des öffentlichen Sektors wurden bislang nicht betrachtet, da angenommen wurde, daß die staatliche Verwaltung ausschließlich den überge-

\footnotetext{
${ }^{202}$ Für weitergehende Ausführungen insb. zur Asymmetrie des Verhaltens zwischen Regierungs- und Oppositionsparteien vgl. Thöni (1986), S. 89 ff., m.w.N.

${ }^{203}$ Schumpeter (1950), S. 448.

${ }^{204} \mathrm{Vgl}$. hierzu grundlegend Schumpeter (1950), S. $427 \mathrm{ff}$.

${ }^{205}$ Vgl. hierzu Nordhaus (1975).

${ }^{206}$ Die Wähler „vergessen” im Laufe der Legislaturperiode, welche Maßnahmen durch die Politiker ergriffen wurden.

${ }^{207}$ Grossekettler (1995), S. 618.

208 Vgl. Brümmerhoff (1996), S. 116.
} 
ordneten Zielen der demokratisch legitimierten Entscheidungsträger verpflichtet ist. Die bürokratische Exekutive wurde „als neutrales Vollzugsinstrument des politischen Willens" ${ }^{209}$ betrachtet, das alle entscheidungsrelevanten Informationen unverzerrt bereitstellt und die politischen Entscheidungen der Regierenden uneigennützig ausführt. ${ }^{210}$

Entsprechend der ökonomischen Theorie der Politik werden nun auch die Bürokraten als Akteursgruppe mit Eigeninteressen begriffen. Sie verhalten sich strategisch, um eigennützige Zielsetzungen wie Macht, Prestige, Aufstiegsmöglichkeiten, Einkommen, Bequemlichkeit oder Sicherheit zu verwirklichen. Der entscheidende Ansatzpunkt für strategische Verhaltensweisen ergibt sich für die Bürokraten durch den Informationsvorsprung, den sie im Hinblick auf die Abläufe und Kosten der bürokratischen Produktion öffentlicher Güter gegenüber den regierenden politischen Entscheidungsträgern besitzen, die wiederum über die Zuweisung von finanziellen Mitteln an die Administration entscheiden. Die Politiker müßten erhebliche Kosten zur Informationssammlung aufwenden, um ihre Informationsdefizite abzubauen. Das Interaktionsgefüge zwischen Politikern und Bürokraten läßt sich in der Marktanalogie „durch ein bilaterales Monopol von Verwaltung und Regierung mit asymmetrischer Informationsverteilung abbilden." ${ }^{211}$ So gewinnen die Bürokraten als alleinige Anbieter öffentlicher Leistungen eigenständige Handlungsspielräume gegenüber den politischen Entscheidungsträgern als alleinigen Nachfragern der öffentlichen Leistungen.

Im bürokratietheoretischen Erklärungsansatz von Niskanen ${ }^{212}$ bemühen sich die Bürokraten darum, ihre Handlungsspielräume zu einer Maximierung des Budgetvolumens des eigenen Zuständigkeitsbereiches zu nutzen. Es wird angenommen, daß die (oben genannten) Eigeninteressen der Bürokraten auf diese Weise am ehesten realisiert werden können. Dabei treten die Bürokraten als sogenannte „monopolistische Optionsfixierer”213 auf, die den Politikern feste Budget-Output-Kombinationen vorlegen. Die Bürokraten beachten hierbei sowohl ihre Kenntnis der Minimalkosten der bürokratischen Leistungserstellung als auch ihr Wissen über die Zahlungsbereitschaft der politischen Entscheidungsträger für unterschiedliche Mengen öffentlicher Leistungen. ${ }^{214}$ Aus Sicht der Politiker läge das optimale Budgetvolumen dort, wo ihre Grenzzahlungsbereitschaft ${ }^{215}$ exakt den Grenzkosten einer zusätzlichen Outputeinheit

\footnotetext{
${ }^{209}$ Hildebrandt (1995), S. 88.

210 Vgl. Grossekettler (1995), S. 618 f.

211 Bohnet-Joschko (1996), S. 210. Es ergibt sich so ein Principal-Agent-Problem.

${ }^{212}$ Vgl. Niskanen (1971); vgl. zu diesem Ansatz auch ausführlich Hildebrandt (1995), S. 89 ff.

213 Frey, B. (1988), S. 664.

${ }^{214}$ Dabei wird von typischen Kostenverläufen, also sinkenden Grenznutzen u. steigenden Grenzkosten ausgegangen.

215 Als Ausdruck des Grenznutzens, den eine durch die Bürokratie produzierte Ausbringungseinheit für die Politiker besitzt.
} 
entspricht. ${ }^{216}$ Die Politiker kennen aber die Kostenverläufe nicht. Diesen Informationsvorsprung schöpfen die Bürokraten als Optionsfixierer aus. Sie dehnen ihr Produktionsangebot soweit über die Optimalmenge hinaus aus, bis die Gesamtkosten der bürokratischen Leistungserstellung gerade eben noch durch das Budgetvolumen gedeckt werden. Die Gesamtzahlungsbereitschaft der Politiker wird auf diese Weise soweit (maximal) ausgeschöpft, bis die Budgetrestriktion eine weitergehende Ausdehnung der Produktion nicht mehr zuläßt.

Im Mittelpunkt weiterer bürokratietheoretischer Modelle stehen alternative Erklärungsansätze über die Art, in der die Bürokraten bestehende Informationsvorsprünge nutzen. ${ }^{217}$ Den verschiedenen Ansätzen ist gemein, daß der diskretionäre Handlungsspielraum der Exekutiven zur Steigerung des Eigennutzens der Bürokraten ausgenutzt wird. Das öffentliche Angebot durch die bürokratische Exekutive wird in allen Modell-Fällen ineffizient. Entweder liegt der Output über der paretoeffizienten Menge (allokative Ineffizienz) oder die Produktion erfolgt zu überhöhten Kosten (technische Ineffizienz). ${ }^{218}$

\section{III-2.3.1.4 Das Verhalten der Interessengruppen}

Der Zusammenschluß einzelner Wirtschaftssubjekte zu einem organisiertem Gruppenverband wird als Interessengruppe bezeichnet. Die Bildung dieser „Pressure Groups”219 erfolgt, um den politischen Entscheidungsprozeß zur Föderung von Interessen zu beeinflussen, die allen Mitgliedern der Interessengruppe gemeinsam sind. In Abgrenzung zu politischen Parteien zielen die Interessengruppen jedoch nicht auf die Erringung politischer Ämter ab. Stattdessen bemühen sich die Interessengruppen in Konkurrenz mit anderen Lobbies um staatlich garantierte Vorteile, insb. Einkommensgewinne, für die eigene Klientel. In diesem Wettstreit um Distributionsvorteile setzen die verschiedenen Pressure Groups Ressourcen ein. Die Interessengruppen betreiben „rent-seeking”.220

Auch das Verhältnis zwischen den Politikern und den Interessengruppen kann als eine Tauschbeziehung aufgefaßt werden. Dabei bieten die Pressure Groups unterschiedliche Leistungen an. Sie versorgen die nur unvollständig informierten Politiker mit speziellen, wahlrelevanten Informationen. Sie leisten finanzielle Zuwendungen an die Politiker bzw. Parteien

\footnotetext{
${ }^{216}$ Sofern die Politiker den Präferenzen der Wähler nachkommen entspricht dieses Budgetvolumen einem Allokationsoptimum (gesellschaftliches Nutzenmaximum).

217 Vgl. bspw. Davis/Dempster/Wildavsky (1974), Migué/Bélanger (1974) u. Williamson (1975).

${ }^{218}$ Vgl. hierzu auch Brümmerhoff(1996), S. $120 \mathrm{f}$.

219 Olson (1968), S. 115.

${ }^{220}$ Vgl. hierzu grundlegend Tullock (1967); auch Pitlik (1997), S. 161. Aktuell die weitergehenden Ausfuihrungen bei Hildebrandt (1995), S. $59 \mathrm{ff}$.
} 
und sie mobilisieren durch ihre Lobbyaktivitäten Wählerstimmen. Darüber hinaus besitzen die Interessengruppen das Drohpotential, ihre Marktmacht ${ }^{221}$ zur Störung des Wirtschaftsablaufs auszunutzen. Als Gegenleistung gewähren die Politiker Vergünstigungen an die Mitglieder der Interessengruppe. 222

Durch die Wechselbeziehung zu den Politikern können die Interessengruppen grundsätzlich einen wichtigen Beitrag zur Realisierung eines funktionsfähige(re)n politischen Entscheidungsprozesses leisten. Sie fördern die „Artikulation der Präferenzen ihrer Mitglieder und die kostengünstige Versorgung politischer Entscheidungsträger mit politisch relevanten Informationen." ${ }^{223}$ Sind alle Bürger gleichmäßig in unterschiedlichen Interessengruppen organisiert und gelingt es den einzelnen Interessengruppen, die Präferenzen ihrer Mitglieder in gleicher Intensität zum Ausdruck zu bringen, so garantiert der „Informationswettkampf der Verbände", 224 daß (im theoretischen Idealfall) alle relevanten Informationen in den politischen Prozeß eingebracht werden. ${ }^{225}$ Die in Abschnitt III-2.3.1.1 beschriebenen Unvollkommenheiten des politischen Wettbewerbs können auf diese Weise (tendenziell) abgemildert werden. Jedoch sind gegen diese Sichtweise zwei wesentliche Einwände zu erheben:

- In der Realität besteht eine große Anzahl unterschiedlicher Interessengruppen, die ein weites Spektrum verschiedener Präferenzen artikulieren. Die politischen Entscheidungsträger sind in der Regel nicht in der Lage, alle Informationen, die an sie herangetragen werden, zu verarbeiten und hierauf aufbauend wohlabgewogene, konsistente Entscheidungen zu treffen. Stattdessen erfolgen politische Einzelentscheidungen im Hinblick auf die speziellen Wünsche singulärer Interessengruppen. „Das Budget wird nicht für alle Bürger optimiert, sondern speziell auf die Interessen der Verbände ausgerichtet. Sonderinteressen kommen daher anstelle des Gemeinwohls zur Geltung."226

- Es ist einzuwenden, daß sich die Interessen verschiedener Gruppen der Bevölkerung keinesfalls gleichmäßig erfolgreich im politischen Prozeß organisieren und vertreten lassen. ${ }^{227}$ Die Vergünstigungen, die die Interessengruppen von den Politikern zu erlangen suchen, weisen die Eigenschaften gruppenspezifischer öffentlicher Güter auf. Die gewährten Vor-

${ }^{221}$ Dabei beruht die bestehende Marktmacht einer Interessengruppe ,auf der Zahl und dem Organisationsgrad der Mitglieder, der Finanzkraft, der Stärke, mit der einzelne Branchen in einer Region vertreten sind, der Unternehmenskonzentration und der Konfliktfähigkeit eines Verbandes." (Brümmerhoff(1996), S. 124.)

222 Vgl. hierzu Frey, B. (1988), S. 663; Brümmerhoff(1996), S. 124; Pitlik (1997), S. 161.

${ }^{223}$ Pitlik (1997), S. 162.

224 Grossekettler (1995), S. 621.

${ }^{225}$ Dies verkörpert eine der zentralen Aussagen der sogenannten Pluralismustheorie, die die effizienzfördernden Wirkungen des Interessengruppenwettbewerbs als Hauptforschungsgegenstand besitzt. Vgl. zur Pluralismustheorie grundlegend Galbraith (1952).

226 Brümmerhoff(1996), S. 124.

227 Vgl. hierzu grundlegend Olson (1968). 
teile kommen allen Mitgliedern einer Pressure Group zugute, unabhängig davon, ob sich ein einzelnes Mitglied tatsächlich aktiv an der Lobbytätigkeit beteiligt. Ein individuelles Gruppenmitglied verhält sich daher rational, indem es als „Freifahrer” agiert und den Nutzen der Interessenvertretung wahrnimmt ohne zur Finanzierung der Organisation beizutragen. Das „free-rider”-Problem kann jedoch, wie Olson demonstriert hat, abgemildert werden, wenn besonders starke Anreize zur aktiven Mitwirkung an der Interessenvertretung bestehen. ${ }^{228}$ Hierzu sind insb. die nachfolgenden Faktoren ${ }^{229}$ zu zählen, so daß die Entstehung einer Interessengruppe vor allem dann zu erwarten ist, wenn

(1)die potentielle Mitgliederzahl einer Interessengruppe gering ist;

(2)die potentiellen Mitglieder sehr intensiv von einem Politikbereich betroffen sind;

(3)durch eine starke gegenseitige Abhängigkeit der potentiellen Mitglieder der Interessengruppe ein ,sozialer Druck”230 zum Verbandsbeitritt besteht;

(4)als Nebenprodukt der Interessengruppenaktivitäten auch private Güter entstehen, die nur von Mitgliedern der Pressure Group erworben werden können. ${ }^{231}$

Die Berücksichtigung dieser Zusammenhänge läßt darauf schließen, daß sich zahlreiche Interessen ${ }^{232}$ gar nicht oder nur in suboptimalen Umfang zur Vertretung ihrer gemeinsamen Anliegen organisieren können. Anderen Interessen ${ }^{233}$ gelingt es hingegen, eine effektive Organisation zu schaffen und so die Präferenzen ihrer Mitglieder mit besonderer Intensität in den politischen Prozeß einzubringen. Es resultiert eine „tendenziell ungleichgewichtige Repräsentation von Interessen in politischen Entscheidungen."234

Insgesamt kann damit die ursprüngliche positive Sicht des Informationswettkampfs der Interessengruppen nicht aufrechterhalten werden. Es besteht die Möglichkeit, daß das Verhalten der Interessengruppen zu einer (zusätzlichen) Verzerrung ökonomisch effizienter, am Gemeinwohl aller Bürger ausgerichteter politischer Entscheidungen fuihrt.

\section{III-2.3.1.5 Zwischenfazit zum intrakollektiven Entscheidungsprozeß}

In den Abschnitten III-2.3.1.1 bis 4 wurden Erklärungsansätze für das Verhalten der am staatlichen Entscheidungsprozeß beteiligten Akteursgruppen gesucht. Es wurde hierbei kein spezi-

\footnotetext{
${ }^{228}$ Vgl. Olson (1968), S. 15 ff.; auch Frey, B. (1988), S. 663; Pitlik (1997), S. 164 f.

229 Über die angefulhrten Faktoren hinaus können Interessengruppen aufgrund staatlichen Zwangs entstehen.

${ }^{230}$ Frey, B. (1988), S. 663.

231 Dies sind ,selektive Anreize”. Als Beispiel sei die Vergabe einer Mitgliedszeitschrift genannt.

${ }^{232}$ Insbesondere große u. heterogene Gruppen, wie bspw. Konsumenten oder Steuerzahler.

${ }^{233}$ Insbesondere kleine u. homogene Gruppen, wie bspw. Produzenten oder auch Bürgerinitiativen.

${ }^{234}$ Hildebrandt (1995), S. 58.
} 
eller Bezug zur Vergabe von FZ hergestellt. Die polit-ökonomische Analyse der Interaktionen zwischen unterschiedlichen Akteursgruppen zeigte Unvollkommenheiten des politischen Wettbewerbs auf, die Handlungsspielräume für eigennützig handelnde Akteure eröffnen. Damit entstehen Ansatzpunkte für die Erklärung von Ineffizienzen bei der Bereitstellung öffentlicher Leistungen aufgrund des staatlichen Willensbildungs- und Entscheidungsprozesses. Die allgemeingültigen Ergebnisse treffen in analoger Weise auch auf den speziellen Bereich der zwischenstaatlichen FZ zu: ${ }^{235}$ Verzerrungen des Umfangs oder der Struktur der von den einzelnen Bürgern gewünschten öffentlichen Leistungen bei der Vergabe von FZ lösen Präferenzkosten aus; es entstehen aber auch Ressourcenkosten, wenn die Produktion der öffentlichen Leistungen aufgrund der bestehenden Handlungsspielräume technisch ineffizient erfolgt. Es kann daher nicht mehr von der vereinfachenden Aussage des Grundmodells ausgegangen werden, daß die staatlichen Akteure die Instrumentqualitäten alternativer FZ nutzen, um als wohlwollende Agenten ausschließlich die Wohlfahrt der Bürger ihres Hoheitsgebietes zu maximieren. Dabei ist zu berücksichtigen, daß die einzelnen Akteursgruppen auf der Transfergeber- und der Transferempfängerseite agieren. Folglich sind Ineffizienzen sowohl bei der Ausgestaltung (Transfergeberseite) als auch bei der Verwendung (Transferempfängerseite) der FZ möglich. Zudem sind Wechselbeziehungen zwischen den beiden Seiten zu beachten:

- Die Wähler unterliegen Informationsdefiziten im Hinblick auf das Entscheidungsverhalten der politischen Akteure. Die Politiker beider Seiten können deshalb durch den strategischen Einsatz der FZ eigene Ziele verfolgen.

- Die Bürokraten beider Seiten besitzen gegenüber den Politikern ein überlegenes Fachwissen in bezug auf die zieladäquate Ausgestaltung bzw. effiziente Durchführung der FZProgramme. Diesen Informationsvorsprung können die jeweiligen Bürokraten ausnutzen, um eigennützige Ziele zu verwirklichen.

- Die Interessengruppen betätigen sich gegenüber den Politikern beider Seiten als Lobbyisten, um die Ausgestaltung und die Verwendung der FZ so zu beeinflussen, daß den Interessen der eigenen Klientel zur Durchsetzung verholfen wird.

- Darüber hinaus besitzen die Akteure der Transferempfängerseite grundsätzlich einen Informationsvorsprung gegenüber den Akteuren der Transfergeberseite in bezug auf die Art, wie die zugewiesene FZ verwendet wurde. Die Transfergeber müssen deshalb Kosten zur begleitenden Beobachtung und nachträglichen Kontrolle des Ausgabegebarens der Transempfänger aufwenden, um die Verwendung der FZ-Mittel entsprechend der vorgege-

${ }^{235}$ Es zeigt sich hier, daß in geeigneter Weise ein enger Zusammenhang zwischen der neuen politischen Ökonomie und den Kostenkategorien des foderativen Referenzrahmens des Kapitels II hergestellt werden kann. 
benen Ausgestaltungsweise zu garantieren. Hierdurch entstehen Spielräume für die Transferempfänger von der „,vorgeschriebenen” Verausgabung der FZ abzuweichen. ${ }^{236}$

Die ökonomische Theorie der Politik erlaubt es, erste konkrete Schlußfolgerungen abzuleiten, die einen Erklärungsbeitrag über die Ergebnisse des mikroökonomischen Grundmodels hinaus leisten. Allerdings müssen die erheblichen Unzulänglichkeiten des gewählten Analyserahmens beachtet werden. ${ }^{237}$ Über das Verhalten der Akteure wurden sehr einfache und undifferenzierte Annahmen getroffen. Es wurde lediglich eine Partialanalyse einzelner Akteursgruppen angestellt. ${ }^{238}$ Die Vielschichtigkeit der Interdependenzen zwischen den Akteursgruppen bleibt daher weitgehend unberücksichtigt. Zudem erfolgte die Analyse ohne einen konkreten Raum- und Zeitbezug und ohne Berücksichtigung beschränkender rechtlich-organisatorischer Rahmenbedingungen. Der Erklärungsgehalt kann daher gesteigert werden, indem konkrete rechtlich-organisatorische Strukturen eines Staatsgebildes berücksichtigt werden und im Einzelfall weniger schematische Verhaltensannahmen getroffen werden. ${ }^{239}$

In jedem Fall sind die Schlußfolgerungen der mikroökonomischen Indifferenzkurvenanalyse neu zu reflektieren. Unter Einbeziehung der polit-ökonomischen Erkenntnisse wird die Entscheidungsgrundlage zur Beurteilung der Geeignetheit einer konkreten Ausgestaltungsform einer $\mathrm{FZ}$ als finanzpolitisches Intstrument deutlich komplexer. Die Analyse kann nicht länger auf die Höhe des FZ-Volumens und den Verlauf der Einkommens- bzw. der Preis-Elastizität in der transfererhaltenden GKS beschränkt bleiben:

- Auf Seiten der Transferempfänger muß thematisiert werden, welchen Akteursgruppen es neben den Wählern gelingt, Einfluß auf die Verwendung der erhaltenen FZ zu nehmen. Je nachdem wessen Präferenzen sich im politischen Entscheidungsprozeß der transferempfangenden GKS durchsetzen und welche Handlungsmotive - ob überwiegend eigennutzoder gemeinwohlorientiert - durch diese Präferenzen widergespiegelt werden, resultieren abweichende Handlungsempfehlungen zur zieladäquaten Ausgestaltung der FZ. ${ }^{240}$

${ }^{236}$ Diese Überlegungen beziehen sich auf den interkollektiven Entscheidungsprozeß. Sie werden im nachfolgenden Abschnitt III-2.3.2 näher ausgeführt.

$237 \mathrm{Vgl}$. hierzu auch die aufschlußreichen Ausführungen von Kirchgässner (1991), S. $102 \mathrm{ff}$.

${ }^{238}$ Es wurden jeweils ausschließlich zwei Akteursgruppen herausgegriffen und in ihren Interaktionen analysiert. In keinem Fall wurden Wechselspiele zwischen mehr als zwei Akteursgruppen zugleich betrachtet.

239 Diese beiden Aspekte finden daher in den folgenden Kapiteln im Hinblick auf die EU-Ebene besondere Beachtung. Vgl. zur Kritik der politisch-ökonomischen Analyse ausführlich Hildebrandt (1995), S. $97 \mathrm{ff}$.

240 Überträgt man diese Überlegung auf die graphischen Darstellungen der Indifferenzkurvenanalyse, so entsteht für die Transfergeber eine (über die ohnehin bestehenden Informationsprobleme hinaus) zunehmende Unsicherheit über den Verlauf der EKK bzw. PKK, der der Entscheidung über die zieladäquate Ausgestaltungsform einer FZ zugrundezulegen ist. (Vgl. hierzu auch Abschnitt III-2.1, insb. S. 34) 
- Die Seite der Transfergeber ist in die Untersuchung zu integrieren. Im Grundmodell blieb die Überlegung, ob es im Interaktionsgeflecht der Akteursgruppen auf der Transfergeberseite überhaupt zu einer am Gemeinwohl orientierten Ausgestaltung der FZ kommt, völlig ausgeklammert. $^{241}$

- Das Analyseschema der ökonomischen Theorie der Politik verdeutlicht die Bedeutung der Kosten der Informationsbeschaffung sowie der Kontrollkosten, die durch Interessenkonflikte und Informationsasymmetrien zwischen den Akteursgruppen ausgelöst wird. Diese Ressourcenkosten sind in die Entscheidung über die Ausgestaltung der FZ einzubeziehen.

\section{III-2.3.2 Der politische Entscheidungsprozeß und seine Akteure - Interkollektiv}

Nachfolgend wird angenommen, daß sich der Politikgestaltungsprozeß zur Vergabe zwischenstaatlicher FZ in einem komplexen Verbund von Transfergebern und Transferempfängern vollzieht (Politikverflechtung). ${ }^{242}$ Die Handlungskompetenzen zur Entscheidungsfindung sind zwischen den beteiligten GKS nicht strikt abgegrenzt, sondern werden jeweils interkollektiv durch gemeinschaftliches Agieren aller betroffenen GKS in einem multidimensionalen, vernetzten Verhandlungssystem wahrgenommen. ${ }^{243}$ Es kommt ein „Politikmodus” zum Zuge, ,in dem Entscheidungen von vornherein an einer Mehrzahl von Bezugseinheiten orientiert sind, in dem es nicht auf Mehrheit, sondern auf allseitiges Einverständnis ankommt, und in dem Widerstrebende nicht zwangsweise zur Raison gebracht werden können.”244 Es treten „Verhandlungen und Vereinbarungen"245 zwischen Transfergebern und -empfängern an die Stelle der hierarchischen Entscheidung durch den allwissenden Diktator der transfergebenden Regierungseinheit, von der bei der Indifferenzkurvenanalyse ausgegangen wurde. ${ }^{246}$

${ }^{241} \mathrm{Vgl}$. hierzu die Ausführungen von Scharpf(1992c), S. 16 ff. u. (1993c), S. 132 ff. zur Handlungsorientierung der Akteure. Würde die Annahme der ökonomischen Theorie der Politik des (ausschließlich) eigennützigen Verhaltens der Entscheidungsträger in der Realität uneingeschränkt zutreffen, so betont Scharpf, würden die Vorteile staatlichen Handeln stets vollständig aufgezehrt werden. Denn es besteht bei wirklichkeitsnaher Betrachtung keine Möglichkeit, eine Struktur der rechtlich-organisatorischen Rahmenbedingungen zu schaffen, „die nicht von intelligenten und eigensüchtigen Agenten unterlaufen und ausgebeutet werden könnte". (Scharpf (1992c), S. 17)

${ }^{242}$ Der Abschnitt konzentriert sich auf die Verflechtungsstrukturen bei der Politikformulierung (Entscheidungsfindung). Die weiteren Phasen des staatlichen Handlungsablaufs, also insb. die Durchfuihrung und Kontrolle der aufgrund der Entscheidung vorzunehmenden Maßnahmen, werden lediglich an besonders wichtigen Schnittstellen in die Untersuchung integriert. Die Ausführungen gründen sich ganz wesentlich auf die Theorie der Politikverflechtung, wie sie von Scharpf (1976) u. (1978) entwickelt wurde. Die allgemeinen Analysen Scharpfs werden auf den speziellen Bereich der zwischenstaatlichen FZ übertragen.

243 Vgl. hierzu auch Grande (1995), S. 327 ff.

${ }^{244}$ Scharpf (1992c), S. 12. Die Entscheidungen werden (im Extremfall) einstimmig getroffen. Präferenzkosten sind dann ausgeschlossen.

245 Scharpf(1992c), S. 12.

246 Die Theorie der Politikverflechtung von Scharpf erhält ihre Bedeutung durch das Modell des „kooperativen Föderalismus". Ausgehend von der Realitătsferne der Existenz eines allwissenden Diktators und „einer zunehmenden, die einzelnen Zuständigkeitsbereiche übergreifenden Interdependenz der von der Entscheidungs- 
Es sind hierbei zwei unterschiedliche Verflechtungsstrukturen zu berücksichtigen. Es liegt eine horizontale Entscheidungsverflechtung vor, sofern die Entscheidungsträger auf der Transfergeber- und der Transferempfängerseite derselben dezentralen Ebene des föderativen Staates angehören. Von einem Verbundsystem wird hingegen gesprochen, wenn neben den Untereinheiten - als Transferempfänger - auch die zentrale Ebene - als Transfergeber - als „Konsenspartner”247 bei der Formulierung der FZ zu berücksichtigen ist. ${ }^{248}$

Die zu untersuchende Fragestellung lautet, unter welchen Voraussetzungen das durch Politikverflechtung gekennzeichnete Entscheidungssystem effiziente Steuerungsleistungen erbringen kann. Als effizient wird eine Steuerungsleistung dann bezeichnet, wenn im Verhandlungsprozeß (exakt) diejenige Ausgestaltung einer FZ vereinbart wird, die im Rahmen der mikroökonomischen Indifferenzkurvenanalyse - unter der realitätsfernen Annahme des allwissenden Diktators - als zieladäquate Ausgestaltungsform abgeleitet wurde. ${ }^{249}$ Die FZ-Formulierung wird ,als ein politischer Prozeß [aufgefaßt], in dem sowohl Sachinformationen als auch nicht gleichgerichtete Interessen zu sachlich realisierbaren und konsensfähigen Lösungen verarbeitet werden müssen." 250 Die Problemlösungsfähigkeit eines verflochtenen Entscheidungssystems hängt daher einerseits von seiner Kapazität zur Gewinnung und Verarbeitung der entscheidungsrelevanten Informationen und andererseits von seiner Möglichkeit zur Konfliktregelung und Konsensfindung zwischen den Verhandlungspartnern $\mathrm{ab}^{251}$

\section{III-2.3.2.1 Das Informationsproblem verflochtener Entscheidungssysteme}

Das Informationsproblem der Entscheidungsträger ist abhängig von der Problemstruktur der spezifischen Funktion, zu deren Erfüllung die FZ instrumentell eingesetzt werden soll. ${ }^{252}$ Bei zunehmender Komplexität der zu lösenden Entscheidungssituation sehen sich die Akteure mit einem ,exponential ansteigenden Informationsbedarf ${ }^{253}$ konfrontiert. Je größer die Anzahl

struktur zu bearbeitenden Aufgaben und Probleme" (Scharpf(1978), S. 23) soll die kooperative Aufgabenerfullung die Lösung von Dezentralisierungsproblemen ermöglichen. Die Politikverflechtung kann daher als eine mehrere Regierungseinheiten eines föderativen Staates verbindende Entscheidungsstruktur bezeichnet werden, die zur Steuerung des Entscheidungsverhaltens aller beteiligten Jurisdiktionen im Interesse der Gesamtheit des föderativen Staates eingerichtet wird.

${ }^{247}$ Scharpf (1976), S. 35.

${ }^{248}$ Vgl. Scharpf (1976), S. 34 f. Scharpf berücksichtigt mit der hierarchischen Verflechtung eine dritte Verflechtungsstruktur. Dann sind die GKS der dezentralen Ebene nur Informationslieferanten aber nicht an der Entscheidung beteiligt. Da im Mittelpunkt dieses Abschnitts gerade die inhaltliche Politikformulierung steht, bleibt dieser Fall aus der Untersuchung ausgeschlossen.

${ }^{249}$ Scharpf bezeichnet dies als empirisch-verhaltenswissenschaftliche Analyse.

${ }^{250}$ Scharpf(1976), S. 36.

${ }^{251}$ Vgl. Scharpf(1978), S. 26.

252 Vgl. hierzu im einzelnen Abschnitt III-3.

253 Scharpf (1978), S. 27. 
der zu berücksichtigenden Handlungsalternativen sowie der in die Entscheidungen einzubeziehenden GKS und je vielschichtiger die wechselseitigen Beziehungen zwischen diesen Handlungsalternativen und GKS, desto umfangreicher und schwerer erfaßbar wird das Gesamtvolumen der Informationen, das für eine rationale Ausgestaltung der $\mathrm{FZ}$ zu verarbeiten ist. Die Anforderungen an das Entscheidungssystem steigen sowohl in quantitativer als auch in qualitativer Hinsicht gravierend an. ${ }^{254}$

Die Verbundsysteme besitzen bei der Informationsgewinnung einen komparativen Vorteil gegenüber den horizontalen Verflechtungsstrukturen. Während letztere lediglich über das Informationspotential der einzelnen dezentralen Jurisdiktionen verfügen können, besitzen die Verbundsysteme zusätzlich den Zugriff auf "gesamtsystem-spezifische"255 Informationen. Dieser Vorteil erhält besonderes Gewicht im Hinblick auf solche Funktionen der FZ, bei denen wechselseitige Auswirkungen und Rückkoppelungen zwischen GKS einer föderativen Ebene eine wichtige Rolle spielen, aber zugleich einem „übergreifenden Problemzusammenhang" ${ }^{\text {256 }}$ Rechnung getragen werden muß, um insgesamt einen in vertikaler wie horizontaler Sichtweise komplexen Gesamtzusammenhang angemessen lösen zu können (qualitativer Aspekt).

Allerdings werden nicht nur horizontale Verflechtungsstrukturen, sondern auch Verbundsysteme bei steigender Anzahl (n) der GKS und (a) der Handlungsalternativen an die Grenzen ihrer Kapazität zur Gewinnung und Verarbeitung von Entscheidungsinformationen stoßen (quantitativer Aspekt). ${ }^{257}$ Geht man bspw. von einer komplexen Problemstruktur aus, bei der zwischen allen (n) GKS jeweils paarweise Wechselbeziehungen bestehen, so ergibt sich für jede der (n) GKS die Notwendigkeit, (n-1) Beziehungskonstellationen zu überprüfen. Insgesamt bestehen also [n*(n-1)] entscheidungsrelevante Wechselwirkungen. Zugleich sind bei jeder Wechselbeziehung $\left(\mathrm{a}^{2}\right)$ Kombinationen unterschiedlicher Handlungsalternativen zu beachten, sofern jeder GKS annahmegemäß (a) Handlungsalternativen verfügbar sind. Im Vergleich zu einer separaten Einzelentscheidung, bei der eine GKS genau (a) Handlungsalternativen zu verarbeiten hat, ergibt sich infolge der besonderen Problemstruktur und der verflochtenen Entscheidungsfindung der Verarbeitungsbedarf $\left(\mathrm{VB}_{\mathrm{n}}\right)$ prinzipiell als:

$\left(\mathrm{VB}_{\mathrm{n}}\right)=\mathrm{n} *(\mathrm{n}-1) * \mathrm{a}^{2}$

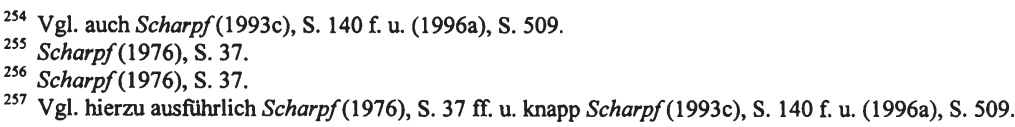


Dieser Informationsverarbeitungsbedarf muß in Beziehung zur Informationsverarbeitungskapazität (VK) des Entscheidungssystems gesetzt werden, um die Grenzen einer rationalen Entscheidungsfindung zu ermitteln. Man kann davon ausgehen, daß jede einzelne GKS eine (autonome) Verarbeitungskapazität $\left(\mathrm{VK}_{1}\right)$ besitzt, die zumindest dem Verarbeitungsbedarf (a) ihrer separaten Einzelentscheidung entspricht $\left[\left(\mathrm{VK}_{1}\right)=\mathrm{a}\right]$. Zudem kann ein horizontales Verflechtungssystem im Idealfall über die gesamte Informationsverarbeitungskapazität aller (n) GKS verfügen. ${ }^{258}$ In diesem Fall ergibt sich die Verarbeitungskapazität des horizontalen Verflechtungssystems $\left(\mathrm{VK}_{\mathrm{HV}}\right)$ als:

$$
\left(\mathrm{VK}_{\mathrm{HV}}\right)=\mathrm{n} *\left(\mathrm{VK}_{1}\right)=\mathrm{n} * \mathrm{a}
$$

Es zeigt sich, daß unter diesen Bedingungen der Informationsverarbeitungsbedarf durch das horizontale Verflechtungssystem nicht gedeckt werden kann. Denn der Quotient aus Informationsverarbeitungskapazität $\left(\mathrm{VK}_{\mathrm{HV}}\right)$ und -bedarf $\left(\mathrm{VB}_{\mathrm{n}}\right)$ ist in jedem Fall kleiner als eins:

$$
\left(\mathrm{VK}_{\mathrm{HV}}\right) /\left(\mathrm{VB}_{\mathrm{n}}\right)=(\mathrm{n} * \mathrm{a}) /\left[\mathrm{n} *(\mathrm{n}-1) * \mathrm{a}^{2}\right]=1 /[(\mathrm{n}-1) * \mathrm{a}]
$$

Die benötigte Informationsverarbeitungskapazität des Entscheidungssystems kann nur geschaffen werden, sofern die einzelnen dezentralen GKS „Überschußkapazitäten” bereitstellen. Diese müßten den Informationsverarbeitungsbedarf (a), der bei einer separaten Einzelentscheidung anfallen würde, mindestens um den Faktor $[(n-1) * a]$ überschreiten. Allerdings ist bei zunehmender Anzahl zu beachtender Handlungsalternativen und beteiligter GKS anzunehmen, daß der Aufbau dieser Entscheidungskapazitäten „die institutionellen Möglichkeiten dezentraler Einheiten sehr bald überfordern würde.,"259

Die analoge Problemstellung ergibt sich auch für das Verbundsystem, wenngleich in diesem Entscheidungssystem über die Informationsverarbeitungskapazitäten aller (n) dezentralen GKS hinaus, auch Entscheidungskapazitäten $\left(\mathrm{VK}_{\mathrm{Z}}\right)$ auf der zentralen Ebene bestehen, die zusätzlich zur Informationsverarbeitung genutzt werden können. Es wird angenommen, daß die $\left(\mathrm{VK}_{\mathrm{Z}}\right)$ ein Vielfaches der Verarbeitungskapazität einer dezentralen GKS umfassen:

$$
\left(\mathrm{VK}_{\mathrm{Z}}\right)=\mathrm{z} *\left(\mathrm{VK}_{1}\right)=\mathrm{z} * \mathrm{a}
$$

\footnotetext{
${ }^{258}$ Bei diesem Idealfall wird davon ausgegangen, daß die dezentralen GKS „unter der Bedingung vollen wechselseitigen Vertrauens" (Scharpf (1976), S. 38) eine effiziente Arbeitsteilung bei der Informationsverarbeitung einrichten, so daß keinerlei Kapazitäten des Gesamtentscheidungssystems zur Mehrfachbeschaffung identischer Informationseinheiten durch mehrere dezentrale GKS aufgewendet werden müssen. Zudem wird angenommen, daß im Rahmen der wechselseitigen Weitergabe entscheidungsrelevanter Informationen zwischen den Teileinheiten des Entscheidungssystems keinerlei Informationsverarbeitungskapazitäten verloren gehen. In der Realität ist jedoch davon auszugehen, daß die „Kommunikations-Effektivität im verflochtenen System" (Scharpf (1976), S. 38) mit steigender Anzahl (n) der beteiligten Teileinheiten abnehmen wird.

259 Scharpf(1976), S. 39.
} 
Die gesamte Informationsverarbeitungskapazität des Verbundsystems (VKVs) beträgt folglich:

$$
\left(\mathrm{VK}_{\mathrm{VS}}\right)=\mathrm{n} *\left(\mathrm{VK}_{1}\right)+\mathrm{z} *\left(\mathrm{VK}_{1}\right)=(\mathrm{n}+\mathrm{z}) *\left(\mathrm{VK}_{1}\right)=(\mathrm{n}+\mathrm{z}) * \mathrm{a}
$$

Es folgt für den Quotient aus Informationsverarbeitungskapazität (VKVs) und -bedarf $\left(\mathrm{Vb}_{\mathrm{n}}\right)$ :

$$
\left(\mathrm{VK}_{\mathrm{VS}}\right) /\left(\mathrm{VB}_{\mathrm{n}}\right)=[(\mathrm{n}+\mathrm{z}) * \mathrm{a}] /\left[\mathrm{n} *(\mathrm{n}-1) * \mathrm{a}^{2}\right]=(\mathrm{n}+\mathrm{z}) /[\mathrm{n} *(\mathrm{n}-1) * \mathrm{a}]
$$

$\mathrm{Ob}$ die Informationsverarbeitungskapazität des gesamten Entscheidungssystems ausreichend ist, hängt demnach von der Höhe des Faktors (z) ab, mit dem die Informationsverarbeitungskapazität der zentralen Ebene, diejenige der einzelnen dezentralen GKS übertrifft. Der Faktor (z) muß so groß ausfallen, daß der Quotient aus Informationsverarbeitungskapazität (VK $\left.\mathrm{VS}_{\mathrm{V}}\right)$ und -bedarf $\left(\mathrm{Vb}_{\mathrm{n}}\right)$ größer oder gleich eins wird:

$$
\begin{aligned}
& (\mathrm{n}+\mathrm{z}) /[\mathrm{n} *(\mathrm{n}-1) * \mathrm{a}] \geq 1 \quad \Rightarrow \\
& (\mathrm{n}+\mathrm{z}) \geq[\mathrm{n} *(\mathrm{n}-1) * \mathrm{a}]
\end{aligned}
$$

Nur wenn die Informationsverarbeitungskapazität $\left(\mathrm{VK}_{\mathrm{Z}}\right)$ der zentralen Ebene, jene der einzelnen dezentralen Untereinheiten $\left[\left(\mathrm{VK}_{1}\right)=\mathrm{a}\right]$ mindestens um den Faktor $\{[\mathrm{n} *(\mathrm{n}-1) * \mathrm{a}]-\mathrm{n}\}$ übertrifft, kann der Informationsbedarf der verflochtenen Entscheidungsfindung erfüllt werden. ${ }^{260}$ Damit wird auch das Verbundsystem bei zunehmender Anzahl der Teileinheiten (n) und Handlungsalternativen (a) an die „Wachstumsgrenzen bürokratischer Makrosysteme”261 stoßen.

In aller Regel können folglich die entscheidungsrelevanten Informationen innerhalb verflochtener Entscheidungssysteme nur in suboptimalem Umfang bereitgestellt werden. Wenngleich ein Verbundsystem eine höhere Informationsverarbeitungskapazität besitzt als ein horizontales Verflechtungssystem, verbleiben auch in erstgenanntem Entscheidungssystem bei zunehmender Vielschichtigkeit der Problemstrukturen und ansteigender Zahl der beteiligten Teilsysteme Informationsdefizite. Die Ausgestaltung der FZ kann dann durch die staatlichen Ent-

\footnotetext{
260 Allerdings entschärft sich das Kapazitătsproblem, sofern auf dezentraler Ebene Überschußkapazitäten bestehen. Übertreffen die Kapazitäten der dezentralen GKS den Informationsverarbeitungsbedarf (a) einer separaten Einzelentscheidung um das Vielfache (k), so ergibt sich die Verarbeitungskapazität jeder dezentralen GKS als $\left(\mathrm{VK}_{1}\right)=(\mathrm{a} * \mathrm{k})$. Die gesamte Informationsverarbeitungskapazität des Verbundsystems $\left[\left(\mathrm{VK}_{\mathrm{Vs}}\right)=\mathrm{n} *\left(\mathrm{VK}_{1}\right)+\mathrm{z} *\left(\mathrm{VK}_{1}\right)\right]$ beträgt dann $[(\mathrm{k} * \mathrm{n}+\mathrm{z}) * \mathrm{a}]$. Für den Faktor $(\mathrm{z})$, mit dem die Informationsverarbeitungskapazität $\left(\mathrm{VK}_{\mathrm{Z}}\right)$ der zentralen Ebene die Verarbeitungskapazität $\left(\mathrm{VK}_{1}\right)$ der einzelnen dezentralen Einheiten mindestens übertreffen muß, ergibt sich dann der folgenden Funktionszusammenhang: $z \geq\{[n *(n-1) * a]-(k * n)\} \div k$.

261 Scharpf (1976), S. 39.
} 
scheidungsträger nur bei unvollständigem Informationsstand erfolgen, wodurch Ineffizienzen bei der Wahl der Formen der FZ wahrscheinlich werden. Jedoch ist darauf hinzuweisen, daß bei einer autonomen Einzelentscheidung auf der zentralen Ebene oder in den einzelnen dezentralen GKS weit weniger Handlungsalternativen berücksichtigt werden, da die Kapazitäten zur Informationsverarbeitung der separat agierenden Jurisdiktionen hinter denen der verflochtenen Entscheidungssysteme zurückbleiben. Aus diesem Blickwinkel steigen die auf Informationsdefiziten beruhenden Ineffizienzen in diesen Entscheidungssystemen weiter an. ${ }^{262}$ Darüber hinaus ist zu betonen, daß neben dem rein quantitativen Vergleich der Möglichkeiten zur Informationsgewinnung und -verarbeitung - der im Mittelpunkt der formalen Ableitung der Informationsverarbeitungskapazitäten in diesem Abschnitt stand - die qualitative Sicht der Informationsproblematik entscheidende Relevanz besitzt. Denn der besondere komparative Vorteil verflochtener Entscheidungssysteme - insb. eines Verbundsystems - besteht im Zusammenspiel der einzelnen Teileinheiten, wodurch es gelingt, auch schwer erfaßbare Informationen komplexer Problemstrukturen zu generieren, die durch getrennt agierende Entscheidungseinheiten gar nicht verfügbar gemacht werden könnten.

\section{III-2 3.2.2 Das Konsensfindungsproblem verflochtener Entscheidungssysteme}

Die Verhandlungen zwischen Transfergebern und -empfängern zur Vergabe zwischenstaatlicher FZ fuihren zu einer strategischen Entscheidungssituation, deren Ergebnis durch einen beteiligten Entscheidungsträger nicht unabhängig von der Entscheidungsauswahl aller anderen Entscheidungsträger bestimmt werden kann. Es besteht daher die Möglichkeit von Interessenskonflikten und Koordinationsproblemen zwischen den Verhandlungsbeteiligten. Dabei ist sich jeder der Entscheidungsträger dieser Interdependenzen bewußt. Die theoretische Analyse derartiger Problemstellungen ist Gegenstand der Spieltheorie.

\section{III-2.3.2.2.1 Die allgemeine Koordinations- und Konfliktregelungsproblematik}

Der Verhandlungsablauf erlaubt es den Transfergebern und -empfängern einen wechselseitigen Kommunikationsprozeß zu führen, aus dem heraus verbindliche Absprachen über die Höhe, Ausgestaltung und Verwendung der FZ getroffen werden können. Existiert zusätzlich eine externe Instanz, die darüber wacht, daß dieses Verhandlungsergebnis tatsächlich eingehalten wird, so liegt eine kooperative Spielsituation vor. ${ }^{263}$

\footnotetext{
${ }^{262}$ Vgl. hierzu auch Biehl (1979), S. 127 f.

${ }^{263}$ Die Spieltheorie kann in dieser Hinsicht in zwei Teilgebiete aufgespalten werden. Während die kooperative Spieltheorie mögliche Verhandlungslösungen unter der Annahme untersucht, daß verbindliche Absprachen getroffen werden können, analysiert die nicht-kooperative Spieltheorie, welche Lösungen sich ergeben wer-
} 
Der grundlegende Charakter dieser Verhandlungsproblematik wird durch Abbildung III-9 verdeutlicht. ${ }^{264}$ Die zwei Verhandlungsparteien X und Y repräsentieren die Transfergeber und empfänger. Die einzelnen Entscheidungsträger nehmen egoistisch-rational ausschließlich die eigenen Vor- und Nachteile in ihr Entscheidungskalkül auf. Zudem wird davon ausgegangen, $\mathrm{da}$ alle entscheidungsrelevanten Informationen gemeinsames Wissen (common knowledge) beider Verhandlungsteilnehmer sind, so daß die Verhandlungspartner sämtliche Handlungsalternativen des jeweils anderen kennen und darüber informiert sind, wie dieser die einzelnen Alternativen bewertet. Daher kann jeder Teilnehmer die optimale Strategie des anderen ableiten. Die Verhandlungspartner verfügen demnach über vollständige Informationen. ${ }^{265}$ Somit besitzen sie auch Kenntnis über die Wohlfahrtsposition aller Verhandlungsergebnisse (Punkte A, B, C, D, E und F in Abb. III-9), die sich in ihrer Auswirkung auf das Nutzenniveau der beiden Akteure unterscheiden. ${ }^{266}$ Auf der Abszisse wird der positive oder negative Nutzen $\mathrm{N}_{\mathbf{x}}$ eines Verhandlungsergebnisses für den Verhandlungspartner $\mathrm{X}$ abgetragen. Auf der Ordinate derjenige $\left(\mathrm{N}_{\mathrm{y}}\right)$ des Verhandlungspartners Y. Durch den Ursprung wird der Status Quo vor Beginn des Verhandlungsprozesses dargestellt. Für den Entscheidungsträger $\mathrm{X}$ sind alle Verhandlungsergebnisse vorteilhaft, die sich rechts von der Ordinate befinden $\left(N_{x}>0\right)$, wohingegen für den Entscheidungsträger $\mathrm{Y}$ alle Verhandlungsergebnisse vorteilhaft sind, die oberhalb der Abszisse lokalisiert sind $\left(\mathrm{N}_{\mathrm{y}}>0\right)$. Erzielen die Verhandlungspartner keine Einigung, so bleibt der Status-Quo erhalten. ${ }^{267}$

Aus wohlfahrtstheoretischer Sicht kann die Bewertung der möglichen Verhandlungslösungen gemäß des (individualistischen) Pareto-Kriteriums oder des (utilitaristischen) KaldorKriteriums erfolgen. Entsprechend des Pareto-Kriteriums werden nur solche Verhandlungslösungen angenommen, die sich im nord-östlichen Quadranten der Abbildung III-9 befinden (B, $\mathrm{C}$ und $\mathrm{F}$ ). In diesem Bereich wird stets zumindest einer der Verhandlungspartner im Vergleich zum Status Quo bessergestellt, ohne daß der andere Verhandlungspartner schlechtergestellt wird $\left(N_{x}>0 ; N_{y} \geq 0\right.$ oder $\left.N_{y}>0 ; N_{x} \geq 0\right)$. Hingegen werden bei Zugrundelegung des Kaldor-

den, wenn keine Absprachen zwischen den Verhandelnden getroffen werden können u. die einzelnen Spieler ausschließlich ihr Eigeninteresse verfolgen (vgl. Illing (1995), S. 509; Pfingsten/Wagener (1995), S. 224 f.).

264 Die so abgeleiteten Ergebnisse lassen sich i.d.R. auf Spielsituationen mit mehr als zwei Verhandlungspartnern übertragen (vgl. Holler/Illing (1996), S. 174). Es können dann weitergehende Schlußfolgerungen abgeleitet werden. Die nachfolgend beschriebene Verhandlungsproblematik wurde von Scharpf in einer ganzen Reihe an Veröffentlichungen aufgegriffen, vgl. bspw. Scharpf (1976), S. 41 ff.; (1992d), S. 53 ff.; (1993c), S. 137 ff.; (1994a), S. 386 ff.; (1994b), S. 30 ff.; (1996a), S. 498 ff.

${ }_{265}$ Vgl. hierzu Holler/Illing (1996), S. $42 \mathrm{ff}$.

${ }^{266}$ Es wird angenommen, daß es lediglich eine begrenzte Anzahl, eindeutig fixierter Verhandlungslösungen gibt. Es bestehen also nicht kontinuierlich variable Verhandlungslosungen im gesamten Raum des Koordinatensystems (vgl. Scharpf(1996a), S. 501).

${ }^{267}$ Es liegt ein Zwangsverhandlungssystem vor. 
Kriteriums alle Verhandlungslösungen akzeptiert, die den aggregierten Gesamtnutzen der beiden Verhandlungsteilnehmer im Vergleich zum Status-Quo erhöhen $\left(\mathrm{N}_{\mathrm{x}}+\mathrm{N}_{\mathrm{y}}>0\right) .{ }^{268}$ Damit werden alle Verhandlungsergebnisse, die nord-östlich der durch den Ursprung führenden Diagonalen $\mathrm{G}$ lokalisiert sind, angenommen (A, B, C und F). Die Diagonale G stellt hierbei eine Nutzenisoquante dar. Alle Verhandlungslösungen auf dieser Diagonalen besitzen den gleichen aggregierten Nutzen für die Gesamtheit der Verhandlungsteilnehmer. In der Graphik sind mit den Diagonalen $\mathrm{H}$ und I zwei weitere Nutzenisoquanten abgebildet, die ein höheres aggregiertes Nutzenniveau repräsentieren. ${ }^{269}$

Abb. III-9: Problemstrukturen in verflochtenen Entscheidungssystemen

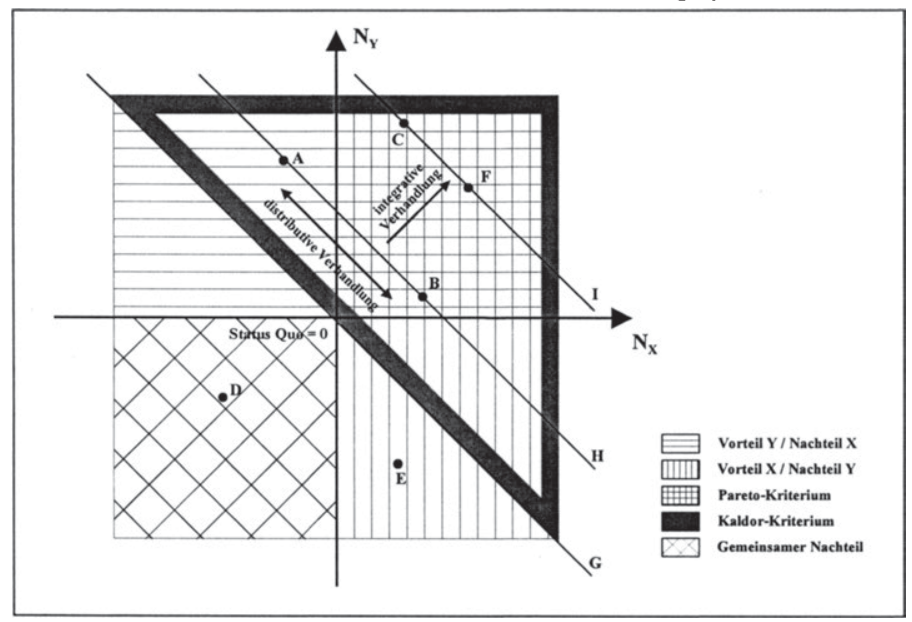

Quelle: Scharpf (1992d), S. 56 u. 58; (1993c), S. 139; (1994a), S. 392 u. 393.

In dieser Problemstruktur lassen sich zwei gegensätzliche Arten von Verhandlungsprozessen abgrenzen, die als integrative und distributive Verhandlungen bezeichnet werden. ${ }^{270}$

Das Ziel eines integrativen Verhandlungsprozesses ist es, durch die Koordinierung der Individualinteressen der Entscheidungsbeteiligten Kooperationsvorteile zu nutzen und so Nutzenzugewinne zu realisieren. Beide Verhandlungsteilnehmer besitzen in diesem Fall - trotz ihrer eigennützigen „subjektiven Interaktionsorientierung”271 - gemeinsame bzw. gleichgerichtete

\footnotetext{
268 Hierbei wird davon ausgegangen, daß ein interpersoneller Nutzenvergleich zwischen den Verhandlungsteilnehmern möglich sei. Auf diese restriktive Anforderung kann bei Zugrundelegung des Pareto-Kriteriums verzichtet werden.

${ }^{269}$ Vgl. Scharpf(1992d), S. 57 f.; (1996a), S. 499 f.

$270 \mathrm{Vgl}$. Scharpf (1994a), S. 391 ff.; auch Break (1980), S. 87 ff.

271 Scharpf(1992d), S.53.
} 
Interessen im Hinblick auf das Verhandlungsergebnis. ${ }^{272}$ Es liegt ein „Positiv-Summen-Spiel” vor, in dem eine einvernehmliche Problemlösung zu Wohlfahrtsgewinnen für jeden Verhandlungsteilnehmer führt. Es handelt sich daher um ein reines Koordinationsproblem. Verteilungsfragen sind nicht virulent. In der Graphik werden integrative Verhandlungen durch Verhandlungslösungen abgebildet, die in nord-östlicher Richtung des Status-Quo liegen. So ist bspw. der Versuch, durch „die kreative Suche nach neuen Lösungen”273 vom Status-Quo aus (Nutzenisoquante G) die Verhandlungslösung F zu erreichen, die durch die höhere Nutzenisoquante I gekennzeichnet ist, eine integrative auf „problem-solving” ausgerichtete Verhandlung. Integrative Verhandlungslösungen erfüllen stets das Pareto-Kriterium. ${ }^{274}$

Distributive Verhandlungssituationen haben dementgegengesetzt ausschließlich die Regelung eines Verteilungskonflikts zwischen den Verhandlungsparteien zum Gegenstand. Die Entscheidungsbeteiligten weisen nun - unter Berücksichtigung ihrer Eigennutzorientierung - separate bzw. gegensätzliche Interessen im Hinblick auf das Verhandlungsergebnis auf. Es liegt in diesen Fällen das aggregierte Wohlfahrtsniveau einer Problemstellung für die Gesamtheit bereits fest, jedoch erfolgt ein „Bargaining-Prozeß” um die Aufteilung des vorgegebenen „Kuchens”. Eine solche Verhandlungskonstellation stellt ein „Nullsummen-Spiel” dar. ${ }^{275}$ In der Abbildung wird eine distributive Verhandlung durch die Festlegung auf eine von zwei möglichen Lösungen in süd-westlicher Richtung auf einer vorgegebenen Nutzenisoquante abgebildet. So stellt bspw. die Auseindersetzung um die Verhandlungslösung A oder B auf der Nutzenisoquante $\mathrm{H}$ eine distributive Verhandlungssituation dar. Distributive Verhandlungen verfehlen stets das Pareto-Kriterium.

Damit ist das Grundgerüst der allgemeinen Koordinations- und Konfliktregelungsproblematik in Form einer kooperativen Spielsituation unter sehr restriktiven Annahmen beschrieben. Die zu analysierende Fragestellung lautet nun, unter welchen Bedingungen ,erfolgreiche” integrative Verhandlungen zu erwarten sind. Hierunter sind solche Verhandlungen zu verstehen, bei

${ }^{272}$ Es wird an dieser Stelle analytisch zwischen einer quasi-objektiven Interessenkonstellation und einer subjektiven Interaktionsorientierung unterschieden. Erstere stellt auf die Frage ab, ob eine Verhandlungslösung für einen bestimmten Verhandlungspartner einen positiven oder aber negativen Nutzen bedeutet. Diese Frage, so wird angenommen, ist unter genauer Berücksichtigung der bestehenden Verhandlungskonstellation ,mit hoher Zuverlässigkeit" (Scharpf (1992d), S. 53) also quasi-objektiv zu beantworten. Letztere bezieht sich hingegen auf die Einstellung der einzelnen Verhandlungspartner zueinander. Hier steht die Frage im Mittelpunkt, wie die einzelnen Akteure die Folgen einer Verhandlungslösung bewerten, die für die übrigen Verhandlungspartner entstehen (vgl. Scharpf (1992d), S. 53; auch Benz (1994), S. 93 ff.).

${ }^{273}$ Scharpf(1994a), S. 393.

274 Scharpf beschreibt die Konstellation einer integrativen Verhandlung abweichend von der hier gegebenen Abgrenzung. Gemäß Scharpfs Definition sind Verteilungsfragen zwar sehr wohl vorhanden, doch sind die Verhandlungsteilnehmer in der Lage diese Fragen auszublenden und ausschließlich das gemeinsame Interesse an der Problemlösung in den Mittelpunkt zu stellen (vgl. Scharpf(1994a), S. 393).

${ }^{275}$ Vgl. hierzu Scharpf (1993c), S. 138 f.; (1994a), S. 391 ff.; (1994b), S. 30 f. 
denen das Verhandlungsergebnis den höchsten aggregierten Nutzen für die Gesamtheit gewährleistet. Bei der Vergabe zwischenstaatlicher FZ entspricht dieses angestrebte Verhandlungsergebnis der ökonomisch zieladäquaten Ausgestaltung der FZ. ${ }^{276}$

Die Lösung einer integrativen Verhandlungssituation erscheint unter den getroffenen restriktiven Annahmen zunächst trivial. Bei vollständiger Kenntnis aller Handlungsalternativen und streng eigennützigem Verhalten der Entscheidungsträger werden sich die Verhandlungspartner stets auf diejenige Verhandlungslösung mit dem höchsten aggregierten Nutzen für die Gesamtheit einigen, die definitionsgemäß auch jedem einzelnen Verhandlungsteilnehmer Wohlfahrtsgewinne garantiert. Ein Verhandlungskonsens ist hingegen sehr viel schwieriger zu finden, wenn der Lösungssuche eine realitätsnähere Verhandlungskonstellation zugrundegelegt wird und einzelne restriktive Annahmen fallen gelassen werden.

Nachfolgend wird deshalb eine realitätsnähere Beschreibung möglicher Verhandlungskonstellationen gegeben, um so die Probleme zu verdeutlichen, die sich bei der Suche nach einem Verhandlungskonsens ergeben können. Es werden Faktoren erläutert, die den Konsensbedarf der Verhandlungssituation erhöhen und so die Wahrscheinlichkeit der Nicht-Einigung im Rahmen einer integrativen Verhandlungssituation steigern (Abschnitt III-2.3.2.2.2). Allerdings gibt es in verflochtenen Entscheidungssystemen auch eine Reihe an Handlungsmöglichkeiten, die gezielt eingesetzt werden können, um die Gefahr des Scheiterns der auf „Problemlösung” gerichteten Verhandlungen zu reduzieren (Abschnitte III-2.3.2.2.3 u. 4). Aus den angestellten Überlegungen können schließlich allgemeine Folgerungen im Hinblick auf die zu erwartenden Verhandlungsergebnisse in Verflechtungssystemen gezogen werden (Abschnitt III-2.3.2.2.5).

\section{III-2.3.2.2.2 Der Konsensbedarf der Verhandlungssituation}

Die einzelnen Faktoren, die den Konsensbedarf einer Verhandlungssituation bestimmen, sind eng miteinander verknüpft, so daß sich eine isolierte Betrachtung einzelner Aspekte problematisch gestaltet. Dennoch lassen sich im wesentlich drei Faktoren abgrenzen:

1. Der Konsensbedarf und somit die Wahrscheinlichkeit der Nicht-Einigung steigt mit der Anzahl der Verhandlungsteilnehmer. Je größer die Zahl der Entscheidungsträger desto schwieriger wird es, die Erfassung und Koordination der bestehenden Interessenlagen gewährleisten zu können.

Von entscheidender Bedeutung ist aber nicht die absolute Zahl der am Verhandlungsprozeß Beteiligten, sondern die Anzahl der Entscheidungsträger, die „,notwendigerweise” und „un-

${ }^{276}$ Eine konkrete Aussage kann daher erst unter Berücksichtigung der einzelnen Funktionen der FZ getroffen werden (vgl. Abschnitt III-3). An dieser Stelle werden die allgemeinen Problemstrukturen herausgearbeitet. 
abhängig voneinander" ihre Zustimmung zur Verhandlungslösung geben muß. Damit ergibt sich ein besonders hoher Konsensbedarf, wenn entsprechend der geltenden Abstimmungsregel Einstimmigkeit gefordert ist, und daher ,notwendigerweise" alle Verhandlungsteilnehmer der Problemlösung zustimmen müssen. Ist hingegen eine Form der Mehrheitsregel institutionalisiert, so reduziert sich der Konsensbedarf. Zudem verringert sich der Konsensbedarf, sofern eine Reihe der Verhandlungspartner gleichgerichtete Interessen im Hinblick auf das anstehende Verhandlungsproblem besitzt und sich daher als Interessenkoalition in einer Gruppe zusammenfassen läßt. Die Anzahl der Entscheidungsträger, die „unabhängig voneinander" zu berücksichtigen sind, reduziert sich in diesem Fall, und so auch die Gefahr einer Nicht-Einigung. ${ }^{277}$

2. Der Konsensbedarf wächst mit der Komplexität der zu lösenden Verhandlungsproblematik. Die (Gesamt-)Komplexität ergibt sich durch verschiedene Einzelaspekte, so daß unterschiedliche Annahmen des Grundgerüsts der Verhandlungsprozesse kritisch beleuchtet werden müssen:

- Es ist darauf hinzuweisen, daß die vorgenommene Trennung der Verhandlungssituationen in rein integrative und rein distributive Problemstellungen bei wirklichkeitsnäherer Betrachtungsweise kaum aufrechtzuerhalten ist. In der Realität liegen fast ausschließlich komplizierte „mixed-motive-games ${ }^{\text {278 }}$ vor, bei denen zugleich Koordinations- und Verteilungsprobleme zu lösen sind. Daher treten gleichgerichtete und gegensätzliche Interessen zumeist ,in einer unauflösbaren Gemengenlage"279 auf, wodurch die einvernehmliche Entscheidungsfindung erschwert wird. Gelingt es nicht die Verteilungsfrage von der integrativen Verhandlungsproblematik $\mathrm{zu}$ trennen, steigt die Wahrscheinlichkeit der NichtEinigung an. ${ }^{280}$

- Diese Problematik entschärft sich tendenziell, sofern die Unterstellung aufgehoben wird, es existiere nur eine begrenzte Anzahl eindeutig fixierter Verhandlungslösungen. Besteht die Möglichkeit die Verhandlungslösung kontinuierlich zu variieren, so erleichtert dies die Suche einer für alle Parteien annehmbaren Kompromißlösung. ${ }^{281}$ Allerdings weist dies zugleich darauf hin, daß in der Realität meist eine sehr viel größere Anzahl möglicher Verhandlungslösungen vorliegt als in Abbildung III-9 vereinfachend angenommen wurde.

${ }^{277}$ Vgl. Scharpf(1976), S. 42 ff.; (1993c), S. $140 \mathrm{ff}$.

${ }^{278}$ Scharpf (1994b), S. 31.

279 Scharpf(1994b), S. 31.

${ }^{280}$ Die Gesamt-Verhandlungssituation der Abb. III-9 zeigt ein „mixed-motive-game”. Ausgehend vom StatusQuo werden die beiden Verhandlungspartner durch die möglichen Verhandlungsergebnisse A-F zugleich vor Koordinations- und Verteilungsprobleme gestellt.

281 Vgl. bspw. Scharpf(1996a), S. $501 \mathrm{f}$. 
Hieraus ergibt sich ein zweiter Begründungsansatz für einen erhöhten Konsensbedarf aufgrund zunehmender Komplexität der zu lösenden Verhandlungsproblematik. Denn existieren keine ausreichenden Informationsgewinnungs- und verarbeitungskapazitäten, um die Vielzahl der Verhandlungslösungen zu erfassen, so verbleiben bei den einzelnen Verhandlungsteilnehmern Unsicherheiten über die Verhandlungsposition aller Verhandlungsteilnehmer. Auf diese Weise ergeben sich Spielräume für strategische Verhaltensweisen. ${ }^{282} \mathrm{Da}$ sich die Verhandlungsteilnehmer dieser "Gefahr” bewußt sind, ergibt sich ein gesteigerter Konsensbedarf und eine Nicht-Einigung wird wahrscheinlicher. ${ }^{283}$

- Zudem sind die (potentiellen) Auswirkungen der Verhandlungslösungen in den einzelnen GKS zu beachten. Je größer die Anzahl der ,ungleichartigen und interdependenten "284 Handlungsalternativen, die durch eine bestimmte Verhandlungslösung zeitgleich berührt werden, desto höher ist die Komplexität der zu lösenden Verhandlungssituation. Die sich infolge der FZ-Vergabe ergebende Wohlfahrtsposition der einzelnen Verhandlungspartner kann dann nicht wie bislang angenommen exakt ermittelt werden. Ob eine bestimmte Verhandlungslösung für eine GKS einen positiven oder negativen Gesamtnutzen auslöst bleibt aufgrund der vielschichtigen Gesamtzusammenhänge unsicher. Diese Unsicherheit steigert wiederum den Konsensbedarf der Verhandlungssituation und verringert die Wahrscheinlichkeit, daß eine einvernehmliche Einigung gefunden werden kann. ${ }^{285}$

1. Der Konsensbedarf hängt von der Wahrscheinlichkeit ab, mit der ein Verhandlungspartner einem Lösungsvorschlag seine Zustimmung verweigert (vgl. Abb. III-10). ${ }^{286}$ Ausgehend von einer egoistisch-rationalen Verhaltensorientierung, wie sie den bisherigen Überlegungen zugrundegelegt wurde, gibt jede Verhandlungspartei nur solchen Verhandlungslösungen ihre Zustimmung, die im Hinblick auf die eigenen Interessen einen positiven NettoNutzen versprechen. Die Interessen der anderen Verhandlungsparteien werden ignoriert. Unter der Annahme der Zufallsverteilung der möglichen Verhandlungslösungen im Koordinatensystem beträgt die Wahrscheinlichkeit, daß ein Beteiligter dem Lösungsvorschlag eines anderen Verhandlungsteilnehmers zustimmt $\left(\mathrm{p}_{Z}=0,5\right) .{ }^{287}$ Weist das Verhandlungssy-

282 So kann es den Verhandlungspartnern in dieser Situation möglicherweise gelingen, Eigenschaften der eigenen GKS ,vorzutäuschen”, die sie im Rahmen der Verhandlung als Transferempfänger qualifizieren.

${ }^{283}$ Vgl. hierzu allgemein Holler/Illing (1996), S. 44 ff.; sowie Scharpf(1996a), S. 519.

${ }^{284}$ Scharpf (1976), S. 44.

${ }^{285}$ Vgl. Scharpf(1976), S. 44.

${ }^{286}$ Vgl. Scharpf (1976), S. 44 f. Diese Wahrscheinlichkeit wird auch als „Konfliktwahrscheinlichkeit” bezeichnet. Abb. III-10 gibt nochmals die Abb. III-9 wieder, jedoch in einer vereinfachten Form.

${ }^{287}$ Besitzt der Akteur $\mathrm{Y}$ in Abb. III-10 eine egoistisch-rationale Verhaltensorientierung, so werden seine Lösungsvorschläge ausschließlich in den beiden nördlichen Quadranten lokalisiert sein. Die Wahrscheinlichkeit, daß der ebenfalls egoistisch-rationale Verhandlungspartner X einem Lösungsvorschlag des $Y$ zustimmt, beträgt bei Zufallsverteilung der möglichen Verhandlungslösungen folglich 0,5 , da für ihn nur die Verhandlungslösungen in den beiden östlichen Quadranten vorteilhaft erscheinen. 
stem drei Entscheidungsträger auf, so reduziert sich die Konsenswahrscheinlichkeit auf ( $\mathrm{p}_{\mathrm{K}}$ $=0,25)$. Allgemein gilt für die Wahrscheinlichkeit der Konsensfindung $\left(\mathrm{p}_{\mathrm{K}}\right)$ im Verhandlungssystem mit (n) egoistisch-rational handelnden Entscheidungsträgern in Abhängigkeit von der Zustimmungswahrscheinlichkleit $\left(\mathrm{p}_{\mathrm{Z}}\right)$ der einzelnen Verhandlungsteilnehmer zu einem Lösungsvorschlag die folgende Funktion:

$$
\left(p_{K}\right)=\left(p_{z}\right)^{(n-1)}
$$

Die Konfliktwahrscheinlichkeit [1 - $\left(\mathrm{p}_{\mathrm{K}}\right)$ ] steigt mit zunehmender Zahl der Verhandlungsteilnehmer exponentiell an, sofern nicht die Zustimmungswahrscheinlichkeit der einzelnen Beteiligten zu einem Verhandlungsvorschlag gegen 1 tendiert. ${ }^{288}$

Abb. III-10: Interessenkonstellationen in verflochtenen Entscheidungssystemen

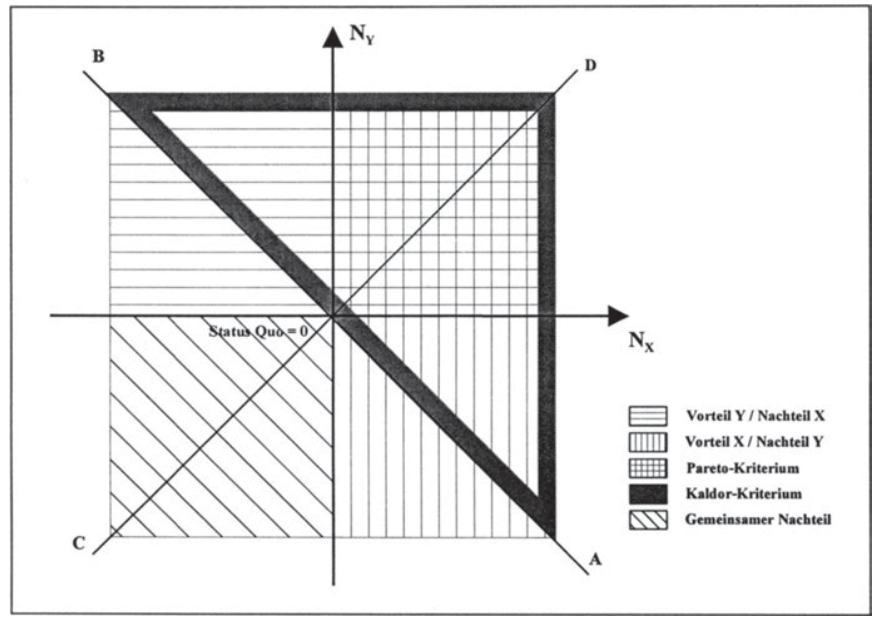

Quelle: Darstellung in Anlehnung an Scharpf (1992d), S. 56 u. 58.

$\mathrm{Zu}$ berücksichtigen ist allerdings die subjektive Interaktionsorientierung der Beteiligten. Wenn einzelne oder sogar alle Verhandlungsteilnehmer sich nicht eigennützig, sondern kooperativ verhalten und den gemeinsamen Nutzen aller Verhandlungspartner in ihr Entscheidungskalkül aufnehmen (kooperative Interaktionsorientierung), verringert sich die Gefahr einer Nicht-Einigung. Geht man erneut von der Zufallsverteilung der möglichen Verhandlungslösungen aus, beträgt die Zustimmungswahrscheinlichkeit $\left(\mathrm{p}_{\mathrm{Z}}\right)$ eines „kooperativen” Verhandlungsteilnehmers zu einem Lösungsvorschlag eines streng eigennützigen

${ }^{288}$ Vgl. hierzu Scharpf(1976), S. 44 f.; (1992d), S. 63 ff; (1993c), S. 129 f. 
Akteurs nun 0,75. ${ }^{289}$ In einem derartigen Verhandlungssystem mit zwei Beteiligten beträgt daher die Wahrscheinlichkeit der Nicht-Einigung lediglich 0,25. Und auch bei zunehmender Zahl der Entscheidungsträger nimmt diese relativ hohe Wahrscheinlichkeit der Konsensfindung nicht ab, „weil dabei ja nicht nur zusätzliche Geschädigte, sondern jeweils auch zusätzliche 'Nutzenträger' ins Spiel kommen.,290

Ein gegensätzliches Bild ergibt sich, wenn die handlungsbestimmende Interaktionsorientierung kompetitiv ist. Das Verhandlungsziel der Akteure ist es in diesem Fall, einen möglichst großen Nutzenvorsprung vor den übrigen Verhandlungsteilnehmern zu gewinnen. ${ }^{291}$ Verhalten sich alle Akteure kompetitiv, so steigt der Konsensbedarf prohibitiv an und eine einvernehmliche Problemlösung bleibt ausgeschlossen. ${ }^{292}$ Auch wenn einzelne Akteure keine kompetitive, sondern „nur” eine eigennützige Handlungsorientierung aufweisen, bleibt im Vergleich zu Verhandlungskonstellationen mit kooperativer und/oder egoistischrationaler Interaktionsorientierung eine höhere Wahrscheinlichkeit der Nicht-Einigung bestehen. $^{293}$

Eine extreme Ausformung der kompetitiven Interaktionsorientierung liegt vor, wenn das Abstimmungsverhalten der Akteure von Merkmalen der Entscheidungsbeteiligten dominiert wird, die in keiner Beziehung zu der zu lösenden sachlichen Problemsituation stehen. Solche Merkmale werden als „cross-cutting-cleavages” bezeichnet. ${ }^{294}$ Sie können sich bspw. auf Sprache, Rasse, Religion, geographische Herkunf, Alter, Einkommens- und Vermögensposition oder politische Ideologie der Verhandlungspartner beziehen. Entwikkelt sich ein solcher „cross-cutting-cleavage” innerhalb eines Verflechtungssystems zum

${ }^{289}$ Besitzt der Akteur $\mathrm{Y}$ in Abb. III-10 eine kooperative Interaktionsorientierung, so werden seine Lösungsvorschläge ausschließlich nord-östlich der Diagonalen (BA) liegen, für die $\left(\mathrm{N}_{X}+\mathrm{N}_{Y}>0\right)$ gilt (Kaldor-Kriterium). Die Wahrscheinlichkeit, daß der egoistisch-rationale Verhandlungspartner X einem Lösungsvorschlag des $Y$ zustimmt, beträgt bei Zufallsverteilung der moglichen Verhandlungslösungen folglich 0,75 , da für ihn alle Verhandlungslösungen in den beiden östlichen Quadranten vorteilhaft erscheinen. Weisen hingegen alle Akteure eine kooperative Interaktionsorientierung auf, so ist die Zustimmungswahrscheinlichkeit $\left(\mathrm{p}_{\mathrm{z}}\right)$ gleich 1 , $\mathrm{da}$ in diesem Fall ausschließlich solche Verhandlungslösungen vorgeschlagen werden, die den gemeinsamen Nutzen aller Beteiligten berücksichtigen (vgl. auch Scharpf(1992d), S. 64, Fn 18).

${ }^{290}$ Scharpf (1992d), S. 64, Fn 18. Es wird allen Lösungsvorschlägen zugestimmt, die dem Kaldor-Kriterium entsprechen.

291 Vgl. hierzu Scharpf(1992d), S. 53 f.

${ }^{292}$ Bei kompetitiver Handlungsorientierung würde X ausgehend vom Status Quo alle Verhandlungslösungen süd-östlich der Diagonalen (CD) vorteilhaft bewerten, für die $\left(N_{X}-N_{Y}>0\right)$ gilt, so daß $X$ einen Nutzenvorsprung vor $Y$ erhält. Y hingegen würde alle Verhandlungslösungen nord-westlich der Diagonalen (CD) annehmen, für die $\left(\mathrm{N}_{Y}-\mathrm{N}_{\mathrm{X}}>0\right)$ ist. Es ist somit kein Lobungsvorschlag denkbar, dem der jeweils andere Akteur zustimmen würde. Die Wahrscheinlichkeit der Nicht-Einigung beträgt 1.

293 Verhält sich der Akteur Y in Abb. III-10 egoistisch-rational, so sind seine Lösungsvorschläge ausschließlich in den beiden nördlichen Quadranten lokalisiert. Die Wahrscheinlichkeit, daß der Verhandlungspartner X, der eine kompetitive Interaktionsorientierung besitzt, einem Lösungsvorschlag des Y zustimmt, beträgt bei Zufallsverteilung der möglichen Verhandlungslösungen 0,25 , da für ihn nur die Verhandlungslösungen südöstlich der Diagonalen (CD) vorteilhaft erscheinen.

${ }^{294}$ Dieser Begriff wurde von Rabushka/Shepsle (1972) geprägt (vgl. insb. S. 62 ff.). Kirsch (1978) hat den Begriff wieder aufgegriffen $u$. seine Bedeutung für interkollektive Willensbildungsprozesse analysiert. 
„alles dominierenden Kriterium,295, so tritt die angestrebte integrative Problemlösung völlig in den Hintergrund. Es bilden sich stattdessen entlang der ,cross-cutting-cleavage” Verhandlungskoalitionen der Akteure mit gleichen Merkmalen. Diese Verhandlungskoalitionen stehen sich nunmehr unabhängig von der zur Lösung anstehenden Problematik unversöhnlich gegenüber. ${ }^{296}$ Im Extremfall verweigert eine Verhandlungsseite in dieser Situation jedem Lösungsvorschlag der anderen Verhandlungsseite(n) die Zustimmung - ohne die eigentlichen Interessenkonstellation in bezug auf den zu entscheidenden Sachzusammenhang zu reflektieren. Es resultiert ein gravierender Konsensbedarf. Die Wahrscheinlichkeit eine einvernehmlichen Problemlösung tendiert gegen null. ${ }^{297}$

Die Existenz eines „cross-cutting-cleavage” besitzt besonderes Gewicht, da seine Auswirkung nicht auf eine isolierte Verhandlungssituation beschränkt bleibt. Ist ein ,polarisierendes Unterscheidungsmerkmal politisch virulent” ${ }^{\text {298 }}$ geworden und hat es „erst einmal ... Resonanz und Wirkmächtigkeit erlangt", 299 so wird es jeden einzelnen Verhandlungsprozeß (mit)beherrschen und so die institutionelle Fähigkeit des Entscheidungssystems zur integrativen Problemlösung lahmlegen.

Dabei steigt die Gefahr der Entstehung einer „cross-cutting-cleavage” mit dem Ausmaß der Heterogenität zwischen den Verhandlungsparteien. Je deutlicher ein bestimmtes bestehendes Unterscheidungsmerkmal wahrnehmbar ist, desto größer wird die Wahrscheinlichkeit, $\mathrm{da}$ es von einem Akteur in das Zentrum aller Verhandlungsprozesse gerückt wird. In (relativ) homogenen Entscheidungskollektiven besteht daher eine größere Wahrscheinlichkeit, $\mathrm{da} ß$ tatsächlich die sachbezogene Problemlösung im Mittelpunkt einer Verhandlung steht, und nicht die Demonstration sachfremder, kollektivinterner Seinsmerkmale. ${ }^{300}$

\section{III-2.3.2.2.3 Strategien der aktiven Konsensbildung}

Integrative Problemlösungen können, wie verdeutlicht, bei vorgegebener Verhandlungssituationen und feststehendem Kreis der Verhandlungsteilnehmer einen derart hohen Konsensbedarf erfordern, daß eine einvernehmliche Problemlösung verhindert wird. Es stellt sich daher die Frage, ob die Verhandlungspartner strategische Maßnahmen ergreifen können, um aktiv

\footnotetext{
${ }^{295}$ Kirsch (1978), S. 36.

${ }^{296}$ Möglicherweise besteht in dieser Situation sogar eine feindselige Interaktionsorientierung. Dann ist ausschließlich der Schaden des anderen Verhandlungspartners handlungsleitend; der eigenen Nutzen spielt keine Rolle mehr (vgl. hierzu Scharpf (1996a), S. 520, insb. Fn 11).

297 Vgl. hierzu Kirsch (1978), insb. S. 33 ff. Es ist auch der umgekehrte Fall denkbar, in welchem alle Verhandlungspartner ein gemeinsames Merkmal besitzen, das handlungsleitend wirkt. Die Konsensfindung im Entscheidungssystem wird dann erheblich erleichtert.

298 Kirsch (1978), S. 36.

299 Kirsch (1978), S. 38.

${ }^{300}$ Vgl. wiederum Kirsch (1978), S. $38 \mathrm{ff}$.
} 
zur Deckung des Konsensbedarfs beizutragen. Diese Strategien zur aktiven Konsensbildung sollen die Zustimmungswahrscheinlichkeit einzelner Verhandlungsteilnehmer zu einer vorgegebenen Verhandlungslösung erhöhen. Hierzu ergeben sich v.a. drei Ansatzpunkte: ${ }^{301}$

1. Der Abbau bestehender Informationsdefizite einzelner Verhandlungspartner (Informationsstrategie). Die gezielte Vermittlung entscheidungsrelevanter Informationen ersetzt „Nicht-

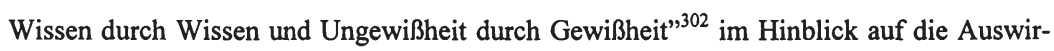
kungen der Verhandlungslösungen und das zu erwartende Entscheidungsverhalten der Verhandlungspartner. ${ }^{303}$ Werden auf diese Weise negative Fehleinschätzungen über mögliche nachteilige Konsequenzen einer bestimmten Entscheidung korrigiert, steigt die $\mathrm{Zu}$ stimmungswahrscheinlichkeit des jeweiligen Akteurs. Allerdings besteht auch die Möglichkeit, daß dem betreffenden Verhandlungspartner bestehende Interessenkonflikte durch die zusätzlichen Informationen erst bewußt gemacht werden, und so eine Einigung erschwert wird.

Eine Bedeutung besitzt die Informationsstrategie zudem für die Gesamtheit der beteiligten Akteure. Insbesondere bei komplexen Verhandlungskonstellationen, die eine Entscheidungsfindung unter Unsicherheit erfordern, unterstützt die Informationsstrategie die Harmonisierung der Wahrnehmung der Entscheidungssituation durch alle Verhandlungsteilnehmer und fördert die Stabilisierung der Erwartungen aller Betroffenen. Da nun jeder Verhandlungspartner in geringerem Ausmaß „seine eigenen, separaten Schlußfolgerungen aus den wenigen Indizien ziehen muß ${ }^{304}$ wird ein gemeinsames Vorgehen und damit auch die Konsensbildung im Entscheidungssystem erleichtert.

2. Die Deckung des Konsensbedarfs durch die aktive „Beeinflussung von Wertungen, Zielen und Interessen"305 einzelner Verhandlungspartner (Überzeugungsstrategie). Während im Rahmen der Informationsstrategie die Wahrnehmung der Wirkungen einer Verhandlungslösung im Mittelpunkt steht, wird nun auf die Bewertung der Wirkungen einer Verhandlungslösung abgestellt. ${ }^{306}$ Diese Überzeugungsstrategie bezieht sich auf zwei Dimensionen persönlicher Werteinschätzungen, die bereits als quasi-objektive Interessenkonstellation

\footnotetext{
${ }^{301}$ Vgl. zum Nachfolgenden Scharpf(1976), S. 45 ff.; auch (1978), S. 28.

302 Scharpf (1976), S. 47.

${ }^{303}$ Die Wirksamkeit der Informationsstrategie ist allerdings stark eingeschränkt, wenn die Struktur des Entscheidungsproblems sowie die bestehenden Handlungsalternativen bereits allen Verhandlungspartnern weitgehend bekannt sind. Besondere Chancen ergeben sich für die Informationsstrategie daher bei solchen am Verhandlungsprozeß beteiligten GKS, deren eigenständige Kapazität zur Informationsgewinnung und -verarbeitung eng begrenzt ist.

304 Scharpf (1976), S. 47.

${ }^{305}$ Scharpf (1976), S. 48.

${ }^{306}$ Vgl. hierzu auch $S$ charpf (1992d), S. 53 f.
} 
und als subjektive Interaktionsorientierung eingeführt wurden. ${ }^{307}$ Im ersten Fall soll die durch den betroffenen Verhandlungspartner erfolgende Einschätzung der individuellen aber "quasi-objektiven" Nutzenposition einer Verhandlungslösung positiv beeinflußt werden. ${ }^{308}$ Im zweiten Fall hingegen soll die eigennützige oder sogar kompetitive Einstellung des betroffenen Akteurs gegenüber den Verhandlungspartnern in Richtung einer kooperativen Interaktionsorientierung verändert werden. ${ }^{309}$

Es ist jedoch fraglich, ob die gezielte Beeinflussung der Präferenzen einzelner Verhandlungsteilnehmer in der kurzen Frist eines Konsensfindungsprozesses gelingen kann. ${ }^{310}$ Die Überzeugungsstrategie ist eher in einer langfristigen Perspektive erfolgsversprechend, um durch den schrittweisen Aufbau einer wechselseitigen Vertrauensbasis, eine homogenere Präferenzenstruktur im gesamten Entscheidungssystem zu fördern. So kann der Konsensbedarf eines Verflechtungssystems nicht nur für eine einzelne Entscheidungssituation reduziert werden. Vielmehr wird das Konsensfindungsproblem ganz allgemein entschärft. ${ }^{311}$

3. Die Veränderung der realen Auswirkungen einer Problemlösung durch aktive Maßnahmen (Durchsetzungsstrategie). Es können entweder monetäre Kompensationszahlungen geleistet oder eine Mehrzahl zu entscheidender Fragestellungen in einem Verhandlungspaket zusammengefaßt werden (Koppelgeschäfte). ${ }^{312}$ Beide Vorgehensweisen verfolgen das Ziel, die Nutzenposition solcher Verhandlungspartner, für die eine isolierte Problemlösung ein nachteilhaftes Verhandlungsergebnis darstellt, soweit zu verbessern, daß sich auch für diese Akteure ein positiver Gesamtnutzen ergibt. So wird selbst bei egoistisch-rationaler Verhaltensorientierung die Zustimmung dieser Verhandlungsteilnehmer gewonnen.

Abbildung III-11 verdeutlicht die Leistung monetärer Kompensationszahlungen. Es existiert eine Problemlösung A, die die Gesamtwohlfahrt des Verflechtungssystems maximiert. Für den Verhandlungspartner $\mathrm{X}$ weist diese Lösung jedoch einen negativen Nutzen in Höhe $0 \mathrm{E}$ im Vergleich zum Status Quo (0) auf. Er lehnt die Lösung daher ab. Jedoch

307 Vgl. hierzu Abschnitt III-2.3.2.2.1, insb. Fn 272.

${ }^{308}$ In der Abb. III-9 würde der Erfolg dieser Art der Überzeugungsstrategie gegenüber Akteur X dadurch abgebildet werden, daß sich die einzelnen Verhandlungslösungen in horizontaler Richtung nach rechts verschieben. Der Nutzen, den X den einzelnen Verhandlungslösungen zuordnet, ist angestiegen, so daß sich die $\mathrm{Zu}$ stimmungswahrscheinlichkeit zu jeder Lösung erhöht.

309 Ist diese Art der Überzeugungstrategie erfolgreich, so werden die Nutzenpositionen der übrigen Verhandlungspartner zukünftig als positives Argument in das Entscheidungskalkül des Akteurs eingeschlossen. Er akzeptiert nunmehr alle Verhandlungslösungen, die dem Kaldor-Kriterium entsprechen.

310 So geht Scharpf davon aus, daß die Präferenzen im Konsensfindungsprozeß „einigermaßen stabil” (Scharpf (1992d), S. 53; vgl. auch Fn 3) sind. Kirchgässner (1991), S. 38 betont, daß, sich die Präferenzen der Individuen wesentlich langsamer verändern als die Restriktionen und daß sie daher für die Zwecke der Analyse als konstant unterstellt werden können." Präferenzänderungen können daher lediglich in einer langfristigen Betrachtung einen Erklärungsbeitrag leisten (vgl. Kirchgässner (1991), S. 38 ff.; auch Tietzel (1988), S. 52 ff.).

311 Vgl. Scharpf(1994b), S. 33; (1996a), S. 520 ff.; auch Benz (1994), S. 63 ff., insb. S. 127 ff.

312 Vgl. hierzu auch Benz (1994), S. $150 \mathrm{ff}$. 
realisiert der Verhandlungspartner $\mathrm{Y}$ durch die Verhandlungslösung A einen positiven Nutzen in Höhe $0 \mathrm{D}$, der den negativen Nutzen des $\mathrm{X}$ übersteigt (OD $>0 \mathrm{E}$ ). Daher kann der einseitige Nachteil von $\mathrm{X}$ durch die Leistung einer Ausgleichszahlung aus dem Nutzenzugewinn des $\mathrm{Y}$ derart kompensiert werden, daß beide Verhandlungsteilnehmer im Endergebnis durch die Verhandlungslösung A besser gestellt werden als im Status Quo. Die Graphik zeigt, daß die Höhe der Kompensationsleistung mindestens dem in monetären Einheiten ausgedrückten Nutzen-Betrag CD entsprechen muß. ${ }^{313}$ Andererseits darf die Zahlung nicht den gesamten Nutzenzugewinn des $\mathrm{Y}$ in Höhe $0 \mathrm{D}$ übersteigen. Als Menge der Verhandlungsergebnisse, die die Zustimmung beider egoistisch-rationaler Verhandlungspartner findet, ergibt sich demnach die Gerade CB.

Abb. III-11: Kompensationszahlungen im Verhandlungssystem

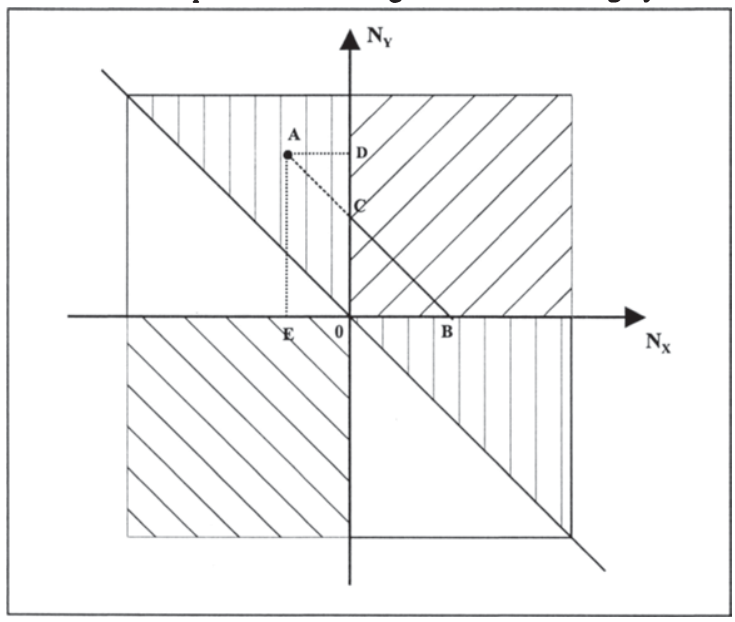

Quelle: Darstellung in Anlehnung an Scharpf (1992d), S. 66.

Abbildung III-12 veranschaulicht die Ausführung von Koppelgeschäften. Wiederum wird von der für das gesamte Verflechtungssystem vorteilhaften Verhandlungslösung A ausgegangen. Dieser stimmt der egoistisch-rationale Verhandlungspartner X nicht zu. Zudem steht innerhalb des Verflechtungssystems eine weitere Problemstellung zur Entscheidung an. Auch deren Verhandlungslösung B ist aus Sicht der Gesamtheit vorteilhaft. Sie ist allerdings mit Nutzeneinbußen für den egoistisch-rationalen Verhandlungspartner $Y$ verbunden. Daher kann auch für diese zweite Fragestellung zunächst keine Einigung gefunden werden. Erfolgt nun aber eine Verkoppelung beider Fragestellungen, so resultiert das Ver-

${ }^{313}$ Dabei entspricht der Nutzen-Betrag CD exakt dem Nutzen-Betrag $0 \mathrm{E}$. 
handlungsergebnis $\mathrm{C}$ aus der Addition der Nutzen und Kosten der beiden separaten Verhandlungslösungen A und B. ${ }^{314}$ Die „Paketlösung” C liegt im nord-östlichen Quadranten des Koordinatensystems und ist damit für beide Verhandlungsparteien vorteilhaft. Damit wird die Konsensfindung ermöglicht. ${ }^{315}$

Abb. III-12: Koppelgeschäfte im Verhandlungssystem

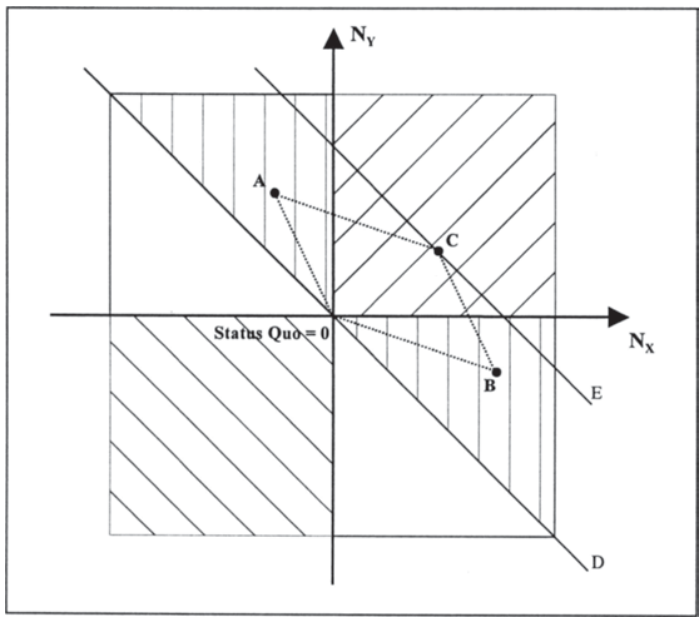

Quelle: Darstellung in Anlehnung an Scharpf (1992d), S. 72.

\section{III-2.3.2.2.4 Strategien zur Minimierung des Konsensbedarfs}

Gelingt es nicht, den vorgegebenen Konsensbedarf einer Verhandlungssituation durch Strategien der aktiven Konsensbildung zu decken, so verbleibt den Entscheidungsträgern eine alternative Vorgehensweise, um eine Blockade des Entscheidungssystems doch noch zu verhindern. Es können Maßnahmen zur systematischen Verringerung des ursprünglichen Konsensbedarfs einer vorgegebenen Entscheidungssituation ergriffen werden: ${ }^{316}$

1. Die Reduzierung der Anzahl der Entscheidungsträger, die „notwendigerweise” und „unabhängig voneinander" der Verhandlungslösung zustimmen muß.

${ }^{314}$ Es wird also angenommen, daß die Problemlösungen A u. B in der gleichen Nutzendimension abbildbar sind. Dann kann in der Graphik eine Vektoren-Addition vorgenommen werden (vgl. Scharpf(1992d), S. 71 f.).

${ }^{315}$ Das beschriebene Koppelgeschäft wird als ,sozial nützlich” (Scharpf (1992d), S. 72) bezeichnet, da der aggregierte Gesamtnutzen der Verhandlungsbeteiligten im Vergleich zum Status-Quo gesteigert wurde. Es sind aber auch sozial schädliche Koppelgeschäfte vorstellbar (vgl. Scharpf (1992d), S. 73 ff.). Diese liegen vor, wenn in die Paketlösung Verhandlungslösungen integriert werden, die separat betrachtet nicht dem KaldorKriterium entsprechen und zudem derart auf das Gesamtergebnis der Paketlösung einwirken, daß der aggregierte Gesamtnutzen der Verhandlungsbeteiligten verringert wird (in der Abb. III-12 wären solche Verhandlungsergebnisse süd-westlich der Nutzenisoquante D des Status-Quo lokalisiert).

${ }^{316}$ Es wird quasi ,eine Lösung auf dem Wege des geringsten Widerstandes” (Scharpf (1976), S. 54) angestrebt. Vgl. hierzu Scharpf(1976), S. 54 ff. u. (1978), S. 28. 
Diese Strategie kann durch eine Änderung der Entscheidungsregel verfolgt werden. Der Übergang zu einer weniger restriktiven Abstimmungsregel (bspw. von der Einstimmigkeits- zur einer Mehrheitsregel) verringert den Konsensbedarf, da nun bereits die Einigung einer (kleineren) Teilmenge aller Verhandlungsteilnehmer die Beschlußfassung ermöglicht. Die Strategie kann auch durch die Modifizierung der Verflechtungsstrukturen des Entscheidungssystems verwirklicht werden. Werden multilaterale durch bilaterale Verbundbeziehungen ersetzt (Verhandlungsbilateralisierung), ${ }^{317}$ so reduziert sich der Konsensbedarf einzelner Entscheidungen, da eine Problemlösung nicht länger zwischen der Gesamtheit aller Jurisdiktionen, sondern lediglich zwischen zwei Verhandlungspartnern gesucht wird. $^{318}$

2. Die Verminderung der Zahl der ,ungleichartigen und interdependenten” Handlungsalternativen, über die bei einer Entscheidung zeitgleich entschieden wird.

Die Aufspaltung einer Gesamtverhandlungsproblematik in Teil-Probleme geringerer Komplexität, ermöglicht es, eine Mehrzahl autonomer Verhandlungslösungen anzustreben. Bei FZ können z.B. Teilentscheidungen über den Adressatenkreis, die Ausgestaltung, die Höhe des Transfervolumens und die Finanzierung der FZ sachlich voneinander abgegrenzt werden. Es wird „ein modulares System von separaten aber ineinandergreifenden Entscheidungssegmenten"319 geschaffen. Diese Einzelsegmente vermögen erst in ihrer Gesamtheit die angestrebte Problemlösung zu leisten. Jedoch erhöht die Segmentierung des Problemkomplexes die Wahrscheinlichkeit, daß insgesamt eine einvernehmliche Einigung gefunden wird, da die Anforderungen an die Konsensfindungskapzität des Entscheidungssystems bei jeder einzelnen Teilverhandlung geringer ausfällt als in der Ausgangssituation. ${ }^{320}$

Eine zweite Strategie wird als negative Koordination bezeichnet und „basiert auf der Respektierung antizipierter Widerstände und Vetopositionen"321 durch die einzelnen Parteien

${ }^{317}$ Die FZ werden dann entweder horizontal zwischen zwei von einer Problemsituation betroffenen GKS oder vertikal zwischen der zentralen Ebene und einer dezentralen GKS ausgehandelt.

${ }^{318}$ Einen noch weitergehenden Schritt zur Reduzierung der ,notwendigen” Entscheidungsbeteiligten stellt die vollständige Entflechtung der Verhandlungsstrukturen durch Entscheidungszentralisierung dar. Diese Möglichkeit besteht daher nur in Verbundsystemen, nicht aber in horizontalen Verflechtungssystemen. Die zentrale Ebene bestimmt nun als alleiniger Entscheidungsträger über die Ausgestaltung der FZ. Es ist jedoch kritisch darauf hinzuweisen, daß bei dieser „Problemlösung”, wie auch bei der Bilateralisierung der Entscheidungsstrukturen, die Kooperationsgewinne ungenutzt bleiben, die ja gerade durch die Entscheidungsverflechtung zwischen den Jurisdiktionen realisiert werden sollen (vgl. hierzu Abschnitt II-3 u. Abschnitt III2.3.2, insb. Fn 246).

319 Scharpf(1976), S. 60.

${ }^{320}$ Die Schwierigkeit dieses Vorgehens besteht darin, die Gesamtproblematik in geeignete Entscheidungseinheiten aufteilen zu können, die einerseits der Interdependenz der einzelnen Teilprobleme gerecht werden, aber andererseits ,doch separat genug [sind], so daß der Konsens in einem Bereich nicht notwendigerweise von noch offenen Fragen in anderen Bereichen gefahrdet werden muß." (Scharpf (1976), S. 60 f.)

321 Scharpf(1992e), S. 101. 
des Verhandlungssystems. ${ }^{322}$ Im Gegensatz zur integrativen Problemlösung, wo durch intensive multilaterale Verhandlungen unter „Berücksichtigung aller Handlungsoptionen aller beteiligten Einheiten" ${ }^{\text {"323 }}$ Kooperationsvorteile auch im Hinblick auf komplexe Gesamtzusammenhänge realisiert werden sollen (positive Koordination), erfolgt bei der negativen Koordination eine „Selbstbeschränkung neuer Programminitiativen”. ${ }^{324}$ Die Verhandlungsbeteiligten bringen nur solche Entscheidungsalternativen in das Verflechtungssystem ein, bei denen ihrer Einschätzung nach negative Auswirkungen für die Zuständigkeitsbereiche anderer Jurisdiktionen ausgeschlossen sind. Damit reduziert sich der Konsensbedarf entscheidend. Die einvernehmliche Annahme einer Entscheidungsvorlage wird bereits gewährleistet, indem im Rahmen bilateraler Gespräche mit den einzelnen betroffenen Verhandlungspartnern bestätigt wird, daß deren jeweilige Interessenposition nicht verletzt wird. Die eigenständigen Handlungsalternativen der Verhandlungspartner bleiben hingegen aus dem Abstimmungsprozeß ausgeklammert. Damit steigt die Wahrscheinlichkeit der Konsensfindung stark an. Allerdings liegt der negativen Koordination ein im Vergleich zur integrativen Problemlösung begrenztes Anspruchsniveau zugrunde. Thr Ziel besteht lediglich darin, durch wechselseitige Rücksichtnahme „unkoordinierte[] Aktionen auszuschließen, die in hochinterdependenten Politikfeldern chaotische Störungen erzeugen müßten." So können zumindest pareto-superiore Verhandlungslösungen realisiert werden und die vollständige Selbstblockade des Verflechtungssystems wird vermieden. Die negative Koordination fördert jedoch ,nicht gerade die Innovationsfähigkeit einer 'aktiven Politik”, , 326 die auch zur kooperativen Lösung komplexer Problemzusammenhänge beiträgt.

3. Die Etablierung konfliktminimierender Entscheidungsregeln. Es wird nur diejenige Teilmenge aller möglichen Lösungen einer gegebenen Verhandlungsproblematik zugelassen, die den festgelegten Charakteristika entspricht. Die folgenden konfliktminimierenden Entscheidungsregeln sind denkbar: $:^{327}$

- Gleichbehandlung: Insbesondere bei komplexen Problemzusammenhängen, die mit einem unvollständigem Informationsstand der Verhandelnden und einer Unsicherheit über die individuellen Auswirkungen möglicher Verhandlungslösungen verbunden sind, fördert die formelle Gleichbehandlung aller Parteien die Entscheidungsfindung. Die Beteiligten

${ }^{322}$ Vgl. hierzu insb. Scharpf (1992e), S. 101 ff.; (1996a), S. 512 f.; auch schon (1973), S. 85 ff.

${ }^{323}$ Scharpf (1996a), S. 512.

${ }^{324}$ Scharpf (1992e), S. 101.

${ }^{325}$ Scharpf $(1992 \mathrm{e})$, S. 101.

${ }^{326}$ Scharpf (1992e), S. 101.

${ }^{327}$ Für die Wirksamkeit der konfliktminimierenden Entscheidungsregeln besitzt die Annahme über die vorliegende subjektive Interaktionsorientierung der Verhandlungspartner eine entscheidende Bedeutung. 
gewinnen die Sicherheit, in Relation zu den anderen Verhandlungsteilnehmern zumindest nicht eklatant benachteiligt werden zu können. ${ }^{328}$

Diese Entscheidungsregel hat jedoch zur Folge, daß nicht primär nach einer differenzierten, flexiblen und somit ökonomisch gerechtfertigten Verhandlungslösung gesucht wird. Auf der Transfergeberseite wird allen Akteuren ein einheitlicher oder eindeutig nachvollziehbarer Finanzierungsanteil aufgebürdet. Auf der Transferempfängerseite wird ein möglichst großer Adressatenkreis in das Zuweisungsprogramm integriert, der auch die Transfergeber miteinschließen kann. Die Ausgestaltungsform der FZ wird nicht in Abhängigkeit der sachlichen Problemlage innerhalb einer Jurisdiktion variiert, sondern für alle Empfänger einheitlich festgelegt. Das Transfervolumen wird anhand einfacher, möglichst unumstrittener Indikatoren aufgeteilt.

- Besitzstandswahrung: Die Wahrscheinlichkeit der Konsensfindung erhöht sich, sofern die Verhandlungslösung so gestaltet wird, daß Besitzstände der einzelnen Verhandlungsparteien unangetastet bleiben. ${ }^{329}$ Diese Vorgehensweise erleichtert es auch bei einer Problemstellung, die die Ungleichbehandlung der verschiedenen Akteure im Rahmen einer differenzierten Verhandlungslösung erfordert, eine einvernehmliche Entscheidung zu finden. Denn die Zustimmungswahrscheinlichkeit der Verhandlungsteilnehmer, die eine relative Benachteiligung hinnehmen müssen, erhöht sich, wenn zumindest ihre absoluten Besitzstände erhalten bleiben.

Bei der Vergabe zwischenstaatlicher FZ droht jedoch ein beständig ansteigendes Transfervolumen. Da das in der Ausgangssituation bestehende (absolute) Volumen der FZ an die einzelnen am Entscheidungsprozeß beteiligten Transferempfänger nicht in Frage gestellt wird, kann die zur Problemlösung notwendige Ungleichbehandlung der Transferempfänger nur durch die Steigerung des Gesamtvolumens der FZ realisiert werden. ${ }^{330}$ Damit wird aber die angestrebte ökonomische Effizienz der gesamten Problemlösung in Frage gestellt. ${ }^{331}$ Insgesamt müssen die Entscheidungsträger nun auf „Flexibilität und Variationsmöglichkeit weitgehend verzichten". ${ }^{332}$ Eine einvernehmliche Einigung zur Reduzierung des Umfangs oder gar zur vollständigen Abschaffung einmal eingerichteter FZ-Programme ist bei dieser Entscheidungsstruktur kaum erzielbar.

\footnotetext{
${ }^{328}$ Dieser konfliktminimierenden Entscheidungsregel liegt (in gewissem Ausmaß) die Annahme einer kompetitiven Interaktionsorientierung der Verhandlungsteilnehmer zugrunde.

${ }^{329}$ Es wird eine (primär) egoistisch-rationale Interaktionsorientierung unterstellt.

${ }^{330}$ Die Ungleichbehandlung kann nur pareto-optimal vorgenommen werden.

${ }^{331} \mathrm{Vgl}$. zur Bedeutung der Höhe des FZ-Volumens Abschnitt III-2.2.5.

${ }^{332}$ Scharpf(1976), S. 65.
} 
- Die Konfliktvertagung: Sie steht in enger Verbindung zur Strategie der Entscheidungssegmentierung, die die Konsensfindung begünstigt, indem eine komplexe Verhandlungsfrage in mehrere sachlich voneinander abgegrenzte Teilprobleme aufgespalten wird. Diese Vorgehensweise wird durch die Konfliktvertagung in zeitlicher Hinsicht ergänzt. Die einzelnen Teilprobleme werden nun nicht zeitgleich, sondern in einer „günstigen” Abfolge in das Verflechtungssystem eingebracht. So kann bspw. bei der Vergabe einer FZ zunächst über die problemadäquate Ausgestaltung und Höhe eines FZ-Programms verhandelt werden, bevor zu einem späteren Zeitpunkt über die Verteilung des Finanzierungsvolumens auf die einzelnen Juridiktionen ,gestritten” wird. ${ }^{333}$ Eine eindeutige Bewertung der Strategie der Konfliktvertagung ist nicht möglich. Sie ist positiv einzuschätzen, wenn sich durch die zeitliche Abgrenzung der Teilentscheidungen der Gesamt-Konsensbedarf einer Entscheidungssituation reduziert und hierdurch eine sachgerechte Problemlösung erst ermöglicht wird. Erfolgt hingegen lediglich eine „unsystematische” Verschiebung besonders konfliktträchtiger Teilprobleme einer Fragestellung in die Zukunft, um eine einvernehmliche Verhandlungslösung zum gegenwärtigen Zeitpunkt gewährleisten zu können, so ist die Konfliktvertagung kritisch zu beurteilen.

\section{III-2.3.2.2.5 Schlußfolgerungen zur Konsensfindungsproblematik}

In den Teilabschnitten M-2.3.2.2.1-4 wurde die vielschichtige Konsensfindungsproblematik eines Verhandlungssystems anhand logisch aufeinander aufbauender Einzelaspekte veranschaulicht. Diese ermöglichen es, die Problemlösungsfähigkeit verflochtener Entscheidungssysteme zur Einrichtung „effizienter" zwischenstaatlicher FZ-Programme zu beurteilen. Es zeigt sich, daß den Akteuren des Verflechtungssystems bei Verhandlungskonstellationen mit einem hohen Konsensbedarf nur begrenzte Handlungsspielräume verbleiben, den Konsensbedarf aktiv zu decken. Dann kann die Notwendigkeit bestehen, auf Strategien zur Konsensminimierung zurückzugreifen, um eine Blockade des Entscheidungssystems zu verhindern. Mit diesen Maßnahmen sind aber zumeist weitere „Kosten” für das Gesamtsystem verbunden: $:^{334}$

- Die Selbstbeschränkung neuer Programminitiativen durch negative Koordination verhindert, daß bestimmte (komplexe) Problemzusammenhänge überhaupt in das Entscheidungssystem eingebracht werden. Die Möglichkeit, durch integrative Problemlösungen Wohlfahrtszugewinne zu realisieren, bleibt dann in vielen Fällen ausgeschlossen.

${ }^{333}$ Dieses Vorgehen strebt nach der bereits angesprochene Trennung der integrativen $u$. der distributiven Problemlösung (vgl. Abschnitt III-2.3.2.2).

334 Im Sinne von Einbußen für die Effizienz der Steuerungsleistungen des Gesamtsystems. Vgl. hierzu wiederum das Effizienzkonzept des allgemeinen Referenzsystems in Abschnitts II-1. 
- Der Übergang von der Einstimmigkeitsregel zu einer Form der Mehrheitsregel verursacht Präferenzkosten.

- Die Etablierung konfliktminimierender Entscheidungsregeln beschränkt die Variationsmöglichkeiten der Entscheidungsträger zur Ausgestaltung der FZ substantiell, wenn es die Herstellung eines Konsens erfordert, daß die FZ einen weiten Kreis an begünstigten Jurisdiktionen umfassen, über die Zeit in ihrem Volumen zumindest stabil gehalten werden, kaum GKS-spezifische Variationen in ihrer Ausgestaltung besitzen und nur eine geringe Eingriffsintensität in die Präferenzen der Betroffenen aufweisen. Diese Beschränkungen der Ausgestaltungsformen der FZ stellen „eine massive Restriktion für die im Verflechtungssystem realisierbaren Steuerungsprogramme ${ }^{\text {335 }}$ dar. Es ist dann fraglich, ob mit den verbleibenden Formen der FZ, die zieladäquaten (differenzierten) Wirkungen der Transfervergabe ausgelöst werden können.

Über die bisher angesprochenen allokativen Gesichtspunkte hinaus ist zu berücksichtigen, daß auch im Willensbildungsprozeß (politische) Transaktionskosten ausgelöst werden: ${ }^{336}$

- Es entstehen Verhandlungs- und Entscheidungskosten. Mit zunehmender Komplexität der Verhandlungsproblematik müssen sich die Verhandlungspartner intensiver und länger um die Aufbereitung der entscheidungsrelevanten Informationen, die Verhandlungsführung und die Formulierung der Entscheidung bemühen, wodurch ansteigende Transaktionskosten ausgelöst werden.

- Die Durchsetzung und Überwachung der Verhandlungslösung löst weitere Transaktionskosten aus. Die Verhandlungsteilnehmer wenden Ressourcen auf, um geeignete institutionelle Vorkehrungen zu treffen, so daß die verhandlungskonforme Verwendung der FZ-Mittel in den Jurisdiktionen der Transferempfänger kontrollierbar wird und bei Verstößen gegen die Vereinbarungen wirksame Sanktionen ergriffen werden können. ${ }^{337}$

Sofern diese Überwachungs- und Durchsetzungskosten sehr hoch ausfallen, besitzen die eingeführten Sanktionen nur eine geringe Glaubwürdigkeit und „die Nichterfüllung von Verträgen [ist] bis zu einem gewissen Grad unvermeidlich." ${ }^{338}$ Denn besitzen die Transferempfänger weitgehende Informationen über die extreme Kostenintensität der Überwachungs- und Durchsetzungsaktivitäten, so wissen sie, daß die Transfergeber nur eingeschränkte Kontrollen

\footnotetext{
335 Scharpf(1976), S. 66.

${ }^{336}$ Vgl. hierzu grundsätzlich Richter/Furubotn (1996), S. 47 ff.; vgl. auch Dixit (1997), insb. S. 37 ff.

${ }^{337}$ In Abschnitt III-2.3.2.2.1 wurden diese institutionellen Vorkehrungen als eine „externe Instanz" zur Durchsetzung der Absprachen bezeichnet.

${ }^{338}$ Richter/Furubotn (1996), S. 52.
} 
durchfuihren werden. Es ergeben sich Spielräume für opportunistische Verhaltensweisen seitens der Transferempfänger. Resultiert infolgedessen eine Verwendung der Transfers in Abweichung von der Verhandlungsvereinbarung, so wird die kooperative Problemlösung im Verflechtungssystem in der Realität gar nicht umgesetzt und Nutzenzugewinne für die Gesamtheit des Systems bleiben ungenutzt. Da keine externe Instanz existiert, die die Einhaltung der Verhandlungsergebnisse über die Verwendung der FZ effektiv durchsetzen kann, ist eine kooperative Problemlösung nur möglich, wenn es im Eigeninteresse aller Beteiligten liegt, sich an die Vereinbarungen der spezifischen Verhandlungsfrage zu halten. Es handelt sich hier also um eine nicht-kooperative Spielsituation. ${ }^{339}$

Allerdings ist zu beachten, daß das Verflechtungssystem langfristigen Bestand besitzt, so daß sich eine Vielzahl an Interaktionen zwischen den Verhandlungspartnern ergibt. Zudem gehen die Entscheidungen im Verflechtungssystem bei ,prinzipiell unvollständiger Information über die Präferenzen und Perzeptionen" ${ }^{340}$ der Verhandlungspartner vonstatten. Es kann unter diesen Bedingungen auch im Eigeninteresse der Transferempfänger liegen, auf kurzfristige Vorteile zu verzichten, die durch die Nichtbeachtung einer spezifischen Verhandlungslösung erzielbar wären, um langfristige Nachteile dieses defektierenden Verhaltens zu vermeiden: ${ }^{341}$

- Unter den getroffenen Annahmen besitzen auch die Transfernehmer nur unvollständiges Wissen darüber, in welchem Ausmaß die Transfergeber ihr abweichendes Verhalten bei der FZ-Verwendung beobachten können. Gerade bei Transfers, die in bestimmten Zeitabständen immer wieder vergeben werden, steigt daher die Wahrscheinlichkeit, daß die Nichteinhaltung der Verhandlungslösung durch Kontrollen festgestellt wird und in zukünftigen Perioden, bspw. durch die Kürzung der Mittelzuweisungen, mit Sanktionen beantwortet wird.

- In dem auf Dauer angelegten Entscheidungssystems finden im Zeitablauf eine Vielzahl an Einzelinteraktionen statt, deren spezifische Auswirkungen auf die eigene Nutzenposition von keinem der Verhandlungspartner im vornherein eingeschätzt werden können. Daher

339 Vgl. hierzu Fn 263 in Abschnitt III-2.3.2.2.1.

340 Scharpf(1996a), S. 519.

${ }^{341}$ Die nachfolgenden Ausführungen gehen über das „Folk-Theorem” der nicht-kooperativen Spieltheorie hinaus (vgl. grundlegend Axelrod (1987), S. 3 ff. u. 23 ff.). Dies Theorem bildet den theoretischen Ausgangspunkt einer dynamischen Sichtweise der Verhandlungsproblematik. Es besagt, daß bei vollständigen Informationen nur durch die unbegrenzte Wiederholung einer Verhandlungssituation die „Evolution von Kooperation" (Axelrod (1987), S. 18) in einem Verhandlungssystem ermöglicht werden kann. Denn bei begrenztem Zeithorizont besteht für die Akteure in der letzten Periode kein Anreiz zur Kooperation, da abweichendes Verhalten in der Zukunft nicht mehr bestraft werden kann. Diese Argumentationskette kann jedoch bis zum Anfangszeitpunkt zurückverfolgt werden („backward-induction”). Letztendlich besteht für die Verhandlungspartner bereits in der ersten Verhandlungsrunde kein Anreiz, die Vereinbarungen einzuhalten. Diese Schlußfolgerung ändert sich jedoch, wenn die Verhandlungspartner nur unvollständige Informationen besitzen. Kooperation kann dann schon bei längerfristigem, aber begrenztem Zeithorizont möglich werden. Von dieser Ausgangssituation wird nachfolgend ausgegangen (vgl. auch $\operatorname{Scharpf}(1996 \mathrm{a})$, S. $516 \mathrm{ff}$.). 
führt bereits „ein geringes Maß an 'Risiko-Aversion “”342 dazu, daß die Einhaltung der Vereinbarungen im Eigeninteresse aller Verhandlungspartner liegt, um so längerfristig mögliche Kooperationsvorteile nutzen zu können. Zudem vermögen die einzelnen Verhandlungspartner, durch beständiges kooperatives Verhalten mit der Zeit „Reputation”343 zu gewinnen. Diese Reputation findet ihren Ausdruck in einem gesteigerten Vertrauen der Verhandlungspartner auf die kooperative Interaktionsorientierung der betreffenden Akteure. Gelingt es im Verflechtungssystem wechselseitig entsprechende Erwartungen aufzubauen, so werden die Entscheidungsträger im Interesse der Aufrechterhaltung der kooperativen Dauerbeziehung im Einzelfall auch solchen Verhandlungslösungen zustimmen, die separat betrachtet einen Nachteil für die eigene Wohlfahrtsposition bedeuten. ${ }^{344}$

\section{III-2.3.2.3 Zwischenfazit zum interkollektiven Entscheidungsprozeß}

In den Abschnitten III-2.3.2.1 u. 2 wurde die Problemlösungsfähigkeit verflochtener Entscheidungssysteme im Rahmen einer differenzierten Analyse der Informationsgewinnung und verarbeitung sowie der Konsensfindungssuche erörtert. Es zeigt sich, daß die Steuerungsleistungen eines Verflechtungssystems von einer Reihe an Aspekten abhängen. Eine Würdigung der Problemlösungsfähigkeit verflochtener Entscheidungssysteme kann daher stets nur im konkreten Einzelfall erfolgen. Allerdings läßt sich allgemein festhalten, daß der vorgestellte Politikmodus über Handlungsoptionen verfügt, die v.a. bei sehr komplexen Problemstellungen zum Einsatz kommen werden, um eine Einigung der Verhandlungspartner zu ermöglichen. Die Anwendung dieser Handlungsoptionen wird aber unter realistischen Voraussetzungen häufig dazu führen, daß nicht die aus Sicht der Gesamtheit zieladäquate (wohlfahrtsmaximierende) Ausgestaltung der FZ erfolgt, die im Rahmen der Indifferenzkurvenanalyse unter idealisierten Bedingungen abgeleitet wurde.

Über diese Feststellungen zur sachlichen Problemverarbeitungskapazität der verflochtenen Entscheidungssysteme hinaus, verdeutlichen die beiden Abschnitte, daß durch den politischen Verhandlungsprozeß Transaktionskosten ausgelöst werden: In den einzelnen Phasen des Ent-

${ }^{342}$ Scharpf (1996a), S. 519.

${ }^{343}$ Vgl. zu diesem Begriff näher Holler/Illing (1996), S. 23 u. S. $163 \mathrm{ff}$.

344 Vgl. Scharpf (1996a), S. 519 ff. Allerdings weist Scharpf auch darauf hin, daß die Reputation als Basis der kooperativen Entscheidungsfindung sehr leicht zerstört werden kann. Da die einzelnen Akteure wechselseitig nur unvollständige Informationen über die Absichten $\mathrm{u}$. Vorgehensweisen der Verhandlungspartner besitzen, „verlangt vertrauenvolle Kooperation immer von neuem die Bereitschaft, sich auf verwundbare Positionen einzulassen." (Scharpf (1996a), S. 520) Aufgrund dieses „Verhandlungsdilemmas” (Scharpf (1992c), S. 20) richten die Akteure besondere Anforderungen an das Verhalten der Partner. „Unbeabsichtigte Fehler [mögen] nach ausreichender Klärung immer noch verziehen werden, aber alle anderen Enttäuschungen würden in aller Regel als Aufkündigung der kooperativen Beziehung selbst interpretiert, die auf der anderen Seite auch den allgemeinen Vertrauensentzug rechtfertigt." (Scharpf (1996a), S. 521) 
scheidungsprozesses müssen zur Einrichtung eines FZ-Programms Ressourcen aufgewendet werden. Es entstehen im Entscheidungsablauf zunächst Such- und Informationskosten, dann Verhandlungs- und Entscheidungskosten und schließlich Überwachungs- und Durchsetzungskosten.

Wenn die staatlichen Entscheidungsträger zunehmend mit Problemstrukturen einer ,gewachsenen Komplexität und Dynamik"345 konfrontiert werden, erhält deshalb der Aufbau eines dauerhaften und stabilen Entscheidungssystems eine immer größere Bedeutung. Denn in einem solchen Entscheidungssystem kann nicht nur die Zieladäquanz der sachlichen Problemlösungen verbessert, sondern auch eine Verringerung der Ressourcenkosten erreicht werden. „The existence of relatively permanent relationships may reduce the transaction costs of negotiations, and hence of positive coordination by increasing the truthfullness of communications and the reliability of commitments."346

\section{III-2.4 Zwischenfazit und Exkurs zur Wirkungsanalyse: die Diskussion meritori- scher Güter als Rechtfertigung eines Eingriffs in die Präferenzen der Trans- ferempfänger}

Die Grundlage der angestellten Wirkungsanalyse bildet die mikroökonomische Indifferenzkurvenanalyse (Abschnitt III-2.2), deren Effizienzkonzept sich ausschließlich auf die sachliche Problemlösung aus der Sicht der Transfergeber bezieht. Die FZ sollen einer bestimmten Verwendung in der transferempfangenden Jurisdiktion zufließen. Transaktionskosten bestehen in dieser Modellwelt nicht.

Die polit-ökonomische Analyse des Abschnitts III-2.3.1 zum intrakollektiven Entscheidungsproze $ß$ verdeutlicht, daß durch die Eigeninteressen der Akteursgruppen sowohl auf Transfergeber- als auch auf der Transfernehmerseite Ineffizienzen beim Einsatz des Instruments FZ ausgelöst werden können. Es entstehen Ansatzpunkte zur Begründung von Präferenzkosten, da sich den Akteuren im politischen Entscheidungsprozeß Handlungsspielräume eröffnen, ihre Entscheidungen in Abweichung von den Wünschen der Wähler zu treffen.

Abschnitt II-2.3.2 geht von der interkollektiven Willensbildung der FZ-Vergabe in einem verflochtenen Entscheidungssystem aus. Es zeigen sich mögliche Defizite im Hinblick auf die sachliche Problemlösungsfähigkeit dieses Politikmodus. Präferenzkosten bleiben hingegen solange ausgeschlossen, wie eine Verhandlungslösung nur durch einstimmige Entscheidungs-

\footnotetext{
345 Mayntz (1995), S. 141.

${ }^{346}$ Scharpf (1993c), S. 150. Vgl. hierzu auch Smekal (1980), S. 186 u. allg. Richter/Furubotn (1996), S. 56.
} 
findung zustande kommen kann. Es tritt dann aber die Problematik politischer Transaktionskosten in den Vordergrund.

Eine integrierte Sichtweise der angestellten Erweiterungsschritte zum Grundmodell des Abschnitts III-2.2 demonstriert, daß bei der Vergabe von FZ eine sehr viel differenziertere Untersuchung erfolgen muß, als dies zunächst innnerhalb der institutionen- und akteurlosen Welt der mikroökonomischen Indifferenzkurvenanalyse der Fall ist. „Die in einer Welt ohne Friktionen erreichbaren genauen und unzweideutigen Lösungen sind in der wirklichen Welt einfach nicht möglich. ${ }^{347}$ Gegenstand des nachfolgenden Abschnitts III-3 sind aus der Wirkungsanalyse abgeleitete Schlußfolgerungen zur aufgabenadäquaten Ausgestaltung der zwischenstaatlichen FZ im Hinblick auf die möglichen Funktionen der Transfers.

Bevor hierzu übergegangen wird soll in einem Exkurs jedoch ein Aspekt beleuchtet werden, der eine enorme Bedeutung besitzt, aber im Rahmen der Wirkungsanalyse fast ausgeblendet blieb: Innerhalb des föderativen Referenzsystems (Abschnitt II-1) wurde jede Abweichung von den Präferenzen der Bürger als Kosten aufgefaßt. In dieser Sichtweise lösen auflagengebundene FZ zwingend Wohlfahrtsverluste aus. Hingegen wurde der Eingriff in die Präferenzen der Transferempfänger innerhalb der mikroökonomischen Indifferenzkurvenanalyse (Abschnitt III-2.2) nicht negativ beurteilt. Sie wurden vielmehr positiv bewertet, sofern hierdurch die Ziele der Transfergeber mit einem geringeren Transfervolumen erreicht wurden. Diese konträren Effizienzkonzepte werfen die Frage auf, wann Präferenzeingriffe normativ begründet werden können und folglich auch im gedanklichen Referenzsystem des Kapitels II nicht Kosten verursachen, sondern Nutzen erzeugen:

Im Mittelpunkt dieser Erörterung steht die Theorie meritorischer Güter. ${ }^{348}$ Sie befaßt sich ursprünglich mit dem „Zusammenspiel” zwischen privatem und öffentlichem Sektor. Es werden Fälle betrachtet, in welchen die staatlichen Akteure die souveräne Konsumentscheidung der einzelnen Bürger korrigieren, obwohl die betrachteten Güter dem Ausschlußprinzip unterliegen, so daß eine marktliche Versorgung ,innerhalb der Grenzen, die die wirksame Nachfrage auferlegt,"349 gewährleistet wäre. ${ }^{350}$ Die staatlichen Entscheidungsträger schätzen in diesen

${ }^{347}$ Richter/Furubotn (1996), S. 11; vgl. auch Benkert (1984b), S. 97.

348 Die Theorie der meritorischen Güter geht auf das Konzept von Richard A. Musgrave zurück (vgl. Musgrave (1957) u. (1959)). Seitdem erfolgt eine kontroverse Diskussion möglicher Interpretationen des Konzepts (vgl. Andel (1984), Head (1988), Priddat (1992) u. jüngst Ebert (1999), S. 196 ff. für kritische Überblicke).

349 Musgrave (1969), S. 15.

${ }^{350}$ Die mit dieser Aussage getroffene Beschreibung des Konzepts der meritorischen Güter ist, wie Andel (1984), S. 638 richtig anmerkt, ,jedenfalls auf der grundsätzlichen Ebene" eine ,unlogische Beschränkung des 'Meritorischen' auf private Güter". Denn, wie es auch Musgrave bereits (1959), S. 13 ausfuihrt, „the satisfaction of social wants falls within the realm of consumer sovereignty, as does the satisfaction of private wants." 
Situationen die Ergebnisse der reinen Marktprozesse aus verschiedenen Gründen als unbefriedigend oder unerwünscht ein und treffen deshalb Budgetentscheidungen in Abweichung von den Präferenzen der Bürger. Bestimmte Güter werden ,als so bedeutend angesehen .., daß für ihre Befriedigung durch das öffentliche Budget über das hinaus Sorge getragen wird, was der Markt zur Verfügung stellt und was von den privaten Käufern gezahlt wird., ${ }^{\text {,351 }}$ Dieses Untersuchungskonzept wird nun auf das Verhältnis zwischen staatlichen Aufgabenträgern übertragen. Es wird so analysiert, ob aus der Theorie der meritorischen Güter Rechtfertigungen für „Beeinflussungen der Konsum- und Produktionsentscheidungen”,352 der transferempfangenden GKS durch die transfergebenden GKS erwachsen können. ${ }^{353}$

Ein erster Begründungsstrang zur Rechtfertigung meritorischen Handelns der Transfergeber verfolgt eine „'nachfrageorientierte' Argumentationsschiene”. ${ }^{354}$ Es wird von einer Verzerrung der individuellen Handlungspräferenzen ${ }^{355}$ der Entscheidungsträger der transferempfangenden GKS ausgegangen, die sich ergibt, wenn die betreffenden Akteure über einen unzureichenden bzw. fälschlichen Informationsstand verfügen oder eine mangelhafte Erfahrung bzw. eingeschränkte Beurteilungsfähigkeit im Hinblick auf die Lösung bestimmter Problemstellungen aufweisen. ${ }^{356}$ Eine auflagengebundene FZ-Vergabe kann in diesem Fall für die Korrektur der Verzerrungen Sorge tragen. Um den transferempfangenden Entscheidungsträgern möglichst weitgehende Gestaltungsspielräume zu belassen (Beachtung des Subsidiaritätsprinzip), ist allerdings zu überprüfen, ob die geeignetere Lösung nicht „eher in der Drosselung von Fehlinformationen und in der Bereitstellung von fehlenden korrekten Informationen" durch eine aktive Informationsstrategie ${ }^{357}$ der Transfergeber liegt. ${ }^{358}$

$\mathrm{Zu}$ rechtfertigen sind möglicherwiese aber vorübergehende Eingriffe in die autonomen Entscheidungen der Transferempfänger, sofern hierdurch deren Beurteilungsfähigkeit zur „effizi-

Der Eingriff in die Präferenzen der Bürger u. somit die Beschränkung der Konsumentensouveränität kann folglich sowohl im Hinblick auf private Güter als auch auf öffentliche Güter erfolgen.

351 Musgrave (1969), S. 15. Schmidt, K. (1988), S. 383 f.; insb. Fn 4 weist richtigerweise daraufhin, daß diese Eingrenzung des staatlichen meritorischen Handelns zu eng gefaßt ist. Der Eingriff in die individuellen Präferenzen erfolgt nicht nur durch budgetäre Interventionen sondern auch durch staatliche Regulierungen, wie bspw. Gebote u. Verbote.

${ }^{352}$ Kops (1989), S. 28.

${ }^{353}$ Vgl. hierzu auch Fischer (1988), S. 71.; Kops (1989), S. 28.

354 Schmidt, K. (1988), S. 390.

${ }^{355}$ Diese individuellen Handlungspräferenzen werden als erste Ebene eines nachfolgend zu bildenden Schemas unterschiedlicher Präferenzkategorien bezeichnet (vgl. zu dieser Vorgehensweise Priddat (1992), insb. S. 249 f.).

356 Vgl. hierzu grundlegend Musgrave (1969), S. 14 ff; auch Head (1966), S. 3 ff.

357 Vgl. hierzu auch die Ausfuhrungen in Abschnitt III-2.3.2.2.3 zu den Konsensbildungsstrategien.

358 Vgl. Schmidt, K. (1970), S. 16; Andel (1984), S. 645; aber auch Head (1988), S. 15 f., der sich dafür ausspricht, daß diejenige Alternative zur Behebung der Informationsdefizite zu wählen sei, die die geringsten Kosten verursacht. 
enten” Verausgabung der FZ erst hergestellt wird. ${ }^{359}$ „Die Produktion der meritorischen Güter deckt [dann] keinen anderen Bedarf als den der Handlungsfähigkeit"360 der Transferempfänger. So kann die FZ-Vergabe bspw. an die Empfangsauflage geknüpft werden, eine adäquate Finanzverwaltung mit qualifizierten Mitarbeitern aufzubauen. Die Transfergeber fungieren dann als „rechtsnormative Institution”, ${ }^{361}$ durch die die Grundbedingungen der Entscheidungsautonomie der Transferempfänger gewährleistet wird. Sind diese Voraussetzungen einmal geschaffen, besteht keine weitere Begründung für diese temporären meritorischen Eingriffe und die FZ sollten fortan ungebunden vergeben werden. ${ }^{362}$

Eine alternative Problemlage ergibt sich aufgrund weitgehender Interdependenzen zwischen den einzelnen Funktionen des öffentlichen Sektors, deren Erfüllung im föderativen Staat gezielt auf die einzelnen gebietskörperschaftichen Ebenen verteilt ist. Selbst wenn das Prinzip der optimalen Kompetenzdifferenzierung exponierte Beachtung findet, sind in dieser Situation „systematische Fehlentscheidungen unvermeidlich”. ${ }^{363}$ Insbesondere wird sich die „Vernachlässigung überregionaler oder gesamtwirtschaftlicher Belange" ${ }^{364}$ durch die Entscheidungsträger dezentraler Ebenen einstellen. Daher ergibt sich aus Sicht des Gesamtkollektivs eine suboptimale Aufgabenerfüllung, die letztendlich in der bestehenden Aufgabenverteilung im föderativen Staat begründet liegt. Dies stellt einen Rechtfertigungsgrund für die zentrale Ebene zum Eingriff in die Präferenzen der Entscheidungsträger der dezentralen Ebenen dar, der gegebenenfalls mittels der Vergabe auflagengebundener FZ erfolgen kann. ${ }^{365}$

Zum zweiten wird der Ansatz verfolgt, die Auflagenbindung der FZ mit der Internalisierung psychischer externer Effekte - also unter Bezugnahme auf Pareto-optimale Verteilung - zu rechtfertigen. ${ }^{366}$ Von der bisherigen Argumentationslinie ,verzerrter” individueller Handlungspräferenzen wird nun abgewichen und stattdessen von Nutzeninterdependenzen zwischen Transfergebern und -nehmern ausgegangen, die in allgemeiner Ausprägung bestehen

${ }^{359} \mathrm{Vgl}$. Andel (1984), S. 646; Musgrave/Musgrave (1984), S. 78; kritisch aber Schmidt, K. (1970), S. 16 f. u. Fn 60.

360 Priddat (1992), S. 254.

361 Priddat (1992), S. 254.

362 Vgl. Andel (1984), S. 646 f.; Priddat (1992), S. 254 f.; auch King (1984), S. 131.

${ }^{363}$ Kops (1989), S. 27.

${ }^{364}$ Kops (1989), S. 28, Fn 53.

${ }^{365}$ Vgl. Kops (1989), S. 27 f. u. 41; auch King (1984), S. 133 f.

${ }^{366}$ Musgrave (1987), S. 452 spricht von ,paternalism in distribution.” Vgl. aber auch Richter/Weimann (1991), insb. S. 121 f. u. 127 ff., die in diesem Zusammenhang gar keine meritorischen Eingriffe feststellen, da es sich ihrer Meinung nach einfach um Maßnahmen zur Internalisierung externer Effekte handelt. Überträgt man den Ansatz der Autoren auf den Bereich der öffentlichen Aufgabenträger, so ist eine verteilungstheoretische Rechtfertigung für meritorische Eingriffe der Transfergeber nur als gegeben anzusehen, sofern interpersonelle Nutzenvergleiche zwischen den Akteuren akzeptiert werden und diese zu dem Ergebnis fuihren, daß die Grenznutzen transferempfangender GKS im Hinblick auf eine bestimmte auflagengebundene FZ höher ausfallen als die Grenznutzen der GKS, die diese FZ nicht erhalten. 
können ${ }^{367}$ oder sich auf konkrete Güter beziehen. ${ }^{368}$ Im zweiten Fall gewährleistet nur eine zweckgebundene Vergabe der FZ, daß den Präferenzen der Transfergeber entsprochen wird. Diese Vorgehensweise ,can serve simultaneously not only the Distribution Branch objective of vertical redistribution but also the Allocation Branch objective of efficiency through internalizing the psychic externality involved."369

Musgrave und auch Andel gehen davon aus, daß in diesem Fall trotz der Zweckbindung gar kein Eingriff in die Präferenzen der Transferempfänger vorliegt, da letztere die Annahme der FZ jederzeit ablehnen können. ${ }^{370}$ Schmidt teilt diese Einschätzung nicht. Da es sich die meisten GKS sowohl aus finanziellen als auch aus politischen Gründen nicht erlauben können, die FZ zurückzuweisen, „kann es sehr wohl Verstöße gegen Präferenzen geben.” ${ }^{\text {,71 }}$ Er sieht jedoch durchaus eine Rechtfertigung für diese Art Eingriff in die Präferenzen der Transferempfänger. Sie entsteht, sofern durch die Zweckbindung der Mittelvergabe die Bereitschaft der Transfergeber ausgelöst wird, ein im Vergleich zur Pauschalzuweisung gesteigertes FZVolumen zu finanzieren. Dann besteht die Möglichkeit, daß die durch die Zweckbindung verursachten Nutzeneinbußen der Transferempfänger durch Nutzenzugewinne aufgrund des gesteigerten FZ-Umfang überkompensiert werden. ${ }^{372}$

Eine weitere ,nachfrageseitige” Argumentationslinie überträgt polit-ökonomische Aspekte auf den Bereich der FZ-Vergabe und zieht sie zur Rechtfertigung meritorischen Handelns der Transfergeber heran. Ausgangspunkt ist die Hypothese, daß die Entscheidungsträger der transferempfangenden GKS ihre Entscheidungen systematisch und beabsichtigterweise nicht in Einklang mit den Präferenzen der Wähler ihrer GKS treffen. ${ }^{373}$ Die Korrektur der individuellen Handlungspräferenzen der Entscheidungsträger der transferempfangenden GKS trägt in dieser Situation zur „Unterstützung von Konsumentenpräferenzen” ${ }^{374}$ bei, wenn man davon ausgeht, daß die Entscheidungsträger der transfergebenden GKS ihr Verhalten am Gemeinwohl orientieren. ${ }^{375}$ Doch besitzen auch für die Transfergeber die polit-ökonomischen Schlußfolgerungen Gültigkeit, so daß die Verfolgung eigennütziger Ziele auf zentraler Ebene genau-

\footnotetext{
367 „General Utility Interdependence” (Head (1988), S. 20).

368 "Particular-Commodity Interdependence" (Head (1988), S. 20).

369 Head (1988), S. 21.

370 Vgl. Musgrave (1987), S. 452; Andel (1984), S. 644 f.

371 Schmidt, K. (1988), S. 389; vgl. auch Folkers (1974), S. 3 ff.

372 Vgl. auch Andel (1984), S. 645; Musgrave/Musgrave (1984), S. 79; Schmidt, K. (1988), S. 389.

373 Die Transferempfänger verhalten sich auf diese Weise trotz ausreichenden Informationsstandes, ausreichender Erfahrungen $u$. ausreichender Beurteilungsfähigkeit (vgl. Musgrave (1987), S. 452). Insbesondere besteht die Befürchtung, daß aufgrund ,politischer Konjunkturzyklen” (vgl. Abschnitt III-2.3.1.2) langfristig ausgerichtete Entscheidungen unterbleiben.

374 Smekal (1980), S. 191.

375 Vgl. Smekal (1980), S. $191 \mathrm{f}$.
} 
sowenig ausgeschlossen ist, wie auf dezentraler Ebene. ${ }^{376}$ Die angeführte Begündung meritorischen Handelns gibt dem transfergebenden Entscheidungsverband jedoch beinahe ,freie Hand für sein Tun oder sein Unterlassen”, ${ }^{377}$ da für eine Beurteilung, „,bis zu welchem Punkt eine Maßnahme wirklich im Hinblick auf die gegebenen individuellen Konsumentenpräferenzen ... erforderlich ist und wo die diese Konsumentenpräferenzen übergehende 'eigenmächtige' diktatorische Entscheidung einsetzt" ${ }^{378}$ kein praktikables Kriterium existiert. Die angeführte Begründungsschiene für meritorisches Handeln ist daher sehr kritisch zu beurteilen. $^{379}$

In enger Anlehnung zum vorhergehenden Gedankengang kann die auflagengebundene FZVergabe durch die Transfergeber als ein Versicherungssystem der Transferempfänger ,gegen die Möglichkeit eigener Regelverstöße" ${ }^{\text {,380 }}$ interpretiert werden. ${ }^{381}$ Es wird angenommen, daß die transferempfangenden GKS auf einer gedanklich übergeordneten Ebene Beschränkungen der eigenen Handlungsspielräume befürworten, die sich auf eine gedanklich untergeordnete Ebene beziehen. Neben die (untergeordneten) individuellen Handlungspräferenzen treten (übergeordnete) Verfassungspräferenzen als eine zweite Ebene im Schema der Präferenzkategorien. Die transfergebende GKS fungiert in diesem Fall als der „wohlmeinende" Vertreter der Interessen des Gesamtkollektivs. Die Eingriffe dieser Instanz in die individuellen Handlungspräferenzen werden von den Transfernehmern anerkannt, da letztere langfristig von der Vorteilhaftigkeit dieser institutionellen „Verfassungsregel” für die eigene Nutzenposition ausgehen. Es erfolgt eine „voluntary delegation of choice”, ${ }^{382}$ die in deutlicher Abgrenzung zur „,coercive or imposed choice” ${ }^{383}$ des vorherigen Absatzes steht.

Die Abstimmungsregeln des politischen Entscheidungsprozesses zur Bestimmung der zu vergebenden FZ werden als von allen Transferempfängern akzeptierte Verfassungsregel interpretiert. ${ }^{384}$ Eine extreme Alternative stellt das Einstimmigkeitsprinzip dar, von dem auch bei der Diskussion der interkollektiven Entscheidungsprozesse ausgegangen wurde. Die Transferempfänger verweigern bei dieser Abstimmungsregel jedewede Einschränkung ihrer Handlungs-

\footnotetext{
${ }^{376}$ Möglicherweise gilt sogar das Gegenteil. Denn die polit-ökonomische Theorie des Föderalismus kommt $\mathrm{zu}$ dem Schluß, daß die Nähe der dezentralen Entscheidungsträger zu ihren Bürgern eine Beschränkung der dezentralen politischen Handlungsspielräume auslösen kann. In diesem Fall setzen sich die Bürgerpräferenzen verbessert durch (vgl. hierzu Thöni (1986), insb. S. 67 ff.).

377 Schmidt, K. (1988), S. 385 f.

378 Andel (1969), S. 212.

379 Vgl. Andel (1969), S. 212; Schmidt, K. (1988), S. 385 f.; Musgrave/Musgrave/Kullmer (1990), S. 74.

${ }^{380}$ Priddat (1992), S. 242.

381 Vgl. hierzu grundlegend Vanberg/Buchanan (1988).

${ }^{382}$ Head (1988), S. 36.

${ }^{383}$ Head (1988), S. 36.

${ }^{384}$ Vgl. Musgrave (1987), S. 452 f.; Priddat (1992), S. 241.
} 
spielräume. Bei Mehrheitswahlentscheidungen hingegen akzeptieren die Akteure, daß die eigenen Präferenzen majorisiert werden können. Die auflagengebundenen FZ erhalten dann eine Rechtfertigung im Rahmen des „,normalen” politischen Entscheidungsprozesses, wenn die Transfergeber durch den Eingriff in die Präferenzen der Transfernehmer, den Präferenzen der Mehrheit zur Durchsetzung verhelfen. ${ }^{385}$ Auf diese Weise kann bspw. die Verwirklichung von Mindeststandards in Verteilungsfragen durch die Vergabe zweckgebundener FZ begründet werden, sofern die Präferenzen der umfassenderen Ebene von jenen einzelner untergeordneter Ebenen abweichen. Letztere hätten bei autonomer Entscheidung ein niedrigeres Bereitstellungsniveau bestimmter Güter realisiert, als von der Gesamt-Mehrheit gewünscht. ${ }^{386}$

Einschränkend muß bei der Rechtfertigung meritorischen Handelns durch Verfassungspräferenzen jedoch wiederum auf polit-ökonomische Argumente verwiesen werden. Denn die transfergebende GKS muß sich keineswegs als „wohlmeinender” Vertreter des kollektiven Gesamtinteresses verhalten, sondern kann als herrschende Gruppe ihre eigene Anschauung für überlegen halten und versuchen, diese den anderen aufzuzwingen. „Eine solcherart zustande gekommene Bestimmung von Bedürfnissen ist letztlich autoritativ und mit unserem normativen Modell, das von der Annahme einer demokratischen Gesellschaft ausgeht, unvereinbar."387

Die Handlungsmotive der Transfergeber werden besonders wichtig, wenn die normative Begründung der Präferenzeingriffe nicht wie bislang primär von der Nachfrageseite sondern von der Angebotsseite her erfolgt. ${ }^{388}$ Nach dieser alternativen Vorstellung verhalten sich die Transfergeber nicht ausschließlich ,reaktiv”, um bereits bestehenden Präferenzen zur Durchsetzung zu verhelfen, sondern bemühen sich ,aktiv”, durch die zielgerichtete Vergabe auflagengebundener FZ, neue Präferenzen bei den Transferempfängern zu bilden. ${ }^{389}$ In Analogie zu den Überlegungen bei Schumpeter und Downs verhalten sich die Transfergeber wie Unternehmer am Markt. Sie „konstatieren also nicht nur Ideenströmungen und Gruppeninteressen, sie formen sie auch. Sie versuchen einerseits das, was aufgrund von Wertvorstellungen und Interessen der Bürger nachgefragt wird, zu befriedigen, und sie versuchen andererseits neue Wertvorstellungen und Interessen zu wecken.",390

\footnotetext{
${ }^{385}$ Vgl. Gläser (1981), S. 102.

${ }^{386}$ Vgl. Scharpf (1976), S. 26; King (1984), S. 132 f. Die Bereitstellung von Wohnraum, Erziehungseinrichtungen und medizinische Leistungen werden in diesem Zusammenhang als typische Güter genannt.

387 Musgrave (1969), S. 16.

388 Vgl. hierzu insb. Schmidt, K. (1988), S. $390 \mathrm{ff}$.

389 Priddat (1992), S. 243 spricht von dem ,Fall der aktiven Präferenzgenese."

390 Schmidt, K. (1988), S. 391. Vgl. hierzu grundlegend Schumpeter (1950), S. 427 ff. u. Downs (1968), S. 24 ff.
} 
Diese FZ stellen für die Transferempfänger zunächst einen wohlfahrtsmindernden Eingriff in die eigenen individuellen Handlungspräferenzen dar. Die betroffenen GKS können den Maßnahmen der Transfergeber jedoch im Anschluß an die Mittelverwendung eine Rechtfertigung verschaffen, sofern sie den FZ-Programmen nachträglich zustimmen. ${ }^{391}$ Die Realisierung dieser ex-post Legitimation des meritorischen Handelns erfordert allerdings eine spezifische institutionelle Struktur des politischen Entscheidungsprozesses. In einem bestimmten Zeitabstand nach der Einführung eines ,angebotsorientierten” FZ-Programms müssen die Transferempfänger die Gelegenheit besitzen, ihre Zustimmung bzw. Ablehnung zu dem spezifischen Eingriff in die eigenen Präferenzen äußern zu können. Ein ablehnendes Votum muß die Beendigung der meritorisierenden Transfervergabe zur Folge haben. ${ }^{392}$ „Faktisch stellen sich dann freilich unlösbare Abgrenzungsprobleme" ${ }^{\text {"393 }}$ gegenüber allen übrigen FZ-Programmen, denen keine angebotsorientierte Argumentationslinie zugrundeliegt. Zudem stellt sich die Frage, ob solche angebotsorientierten Eingriffe gerechtfertigt werden können, „deren Konsequenzen erst viel später voll erfahren werden, dann aber kaum mehr korrigierbar sind." ${ }^{\text {394 Eine }}$ ablehnende Haltung der Transferempfänger bleibt in diesen Fällen praktisch wirkungslos. Schließlich ist zu hinterfragen, ob das ex-post Votum der Transferempfänger, deren ex-ante Beurteilung stets überlegen sein muß. „Gerade wenn die ursprünglichen Entscheidungen zunächst mit Entbehrungen verbunden waren kann die spätere Zustimmung dazu einfach einseitig aus der Sicht eines dann höheren Lebensstandards erfolgen, ohne die früheren Opfer dafür adäquat zu berücksichtigen". ${ }^{395}$

Eine zu allen bisherigen Argumentationslinien gegenläufige Rechtfertigung meritorischen Handelns verfolgt der Rekurs auf kollektive Bedürfnisse in Abgrenzung zu individuellen Präferenzen. Es wird in diesem Fall über die individualistische Begründung der Staatstätigkeit hinausgegangen. Neben den individuellen Handlungs- und Verfassungspräferenzen wird mit

${ }^{391}$ Zur Begründung, warum die ex-ante Entscheidungen (,actual choice”) der GKS von ihren ex-post Entscheidungen (,retrospective choice") abweichen können vgl. Basu (1975/1976).

392 Vgl. Schmidt, K. (1988), S. 392; Priddat (1992), S. 243. Der entscheidende Aspekt ist letztlich, daß die Transferempfänger jeder einzelnen, ,angebotsorientierten" FZ auch eine spezifische ex-post Zustimmung erteilen müssen. Dies scheint im Verhältnis der transfergebenden u. -empfangenden GKS zumindest grundsätzlich möglich; so bspw. im Rahmen eines verflochtenen Entscheidungssystems, in das die einzelnen FZProgramme getrennt in die Abstimmungsverhandlungen eingebracht werden können. Im Verhältnis zwischen privatem u. öffentlichem Sektor ist eine derartige ex-post-Rechtfertigung meritorisierenden Handelns hingegen praktisch unmöglich, da die Bürger anläßlich von Wahlen zumeist nur Globalentscheidungen über eine Vielzahl öffentlicher Maßnahmen treffen können (vgl. hierzu wiederum Schmidt, K. (1988), S. 392).

393 Schmidt, K. (1988), S. 392.

394 Andel (1984), S. 646.

395 Andel (1984), S. 646; auch Basu (1975/1976). Schmidt, K. (1970), S. 17, weist sehr kritisch darauf hin, daß gar nicht klar sei, ob bei der ex-post Zustimmung noch „die 'wahren' Präferenzen der Betroffenen” zur Geltung kommen. Die Zustimmung könne, so K. Schmidt, genauso gut „auf eine Art 'Gehirnwäsche“" durch die Transfergeber zurückgehen. 
den Gemeinschaftsbedürfnissen eine neue Dimension (dritte Ebene) der Präferenzen eingefuihrt, „where consumer sovereignty is replaced by an alternative norm." ${ }^{396}$ Musgrave argumentiert, daß sich zwischen den Akteuren einer Gemeinschaft als Ergebnis eines historischen und andauernden Interaktionsprozesses gemeinsame Präferenzen herausbilden, die über individuelle Wertschätzungen hinausgehen. Diese schaffen innerhalb der Gemeinschaft besondere Konsensmöglichkeiten, die „als außerhalb der üblichen individuellen Entscheidungsfreiheit liegend, akzeptiert werden."397 Aus dieser „gesellschaftlichen Einverständigkeit” resultiert auch die Rechtfertigung meritorischer Eingriffe der Transfergeber in die individuelle Handlungspräferenzen der Transferempfänger, „die keiner besonderen Auseinandersetzung [zwischen Transfergebern und Transfernehmern; A.d.V.] mehr bedarf." 398

Sehr kritisch beurteilt Priddat diese Begründungslinie. Zwar stellt auch er zunächst allgemein fest, daß sich die Theorie der meritorischen Güter ,mit dem Faktum auseinandersetzen [muß], daß staatliche Maßnahmen durchgesetzt werden können, die keine individuellen Interessen zum Ausdruck bringen, sich zum Teil gegen sie stellen, und dennoch akzeptiert werden."399 Er erklärt dieses Phänomen jedoch in Anlehnung an Brennan/Lomasky mit den Besonderheiten des politischen Abstimmungsprozesses. ${ }^{400} \mathrm{Da}$ die einzelne transferempfangende GKS kaum Einfluß auf die Entscheidungen zur FZ-Vergabe besitzt, ${ }^{401}$ hat sie wenig Grund, sich im Verhandlungsprozeß zwischen den staatlichen Akteuren überhaupt um die Durchsetzung ihrer (kurzfristigen) individuellen Handlungspräferenzen zu bemühen. Deshalb liegt es für die Transferempfänger nahe, für übergeordnete Überzeugungen und Werthaltungen zu stimmen

${ }^{396}$ Musgrave (1987), S. 452. Vgl. zu diesem Ansatz Musgrave (1987); Priddat (1992); Brennan/Lomasky (1983) u. Head (1988).

397 Musgrave/Musgrave/Kullmer (1990), S. 75. Musgrave will diese Präferenzen aber ausdrücklich nicht als Ausdruck einer organischen Staatstheorie, wie sie „als sittlicher Standard der deutschen Nationalökonomie des 19. Jahrhunderts so selbstverständlich war" (Priddat (1992), S. 248) und damit auch nicht als ,notwendigen Gemeinsinn des Volkes" (Hildebrand (1848), S. 26, Fn 1) verstanden wissen (vgl. schon Musgrave (1969), S. 70 u. später (1987), S. 452; zustimmend auch Head (1988), S. 36).

398 Priddat (1992), S. 249. Diese Begründung grenzt sich nicht nur von der Argumentationslinie bei (untergeordneten) individuellen Handlungspräferenzen (erste Präferenzebene), sondern auch von jener bei (übergeordneten) Verfassungspräferenzen (zweite Präferenzebene) deutlich $a b$, die sich beide auf die individuelle Entscheidungsfreiheit der Akteure beziehen. Denn auch bezüglich der Verfassungspräferenzen wird von einem individuell begründeten Kalkül der Akteure ausgegangen. Diese geben bewußt Handlungskompetenzen ab, weil sie befürchten, daß bestimmte eigene Entscheidungen nur im Rahmen eines kurzfristigen Zeithorizonts vorteilhaft sein werden, langfristig aber zum eigenen Nachteil gereichen können.

399 Priddat (1992), S. 248.

${ }^{400}$ Vgl. Priddat (1992), S. 251 ff.; Brennan/Lomasky (1983). Die Ausführungen der Autoren beziehen sich auf das Verhältnis zwischen privatem und öffentlichem Sektor. Sie werden an dieser Stelle auf das Verhältnis zwischen transfergebenden und -empfangenden GKS übertragen.

$401 \mathrm{Vgl}$. auch Brennan/Lomasky (1983), S. $187 \mathrm{f}$. Es zeigt sich an dieser Stelle, daß die Überlegungen Priddats nicht problemlos auf den Bereich der staatlichen Aufgabenträger übertragen werden können. Denn in einem verflochtenen Entscheidungssystem besitzen die einzelnen Transferempfänger durchaus wesentlichen Einfluß auf die Ergebnisse des politischen Entscheidungsprozesses. Priddats Ausfuhrungen sind hingegen einleuchtend, sofern zwischen den Transfergebern und -empfängern eine strikte Hierarchie besteht. 
(Verfassungspräferenzen), um langfristig solchen Normen zur Durchsetzung zu verhelfen, „nach denen man selbst vornehmlich behandelt werden möchte" ${ }^{402}$

Da die Transferempfänger sich nun aber nicht an ihre individuellen Handlungspräferenzen gebunden sehen, besteht die Möglichkeit, daß FZ ohne Bewußtsein für die entstehenden Finanzierungskosten befürwortet werden. ${ }^{403}$ Es wird dann die Nutzen- von der Kostendimension entkoppelt und es entsteht eine Tendenz zur allokationsunabhängigen Ausweitung der FZ. Priddat fordert daher eine Restriktionsregel für das meritorische Handeln der Transfergeber, die - analog zur bereits zuvor angesprochenen Argumentationslinie - nur temporäre Eingriffe in die autonomen Entscheidungen der Transferempfänger zuläßt. Meritorisierende FZ dürfen demnach ausschließlich gewährt werden, um die „Allokationskompetenz”404 der transferempfangenden GKS herzustellen. Die Theorie der meritorischen Güter beschreibt in diesem Begründungszusammenhang ,eine spezifische Allokationspolitik, die die Herstellung von Allokationsausgangspositionen zum Ziel hat. ${ }^{\text {405 }}$ Von einer alternativen Norm, die Musgrave durch die „community preferences” begründet sieht, kann daher, so resümiert Priddat, ,nur im eingeschränkten Sinne geredet werden. ${ }^{, 406}$

Zusammenfassend ist festzuhalten, daß die Theorie der meritorischen Güter ein äußerst komplexes und in sich keinesfalls (logisch) geschlossenes Konzept darstellt. ${ }^{407}$ Es findet sich eine Mehrzahl unterschiedlicher Ansatzpunkte, die eine normative Begründung für Eingriffe in die Präferenzen der Transferempfänger durch die Transfergeber ,vermuten” läßt. Dabei bewegt sich die Analyse jedoch zum Teil ,im Grenzbereich zwischen staatsrechtlich-normativer und ökonomischer Politik." ${ }^{408}$ Im Rahmen einer rein neoklassischen (Modell-)Welt sind derartige Eingriffe in die individuellen Präferenzen der Akteure kaum zu rechtfertigen. ${ }^{409} \mathrm{Die} \mathrm{Be}-$ gründgung meritorischen Handelns ist daher, wie bereits Musgrave resümiert, eine „heikle Aufgabe". ${ }^{410}$ Bemüht man sich jedoch um Schritte zu einer realistischen Betrachtung des Verhältnisses zwischen den an der Transfervergabe beteiligten Akteuren, so erscheinen die Überlegungen „central rather than peripheral to satisfactory economic policy analysis." ${ }^{411}$

\footnotetext{
${ }^{402}$ Priddat (1992), S. 253.

${ }^{403}$ Vgl. auch King (1984), S. 129 f.

${ }^{404}$ Priddat (1992), S. 254.

405 Priddat (1992), S. 254; vgl. auch Head (1988), S. 23.

${ }^{406}$ Priddat (1992), S. 255.

407 So auch Andel (1984), S. 648.

408 Priddat (1992), S. 239.

409 Vgl. hierzu Ebert (1999), S. 204 f.; eine extrem abweisende Haltung gegenüber jeder Art meritorischen Handelns begründet McLure (1968), der das Konzept der meritorischen Güter als eine „,normatively empty box" (McLure, (1968), S. 474) bezeichnet.

410 Musgrave (1969), S. 16.

411 Head (1988), S. 37; so auch Brennan/Lomasky (1983), S. 206.
} 


\section{III-3 Die Ausgestaltung der Finanzzuweisungen im Hinblick auf ihre Funktionen}

In diesem normativ-analytischen Abschnitt werden die Funktionsbereiche diskutiert, in denen der Einsatz zwischenstaatlicher FZ einen Beitrag zur Aufgabenerfuillung leisten kann und auf Grundlage der Abschnitte III-1 u. 2 Konsequenzen für die adäquate Ausgestaltung der FZ im Hinblick auf die einzelnen Funktionen abgeleitet. Hierbei werden ökonomische von nichtökonomischen Funktionen abgegrenzt, um der besonderen Berücksichtigung politischer Entscheidungsprozesse gerecht $\mathrm{zu}$ werden.

\section{III-3.1 Die Ausgestaltung der Finanzzuweisungen im Hinblick auf ökonomische Funktionen}

Im Rückgriff auf Musgrave wird zur Klassifizierung der ökonomischen Funktionen der FZ die Dreiteilung der öffentlichen Aufgabenbereiche in allokative, distributive und stabilitätspolitische Funktionen zugrundegelegt. Es zeigt sich jedoch, daß eine trennscharfe Zuordnung einzelner Problembereiche in das gewählte Schema nicht möglich ist. Es bestehen zahlreiche Interdependenzen und Überschneidungen zwischen den Funktionen, auf die im Ablauf der Analyse gegebenenfalls einzugehen ist. ${ }^{412}$

\section{III-3.1.1 Allokationsfunktion}

\section{III-3.1.1.1 Die Kompensation räumlicher externer Effekte}

Die Bereitstellung öffentlicher Güter kann mit dem Auftreten räumlicher externer Effekte verbunden sein. Solche Spillover-Effekte entstehen, wenn die territorialen Grenzen der GKS, die eine bestimmte öffentliche Leistung erbringt, nicht mit dem räumlichen Wirkungsbereich der bereitgestellten öffentlichen Leistung übereinstimmen. ${ }^{413}$

Die Folge dieser Inkongruenz ist ein aus gesamtwirtschaftlicher Sicht ineffizientes Versorgungsniveau der Bevölkerung mit dem betreffenden öffentlichen Gut. Die Ursache hierfür liegt darin begründet, daß die anbietende GKS die positiven Wohlfahrtseffekte, die durch die Spillovers in benachbarten GKS auslöst werden, bei ihrer Entscheidung über den Umfang der

\footnotetext{
${ }^{412}$ Hierauf weist schon Gläser (1981), S. 48 hin. So könnte bspw. der Problembereich mobilitätsinduzierter Externalitäten, der nachfolgend im Rahmen der Distributionsfunktion analysiert wird, als allokatives Problem behandelt werden. Ebenso könnten die Erörterungen zur regionalen Wirtschaftsstruktur nicht im Bereich der Allokation sondern der Distribution angestellt werden. Auch bestehen bei der Beeinflussung des Wirtschaftswachstums, die innerhalb der Stabilisationsfunktion untersucht wird, erhebliche Überschneidungen zur Allokationsfunktion.

${ }^{413}$ Das Kongruenzprinzip wird mißachtet. Vgl. Oates (1972), S. 66 ff.; Break (1980), S. 77 ff.
} 
Güterbereitstellung nicht mitberücksichtigt. Da zwar die gesamten Kosten der Güterbereitstellung von der anbietenden GKS getragen werden müssen, aber ein Teil der Nutzen dieser Güter in benachbarte GKS abfließt, resultiert ein suboptimales Leistungsangebot. Die anbietende GKS weitet das Bereitstellungsvolumen lediglich bis zu jenem Punkt aus, an dem die Summe der Grenznutzen der Mitglieder innerhalb der eigenen GKS den Grenzkosten des Leistungsangebots entspricht, nicht aber bis zu jenem "socially optimal point", 414 an dem die Summe der Grenznutzen aller von der Güterbereitstellung profitierenden Bürger innerhalb wie außerhalb der Jurisdiktion ${ }^{415}$ den Grenzkosten des Leistungsangebots entspricht. ${ }^{416}$

Um diese Ineffizienzen zu vermeiden, könnte die territoriale Ausdehnung der GKS neu geordnet werden. Die Schaffung einer Vielzahl monofunktionaler Bereitstellungseinheiten würde das Auftreten von Spillover-Effekten verhindern. Die Ausführungen zum allgemeinen föderativen Referenzrahmen verdeutlichen jedoch, daß diese uneingeschränkte Durchsetzung des Kongruenzprinzips bei Beachtung weiterer föderativer Teilprinzipien keine optimale Lösung verkörpert. ${ }^{417}$ Ein alternativer Lösungsansatz wäre die zentrale Bereitstellung der betreffenden öffentlichen Güter durch eine übergeordnete Ebene im föderativen Staat. Ist auch dieser Lösungsansatz unerwünscht, da unter Beachtung des Subsidiaritätsprinzips Zentralisierungstendenzen verhindert werden sollen, so besteht im weiteren die Möglichkeit zur Internalisierung der externen Effekte über den Coaseschen Verhandlungsmechanismus. ${ }^{418}$ Das Coase-Theorem stellt auch ohne den Eingriff einer externen bzw. übergeordneten Instanz einen optimalen Bereitstellungsumfang der öffentlichen Güter in Aussicht, da es sowohl für die Anbieter als auch die (externen) Nutznießer von Vorteil ist, eine „bargaining”-Lösung zur Internalisierung der Spillover-Effekte zu finden. Jedoch wird bei diesem Ansatz von Verhandlungskosten und der Möglichkeit strategischer Verhaltensweisen der Verhandlungspartner abstrahiert. Werden diese aber berücksichtigt, so nehmen mit zunehmender Zahl der von einer Externalität betroffenen GKS die Realisierungchancen einer effizienten Verhandlungslösung $\mathrm{ab}$, da nun erhebliche Verhandlungskosten auftreten und die Anreize zu Trittbrettfahrerverhalten für alle Beteiligten zunehmen. ${ }^{419}$

\footnotetext{
${ }^{414}$ Break (1980), S. 77.

415 Diese Summe kann als sozialer Grenznutzen bezeichnet werden.

${ }^{416}$ Hier wurde der Fall positiver externer Effekte beschrieben. Es resultiert ein supoptimales Bereitstellungsniveau. In Analogie hierzu wird im Fall negativer externer Effekte, wie sie bspw. im Umweltbereich auftreten können (vgl. hierzu bspw. Brunton/Meyer (1996), S. 292 ff.), eine am sozialen Optimum gemessen übergroße Menge des betreffenden Guts bereitgestellt.

$417 \mathrm{Vgl}$. Abschnitt II-2.

${ }^{418}$ Vgl. hierzu grundlegend Coase (1960).

419 Vgl. Oates (1972), S. 68 f.
} 
In einer solchen Situation erscheint eine zwischenstaatliche FZ, die für eine Internalisierung der externen Effekte Sorge trägt, „to be the preferred policy instrument”. ${ }^{420}$ Es wird dann der klassische Ansatz von Pigou $^{421}$ zur Lösung des Externalitätenproblems vom privaten Bereich auf das Verhältnis zwischen GKS übertragen. Durch eine FZ an die bereitstellende GKS soll gewährleistet werden, daß die Grenzkosten und der soziale Grenznutzen bei der Güterversorgung in Einklang gebracht werden. Um dies zu realisieren, muß die Höhe des Transfers der Summe der Grenznutzen entsprechen, die den gebietskörperschaftsexternen Bürgern bei dem effizienten Ausbringungsniveau zufließen. Bei der Ausgestaltung der FZ sind die folgenden Aspekte zu beachten: ${ }^{422}$

- Es ist eine Zweckbindung erforderlich, da nicht das Leistungsangebot der transferempfangenden GKS im allgemeinen, sondern nur im Hinblick auf das positive externe Effekte auslösende öffentliche Gut stimuliert werden soll. ${ }^{423}$

- Es ist eine Eigenbeteiligung der Transferempfänger festzusetzen, die für den Ausgleich der Grenzkosten und sozialen Grenznutzen für jede einzelne Einheit des öffentlich bereitgestellten Guts sorgt. Die Finanzierungsbeteiligung durch die Transfergeber führt zu einer Senkung der Grenzkosten und so zu einer Reduktion des Preises des geförderten öffentlichen Gutes in Relation zu allen anderen nicht-geförderten Gütern. ${ }^{424}$ Die Höhe der Finanzierungsbeteiligung der Transfergeber muß dabei exakt dem Anteil des Gesamtnutzens einer angebotenen Leistung entsprechen, der außerhalb der bereitstellenden Jurisdiktion anfällt. $^{425}$ Die effiziente Finanzierung der FZ erfordert darüber hinaus, daß die einzelnen nutznießenden GKS außerhalb der anbietenden GKS in dem Umfang zur Finanzierung der FZ beitragen, der ihrem Nutzenanteil am Gesamtnutzen der Leistungsbereitstellung entspricht (Verwirklichung des Korrespondenzprinzips). ${ }^{426}$

\footnotetext{
${ }^{420}$ Break (1980), S. 77.

421 Vgl. Pigou (1932).

${ }^{422}$ Vgl. hierzu Oates (1972), S. 72; Break (1980), S. 77 u. S. 102 ff; Smekal (1980), S. 189 f.

${ }^{423}$ Eine Pauschalzuweisung wäre nur dann zu begründen, wenn alle von einer GKS angebotenen öffentlichen Güter mit den gleichen externen Effekten verbunden wären (vgl. Fischer (1988), S. 65). Rückblickend auf die Ausfuihrungen zur Theorie der meritorischen Güter sei an dieser Stelle darauf hingewiesen, daß die hier erfolgende Zweckbindung nicht als ein Eingriff in die Präferenzen der Transferempfänger zu werten ist, sondern vielmehr deren Präferenzen erst zur Durchsetzung verhelfen soll. Die Transfergeber nehmen zur Internalisierung externer Effekte „die Funktion einer neutralen Schiedsinstanz [ein], die in 'objektiver' Weise die Leistungs- u. Finanzierungsverpflichtungen der nachgeordneten Ebenen zu korrigieren versucht.., ohne die eigenen Zielsetzungen ins Spiel zu bringen." (Gläser (1981), S. 101)

${ }^{424}$ Wie die Ausführungen in Abschnitt III-2.2.3 verdeutlichen führt ausschließlich eine FZ mit Eigenbeteiligung zu einer Veränderung der relativen Preise.

${ }^{425}$ Anders ausgedrückt ist es erforderlich, daß die Eigenbeteiligungsquote der Transferempfänger mit dem Anteil des Gesamtnutzens übereinstimmt, der innerhalb der GKS verbleibt. Sofern das relative Ausmaß der externen Effekte mit ansteigendem Bereitstellungsvolumen der öffentlichen Leistung variiert, ist eine dementsprechende „variable matching formula” (Oates (1972), S. 72, Fn 10) auszuarbeiten. Die Eigenbeteiligungsquote der Transferempfänger ändert sich dann in Abhängigkeit vom Umfang der öffentlichen Leistungsbereitstellung.

${ }^{426}$ Aus dieser Sicht müssen die Transfers als horizontale FZ vergeben werden; vgl. Fischer (1988), S. $66 \mathrm{ff}$.
} 
- Die FZ ist betragsmäßig unbegrenzt zu vergeben, da nicht davon auszugehen ist, daß ab einem bestimmten Versorgungsniveau keine zusätzlichen Spillover-Effekte mehr auftreten. „Es spricht eine Vermutung dafür, daß bei wachsenden Ausgaben sowohl die internen wie auch die externen Nutzen steigen." ${ }^{\text {427 }}$

Die Internalisierung der externen Effekte durch FZ ist eine theoretisch einleuchtende Problemlösung. In der Realität ergeben sich jedoch eine Reihe erheblicher Umsetzungsschwierigkeiten. ${ }^{428}$ So unterliegen die staatlichen Entscheidungsträger einem annähernd unlösbaren Informationsproblem im Hinblick auf die bestehenden Präferenzen der Bürger der einzelnen GKS sowie das Ausmaß der auftretenden Spillover-Effekte. Selbst wenn diese Informationen vorliegen würden erforderte die Berechnung der optimalen Eigenbeteiligungsquote der transferempfangenden und der Finanzierungsquoten der transfergebenden GKS einen interpersonellen bzw. interjurisdiktionalen Nutzenvergleich, dessen Durchführbarkeit in der ökonomischen Theorie als impraktikabel angesehen wird. ${ }^{429}$

Zusammenfassend zeigt sich daher, daß keine der alternativen Ansätze zur Internalisierung von Spillover-Effekten eine optimale Allokation garantieren kann. Insbesondere wenn eine Verhandlungslösung zwischen den betroffenen GKS ausgeschlossen ist, repräsentiert die FZVergabe aber eine geeignete wirtschaftspolitische Maßnahme, da sie in jedem Fall einen Teilbeitrag zur Problemlösung leistet: „There are admittedly real obstacles to determining the precise set of grants necessary to induce efficient behavior, but there is at least the presumption that the effects of such programs are in the proper direction.

\section{III-3.1.1.2 Die Beeinflussung regionaler Wirtschaftsstrukturen}

Im Mittelpunkt steht nachfolgend die Rolle, die zwischenstaatliche FZ im Dienste der Regionalpolitik einnehmen können, um „über die Beeinflussung der Wirtschaftsentwicklung bzw. der Wirtschaftsstruktur von Regionen das Regionalgefüge einer Volkswirtschaft so zu verändern, daß eine bessere Durchsetzung gesellschaftlicher und wirtschaftspolitischer Anliegen erreicht werden kann." ${ }^{431}$ Die den Gesamtraum umfassende GKS bemüht sich durch die Vergabe zwischenstaatlicher FZ um die zielgerichtete Beeinflussung der räumlichen Verteilung

427 Peffekoven (1988), S. 624; vgl. auch Costello (1993a), S. 113.

${ }^{428}$ Vgl. hierzu Oates (1972), S. 72 f.; Fischer (1984), S. 230; (1988), S. 69 f.; Costello (1993a), S. 113.

${ }^{429} \mathrm{Vgl}$. hierzu auch Abschnitt II-1, Fn 50.

430 Oates (1972), S. 74; analog Fischer (1988), S. 70 u. Costello (1993a), S. 113.

${ }^{431}$ Klemmer (1998), S. 459. Vgl. zum Folgenden insb. Smekal (1980), S. 199 ff.; Gläser (1981), S. 104 ff.; Fischer (1988), S. $73 \mathrm{ff}$. 
der privaten Produktionsfaktoren auf die untergeordneten GKS. Smekal weist darauf hin, daß die finanzielle Unterstützung der transferempfangenden GKS zwei gegensätzliche Motive verfolgen kann. Entweder soll die räumliche Mobiliät der privaten Produktionsfaktoren gebremst werden, so daß bestehende Strukturen erhalten bleiben, oder sie soll gesteigert werden, so daß strukturelle Anpassungsprozesse beschleunigt werden. ${ }^{432}$

Dabei erweist sich die Einflußnahme auf die regionale Verteilung des Angebots öffentlicher Infrastruktureinrichtungen als entscheidender Ansatzpunkt der FZ-Vergabe, da diese als unentgeltliche öffentliche Vorleistungen insb. für die Standortwahl der Unternehmen einen der wichtigsten raumdifferenzierenden Faktoren verkörpern. ${ }^{433}$ Die regionalpolitische Zielkonzeption kann wachstums-, verteilungs- oder auch stabilitätsorientiert sein. ${ }^{434}$ Je nachdem, welche Zielkonzeption von den Entscheidungsträgern verfolgt wird, muß die Förderung der öffentlichen Infrastruktur in unterschiedlichen Teilräumen des Gesamtstaates erfolgen.

Im Zentrum der wachstumsorientierten Regionalpolitik steht die optimale Allokation der Produktionsfaktoren im Raum, um ein möglichst starkes Wachstum der Gesamtwirtschaft zu ermöglichen, und so zur dynamischen Wohlstandsmaximierung in der gesamten Volkswirtschaft beizutragen. Es sind dann die GKS zu unterstützen, in deren Gebiet der Einsatz der privaten Produktionsfaktoren durch eine besonders hohe Produktivität gekennzeichnet ist. ${ }^{435}$

Der verteilungsorientierten Regionalpolitik liegt hingegen das Ziel möglichst gleichwertiger Lebensbedingungen in den einzelnen Teilgebieten des Gesamtraums zugrunde. Durch den Einsatz staatlicher Instrumente sollen in jeder einzelnen GKS die strukturellen Voraussetzungen geschaffen werden, aus eigener Kraft einen bestimmten Mindestlebensstandard verwirkli-

${ }^{432}$ Kritisch äußert sich Noll (1994), insb. S. 122 ff. zu diesem traditionellen Schema der aktiven Strukturerhaltung u. Strukturanpassung. Er weist auf die Informations-, Anreiz- und Lagproblematik des staatlichen Sektors hin, die es praktisch ausschließen, ,zukünftige Strukturen ex-ante zu fixieren." (Noll (1994), S. 123) Vielmehr müsse es in einem evolutorischem Verständnis der Strukturpolitik das Ziel sein, strukturelle Flexibilität $\mathrm{zu}$ erhalten, indem Wandel behutsam gefördert wird und erkannte Verkrustungen aufgebrochen werden, so „daß die Möglichkeit der Bildung bestimmter Strukturen nicht von vornherein ausgeschlossen ist." (Noll (1994), S. 125)

${ }^{433}$ Vgl. Gläser (1981), S. 109; Fischer (1988), S. 73; auch Noll (1994), S. 120 f. Grundsätzlich könnte die zielgerichtete Beeinflussung der räumlichen Verteilung der privaten Produktionsfaktoren an allen raumdifferenzierenden Faktoren anknüpfen, die als Potentialfaktoren bezeichnet werden. Neben der öffentlichen Infrastruktur sind hierzu insb. die wirtschaftsgeographische Lage, der Agglomerationsgrad einschließlich der Siedlungsstruktur und die sektorale Wirtschaftsstruktur zu zählen. „Da aber Lage, Agglomeration und Sektorstruktur zumindest in Marktwirtschaften nicht unmittelbar politisch einsetzbare Instrumente darstellen, bleibt als entscheidendes Instrument nur die Infrastrukturpolitik übrig." (Biehl (1995b), S. 64.) Die potentialfaktororientierte Infrastrukturpolitik umfaßt in einer weiten Abgrenzung nicht nur Investitionen in Sachkapital (z.B. Straßenbau), sondern auch Investitionen in Humankapital (z.B. öffentliche Fortbildungsmaßnahmen).

${ }^{434}$ Vgl. Gläser (1981), S. 104 f.; Beckmann (1995), S. 70 f. Vgl. auch schon Hansmeyer (1970), S. 447, der eine „wachstumspolitische" u. eine ,sozialpolitische" Ausrichtung der Regionalpolitik voneinander abgrenzt. Hier zeigen sich deutliche Überschneidungen zu anderen Funktionen der FZ.

${ }^{435}$ Die entscheidende Frage ist, ob sich diese optimale Faktorallokation allein durch das freie Spiel der Marktkräfte einstellt, oder ob die FZ einen Beitrag leisten können, diese erst durch staatliche Intervention ,aktiv" herzustellen. Vgl. hierzu die weitergehenden Ausführungen in Abschnitt III-3.1.3.2. 
chen zu können. Die Zielsetzung kann daher in Abgrenzung zu rein umverteilenden staatlichen Aktivitäten als ,allokativ orientierte Ausgleichspolitik ${ }^{\natural 436}$ bezeichnet werden. Die Förderung der öffentlichen Infrastrukturinvestitionen hat demnach gerade in den benachteiligten GKS zu erfolgen, um dort eigenständige Einkommenserzielungsmöglichkeiten zu schaffen. ${ }^{437}$ Diese verteilungsorientierte Regionalpolitik wird durch den sogenannten Potentialfaktoransatz begründet. ${ }^{438}$ Dessen Grundthese lautet, daß die Spielräume „für die wirtschaftliche Entwicklung einer Region umso größer sind, je besser die Ausstattung einer Region mit Ressourcen mit hohem Öffentlich-Gut-Charakter und je mehr freie Kapazitäten diese Ressourcen aufweisen." ${ }^{439}$ Daher können in benachteiligten Regionen, die durch eine unterentwickelte öffentliche Infrastruktur gekennzeichnet sind, regionale Entwicklungspotentiale geschaffen werden, indem die Potentialfaktorkapazität der öffentlichen Infrastruktur gesteigert wird. Diese Investitionen in Sachkapital und Humankapital ermöglichen Produktivitätsfortschritte im privaten Bereich, so daß Standortnachteile gegenüber hochentwickelten Regionen verringert werden. In den geförderten Regionen werden so zusätzliche poduktive Investitionen im Unternehmenssektor „lohnenswert”, die den Aufbau autonomer Einkommenserzielungsmöglichkeiten in der Region nachsichziehen.

Mit der Verwirklichung dieser verteilungsorientierten Zielsetzung wird zugleich ein Beitrag zur Verwirklichung der stabilitätsorientierten Regionalpolitik geleistet. In deren Mittelpunkt steht der Aufbau „möglichst stabile[r] Beschäftigungs- und Einkommensverhältnisse im Gesamtraum auf der Grundlage 'ausgewogener' teilräumlicher Wirtschaftsstrukturen" ${ }^{\text {"40 }}$. Durch die Schaffung neuer Einkommenserzielungsmöglichkeiten werden in den betreffenden GKS Anpassungsspielräume geöffnet, die die Verfestigung überkommener Strukturen zu überwinden helfen und so dazu beitragen, daß sich ein in geordneten Bahnen verlaufender Strukturwandel vollzieht. ${ }^{441}$

Die Ausgestaltung der FZ hat zweckgebunden zur Verwendung im Bereich öffentlicher Infrastrukturinvestitionen zur erfolgen. Da lediglich ein bestimmtes Infrastrukturniveau geschaffen werden soll, kann das FZ-Programm betragsmäßig limitiert werden. Die Festlegung einer adäquaten Finanzierungsbeteiligung ist aus Effizienzüberlegungen zu befürworten, da die Investitionen auch für die bereits ortsansässigen Unternehmen von Nutzen $\operatorname{sind}^{442}$ und sich zu-

\footnotetext{
${ }^{436}$ Beckmann (1995), S. 74.

437 Vgl. Beckmann (1995), S. $74 \mathrm{f}$.

${ }^{438}$ Vgl. zum Potentialfaktoransatz grundlegend Biehl (1991b); (1995b).

439 Biehl (1995b), S. 59.

440 Gläser (1981), S. 105.

441 Vgl. hierzu wiederum Noll (1994).

${ }^{442}$ So v.a. Gläser (1981), S. 126 u. Fischer (1988), S. 76.
} 
dem (möglicherweise) Sickerverluste verhindern lassen. Allerdings sind in bezug auf die Eigenbeteiligung Verteilungsüberlegungen zu berücksichtigen. Ist die Finanzkraft der transferempfangenden GKS sehr gering, so besteht die Gefahr, daß die Kofinanzierungsmittel nicht aufgebracht werden können und die angestrebten Infrastruktureinrichtungen nicht realisiert werden.

\section{III-3.1.2 Distributionsfunktion}

Innerhalb eines föderativen Staates ergeben sich eine Reihe an Faktoren, die es verhindern, daß die Ausgabenverpflichtungen der einzelnen GKS stets exakt den ihnen verfügbaren Einnahmequellen entsprechen. Die GKS weisen Unterschiede in der Relation zwischen ihrer „Leistungsfähigkeit” (der Finanzkraft) und ihrer „Bedürftigkeit” (dem Finanzbedarf) auf, die als fiskalische Ungleichgewichte bezeichnet werden. Sie treten entweder in vertikaler Sicht zwischen GKS unterschiedlicher Ebenen ${ }^{443}$ oder in horizontaler Sicht zwischen den GKS einer Ebene des föderativen Staates auf. Diese Ungleichgewichte sind sowohl aus distributiven als auch aus effizienzorientierten Überlegungen heraus von Bedeutung. Sie können grundsätzlich durch eine Änderung der bestehenden Aufgaben- oder (originären) Einnahmenverteilung zwischen den GKS beseitigt werden. Bereits der allgemeine föderative Referenzrahmen verdeutlichte jedoch, daß diese Lösung aufgrund einer Reihe von Zielkonflikten und Interdependenzen nicht in jedem Fall erstrebenswert sein muß. ${ }^{444}$ Dann kann ein Ausgleich zwischen Finanzkraft und Finanzbedarf mit Hilfe zwischenstaatlicher FZ angestrebt werden. ${ }^{445}$

\section{III-3.1.2.1 Vertikale fiskalische Ungleichgewichte}

Vertikale fiskalische Ungleichgewichte ergeben sich aus einer Mehrzahl an Gründen.

Sie können bewußt in Kauf genommen werden, um aus gesamtstaatlicher Sicht Kosten bei der Einnahmeerzielung einzusparen. Diesem Vorgehen liegt die Annahme steigender Skalenerträge bei der Steuererhebung zugrunde, so daß ,the most efficient tax-collecting unit may be, in many cases, considerably larger than the most efficient public-spending unit." ${ }^{\text {446 }}$ Der ge-

${ }^{443}$ Die Mehrzahl an GKS einer föderativen Ebene wird in diesem Fall als eine Gruppe aufgefaßt (vgl. King (1984), S. 137).

${ }^{444}$ Vgl. insb. die Prinzipien der optimalen Kompetenzdifferenzierung und der gerechten Lastenverteilung in Abschnitt II-2; vgl. auch Kops (1989), S. 14 ff., insb. 39 ff.

${ }^{445}$ Vgl. hierzu unter vielen Break (1980), S. 84 ff.; Smekal (1980), S. 192 ff.; King (1984), S. 137 ff.

${ }^{446}$ Buchanan (1970), S. 440. Vgl. auch King (1984), S. 215 f. Jedoch verringern technische Fortentwicklungen die Größenvorteile bei der zentralen Ebene, so daß im Bereich der Steuererhebung u. -verwaltung auch ,diseconomies of scale" denkbar sind (vgl. hierzu Groenewegen (1988), S. 21 ff.). 
bietskörperschaftlichen Ebene mit der „effizientesten” Steuerverwaltung werden daher mehr Steuerquellen zugeordnet, als zur Aufgabenwahrnehmung erforderlich.

Zum zweiten liefert die hohe Mobilität bestimmter Steuerbasen einen Begründungsansatz für vertikale fiskalische Ungleichgewichte. Dies gilt insb. für die Besteuerung der Produktionsfaktoren Kapital und Arbeit. Um eine ruinöse Steuerkonkurrenz zwischen den dezentralen GKS zu vermeiden, kann die Zuweisung dieser Steuerarten an die zentrale Ebene des föderativen Staates angezeigt sein. ${ }^{447}$ Sofern die dezentralen GKS nicht auf alternative Einnahmequellen mit ausreichender fiskalischer Ergiebigkeit ausweichen können, resultieren aus dieser Gestaltung des föderativen Steuersystems einnahmeseitige Defizite auf dezentraler Ebene. ${ }^{448}$ Zum dritten enstehen vertikale fiskalische Ungleichgewichte auch ausgehend von einer Situation, in welcher zunächst eine ausgewogene Balance zwischen den Ausgabeverpflichtungen und verfügbaren Einnahmequellen der einzelnen Ebenen des föderativen Staates zu konstatieren ist. Hierfür können bei gegebener Aufgabenverteilung zwei dynamische Entwicklungen verantwortlich sein: zum einen die heterogene Veränderung der Ausgabenintensität der Aufgabenerfüllung, die den Finanzbedarf der einzelnen Ebenen verschiebt; zum anderen das Auftreten unterschiedlicher Wachstumsraten der Steuereinnahmen, die die Finanzkraft der einzelnen Ebenen verändern. In beiden Fällen gerät die Relation zwischen Finanzkraft und -bedarf der gebietskörperschaftichen Ebenen im Zeitablauf aus dem Gleichgewicht. ${ }^{449}$

Da die Zielsetzung der FZ-Vergabe ausschließlich die Umverteilung von Steuereinnahmen zwischen zwei Ebenen des föderativen Staates ist, hat die Ausgestaltung der FZ stets als Pauschalzuweisung zu erfolgen. ${ }^{450}$ Eine Verhaltenslenkung bei den Transferempfängern ist nicht bezweckt. Insbesondere sollen keine differenzierenden horizontalen Wirkungen auf der transferempfangenden Ebene ausgelöst werden. Das Volumen der FZ ist betraglich so zu beschränken, daß der erwünschte Ausgleich des vertikalen fiskalischen Ungleichgewichts realisiert wird. ${ }^{451}$

${ }^{447}$ Es ist jedoch wissenschaftlich umstritten, ob die Steuerkonkurrenz zwischen dezentralen GKS positiv oder negativ zu bewerten ist (vgl. zu dieser Diskussion bspw. Groenewegen (1988); ACIR (1991)). Darüber hinaus besteht neben der Zentralisierung der Steuerarten auch die Möglichkeit, die Steuerkonkurrenz durch die Harmonisierung der Besteuerung abzumildern (vgl. bspw. Spahn (1993a) u. (1993b)).

448 Vgl. bspw. Break (1980), S. 80; King (1984), S. 138 f.; auch Oates (1990), S. 46 ff.

449 Vgl. Break (1980), S. 82 f.; Smekal (1980), S. 195. Hier zeigt sich, daß der Ausgleich vertikaler fiskalischer Ungleichgewichte eine Daueraufgabe darstellt, „da ein einmal erreichtes Gleichgewicht praktisch immer zu Instabilitäten neigt." (Gläser (1981), S. 183)

${ }_{450}$ Vgl. Costello (1993a), S. 113; auch Oates (1990), S. $46 \mathrm{ff}$.

${ }^{451}$ Bei der Bestimmung der Höhe der FZ sowie der angemessenen Verteilung der FZ auf die einzelnen GKS der transferempfangenden föderativen Ebene bestehen jedoch erhebliche Meß- und Abgrenzungsprobleme (vgl. Buchanan (1970), S. 440 f.; auch Smekal (1980), S. 195 u. 196). 
III-3.1.2.2 Horizontale fiskalische Ungleichgewichte

III-3.1.2.2.1 Von der fiskalischen Gleichheit zwischen Individuen zur fiskalischen Gleichheit zwischen Gebietskörperschaften

Bestehen zwischen den GKS einer Ebene des föderativen Staates Unterschiede in der Relation von Finanzkraft und Finanzbedarf, so wird die Realisierung eines vorgegebenen öffentlichen Leistungsangebots $\mathrm{zu}$ unterschiedlichen individuellen Steuerbelastungen in den einzelnen GKS führen, bzw. wird sich bei gleicher individueller Steuerbelastung ein divergierendes öffentliches Leistungsangebot einstellen. Dies wirft die Frage der horizontalen Gerechtigkeit auf. Durch den Ausgleich von Finanzbedarf und Finanzkraft können die räumlichen Ungleichgewichte beseitigt und so die fiskalische Gleichheit („fiscal equity”) zwischen den GKS verwirklicht werden. ${ }^{452}$ Das Konzept der fiskalischen Gleichheit wird jedoch nicht einheitlich interpretiert. Es wird entweder auf einzelne Individuen oder auf einzelne GKS einer föderativen Ebene bezogen.

Buchanan ${ }^{453}$ überträgt den Grundsatz der horizontalen Gerechtigkeit in der Besteuerung, wonach alle Individuen, die sich in gleichen ökonomischen Verhältnissen befinden, einer gleichen steuerlichen Belastung unterliegen sollen, auf den Bereich der öffentlichen Leistungsbereitstellung. Demnach gilt die fiskalische Gleichheit als realisiert, sofern alle Individuen, die gleichen ökonomischen Verhältnissen unterliegen, einen einheitlichen fiskalischen Restwert („fiscal residiuum”) aufweisen, unabhängig davon, in welcher GKS des föderativen Staates sich ihr Wohnort befindet. Dabei ergibt sich der fiskalische Restwert als Differenz aus der Steuerlast, die ein Individuum tragen muß, und dem ihm aus der Staatsausgabentätigkeit zufließenden Nutzen. Bestehende Unterschiede in den fikalischen Restwerten zwischen Wirtschaftssubjekten in gleichen ökonomischen Verhältnissen sollen durch eine räumlich diskriminierende Einkommensteuer, die auf zentraler Ebene erhoben wird, beseitigt werden.

Eine kritische Betrachtung dieses Lösungsansatzes zeigt aber, daß er in der Realität kaum praktikabel ist. Denn der Einführung einer räumlich differenzierenden Einkommensteuer stehen erhebliche verfassungsrechtliche und politische Hindernisse gegenüber. Zudem stellt sich den Entscheidungsträgern ein praktisch unlösbares Nutzenbewertungsproblem: um die Kon-

\footnotetext{
452 Die Überlegungen gehen wesentlich auf Buchanan (1950) zurück. Sie wurden danach immer wieder z.T. sehr kritisch diskutiert, so bspw. bei Musgrave (1961), insb. S. $117 \mathrm{ff}$. u. Scott (1964). Vgl. darüber hinaus in jüngerer Zeit Fischer (1988), S. 78 ff.; Peffekoven (1988), S. 627 ff. oder Walthes (1996), S. 233 ff.

453 Vgl. Buchanan (1950); auch Oates (1972), S. 83 f.
} 
zeption anwenden zu können, müßte der Nutzen, der jedem Individuum durch die Bereitstellung der (unteilbaren) öffentlichen Leistungen zufließt, bestimmbar sein. ${ }^{454}$

Wegen dieser Durchführungsschwierigkeiten wird das Konzept der fiskalischen Gleichheit zumeist auf die GKS einer föderativen Ebene bezogen. Ohne den Rückgriff auf die Nutzenpositionen der einzelnen Bewohner wird ein Ausgleich zwischen Leistungsfähigkeit und Bedürftigkeit der einzelnen GKS angestrebt, der durch zwischenstaatliche FZ realisiert wird. Diese Transfer können sowohl ökonomisch als auch politisch gerechtfertigt werden. ${ }^{455}$ Aus ökonomischer Perspektive sollen ineffiziente Wanderungsbewegungen zwischen den GKS vermieden werden, die durch die Unterschiede in dem Leistungsangebot bzw. der Steuerbelastung der GKS ausgelöst werden. ${ }^{456}$ Wanderungsbewegungen sind ineffizient, wenn in den Zuwanderungs- und Abwanderungsgebietskörperschaften externe Effekte ausgelöst werden. ${ }^{457}$ Diese bestehen darin, „daß zum einen migrationsinduzierte fiskalische Externalitäten, zum anderen Überfüllungseffekte generiert werden, so daß die privaten und sozialen Kosten der Migrationsentscheidungen auseinanderfallen."458

Die politische Forderung der Transfers begründet sich auf der Einsicht, daß „ein föderatives Staatswesen .. langfristig nur stabil sein [kann], wenn es sich auf die Zustimmung der Mehrheit der Bürger in allen Teilregionen stützen kann." ${ }^{459}$ Diese Zustimmung wird entscheidend gefördert, wenn im gesamten Staatsgebiet zumindest vergleichbare Lebensbedingungen bestehen. Daher soll - unabhängig vom ökonomischen Entwicklungspotential einer GKS - innerhalb jeder einzelnen GKS die Bereitstellung eines bestimmten Mindestversorgungsniveaus an öffentlichen Gütern bei angemessener Steuerbelastung ermöglicht werden. ${ }^{460}$

\footnotetext{
${ }^{454}$ Vgl. Smekal (1980), S. 193; Fischer (1988), S. 82; vgl. auch Abschnitt II-1, Fn 50 zur Problematik der Nutzenerfassung. Peffekoven (1988), S. 628 weist jedoch richtigerweise daraufhin, daß diese Problematik bei allen ,nutzentheoretischen Ansätzen” besteht, so bspw. auch bei der Internalisierung externer Effekte.

${ }^{455}$ So auch Fischer (1988), S. 83; Peffekoven (1988), S. 628; Walthes (1996), S. 233.

${ }^{456}$ Hier zeigt sich eine enge Verbindung zu den vertikalen fiskalischen Ungleichgewichten, die aufgrund der Zentralisierung von Steuerquellen mit sehr mobiler Steuerbasis entstehen.

${ }^{457}$ Vgl. hierzu bspw. Flatters/Henderson/Mieszkowski (1974).

${ }^{458}$ Thomas (1997), S. 70. Die migrationsinduzierten fiskalischen Externalităten entstehen dadurch, daß durch die Migration eines Bürgers in der Zuwanderungs-GKS die Pro-Kopf-Steuerbelastung zur Finanzierung eines gegebenen öffentlichen Güterangebots sinkt, wohingegen sie in der Abwanderungs-GKS ansteigt. Die Überfüllungseffekte bestehen darin, daß ein (annahmegemåß) innerhalb beider GKS bestehendes Agglomerationsoptimum verlassen wird. Beide Arten der Externalitäten bleiben von den Individuen bei ihrer Wanderungsentscheidung jedoch unberücksichtigt, woraus eine ineffiziente Bevölkerungsverteilung resultiert. Vgl. Thomas (1997), S. 68 ff.; auch Break (1980), S. 84 ff.; King (1984), S. 144 ff.

${ }^{459}$ Peffekoven (1988), S. 628.

${ }^{460}$ Vgl. Gläser (1981), S. 137 ff.; King (1984), S. 140 ff.; Peffekoven (1988), S. 628 f.
} 
Die Vergabe der FZ zur Herstellung horizontaler fiskalischer Gleichheit hat ohne Verwendungsauflagen und ohne eine Eigenbeteiligung der Transferempfänger zu erfolgen: es soll eine bestimmte Angleichung zwischen der Finanzkraft und dem Finanzbedarf der einzelnen GKS erfolgen; eine Lenkung des Verhaltens der Transferempfänger wird nicht angestrebt. ${ }^{461}$ Um die konkrete Grundlage für die Berechnung der Ausgleichszahlungen zu schaffen, muß exakt definiert werden, was unter dem Begriff fiskalischer Gleichheit zu verstehen ist. Es werden eine ganze Reihe an Ansätzen diskutiert. Allein Musgrave hat sechs unterschiedliche „pure equalization plans" als mögliche Ausgleichsmodelle vorgeschlagen. ${ }^{462}$ Einerseits bestehen Modelle, die isoliert einen reinen Finanzkraftausgleich oder einen reinen Finanzbedarfsausgleich anstreben; andererseits werden Modelle formuliert, die einen kombinierten Finanzkraft-Finanzbedarfsausgleich verfolgen. Mit Fischer kann geschlossen werden, daß bei den „reinen” Modellen stets „,nur eine Seite der Medaille betrachtet wird.” Daher können aus theoretischer Sicht nur solche Ausgleichsmodelle überzeugen, ,bei denen sowohl die Ausgabenverpflichtungen als auch die Möglichkeiten der Einnahmenbeschaffung in den Kalkül einbezogen werden. ${ }^{\not 463} \mathrm{Um}$ einen solchen Ausgleich der fiskalischen Ungleichgewichte vornehmen zu können, sind drei Aspekte zu klären. Es müssen geeignete Indikatoren zur Messung der Finanzkraft und zur Messung des Finanzbedarfs der GKS bestimmt werden. Darüber hinaus muß festgelegt werden, wie weit der Ausgleich von Finanzkraft und Finanzbedarf gehen soll (Ausgleichs- bzw. Nivellierungsintensität).

\section{III-3.1.2.2.3 Zur Bestimmung der Finanzkraft}

Mit der Finanzkraft ${ }^{464}$ sollen die Möglichkeiten einer GKS zur eigenständigen Erzielung von Einnahmen erfaßt werden. Diese Möglichkeiten kommen durch ihre Steuereinnahmen ,im großen und ganzen zutreffend zum Ausdruck." ${ }^{\text {465 }}$

\footnotetext{
${ }^{461}$ Vgl. hierzu bspw. Smekal (1980), S. 194 f.; Fischer (1984), S. 231.

${ }^{462}$ Vgl. Musgrave (1961), S. 99 ff. Die Ansätze Musgraves unterscheiden sich im Hinblick auf die Reichweite des Ausgleichs der fiskalischen Ungleichgewichte. Im einzelnen unterscheidet Musgrave die (1) Angleichung der effektiven Pro-Kopf-Ausgaben (,equalization of actual outlay”), die (2) Angleichung der Versorgung mit öffentlichen Leistungen („equalization of performance levels”), die (3) Angleichung der Unterschiede zwischen Finanzbedarf u. -kraft (,equalization in differentials in need and capacity"), die (4) Angleichung der Finanzkraft (,equalization of fiscal capacity”), die (5) Angleichung der Versorgung mit öffentlichen Leistungen pro Einheit eigener Steuereinnahmen (,equalization of performance levels per dollar of own tax revenue collected") u. die Anpassung der Versorgung mit öffentlichen Leistungen pro Einheit eigener Anstrengung (,equalization of performance levels per effort unit”). Dieser letzte Ansatz stellt das umfassendste Ausgleichskonzept dar, dem von Musgrave offensichtlich der Vorzug gegeben wird, da er dieses Konzept im Vergleich zu den anderen Ausgleichsmodellen als „a more nearly perfect equalization scheme” (Musgrave (1961), S. 109) bezeichnet.

${ }^{463}$ Fischer (1984), S. 231. So auch Gläser (1981), S. 143.

${ }^{464}$ Vgl. zu diesen Überlegungen ausführlich Gläser (1981), S. 154 ff. u. Fischer (1988), S. 97 ff.
} 
Ein sinnvoller Vergleich der Finanzkraft der GKS kann jedoch nur angestellt werden, wenn die Einnahmen der einzelnen Jurisdiktionen im Rahmen eines homogenen Steuersystems erzielt werden. Ein solches zeichnet sich v.a. durch die Einheitlichkeit des Steuerrechts und der Steuererhebungsverfahren aus. Nur wenn in den einzelnen GKS die gleichen Steuerarten erhoben werden und auch der Anspannungsgrad (,tax-effort”) der Besteuerung übereinstimmt, stellen die tatsächlichen Steuereinnahmen einen geeigneten Indikator der Finanzkraft dar. In föderativen Staaten mit Teileinheiten, die über eine hohe Einnahmeautonomie verfügen, müssen deshalb bestimmte Korrekturen vorgenommen werden, um eine homogene Bemessungsgrundlage zur Berechnung der originären Finanzkraft zu schaffen. Es sind diejenigen Faktoren der Einnahmeerzielung auszuschließen, die eigenständige Handlungsparameter der dezentralen Einheiten darstellen und deshalb auch autonom zu verantworten sind. Hierzu gehören bspw. differierende Hebesätze oder Zuschläge der einzelnen GKS zu bestimmten Steuerarten. Diese Parameter sind bei der Berechnung der Finanzkraft durch einheitliche, bzw. durchschnittliche Steuersätze zu ersetzen. ${ }^{466}$ So wird gewährleistet, „daß für jeden einzelnen Aufgabenträger eine Finanzkraft angesetzt werden kann, die sich bei durchgängig gleicher Ausschöpfung der möglichen Steuerkraft ergäbe. ${ }^{467}$

Ein weiteres Problemfeld der Finanzkraftmessung stellt die Möglichkeit des Steuerexports zwischen den GKS dar. Werden Steuerlasten auf die Bewohner anderer GKS überwälzt, so kann von den Steuereinnahmen der GKS nicht länger auf die effektive Steuerbelastung ihrer Bewohner geschlossen werden. Die tatsächlichen Steuereinnahmen der GKS sind auch in diesem Fall kein geeigneter Indikator für ihre finanzielle Leistungsfähigkeit. ${ }^{468}$

${ }^{465}$ Fischer-Menshausen (1988), S. 658. Er weist darauf hin, daß insb. im kommunalen Bereich weitere Einnahmequellen wie Gebühren, Beiträge und Vermögenseinnahmen eine wichtige Rolle spielen. Auf regionaler oder gar nationaler Ebene sei aber die aus praktischen Gründen erfolgende Beschränkung auf Steuereinnahmen zu akzeptieren (vgl. auch Lenk (1993), S. 82). Recht kritisch äußern sich zu dieser Vorgehensweise jedoch jüngste Studien zu horizontalen Ausgleichszahlungen wie Carl (1995), S. 51 ff.; Häde (1996), S. 231 f. u. Korioth (1997), S. 548 ff. Die Autoren plädieren für eine über die reine Steuerkraft hinausgehende, weite Definition der Finanzkraft.

${ }^{466}$ Diese Vorgehensweise kann es auch erfordern, daß einzelnen GKS ,nicht erzielte, aber unter bestimmten Bedingungen erzielbare Einnahmen fiktiv hinzugerechnet werden müssen.” (Kops (1989), S. 43)

467 Lenk (1993), S. 82.

${ }^{468}$ Vgl. Fischer (1984), S. 231; Peffekoven (1988), S. 632 f. Das Problemfeld des Steuerexports hat jüngst Thomas (1997) ausführlich aufgegriffen. Dort steht jedoch die Gefahr eines ineffizienten Bereitstellungsniveaus öffentlicher Güter im Mittelpunkt. Die Lösung dieser Problematik wird v.a. durch Maßnahmen der Steuerharmonisierung angestrebt. Daher bleibt dieser Aspekt als explizite Funktion der zwischenstaatlichen FZ aus der Untersuchung ausgeklammert (vgl. Thomas (1997) aber auch Andel (1983), insb. S. 316 u. 348 ff. u. Fuest (1995)). 


\section{III-3.1.2.2.4 Zur Bestimmung des Finanzbedarfs}

Die Aufgabenverteilung innerhalb des föderativen Staates stellt die Grundlage zur Bestimmung des Finanzbedarfs ${ }^{469}$ einer GKS dar. Denn der Finanzbedarf ist diejenige Einnahmenausstattung, die zur Erfüllung der einer GKS zugewiesenen Aufgaben erforderlich ist. Der Finanzbedarf einer GKS bezüglich einer spezifischen Aufgabe ist hauptsächlich von drei Komponenten abhängig: ${ }^{470}$

- dem Bedarfsumfang im Zuständigkeitsbereich der GKS, der sich durch die Nachfrage der Bewohner ausdrückt; ${ }^{471}$

- dem angestrebten Versorgungsniveau, welches die Qualität und das Ausmaß der politisch erwünschten Bedarfsdeckung festlegt ${ }^{472}$ und

- dem in der GKS bestehenden Kostenniveau zur Bereitstellung der Leistungseinheiten. ${ }^{473}$

Der gesamte Finanzbedarf einer GKS resultiert aus der Addition der Ausgabenbedarfe der einzelnen zu erfüllenden Aufgabenbereiche („originäre Ermittlung”474 des Finanzbedarfs). Diese Vorgehensweise stellt aus theoretischer Sicht das ideale Verfahren zur Berechnung des Ausgabenbedarfs dar, doch ,zeigen sich auf dem 'Prüfstand' der praktischen Anwendung .. schnell die Grenzen der Meßbarkeit." ${ }^{475}$ Die Indikatoren, die sich im Bereich der Einzelkomponenten ergeben, sind komplex und nur schwer operationalisierbar. Zumeist lassen sie eine Mehrzahl möglicher Interpretationen zu. Folglich sind politische Entscheidungen unabdingbar. „Damit stellt das vereinbarte Ausgleichsziel keine ökonomisch-rational nachprüfbare Entscheidung, sondern im wesentlichen immer einen Kompromiß dar, der den Vorstellungen und Interessen der beteiligten politischen Vertreter am nächsten kommt. ${ }^{, 476}$

Wegen dieser Schwierigkeiten bei der differenzierten Bestimmung des Finanzbedarfs, wird zumeist auf einfache Hilfsgrößen ausgewichen, um die Finanzbedarfsrelationen zwischen den

\footnotetext{
${ }^{469}$ Vgl. zum Folgenden ausführlich Seiler (1980), S. 32 ff.; Gläser (1981), S. 169 ff.; Fischer (1988), S. 112 ff. und Fischer-Menshausen (1988), S. $658 \mathrm{ff}$.

470 Vgl. Seiler (1980), S. 18 ff. u. 32 f.; auch Fischer-Menshausen (1988), S. 659 und Noll (1993), S. 90 f.

471 Als anschauliches Beispiel sei der Bedarf an Schulen innerhalb einer GKS genannt. In Abhängigkeit von der Zahl u. Altersstruktur der Kinder u. Jugendlichen - also jenen Gruppen, die Nachfrage erzeugen - ergibt sich ein abweichender Bedarf zur Bereitstellung von Schulen, Lehrmitteln und Lehrpersonal.

${ }^{472}$ Hierbei ist insb. zu entscheiden, ob ein Durchschnittsstandard, Minimalstandard oder ein Standard, der sich an einer bestimmten GKS - bspw. jener mit dem höchsten Versorgungsniveau - orientiert, angestrebt werden soll (vgl. Gläser (1981), S. 172; auch Mathews (1977), S. 424).

${ }^{473}$ Es können insb. unterschiedliche Kosten des Erwerbs von Input-Faktoren vorliegen, bspw. Lohnkostenunterschiede, die durch regionale Arbeitsmarktunterschiede ausgelösen werden (vgl. hierzu näher Gläser (1981), S. 174).

474 Zimmermann (1983), S. 48.

${ }^{475}$ Gläser (1981), S. 174. Vgl. dort auch die aufschlußreiche Analyse S. $171 \mathrm{ff}$.

${ }^{476}$ Lenk (1993), S. 83.
} 
GKS abzubilden. Ein einzelner, simplifizierender Indikator wird für alle Aufgabenkategorien herangezogen. Die am weitesten verbreitete Hilfsgröße ist die Einwohnerzahl der einzelnen GKS. Im Extremfall wird „schon auf der Anfangsstufe kein direkter Bezug zu den Ausgaben verwendet", ${ }^{477}$ sondern ganz einfach die durchschnittliche Pro-Kopf-Finanzkraft im föderativen Staat als Pro-Kopf-Finanzbedarf auf die einzelnen GKS übertragen. Der absolute Finanzbedarf einer GKS ergibt sich dann aus der Multiplikation des (simplifizierten) Pro-KopfFinanzbedarfs mit der Einwohnerzahl der GKS. ${ }^{478}$

Basierend auf dieser Finanzausstattung können nunmehr einzelne Änderungen bzw. Ergänzungen eingeführt werden. Sie verfolgen das Ziel, über die Einwohnerzahl hinaus die wichtigsten Faktoren für Finanzbedarfsunterschiede zwischen den GKS zu erfassen. Als Beispiel sei die Gewichtung der Bevölkerungszahl nach der Größe der GKS genannt. Durch die „Veredelung” der Einwohnerzahl soll der These Rechnung getragen werden, daß mit zunehmender Bevölkerungsdichte die Pro-Kopf-Ausgaben einer GKS zur Aufgabenerfüllung ansteigen. ${ }^{479}$ Allgemein wird der Versuch unternommen, Indikatoren zu entwickeln, die auf besondere Bedarfssituationen oder Sonderlasten - bspw. aufgrund demographischer, sozio-ökonomischer, wirtschaftsstruktureller oder geographisch-natürlicher Fakten ${ }^{480}$ - hinweisen und daher einen zusätzlichen Finanzbedarf spezifischer GKS rechtfertigen. ${ }^{481}$ Von entscheidender Bedeutung ist es, daß alle Mehr- oder Minderausgaben bei der öffentlichen Leistungserstellung, die von den Aufgabenträgern autonom zu verantworten sind, nicht berücksichtigt werden. Denn werden auch für diese Kosten-Faktoren ,interner Art” zusätzliche Finanzmittel gewährt, so würde den staatlichen Entscheidungsträgern ein „Anreiz zur wirtschaftlichen und sparsamen Verwendung öffentlicher Gelder genommen." „internen” und „externen” Ursachen zusätzlicher Finanzbedarfe jedoch außerordentlich problematisch. ${ }^{483}$ Wenngleich es aus theoretischer Sicht unbestritten bleibt, „daß für die Ermittlung des Finanzbedarfs ein mehrdimensionaler Index heranzuziehen ist", ${ }^{484}$ um eine möglichst

477 Zimmermann (1983), S. 49.

478 Vgl. Gläser (1981), S. 180; Peffekoven (1988), S. 631; Zimmermann/Henke (1994), S. 193; auch schon Schmölders (1965), S. 40. Diese Vorgehensweise gelangt (mit bestimmten Einschränkungen bzw. Ergänzungen) bspw. im Länderfinanzausgleich der Bundesrepublik zur Anwendung.

479 Diese Annahme geht auf Brechts „Gesetz der progressiven Parallelität von Ausgaben u. Bevölkerungsmassierung” zurück (vgl. Brecht (1932). Wenngleich empirische Untersuchungen das „Gesetz” Brechts weitgehend unterstützen, bleibt die theoretische Begründung der Aussage umstritten, so daß keine einfachen Schlußfolgerungen für einen objektiven Mehrbedarf in großen GKS abgeleitet werden können (vgl. Fischer (1988), S. 114 ff.; Andel (1992), S. 192 f.).

${ }^{480}$ Vgl. hierzu Gläser (1981), S. 173; Lenk (1993), S. 83. Eine gelungene Systematisierung möglicher Sonderbedarfe nimmt auch Peffekoven (1990) vor. Er unterscheidet Sonderbedarfe infolge externer Effekte, Strukturschwächen, Kostenunterschieden und autonomer politischer Entscheidungen.

${ }^{481}$ Vgl. zur Diskussion von Sonderbedarfen auch Kops (1989), S. 106 ff. u. Carl (1995), S. 181 ff.

482 Peffekoven (1990), S. 332.

483 Vgl. Gläser (1981), S. 174 f.; Peffekoven (1990), S. 328; Lenk (1993), S. 83 f.

484 Peffekoven (1988), S. 632. 
objektive Grundlage für FZ-Zahlungen zu schaffen, bleibt die Berechnung des Finanzbedarfs daher weitgehend eine politische Entscheidung. ${ }^{485}$

\section{III-3.1.2.2.5 Die Ausgleichsintensität}

Sind Finanzkraft und Finanzbedarf der einzelnen GKS ermittelt, kann durch die Gegenüberstellung der beiden Größen die Deckungsrelation jeder GKS bestimmt werden. Es muß dann eine politische Entscheidung darüber getroffen werden, in welchem Ausmaß die bestehenden Differenzen zwischen Finanzkraft und Finanzbedarf ausgeglichen werden sollen. ${ }^{486}$

Bei dieser Entscheidung müssen die staatlichen Verantwortungsträger eine Balance zwischen allokativen und (re)distributiven Zielen finden. Wird das distributive Ziel zur Schaffung einheitlicher Lebensbedingungen in den Vordergrund gestellt, so hat ein weitgehender Ausgleich bestehender Finanzkraft-Finanzbedarfs-Differenzen zu erfolgen, um allen Aufgabenträgern „in etwa gleiche Deckungsmöglichkeiten für einen einheitlichen Aufgabenkatalog,"487 zur Verfügung zu stellen. Das Zustandekommen einer solchen Entscheidung im politischen Entscheidungsprozeß ist Ausdruck einer ausgeprägten Solidarität zwischen den Teileinheiten des föderativen Staats. Allerdings werden gegen einen extremen Nivellierungsgrad allokative Einwände vorgebracht, da er eine hohe (marginale) Abschöpfung zusätzlicher Steuereinnahmen bei den GKS auslöst, wodurch die Anreize der dezentralen Entscheidungsträger zur eigenständigen Ausschöpfung und Pflege autonomer Einnahmequellen verringert wird. Dieser allokative Blickwinkel spricht für eine beschränkte Ausgleichsintensität. ${ }^{488}$

Darüber hinaus ist bei der Bestimmung der Ausgleichsintensität zu beachten, ob die FZ (direkt) horizontal oder vertikal (mit horizontaler Wirkung) vergeben werden. Im ersteren Fall werden die GKS mit überdurchschnittlicher originärer Deckungsrelation zu direkten Ausgleichszahlungen an die GKS mit unterdurchschnittlicher originärer Deckungsrelation herangezogen. Die konkrete Ausgestaltung der Ausgleichszahlungen muß dann gewährleisten, daß keine der ausgleichspflichtigen GKS unter die durchschnittliche Finanzkraft aller GKS sinkt. Im letzteren Fall stellt sich dieses Problem nicht. Es ist aber darauf zu achten, daß nur solche GKS FZ erhalten, die eine unterdurchschnittliche Deckungsrelation aufweisen. ${ }^{489}$

\footnotetext{
${ }^{485}$ Vgl. Fischer (1988), S. 117; Walthes (1996), S. 254.

${ }^{486}$ Diese Entscheidung bestimmt auch den Umfang der FZ. Solange die politischen Entscheidungsträger keinen maximalen Höchstbetrag vor Beginn des Ausgleichsverfahrens festlegen, ergibt sich das genaue Transfervolumen jedoch erst ex-post und die $\mathrm{FZ}$ ist als betragsmäßig unbegrenzt zu bezeichnen.

487 Fischer (1988), S. 118.

${ }^{488}$ Vgl. Peffekoven (1988), S. 633; Lenk (1993), S. 84 f. Zur kontroversen Diskussion über die empirische Relevanz der negativen Anreizwirkungen eines hohen Nivellierungsgrades vgl. Homburg (1993); (1994) u. (1997) sowie Wissenschaftlicher Beirat (1992), S. 74 f.; aber auch Ebert/Meyer (1998a); (1999).

489 Vgl. Fischer (1984), S. 231; (1988), S. 118 f. Walthes (1996), S. 255 weist richtigerweise darauf hin, „daß die ordnungspolitische Ausgestaltung des Finanzausgleichs überprüft werden muß," wenn alle GKS unabhän-
} 
Abschließend sei betont, daß „,dem horizontalen Ausgleich .. seiner Idee nach nur subsidiärer Charakter zu[kommt]. ${ }^{, 490}$ Daher sind bei lang anhaltenden oder sehr großen Differenzen in den Deckungsrelationen der einzelnen GKS, grundlegende Überlegungen zur Finanzverfassung des föderativen Staates anzustellen. Es ist zu reflektieren, ob eine Veränderung der Aufgabenverteilung bzw. der originären Einnahmeverteilung angezeigt ist, um langfristig stabile horizontale Finanzbeziehungen zwischen den GKS zu ermöglichen. ${ }^{491}$

\section{III-3.1.3 Stabilisationsfunktion}

Im Rahmen der gewählten Abgrenzung der ökonomischen Funktionen können zwischenstaatliche FZ auch zur Verfolgung der Ziele der Konjunkturstabilisierung und des Wirtschaftswachstums instrumentalisiert werden. Entsprechend der Vorgehensweise Musgraves wird eine weite Abgrenzung des Begriffs Stabilisationsfunktion zugrundegelegt, die beide Aspekte zu einer öffentlichen Funktion zusammenfaßt. ${ }^{492}$

\section{III-3.1.3.1 Ausgleich konjunktureller Schwankungen}

Nach der ökonomischen Theorie des Föderalismus liegt die Aufgabe des Ausgleichs konjunktureller Schwankungen vor allem im Verantwortungsbereich der zentralen Ebene. ${ }^{493} \mathrm{Je}-$ doch besitzt die Ausgabetätigkeit der dezentralen GKS einen erheblichen Einfluß auf den Erfolg der zentralen Stabilisierungsbemühungen. ${ }^{494}$ Daher ist die Minimalanforderung an das

gig von ihren Deckungsrelationen von vertikalen FZ profitieren. Offensichtlich liegen der FZ-Vergabe dann v.a. politische u. nicht distributive Überlegungen zugrunde (vgl. hierzu weiter unten Abschnitt III-3.2 zu den nicht-ökonomischen Funktionen der FZ).

490 Peffekoven (1988), S. 633.

491 Vgl. Peffekoven (1988), S. 633; Walthes (1996), S. 255.

${ }^{492}$ Diese Vorgehensweise entspricht auch der Struktur des bundesdeutschen „Gesetzes zur Förderung der Stabilität u. des Wachstums der Wirtschaft" aus dem Jahre 1967, in welchem neben der Stabilität des Preisniveaus, dem hohen Beschäftigungsstand und dem außenwirtschaftlichen Gleichgewicht auch ein stetiges und angemessenes Wirtschaftswachstum als Ziel der wirtschafts- u. finanzpolitischen Maßnahmen genannt wird (vgl. hierzu Möller (1969)). Auf die enge Verbindung der wachstumspolitischen Überlegungen zur Allokationsfunktion wurde bereits hingewiesen.

${ }^{493}$ Bei dezentralen Steuer- u. Ausgabenprogrammen treten gehörige Sickerverluste auf, da die dezentralen Märkte eng miteinander verknüpft sind. Aufgrund dieser Schwierigkeiten zur Durchfulhrung einer wirksamen Stabilisierungspolitik, bestehen erheblich Anreize für die dezentralen GKS, auf eine unerwünschte Strategie des „beggar-thy-neighbour” (Oates (1968), S. 10) auszuweichen (vgl. hierzu und zu weiteren Argumenten gegen eine dezentrale Zuordnung der Stabilisierungsfunktion Oates (1972), S. 3 ff.; auch Zimmermann (1983), S. 30 f.). Allerdings bestehen auch Argumente, die für eine (begrenzte) Rolle dezentraler Stabilisierungsmaßnahmen sprechen (vgl. hierzu Dye (1990) u. Gramlich (1993)).

494 Die Auswirkung des Ausgabegebarens der dezentralen GKS ist insb. deshalb so erheblich, weil die Allokationsfunktion im föderativen Staat v.a. der dezentralen Ebene zugeordnet ist. Folglich wird der Großteil aller öffentlichen Investitionen, von denen besonders starke konjunkturelle Effekte ausgelöst werden, innerhalb dieser GKS durchgefuihrt. 
Verhalten der dezentralen GKS zu stellen, durch ihr Finanzgebaren, die konjunkturpolitischen Maßnahmen der zentralen Ebene zumindest nicht zu konterkarieren. ${ }^{495}$

Um diese Forderung zu erfüllen, kann eine Verstetigung der dezentralen Einnahmen mittels der FZ-Vergabe durch die zentrale Ebene angestrebt werden. Dieser Zielsetzung wird mit einer antizyklischen Variation des Volumens der FZ genüge geleistet. Eine Zweckbindung der FZ ist nicht notwendig, ${ }^{496}$ denn die dezentralen GKS besitzen selbst „ein sehr starkes Interesse .., Beschäftigungslosigkeit so rasch als möglich zu beseitigen”, ${ }^{497}$ so daß sie die Mittel auch ohne die Beeinflussung durch die Transfergeber zieladäquat verwenden werden. Zudem würden komplexe Verwendungsauflagen den schnellen Mitteleinsatz verzögern und somit möglicherweise kontraproduktive Expansionseffekte in der folgenden Boomphase auslösen. ${ }^{498}$

Grundsätzlich bieten sich zwei Wege zu dieser Verstetigung der dezentralen Einnahmen an. Zum ersten kann eine antizyklische Variation von FZ-Programmen erfolgen, die bereits zur Verwirklichung bestimmter (nicht stabilisierungspolitischer) Zielsetzungen bestehen. In diesem Fall sind Konflikte mit den (ursprünglichen) distributiven oder allokativen Zielen nicht zu vermeiden. Zudem können sich unerwünschte Verteilungseffekte zwischen den einzelnen GKS ergeben, denn werden in einer Boomphase die FZ allgemein gekürzt, so sind hiervon insb. jene finanzschwachen Jurisdiktionen betroffen, die relative hohe FZ erhalten. Finanzstarke Jurisdiktionen hingegen, die keinen Anspruch auf redistributive FZ besitzen, müssen keine Mittelkürzungen verkraften. ${ }^{499}$

Zum zweiten können explizit zusätzliche Verstetigungszuweisungen eingeführt werden. Damit werden Zielkonflikte mit den bereits bestehenden FZ-Programmen verringert. Zudem ist positiv zu bewerten, daß die stabilisierungspolitischen Maßnahmen der zentralen Ebene transparent ausgewiesen werden. Ein erhebliches Problem ist jedoch die Verteilung der FZ auf die einzelnen GKS. Diese müßte der Zielsetzung entsprechend gegenläufig zur jeweiligen wirtschaftlichen Entwicklung in den einzelnen GKS erfolgen. Eine globale Kürzung oder Erhöhung der Verstetigungszuweisungen ist daher nur gerechtfertigt, sofern alle GKS in gleicher Weise von einem symmetrischen Konjunkturabschwung betroffen sind. Bei asymmetrischen realen Schocks, die nur einzelne GKS tangieren, hat eine differenzierte FZ-Vergabe zu erfol-

\footnotetext{
495 So bspw. Benkert (1984b), S. 96 f.; Fischer (1984), S. 232.

${ }^{496}$ Vgl. Smekal (1980), S. 199; Fischer (1984), S. 232; Kops (1984), S. 344; Fischer (1988), S. 129.

497 Smekal (1980), S. 197.

498 Vgl. Zimmermann (1983), S. 31.

499 Vgl. Smekal (1980), S. 197; Gläser (1981), S. 222 ff.; auch Fischer (1988), S. 127 f.
} 
gen. ${ }^{500}$ Allerdings sind die Verstetigungszuweisungen „durch eine Asymmetrie in ihren Wirkungen gekennzeichnet". ${ }^{501}$ Während in einer Rezession sehr wohl Anreize für zusätzliche Ausgaben geschaffen werden, können die Verstetigungs-FZ in einer Boomphase lediglich wieder abgebaut werden. Ein „Überschießen”502 der dezentralen Einnahmen kann so nicht verhindert werden. ${ }^{503}$

Eine Zweckbindung der Stabilisierungszuweisungen für öffentliche Investitionen ist sinnvoll, wenn über eine reine Verstetigung der dezentralen Einnahmen hinaus, zusätzliche Lenkungseffekte erzielt werden sollen. Zum einen, weil in diesem Ausgabenbereich besonders hohe Einkommens- und Beschäftigungseffekte ausgelöst werden. ${ }^{504}$ Zum anderen, weil die Investitionsausgaben im Vergleich zu anderen Ausgabenkategorien leicht variiert werden können, und sich daher flexibel für kurz- bis mittelfristige konjunkturelle Phänomene instrumentalisiert werden können. ${ }^{505}$ In einer längerfristigen Perspektive entstehen jedoch Konflikte mit allokativen und wachstumsorientierten Zielen. Zudem besteht die Gefahr, daß die geförderten Investitionsvorhaben mit Folgekosten und -lasten verbunden sind, die die finanziellen Handlungsspielräume der Transferempfänger in den Folgejahren einschränken. ${ }^{506}$ Neben der Zweckbindung der FZ ist eine Eigenbeteiligung angezeigt, um besonders große Wirkungen auszulösen. Jedoch hat die Wirkungsanalyse verdeutlicht, daß auch im Fall einer Zweckbindung mit Eigenbeteiligung Sickerverluste nicht ausgeschlossen sind. ${ }^{507}$ Im weiteren sind die

500 An dieser Stelle zeigt sich ein Ansatzpunkt für eine horizontale Ausgestaltung der stabilisierungspolitischen FZ. Sind asymmetrische Schocks zu konstatieren, so daß sich einzelne GKS des foderativen Staates in unterschiedlichen Phasen des Konjunkturzyklus befinden, könnten jene GKS, die sich in einer Boomphase befinden zur Leistung von horizontalen FZ an jene GKS herangezogen werden, die sich gerade in einer Rezession befinden.

501 Fischer (1984), S. 232.

${ }^{502}$ Fischer (1988), S. 130.

${ }^{503} \mathrm{Vgl}$. Smekal (1980), S. 198 f.; Fischer (1988), S. 129 ff. Die horizontale Ausgestaltung der Verstetigungszuweisungen (vgl. Fn 500 in diesem Abschnitt) bietet einen Lðsungsansatz, das „Überschießen” der dezentralen Einnahmen zu unterbinden. Denn dann erhalten die GKS in einer Boomphase nicht nur keine Verstetigungszuweisungen, sondern müssen darüber hinaus weitere Einnahmen an GKS der gleichen Ebene abtreten. Derselbe Effekt ist auch zu erzielen, wenn die GKS in einer Boomphase verpflichtet werden, einen bestimmten Anteil ihrer Einnahmen in eine Konjunkturausgleichsrulcklage einzubezahlen, aus der dann in der gleichen oder in späteren Perioden Transfers an GKS, die sich in einer Rezession befinden, geleistet werden.

${ }^{504}$ Die hohe Multiplikatorwirkung öffentlicher Investitionsausgaben betont insb. Benkert (1984b), S. 97 und plädiert für eine Zweckbindung der FZ-Vergabe. Mit Smekal (1980), S. 197 f. ist jedoch einzuwenden, daß diese Zweckbindung mit großer Wahrscheinlichkeit überflüssig ist, da die GKS, wie oben bereits ausgeführt, selbst an einer schnellen Beendigung der Rezession interessiert sind und die Mittel deshalb auch bei autonomer Verwendungsentscheidung investiv verausgaben werden.

$505 \mathrm{Vgl}$. Fischer (1988), S. 132.

506 Vgl. Smekal (1980), S. 198.

507 Es entstehen Mitnahmeeffekte, sofern Investitionsprojekte unterstützt werden, die ohnehin durchgeführt worden wären. Zudem ist nicht auszuschließen, daß die dezentralen GKS geplante Investitionsprojekte solange zurückstellen, bis aufgrund der konjunkturellen Lage FZ die Finanzierung erleichtern. Aus wachstumspolitischen Überlegungen kann dieses Verhalten jedoch kontraproduktive Auswirkungen auslösen (vgl. Fischer (1988), S. 135 f.; Walthes (1996), S. 232). 
bereits mehrfach angeführten Zielkonflikte mit der Verteilungsfunktion zu beachten. Möglicherweise werden finanzschwache GKS, die die Kofinanzierung nicht aufbringen können, völlig von der Nutzung der FZ ausgeschlossen. ${ }^{508}$

Für alle stabilisierungspolitischen FZ gilt, daß die Mittelvergabe sowohl betraglich als auch zeitlich begrenzt zu erfolgen hat, um hierdurch den Ausgleich der vorliegenden konjunkturellen Schwankung zu gewährleisten. Die Bestimmung der zieladäquaten Dauer und Höhe der FZ wird jedoch durch „sämtliche aus der Konjunkturtheorie und Wirtschaftspolitik bekannten Probleme der Diagnose, Prognose, Dosierung und Terminierung" ${ }^{509}$ erheblich erschwert. ${ }^{510}$

In einer zusammenfassenden Betrachtung aller Argumente fällt das Urteil in der Literatur hinsichtlich stabilisierungspolitischer FZ negativ aus. Die Vielzahl bestehender Zielkonflikte sowie die unsichere konjunkturpolitische Effizienz der FZ-Vergabe führen zu dieser Schlußfolgerung. Als Alternativlösung wird die konjunkturgerechtere Gestaltung der originären Aufgaben- und Einnahmenverteilung im föderativen Staat vorgeschlagen. ${ }^{511}$

\section{III-3.1.3.2 Die Beeinflussung des Wirtschaftswachstums}

Im Mittelpunkt der Konjunkturpolitik stehen Maßnahmen zur Vermeidung kurz- bis mittelfristiger Schwankungen im Auslastungsgrad der Produktionsfaktoren. Nun wird betrachtet, welche Rolle der Einsatz zwischenstaatlicher FZ im Hinblick auf das Wachstumsziel und damit auf die langfristige Steigerung der Produktionsmöglichkeiten innerhalb einer Volkswirtschaft spielen kann. Dabei rückt der Bezug zum föderativen Staat den räumlichen Aspekt ins Zentrum. Es stellt sich die Frage, ob bzw. wie die Verteilung der Produktionsfaktoren auf die einzelnen GKS beeinflußt werden kann, so daß das positive Wachstumsimpulse ausgelöst werden. $^{512}$

${ }^{508}$ Vgl. auch Noll (1983), S. 615. Fischer (1988), S. 133 sieht sogar die Gefahr eines anhaltenden Teufelskreises. Sinken die Investitionen finanzschwacher GKS aufgrund fehlender FZ, so wird dies langfristig deren Finanzkraft zusätzlich beeinträchtigen. Die Möglichkeit der GKS zur Kofinanzierung der FZ nimmt damit weiter ab. Auf diese Weise schließt sich der ,circulus vitiosus”.

${ }^{509}$ Walthes (1996), S. 232.

510 Vgl. auch Smekal (1980), S. 199; Gläser (1981), S. 221; vgl. zur Problematik der Implementierung stabilisierungspolitischer Maßnahmen bspw. Nowotny (1996), S. 609 ff.

S11 So bspw. Gläser (1981), S. 216 ff.; Fischer (1984), S. 232; Walthes (1996), S. 232.

512 Vgl. zum Folgenden Spiess (1973), S. 73 ff; Gläser (1981), S. 104 ff. u. Fischer (1988), S. 137 ff. Einen aufschlußreichen Überblick über die unterschiedlichen wachstumspolitischen Instrumente geben Ahrns/Feser (1987), S. 123 ff. Die Autoren betonen den engen wechselseitigen Zusammenhang zwischen Wachstums- u. Strukturpolitik. Denn ein beständig sektoraler wie regionaler Strukturwandel ist ,nicht nur Ergebnis, sondern auch Voraussetzung des wirtschaftlichen Wachstums." (Ahrns/Feser (1987), S. 128) Dies verdeutlicht nochmals die Verknüpfung, der an dieser Stelle angestellten Überlegungen mit der Funktion der FZ zur Beeinflussung der regionalen Wirtschaftsstruktur (vgl. Abschnitt III-3.1.1.2). 
Es sind zwei grundsätzliche Konzeptionen voneinander abzugrenzen. Der erste Ansatz verfolgt das Ziel, die freie räumliche Allokation der Produktionsfaktoren möglichst unverzerrt zur Geltung kommen zu lassen. Dahinter steht die These, „der Marktmechanismus werde grundsätzlich in der Lage sein, selbsttätig die ökonomisch richtige Allokation der Produktionsfaktoren herbeizuführen." ${ }^{\text {} 13}$ Die Vor- und Nachteile dynamischer Agglomerationsprozesse werden durch die Marktkräfte automatisch und effizient signalisiert, so daß sich ohne staatliche Interventionen eine optimale Verteilung der Produktionsfaktoren im Raum einstellt. Eine wachstumsorientierte Rolle existiert in dieser Sichtweise für zwischenstaatliche FZ nicht.

Demgegenüber stellt der zweite Ansatz die Effizienz der Marktkräfte als räumlichen Allokationsmechanismus in Frage. Demnach ergibt sich ein Handlungsbedarf zur (staatlichen) Korrektur der marktlichen Faktorallokation im Raum, um die vorhandenen Wachstumspotentiale der Volkswirtschaft zu erschließen. ${ }^{514}$ Der Argumentation in Abschnitt III-3.1.1.2 folgend ist die Einflußnahme auf die räumliche Verteilung des Angebots öffentlicher Infrastrukturleistungen als zentraler Handlungsparameter der Transfergeber zu betrachten. ${ }^{515}$

In welcher Weise diese Einflußnahme zu erfolgen hat ist abhängig von der konkreten Zielsetzung der räumlich orientierten Wachstumspolitik. ${ }^{516}$ Wird ein gleichmäßiges Wachstum im Gesamtraum des föderativen Staates angestrebt („balanced growth”), so muß die Vergabe der FZ eine angemessene Infrastrukturausstattung in allen GKS gewährleisten. Die FZ haben dann insb. die benachteiligten GKS zu unterstützen, doch wird sich insgesamt ein relativ weiter Kreis unterstützter GKS ergeben. In diesem Fall stehen „eher versorgungs- als wirklich wachstumspolitische Überlegungen im Vordergrund." 517

Wird demgegenüber ein „maximales" Wachstum im Gesamtstaat angestrebt, so sind ausschließlich diejenigen Teilräume durch die FZ-Vergabe zu unterstützen, in denen der Einsatz der Produktionsfaktoren eine besonders hohe Produktivität aufweist („unbalanced-growth”). Durch ein verbessertes Angebot öffentlicher Infrastruktureinrichtungen sollen diese Gebiete zusätzliche Produktionsfaktoren anziehen. Im Extremfall werden nur wenige regionale Wachstumskerne gefördert, in denen die höchsten Wachstumsraten zu erwarten sind.

Im Rahmen dieser Betrachtung ist jedoch die Zeitperspektive von elementarer Bedeutung. Es muß abgewogen werden, ob nur solche GKS gefördert werden sollen, die bereits zum Gegen-

\footnotetext{
\$13 Gläser (1981), S. 119.

514 Vgl. Gläser (1981), S. 107 ff.; Fischer (1988), S. 74 f.

515 So auch schon Hansmeyer (1970), S. 446.

516 Vgl. zur nachfolgenden Abgrenzung zwischen „balanced growth” und „unbalanced growth” grundlegend Hirschman (1958), S. 183 f.

${ }^{517}$ Fischer (1988), S. 138. Es entsteht die enge Verbindung zur verteilungsorientierten Regionalpolitik.
} 
wartszeitpunkt besonders hohe Grenzproduktivitäten der Produktionsfaktoren aufweisen, oder ob in einer langfristigen Entwicklungsstrategie solche GKS von FZ profitieren sollen, die momentan (noch) geringe Beiträge zum Gesamtwachstum im föderativen Staat leisten, jedoch durch besondere regionale Entwicklungspotentiale charakterisiert sind, die für die Zukunft hohe Wachstumsbeiträge versprechen. In einer solchen dynamischen Sichtweise ist es möglich, daß (langfristig) nicht die Förderung weniger Wachstumskerne (,unbalanced-growth”), sondern gerade die Förderung eines ausgewogenen Wachstums in einer Vielzahl an Teilregionen („,balanced-growth”) zu einem „maximalen” Wachstum für den Gesamtstaat führt.

Für die Ausgestaltung der FZ gelten die gleichen Schlußfolgerungen wie sie im Hinblick auf die FZ zur Beeinflussung der regionalen Wirtschaftsstruktur abgeleitet wurden. Die FZ sind zweckbunden für öffentliche Investitionsvorhaben mit einer Eigenbeteiligung der Transferempfänger zu vergeben. Allerdings sollte die investive Verwendungsauflage nicht zu restriktiv formuliert werden, so daß den dezentralen Entscheidungsträgern genügend Handlungsspielräume verbleiben, ihre überlegenen Informationen über die wachstumspolitisch sinnvollsten Investitionsprojekte in ihrer GKS auszunutzen. ${ }^{518}$ Die Vergabe der FZ ist zudem betraglich bzw. zeitlich zu begrenzen, da sie "lediglich eine 'Initialzündung' bewirken" 519 soll. Sobald eine leistungsfähige öffentliche Infrastruktur als Grundlage für eine aussichtsreiche und eigenständige Fortentwicklung der GKS verwirklicht ist, ist die Zuweisung der Finanzmittel zu beenden. ${ }^{520}$

Das entscheidende Problem der wachstumsorientierten Vergabe von FZ ist jedoch die Auswahl der förderungswürdigen GKS und damit die Festlegung der Empfangsauflagen. Es existiert kein uneingeschränkt geeigenter Indikatorenkatalog zur zuverlässigen Bestimmung derjenigen GKS, die über besondere Entwicklungs- und Wachstumspotentiale verfügen. Die Vergabe der wachstumsorientierten FZ ist daher stets mit erheblichen Unsicherheiten behaftet. In der Literatur wird aus diesem Grund ,an Stelle der mit einem großen Risiko verbundenen punktuellen Unterstützung ausgesuchter Regionen .. durchweg einer breit angelegten Investitionsförderung der Vorzug gegeben, bei der die Detailentscheidungen über die Durchführung der unterstützten Projekte bei den nachgelagerten Körperschaften verbleiben sollten." ${ }^{\text {„521 }}$

\footnotetext{
${ }^{518}$ Vgl. Fischer (1988), S. 140 f. Dieser Handlungsspielraum kann auch die grundsätzliche Frage umfassen, ob die Investitionen in Sachkapital oder in Humankapital erfolgen.

519 Gläser (1981), S. 126.

${ }^{520}$ Vgl. Spiess (1973), S. 94 f. u. 104; Gläser (1981), S. 125 f. Hiermit ist auch die Vorstellung verbunden, daß die GKS in den zukünttigen Perioden - v.a. aufgrund verbesserter Einnahmeerzielungsmöglichkeiten - autonom in der Lage sein werden, die notwendigen Folgeausgaben zu finanzieren, um den erreichten Bestand der öffentlichen Infrastruktureinrichtungen (zumindest) zu erhalten.

${ }^{521}$ Fischer (1988), S. 141; so auch Gläser (1981), S. 121 ff. u. S. 126. Vgl. auch Noll (1994), S. 122 ff.
} 
III-3.2 Die Ausgestaltung der Finanzzuweisungen im Hinblick auf nichtökonomische Funktionen

Neben den ökonomischen Zielen bestehen eine Reihe nicht-ökonomischer, insb. allgemeinbzw. staatspolitischer Ziele, deren Erreichung durch die Vergabe zwischenstaatlicher FZ verfolgt wird. In vielen Fällen verkörpern diese Funktionen sogar die wesentlichen Faktoren zur Erklärung der in föderativen Staaten bestehenden FZ-Systeme. ${ }^{522}$ Es zeigt sich jedoch, daß die betreffenden Aspekte zum Teil in sehr enger Verknüpfung zu den bereits behandelten ökonomischen Zielen stehen bzw. schon innerhalb des allgemeinen Referenzrahmens der erweiterten ökonomischen Theorie des Föderalismus (vgl. Kapitel II) und der politisch-institutionellen Erweiterungen des mikroökonomischen Grundmodells (vgl. Abschnitt III-2.3) in die Analyse eingebracht wurden. Dies rechtfertigt an dieser Stelle eine sehr knappe Erörterung.

\section{III-3.2.1 Die Aufrechterhaltung der dezentralen Organisation des Staates}

In einem föderativen Staat spricht die Beachtung der beiden eng miteinander verbundenen (staats)politischen Prinzipien der vertikalen Gewaltenteilung und des Subsidiaritätsprinzips ${ }^{523}$ dafür, die Erfüllung bestimmter Aufgaben der dezentralen Ebene zuzuordnen, obwohl die Art bzw. der Umfang der zu erfüllenden Aufgabe aus ökonomischer Sicht eine Kompetenzzentralisierung angezeigt erscheinen lassen. In dieser Situation können vertikale zwischenstaatliche FZ dazu beitragen, einen politisch angestrebten Dezentralisierungsgrad aufrecht zu erhalten. Sie ermöglichen eine weitgehende Zentralisierung der Finanzierungszuständigkeiten, ohne damit die dezentralen Aufgabenverantwortung an die zentrale Ebene abzugeben. ${ }^{524}$

Um die dezentrale Entscheidungsautonomie auf der Ausgabenseite zu garantieren, müssen die FZ zweckungebunden und „stetig und damit für die Körperschaften vorhersehbar" ${ }^{\text {,55 }}$ vergeben werden. ${ }^{526}$ Werden die FZ mit Auflagen verbunden, so wird über den einnahmeseitigen Handlungsspielraum hinaus auch der ausgabenseitige der dezentralen Organisationsstufen eingeschränkt und es ist „eine qualitative Strukturveränderung im Bereich der Aufgabenzuständigkeit und der Aufgabenentscheidung in Richtung Zentralisierung die Folge." ${ }^{\text {} 57}$ Diese Entwicklung soll aber gerade verhindert werden. Die Beurteilung, ob die Vergabe zwischen-

\footnotetext{
${ }_{522}$ Vgl. Andel (1992), S. 462; Bird (1993), S. 220; auch schon Zimmermann (1983), S. 32.

${ }^{523}$ Beide Prinzipien sind wiederum Ausfluß der erweiterten Distributionsfunktion, die innerhalb des allgemeinen Referenzrahmens eingeführt wurde.

524 Vgl. Smekal (1980), S. 202; Gläser (1981), S. 249 f. Diese Vorgehensweise entspricht der Beachtung des Prinzips der optimalen Kompetenzdifferenzierung; vgl. Abschnitt II-2.

525 Fischer (1988), S. 144.

526 Vgl. auch Korioth (1997), S. 285 u. schon Zeitel (1970), S. 14 f.

527 Smekal (1980), S. 202. Vgl. auch Fischer (1984), S. 233 f. und aktuell Meyer (1998).
} 
staatlicher FZ einen positiven Beitrag zur Aufrechterhaltung einer dezentralen Entscheidungsstruktur im föderativen Staat leisten kann, hängt daher von der konkreten Ausgestaltung der Transfers ab. ${ }^{528}$

\section{III-3.2.2 Die Beeinflussung des Verhaltens der Wähler}

FZ werden von den staatlichen Entscheidungsträgern der transfergebenden Ebene instrumentalisiert, um Wählerstimmen zu gewinnen. Auf diese zweite nicht-ökonomische Funktion der FZ wurde im Rahmen der polit-ökonomischen Erweiterung der mikroökonomischen Indifferenzkurvenanalyse bereits eingegangen. ${ }^{529}$

Die transfergewährenden politischen Akteure bemühen sich in diesem Fall durch die gezielte Vergabe der Finanzmittel, das Wahlverhalten der Bürger in den durch die Transfers begünstigten GKS zugunsten der eigenen Person oder Partei zu beeinflussen. Aus diesem Grund müssen die FZ so auf die dezentralen GKS verteilt werden, daß sie mit einem möglichst ,großen politischen Werbeeffekt" ${ }^{, 530}$ verbunden sind. Einerseits eignen sich hierfür zweckgebundene und betraglich limitierte FZ für einzelne Projekte, die entweder sichtbare Engpässe in der Versorgung mit öffentlichen Leistungen beseitigen oder die Realisierung besonders plakativer Prestigeobjekte erlauben. ${ }^{531}$ Andererseits scheint die Begünstigung einzelner Teilgruppen der Bevölkerung erfolgsversprechend, da es so gelingt, den einzelnen Betroffenen auch mit einem begrenzten Transfervolumen spürbare Vorteile zukommen zu lassen. ${ }^{532}$

Dennoch bestehen „Bedenken gegen die Wählerwirksamkeit” ${ }^{\text {"53 }}$ der FZ. Da die Begünstigung der Bevölkerung nur indirekt über die Unterstützung der dezentralen GKS erfolgt, ist fraglich, ob die Wähler die positiven Auswirkungen der Transfers überhaupt mit den politischen Akteuren der transfergebenden GKS in Verbindung setzen und dieses Wissen bei der nächsten Stimmabgabe zur Vergabe politischer Ämter zum Ausdruck bringen.

\footnotetext{
${ }^{528}$ Vgl. Smekal (1980), S. 202 f.; Gläser (1981), S. 250; Fischer (1988), S. 143 f.

529 Vgl. hierzu insb. Abschnitt III-2.3.1.2 zum Verhalten der Politiker (u. Parteien).

530 Zeitel (1970), S. 15.

531 Prestigeobjekte oder die Beseitigung von Engpässen in der Versorgung mit öffentlichen Leistungen, wie bspw. im Bereich der Verkehrsinfrastruktur, werden v.a. in verdichteten Ballungsrăumen und weniger in ländlichen Regionen eine hohe politische Werbewirksamkeit auslösen. Smekal (1980), S. 201 u. Gläser (1981), S. 248 f. sehen hierin einen wesentlicher Grund für eine „ballungsfördernde Wirkung des Finanztransfersystems." (Gläser (1981) S. 249) Denn die Transfergeber werden die höheren Werbeeffekte nutzen und die FZ bevorzugt in die Verdichtungsräume lenken.

532 Diese Teilgruppen können v.a. in sektoraler und regionaler Hinsicht gebildet werden. Vgl. Fischer (1988), S. 145.

533 Fischer (1988), S. 146.
} 


\section{III-3.2.3 Die Beeinflussung des Verhaltens der politischen Entscheidungsträger}

Die FZ können zur Förderung der Konsensbildung im politischen Entscheidungsprozeß vergeben werden. Wie beschrieben erfordert die Problemlösung im föderativen Staat in vielen Politikbereichen das gemeinsame, bzw. koordinierte Vorgehen einer Mehrzahl an staatlichen Entscheidungsträgern. In diesem Zusammenhang können FZ als monetäre Ausgleichszahlungen an diejenigen GKS geleistet werden, die als Verlierer einer aus Sicht der Gesamtheit ,effizienten" Problemlösung gesehen werden. Die FZ übernehmen eine Kompensationsfunktion, die auch die Zustimmung der „Verlierer” im Abstimmungsprozeß sichert. ${ }^{534}$

Diese FZ stehen in enger Verbindung zur erweiterten Stabilisierungsfunktion des öffentlichen Sektors. Da durch die Kompensationsleistungen die allgemeine Funktions- und Problemlösungsfähigkeit des politischen Entscheidungssystems gesteigert wird, fördern die FZ (indirekt) die Akzeptanz der politischen Entscheidungsvorgänge in der Bevölkerung und tragen so zur Stabilität nicht nur des politischen, sondern auch des gesellschaftlichen und institutionellen Systems bei. ${ }^{535}$

\section{III-3.3 Zusammenfassung - Funktionen der Finanzzuweisungen}

In den voranstehenden Abschnitten III-3.1 u. 2 wurden Schlußfolgerungen zur aufgabenadäquaten Ausgestaltung der FZ abgeleitet, um die unterschiedlichen Ziele der Zuweisungen möglichst effizient erfüllen zu können.

Die Ergebnisse zu den ökonomischen Funktionen basieren ganz wesentlich auf den Resultaten der mikroökonomischen Indifferenzkurvenanalyse des Abschnitt III-2.2. Es scheint aus diesem Blickwinkel zunächst möglich, den politischen Entscheidungsträgern eindeutige Handlungsempfehlungen zur ,zielorientierten Instrumentauswahl” geben zu können. Jedoch gestaltet sich die konkrete Umsetzung der theoretischen Erkenntnisse sehr problematisch. Es wird deutlich, daß die exakte Bestimmung der Ausgestaltungscharakteristika - bspw. der sachlich angemessenen Formulierung von Verwendungs- oder Empfangsauflagen, der korrekten Höhe von Eigenbeteiligungen oder betraglichen Begrenzungen sowie der Bestimmung der zeitlichen Limitierung - in der Realität aufgrund erheblicher Meß- und Abgrenzungsprobleme und zahlreicher Zielkonflikte kaum zu leisten ist. Trotzdem dürfen aus dieser (rein ökonomischen) Perspektive, sofern die Bewertungsprobleme nicht $z u$ hoch ausfallen, FZ-

\footnotetext{
${ }^{534}$ Vgl. hierzu Abschnitt III-2.3.2.2 zum Konsensfindungsproblem verflochtener Entscheidungssysteme. Vgl. aber auch Hackenbroch (1983), S. 35 ff.

${ }^{535}$ Vgl. hierzu auch Gläser (1981), S. $250 \mathrm{ff}$.
} 
Maßnahmen erwartet werden, die „eine hinreichende Annäherung an die theoretisch optimalen Lösungen darstellen", ${ }^{536}$ und dann insgesamt positiv einzuschätzen sind. ${ }^{537}$

Der politische Entscheidungsprozeß und seine Akteure (Abschnitt III-2.3) wurden bei den Ausgestaltungsempfehlungen in Abschnitt III-3.1 nur am Rande berücksichtigt, obwohl sie zur ökonomischen Sichtweise gehören. Welchen Einfluß die Beachtung dieser rechtlichorganisatorischen und polit-ökonomischen Aspekte auf die Handlungsempfehlungen zur effizienten Ausgestaltung der FZ nimmt, ist ,infolge nicht quantifizierbarer Bewertungsmaßstäbe im nichtmarktlichen Bereich der politischen Zielverfolgungen" ${ }^{\text {538 }}$ kaum einzuschätzen, und muß daher in jedem Einzelfall gesondert analysiert werden. Diese Faktoren werden deshalb bei der konkreten Anwendung der theoretischen Überlegungen auf die EU stärker in den Mittelpunkt gerückt.

Noch weitaus schwieriger ist es, konkrete Aussagen zur zieladäquaten Ausgestaltung und Höhe der FZ mit nicht-ökonomischer Funktion (Abschnitt III-3.2) abzuleiten. Da hier quantitativ kaum erfaßbare politisch-institutionelle Aspekte im Vordergrund stehen und zudem persönliche Bewertungsmaßstäbe die entscheidende Rolle spielen, bleibt es zum Teil sogar unklar, ob gegenüber der FZ-Vergabe aus theoretischer Sicht eine befürwortende oder ablehnende Haltung einzunehmen ist.

Schließlich ist darauf zu verweisen, daß die FZ in der Realität zumeist nicht in der hier beschriebenen reinen Form zur Erfüllung einer isolierten Funktion vergeben werden. Die Ableitung der Handlungsempfehlungen zur Ausgestaltung der FZ wird ungleich schwerer, wenn „von einer mehrfachen Zielbesetzung" ${ }^{539}$ einer FZ auszugehen ist. Doch selbst falls jede FZ stets nur ein gesondertes Einzelziel verfolgt, besteht in einem föderativen Staat eine Vielzahl unterschiedlich ausgestalteter FZ nebeneinander. Aufgrunddessen sind erhebliche Abgrenzungsschwierigkeiten und Zielkonflikte möglich, die einen Koordinationsbedarf im föderativen Entscheidungssystem begründen.

\section{III-4 Anforderungen an das (Gesamt-)System zwischenstaatlicher Finanzzuweisungen}

Die vorangehende Feststellung macht es notwendig, gesonderte Überlegungen zu den Anforderungen an das Gesamtsystem der FZ anzustellen. Die hierbei postulierten Gesichtspunkte sind als formelle und technische Aspekte zu sehen, ${ }^{540}$ denen ,der Charakter einer notwendi-

\footnotetext{
${ }^{536}$ Fischer (1988), S. 78.

537 Vgl. hierzu auch schon die Schlußfolgerungen bei Thurow (1966) zur Welt des Zweitbesten.

538 Smekal (1980), S. 203.

539 Smekal (1980), S. 203.

540 Vgl. Spiess (1973), S. 8 f.; Lenk (1993), S. 222 f.
} 
gen, aber nicht hinreichenden Bedingung für die Effizienz" ${ }^{\text {541 }}$ des FZ-Systems zukommt. ${ }^{542}$ Aufbauend auf die Wirkungsanalyse und die Bestimmung der aufgabenadäquaten Ausgestaltung der einzelnen FZ werden zusätzliche Einzelforderungen an das Gesamtsystem gestellt, die sich zum Teil aber überschneiden oder im Zielkonflikt zueinander stehen. ${ }^{543}$

\section{III-4.1 Widerspruchsfreiheit und Vollständigkeit}

Abschnitt III-3 hat die Vielzahl der möglichen Funktionen der FZ deutlich gemacht. Um den verschiedenen Zielsetzungen gerecht werden zu können, bedarf es einer Reihe unterschiedlich ausgestalteter FZ. ${ }^{544}$ Daher verkörpert die Frage der "Systemhaftigkeit” ${ }^{545}$ der Vielzahl nebeneinander bestehenden Regelungen den zentralen Ausgangspunkt zur Beurteilung des Gesamtsystems der FZ. ${ }^{546}$ Die Überlegungen konzentrieren sich auf das Zusammenwirken der einzelnen Bestimmungen im Hinblick auf deren Widerspruchsfreiheit und Vollständigkeit. Diese interne Konsistenz der Einzelnormen umfaßt zwei wesentliche Aspekte: ${ }^{547}$

- Es muß ausgeschlossen werden, daß einzelne FZ neutralisierende oder sogar konterkarierende Wirkungen auf die Zielerreichung im Bereich anderer FZ-Programme auslösen. Daher müssen sachliche Überschneidungen zwischen FZ nach Möglichkeit unterbunden werden. Zugleich ist aber auch die Doppel- oder Mehrfachförderung eines ausgewählten Sachbereichs oder Projekts durch eine Reihe analog ausgestalteter FZ-Programme zu vermeiden. Hierdurch würde die Transparenz $z^{548}$ des Zuweisungssystems beeinträchtigt und zudem die Gefahr ungewollter Überkapazitäten im geförderten Sachbereich heraufbeschworen. ${ }^{549}$

541 Fischer (1988), S. 148.

${ }^{542} \mathrm{Die}$ Überlegungen erfolgen in enger Analogie zu den Anforderungen, die an ein rationales Steuersystem insb. in steuerrechtlicher u. steuertechnischer Hinsicht - gestellt werden; vgl. hierzu grundlegend Neumark (1970) u. Haller (1981); auch Franke (1993), S. 61 ff. Mit Bezug zu den FZ fuihrte diese Vorgehensweise zuerst Gläser (1981), S. 254 ff. vor.

${ }^{543}$ Es zeigt sich zudem, daß die Gesichtspunkte oft auch auf einzelne FZ-Programme bezogen werden können.

544 So auch schon Thurow (1966), S. 376.

545 Gläser (1981), S. 254.

546 Smekal weist in diesem Zusammenhang prägnant auf den eigentlichen Kern dieser Problematik hin, den er als das „Phänomen eines 'Transferparadoxon”” (Smekal (1980), S. 152) bezeichnet. Es stellt sich die Frage, ob nicht gerade das Bestreben, die einzelnen FZ-Programme möglichst effizient u. genau auszugestalten, dazu führt, „daß die Transfersysteme insgesamt immer vielfältiger, unübersichtlicher, bürokratischer und unkontrollierbarer werden". (Smekal (1980), S. 152) Die Effizienz der einzelnen FZ führt dann zur scheinbar paradoxen Ineffizienz des Gesamtsystems.

${ }^{547}$ Hierbei ist zu betonen, daß nur dann von einem rationalen Gesamtsystem gesprochen werden kann, wenn die staatlichen Entscheidungsträger sich zielgerichtet, um die interne Konsistenz der einzelnen Normen bemühen. Eine zufällige Realisierung der Widerspruchsfreiheit $u$. Vollständigkeit entspricht der Anforderung an ein rationales FZ-System nicht (vgl. auch Spiess (1973), S.8).

$548 \mathrm{Vgl}$. hierzu auch weiter unten Abschnitt III-4.2.

${ }^{549}$ Vgl. hierzu Gläser (1981), S. 254; Fischer (1988), S. 148; vgl. auch Mathews (1977), S. 430 f., der verschiedene Vorschläge zur Lősung der Konflikte zwischen konterkarierenden oder kumulierenden FZ macht. 
- Es ist darauf achten, daß eine vollständige und erschöpfende Beachtung aller Funktionen erfolgt, zu deren Zweck eine bestimmte FZ-Ausgestaltungsform instrumentalisiert werden kann. Es dürfen keine Lücken im System der FZ-Vergabe bestehen bleiben. ${ }^{550}$

Es wird in Analogie zu den Anforderungen eines rationalen Steuersystems der Versuch unternommen, ein koordiniertes FZ-System aufzubauen, „das so gut als möglich abgestimmt wäre auf die mehreren, nebeneinander geltenden Zielsetzungen". ${ }^{51}$ Dieser Gestaltungsanspruch setzt ein gesichertes Wissen im Hinblick auf die komplexen Wirkungszusammenhänge $z w i-$ schen den einzelnen FZ voraus. Die mikroökonomische Wirkungsanalyse (vgl. Abschnitt III2.1) und deren kritische Erweiterungen (vgl. Abschnitt III-2.3) haben jedoch verdeutlich, daß abschließende Schlußfolgerungen nicht einmal zur zieladäquaten Ausgestaltung einzelner $\mathrm{FZ}$ möglich sind. ${ }^{552} \mathrm{Da}$ zudem stets von dem bestehenden historischen FZ-System ausgegangen werden $\mathrm{mu} \beta^{553}$ ist ein völlig konsistents rationales Gesamtsystem der FZ praktisch nicht konzipierbar. Jedoch können „durch das Aufzeigen der gröbsten Widersprüche und von Konstruktionsfehlern in den praktizierten Systemen," 554 inkrementale Schritte zu einer Verbesserung des Gesamtsystems eingeleitet werden.

\section{III-4.2 Transparenz und Praktikabilität}

Die Bestimmungen jeder einzelnen FZ aber auch des Gesamtsystems sollen ein Höchstmaß an Verständlichkeit und Durchschaubarkeit aufweisen. Dies erfordert, daß die Regelungen unter Beachtung der technischen und rechtlichen Notwendigkeiten möglichst eindeutig, allgemeinverständlich und einfach formuliert werden. ${ }^{555}$

Dieser Grundsatz gewährleistet eine effiziente und korrekte Handhabung des bestehenden Instrumentariums (Praktikabilität) durch die betroffenen staatlichen Verwaltungsstellen so-

${ }^{550}$ Vgl. Gläser (1981), S. 254; Lenk (1992), S. 12.

551 Haller (1972), S. 236.

552 Im Gegensatz zu dieser Einschätzung ist Haller optimistisch, daß es durch andauernde wissenschaftliche Analyse gelingen kann, ein rationales Gesamtsystem ,mit stets wachsender Sicherheit und Genauigkeit eruieren [zu] können." (Haller (1972), S. 238) Andere Autoren betonen hingegen, daß unabhängige politische Entscheidungen stets im erheblichen Umfang notwendig sein werden, um Zielkonflikte zu lösen und Unsicherheiten hinsichtlich der zu erwartenden ökonomischen Wirkungen einzelner FZ zu überwinden. Vgl. bspw. Lenk (1993), S. 220; auch Fischer (1988), S. 149; mit Bezug zum bundesdeutschen Finanzausgleich akzentuieren diesen Aspekt Buhl/Pfingsten (1986).

553 Vgl. wiederum Haller (1972), S. 237 u. 276. Es kann eben in der Realität kein FZ-System ,auf dem Reißbrett" entworfen werden.

554 Fischer (1988), S. 149.

555 Vgl. bspw. Gläser (1981), S. 255; Taube (1990), S. 374; Hüther (1993), S. 44. 
wohl auf der Transfergeber- als auch der Transferempfängerseite „ohne komplizierte und damit (kosten-)aufwendige Verfahrensprozeduren". 556

Zudem erleichtert es diese Norm allen von den Regelungen direkt oder indirekt Betroffenen, sich über die Folgen der FZ-Vergabe ausreichend zu informieren. Dies ist im politischen Bereich von Bedeutung, wo sich die staatlichen Akteure aufgrund der Transparenz des Transfersystems bei vertretbarem Aufwand einen hohen Informationsstand im Hinblick auf das bestehende Regelungsgeflecht aneignen können und so eine problemgerechte Entscheidung treffen können. Es wird so ausgeschlossen, daß einzelne GKS aufgrund bestehender Informationsdefizite oder -asymmetrien bei der Transfervergabe besondere Bevorteilungen erreichen können oder Benachteiligungen hinnehmen müssen. ${ }^{557}$ Eine hohe Transparenz der Regelungen begünstigt außerdem „eine gezielte Meinungsbildung und sachbezogene Auseinandersetzung" der Bevölkerung, die als eine entscheidende Voraussetzung für die Kontrolle der politischen Verantwortlichen anzusehen sind. Die Gefahr willkürlicher oder unbegründeter Entscheidungen durch die staatlichen Entscheidungsträger wird so verringert. Darüber hinaus steigt die Akzeptanz des FZ-Systems bei den Betroffenen, wenn sie die Regelungen inhaltlich verstehen. Daher erhöht die Transparenz und die Praktikabilität des Gesamtsystems die Wahrscheinlichkeit, einen (breiten) Konsens zur Vergabe der FZ zu finden. ${ }^{559}$ Dieser Konsens wiederum kann einen wesentlichen Beitrag dazu leisten, daß im Rahmen des politischen Entscheidungsprozesses ein ausreichendes Transfervolumen für das Gesamtsystem der FZ durchsetzbar wird. ${ }^{560}$

\section{III-4.3 Minimierung des Verwaltungsaufwandes}

Selbst wenn differenzierende FZ-Regelungen sachlich geboten sind, muß geprüft werden, ob mit dem FZ-System nicht ,unangemessen hohe Aufwendungen an personellen und sachlichen

556 Gläser (1981), S. 256.

557 Vgl. hierzu Lehner (1971), S. 50; Gläser (1981), S. 256.

558 Lenk (1992), S. 16.

559 Vgl. Lenk (1992), S. 15 f.; (1993), S. 231 f. Eine andere Meinung vertritt allerdings Walthes (1996), S. 323, der darauf hinweist, daß gerade eine zunehmende Intransparenz der Regelungen erwinscht sein kann, um die politische Konsensfähigkeit der FZ-Regelungen zu erhöhen. Letztendlich sind hier die im Einzelfall bestehenden Interessenkonstellationen und subjektiven Interaktionsorientierungen von ausschlaggebender Bedeutung, welcher Blickwinkel als zutreffend zu bezeichnen ist; vgl. in diesem Zusammenhang die Ausfuhrungen zur Informationsstrategie und zur Durchsetzungsstrategie in Abschnitt III-2.3.2.2.3.

${ }^{560}$ In Analogie zum Besteuerungsgrundsatz der Ausreichendheit der Steuererträge wird hier für das FZ-System der Grundsatz der Ausreichendheit des Transfervolumens angesprochen. Ansich müßte dieser Grundsatz nicht gesondert diskutiert werden, da die Norm bereits im Hinblick auf jedes einzelne FZ-Programm erfullt sein muß, um die Funktion der FZ-Vergabe erfullen zu können. Hier wird allerdings argumentiert, daß die Transparenz des Gesamtsystems die Akzeptanz der Bevölkerung für die Regelungen im allgemeinen erhöhen kann, unabhängig von der konkreten Funktion eines FZ-Programms. Daher entsteht eine Wechselwirkung zwischen dem Gesamtsystem und den einzelnen Funktionen der FZ, die bislang nicht beachtet wurde. 
Ressourcen" bern zur Einrichtung, Durchführung und Kontrolle der FZ und bei den Transferempfängern zur Beantragung und Verausgabung der Mittel. Es zeigt sich eine enge Verbindung zur Forderung nach Transparenz und Praktikabilität des Gesamtsystems. ${ }^{562}$

Zur Minimierung des Verwaltungsaufwandes wird häufig der Übergang von auflagengebundenen FZ zu ungebundenen Pauschalzuweisungen gefordert, da so eine Zusammenlegung zahlreicher Einzelprogramme ermöglicht und folglich der Verwaltungsaufwand des Gesamtsystems reduziert würde. Es besteht ein Zielkonflikt. Im Zweifelsfalle ist aber wohl der Verwaltungsaufwand bzw. die Kostengünstigkeit als das im Vergleich zur sachlichen Problemlösung nachgelagerte Entscheidungskriterium zu betrachten. ${ }^{563}$ „Solange die FZ ... zur Verfolgung allokations- und distributions-, und unter Umständen sogar stabilisationspolitischer Ziele eingesetzt werden sollen, kann [daher] eine grundlegende Vereinfachung des Systems kaum erwartet werden." 564

Es bleibt aber „quasi als Minimalanforderung" ${ }^{565}$ die Forderung bestehen, alle vermeidbaren Verwaltungskosten abzustellen. Dies impliziert die Zusammenlegung der Verwaltung einzelner FZ-Programme, dort wo sich im administrativen Bereich Skalenerträge realisieren lassen und zugleich die effiziente sachliche Problemlösung durch die Konsolidierung der Verwaltungsabläufe nicht beeinträchtigt wird. ${ }^{566}$

\section{III-4.4 Stetigkeit und Flexibilität}

Der Grundsatz der Stetigkeit fordert eine im Zeitablauf kontinuierliche Ausgestaltung der Bestimmungen des FZ-Systems. Daher sind „kurzfristige und kurzatmige Gelegenheits- und Stückwerksregelungen", 567 die bspw. durch wahltaktischen Aktionismus ausgelöst werden, zu unterbinden. Diese Norm soll die Entstehung von Intransparenz, Impraktikabilitäten und Widersprüchlichkeiten im Gesamtsystem der FZ verhindern. Eine beständige, unvorhersehbare und unsystematische Veränderung einzelner FZ-Regelungen würde für alle direkt und indirekt Betroffenen erhebliche Anpassungslasten auslösen (zunehmende Intransparenz). Vor allem die Administrationen der Transfergeber und -empfänger müßten einen hohen Verwaltungs-

\footnotetext{
${ }^{561}$ Gläser (1981), S. 257.

${ }^{562}$ Zugleich verdeutlicht sich hierdurch eine Verbindung zum allgemeinen Referenzrahmen des Kapitel II. Neben der sachlichen Problemlösung (und den Präferenzkosten) sind im Rahmen einer umfassenden Analyse auch die mit der öffentlichen Leistungsbereitstellung verbundenen Ressourcenkosten zu berücksichtigen.

563 Vgl. Lenk (1993), S. 233.

${ }^{364}$ Fischer (1988), S. 149 f.

565 Fischer (1988), S. 150.

${ }^{566} \mathrm{Vgl}$. hierzu Lenk (1993), S. 233 f.

567 Gläser (1981), S. 256
} 
aufwand betreiben, um die wechselnden Bedingungen der FZ-Vergabe verstehen und umsetzen zu können (Impraktikabilität). Es wäre zudem eine fortlaufende Abstimmung der neuen Regelungen mit allen anderen FZ-Programmen durchzuführen. Im Zeitablauf ist dabei die Entstehung von Widersprüchlichkeiten im Gesamtsystem nicht auszuschließen. ${ }^{568}$

Andererseits ist jedoch gerade die Flexibilität der FZ-Regelungen erforderlich, um die Struktur des Gesamtsystems systematisch an sich fortentwickelnde ökonomische Rahmenbedingungen und sich verändernde politische Zielvorstellungen anzupassen. Diese Anforderung kann nur erfüllt werden, wenn im betrachteten föderativen Staat „effiziente” politische Entscheidungsprozesse bestehen, die ausreichende Handlungs- und Problemlösungskapazitäten bereitstellen, um zu einer sachlich adäquaten Entscheidung zu gelangen. ${ }^{569}$ Von besonderer Bedeutung ist es, daß die geforderten ,flexiblen" FZ-Bestimmungen dennoch eindeutig formuliert werden. Denn sind die Regelungen strategieanfällig, so werden anhaltende und ineffiziente politische Auseinandersetzungen zwischen (eigennützigen) Transfergebern und empfängern wahrscheinlich, in deren Verlauf alle GKS eine Verbesserung der eigenen Transferposition anstreben, ohne hierbei ökonomische Argumente zu beachten. ${ }^{570}$

\section{III-5 Rekapitulation des theoretischen Kapitels III}

Zum Abschluß dieses Kapitels III soll die analytische Vorgehensweise nochmals knapp rekapituliert werden, um dem Leser ein übersichtliches Bild des ,theoretischen Rüstzeugs" dieser Arbeit zu vermitteln (vgl. Abbildung III-13). Von zentraler Bedeutung ist die enge Verbindung zwischen dem (rein) ökonomischen Bereich und dem politischen bzw. politökonomischen Bereich:

\footnotetext{
568 Vgl. Gläser (1981), S. 256 f.; Fischer (1988), S. 150.

569 Vgl. hierzu ausfuhrlich Abschnitt III-2.3.2.

570 Am geeignetsten sind FZ-Bestimmungen, die auch die Möglichkeit gravierenderer Veränderungen bestehender Rahmenbedingungen berücksichtigen und daher ,einen künftigen Handlungsbedarf weitgehend ausschlieBen und institutionalisiert fortlaufende Verhandlungen zwischen den Beteiligten überflüssig machen." (Hüther (1993), S. 44) Vgl. auch Franke (1989), S. 73 ff. u. 75 f., der die Problematik mit Bezug zum bundesdeutschen Länderfinanzausgleich analysiert.
} 
Abb. III-13: Der theoretische Gesamtzusammenhang

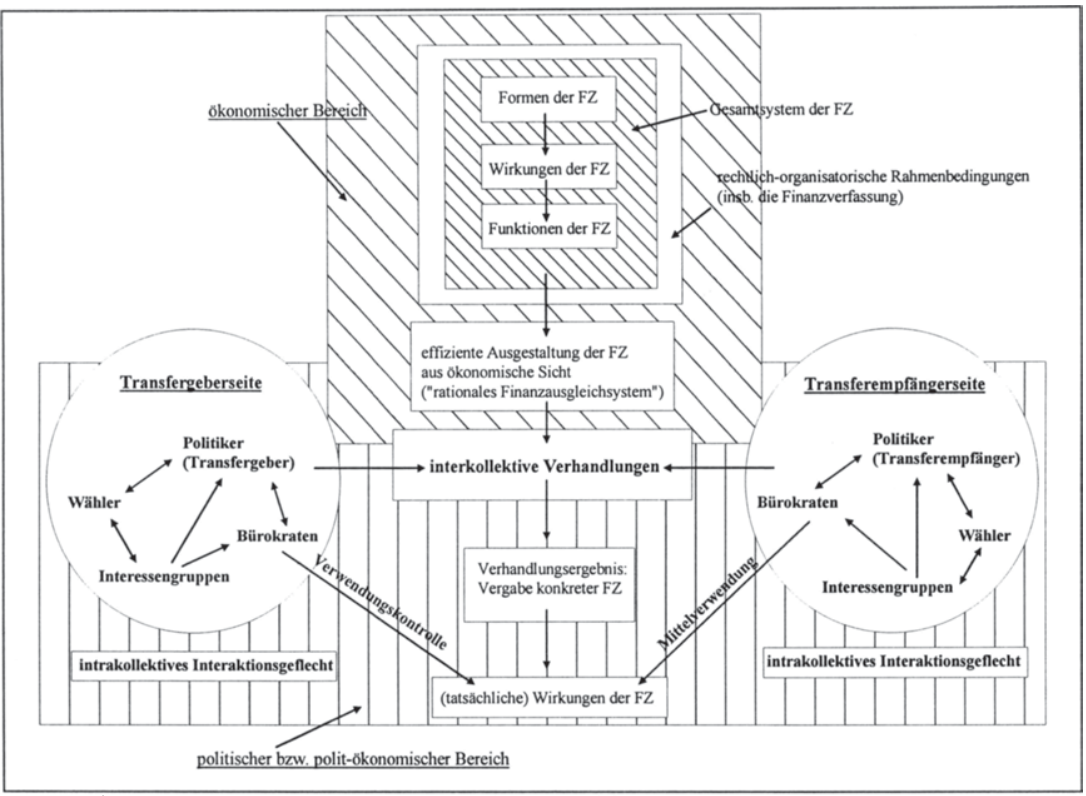

Quelle: eigene Darstellung

Die Untersuchung bezog sich zunächst auf den ökonomischen Bereich. Ohne den politischen Entscheidungsprozeß und seine Akteure explizit zu berücksichtigen wurde die effiziente Ausgestaltung zwischenstaatlicher Transfers durch eine eingehende Analyse der Formen, Wirkungen und Funktionen der FZ abgeleitet. Da insgesamt die Einrichtung eines rationalen Finanzausgleichsystems angestrebt wird, wurden Anforderungen an das Gesamtsystem der FZ formuliert. Es wurde zudem darauf verwiesen, daß konkrete Schlußfolgerungen zur sachlich effizienten Problemlösung nur gezogen werden können, wenn die Einbettung der FZ-Systems in den umfassenden rechtlich-organisatorischen Rahmen des Staates beachtet wird. ${ }^{571}$

Die Erkenntnisse zur effizienten Ausgestaltung der FZ aus rein ökonomischer Sicht wird als Entscheidungsgrundlage in den Willensbildungsprozeß des betrachteten Staates eingebracht. Daher wurde als zweiter Schwerpunkt der Untersuchung des Kapitels II die Frage in den Mittelpunkt gerückt, wie die theoretischen Schlußfolgerungen innerhalb des politischen bzw.

571 Vgl. hierzu ausführlich das nachfolgende Kapitel IV. 
polit-ökonomischen Bereichs durch die staatlichen Entscheidungsträger zu verbindlichen Entscheidungen über die Vergabe konkreter FZ „verarbeitet” werden. ${ }^{572}$

In einem verflochtenen Entscheidungssystem war deshalb auf der Transfergeber- und Transferempfängerseite das intrakollektive Interaktionsgeflecht der an der Entscheidungsfindung direkt oder indirekt beteiligten Akteursgruppen zu problematisieren. Denn die intrakollektiven Interessenskonstellationen zwischen Politikern, Wählern, Interessengruppen und Bürokraten bestimmen wesentlich das Verhalten der Entscheidungsträger bei den interkollektiven Verhandlungen zwischen Transfergebern und -empfängern und besitzen hierdurch (indirekt) einen wichtigen Einfluß auf die Vergabe der FZ.

Das Ergebnis der interkollektiven Verhandlungsprozesses hängt entscheidend von der Problemlösungsfähigkeit des verflochtenen Entscheidungssystems ab. Das letztendliche Verhandlungsergebnis wird durch die Vergabe konkreter FZ umgesetzt, deren Ausgestaltung mehr oder weniger stark von der aus (rein) ökonomischer Sicht als zieladäquat abgeleiteten Ausgestaltung abweichen kann.

Abschließend muß beachtet werden, daß die Bürokratien beider Seiten, durch die Verwendung der FZ-Mittel (Transferempfänger) bzw. die Kontrolle dieser Mittelverwendung (Transfergeber) einen wichtigen Einfluß auf die zu erwartenden Wirkungen der einzelnen FZ ausüben.

572 Die rein statische, ergebnisorientierte mikroökonomische Indifferenzkurvenanlyse wurde durch die dynamische, prozeßorientierte Analyse des Willensbildungsprozesses ergänzt. 


\section{Zielsystem und Rahmenbedingungen eines rationalen Finanzaus- gleichsystems in der zusammenwachsenden EU}

Im Mittelpunkt dieses Kapitels IV stehen das globale Zielsystem sowie die rechtlichorganisatorischen, ökonomischen und politischen Rahmenbedingungen des europäischen Einigungsprozesses. Die Untersuchungen verdeutlichen die grundlegenden Strukturen, in die ein rationales Finanzausgleichsystem auf der Ebene der EU eingebettet werden muß. So entsteht ein Brückenschlag von den voranstehenden Kapiteln II und III zum nachfolgenden Kapitel V. Über das „theoretische Rüstzeug” hinaus wird nun das „praktische (empirische) Rüstzeug” bereitgestellt, um ein rationales Finanzausgleichsystem für die EU ableiten zu können.

Zunächst werden die Ziele der EU betrachtet (Abschnitt IV-1). Das Maastrichter Vertragswerk stellt dabei einen geeigneten Fixpunkt dar, anhand dessen die globalen Ziele des europäischen Integrationsprozesses deduziert (Abschnitte IV-1.1 bis 1.4) und anschließend in ihrer Bedeutung für ein Finanzausgleichsystem bewertet werden können (Abschnitt IV-1.5). Anschließend wird die Entwicklung der institutionellen Struktur der EU beschrieben (Abschnitte IV2.1 u. 2.2). Dieser Prozeß erhält vor dem Hintergrund des momentanen Integrationsstandes der EU (vgl. Abschnitt IV-2.3) eine besondere Relevanz. Die strukturellen Gesamtzusammenhänge, die sich aus den angestellten Überlegungen ergeben, erlauben es schließlich, Problembereiche und Konfliktfelder der institutionellen Struktur der zusammenwachsenden EU abzuleiten, die herausragende Wichtigkeit bei der Vergabe zwischenstaatlicher FZ besitzen (Abschnitt IV-2.4).

\section{IV-1 Das Zielsystem der EU im Spiegel der rechtlichen Grundlagen der Integration}

Die Grundlegung für den europäischen Integrationprozeß geht zurück auf drei zwischenstaatliche Abkommen, die in den 50er Jahren getroffen wurden. Die Unterzeichnung des Vertrages zur Gründung der Europäische Gemeinschaft für Kohle und Stahl (EGKS) 1951 sowie der Verträge zur Gründung der Europäischen Wirtschaftsgemeinschaft (EWG) und der Europäischen Atomgemeinschaft (EAG) 1957 bildet den Ausgangspunkt des Einigungsprozesses auf dem europäischen Kontinent. ${ }^{573}$ Seitdem wurden die Verträge beständig ergänzt und erneuert, um sie den wandelnden Zielvorstellungen und Rahmenbedingungen des Integrationsprozesses anzupassen. Diese Modifikationen sind eine unabdingbare Voraussetzung für die Stabilität des Integrationsprozesses. Nicht die Erhaltung überkommener Strukturen, sondern die stete Wei-

\footnotetext{
${ }^{573} \mathrm{Vgl}$. zur Entstehung und Weiterentwicklung des europăischen Integrationsprozesses Hrbek (1993).
} 
terentwicklung der bestehenden rechtlich-organisatorischen Rahmenbedingungen ermöglicht eine dynamische Stabilität des Systems der EU und schafft eine „stabile föderale Balance” zwischen den gebietskörperschaftlichen Ebenen. ${ }^{575}$ So erfolgte mit der Einheitlichen Europäischen Akte (EEA) ${ }^{576} 1987$ ein entscheidender Schritt im Hinblick auf eine zukunftsfähige institutionelle Struktur der EG sowie eine politische Zusammenarbeit der Mitgliedstaaten. Den vorläufigen Höhepunkt des Integrationsprozesses stellt der Vertrag über die Europäische Union (EUV) ${ }^{577}$ (1993) dar. Er hat umfassende Ergänzungen, Erweiterungen und Erneuerungen sowohl der Römischen Verträge als auch der EEA zum Inhalt. ${ }^{578}$

Der EUV ist das Resultat einjähriger Regierungsverhandlungen der Mitgliedstaaten zu Fragen einer europäischen Wirtschafts- und Währungsunion (WWU) sowie Politischen Union. Der Vertragsabschluß beinhaltet in einer vergangenheitsbezogenen Sichtweise den (rechtlichen) Abschluß einer langdauernden Phase politischer wie ökonomischer Integrationbemühungen und in einer zukunftsbezogenen Sichtweise die Fixierung der gemeinschaftlichen Vorstellungen zur Weiterentwicklung des Integrationsprozesses im Rahmen eines mittel- bis langfristigen Zeithorizonts. ${ }^{579}$ Dabei bleiben die globalen Ziele der EU, wie sie im Maastrichter Vertrag festgelegt wurden, bei der weiteren Entwicklung des Integrationsprozesses von Reformüberlegungen ausgeschlossen. So war es zwar die Aufgabe der MaastrichtFolgekonferenz von 1996/97, unter Beachtung der seit der Unterzeichnung des Maastrichter Vertrages gewonnenen Erfahrungen über notwendige Schritte zur Revision der Vertragsbestimmungen zu beschließen, jedoch ausdrücklich ,in Übereinstimmung mit den Zielen der

${ }^{574}$ Scharpf(1991), S. 415.

${ }^{575}$ Vgl. auch Bieber (1991), S. 411.

${ }^{576}$ Vgl. zu den Bestimmungen u. der Bedeutung der EEA Hrbek/Läufer (1986); Läufer (1994a).

577 Der EUV wird auch als Maastricht-Vertrag bezeichnet. Im Folgenden wird mit Bezug zu dem Zusammenschluß der Mitgliedstaaten stets die Begrifflichkeit Europäische Union $(E U)$ verwendet. Aus Gründen der Übersichtlichkeit wird auf die Differenzierung verzichtet, mit Bezug zu einem Untersuchungszeitraum vor dem 1 . November 1993 von der $E G$ und nach dem 1 . November 1993 von der $E U$ zu sprechen.

${ }^{578}$ So auch Leipold (1994a), S. 3. Diese Aussage bleibt bestehen, obgleich am 2. Oktober 1997 der Vertrag von Amsterdam unterzeichnet wurde. Denn der Vertrag von Amsterdam ,ist kein so grundlegend neues Vertragswerk wie der Maastricht-Vertrag." (Thiel (1997), S. 7) Es erfolgt lediglich in verschiedenen Punkten eine Ergänzung sowie Konsolidierung des Vertragswerks von Maastricht. Nachfolgend wird auf jene neuen Vertragsbestimmungen eingegangen, sofern sie von Relevanz für die Themenstellung dieser Arbeit sind. Die Angaben zu den Vertragsartikeln beziehen sich, sofern kein gesonderter Hinweis erfolgt, auf die nichtkonsolidierte Fassung der Maastrichter-Verträge. Vgl. zum Vertrag von Amsterdam o.V. (1997), Läufer (1998) sowie den Kommentar von Thiel (1997). Eine erste weitergehende Bewertung des Vertrags nehmen in einem Zeitgespräch Brok (1997), Hrbek (1997b), Bulmer/Burch (1997) und Wolter/Hasse (1997) vor.

579 Dieser Zeithorizont erhält einen konkreten Bezug durch Art. N (2) des EUV. Bereits dort wird eine Konferenz der Vertreter der Regierungen der Mitgliedstaaten, die 1996 und 1997 in Amsterdam als sogenannte "Maastricht Folgekonferenz" stattgefunden hat, verbindlich vorgeschrieben, um die Problemadäquanz der Bestimmungen des EUV zur Erreichung der Ziele der Union zu überprüfen. Vgl. zur Schaffung der WWU den umfassend kommentierten Dokumentenband von KrägenauWetter (1993). 
Artikel A [Grundlage und Aufgabe der Union] und B [Ziele der Union]" ges. $^{581}$

Aufgrund dieser strategischen Bedeutung können die Bestimmungen des Maastrichter Vertragswerkes als geeigneter Referenzrahmen zur Explikation derjenigen gemeinschaftsweiten Ziele herangezogen werden, die auch in den folgenden Abschnitten dieser Arbeit der Ableitung eines rationalen Finanzausgleichsystems zugrundegelegt werden. Zwei Aspekte stehen im Vordergrund der Analyse ökonomischer Zielsetzungen der EU:

- Zum ersten werden das Maastrichter-Vertragswerk daraufhin untersucht, ob es ein sinnvoll strukturiertes Zielsystem enthält. Je detaillierter auch nachgeordnete wirtschaftspolitische Zielebenen durch den EUV bestimmt werden, desto stärker werden nicht nur die ökonomischen Ziele, sondern zugleich auch die Instrumente, die zur Zielerreichung eingesetzt werden ,dürfen”, durch den institutionellen Rahmen vorbestimmt. ${ }^{582}$

- Zum zweiten ist solchen Zielformulierungen des Vertragswerkes eine besondere Beachtung zu schenken, die nur einen geringen Bestimmtheitsgrad besitzen. Solche Normen vermitteln keine empirisch gehaltvolle Formulierung des konkreten Zielinhaltes. In Anlehnung an die von Fischer-Menshausen getroffene Unterscheidung ist zu überprüfen, ob das Maastrichter-Vertragswerk in diesen Fällen reine „Leerformeln verwendet, denen selbst ein Minimum an konkretisierbaren Rechtsgehalt fehlt” oder aber zielgerichtet auf „unbestimmte Rechtsbegriffe" zurückgreift, ,[die] nur den normativen Kern und die generelle Tendenz einer Vorschrift [umschreiben], aber durch Unschärfe und Mehrdeutigkeit des Ausdrucks eine Bandbreite zulässiger Interpretationen [offenhalten]." 583

Im ersteren Fall handelt es sich zumeist um allgemeine gesellschaftliche Grundwerte. Diese sind nicht operationalisierbar. Sie suggerieren aber einen (scheinbaren) Konsens aller Entscheidungsbeteiligten, da die Zielsetzungen in ihrer unverbindlichen Form stets uneingeschränkte Zustimmung finden. ${ }^{584}$ Eine Konkretisierung dieser Leerformeln enthüllt jedoch in der Regel umstrittene Entscheidungsprobleme, die im Maastrichter-Vertragswerk durch

${ }^{580}$ Art. N (2) EUV.

581 Vgl. zu den Themenschwerpunkten der Maastricht-Folgekonferenz Weidenfeld (1995); Club von Florenz (1996); Rambow (1996) sowie Grimm u.a. (1997). Die Ergebnisse der Maastricht-Folgekonferenz spiegeln sich im Vertrag von Amsterdam wider.

${ }^{582}$ Damit ergibt sich grundsätzlich folgender Zielkonflikt: nähern sich die politischen Entscheidungsträger im Rahmen der Vertragsausgestaltung auch der „Basis” der Zielpyramide, so verbessern sich ,die Möglichkeiten einer empirisch gehaltvollen Formulierung der Einzelziele” (Tuchtfeldt (1977), S. 182), wodurch eine Erfolgskontrolle der ergriffenen Politikmaßnahmen erst ermöglicht wird. Jedoch werden die vorhandenen $\mathrm{Be}-$ urteilungs,- Anpassungs- und Reaktionsspielrăume der politischen Entscheidungsträger beschnitten, da die Anzahl der Instrumente, die je nach vorliegender (wirtschafts- und gesellschaftspolitischer) Situation zur Zielerreichung eingesetzt werden könnten, institutionell beschränkt werden.

583 Fischer-Menshausen (1978), S. 136 u. 137.

${ }^{584}$ Vgl. hierzu Albers (1977), S. 125 f.; sowie Fischer-Menshausen (1978), S. 137 f. 
dilatorische Kompromißformeln unentschieden geblieben sind. Diese Kompromißformeln verdecken den bestehenden Dissens zwischen den Mitgliedstaaten. In diesen Bereichen müssen im weiteren Verlauf des Integrationsprozesses konsensfähige Lösungen und konkretere Zielformulierungen gefunden werden.

Im letzteren Fall ist es gerade intendiert, den Entscheidungsträgern durch die Formulierung der „unbestimmten Rechtsbegriffe” nur „konkretisierungs- und ergänzungsbedürftige Richtlinien” oder „allgemein anerkannte Wertmaßstäbe" 585 vorzugeben. Die Entscheidungsträger sollen weitgehende Handlungsspielräume behalten, da sich diese ,unbestimmten Rechtsbegriffe" auf Zielbereiche beziehen, ,die so geartet sind, daß sie für künftige Entwicklungen oder neue Erkenntnisse offengehalten werden müssen oder der freien politischen Auseinandersetzung, Entscheidung und Gestaltung vorbehalten bleiben sollen."586

\section{IV-1.1 Die Struktur des Vertrags über die Europäische Union (EUV)}

Das vom Europäischen Rat verabschiedete Vertragswerk umfaßt eine komplizierte Zusammenstellung unterschiedlicher Bestandteile, ${ }^{587}$ die in ihrer Gesamtheit die rechtlichen Grundlagen der europäischen Integration bilden. Die besondere Bedeutung des EUV liegt darin, daß verschiedene, sowohl sachlich (funktional) als auch zeitlich voneinander abgegrenzte, aber eng miteinander verflochtene Stränge des europäischen Integrationsprozesses in einem einheitlichen Rahmen zusammengeführt werden. Die Vertragsparteien stellen den Integrationsprozeß damit qualitativ auf ein neues Fundament, das den Orientierungspunkt für alle weiteren Integrationsschritte darstellt: ${ }^{588}$

Die komplexe Struktur der Maastrichter-Beschlüsse läßt sich anhand der einzelnen Vertragsbestandteile verdeutlichen. Es zeigt sich, daß die neugeschaffene EU auf drei „Säulen” aufbaut:

${ }^{585}$ Fischer-Menshausen (1978), S. 136.

586 Fischer-Menshausen (1978), S. 136.

587 Vgl. bspw. Wessels (1992), S. 4. Everling (1995), S. 171 meint, daß „die beklagenswert unzulängliche Redaktion des Unionsvertrages das Verständnis der Zusammenhänge weiter erschwert und die Funktion der Gemeinschaftsverträge als Verfassung weiter verdunkelt [hat]."

${ }^{588}$ Vgl. hierzu bspw. Hrbek (1992a); (1992b); Krägenau/Wetter (1993), S. 81 ff. u. Ensthaler (1995), S. $11 \mathrm{ff}$. Die Bewertung des Vertrages geht jedoch in der wissenschaftlichen Literatur weit auseinander. Wăhrend bspw. Bitterlich (1995a), S. 131 zu einer positiven Gesamtbewertung gelangt, äußert sich Wessels (1992), S. 15 kritisch: „Auch ohne den Aspekt der Erweiterung einzubeziehen, wird mit den Beschlüssen von Maastricht kein stabiler Zustand erreicht oder auch nur ein glatter Evolutionsprozeß eingeleitet. Zu einer Verfassung, insb. eines derartig weitreichenden und innovativen Charakters, brauchen die europäischen Staaten wohl mehrere Anläufe." 
- Um der Bestimmung als einheitlicher institutioneller Rahmen gerecht werden zu können, ist der EUV als „Mantelvertrag” ${ }^{589}$ angelegt. Dabei erfüllt der EUV zunächst eine Klammerfunktion, indem die einzelnen, heterogenen Elemente des Vertragswerks von einer Präambel und Gemeinsamen Bestimmungen (Titel I des Vertrages) sowie Schlußbestimmungen (Titel VII des Vertrages) eingerahmt werden. Hierin werden allgemeine Aussagen über die Ziele, Aufgaben, Struktur und das Handeln der EU getroffen, die für alle Bestandteile des gesamten Vertragswerks gleiche Gültigkeit besitzen.

- Innerhalb dieser Klammer befinden sich die verschiedenen, eigenständigen Teilelemente der Vertragstextes. Diese verdeutlichen, daß die Union durch den EUV strukturell auf drei Säulen gestellt wird:

1. Die Titel II, III und IV beinhalten die Bestimmungen zur Ergänzung und Erneuerung der drei Gründungsverträge der EG. Diese Titel bilden die erste Säule des EU. Hierbei kommt den neuen Bestimmungen des EGV eine herausragende Bedeutung zu. ${ }^{590}$ Dort werden die weiteren Integrationsschritte zur Errichtung der WWU verbindlich festgelegt und es erfolgt eine Erweiterung des EWG-Vertrags um eine Reihe wichtiger Aufgabenbereiche (Sozialpolitik, berufliche Bildung, Jugendpolitik, Kultur, Gesundheitswesen, Verbraucherschutz, Transeuropäische Netze, Industriepolitik, Kohäsion, Forschung und technologische Entwicklung, Umweltschutz und Entwicklungszusammenarbeit). Diese Säule ist Ausdruck der ökonomischen Dimension des Integrationsprozesses.

2. Zudem werden innerhalb der Klammer zwei Politikbereiche in den EUV integriert, die als die zweite und dritte Säule der EU bezeichnet werden. Titel V und VI enthalten die Bestimmungen über die Gemeinsame Außen- und Sicherheitspolitik (GASP) ${ }^{591}$ und über die künftige Zusammenarbeit in den Bereichen Justiz und Inneres (ZBJI). ${ }^{592}$ In beiden Bereichen werden bereits bestehende Formen der Zusammenarbeit der Mitgliedstaaten fortentwickelt und neue Formen der Zusammenarbeit eingeführt. Durch den EUV erfolgt so eine Stärkung der politische Dimension des Einigungsprozesses. ${ }^{593}$

589 Läufer (1993), S. 10.

590 Aus diesem Grund wird diese erste Säule nachfolgend als „EG-Säule” bezeichnet. Zudem bleiben die Untersuchungen aus diesem Grund weitgehend auf die Bestimmungen des EGV beschränkt. So auch Wessels (1996), S. 25 oder Walthes (1996), S. 58.

591 Vgl. hierzu bspw. Hrbek (1993), S. 19; Regelsberger (1994) oder Pfetsch (1997), S. 209 ff.

592 Vgl. hierzu bspw. Hrbek (1993), S. 19 f.; Leyendecker (1994) oder Borchardt (1996), S. 368 ff.

593 Dieser Schlußfolgerung widersprechen jedoch eine Reihe an Autoren. So bspw. Ensthaler (1995), S. 26 f., der den Schluß zieht, daß die Bestimmungen des EUV zur politischen Union den Integrationsprozeß keinesfalls ,auf eine neue, nach den bisherigen Entwicklungen nicht zu erwartende Schiene gehoben hat." 
- Schließlich sind dem Vertragswerk 17 Protokolle und 33 Erklärungen beigefügt, die als ranggleiche Bestandteile der Verträge anzusehen sind und folglich eine erhebliche Bedeutung bei der näheren Bestimmung der Vertragsinhalte besitzen. ${ }^{594}$

Der Aufbau der EU kann durch das Bild eines Tempels mit den drei Säulen der EG, der GASP und der ZJIP verdeutlicht werden (vgl. Abb. IV-1): $:^{595}$

Abb. IV-1: Der strukturelle Aufbau der EU aus vertraglicher Sicht

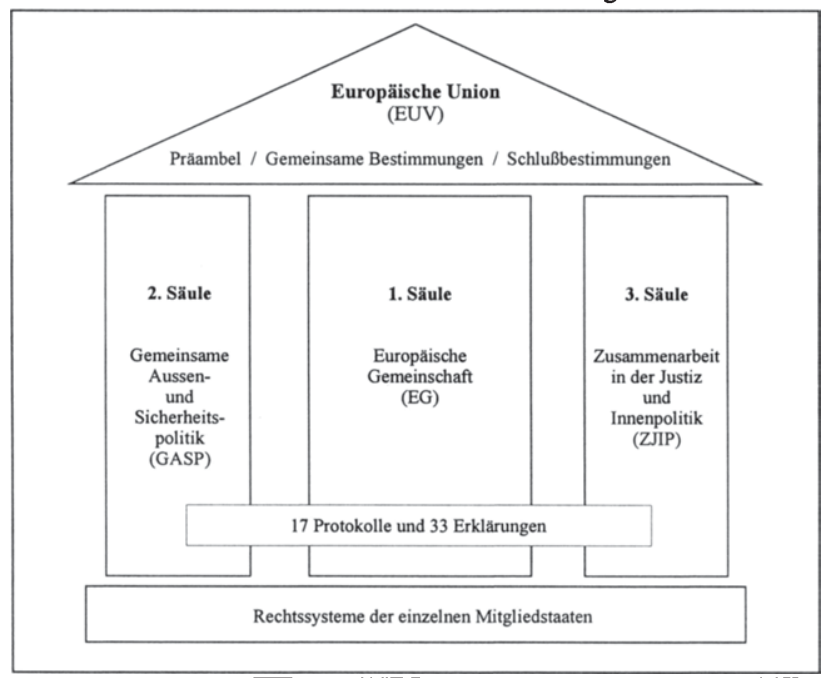

Quelle: Darstellung in Anlehnung an Ensthăler (1995), S. 13 u. Wessels (1996), S. 25.

Das allumfassende Dach des Tempels bilden die Präambel, die Gemeinsamen Bestimmungen und die Schlußbestimmungen, wohingegen die Rechtssysteme der einzelnen Mitgliedstaaten als Fundament der Konstruktion anzusehen sind. Ausgehend von den Elementen dieser Konstruktion wird anschließend der Versuch unternommen, Ziele der EU abzuleiten. Da v.a. die ökonomische Ziele für die vorliegende Arbeit von Bedeutung sind, bleiben die zweite und dritte Säule als politische Dimension der EU ausgeklammert.

$594 \mathrm{Vgl}$. hierzu auch Schönfelder/Thiel (1996), S. $145 \mathrm{f}$.

595 Dabei wird die erste Săule auch graphisch besonders hervorgehoben und an zentraler Stelle plaziert, um die besondere Bedeutung der ökonomischen Dimension im bisherigen Integrationsprozeß zu betonen. 


\section{IV-1.2 Ziele der Präambel des EUV}

Die Präambel des EUV nennt „die wesentlichen Entschlüsse, Absichten, Wünsche, Bekräftigungen und Willenserklärungen der Vertragsparteien”, wobei es sich letztendlich „nur um eine schlagwortartige Vorwegnahme späterer Vertragsteile [handelt]." ${ }^{, 596}$ Daher läßt sie keine Schlüsse über den jeweiligen Stellenwert der angesprochenen Zielsetzungen zu. ${ }^{597}$ Zudem besteht eine Reihe von Wiederholungen und Überschneidungen. ${ }^{598}$ Für den ökonomischen Bereich lassen sich aus der Präambel kaum konkrete Handlungsanweisungen ableiten.

Die Präambel rückt die gesellschaftlichen Grundwerte der Freiheit, des Friedens, der Sicherheit und des Fortschritts, die durch die „Schaffung einer immer engeren Union der Völker Europas" ${ }^{599} \mathrm{zu}$ fördern sind, in den Ziel-Mittelpunkt der EU.

\section{IV-1.3 Ziele der Gemeinsamen Bestimmungen und Schlußbestimmungen des EUV}

Die Gemeinsamen Bestimmungen des EUV wiederholen zum großen Teil die Ausfuihrungen der Präambel, jedoch in einer strukturierteren Form. Art. A weist erneut darauf hin, daß der EUV einen Schritt „bei der Verwirklichung einer immer engeren Union der Völker Europas” darstellt. Die Bezugnahme auf die „Völker Europas"600 drückt die Zielsetzung aus, die Erweiterung der EU anzustreben. ${ }^{601}$ Art. $\mathrm{O}$ bekräftigt diese Aussage, da er es grundsätzlich jedem europäischen Staat ermöglicht, einen Aufnahmeantrag zu stellen. Eine Konkretisierung der Bedeutung einer „immer engeren Union” erfolgt im Vertragswerks jedoch nicht. ${ }^{602}$

596 Walthes (1996), S. 59.

597 Über die Bezugnahme auf gesellschaftliche Grundwerte hinaus, werden auch konkretere wirtschaftspolitische Zielsetzungen, wie die „Stärkung und Konvergenz” der Volkswirtschaften der Mitgliedstaaten, die Errichtung einer „Wirtschafts- und Wăhrungsunion” und die „Verwirklichung des Binnenmarktes”, weitere Zielbereiche der $E U$, wie eine gemeinsame Außen- und Sicherheitspolitik und Bestimmungen über Justiz und Inneres, sowie allgemeine Strukturprinzipien des europäischen Integrationsprozesses, wie bspw. das Subsidiaritätsprinzip, bereits in der Präambel erstmals angesprochen. Vgl. hierzu auch die kritische Einschätzung zum Nebeneinander „unverbindlicher” und „detailreicher” Bestimmungen im EUV bei Sarrazin (1997), S. $98 \mathrm{f}$.

598 So wird bspw. an vier Stellen in unterschiedlicher Formulierung auf die „europäische Integration” als Ziel der neugegründeten $E U$ eingegangen.

599 Präambel des EUV.

600 Insbesondere in Abgrenzung zu einer Bezugnahme auf die Mitgliedstaaten der $E U$.

601 Vgl. Leipold (1994b), S. 59.

${ }^{602}$ Das Maastrichter-Vertragswerk macht keine präzisen Aussagen zur Finalität des Integrationsprozesses, da in diesbezüglich nach wie vor ein deutlicher Dissens zwischen den Mitgliedstaaten besteht (vgl. Hrbek (1992a), S. 137). Während Deutschland, aber auch Italien und die Benelux-Staaten das Leitbild eines Europäischen Bundesstaates mit primär supranationalen Entscheidungsstrukturen befürworten, stehen Frankreich und Großbritannien diesen Vorstellungen eher ablehnend gegenüber und treten für einen Europäischen Staatenbund (,Europa der Vaterländer”) mit vorwiegend intergouvernementaler Zusammenarbeit der Mitgliedstaaten ein (vgl. Janning (1994), S. 266 ff.; zur Begründung der divergierenden Standpunkte aus historischen Perspektive vgl. Schauer (1997)). Die Formulierung ,immer engere Union der Völker Europas” ist deshalb als eine unverbindliche Leerformel zu werten, die gewählt wurde, um die Zustimmung aller Mitgliedstaaten zum Vertragswerk zu sichern. Eine Präzisierung dieser elementaren Zielvorstellung ist jedoch unabdingbar, um dem ohnehin „offenen” Integrationsprozeß rational (zielgerichtet) gestalten zu können. 
Die gesamte Verlautbarung betont den dynamischen Charakter der europäischen Einigung, die auch mit der Umsetzung der Vertragsinhalte des EUV keineswegs abgeschlossen ist. ${ }^{603}$ Daher bestimmen die Art. A, B und C die grundlegenden Richtlinien und Wertmaßstäbe für das (zukünftige) Entscheidungsverhalten im Integrationsprozeß. Diese Richtlinien können als ein Komplex unbestimmter Rechtsbegriffe identifiziert werden, die bei der Entscheidungsfindung durch die verantwortlichen staatlichen Akteure im Rahmen des durch den EUV belassenen Auslegungsspielraumes inhaltlich konkretisiert werden müssen:

- Art A bestimmt „Bürgernähe”, „Kohärenz” und „Solidarität” als die maßgeblichen Strukturprinzipien für die Gestaltung der Beziehungen zwischen den Mitgliedstaaten.

- Art. B fordert darüber hinausgehend die Beachtung des „Subsidiaritätsprinzips” bei der Verfolgung aller Ziele der EU. ${ }^{604}$

- Art. C schließlich unterstreicht den Stellenwert, der der „Kontinuität” aller durch die Entscheidungsträger zur Zielerreichung gewählten Maßnahmen beigemessen wird.

Auf Basis dieser unbestimmten Rechtsbegriffe nennt Art. B der Gemeinsamen Bestimmungen die einzelnen „Ziele der Union”. Hierbei wird erneut auf die einzelnen Vertragsbestandteile des EUV Bezug genommen. Über die Ausführungen der Präambel hinausgehend wird ein Orientierungsrahmen für den Integrationsprozeß geschaffen. Die einzelnen Teilbestandteile geben jeweils ein grobes Ziel-Mittel-System vor. So wird im ökonomischen Zielbereich explizit das Ziel der „Förderung eines ausgewogenen und dauerhaften wirtschaftlichen und sozialen Fortschritts” genannt, das „durch Schaffung eines Raumes ohne Binnengrenzen, durch Stärkung des wirtschaftlichen und sozialen Zusammenhalts und durch die Errichtung einer Wirtschafts- und Währungsunion" zu verwirklichen ist.

\section{IV-1.4 Ziele des Vertrags über die Europäische Gemeinschaft (EGV)}

Der EGV bestimmt die ökonomische Dimension und damit die wirtschaftspolitischen Ziele der europäischen Integration. Dies läßt darauf schließen, daß im EGV die allgemeine Richtschnur für wirtschaftspolitische Aktivitäten („Förderung eines ausgewogenen und dauerhaften

${ }^{603}$ Hierauf weist auch Art. B (fünfter Spiegelstrich) hin, wo bereits auf die Frage der Weiterentwicklung der „Mechanismen und Organe der Gemeinschaft” im Rahmen der Maastricht-Folgekonferenz gemäß Art. N (2) der Schlußbestimmungen des EUV eingegangen wird.

${ }^{604}$ Hierbei wird direkt Bezug genommen zu Art. 3b des EG-Vertrages. Dort erfolgt eine Konkretisierung der Bedeutung des Subsidiaritätsprinzips. Vgl. hierzu weiter unten in diesem Kapitel den Abschnitt IV-2.1.1.2 sowie zur allgemeinen Bedeutung des Subsidiaritätsprinzips Abschnitt II-2. 
wirtschaftlichen und sozialen Fortschritts"), die in den Gemeinsamen Bestimmungen des EUV genannt wird, näher konkretisiert wird.

Art. 3a bestimmt ein wirtschaftspolitisches Ordnungsprinzip für die EU. Der Artikel verpflichtet die politischen Akteure, bei ihren Entscheidungen „dem Grundsatz einer offenen Marktwirtschaft mit freiem Wettbewerb” zu folgen. Dennoch bleibt es aufgrund der Ausgestaltung des gesamten Vertragswerkes umstritten, ob die EU ausschließlich auf das Ordnungsprinzip einer freien Wettbewerbswirtschaft festgelegt ist. Einige Autoren legen den Vertragstext uneingeschränkt im Sinne dieser wirtschaftspolitischen Konzeption aus und kritisieren lediglich dessen unzureichende Verankerung im Vertragswerk. ${ }^{605}$ Andere Autoren hingegen interpretieren den EUV im Sinne eines alternativen Orientierungsrahmen. So führt der ehemalige Präsident der EK Delors aus, daß das Ordnungsprinzip der EU ,in sich die Merkmale eines von Beschränkungen freien gemeinsamen Marktes mit einer Reihe von Regeln, die für ihr reibungsloses Funktionieren unerläßlich sind"606 verbinden muß. Auch der Wissenschaftliche Beirat beim Bundesministerium für Wirtschaft erkennt trotz grundsätzlich positiver Beurteilung der „Dynamik von Wettbewerbsmärkten”, daß „freie wirtschaftliche Betätigung und Wettbewerbsmärkte einer Ergänzung durch soziale Sicherheit [bedürfen]. ${ }^{, 607}$ Walthes zieht aus der wissenschaftlichen Diskussion sowie der Ausgestaltung des MaastrichterVertragswerks den Schluß, daß der Einigungsprozeß im Sinne Müller-Armacks vom „Leitbild der sozialen Marktwirtschaft geprägt wird" ${ }^{\text {608 }}$. Hierdurch wird angestrebt, „das Prinzip der Freiheit auf dem Markte mit dem des sozialen Ausgleichs" ${ }^{\text {,09 }}$ auch auf Ebene der EU zu verbinden.

Auf Basis des Art. 3a sowie des Subsidiaritätsprinzips des Art. 3b bestimmt Art. 2 des EGV ein „Zielpolygon" ${ }^{, 610}$ für die EU. Sie hat demnach zur Förderung

- einer harmonischen und ausgewogenen Entwicklung des Wirtschaftslebens innerhalb der Gemeinschaft,

- eines beständigen, nicht-inflationären und umweltverträglichen Wachstums,

\footnotetext{
${ }^{605}$ Insbesondere das neu definierte Tätigkeitsfeld zur „Stärkung der Wettbewerbsfähigkeit der Industrie der Gemeinschaft", aber auch die Einführung einer „Sozialpolitik mit einem Europäischen Sozialfonds” stimmen die Autoren nachdenklich, ob das Ordnungsprinzip tatsächlich verwirklicht werden kann. Vgl. bspw. Berthold (1993a), (1993b); Krägenau/Wetter (1995), S. 530 u. Berg/Schmidt (1997), S. 172.

606 Delors-Bericht (1989), Z. 25, S. 149. Analog äußerst sich im sogenannten „Herman Bericht” auch das EP (vgl. Europäisches Parlament (1994), S. 391).

607 Wissenschaftlicher Beirat (1994), S. 16 u. 17. Vgl. aber auch die Ausführungen zur „Wirtschaftsordnung und Marktverfassung" S. 32 ff.

${ }^{608}$ Walthes (1996), S. 65. Hervorhebung im Original.

${ }^{609}$ Müller-Armack (1956), S. 390.

${ }^{610}$ Tuchtfeldt (1977), S. 182.
} 
- eines hohen Grads an Konvergenz der Wirtschaftsleistungen,

- eines hohen Beschäftigungsniveaus,

- eines hohen Maßes an sozialem Schutz,

- der Hebung der Lebenshaltung und der Lebensqualität,

- des wirtschaftlichen und sozialen Zusammenhalts (Kohäsion) sowie

- der Solidarität zwischen den Mitgliedstaaten beizutragen.

Der Bestimmtheitsgrad dieses ökonomischen Zielbündels bleibt jedoch gering. Die zur Zielbeschreibung verwendeten Schlüsselwörter „Konvergenz” und „Kohäsion” sind der Gruppe der unbestimmten Rechtsbegriffe hinzuzufügen. Darüber hinaus wird auch an dieser Stelle des Maastrichter-Vertragswerks eine zum EUV beinahe analoge Ziel-Mittel-Relation aufgebaut. Art. 2 nennt „die Errichtung eines Gemeinsamen Marktes und einer Wirtschafts- und Währungsunion” sowie die Durchführung einer Reihe „gemeinsame[r] Politiken oder Maßnahmen" als Zwischenziele zur Erreichung des übergeordneten ökonomischen Zielpolygons. Die „gemeinsamen Politiken oder Maßnahmen” des Art. 3 umfassen insgesamt 20 unterschiedliche Tätigkeitsfelder, „die wie ein 'Sammelsurium' unterschiedlich differenzierter Handlungsanweisungen wirken." ${ }^{611}$ Der Vertrag bestimmt so in fast allen ökonomischen wie gesellschaftlichen Politikbereichen Zuständigkeiten der EU. ${ }^{612}$

Diese umfassende Betrachtung verdeutlicht, daß sich die Zielvorgaben der einzelnen Elemente des Maastrichter-Vertragwerkes nur schwer zu einem konsistenten Gesamtkonzept verbinden lassen. Denn auch die Ausführungen der Grundsätze des EGV lassen es kaum zu, gehaltvolle Aussagen zu einer hierarchischen Gliederung von übergeordneten Zielen mit stärkerem Zielcharakter und nachgeordneten Zielen mit zunehmenden Instrumentalcharakter abzuleiten. Die zielbezogenen inhaltlichen Verbindungen zwischen den einzelnen Elementen der Maastrichter-Vertragstexte erweisen sich somit insgesamt als unsystematisch und zum Teil auch widersprüchlich oder mißverständlich. ${ }^{613}$

${ }^{611}$ Walthes (1996), S. 63. Vgl. zu den Tătigkeitsfeldern der EU gemäß Art. 3 Laufer/Fischer (1995).

${ }^{612}$ Laufer/Arens (1995), S. 193 bezeichnen den Art. 3 des EG-Vertrages deshalb als „Generalklausel für die Zuständigkeit der Europäischen Gemeinschaft”. Für Walthes (1996), S. 63 belegt Art. 3 „faktisch eine 'Allzuständigkeit' der Gemeinschaft".

${ }^{613}$ So nennt bspw. Art. 2 den ,wirtschaftlichen und sozialen Zusammenhang" als ein Ziel, das durch die Durchführung der Maßnahmen des Art. 3 zu verwirklichen sei. Dort wird unter anderem die Maßnahme der Stärkung des „wirtschaftlichen und sozialen Zusammenhalts” gefordert. Dies stellt eine rein tautologische Aussage dar. Als weiteres Beispiel sei auf die ich unklare Wortwahl der einzelnen Vertragsteile im Hinblick auf die ökonomische Integration verwiesen. Art. B des EUV nimmt Bezug auf die Schaffung eines „Raumes ohne Binnengrenzen”, Art. 2 des EG-Vertrags auf die Errichtung eines „Gemeinsamen Marktes”, Art. 3 schließlich fordert Maßnahmen zur Herstellung eines „Binnenmarkt[es]”. Vgl. zur Unsystematik des MaastrichterVertragswerks auch Allais (1992), insb. S. $701 \mathrm{ff}$. 


\section{IV-1.5 Zusammenfassende Betrachtung und Schlußfolgerungen}

Trotz der kritischen Beurteilung der Konzeption des Zielsystems der EU wird zur Veranschaulichung der bislang angestellten Untersuchung eine Zielpyramide für die EU aus den einzelnen Elementen der Tempelkonstruktion abgeleitet (vgl. Abb. IV-2.):

Abb. IV-2: Die Zielpyramide des Maastrichter-Vertragswerks

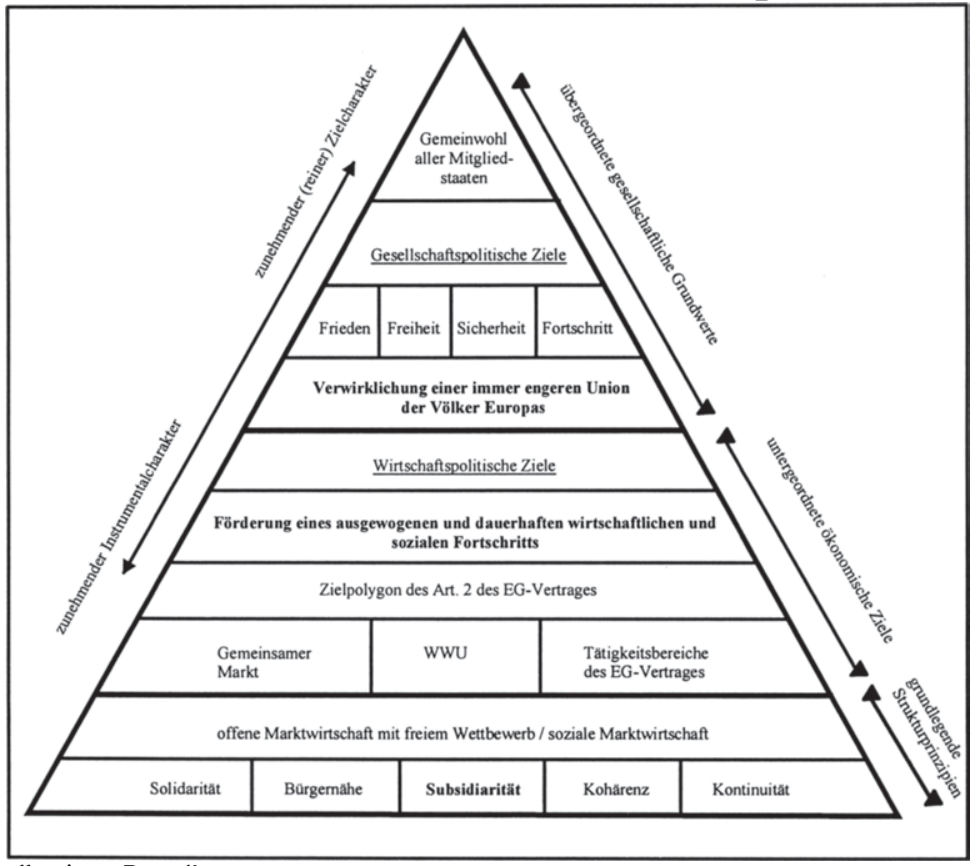

Quelle: eigene Darstellung

An der Spitze der Pyramide stehen die übergeordneten gesellschaftlichen Grundwerte des Friedens, der Freiheit, der Sicherheit und des Fortschritts als Ausfächerung des Endziels der EU „Gemeinwohl aller Mitgliedstaaten”. In Richtung zur Basis der Pyramide folgen die untergeordneten ökonomischen Ziele, die zunehmend den Charakter wirtschaftspolitischer Zwischenziele besitzen und jeweils der „Förderung eines ausgewogenen und dauerhaften wirtschaftlichen und sozialen Fortschritts” dienen. Der „Gemeinsame Markt”, die „WWU” und die „Tätigkeitsbereiche des EGV” stellen Instrumente zur Verwirklichung des ökonomischen Zielpolygons des Art. 2 des EGV dar. Den Sockel der Pyramide füllen die aus den unterschiedlichen Vertragselementen abgeleiteten „grundlegenden Strukturprinzipien” des Integra- 
tionsprozesses der EU aus. Diese stellen allgemeine Wertmaßstäbe für das Entscheidungsverhalten der Akteure dar. ${ }^{614}$

Zur Bedeutung der ermittelten Zielpyramide als ein grundlegendes Element für die Bestimmung eines rationalen Finanzausgleichsystems im weiteren Verlauf der Untersuchung lassen sich abschließend die folgenden Schlüsse ziehen:

1. Die Definition der Ziele des Maastrichter Vertragswerks ist gerade dadurch gekennzeichnet, daß die Konkretisierung eines hierachischen Zielbündels oder substantieller ZielMittel-Relationen nicht erfolgt. Vielmehr verbleiben den europäischen Entscheidungsträgern weitreichende Handlungsspielräume sowohl bei der Bestimmung der Einzelziele der EU als auch bei der Auswahl der Instrumente, um die jeweiligen Ziele zu verfolgen.

Gravierend ist dabei die Erkenntnis, daß zwischen den Mitgliedstaaten lediglich Einigkeit über die übergeordneten Globalziele der EU (gesellschaftliche Grundwerte) besteht. Bereits bei der Operationalisierung der Zwischenziele scheitert die Konsenssuche zwischen den Handlungsberechtigten der 15 Nationen, so daß dilatorische Kompromisse mit Leerformelcharakter geschlossen werden. ${ }^{615}$ Elementare Bedeutung besitzt der andauernde Dissens im Hinblick auf die Bedeutung der Formulierung „Verwirklichung einer immer engeren Union der Völker Europas" des Art. A EUV. ${ }^{616}$ Die Instrumentauswahl zur Zielverwirklichung erfolgt infolgedessen notwendigerweise ohne gemeinsame Zielorientierung. Ein systematisches, konsistentes und gleichgerichtetes Handeln aller Mitgliedstaaten ist unter diesen Rahmenbedingungen wesentlich erschwert. ${ }^{617}$

2. Das Maastrichter-Vertragswerk beinhaltet eine Reihe „unbestimmter Rechtsbegriffe”. Erst eine präzise inhaltliche Auslegung dieser „konkretisierungs- und ergänzungsbedürftigen

${ }^{614}$ Die anhaltende Kontroverse um das wirtschaftspolitische Ordnungsprinzip des europäischen Integrationsprozesses wird dadurch verdeutlicht, daß bei den grundlegenden Strukturprinzipien die Entscheidung für die wirtschaftspolitische Konzeption der „offenen Marktwirtschaft mit freiem Wettbewerb” oder der „,sozialen Marktwirtschaft" offen bleibt. Zudem ist das Subsidiaritätsprinzip besonders hervorgehoben, um bereits an dieser Stelle die zentrale Bedeutung zu signalisieren, die diesem Strukturprinzip für einen erfolgreichen Integrationsprozeß zufällt.

615 Vgl. auch Hesse, J.J. (1997), S. 102 ff.

${ }^{616}$ Gerken (1993), S. 14 drückt die fehlende Zielbestimmtheit der politischen wie ökonomischen Integration prägnant aus: „Die Entwicklung der europäischen Integration bis zum Vertrag von Maastricht ... macht deutlich, daß von Beginn an die Integrationsbestrebungen und Integrationsschritte, gerade auch im wirtschaftlichen Bereich getragen waren von der Vorstellung und der Perspektive eines engen und vor allem umfassenden Zusammenschlusses der Staaten Westeuropas. Konkrete Vorstellungen darüber, auf welchem Niveau diese Entwicklung vollendet sein und welcher Endzustand angestrebt werden sollte, bestanden indessen zu keinem Zeitpunkt."

617 Vgl. hierzu allgemein Tuchtfeldt (1977), S. 181 f.; auch Spiess (1973), S. 8 f. Mit konkretem Bezug zur EU Hackenbroch (1983), S. 85 f.; Mussler/Streit (1996), S. 265 sehen sogar die Gefahr, daß der Dissens um die Finalität der Union den gesamten europäischen Integrationsprozeß ,in eine Sackgasse” lenkt. 
Richtlinien"618 ermöglicht es, Aussagen zur geeigneten Ausgestaltung des zu untersuchenden europäischen Finanzausgleichsystems abzuleiten. Zum einen sind die grundlegenden Strukturprinzipien der EU zu nennen:

- Subsidiarität;

- Bürgernähe;

- Kohärenz;

- Solidarität;

- Kontinuität.

Zum anderen vor allem die folgenden beiden Einzelziele des ökonomischen Teilbereichs des europäischen Zielkataloges:

- Kohäsion (wirtschaftlicher und sozialer Zusammenhalt);

- Konvergenz.

3. Zudem gibt das Vertragswerk von 1992 eine Anzahl „unwiderruflicher” Ziele des weiteren Integrationsprozesses mit weitreichenden Auswirkungen auf den ökonomischen Bereich vor, die bei den weiteren Analysen als restringierende Daten zu berücksichtigen sind:

- Die Errichtung der WWU mit der Einfuihrung einer einheitlichen Währung;

- Die Vollendung des Binnenmarkts;

- Die Erweiterung der EU durch die Aufnahme neuer Mitgliedstaaten.

\section{IV-2 Die institutionelle Struktur der EU}

In den beiden anschließenden Teilabschnitten (IV-2.1 u. 2.2) wird die Entwicklung der institutionellen Struktur der EU nachgezeichnet. Es werden die rechtlich-organisatorischen Rahmenbedingungen beschrieben. Hierzu sind Rechtsinstitutionen (geschriebene Normen, v.a. die Finanzverfassung und die Entscheidungsregeln der EU) und Organisationen (staatliche Einrichtungen, v.a. die Entscheidungsorgane der EU) zu zählen. ${ }^{619}$ Primärrechtliche Grundlage

${ }^{618}$ Fischer-Menshausen (1978), S. 136.

619 Vgl. zu dieser Abgrenzung North (1992), S. 3 ff. Die Rechtsinstitutionen, so stellt North fest, „bestehen aus förmlichen, schriftlich niedergelegten Regeln ebenso wie aus typischerweise ungeschriebenen Verhaltenskodices" (North (1992), S. 4). Die vorliegende Untersuchung bleibt jedoch auf das objektiv feststellbare gesetzte Recht beschränkt. Die Bedeutung von gemeinschaftsweiten impliziten „Übereinkünften, Gepflogenheiten und Verhaltensnormen" (North (1992), S. 6) für die stabile Fortentwicklung des europäischen Integrationsprozesses wird jedoch an anderen Stellen dieser Arbeit betont (vgl. hierzu insb. die Überlegungen zur Abgrenzung zwischen formaler und informeller Integration in Abschnitt IV-2.3.1). 
der institutionellen Struktur ist der EUV in Verbindung mit den hierin enthaltenen Bestimmungen des EGV. ${ }^{620}$

Die Darstellung der institutionellen Rahmenbedingungen verdeutlicht die existierenden Kompetenzspielräume und -grenzen sowie das Zusammenspiel der finanzpolitischen Entscheidungsträger auf der EU-Ebene. Die so vermittelten Kenntnisse stellen eine entscheidende Grundlage dar, um im Verlauf des Kapitels V realitätsbezogene Aussagen ableiten zu können. Denn es wird so gewährleistet, daß der Einsatz der FZ als finanzwirtschaftliches Instrument nicht im institutionellen Vakuum, sondern gerade mit Verständnis für bestehende rechtliche und organisatorische Bindungen, Zwänge und Entwicklungsmöglichkeiten abgeleitet wird. ${ }^{621}$ Institutionelle Rahmenbedingungen weisen stets eine zeitliche und sachliche Bedingtheit auf. Diese Aussage besitzt im Hinblick auf die sich dynamisch fortentwickelnde EU-Ebene besondere Gültigkeit. Um eine wesentliche Voraussetzung für einen stabilen Verlauf des europäischen Einigungsprozesses zu schaffen, muß die institutionelle Struktur der EU stets qualitativer Ausdruck des jeweiligen Integrationsstandes der EU sein. ${ }^{622}$ Der Status-Quo der Finanzverfassung sowie der Organe und Entscheidungsprozesse der EU stellt deshalb lediglich eine Momentaufnahme dar, die anschließend vor dem Hintergrund der Entwicklungsdynamik und logik des europäischen Integrationsprozesses kritisch beleuchtet werden muß (Abschnitt IV2.3). Erst diese tiefergehende Analyse erlaubt es, sachlich und zeitlich differenzierte Schlußfolgerungen zur Frage rechtlich-organisatorischer Konfliktfelder zu bestimmen, die der Ableitung eines europäischen Finanzausgleichsystems zugrundezulegen sind (Abschnitt IV-2.4).

\section{IV-2.1 Die Finanzverfassung der EU}

Die Finanzverfassung der EU legt den rechtlichen Rahmen fest, an den die staatlichen Entscheidungsträger bei ihren finanzwirtschaftlichen Aktivitäten gebunden sind. Da die EU eine neue Ebene der öffentlichen Finanzwirtschaft bildet, ${ }^{623}$ erfolgt eine Abgrenzung der Kompetenzen zwischen der EU und den untergeordneten gebietskörperschaftlichen Ebenen. Die Normen bestimmen die Zuordnung staatlicher Aufgaben an die EU-Ebene, die Verantwortlichkeit für die zur Aufgabenerfüllung erforderliche Ausgabetätigkeit, sowie die Regelung der

${ }^{620}$ Die betreffenden Bestimmungen des EUV u. des EGV wurden zuletzt durch den Amsterdamer Vertrag vom 2. Oktober 1997 weiterentwickelt.

${ }^{621} \mathrm{Vgl}$. hierzu und zum folgenden Geske (1988).

622 Vgl. allgemein North (1992), S. 6; mit Bezug zur EU Biehl (1988b), S. 66; Hesse, J.J. (1997).

${ }^{623}$ Vgl. stellvertretend für viele Nowotny (1996), S. 154. 
Beschaffung der zur Deckung der Ausgaben notwendigen Einnahmen. Darüber hinaus werden die Grundsätze der europäischen Haushaltswirtschaft betrachtet. ${ }^{624}$

\section{IV-2.1.1 Die Aufgabenverteilung}

Da die Aufgabenverteilung die maßgebliche erklärende Variable des sich ergebenden Ausgabenvolumens und des erforderlichen Einnahmebedarfs einer gebietskörperschaftlichen Ebene darstellt, hat die Beschreibung der Finanzverfassung an diesem Teilaspekt anzusetzen. ${ }^{625} \mathrm{Da}-$ bei wird der Schwerpunkt auf die Darstellung struktureller Eigenschaften der Aufgabenverteilung gelegt, wohingegen von einer (reinen) Auflistung und Beschreibung der einzelnen Aufgabenbereiche der EU-Ebene abgesehen wird. ${ }^{626}$

\section{IV-2.1.1.1 Grundsatzregelung - das Prinzip der begrenzten Einzelermächtigung}

Art. 3b (1) des EGV bestimmt, daß „die Gemeinschaft innerhalb der Grenzen der ihr in diesem Vertrag zugewiesenen Befugnisse und gesetzten Ziele tätig [wird]." Der Handlungsspielraum der EU-Organe ist gemäß Art. 4 (1) ,nach Maßgabe der ihm in diesem Vertrag zugewiesenen Befugnisse” begrenzt. ${ }^{627}$ Der Erlaß von Rechtsakten ist den Organen nur ,zur Erfüllung ihrer Aufgaben und nach Maßgabe dieses Vertrages" (Art. 189 (1) EGV) gestattet. Diese Vorschriften verdeutlichen das Bestreben der Mitgliedstaaten, eine Zuständigkeit der EU-Ebene für bestimmte Aufgabenbereiche nur zuzulassen, sofern die Vertragsbestimmungen eine ausdrückliche Kompetenzgrundlage für das Handeln der zentralen Ebene benennen. Die Zuweisung der Aufgabenfelder folgt dem Prinzip der begrenzten Einzelermächtigung. „Eine Zuständigkeitsvermutung zugunsten der Gemeinschaft gibt es deshalb nicht. Vielmehr besteht grundsätzlich eine Vermutung für die Zuständigkeit der Mitgliedstaaten." ${ }^{628}$ Die Entscheidung über die Zuteilung von weiteren, bislang in den Vertragswerken nicht explizit genannten Aufgabengebieten an die EU-Ebene obliegt den Mitgliedstaaten gemäß der notwendigerweise einstimmigen Beschlußfassung im Europäischen Rat. ${ }^{629}$

Auf dieser Basis enumerieren die Art. 3 und 3a EGV sowie die Titel V und VI des EUV die einzelnen Aufgabenbereiche der EU, die sich einerseits auf bestimmte abgegrenzte Sachberei-

\footnotetext{
624 Vgl. Genser (1995), S. 7; auch Caesar (1996a), S. 235.

${ }^{625}$ So schon Popitz (1927).

626 Vgl. zu letzterem Aspekt ausfuihrlich Seidel (1992), S. $69 \mathrm{ff}$.

${ }^{627}$ Analog auch Art. E des EUV.

${ }^{628}$ Häde (1996), S. 347.

${ }^{629}$ Vgl. hierzu Seidel (1992), S. 72; Wissenschaftlicher Beirat (1994), S. 48; Möschel (1995), S. 232.
} 
che (bspw. Landwirtschaft oder Verkehr), andererseits auf konkret vorgegebene Zielbereiche (bspw. Herstellung der Freizügigkeit) beziehen. ${ }^{630}$ Die Entscheidungsträger der EU erhalten in diesen Bereichen entweder Primärkompetenzen oder aber Partialkompetenzen zugewiesen. ${ }^{631}$ Dabei kennzeichnen Primärkompetenzen solche Aufgabenfelder, in denen ausschließlich die EU-Ebene die Zuständigkeit zur Regelsetzung besitzt. ${ }^{632}$ Partialkompetenzen hingegen weisen auf solche Aufgabenfelder hin, bei denen die grundsätzliche Verantwortlichkeit bei der mitgliedstaatlichen Ebene liegt. Es werden jedoch explizit einzelne Ausnahmebereiche bestimmt, in denen die EU-Ebene neben der mitgliedstaatlichen Ebene Aktivitäten entfalten darf. Es resultieren Bereiche konkurrierender Zuständigkeiten. „Die Kompetenzordnung des Unionsvertrages ist somit als duale Struktur zu begreifen, die im Grundsatz ein Verhältnis von Regel und Ausnahme beschreibt. In diesem Rahmen kann die primäre Zuständigkeit einer Ebene für einen Politikbereich lediglich durch enumerierte Teilzuständigkeiten (Partialkompetenzen) der anderen Ebene durchbrochen werden."633

\section{IV-2.1.1.2 Die dynamische Entwicklung der Aufgabenverteilung}

Die Zuteilung der Primär- und Partialkompetenzen an die EU-Ebene ist im EGV „oft nur vage umrissen" ${ }^{634}$ und ,so allgemein gehalten”, 635 daß viele der Formulierungen einen erheblichen Auslegungsspielraum im Hinblick auf die Kompetenzzuständigkeit und die Intensität der Aufgabenerfüllung belassen. ${ }^{636}$ Ein expliziter und systematisch geordneter Kompetenzkatalog, wie er im deutschen Grundgesetz durch die erschöpfende Auflistung der Gegenstände der ausschließlichen, der konkurrierenden Gesetzgebung und der Rahmengesetzgebung der Art. 73-75 erfolgt, existiert für die EU-Ebene nicht. ${ }^{637}$ Als Folge der wenig stringenten Aufgaben-

${ }^{630} \mathrm{Vgl} . \mathrm{zu}$ dieser Abgrenzung Häde (1996), S. $381 \mathrm{ff}$.

${ }^{631} \mathrm{Vgl}$. Europäische Strukturkommission (1995), S. $24 \mathrm{ff}$. In analoger Vorgehensweise kann unter Bezugnahme auf die Formulierung des Art. 3b (2) EGV die Unterscheidung von ausschließlichen und konkurrierenden Zuständigkeiten der EU-Ebene getroffen werden; vgl. hierzu bspw. Häde (1996), S. $348 \mathrm{f}$.

${ }^{632}$ Der Begriff der ausschließlichen Zuständigkeit umfaßt zwei kumulative Elemente. Zum ersten als funktionales Element, die Verpflichtung der EU-Ebene als allein zuständige Instanz bei der Wahrnehmung bestimmter Aufgaben tätig zu werden. Zum zweiten als materielles Element, die Untersagung an die Mitgliedstaaten einseitig tătig zu werden. Letzterer Aspekt bedeutet jedoch nicht, daß die $E U$ die einzige gesetzgebende Instanz in einem Bereich der ausschließlichen Zuständigkeit sein muß. Sofern die $E U$ dies zuläßt, können die Mitgliedstaaten ebenso Gesetze beschließen oder Rahmenregelungen erlassen. Allerdings kann die EU-Ebene den Mitgliedstaaten diese Rechte entziehen, sofern dies als notwendig zur Aufgabenerfullung erachtet wird. Sie besitzt das „Primat des Handelns” (Reichenbach (1992), S. 3; vgl. auch Europäische Kommission (1992a), S. 5 ff.).

633 Europäische Strukturkommission (1995), S. 31.

634 Andel (1983), S. 313.

635 Laufer/Fischer (1995), S. 214.

${ }^{636}$ So schon vor den Maastricht-Verträgen Andel (1983), S. 313 und Seidel (1992), S. 72. Mit direktem Bezug zum Maastrichter-Vertragswerk vgl. Laufer/Fischer (1995), S. 214 ff.

${ }^{637}$ Vgl. Europäische Kommission (1992a), S. 3 f.; auch Europäische Strukturkommission (1995), S. 35 f.; Häde (1996), S. 381. 
verteilung im EGV ist „die Entwicklung der europäischen Aufgabenverteilung .. von einer dynamischen Expansion der gemeinschaftlichen Zuständigkeiten gekennzeichnet. ${ }^{, 638}$ Die folgenden strukturellen Merkmale des Vertragswerks sind als entscheidende Begründungsansätze für diese Entwicklungstendenzen anzuführen: ${ }^{639}$

(1)Die weitreichenden Interpretationsspielräume der Formulierungen zur Aufgabenverteilung können ,in der Praxis wie eine Primärkompetenz wirken”. ${ }^{640}$ Die Unklarheit in der Kompetenzverteilung führt dazu, daß die EU-Ebene im Zeitablauf mehr und mehr die ausschließliche Zuständigkeit für Aufgabenbereiche übernimmt, für die sie ursprünglich nur in begrenzten Ausnahmefällen Entscheidungskompetenzen besessen hatte. Diese Entwicklung widerspricht dem Grundsatz der begrenzten Einzelermächtigung. Als markantes Beispiel sei auf Art. 100a EGV verwiesen, der den EU-Entscheidungsträgern die Befugnis erteilt, alle „Maßnahmen zur Angleichung der Rechts- und Verwaltungsvorschriften der Mitgliedstaaten, welche die Errichtung und das Funktionieren des Binnenmarktes zum Gegenstand haben", zu erlassen. ${ }^{641}$

(2)Sofern ein Tätigwerden der Gemeinschaft erforderlich erscheint, besitzt die EU-Ebene nach Art. 235 EGV die Möglichkeit, die geeigneten Vorschriften zu erlassen, um die Ziele des Gemeinsamen Marktes zu verwirklichen, selbst wenn in dem Vertragswerk die hierfür erforderlichen Befugnisse nicht vorgesehen sind. Da Art. 235 EGV es den EUEntscheidungsträgern ermöglicht, auch in vertraglich nicht explizit genannten Aufgabenfeldern tätig zu werden, verkörpert die Bestimmung eine Art Generalermächtigung, die eine Expansion der Aufgabenwahrnehmung durch die zentrale Ebene begünstigt. ${ }^{642}$ Jedoch ist zu betonen, daß ,die Vorschrift auf bloße Kompetenzergänzung und auf unvorhergesehene Fälle ausgerichtet [ist]. Sie bietet keine Handhabe für eine beliebige Kompetenzbe-

${ }^{638}$ Bohnet-Joschko (1996), S. 164. Auf die Gefahren dieser Entwicklung weisen neben Bohnet-Joschko eine Reihe weiterer Autoren deutlich hin. So fordern bspw. auch Scharpf (1991); Berthold (1993a); Hesse, H. (1993), S. 51 f.; Europäische Strukturkommission (1995), S. 24 ff.; Everling (1995) und Laufer/Arens (1995) eine klare Abgrenzung der Aufgaben zwischen der EU-Ebene und den weiteren föderativen Ebenen der Union, um Zentralisierungstendenzen zu verhindern. Jedoch weist Hesse, J.J. (1997), S. $116 \mathrm{f}$. darauf hin, daß auch die von diesen Autoren angestrebte Vereinfachung durch klare Kompetenzkataloge den Anforderungen des europäischen Integrationsprozesses nicht gerecht wird. Denn „die 'Vereinfacher' übersehen, daß auch 'reife' Főderationen durch unzählige (horizontale wie vertikale) Verbundprozesse geprägt sind, die zwar das Risiko der 'Politikverflechtungsfalle' bergen, gleichzeitig aber Vollzug, Stabilität und Identität gewährleisten". (Hesse, J.J. (1997), S. 117)

639 Vgl. auch die ähnlichen Überlegungen bei Nicolaysen (1995), S. $158 \mathrm{ff}$.

640 Europäische Strukturkommission (1995), S. 36.

${ }^{641}$ Vgl. hierzu Europäische Strukturkommission (1995), S. 36; Nicolaysen (1995), S. 159. Häde (1996), S. 353 nennt dies „Kompetenzen kraft Sachzusammenhangs”, wobei es zwingend zur Kompetenzausweitung kommt, um die Aufgabenerfullung der EU-Ebene sicherzustellen.

642 Bohnet-Joschko (1996), S. 165 spricht von der „Nutzung des 'Zauberartikels' 235”. Laufer/Fischer (1995), S. 214 betrachten Art. 235 als ein „'Einfallstor' in immer weitere nationale Souveränitätsrechte”. 
gründung auf europäischer Ebene." ${ }^{, 643}$ Aus diesem Blickwinkel gewährleistet der Art. 235 eine wünschenswerte Flexibilisierung der ,theoretische[n] Starrheit des Prinzips der limitierten Einzelermächtigung", ${ }^{644}$ die eine problemadäquate Aufgabenkritik im dynamischen Integrationsprozeß ermöglicht. ${ }^{645}$

(3)An dieser Stelle ist zudem auf Art. F (3) EUV Bezug zu nehmen, der folgendes konstatiert: „Die Union stattet sich mit den Mitteln aus, die zum Erreichen ihrer Ziele und zur Durchfuihrung ihrer Politiken erforderlich sind." Die Bestimmung besitzt trotz des Wortlautes als Begründungsansatz für eine Ausweitung der Aufgabenbereiche der EU-Ebene eine untergeordnete Bedeutung. Denn Art. F (3) EUV ist nicht wie Art. 235 EGV als eine echte Kompetenzzuweisungsnorm zu verstehen, sondern als eine Absichtserklärung aller Mitgliedstaaten, die EU im Ablauf des europäischen Einigungsprozesses - gegebenenfalls im Rahmen ordentlicher Vertragsänderungen - stets mit den dem erreichten Integrationsstand entsprechenden Aufgaben zu betrauen. Art. F Abs. 3 EUV bringt folglich „keine Kompetenzzuweisung, sondern eine zukünftige Aufgabe der Vertragspartner zum Ausdruck."

(4)Schließlich ist das Subsidiaritätsprinzip des Art. 3b (2) EGV als „fundamentale[s] Gestaltungsprinzip" ${ }^{647}$ bei der Aufgabenverteilung der EU anzuführen. ${ }^{648}$ Die EU-Ebene wird demnach ,in den Bereichen, die nicht in ihre ausschließliche Zuständigkeit fallen, ... nur tätig, sofern und soweit die Ziele der in Betracht gezogenen Maßnahmen auf Ebene der Mitgliedstaaten nicht ausreichend erreicht werden können und daher wegen des Umfangs oder ihrer Wirkungen besser auf Gemeinschaftsebene erreicht werden können." Dieser Absatz (2) befaßt sich mit der Frage, „ob” die EU-Ebene überhaupt Aktivitäten entfalten soll. „Eine Chance, Zentralisierungstendenzen in der Europäischen Gemeinschaft entgegenzutreten"649 ergibt sich basierend auf Art. 3b (2) EGV aus verschiedenen Gründen aber nur sehr eingeschränkt:

643 Wissenschaftlicher Beirat (1994), S. 21. Art. 235 EGV schafft damit insb. keine Kompetenz-Kompetenz der EU-Ebene. Vgl. hierzu auch ausfuhrlich Häde (1996), S. $355 \mathrm{ff}$.

644 Wissenschaftlicher Beirat (1994), S. 21.

${ }^{645}$ Entscheidend für die Bewertung der Vorschrift ist das Verhalten der staatlichen Entscheidungsträger. Wird die Ermächtigungsgrundlage des Art. 235 restriktiv ausgelegt, so daß lediglich Teilkompetenzen ergänzt werden, ist Art. 235 positiv zu bewerten. Erfolgt in Anwendung des Art. 235 hingegen die Einbeziehung vőllig neuer Aufgaben in den Verantwortungsbereich der EU-Ebene, kommt es zu einer "faktischen Ausweitung der Rechtsetzungstätigkeit der Gemeinschaf”" und die Norm ,kann ... nicht mehr überzeugen.” (Europäische Strukturkommission (1995), S. 36) Ähnlich auch Oppermann (1991), S. 168 ff.; Wissenschaftlicher Beirat (1994), S. 21 f.; Häde (1996), S. 373 ff.; deutlich kritischer Berg/Schmidt (1996), S. 133.

${ }^{646}$ Häde (1996), S. 376. Vgl. hierzu Häde (1996), S. 375 f., m.w.N.

647 Reichenbach (1992), S. 2.

${ }^{648} \mathrm{Vgl}$. zur inhaltlichen Konkretisierung des Subsidiaritătsprinzip als allgemeines gesellschaftliches Ordnungsund Gliederungsprinzip Abschnitt II-2.

649 Wissenschaftlicher Beirat (1994), S. 23. 
- Die Formulierung des Absatz 2 verdeutlicht, daß das Subsidiaritätsprinzip in seiner spezifischen Verankerung im EGV lediglich ein Ordnungsprinzip für die Kompetenzausübung nicht aber für die Kompetenzverteilung darstellt. Die Aufgabenverteilung selbst ergibt sich ausschließlich durch die Bestimmungen des Maastrichter-Vertragswerks und liegt daher in der Zuständigkeit der mitgliedstaatlichen Vertragsparteien. ${ }^{650}$ Das Subsidiaritätsprinzip des EUV kann daher nicht als Grundsatz zur dynamischen Fortentwicklung der Aufgabenverteilung herangezogen werden. ${ }^{651}$ Der Subsidiaritätsbegriff des EGV ist statisch. ${ }^{652}$

- Der Anwendung des Subsidiaritätsprinzips des Absatz 2 ist auf die Bereiche der konkurrierenden Zuständigkeiten beschränkt. Jedoch ergibt sich auch im Bereich der ausschließlichen Zuständigkeiten keinesfalls automatisch die Notwendigkeit, die Aufgabenbereich vollständig durch die EU-Ebene zu erfüllen. ${ }^{653}$ Die Ausdehnung des Anwendungsbereichs des Subsidiaritätsprinzips auf den Bereich ausschließlicher Zuständigkeiten könnte daher Zentralisierungstendenzen vermeiden, da die EU-Entscheidungsträger dazu verpflichtet würden, „auch bei der Wahrnehmung ihrer ausschließlichen Kompetenz, jedenfalls bei Ausgestaltung und Durchfuihrung, den Mitgliedstaaten Spielräume zu überlassen, soweit das Ziel der Regelungen von ihnen ausreichend verwirklicht werden kann."

- Die Vertragstexte nehmen keine deutliche Abgrenzung der ausschließlichen Zuständigkeiten der EU-Ebene vor. ${ }^{655}$ Es entstehen deshalb Kompetenzstreitigkeiten zwischen den Mitgliedstaaten und der EU-Ebene, wobei es in den Aufgabenbereich der EU-Organe fällt „ein gemeinsames Konzept zu erarbeiten, um ständige Abgrenzungskonflikte zwischen ausschließlichen und konkurrierenden Zuständigkeiten ... zu vermeiden." ${ }^{656}$ Die (politökonomisch abgeleiteten) Interessenlagen der beteiligten Organe bieten aber keinen Anreiz „für eine wirklich einschneidende Anwendung des Subsidiaritätsprinzips. "657 Die Europäische Kommission (EK) befürwortet weitgehende eigene Handlungsspielräume und ist da-

${ }_{650}^{65}$ Vgl. Europäische Kommission (1992a), S. 3.

${ }^{651}$ Zwar weist der Europäische Rat bei der Entwicklung eines Gesamtkonzeptes für die Anwendung des Subsidiaritätsprinzips unter Bezugnahme auf die Art. A u. B des EUV darauf hin, daß das Subsidiaritätsprinzip durch den EUV eine neue rechtliche Bedeutung erlange und somit über Art. $3 \mathrm{~b}$ EGV hinaus ein allgemeines Grundprinzip für alle Tătigkeiten der EU verkörpere (vgl. Europäischer Rat in Edinburgh (1992), S. 1280). Jedoch bezieht sich Art. B ausschließlich auf den engen Subsidiaritătsbegriff des Art. 3b EGV. Zudem geht die Bestimmung des Art. A nicht über die lapidare Feststellung hinaus, daß die „Entscheidungen möglichst bürgernah getroffen werden”. Eine justiziable Verankerung eines allgemeinen Subsidiaritătsprinzips stellt diese Regelung nicht dar (so auch Bitterlich (1995b), insb. S. 186 ff.).

${ }^{652} \mathrm{Vgl}$. Dams/Heide (1995), S. 941.

653 Vgl. hierzu Fn 632 in Abschnitt IV-2.1.1.1.

654 Nicolaysen (1995), S. 174.

$655 \mathrm{Vgl}$. hierzu weiter oben in diesem Abschnitt IV-2.1.1.2.

${ }^{656}$ Europäische Kommission (1992a), S. 4.

657 Möschel (1995), S. 234. Vgl. zu den Interessenlagen der Akteure aus polit-ökonomischer Sicht grundlegend Vaubel (1992) u. (1994). 
her an einer Maximierung der Zuständigkeiten der EU-Ebene interessiert. ${ }^{658}$ Der Ministerrat als EU-Rechtssetzungsorgan in Zusammensetzung der Regierungen der Mitgliedstaaten ist daran interessiert, umfangreiche politische Entscheidungen auf europäischer Ebene treffen zu können. So wird die Mitwirkung der nationalen Parlamente an der Entscheidungsfindung verhindert. ${ }^{659} \mathrm{Da}$ zudem der Europäische Gerichtshof (EuGH) den Gemeinschaftsorganen einen weiten Beurteilungsspielraum bei der Kompetenzabgrenzung beläßt, ${ }^{660}$ ist zu erwarten, daß der Bereich der für die Anwendung des Subsidiaritätsprinzips ausschlaggebenden konkurrierenden Zuständigkeiten (äußerst) restriktiv ausgelegt wird. ${ }^{661}$

- Analoge polit-ökonomische Überlegungen sind zu den konkurrierenden Zuständigkeiten anzustellen, wenn in konkreten Einzelfällen überprüft wird, ob gemäß des Subsidiaritätsprinzips die Notwendigkeit zur Ausübung von Kompetenzen durch die EU besteht. Die EU-Ebene hat den Nachweis zu führen, „daß ihr Handeln gegenüber den Maßnahmen, die die Mitgliedstaaten zur Erreichung der Vertragsziele treffen oder treffen könnten, begründet ist. ${ }^{662}$ Hierzu erfolgt eine Prüfung anhand zweier Kriterien: ${ }^{663} \mathrm{Im}$ komparativen Effizienztest wird untersucht, ob die Mitgliedstaaten mit den entsprechenden Mitteln ${ }^{664}$ ausgestattet sind, um wirksame Maßnahmen zur Zielerreichung durchführen zu können. Im Mehrwert-Test wird hingegen die relative Effizienz des Handelns der EU „aufgrund des Umfangs der Maßnahmen, grenzüberschreitender Schwierigkeiten, der notwendigen kritischen Masse, oder der Kosten der Nichtdurchführung der Maßnahmen"665 bewertet. Dieses Prüfungsverfahren beläßt weitreichende Auslegungsspielräume, so daß eine Kompetenzausübung der zentralen Ebene zumeist problemlos zu rechtfertigen ist. ${ }^{666}$ Letztendlich entscheiden wiederum die EK und der Ministerrat unter Berücksichtigung ihrer spezifischen Interessenlagen. Unter diesen Voraussetzungen ,zeichnet sich die Tendenz ab, daß im Endergebnis eine stärkere Zentralisierung der Entscheidungen auf [!] EU-Ebene gefördert wird." 667

${ }^{658}$ Vgl. Nicolaysen (1995), S. 161 f.; Bohnet-Joschko (1996), S. 216 ff, hier insb. S. 220.

659 Vgl. Möschel (1995), S. 234; Bohnet-Joschko (1996), S. 227 f.

${ }^{660}$ Vgl. Everling (1995), S. 175 f.; auch Laufer/Fischer (1995), S. 219. Zurückhaltender äußert sich jedoch Häde (1996), S. 352 f. Vgl. auch Abschnitt IV-2.2.1.3 zum EuGH.

${ }^{661}$ Abschließend stellt Häde (1996), S. 351 fest: „Das Fehlen einer ausdrücklichen Abgrenzung zwischen ausschließlichen und sonstigen Kompetenzen der Gemeinschaft im EG-Vertrag könnte eines der wesentlichen Hindernisse für eine effektive Anwendung des Subsidiaritätsprinzip darstellen."

662 Europäische Kommission (1992a), S. 4.

${ }^{663} \mathrm{Vgl}$. zum Folgenden Europäische Kommission (1992a), S. 10 f.; Reichenbach (1992), S. 2.

${ }^{664}$ Hierzu sind auch finanzielle Ressourcen zu zählen.

${ }^{665}$ Reichenbach (1992), S. 2.

${ }^{666}$ Vgl. Möschel (1995), S. 234; auch Wieland (1991), S. 447.

${ }^{667}$ Dams/Heide (1995), S. 942. 
Insgesamt besitzt das Subsidiaritätsprinzip in seiner momentanen vertraglichen Ausgestaltung kaum konkrete Wirkungspotentiale, um bestehende Entwicklungstendenzen zur Ausdehnung gemeinschaftsweiter Aufgabenwahrnehmung abzuschwächen. Einen wesentlichen Einfluß erhält das Subsidiaritätsprinzip vielmehr in seiner allgemeinen, auf die Enzyklika „Quadragesimo Anno" zurückgehenden Bedeutung als eine - unabhängig von bestehenden Vertragsinhalten - akzeptierte Leitlinie für die Aufgabenverteilung im weiteren europäischen Integrationsprozeß. ${ }^{668}$ Mit dem allgemeinen Subsidiaritätsprinzip „verbundene Begründungslasten und eine darauf bezogene Diskussion in der interessierten Öffentlichkeit mögen eine begrenzende Wirkung [auf die zentrale Aufgabenwahrnehmung] entfalten. ... Das Subsidiaritätsprinzip bietet insoweit auch ein Einfallstor, um Stimmungen und Vorbehalte in den öffentlichen Meinungen der Mitgliedstaaten gegen europäische Zentralisierungstendenzen aufzunehmen." ${ }^{, 699}$

Zudem lenkt die kritische Einschätzung zur Tragweite des Subsidiaritätsprinzips nach Art. 3b (2) die Aufmerksamkeit auf Art. 3b (3), der bestimmt, daß „die Maßnahmen der Gemeinschaft .. nicht über das für die Erreichung der Ziele dieses Vertrages erforderliche Maß hinaus[gehen].” Dieser Verhältnismäßigkeitsgrundsatz findet uneingeschränkt auf alle Maßnahmen der EU Anwendung, unabhängig davon, ob das jeweilige Aufgabengebiet in die ausschließliche oder konkurrierende Zuständigkeit fällt. ${ }^{670}$ Entscheidender Ausfluß des Grundsatzes ist die Verpflichtung, „daß die Gemeinschaft, wenn sie zwischen mehreren Aktionsmitteln wählen kann, bei der Wahrnehmung ihrer Zuständigkeit sich für das Mittel entscheiden muß, das - bei gleicher Wirksamkeit - für Staaten, Einzelpersonen, Unternehmen am wenigsten zwingend ist." ${ }^{, 671}$ Damit rücken die alternativen Formen der Rechtssetzung der EU-Ebene in den Mittelpunkt des Interesses.

\section{IV-2.1.1.3 Die Formen der Rechtssetzung}

Art. $189 \mathrm{EGV}$ nennt die verschiedenen Rechtshandlungen, die die EU-Ebene „zur Erfüllung ihrer Aufgaben und nach Maßgabe dieses Vertrages” zu erlassen befugt ist. Die alternativen Maßnahmen umfassen Verordnungen, Richtlinien, Entscheidungen, Empfehlungen und Stellungnahmen: ${ }^{672}$

\footnotetext{
668 So auch Nicolaysen (1995), S. 176 und Häde (1996), S. 353.

${ }^{669}$ Möschel (1995), S. 235.

${ }^{670} \mathrm{Vgl}$. Europäischer Rat in Edinburgh (1992), S. 1282.

${ }^{671}$ Europäische Kommission (1992a), S. 13.

672 Vgl. zu den Rechtssetzungsformen Borchardt (1996), S. 137 ff. und Oppermann (1991), S. 172 ff. sowie knapper Häde (1996), S. 377 ff. und Weindl (1996), S. 61 ff.
} 
- Die Verordnung besitzt gemäß Art. 189 (2) allgemeine Geltung, ist in allen ihren Teilen verbindlich und gilt unmittelbar in jedem Mitgliedstaat. Sie ist die Rechtshandlung mit der höchsten Eingriffsintensität aller gemeinschaftlichen Steuerungsinstrumente. Die Verordnung tritt direkt an die Stelle bestehender mitgliedstaatlicher Gesetze, so daß eine Rechtsvereinheitlichung im gesamten EU-Raum resultiert. Als „quasi-legislatorische Maßnahmen"673 stellen die Verordnungen die eigentlichen Gemeinschaftsgesetze dar. Den Mitgliedstaaten verbleiben weder Handlungsspielräume, „Bestimmungen einer Verordnung unvollständig anzuwenden oder unter ihnen eine Auswahl zu treffen" noch „die darin verbürgten Rechte und Pflichten aufzuheben, auszusetzen oder inhaltlich abzuändern."

- Die Richtlinie ist nach Art. 189 (3) für jeden Mitgliedstaat hinsichtlich des zu erreichenden Zieles verbindlich, überläßt aber den innerstaatlichen Stellen die Wahl der Form und der Mittel. Die Richtlinie stellt daher eine mildere Form des Eingriffs in den Handlungsspielraum der einzelstaatlichen Entscheidungsträger dar als die Verordnung. Während letztere zu einer Rechtsvereinheitlichung fuihrt, ist die Richtlinie auf das Ziel der Rechtsangleichung (Rechtsharmonisierung) beschränkt. Die Mitgliedstaaten behalten die Möglichkeit besonderen einzelstaatlichen Merkmalen und Vorlieben Rechnung zu tragen.

- Die Entscheidung ist diejenige Rechtshandlung der EU-Ebene, die „zur verbindlichen Einzelfallregelung dienen soll." ${ }^{675}$ Art. 189 (4) bestimmt, daß „die Entscheidung .. in allen ihren Teilen für diejenigen verbindlich [ist], die sie bezeichnet." Dabei können Entscheidungen sowohl an Einzelpersonen und Unternehmen als auch an Mitgliedstaaten gerichtet sein und von den Betroffenen ,ein Handeln oder Unterlassen verlangen, ihnen Rechte einräumen oder Pflichten auferlegen." 676

- Zudem kann die EU-Ebene Empfehlungen aussprechen und Stellungnahmen abgeben. Diese Aktionsmittel sind nach Art. 189 (5) nicht verbindlich. Sie erlauben es den Organen der EU, den Entscheidungsträgern der Mitgliedstaaten unverbindliche Beurteilungshilfen bei ihrer Entscheidungsfindung zu vermitteln oder ein bestimmtes sachgerechtes Verhalten nahezulegen, ohne den Adressaten verbindliche Rechte oder Pflichten aufzuerlegen.

${ }^{673}$ Oppermann (1991), S. 174.

674 Borchardt (1996), S. 140.

675 Oppermann (1991), S. 180.

${ }^{676}$ Borchardt (1996), S. 149. Als Anwendungsbeispiele von Entscheidungen seien im Hinblick auf Unternehmen die Untersagung wettbewerbswidriger Kartellvereinbarungen (Art. 85 EGV) sowie die hiermit verbundene Verhängung von Geldbußen und Zwangsgeldern (Art. 87 EGV) genannt; im Hinblick auf Mitgliedstaaten zum einen die Erlaubnis zum Erlaß von Schutzmaßnahmen, um die Verlagerung von Handelsströmen zu verhindern (Art. 115 EGV), zum anderen die Entscheidung über die Zulässigkeit der Gewährung mitgliedstaatlicher Beihilfen an Unternehmen oder Produktionszweige (Art. 92 f. EGV). 
Das Maastrichter-Vertragswerk legt keine Rangfolge der Rechtssetzungsformen fest. Der Intention des Verhältnismäßigkeitsgrundsatzes des Art. 3b (3) EGV entspricht jedoch eine Normenhierachie, die den Empfehlungen und Stellungnahmen als nicht rechtsverbindlichen Aktionsmitteln systematisch den Vorzug gibt. Sofern die unverbindlichen Anordnungen zu keiner befriedigenden Problemlösung führen, bleibt der EU-Ebene eine späteren verbindlichen Rechtsetzungstätigkeit unbenommen, wobei es das Subsidiaritätsprinzip erfordert, „unter sonst gleichen Bedingungen eine Richtlinie einer Verordnung und eine Rahmenrichtlinie einer detaillierten Maßnahme vorzuziehen." 677

In der Realität bestehen jedoch erhebliche Durchsetzungsprobleme dieser Normenhierachie, so daß eine explizite (vertragliche) Verankerung der Rangfolge der Rechtsetzungsformen notwendig erscheint. ${ }^{678}$ Denn obwohl die Organe der EU die bevorzugte Anwendung der Richtlinie explizit befürworten, ${ }^{679}$ erfolgt der überwiegende Teil der Rechtssetzunghandlungen durch Verordnungen. 1996 verabschiedete der Ministerrat 247 Verordnungen gegenüber nur 58 Richtlinien. ${ }^{680}$ Zudem fällt die deutliche Unterscheidung der einzelnen Aktionsmittel der EU im Rahmen der Normenhierachie schwer. „Zumeist enthalten Richtlinien ebenso detaillierte Vorschriften wie Verordnungen und lassen den Mitgliedstaaten bei der Umsetzung kaum noch Handlungsfreiheit." ${ }^{681}$ Hierdurch verschwimmt jedoch die Abgrenzungslinie zwischen Richtlinien und Verordnungen und die Eingriffsintensität der Rechtssetzungsaktivitäten steigt an. Daher ist es zur substantiellen Durchsetzung des Subsidiaritätsprinzips geboten, der ursprünglichen Intention der alternativen Aktionsmittel stärkere Beachtung zu schenken, „um die Gemeinschaftsgesetzgebung auf das Wesentliche zurückzuführen und den Spielraum der Mitgliedstaaten sowie der Kommission in den Fällen zu erweitern, in denen einheitliche Vorschriften erforderlich sind." 682

\section{IV-2.1.2 Grundsätze der Haushaltswirtschaft}

Die Ausgaben- und Einnahmetätigkeit auf europäischer Ebene findet ihren Niederschlag im Haushaltsplan der EU. Dieser umfaßt die in regelmäßigen Zeitabständen stattfindende syste-

\footnotetext{
677 Europäischer Rat in Edinburgh (1992), S. 1282. Vgl. hierzu auch Europäische Kommission (1992a), S. 14 f.; Wissenschaftlicher Beirat (1994), S. 24 f. und Laufer (1995), S. 206 f.

${ }^{678}$ Vgl. Europäische Strukturkommission (1995), S. 37.

679 Vgl. bspw. Europäische Kommission (1993b), S. $381 \mathrm{ff}$.

${ }^{680}$ Beruldksichtigt man, daß auch die EK Verordnungen und Richlinien erlassen kann, insb. sofern der Ministerrat der EK gemå Art. 145 u. 155 EGV die Befugnis zum Erlaß sogenannter Durchfulhrungs-Verordnungen und Durchfuhrungs-Richtlinien überträgt, so ergibt ein noch deutlicheres zahlenmäßiges Übergewicht der Verordnungen: insgesamt stehen im Jahr 19962588 Verordnungen nur 97 Richtlinien gegenüber (vgl. Europäische Kommission (1997b), S. $483 \mathrm{ff}$.).

${ }^{681}$ Europäische Kommission (1992a), S. 15. Vgl. auch Scharpf(1993a), S. 19; Borchardt (1996), S. 142 f.

${ }^{682}$ Europäische Kommission (1992a), S. 16.
} 
matische Zusammenstellung der erwarteten Einnahmen und voraussichtlich zu leistenden Ausgaben einer Haushaltsperiode. ${ }^{683}$ Daher wird zunächst die Systematik der europäischen Haushaltswirtschaft anhand der wesentlichen Haushaltsgrundsätze beleuchtet, bevor auf die Ausgaben- und Einnahmenseite der EU-Finanzverfassung eingegangen wird. Die maßgeblichen Bestimmungen finden sich in den Art. 199-209a des EGV zu den Finanzvorschriften. ${ }^{684}$

\section{- Die Einheit des Gemeinschaftshaushalts:}

Nach Art. 199 EGV werden alle Einnahmen und Ausgaben der Gemeinschaft für jedes Haushaltsjahr veranschlagt und in den Haushaltsplan eingesetzt. Es müssen alle finanziellen Aktivitäten der EU im Rahmen eines einzigen Haushaltsplans ausgewiesen werden. Hierdurch soll die effektive Kontrolle der Einnahmen und Ausgaben ermöglicht werden.

Jedoch bestehen Abweichungen vom Grundsatz der Einheit des Gemeinschaftshaushalts. In etwa 5-7 Prozent der Finanztätigkeiten werden nicht vom Gesamthaushalt, sondern als „offbudget-activities" durch verschiedener Nebenhaushalte erfaßt. ${ }^{685}$ Damit ist der Gesamthaushalt zwar das „bei weitem wichtigste Finanzinstrument” ${ }^{\text {"b6 }}$ der EU, doch liefert er „kein vollständiges Bild der finanzrelevanten Aktivitäten der EU." ${ }^{687}$ Die Transparenz und die Kontrollmöglichkeit der Einnahme- und Ausgabetätigkeit der EU wird hierdurch eingeschränkt.

\section{- Die Universalität des Gemeinschaftshaushalts:}

Die Haushaltseinnahmen der EU dürfen nicht zweckgebunden erhoben werden; eine Verrechnung zwischen Einnahmen und Ausgaben ist untersagt. ${ }^{688}$ Der Grundsatz umfaßt das Nonaffektationsprinzip, so daß sämtliche Einnahmen als Deckungsmittel für den gesamten Ausgabenbedarf bereitzuhalten sind und bestimmt zudem, daß alle Einnahmen und Ausgaben in voller Höhe im Haushalt eingesetzt werden müssen. ${ }^{689}$

\section{- Die Jährlichkeit des Gemeinschaftshaushalts:}

Um die Kontrolle der haushaltswirksamen Aktivitäten zu erleichtern, sind alle Haushaltsvorgänge gemäß Art. 199 (1); Artikel 202 (1) und Art. 203 (1) des EGV an ein Haushaltsjahr

\footnotetext{
${ }^{683} \mathrm{Vgl} . \mathrm{zu}$ Begriff und Aufgaben des Haushalts Noll (1979), S. $23 \mathrm{ff}$.

${ }^{684}$ Weitergehende haushaltsrechtliche Vorschriften beinhaltet die Haushaltsordnung der $E U$, die gemäß Art. 209 EGV erlassen wurde. Die folgenden Ausfulhrungen orientieren sich wesentlich an Europäische Kommission (1995a), S. $55 \mathrm{ff}$.

${ }^{685} \mathrm{Vgl}$. zu den Bereichen, die sich nicht oder nur zum Teil im Gesamthaushalt wiederfinden näher Europäische Kommission (1995a), S. 131 ff.; Caesar (1996a), S. 244 f.; auch Seidel (1992), S. 102 ff.

${ }^{686}$ Europäische Kommission (1995a), S. 56.

687 Caesar (1996a), S. 244.

${ }^{688}$ Dieser Grundsatz folgt logisch aus der Einheit des Haushalts. Er leitet sich jedoch nicht unmittelbar aus dem EGV ab, sondern basiert auf Artikel 4 und 27 der HO. Vgl. Europäische Kommission (1995a), S. 59.

${ }^{689}$ Es bestehen einzelne Ausnahmen von beiden Aspekten (vgl. hierzu Europäische Kommission (1995a), S. 59 f.), die aber keine entscheidende Bedeutung im Rahmen dieser Arbeit besitzen.
} 
gebunden. Eine wichtige Ergänzung stellt in diesem Zusammenhang die „Finanzielle Vorausschau" dar, die 1988 als neues Element in die institutionelle Struktur der EU eingefuigt wurde. Sie gibt als mittelfristige Planung den Ausgabenrahmen für die kommenden Hauhaltsperioden vor, mit dem Ziel, „ein Ausufern der Gemeinschaftsausgaben zu verhindern und gleichzeitig eine ausgewogene Entwicklung der Interventionen in den einzelnen Bereichen zu gewährleisten." ${ }^{690}$ Die momentane finanzielle Vorausschau gibt den Finanzrahmen für die Zeit von 1993-1999 vor. Die Vorausschau wird jährlich an die Entwicklung des Preisniveaus und der Bruttosozialprodukte der Mitgliedstaaten angepaßt. Darüber hinaus sind Änderungen jedoch nur ,aus zwingenden politischen Gründen und unter Zusammenwirken aller drei Organe (Vorschlag der EK, Zustimmung des EP und des Rates) möglich."691

\section{- Der Haushaltsausgleich:}

Nach Art. 199 (3) muß der Haushalt in Einnahmen und Ausgaben den gleichen Betrag ausweisen. Dieser Haushaltsausgleich darf nicht durch Aufnahme von Krediten hergestellt werden. Bei der Aufstellung des Haushaltsplanes ist es unzulässig, Ausgaben durch Kredite zu decken. Diese Vorschrift besitzt auch in der Ausführungphase des Haushaltsjahres Gültigkeit. Ergibt sich im Laufe des Haushaltsvollzugs ein Rechnungsabschluß mit einem negativen Saldo, so muß dieses Budgetdefizit auf das folgende Haushaltsjahr übertragen und dort als Ausgabe verbucht werden. Eine besonderes Gewicht erhalten diese Überlegungen unter Beachtung der bestehenden fixen Obergrenze für das Gesamtvolumen der EU-Einnahmen (Eigenmittelobergrenze). Erfolgen im Verlauf eines Haushaltsjahres (n) Mindereinnahmen relativ zu den geplanten Haushaltsansätzen, so löst der resultierende negative Budgetsaldo des Jahres (n) als Ausgabeposten im Haushalt des Jahres $(n+1)$ eine Beschränkung des ausgabeseitigen finanziellen Handlungsspielraums im Jahr $(n+1)$ aus. Schöpft das für das Jahr $(n+1)$ vorausgeplante Einnahmevolumen bereits die bestehende Einnahmenobergrenze aus kann der finanzielle Handlungsspielraum auch einnahmeseitig nicht zurückgewonnen werden.

\section{- Der Grundsatz der Spezialität:}

Um „Klarheit bei der Bewilligung und Ausführung der Mittel, Transparenz des Haushaltsplans und einen den Vorstellungen der Haushaltsbehörde entsprechenden Haushaltsvollzug" zu gewährleisten, bestimmt Art. 202 des EGV, daß jedem Ausgabeansatz eine „spezifische

690 Europäische Kommission (1995a), S. 48.

691 Caesar (1996a), S. 241. Als Beispiel eines ,Zwingenden politischen Grundes" sei auf die Erweiterung der EU um die Mitgliedstaaten Finnland, Österreich und Schweden 1995 verwiesen, die eine Revision der geltenden Finanziellen Vorausschau von 1993-1999 auslöste. Vgl. hierzu Abschnitt IV-2.1.3.2. 
Zweckbestimmung zugewiesen wird." ${ }^{692}$ Ausdruck dieses Grundsatzes ist die planvolle Gliederung der einzelnen Ausgabenposten nach Art und Bestimmung der Mittelansätze. Der Haushaltsplan der EU weist eine horizontale und vertikale Gliederung auf:

- Die horizontale Gliederung umfaßt den Gesamteinnahmenplan und sechs Einzelpläne. In letzteren sind jeweils die Einnahmen- und Ausgabenansätze des EP (Einzelplan I), des Ministerrates (Einzelplan II), der EK (Einzelplan III), des EuGH (Einzelplan IV) und des Rechnungshofs (Einzelplan V) sowie des Wirtschafts- und Sozialausschuß (WSA) und des Ausschuß der Regionen (AdR) (Einzelplan VI) enthalten. Eine besondere Gliederung hat hier ausschließlich der Einzelplan III - EK. Während alle anderen Einzelpläne ausschließlich Verwaltungsausgaben beinhalten, weist der Einzelplan der EK einen Teil A (Verwaltungsmittel) und einen Teil B (Operative Mittel) auf. Teil B ist wiederum aufgegliedert in 9 Teileinzelpläne, in denen alle haushaltswirksamen Transaktionen zur Erfüllung des Aufgabenkataloges der EU veranschlagt werden. Dieser Teil umfaßt ca. 95 Prozent der Ausgaben der EU.

- Die vertikale Gliederung stellt den sogenannten Eingliederungsplan dar. Der Gesamteinnahmenplan sowie jeder Einzelplan des horizontalen Gliederungsschemas wird nach Art und Zweckbestimmung sowohl auf der Ausgabenseite als auch auf der Einnahmenseite in Titel, Kapitel, Artikel und Posten untergliedert, um so die Vielschichtigkeit der Aufgabenbereiche der EU angemessen erfassen zu können.

\section{IV-2.1.3 Die Ausgabenseite der Finanzverfassung}

\section{IV-2.1.3.1 Die Ausgabenverteilung}

Im EUV existiert keine Grundsatzvorschrift zur Ausgabenverteilung zwischen den Mitgliedstaaten und der EU-Ebene. „Insgesamt stehen der Gemeinschaft deshalb überall dort Finanzierungszuständigkeiten zu, wo sie nach dem Vertrag tätig werden darf, es sei denn, die einschlägige Ermächtigungsnorm schließt gerade die Kostentragung aus. ${ }^{693}$ Damit begründet sich die Ausgabenverteilung innerhalb der EU implizit auf das Konnexitätsprinzip. Die EU-Ebene trägt grundsätzlich diejenigen Ausgaben, die sich aus der Wahrnehmung ihrer vertraglichen Aufgabenbereiche ergibt. ${ }^{694}$

692 Europäische Kommission (1995a), S. 68.

693 Häde (1996), S. 402 f.

694 Vgl. allgemein zu Begriff und Problematik des Konnexitătsprinzips Zimmermann (1983), S. 38 und aktuell Geske (1996) u. (1998). 
Jedoch unterliegt die Anwendung des Konnexitätsprinzip in der Realität großen Schwierigkeiten, denn die Mitgliedstaaten können selbst in Feldern, in denen die EU-Ebene die Primärkompetenz besitzt, in einem bestimmten Umfang an der Aufgabenerfullung beteiligt sein, ${ }^{695}$ so daß sich unter Berücksichtigung des Konnexitätsprinzips zumeist eine parallele Beteiligung der Mitgliedstaaten und der EU-Ebene an den Ausgaben eines Tätigkeitsbereiches ergibt. Die exakte Bestimmung des Grades der Aufgabenerfüllung der mitgliedstaatlichen bzw. zentralen Ebene, die aus dem der Anteil der Ausgabenverantwortung abzuleiten wäre, ist jedoch in der Praxis kaum durchführbar. Zudem ergeben sich aufgrund der Unklarheit des EUV im Hinblick auf die Aufgabenverteilung Zuständigkeitsauseinandersetzungen zwischen den Mitgliedstaaten und der EU-Ebene. Damit bleibt aber die Aufgabenverteilung, auf deren Basis die Ausgabenverteilung zu erschließen wäre, „politisch" umstritten und die Anwendung des Konnexitätsprinzips wird erschwert. Eindeutig ist die Ausgabenverteilung nur innerhalb jener Aufgabenbereiche zu bestimmen, in denen das Primärrecht der EU entweder das Handeln der Mitgliedstaaten explizit untersagt oder die Finanzierungskompetenz der EU-Ebene ausdrücklich ausschließt. ${ }^{696}$

\section{IV-2.1.3.2 Das Volumen und die Struktur der Ausgabentätigkeit}

Die Ausgaben der EU sind stets Ausdruck des Entwicklungsstandes des europäischen Einigungsprozesses. Vertiefungs- und Erweiterungsphasen im Integrationverlauf wandeln das Aufgabenspektrum und den Ausgabenbedarf der EU-Ebene. Diese Entwicklungsprozesse spiegeln sich in der dynamischen Entwicklung des Volumens und der Struktur der EUAusgaben wider, ${ }^{697}$ wie die nachfolgenden Betrachtungen zur von 1993-1999 geltenden Finanziellen Vorausschau und zur Ausgabenentwicklung seit 1970 verdeutlichen.

Die Finanzielle Vorausschau besitzt eine funktionsbezogene Klassifizierung. Sie bildet die Ausgabenstruktur der EU im Hinblick auf ihre wesentlichen Aufgabenbereiche ab. ${ }^{698}$ Im einzelnen werden die folgenden sieben Rubriken voneinander abgegrenzt: ${ }^{699}$

${ }^{695} \mathrm{Vgl}$. hierzu Fn 632 in Abschnitt IV-2.1.1.1.

696 Vgl. Häde (1996), S. 402 ff., m.w.N.

${ }^{697}$ Vgl. Europäische Kommission (1993a), S. 61 ff.; Caesar (1996a), S. 235 f. u. 245.

${ }^{698}$ Für den Haushalt der EU wird durch die EK neben dieser Gliederung nach Aufgabengebieten keine weitere Systematisierung der Einnahmen und Ausgaben vorgenommen. Insbesondere existiert keine Gliederung nach ökonomischen Kriterien, zu denen auch die Einnahmen und Ausgaben für Zuweisungen und Zuschulsse zăhlen (vgl. hierzu Noll (1979), S. 26 ff.). Daher ist es an dieser Stelle nicht möglich zu bestimmen, welches Volumen die FZ zwischen den Mitgliedstaaten aus institutioneller Sicht besitzen. In Kapitel V wird deshalb der Versuch unternommen, von den Wirkungen der FZ her argumentierend, zu einer Aussage über die Höhe der zwischenstaatlichen FZ im Haushalt der EU zu gelangen. Es zeigt sich dort aber, daß die Definition der FZ von den Wirkungen her umstritten bleibt und deshalb die Hobhe der FZ nicht exakt ermittelt werden kann (vgl. hierzu insb. Abschnitt V-5.2). 
- Die Gemeinsame Agrarpolitik des Europäischen Ausrichtungs- und Garantiefonds für die Landwirtschaft (EAGFL) - Abteilung Garantie zur Finanzierung klassischer Unterstützungsmaßnahmen im Bereich der Landwirtschaft sowie der Fischerei. Strukturelle Anpassungmaßnahmen im landwirtschaftlichen Sektor werden hingegen im EAGL - Abteilung Ausrichtung in der Rubrik II - Strukturmaßnahmen verbucht.

- Die Strukturmaßnahmen zur Förderung des wirtschaftlichen und sozialen Zusammenhalts. Sie umfassen die traditionellen Strukturfonds (Europäischer Fonds für Regionale Entwicklung (EFRE), Europäischer Sozialfonds (ESF) und EAGL - Abteilung Ausrichtung) ${ }^{700}$ und den 1993 eingerichtete Kohäsionsfonds.

- Die internen Politikbereiche fassen alle Maßnahmen der EU innerhalb bestehender und weiter auszubauender Politikbereiche (bspw. Ergänzung der Strukturpolitiken, Bildungspolitik, Energiepolitik, Umweltpolitik, und Industriepolitik) zusammen, die der beschleunigten Verwirklichung des Europäischen Binnenmarktes zuträglich sein sollen. Einen besonders wichtigen Schwerpunkt stellen die Programme im Bereich der Forschung und technologischen Entwicklung dar.

- Die externen Politikbereiche. Hierunter werden alle Ausgaben der EU zugunsten von Drittländern subsummiert.

- Die Verwaltungsausgaben der insgesamt sieben Organe der EU.

- Die Reserven. Im Rahmen dieser Ausgabenkategorie wird ein Spielraum zur Deckung unvorhergesehener Ausgaben geschaffen.

- Die Ausgleichszahlungen. Diese Rubrik wurde im Rahmen der EU-Erweiterung auf 15 Mitgliedstaaten zeitlich befristet eingerichtet. Sie weist Kompensationszahlungen an die Beitrittsstaaten Schweden, Österreich und Finnland für den Zeitraum 1995-1998 aus. ${ }^{701}$

Abb. IV-3 verdeutlicht die aktuelle Struktur der Ausgabenkategorien. Es verdeutlicht sich zudem selbst bei mittelfristigem Zeithorizont eine dynamische Entwicklung der gesamten EUAusgaben. Darüber hinaus demonstriert die Abbildung den Einfluß von Erweiterungsphasen der EU auf die Höhe des Budgets. Die „Norderweiterung” der EU im Jahr 1995 führte nicht nur zur Gewährung vorübergehender Kompensationszahlungen an die neuen Mitglieder, die sich auf über 2,5 Mrd. ECU von 1995-1998 summieren. Zusätzlich erfolgten prozentuale Steigerungen der Ausgabenplanungen für den Zeitraum 1995-1999 innerhalb aller traditonel-

\footnotetext{
699 Vgl. hierzu Europäische Kommission (1995a), S. 92 ff.

7001993 wurde zusătzlich der Fischerei-Sektor (Finanzinstrument für die Ausrichtung der Fischerei - FIAF) in den Anwendungsbereich der Strukturmaßnahmen aufgenommen.

${ }^{701} \mathrm{Vgl}$. hierzu Europäische Kommission (1995a), S. 35 ff.
} 
len Rubriken der Finanziellen Vorausschau, so daß sich im Vergleich zur ursprünglichen mittelfristigen Finanzplanung für die EUR 12 jährliche Gesamtausgabensteigerungen zwischen 3,4 Prozent (1999) und 4,6 Prozent (1996) ergeben: ${ }^{702}$

Abb. IV-3: Die Finanzielle Vorausschau der EU von 1993-1999 in Mrd. ECU

\begin{tabular}{|l|c|c|c|c|c|c|c|c|}
\hline \multirow{2}{*}{} & \multicolumn{2}{|c|}{ EUR 12 } & \multicolumn{5}{|c|}{ EUR 15 } \\
\cline { 2 - 8 } & \multicolumn{3}{|c|}{ (jeweilige Preise; für 1999 Preise des Jahres 1998) } \\
\cline { 2 - 8 } & 1993 & 1994 & 1995 & 1996 & 1997 & 1998 & 1999 \\
\hline Verpflichtungsermächtigungen: & & \multicolumn{5}{|c|}{} \\
\hline 1. Gemeinsame Agrarpolitik & 36,7 & 36,5 & 37,9 & 40,8 & 41,8 & 43,3 & 44,1 \\
\hline 2. Strukturmaßnahmen & 22,2 & 23,2 & 26,3 & 29,1 & 31,4 & 33,5 & 36,6 \\
\hline darunter: & & & & \multicolumn{4}{|c|}{} \\
\hline 2.1 Strukturfonds & 20,6 & 21,3 & 24,1 & 26,6 & 28,6 & 30,5 & 33,7 \\
\hline 2.2 Kohäsionsfonds & 1,6 & 1,9 & 2,2 & 2,4 & 2,8 & 2,9 & 2,9 \\
\hline 3. Interne Politikbereiche & 4,1 & 4,4 & 5,1 & 5,3 & 5,6 & 6,0 & 6,2 \\
\hline 4. Maßnahmen im Außenbereich & 4,1 & 4,3 & 4,9 & 5,3 & 5,6 & 6,2 & 6,7 \\
\hline 5. Verwaltung & 3,4 & 3,6 & 4,0 & 4,2 & 4,4 & 4,5 & 4,6 \\
\hline 6. Reserven & 1,5 & 1,5 & 1,2 & 1,2 & 1,2 & 1,2 & 1,2 \\
\hline 7. Ausgleichszahlungen & - & - & 1,5 & 0,7 & 0,2 & 0,1 & - \\
\hline $\begin{array}{l}\text { Verpflichtungsermächtigungen ins- } \\
\text { gesamt: }\end{array}$ & $\mathbf{7 2 , 0}$ & $\mathbf{7 3 , 5}$ & $\mathbf{8 0 , 9}$ & $\mathbf{8 6 , 6}$ & $\mathbf{9 0 , 2}$ & $\mathbf{9 4 , 7}$ & $\mathbf{9 9 , 4}$ \\
\hline $\begin{array}{l}\text { Ausgabensteigerungen im Vergleich zur ursprünglichen } \\
\text { Finanziellen Vorausschau der EUR 12 (in Prozent): }\end{array}$ & $4,1 \%$ & $4,6 \%$ & $3,9 \%$ & $3,7 \%$ & $3,4 \%$ \\
\hline
\end{tabular}

Quelle: Europäische Kommission (1997a), S. 63 f. u. 66.

Abb. IV-4 zeigt demgegenüber die längerfristige Entwicklung der Ausgabenstrukturen. Sie belegt die dominierende Bedeutung, die traditionell den Ausgaben im Agrarsektor zukommt. Mit der Einrichtung des EAGFL im Jahr 1962 stellte die Gemeinsame Agrarpolitik (GAP) den zentralen Tätigkeitsbereich der EU dar, in dem bis weit über 80 Prozent aller EU-Ausgaben erfolgten. Im Laufe des Integrationsprozesses übertrugen die Mitgliedstaaten jedoch weitere Kompetenzbereiche an die EU, wodurch eine fortschreitende Veränderung der Ausgabenstrukturen ausgelöst wurde. Die Strukturmaßnahmen der EU erhielten im Zusammenspiel

${ }^{702}$ Die Erweiterung der $E U$ fulhrt zu Niveauverschiebungseffekten bei den Ausgaben. Diese können sich nicht nur auf die absolute Höhe der Ausgaben, sondern auch auf die Ausgabenstruktur beziehen; zudem weisen die Effekte je nach spezifischem Integrationsschritt eine unterschiedliche Intensität auf. Unter diesem Blickwinkel konnte die Norderweiterung als unproblematisch bezeichnet werden, da die Ausgabenstruktur der $E U$ kaum beeinflußt wurde und sich der entstehende zusätzliche Ausgabenbedarf in Grenzen hielt. Er konnte zudem wegen der Finanzstärke der neuen Mitglieder leicht bewältigt werden. Größere Auswirkungen besaß demgegenüber die Erweiterung der $E U$ im Jahr 1986 um die finanzschwachen Beitrittskandidaten Spanien und Portugal. Das Gesamtausgabevolumen der EU erhöhte sich von 1985 auf 1986 um mehr als 24 Prozent (vgl. Europäische Kommission (1995b, S. 28). In diesem Zusammenhang bestehen auch erhebliche Bedenken im Hinblick auf weitere anstehende Erweiterungsschritte. Die Beitrittskandidaten in Mittel- und Osteuropa sind außerst finanzschwach und wïrden unter Anwendung der bestehenden Rahmenbedingungen im Agrarund im Strukturbereich einen Anspruch auf enorme Zahlungen durch die $E U$ besitzen (vgl. hierzu näher Abschnitt V-2.5). 
zwischen Vertiefung und Erweiterung der Gemeinschaft eine beständig zunehmende Bedeutung, um durch die Unterstützung der strukturschwächeren Mitgliedstaaten den wirtschaftlichen und sozialen Zusammenhalt im Integrationsprozeß zu fördern. ${ }^{703} \mathrm{Zudem}$ wurde mit Beschlüssen der EU des Jahres 1988 und 1992 eine Reform der GAP eingeleitet, die u.a. jährliche Höchstgrenzen für Ausgabensteigerungen im Agrarbereich bestimmt. ${ }^{704}$ Dennoch verkörpern die Ausgaben im Bereich des EAGFL - Garantie 1998 mit über 47 Prozent weiterhin den größten Block der Gesamtausgaben. Die Strukturmaßnahmen, auf die $1970^{\circ}$ nur knapp drei Prozent aller Ausgaben entfielen, bilden nunmehr die zweitwichtigste Ausgabekategorie mit einem Anteil von ca. 33 Prozent. Diese beiden Felder stellen die mit Abstand ausgabenintensivsten Tätigkeitsbereiche der EU dar, auf die über 80 Prozent aller EU-Ausgaben entfallen.

Abb. IV-4: Die Entwicklung der Ausgabenstruktur der EU, ausgewählte Jahre 1970-98

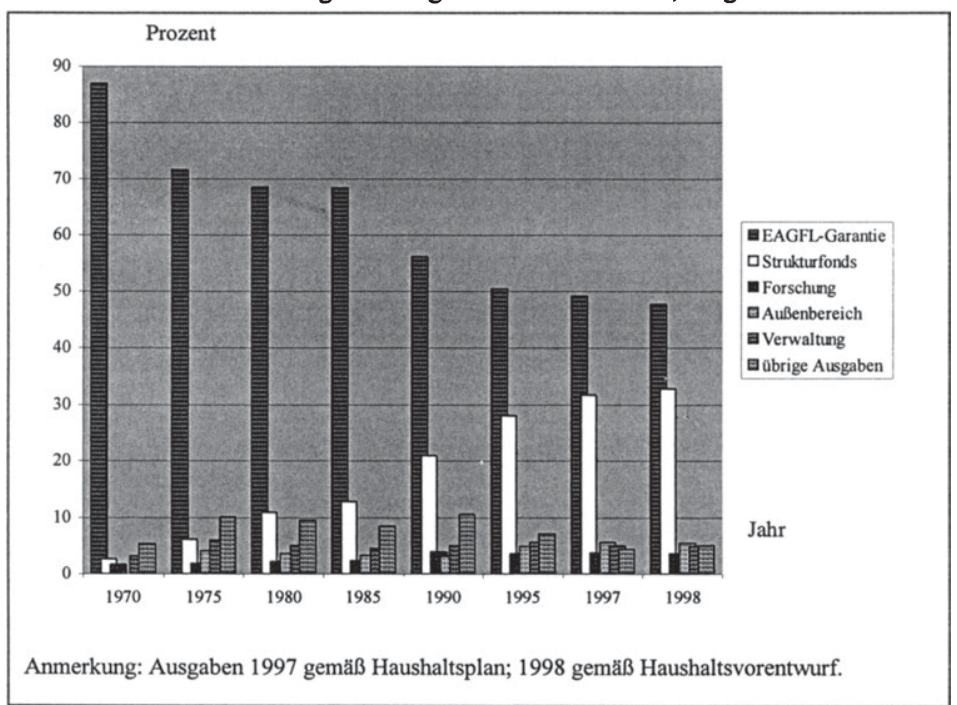

Quelle: Europăische Kommission (1997a), S. 32 ff.

Als weitere Ausgabenfelder mit im Zeitablauf zunehmenden Bedeutung sind die Forschungsausgaben im Bereich der internen Politiken und die Maßnahmen zur Zusammenarbeit mit Drittländern im Außenbereich zu nennen, wobei deren Ausgabenanteile weiterhin gering bleiben. Die Verwaltungausgaben weisen trotz der beständigen Verdichtung der institutionellen Strukturen der EU im gesamten Zeitraum einen relativ stabilen Ausgabenanteil auf.

703 Vgl. hierzu năher Abschnitt V-2 dieser Arbeit.

${ }^{704}$ Vgl. zur bisherigen Reform der GAP und dem weiterhin bestehenden Reformbedarf Pfetsch (1997), S. 170 ff.; Schmitt (1998) und insb. den Report der Europäische Kommission (1997e). 
Die EU-Ausgaben betragen $1998 \mathrm{ca} .87 \mathrm{Mrd}$. ECU. ${ }^{705}$ Im Vergleich mit dem Budget des Jahres 1970 in Höhe von knapp 3,6 Mrd. ECU stellt dies absolut betrachtet ein beträchtliches Ausgabevolumen dar. In relativer Betrachtung zum BSP der EU oder zu den öffentlichen Ausgaben der Mitgliedstaaten erscheint das Budget hingegen vergleichsweise gering. So verkörpern die Gemeinschaftsausgaben weniger als 1,2 Prozent des BSP der Mitgliedstaaten und nur in etwa 2,4 Prozent der öffentlichen Ausgaben der Mitgliedstaaten. ${ }^{706}$

Eine aussagefähige Bewertung des Gesamtumfangs des EU-Haushalts kann jedoch nur unter Berücksichtigung der Aufgabenverteilung zwischen der EU und den Mitgliedstaaten erfolgen. ${ }^{707}$ Zudem ist die Ausgabenintensität der Aufgabenerfüllung in die Überlegungen einzubeziehen ${ }^{708}$ und zu berücksichtigen, daß eine Reihe der ausgabewirksamen Aktivitäten der EU ihren Niederschlag außerhalb des Budgets finden. ${ }^{709}$

\section{IV-2.1.4 Die Einnahmenseite der Finanzverfassung}

Die Einnahmeseite der Finanzverfassung der EU unterscheidet sich maßgeblich von jenen traditioneller (föderativer) Nationalstaaten, insb. im Hinblick auf die Verteilung der Gesetzgebungs-, Ertrags- und Verwaltungskompetenz der Besteuerung. ${ }^{710}$ Im derzeitigen „System der

${ }^{705}$ Zahlungen gemäß Haushaltsvorentwurf 1998; vgl. Europäische Kommission (1997a), S. 30.

706 Vgl. Europäische Kommission (1997a), S. 37. Als Vergleichsgröße wird auf die Offentlichen Ausgaben in Deutschland verwiesen. Die Ausgaben der GKS betragen dort momentan ca. 34 Prozent des BSP Deutschlands; unter Berücksichtigung der Sozialversicherungsausgaben erreichen die gesamten öffentlichen Ausgaben sogar einen Anteil von ubber 50 Prozent, wobei der Anteil des Bundes fast 13 Prozent des BSP umfaßt. In dieser Relation besitzt folglich allein der Bundeshaushalt ein mehr als zehnfaches Volumen der Gesamtausgaben der EU (vgl. Institut der deutschen Wirtschaft Köln (1997), Tabelle 80).

$707 \mathrm{Vgl}$. hierzu die Ausfuihrungen in Abschnitt IV-2.1.1. Unter Beachtung bestehender allokations-, verteilungsund stabilitătspolitischer Aufgabenbereiche gelangte die $E K$ im Jahre 1993 zu dem Ergebnis, daß der EUHaushalt in den ersten Jahren nach Einfuhrung einer einheitlichen Wăhrung einen Umfang von ca. 1,75-2,10 Prozent des BSP der Mitgliedstaaten umfassen müßte (vgl. Europäische Kommission (1993a), S. 76 u. 82 ). Auch Biehl (1991a), S. 356 bezweifelt mit Blick auf bestehende foderative Staaten, daß die Aufgaben der sich fortentwickelnden EU-Ebene beim derzeitigen Ausgabevolumen von weniger als 1,3 Prozent des BSP erfolgreich erfullt werden können. Schon 1977 vertrat die sogenannte MacDougall-Gruppe in einem für die EK erstellten Gutachten die Auffassung, daß zumindest ein Ausgabevolumen von 5-7 Prozent des BSP im Integrationsprozeß vonnöten sein wird, um die Wirtschafts- und Wăhrungsunion wirksam zu untermauern (vgl. Europäische Kommission (1977a), S. $74 \mathrm{ff}$ ).

${ }^{708} \mathrm{Vgl}$. hierzu Abschnitt IV-2.1.1.3. Ein relativ geringes EU-Ausgabevolumen kann daher sehr wohl mit einem erheblichen Aufgabenerfullungsanteil der EU-Ebene verbunden sein. Vgl. hierzu auch Zimmermann/Henke (1994), S. 208.

709 Vgl. hierzu Abschnitt IV-2.1.2. zum Haushaltsgrundsatz der Einheit des Gemeinschaftshaushalts.

710 Diese drei Teilkompetenzen verkörpern die Elemente der Steuerhoheit des offentlichen Sektors. Ihre Verteilung auf die bestehenden GKS bestimmt die Einnahmeautonomie der einzelnen Ebenen des betrachteten Staatsgebildes. Dabei besitzt die Verwaltungskompetenz eine eher untergeordnete, im wesentlichen auf die Minimierung des Erhebungs- und Entrichtungsaufwandes der Besteuerung beschränkte Bedeutung. Deshalb wird im Folgenden auf diesen Kompetenzbereich nicht näher eingegangen. Jedoch sei an dieser Stelle darauf hingewiesen, daß innerhalb der $E U$ größtenteils die Mitgliedstaaten die Verwaltungskompetenz besitzen. Sie nehmen die Einnahmen ein und leiten sie an die EU-Ebene weiter (vgl. hierzu Europäische Kommission (1995a), S. 45; Henke (1997), S. 45). 
Eigenmittel"711 ist die Einnahmeautonomie der europäischen Entscheidungsträger sehr stark begrenzt. Sie verfügen nur über äußerst eingeschränkte Kompetenzen zur Beeinflussung der Struktur der Einnahmenerzielung. Zudem unterliegen die Einnahmen durch die sogenannte „Eigenmittelobergrenze” dem Volumen nach einer fixen Beschränkung. ${ }^{712}$

\section{IV-2.1.4.1 Die Besonderheit des Einnahmensystems der EU}

Die heutige Struktur des Einnahmensystems entstand Schritt für Schritt im Laufe des europäischen Integrationsprozesses. Die Fortentwicklung des Systems findet ihre rechtliche Grundlage in Art. 201 (2) EGV, der die Möglichkeit zur Weiterentwicklung des ursprünglichen Einnahmensystems der Gemeinschaft durch die Verabschiedung sogenannter „Eigenmittelbeschlüsse" vorsieht. ${ }^{713}$ Das besondere Entscheidungsverfahren des Art. 201 EGV demonstriert die stark begrenzte Einnahmenautonomie der EU-Ebene bezüglich der Gesetzgebungskompetenz: Auf Vorschlag der EK und nach Anhörung des EP trifft der Ministerrat den Beschluß über die Bestimmungen der Einnahmenerzielung, der grundsätzlich einstimmig zu erfolgen hat. Darüber hinaus erfordert jeder Eigenmittelbeschluß die Ratifizierung durch die Mitgliedstaaten gemäß deren verfassungsrechtlichen Vorschriften. Folglich verbleibt die letzte Entscheidungskompetenz hinsichtlich der Struktur und des Volumens des Einnahmesystems uneingeschränkt bei den Mitgliedstaaten. Die EU-Ebene besitzt keine von den Mitgliedstaaten unabhängige Steuergesetzgebungshoheit. ${ }^{714}$

Die EU finanzierte sich zunächst bis zum Jahr 1970 aus Finanzbeiträgen, die nach einem festen Verteilungsschlüssel von den einzelnen Mitgliedstaaten geleistet wurden. Seitdem erfolgte im Rahmen vierer „Eigenmittelbeschlüsse” der Jahre 1970, 1985, 1988 und 1994 die schrittweise Ersetzung dieser Finanzbeiträge durch sogenannte „eigene Mittel” der EU. ${ }^{715}$ Diese werden nach den Vorstellungen der EK durch eine Reihe von Definitionsmerkmalen gekennzeichnet: Eigene Mittel sind zum ersten unmittelbar von Einzelpersonen oder Unternehmen in der Gemeinschaft aufzubringen; sie unterliegen zum zweiten nicht den Beschlüssen der Mitgliedstaaten und müssen auch durch deren Parlamente nicht genehmigt werden; zum dritten sind Eigenmittel nicht Teil der Einnahmen der Mitgliedstaaten und brauchen da-

\footnotetext{
711 Art. 201 (2) EGV.

712 Vgl. Europäische Kommission (1993a), S. 83.

713 Vgl. Oppermann (1991), S. 269 f.

${ }^{714}$ Vgl. Europäische Kommission (1993a), S. 21 f.; Häde (1996), S. 207; Henke (1997), S. 45.

${ }^{715}$ Für das Jahr 1999 steht erneut eine Revision an. Der Europäische Rat hat die Kommission aufgefordert, bis zu diesem Zeitpunkt einen umfassenden Bericht zur Beurteilung des derzeitigen Einnahmesystems anzufertigen, auf dessen Grundlage als notwendig erachtete Reformen durchgefuhrt werden können (vgl. Europäische Kommission (1995a), S. 47).
} 
her im Haushaltsplan der Mitgliedstaaten nicht ausgewiesen werden. ${ }^{716}$ Zum heutigen Zeitpunkt werden zu diesen Eigenmitteln die „traditionellen Eigenmittel” der Agrarabschöpfungen und der Zölle sowie die „sonstigen Eigenmittel” der MwSt.-Eigenmittel und der Eigenmittel auf Grundlage des BSP der Mitgliedstaaten gezählt. Darüber hinaus verzeichnet die EU im Rahmen ihres Gesamthaushaltsplans verschiedene ,andere” Einnahmen geringeren Umfangs, die nicht als Eigenmittel bezeichnet werden. ${ }^{717}$

Das Finanzierungskonzept des Gemeinschaftshaushalt wird als „Ausgabenhaushalt" ${ }^{718}$ bezeichnet, da in einem ersten Schritt die Veranschlagung der Ausgaben erfolgt, bevor in einem zweiten Schritt die Berechnung der zum Haushaltsausgleich erforderlichen Einnahmen durchgeführt wird. Hierbei werden von dem geplanten Gesamtausgabenbetrag zunächst die gerade beschriebenen verschiedenen ,anderen” Einnahmen, die keine Eigenmittel darstellen abgezogen, um den Betrag zu ermitteln, der durch Eigenmittel finanziert werden muß. Daraufhin werden die veranschlagten Einnahmen im Bereich der traditionellen Eigenmittel abgezogen. Es verbleibt der Restfinanzierungsbetrag, der durch die sonstigen Eigenmittel auf Grundlage der MwSt. und des BSP finanziert werden muß. ${ }^{719}$

Die Eigenmittelbeschlüsse drücken das Bemühen aus, das Einnahmensystem der EU in Einklang mit der fortschreitenden Vertiefung des Integrationsprozesses weiterzuentwickeln. Mit zunehmender Herausbildung einer „echten” vierten Ebene eines föderativen Staatengebildes soll der EU eine ansteigende Einnahmenautonomie eingeräumt werden. ${ }^{720}$ Daher erfolgte der Übergang von einer reinen Beitragsfinanzierung, wie sie typischerweise im Rahmen internationaler Organisationen erfolgt, zur Finanzierung über eigene Mittel. Die nachfolgende Beschreibung der Eigenmittelarten verdeutlicht jedoch, daß die Gesetzgebungs- und Ertragskompetenzen der EU nach wie vor stark eingeschränkt sind. Die einzelnen Einnahmequellen erfüllen die Eigenschaften, die die EK zur Definition von „Eigenmitteln” aufgestellt hat nur in sehr eingeschränktem und zudem unterschiedlichem Maße:

- Agrarabschöpfungen und Zölle werden als die traditionellen Eigenmittel der EU bezeichnet. Die Nutzung dieser Einnahmen entspricht „der Logik des Gemeinsamen Marktes”, 721 da sie bei Importen von Agrarprodukten bzw. Waren aus Drittstaaten an den Außengrenzen

\footnotetext{
${ }_{716}^{716}$ Vgl. Europäische Kommission (1978).

717 Diese werden im Rahmen dieser Arbeit nachfolgend als „andere” Einnahmen bezeichnet; häufig werden sie als „sonstige" Einnahmen betitelt, wie bspw. auch von der Europäischen Kommission (1995a), S. 86, dann jedoch besteht die Gefahr der Verwechslung mit den sonstigen Eigenmitteln. Vgl. zu den ,anderen” Einnahmen Europäische Kommission (1995a), S. 86; Häde (1996), S. 449 ff.

718 Europäische Kommission (1995a), S. 89.

719 Vgl. Europäische Kommission (1995a), S. 89 ff.

${ }^{720} \mathrm{Vgl}$. Europäische Kommission (1993a), S. 83 ff. u. $111 \mathrm{ff}$.

721 Oppermann (1991), S. 273.
} 
der EU erhoben werden. Die EU besitzt die uneingeschränkte Ertragskompetenz für die traditionellen Eigenmittel. ${ }^{722}$ Zudem verfügen die EU-Entscheidungsträger in diesem Bereich auch über die ausschließliche Gesetzgebungskompetenz. Jedoch erfolgt die Ausübung dieser Gesetzgebungskompetenz nicht aus fiskalischen Überlegungen zur Einnahmeerzielung, sondern ausschließlich unter Beachtung handels- und agrarpolitischer Erwägungen, insb. zum Schutz inländischer Wirtschaftssubjekte. ${ }^{723}$

- MwSt.-Eigenmittel gehören zur Kategorie der sonstigen Eigenmittel. Sie wurden bereits mit dem ersten Eigenmittelbeschluß 1970 als dritte Einnahmequelle der EU eingeführt, nachdem sich herausgestellt hatte, daß die traditionellen Eigenmittel die Finanzierung der EUAusgaben nicht länger garantieren können. ${ }^{724}$ Die MwSt.-Eigenmittel übernahmen die Restfinanzierung des Ausgabenanteils, der durch die traditionellen Eigenmittel nicht abgedeckt werden konnte. Mit der Einführung der „vierten” Einnahmenquelle im Jahr 1988 wurde diese Funktion jedoch von den BSP-Eigenmitteln übernommen. ${ }^{725}$

Die Einnahmen werden durch die Anwendung eines für alle Mitgliedstaaten übereinstimmenden Satzes auf die Bemessungsgrundlage der MwSt. jedes Mitgliedstaates gewonnen. Die Bemessungsgrundlage ist nach EU-Vorschriften einheitlich festgelegt und zwischen den Mitgliedstaaten harmonisiert. Der anzuwendende Prozentsatz wird im jährlichen Haushaltsverfahren festgelegt. Hierbei besteht eine Obergrenze, die zunächst 1,0 Prozent der einheitlichen Bemessungsgrundlage betrug. Um zusätzliche Ausgabebedarfe infolge der EU-Erweiterung auf zwölf Mitglieder alimentieren zu können, wurde dieser Höchstsatz im Jahr 1986 auf 1,4 Prozent angehoben. Diese Erhöhung wird im Zeitraum von 19951999 schrittweise wieder rückgängig gemacht. ${ }^{726}$ Bis zum Jahr 1994 durfte die Bemessungsgrundlage der MwSt. eines Mitgliedstaats, die zur Berechnung der abzuführenden MwSt.-Eigenmittel herangezogen wurde, 55 Prozent seines BSP nicht überschreiten. Vom Jahr 1995 an wird diese Kappungsgrenze für Mitgliedstaaten, die ein Pro-Kopf-BSP von weniger als 90 Prozent des EU-Durchschnitts aufweisen, auf 50 Prozent abgesenkt; für alle anderen Staaten wird diese Begrenzung schrittweise bis zum Jahr 1999 vollzogen. ${ }^{727}$

\footnotetext{
${ }^{722}$ Allerdings erhalten die Mitgliedstaaten, durch deren Behörden die Erhebung der Zölle bzw. Agrarabschöpfungen erfolgt, einen Pauschalbetrag von 10 Prozent der jeweils erzielten Gesamteinnahmen, um hierdurch die Erhebungskosten abzudecken. Diese Regelung stell jedoch keine Beteiligung der Mitgliedstaaten am Aufkommen und damit auch keine partielle Ertragskompetenz der Mitgliedstaaten dar (vgl. hierzu Europäische Kommission (1995a), S. 82; Häde (1996), S. 444 f.).

${ }^{723}$ Vgl. Caesar (1996b), S. 147 sowie Häde (1996), S. 439 f. und Hünger (1996), S. 20.

${ }^{724}$ Vgl. Europäische Kommission (1995a), S. 82 f. Zu dieser Entwicklung trugen neben Ausgabensteigerungen auch die im Rahmen der GATT.Verhandlungen beschlossenen Zollsenkungen bei, die das Einnahmevolumen beider traditioneller Eigenmittelarten begrenzten (vgl. Caesar (1996a), S. 248).

${ }^{725} \mathrm{Vgl}$. Häde (1996), S. 442 f.

${ }^{726}$ Vgl. hierzu Häde (1996), S. 442.

${ }^{727}$ Vgl. Europäische Kommission (1995a), S. 83.
} 
Beide Maßnahmen, sowohl die Kappung des Anteils der zu berücksichtigenden Bemessungsgrundlage als auch die Begrenzung des darauf anzuwendenden Höchstsatzes, tragen zur Reduzierung des Einnahmeanteils der MwSt.-Eigenmittel an den Gesamteinnahmen der EU bei. Aufgrund ihrer Funktion als Restfinanzierungsquelle im „Ausgabenhaushalt” der EU resultiert eine entsprechende Erhöhung des Einnahmeanteils der BSPEigenmittel. ${ }^{728} \mathrm{Da}$ die MwSt.-Eigenmittel von den EU-Entscheidungsträgern als regressive Einnahmequelle angesehen werden, ist diese Entwicklung beabsichtigt, um zur Verwirklichung einer proportionalen Verteilung der Finanzierungslasten zwischen den Mitgliedstaaten der EU beizutragen. ${ }^{729}$ Denn das BSP eines Mitgliedstaates stellt einen geeigneten Leistungsfähigkeits-Indikator dar. ${ }^{730}$

Die EU-Ebene besitzt in bezug auf die MwSt. eine partielle Gesetzgebungshoheit. Nach Art. 99 EGV darf die EU Bestimmungen zur Harmonisierung der Rechtsvorschriften erlassen soweit dies zur Durchsetzung des Binnenmarktes erforderlich ist. In Anwendung dieser Befugnis legt die EU eine einheitliche Bemessungsgrundlage fest und begrenzt den Gesetzgebungsspielraum der Mitgliedstaaten bei der Tarifgestaltung. Seit 1993 bestehen Untergrenzen für die MwSt.-Sätze. ${ }^{731}$ Allerdings müssen die Beschlüsse der EU-Ebene gemäß Art. 99 EGV einstimmig durch den Ministerrat verabschiedet werden. ${ }^{732}$ Hinsichtlich der Ertragskompetenz wird der EU-Ebene ab 1999 ein Prozent des Steueraufkommens der beschränkten MwSt.-Bemessungsgrundlage garantiert. Jedoch gibt es keine Bestimmung, „daß Mehrwertsteuer-Eigenmittelzahlungen aus den nationalen MehrwertsteuerEinnahmen zu leisten sind." ${ }^{\text {733 }}$ Aus diesem Grund sind die MwSt.-Eigenmittel „nicht als echte Steuereinnahmen der Gemeinschaft, sondern faktisch als Finanzbeiträge einzustufen", ${ }^{734}$ die nicht direkt von den Unternehmen oder Einzelpersonen geleistet, sondern von den Mitgliedstaaten aus deren allgemeinen Einnahmen an die EU abgeführt werden. ${ }^{735}$

- Die Eigenmittel auf der Grundlage des BSP wurden mit dem Eigenmittelbeschluß von 1988 als „vierte” Einnahmequelle eingefuihrt und werden zur Kategorie der sonstigen Eigenmittel gerechnet. Die Einnahmen ergeben sich durch die Anwendung eines im Rahmen

\footnotetext{
${ }^{728} \mathrm{Vgl}$. zu dieser Entwicklung auch Abb. IV-7 in Abschnitt IV-2.1.4.2.

${ }^{729}$ Eine proportionale Verteilung der Finanzierunglasten ist dann verwirklicht, wenn der Finanzierungsanteil eines Mitgliedstaates an den Gesamteinnahmen dem Pro-Kopf-Einkommen in diesem Mitgliedstaat entspricht. Vgl. Europäische Kommission (1993a), S. 85.

${ }^{730} \mathrm{Vgl}$. Europäische Kommission (1993a), S. 84 f.

${ }_{731}$ Dieser betrăgt 15 Prozent für den Normalsatz und 5 Prozent für den ermäßigten Satz der MwSt.

732 Zudem wilrde eine Änderung der Vorschriften über den der $E U$ zustehenden Anteil an den Erträgen der MwSt. einen neuen Eigenmittelbeschluß erfordern, der gemäß Art. 201 EGV durch alle Mitgliedstaaten ratifiziert werden müßte. Vgl. Peffekoven (1994), S. 60.

733 Seidel (1992), S. 147.

734 Caesar (1996b), S. 147.

735 Vgl. hierzu Seidel (1992), S. 146 ff.; Zimmermann/Henke (1994), S. 209; Caesar (1996b), S. 147 f.
} 
des Haushaltsverfahrens jährlich festzulegenden Satzes auf den Gesamtertrag des BSP aller Mitgliedstaaten. Dieses Festlegungsverfahren trägt der Funktion der BSP-Eigenmittel zur Restfinanzierung des EU-Haushaltes Rechnung. Der einheitliche BSP-Abrufsatz wird unter Berücksichtigung des Aufkommens aller übrigen Einnahmen so festgesetzt, daß der Haushaltsausgleich durch die Einnahmen der Restfinanzierungsquelle exakt gewährleistet wird. $^{736}$

Wie die MwSt.-Eigenmittel sind die BSP-Eigenmittel Finanzbeiträge der Mitgliedstaaten. Sie werden in ihrer Höhe auf Grundlage des BSP errechnet und von den Mitgliedstaaten aus deren allgemeinen Einnahmen an die EU überwiesen. Sie stellen daher keine eigenen Steuereinnahmen der EU-Ebene dar. Gesetzgebungskompetenz der EU beschränkt sich auf die jährliche Festlegung des BSP-Abrufsatzes. Hier verbleibt jedoch kein eigenständiger Handlungsspielraum, da sich die Höhe des Satzes wegen der Restfinanzierungsfunktion der BSP-Eigenmittel quasi automatisch als Ergebnis eines rein technischen Rechenverfahrens ergibt. Bezüglich der Ertragskompetenz kann „eine Quotierung der Erträge im Einnahmeverbund zwischen EU und Mitgliedstaat erkannt werden." ${ }^{, 737}$ Diese Quotierung bezieht sich auf das allgemeine Einnahmensystem der Mitgliedstaaten, so daß sich hieraus eine Einschränkung ihrer globalen Ertragshoheit ergibt. Die EU erhält jedoch keine Ertragkompetenz im Rahmen einer spezifischen Steuerart. ${ }^{738}$

Der Überblick zu den unterschiedlichen Eigenmitteln verdeutlicht, daß „die Einnahmenhoheit der EU nicht als sehr hoch einzuschätzen [ist], wenn sie an den Merkmalen eigener Steuern einer Ebene beurteilt wird." ${ }^{739}$ Diese Auffassung vertritt auch der WSA der EU, ${ }^{740}$ der eine substantielle Einnahmeautonomie erst dann gewährleistet sieht, wenn Mehrheitsentscheidungen der EU-Ebene über die Höhe und Struktur der Einnahmen möglich sind. ${ }^{741}$ Zum heutigen Zeitpunkt sind jedoch Einstimmigkeitsentscheidungen im Rat zu treffen, die zumeist gemäß der Verfassungsvorschriften der Mitgliedstaaten zu ratifizieren sind. Insgesamt ist es deshalb fraglich, ob die EU „mit dem derzeit praktizierten Eigenmittelsystem die notwendige finanzielle Autonomie schon erhalten hat, um als 'Körperschaft der vierten Ebene' eigenverant-

${ }^{736}$ Der jăhrliche Abrufsatz ist folglich eine flexible Rechengroße, die von Jahr zu Jahr in Abhängigkeit von Aufkommensschwankungen der übrigen Einnahmearten der $E U$ Veränderungen unterliegt. Im Gesamthaushaltsplan 1993 betrug der einheitliche Abrufsatz bspw. 0,2383 Prozent. Im nachfolgenden Jahr 1994 hingegen 0,3247 Prozent. Vgl. Europäische Kommission (1995a), S. 85.

737 Walthes (1996), S. 210.

738 Vgl. Seidel (1992), S. 147 f.; Häde (1996), S. 446.

739 Zimmermann/Henke (1994), S. 210.

${ }^{740}$ Der WSA verkörpert ein Nebenorgan der $E U$, das die $E K$ und den Ministerrat beratend unterstützt. Vgl. zum WSA näher Abschnitt IV-2.2.1.3.

741 Vgl. Wirtschafts- und Sozialausschuß (1970), S. 24; vgl. hierzu auch Häde (1996), S. 433 ff. 
wortlich und gestalterisch tätig werden zu können."742 Dieser Zweifel wird durch den Eigenmittelbeschluß des Jahres 1988 gestärkt, der die Kompetenzen der EU-Entscheidungsträger zusätzlich einschränkt. Der EU-Haushalt besitzt seitdem eine obere Schranke für das Einnahmenvolumen. ${ }^{743}$ Diese Eigenmittel-Obergrenze wird in bezug zum BSP der Mitgliedstaaten ausgedrückt. Die Höhe der Eigenmittelobergrenze wird im Rahmen der Finanziellen Vorausschau der EU jährlich fortgeschrieben. Abb. IV-5 zeigt die Entwicklung der Eigenmittelobergrenze im Rahmen der ersten und zweiten Finanziellen Vorausschau von 1988-1992 bzw. 1993-1999:

Abb. IV-5: Die Eigenmittel-Obergrenze der EU

\begin{tabular}{|l|c|c|c|c|c|c|c|c|c|c|c|c|}
\hline & \multicolumn{4}{|c|}{ 1. Finanzielle Vorausschau } & \multicolumn{5}{|c|}{ 2. Finanzielle Vorausschau } \\
\hline Jahr: & 1988 & 1989 & 1990 & 1991 & 1992 & 1993 & 1994 & 1995 & 1996 & 1997 & 1998 & 1999 \\
\hline $\begin{array}{l}\text { Eigenmittelobergrenze } \\
\text { in Prozent des BSP: }\end{array}$ & 1,15 & 1,17 & 1,18 & 1,19 & 1,20 & 1,20 & 1,20 & 1,21 & 1,22 & 1,24 & 1,26 & 1,27 \\
\hline
\end{tabular}

Quelle: Europăische Kommission (1995b), S. 53 u. S. 61; eigene Darstellung.

Die Eigenmittel-Obergrenze schränkt die Ertragskompetenz der EU-Ebene ein, wodurch deren Einnahmeautonomie verringert wird. ${ }^{744}$ Allerdings wächst der finanzielle Handlungsrahmen des EU-Haushalts durch die Verbindung zur Entwicklung des BSP der Mitgliedstaaten und der schrittweisen Anhebung des Eigenmittel-Plafonds deutlich an. Für den Zeitraum der zweiten Finanziellen Vorausschau von 1993-1999 ergibt sich unter der Annahme einer jährlichen (nominalen) Wachstumsrate des BSP der EU von 6,9 Prozent $^{745}$ ein durchschnittliches Wachstum des Haushaltsvolumen der EU von 8,6 Prozent. ${ }^{746}$

${ }^{742}$ Walthes (1996), S. 210 f. Diesem Zweifel müssen jedoch Überlegungen zur Ausgabenseite des EU-Haushalts gegenübergestellt werden. Dort besitzt die EU-Ebene erhebliche Handlungsspielrăume, um eigenverantwortlich und gestalterisch tätig werden zu können.

${ }^{743}$ Mit der Einfulhrung der Eigenmittel-Obergrenze 1988 ist das Finanzierungskonzept der EU nur noch eingeschränkt als „Ausgabenhaushalt” zu bezeichnen. Der Handlungsspielraum der Entscheidungsträger ist nunmehr auf der Einnahmeseite eng begrenzt, so daß auch auf der Ausgabenseite keine „beliebige” Veranschlagung der Ausgaben mehr erfolgen kann. Wird die Eigenmittelobergrenze voll ausgeschöpft, so geht es bei der Haushaltsaufstellung im wesentlichen um eine Verteilung eines vorgegebenen Einnahmevolumens auf verschiedene Ausgabenkategorien (vgl. Europäische Kommission (1995a), S.92).

744 Diese Aussage besitzt unabhångig davon Gültigkeit, ob diese Beschränkung zur Disziplinierung der Ausgabetătigkeit der EU-Entscheidungsträger als wilnschenswert erachtet wird.

745 Dies entspricht der Wachstumsprognose der EU für diesen Zeitraum. Vgl. Messal/Klein (1993), S. 376.

746 Vgl. Messal/Klein (1993), S. 375 f. Die Koppelung des Einnahmevolumens an das BSP der Mitgliedstaaten fuhrt jedoch zugleich zu einer verstärkten Konjunkturreagibilităt des finanziellen Handlungsspielraums der $E U$. Damit wird ein prozyklisches Ausgabeverhalten der $E U$ ausgelöst, das aus stabilitătspolitischen Gründen unerwilnscht ist (vgl. Peffekoven (1994), S. 93 f.). Daruber hinaus ist anzumerken, daß eine sinnvolle Bewertung der beschriebenen Entwicklung des Einnahmevolumens nur unter Beachtung der zur Erfullung bestehender Aufgaben notwendigen Ausgaben erfolgen kann. Vgl. hierzu die Anmerkungen zur Interpretation des momentanen Ausgabevolumens der EU-Ebene weiter oben in Abschnitt IV-2.1.3.2 dieses Kapitels. 
IV-2.1.4.2 Das Volumen und die Struktur der Einnahmen

Infolge der Eigenmittelbeschlüsse der EU erfolgte im Zeitverlauf der Integration nicht nur eine erhebliche Veränderung des Volumens sondern auch der Zusammensetzung der EUEinnahmen. Abb. IV-6 verdeutlicht beide Entwicklungslinien in absoluten Zahlen:

Abb. IV-6: Die Entwicklung der Einnahmen der EU, ausgewählte Jahre 1971-98

\begin{tabular}{|l|c|c|c|c|c|c|c|c|c|}
\hline \multicolumn{7}{|l|}{ in Mrd. ECU } \\
\hline \multicolumn{2}{|l|}{1971} & 1975 & 1980 & 1985 & 1990 & 1995 & $1997^{1}$ & $1998^{2}$ \\
\hline Gesamthaushaltsplan: \\
\hline Agrarabschöpfungen & 0,7138 & 0,5901 & 2,0023 & 2,1791 & 1,8757 & 1,9446 & 2,0155 & 1,6709 \\
\hline Zölle & 0,5823 & 3,151 & 5,9057 & 8,3101 & 10,2851 & 12,5086 & 12,2032 & 11,1443 \\
\hline MwSt.-Eigenmittel & - & - & 7,2585 & 15,2189 & 27,4401 & 39,1832 & 34,5877 & 34,1345 \\
\hline BSP-Eigenmittel & - & - & - & - & 0,0949 & 14,1912 & 32,9472 & 37,1466 \\
\hline Verschiedene Einnahmen & 1,0332 & 2,644 & 1,2658 & 2,377 & 6,7733 & 7,2495 & 0,612 & 0,6311 \\
\hline Insgesamt & 2,3293 & 6,3851 & 16,4323 & 28,0851 & 46,4691 & 75,0771 & 82,3656 & 84,7275 \\
\hline Anmerkung: 1) Haushaltsplan $1997 ; 2)$ Haushaltsvorentwurf 1998 \\
\hline
\end{tabular}

Quelle: Europäische Kommission (1997a), S. 40 f.

Die Einnahmen des Gesamthaushalts betragen 1998 über 84 Mrd. ECU; im Jahr 1971 weniger als 2,5 Mrd. ECU. Der Anteil der EU-Einnahmen am BSP der Mitgliedstaaten erhöhte sich in dieser Zeitspanne von weniger als 0,5 Prozent auf über 1,2 Prozent und verdeutlicht so die zunehmende Bedeutung des EU-Haushalts.

Das Aufkommen der MwSt.- und BSP-Eigenmittel hat seit ihrer Einführung in den 80erJahren gewaltig zugenommen. Im Jahr 1998 stammen über 71 Mrd. ECU aus diesen beiden Einnahmequellen. Demgegenüber hat sich die Bedeutung der Agrarabschöpfungen und Zölle seit 1971 beständig verringert. Während sich das gesamte Einnahmenvolumen seit $1971 \mathrm{mehr}$ als versechsunddreißigfacht hat, erfolgte lediglich eine Verzehnfachung der Einnahmen aus Agrarabschöpfungen und Zöllen, die 1998 zusammen ca. 13 Mrd. ECU umfassen. ${ }^{747} \mathrm{Zu}$ den „verschiedenen Einnahmen" zählen in der Abbildung alle Arten von Einnahmen des Gesamthaushalts, die keine Eigenmittel sind. Hierzu gehören die bereits zuvor als ,andere Einnahmen" abgegrenzten Beträge geringeren Umfangs, darüber hinaus aber in den ersten Jahren des betrachteten Zeitraums vor allem die Finanzbeiträge der Mitgliedstaaten. Diese besaßen bis zur Einführung der MwSt.-Eigenmittel einen Einnahmenanteil von über 40 Prozent bevor sie als Einnahmeart vollständig abgeschafft wurden. ${ }^{748}$

\footnotetext{
${ }^{747} \mathrm{Vgl}$. zur Begrüindung dieser Entwicklung Fn 724 weiter oben in Abschnitt IV-2.1.4.1.

${ }^{748}$ Vgl. Europäische Kommission (1995b), S. 19.
} 
Abb. IV-7: Die Entwicklung der Einnahmestruktur der EU, ausgewählte Jahre 1971-98

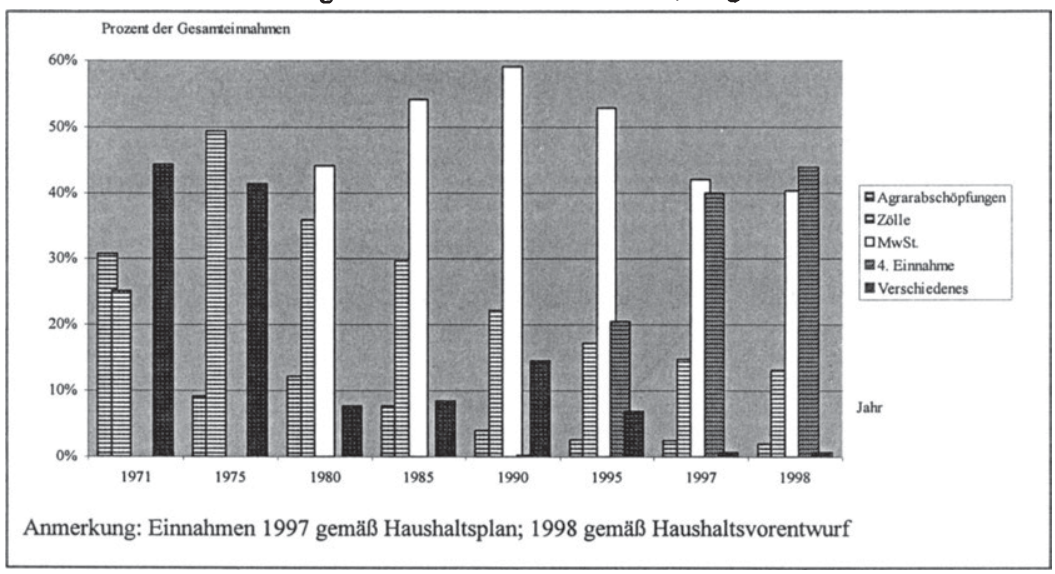

Quelle: Europäische Kommission (1997a), S. 40 f.

Abb. IV-7 faßt die Entwicklung der Einnahmenstruktur der EU seit 1971 zusammen. Es zeigt sich die große Bedeutung der Zölle und Agrarabschöpfungen zu Beginn des betrachteten Zeitraums. Sie tragen 1971 zusammen fast 56 Prozent der Gesamteinnahmen. Seitdem hat sich ihr Einnahmenanteil jedoch stetig verringert. Sie steuern zum Gesamthaushalt 1998 weniger als 16 Prozent der Gesamteinnahmen bei. Im Gegensatz hierzu entwickelten sich die MwSt.- und BSP-Eigenmittel infolge der Einnahmebeschlüsse der EU zu den beiden herausragenden Einnahmearten (1998: ca. 84 Prozent der Gesamteinnahmen). Als Konsequenz der jüngsten Maßnahmen zur Einschränkung der MwSt.-Einnahmen übernehmen hierbei die BSP-Einnahmen einen zunehmenden Anteil im Vergleich beider Einnahmequellen. 1998 übertrifft der Anteil der BSP-Einnahmen (ca. 44 Prozent) erstmals jenen der MwSt.-Einnahmen (ca. 40 Prozent). Im Laufe des verbleibenden Zeitraums der zweiten Finanziellen Vorausschau wird der Anteil der BSP-Eigenmittel auf ca. 48 Prozent weiter ansteigen, der der MwSt.-Eigenmittel hingegen auf ca. 34 Prozent absinken. ${ }^{749}$

\section{IV-2.2 Die Organe und Entscheidungsverfahren der EU}

Im vorhergehenden Abschnitt wurde die Entstehungsgeschichte der EU-Finanzverfassung anhand konkreter Fakten und Entscheidungen nachvollzogen. Das Zustandekommen dieser Entwicklungen im politisch-administrativen Entscheidungsprozeß blieb jedoch ausgeblendet. Um die Beschreibung der institutionellen Struktur der EU zu vervollständigen, erfolgt deshalb

\footnotetext{
${ }^{49}$ Vgl. hierzu Peffekoven (1994), S. 80.
} 
im Folgenden eine Analyse der Entscheidungsstrukturen. Hierbei ist zu beachten, daß die Gesamtheit der EU-Organe die Doppelfunktion des öffentlichen Sektors erfüllt: ${ }^{750}$ Je nach dem, ob die Funktion zur Bereitstellung (europäischer) öffentlicher Güter oder die (übergeordnete) Verfassungsfunktion zur (strategischen) Steuerung des Integrationsprozesses wahrgenommen wird, variieren die Zusammensetzung der entscheidungsberechtigten Organe und die Entscheidungs- und Abstimmungsregeln. Diese strukturellen Merkmale der Entscheidungsfindung sollen nachfolgend herausgearbeitet werden. ${ }^{751}$

\section{IV-2.2.1 Die Entscheidungsorgane}

Um die unterschiedliche Bedeutung der einzelnen Organe hervorzuheben, wird sinnvollerweise die folgende Dreiteilung vorgenommen: ${ }^{752}$

- Als übergeordnetes strategisches Lenkungsorgan ist der Europäische Rat von allen übrigen Organen der EU abzugrenzen.

- Die EK, der Rat der Europäischen Union ${ }^{753}$ und das EP sind die maßgeblichen, am Entscheidungsprozeß beteiligten Organe, die im EGV als „Verfassungsorgane” bestimmt werden. Sie sind daher als Hauptorgane der EU zu bezeichnen.

- Im EGV sind mit dem EuGH und dem EuRH zwei weitere „Verfassungsorgane” verankert, deren Funktion im Entscheidungsprozeß nur subsidiärer Natur ist. Sie werden aus diesem Grund als Nebenorgane tituliert. Zudem werden dieser Gruppe weitere ergänzende Organisationen zugerechnet, die als ,intermediäre Akteure im politischen System” ${ }^{\text {754 }}$ beratend und vermittelnd tätig werden. ${ }^{755}$

${ }^{750}$ Diese Doppelfunktion wurde im foderativen Referenzsystems in die Untersuchung eingeführt (vgl. Abschnitt II-1).

${ }^{751}$ Die eindeutige Einordnung einzelner Entscheidungen der Organe in die Kategorie der Bereitstellungs- bzw. der Verfassungsfunktion ist jedoch problematisch. Die Abgrenzungslinie zwischen den beiden Bereichen verläuft oftmals fließend. Vgl. Häde (1996), S. $342 \mathrm{ff}$.

752 Vgl. die ähnliche Abgrenzung bei Borchardt (1996), S. 89 ff; vgl. zu den Organen der EU zudem Oppermann (1991), S. 93 ff. und jüngst unter vielen Beckmann (1995), S. 18 ff.; Boldt (1995), S. 55 ff.; Berg/Schmidt (1996), S. 125 ff.; Bohnet-Joschko (1996), S. 215 ff.; Jones (1996), S. 65 ff. oder Wessels (1996), $26 \mathrm{ff}$.

753 Der Rat der Europäischen Union wird häufig als Ministerrat bezeichnet. Um Mißverständnisse mit dem Europäischen Rat zu vermeiden wird diese Titulierung übernommen.

754 Wessels (1996), S. 34.

755 Die folgenden Ausfuihrungen beschränken sich hierbei auf den WSA und den AdR, die beide eine Rolle in den Entscheidungsprozessen spielen. Auf die EIB, das Europäische Währungsinstitut und die Europäische Zentralbank, die ebenfalls als ergänzende Einrichtungen in den Verträgen der $E U$ institutionalisiert sind, wird an dieser Stelle nicht eingegangen, da sie nicht in die allgemeinen Entscheidungsprozesse der $E U$ integriert sind. 


\section{IV-2.2.1.1 Der Europäische Rat}

Der Europäische Rat wurde 1974 geründet, aber erst 1986 mit der EEA formell in das Gemeinschaftsrecht aufgenommen. Als Art. D ist der Europäische Rat im EUV verankert. Im Rahmen mindestens zwei mal jährlich stattfindender Zusammentreffen aller Staats- und Regierungschefs der Mitgliedstaaten sowie dem Präsidenten der EK ,gibt [er] der Union die für ihre Entwicklung erforderlichen Impulse und legt die allgemeinen politischen Zielvorstellungen für diese Entwicklung fest., ${ }^{, 756}$ Darüber hinaus erörtert der Europäische Rat „Schlußfolgerungen zu den Grundzügen der Wirtschaftspolitik der Mitgliedstaaten und der Gemeinschaft"757 und „bestimmt die Grundsätze und die allgemeinen Leitlinien der Gemeinsamen Außen- und Sicherheitspolitik." ${ }^{758}$ Der Europäische Rat ist jedoch nicht in das reguläre Kompetenzgefüge zur Entscheidungsfindung des EUV eingeflochten, sondern bleibt „außerhalb der vertraglichen Kontrollen des EG angesiedelt."759

Die besondere Bedeutung des Europäischen Rats liegt in seiner Funktion als ,übergeordneter Integrationsfaktor" ${ }^{, 760}$ und ,konstitutioneller Architekt"761 der EU, der strategische Vorstellungen und Grundsatzentscheidungen für den weiteren Integrationsprozeß entwickelt. Der Europäische Rat erfüllt hiermit ganz wesentlich die Verfassungsfunktion der EU-Ebene. Die Fortentwicklung der institutionellen Struktur durch wesentliche Reformen oder Ergänzungen der Verträge der EU findet ihren Ausgangspunkt in der Willensbildung des Europäischen Rates.

Die Entscheidungsfindung erfolgt in allen Fällen einstimmig, so daß die Beratungen wesentlich von der Konsenssuche aller Beteiligten geprägt sind. Die Verhandlungsergebnisse sind aus diesem Grund häufig von kompromißgesteuerten, ressortübergreifenden Paketlösungen geprägt. Interessendivergenzen werden durch von Kompensationsleistungen der "Gewinner" an die ,Verlierer” überbrückt.

Der Europäische Rat verabschiedet grundsätzlich keine rechtsverbindlichen Beschlüsse. ${ }^{762}$ Die allgemeinen Erklärungen und Leitlinien des Europäischen Rates entfalten ihre richtungs-

\footnotetext{
756 Art. D EUV.

757 Art. 103 (2) EGV.

758 Art. J.8 (3) EUV.

759 Wessels (1996), S. 27. Die Staats- und Regierungschefs erhalten ihre Legitimation durch Wahlen in den Mitgliedstaaten.

760 Bohnet-Joschko (1996), S. 243.

761 Wessels (1996), S. 27.

${ }^{762}$ Diese Aussage ist allerdings mit einer Einschränkung zu versehen. In bestimmten vertraglich vorgesehenen Fällen kann der Europäische Rat als Rat der EU zusammentreten und in dieser Funktion Gemeinschaftsrechtsakte erlassen. So tagte der Rat der EU bspw. im Mai 1998 gemäß Art. 109j (3) ,in seiner Zusammensetzung der Staats- und Regierungschefs", um zu entscheiden, „welche Mitgliedstaaten die notwendigen Voraussetzungen für die Einfulhrung einer einheitlichen Währung erfullen.”
} 
weisende Bedeutung für die Arbeit der EK, des Ministerrates und des EP durch die Autorität der versammelten Entscheidungsträger als Regierungsoberhäupter der Mitgliedstaaten. ${ }^{763} \mathrm{Be}-$ schlüsse des Europäischen Rates zu Reformen und Änderungen der EU-Verträge erhalten ihre Rechtsverbindlichkeit erst durch die Vertragsratifizierung in den Mitgliedstaaten. ${ }^{764}$ Daher ist festzuhalten, daß die Weiterentwicklung der rechtlich-organisatorischen Rahmenbedingungen der EU gemäß dem Einstimmigkeitsprinzip und auf intergouvernementaler Ebene erfolgt. Die Ergänzung des organisatorischen Gefüges der EU um den Europäischen Rat seit 1974 „constitutes an additional intergovernmental layer and therefore .. has arguably weakened the importance of the Union's supranational elements."

\section{IV-2.2.1.2 Die Hauptorgane der EU}

\section{IV-2.2.1.2.1 Die Europäische Kommission}

Die EK ist der zentrale Planungsstab der EU. ${ }^{766}$ Die Mitglieder der EK sind die Bürokraten der EU. Die EK setzt sich seit der Erweiterung der EU um Österreich, Finnland und Schweden im Jahr 1995 aus 20 Mitgliedern zusammen. Im Vertrag von Amsterdam wurde bestimmt, daß diese Anzahl auch bei einer erneuten Erweiterungsrunde nicht überschritten wird. Die Kommissionsmitglieder werden von den Regierungen der Mitgliedstaaten im gegenseitigen Einvernehmen ernannt und stellen sich als gesamtes Kollegium einem Zustimmungsvotum des EP. Die Kommissare sind ausschließlich dem allgemeinen Wohl der EU verpflichtet. Sie sind von den Weisungen ihrer nationalen Regierungen unabhängig und können nicht abberufen werden. Die EK stellt daher dasjenige Organ im Organisationsgefüge der EU zur Interessenvertretung der Gesamtheit der Union dar.

„Um das ordnungsgemäße Funktionieren und die Entwicklung des Gemeinsamen Marktes zu gewährleisten", ${ }^{767}$ ist der EK die Erfüllung verschiedener Aufgabenbereiche zugewiesen:

- Die EK fungiert als „Motor der europäischen Integration”, der auf Grundlage der bestehenden Verträge, Vorschläge zur Erfüllung der Vertragsziele erarbeitet und Perspektiven zur Fortentwicklung der Verträge aufzeigt. Ohne diese Vorschläge der EK kann der Ministerrat keine Rechtsakte erlassen. Diese Funktion wird als Initiativaufgabe der EK bezeichnet. Sie umfaßt jedoch sowohl ein Initiativrecht als auch ein Initiativpflicht. Einerseits kann die EK

\footnotetext{
${ }^{763} \mathrm{Vgl}$. Bohnet-Joschko (1996), S. 244; Jones (1996), S. 82.

764 Vgl. hierzu Art. N (1) EUV.

765 Jones (1996), S. 82.

${ }_{766}$ Die vertraglichen Bestimmungen zur Europäischen Kommission finden sich in den Art. 155-163 EGV.

767 Art. $155 \mathrm{EGV}$.
} 
durch eigenständige Initiativen die politische Agenda der Union beeinflussen, andererseits aber vom EP und dem Ministerrat verbindlich aufgefordert werden, Vorschläge zu spezifischen Problembereichen zu unterbreiten. 1996 legte die EK insgesamt 524 Vorschläge, Empfehlungen und Entwürfe von Rechtsakten vor. ${ }^{768}$

Alle Vorschläge, Empfehlungen und Entwürfe erfolgen nach einer intensiven Abwägung aller Interessen innerhalb und außerhalb der EK. Zur Entscheidungsfindung werden Kontakt- und Beratungsgespräche mit nationalen Beamten, unabhängigen Sachverständigen und Expertengruppen sowie Vertretern europäischer Interessenverbände geführt. So soll ein breiter Konsens für die Rechtsetzungstätigkeit der EU gewonnen werden.

- Als „Hüterin des Gemeinschaftsrechts” überwacht die EK die korrekte Anwendung und Durchführung der bestehenden EU-Verträge (Primärrecht der EU) und der durch die Gemeinschaftsorgane erlassenen Bestimmungen (Sekundärrecht der EU) in den Mitgliedstaaten. Die EK kann Klage beim EuGH erheben, wenn sie Verstöße gegen geltendes Recht feststellt.

- Die EK übernimmt Aufgaben als Exekutivorgan der EU. Ihr obliegt die jährliche Ausarbeitung des Haushaltsentwurfs sowie die Verwaltung der Haushaltsmittel. Darüber hinaus hat die EK für eine effiziente Durchführung bestehender Politiken der EU Sorge zu tragen, wie bspw. im Bereich des Wettbewerbsrechts oder der gesamten Fondswirtschaft der EU. In diesem Zusammenhang besitzt die EK eigenständige Rechtsetzungsbefugnisse in Form sogenannter Durchfuhrungsvorschriften. Schließlich vertritt die EK die EU nach außen.

Die Ausführungen verdeutlichen den erheblichen Einfluß, den die EK auf politischen Entscheidungsprozesse der Union ausübt. Das Initiativmonopol räumt der EK neben dem Europäischen Rat die wesentliche Rolle bei der Fortentwicklung der rechtlich-organisatorischen Strukturen der EU (Verfassungsfunktion) ein. Die exekutiven Aufgaben beteiligen die EK wesentlich an der Bereitstellungsfunktion der EU. Eine direkte demokratische Legitimation besitzt die EK besteht jedoch nicht. Die Kommissionsmitglieder sind in Ausübung ihrer Funktionen unabhängig vom Wählerwillen der Bürger ausschließlich dem übergeordneten Wohl der EU verpflichtet. Diese formale Unabhängigkeit schafft der EK erhebliche diskretionäre Handlungsspielräume zur Gestaltung des europäischen Integrationsprozesses. ${ }^{769}$

\footnotetext{
${ }^{768} \mathrm{Vgl}$. Europäische Kommission (1997b), S. 460.

769 Vgl. Beckmann (1995), S. 21; Bohnet-Joschko (1996), S. 219 ff.
} 
Der Ministerrat ist das zentrale Entscheidungsorgan der EU im Rahmen der bestehenden Vertragsbestimmungen. ${ }^{770}$ Seine Mitglieder sind die wesentlichen politischen Entscheidungsträger im Akteursgeflecht der EU. Das Gremium setzt sich bei seinen Tagungen aus je einem Vertreter jedes Mitgliedstaates auf Ministerebene zusammen, der befugt ist, für die Regierung des Mitgliedstaates verbindlich zu handeln. Er ist daher Oberbegriff für eine Reihe von Fachsitzungen, in denen das Organ je nach Sachgebiet und mitgliedstaatlicher Ressortaufteilung eine unterschiedliche Zusammensetzung aufweist. ${ }^{771}$ Die Vertreter sind durch die Mitgliedstaaten beauftragt, die partikularen Interessen des eigenen Mitgliedstaates zu vertreten. Der Ministerrat ist folglich das Organ der EU, in welchem Rahmen der Ausgleich zwischen den Interessen der einzelnen Mitgliedstaaten und dem Gesamtinteresse der EU gefunden werden muß. ${ }^{772}$

Der Vorsitz im Ministerrat wird durch die Mitgliedstaaten abwechselnd für je sechs Monate geführt. Der Ratsvorsitz hat für die problemadäquate Durchführung der Tagungen Sorge zu tragen. Dies umfaßt die Ausarbeitung angemessener Lösungsvorschläge in den einzelnen Fachbereichen, aber auch die Wahrung einer integrationsfördernden Kontinuität der Gesamtheit der Entscheidungen. ${ }^{773}$ Die konkrete Vorbereitung der Willensbildung im Rahmen der Fachtagungen erfolgt durch den Ausschuß der Ständigen Vertreter der Mitgliedstaaten (AStV). ${ }^{774}$

Art. 145 EGV umschreibt die Rechte und Pflichten des Ministerrates. Seine wichtigste Aufgabe ist die Rechtssetzungstätigkeit nach Maßgabe des EGV, um die vertraglich vorgegebenen Ziele der EU zu verwirklichen. Während der Europäische Rat die strategischen Grundsatz-Entscheidungen für die Fortentwicklung des Integrationsprozesses entwirft, ist der Ministerrat maßgeblich für den Erlaß der ,sekundären” Rechtsvorschriften und damit die konkrete

770 Die vertraglichen Bestimmungen zum Ministerrat Union finden sich in den Art. 145-154 EGV.

771 Es finden regelmäßige Tagungen des Ministerrats zu mehr als 25 unterschiedlichen Sachbereichen statt. 1996 konferierte der Ministerrat insgesamt $88 \mathrm{mal}$ (vgl. Europäische Kommission (1997b), S. 458).

772 Vgl. Beckmann (1995), S. 21; Borchardt (1996), S. 99.

${ }^{773}$ Der Ratsvorsitz wird bei seiner Arbeit in verwaltungstechnischer Hinsicht durch das Generalsekretariat unterstützt (vgl. Art. 151 (2) EGV), dem mehr als 2400 Beamte angehören (vgl. Europäische Kommission (1997b), S. 458.). Um die Kontinuităt der Tătigkeit des Ratsvorsitzes zu fordern, wurde der Informationsaustausch zwischen dem vergangenen, dem amtierenden und dem zukünftigen Ratsvorsitzenden als sogenannte "Troika" institutionalisiert (vgl. Borchardt (1996), S. 94; auch Bohnet-Joschko (1996), S. 222).

774 Vgl. Art. 151 (1) EGV. Die Stăndigen Vertreter werden von den Mitgliedstaaten entsandt und sind an die Weisungen der mitgliedstaatlichen Regierungen gebunden. Sie prüfen die Rechtssetzungsvorschläge der $E K$ unter Hinzuziehung von Stellungnahmen nationaler Sachverständiger und bemühen bereits auf der Ebene des $A S t V$ zu konsensfähigen Problemlösungen zu gelangen. Der $A S t V$ gewährleistet auf diese Weise eine Reduzierung der Arbeitsbelastung der Fachministertagungen, da nur diejenigen Angelegenheiten im Ministerrat eingehend behandelt werden müssen, über deren Lösung auf Ausschußebene keine Einigkeit erzielt werden konnte (vgl. Borchardt (1996), S. 96 ff; Weindl (1996), S. 30 f.). 
Ausgestaltung der Politik in den verschiedenen Aufgabenbereichen der EU verantwortlich. ${ }^{775}$ Der Ministerrat ist daher als die Legislative der EU zu bezeichnen. Die Entscheidungskompetenz des Ministerrates wird jedoch durch den Vertrag beschränkt. Zum einen kann die Rechtssetzungstätigkeit des Ministerrats innerhalb der traditionellen ersten Säule der EU nur auf Initiative der EK hin erfolgen. ${ }^{776}$ Zum anderen besitzt das EP Mitwirkungsrechte im Entscheidungsprozeß, so daß zahlreiche Entscheidungen von Parlament und Ministerrat gemeinsam getroffen werden. ${ }^{777}$

Die Entscheidungsfindung im Ministerrat erfolgt nach folgenden Regelungen (Art. 148 EGV):

- Je nach Entscheidungsinhalt ist die einfache Mehrheit, qualifizierte Mehrheit oder Einstimmigkeit der Mitglieder zur Beschlußfassung notwendig. Dabei sind Beschlüsse mit einfacher Mehrheit in der Realität praktisch bedeutungslos. Die Entscheidungen müssen fast ausschließlich einstimmig oder mit qualifizierter Mehrheit erfolgen.

- Sowohl bei einstimmiger Entscheidung als auch bei einfacher Mehrheit besitzt jedes Mitglied des Ministerrats eine Stimme.

- Bei Entscheidungen, die eine qualifizierte Mehrheit erfordern, wird eine Gewichtung der Stimmen vorgenommen. Abb. IV-8 zeigt die Anzahl der Stimmen jedes Mitgliedstaates:

Abb. IV-8: Die Beschlußfassung mit qualifizierter Mehrheit im Ministerrat

\begin{tabular}{|l|c|}
\hline Deutschland, Frankreich, Italien, Vereinigtes Königreich: & 10 \\
\hline Spanien: & $\mathbf{8}$ \\
\hline Belgien, Griechenland, Niederlande, Portugal: & 5 \\
\hline Österreich, Schweden: & 4 \\
\hline Irland, Dänemark, Finnland: & 3 \\
\hline Luxemburg: & 2 \\
\hline \multicolumn{1}{|c|}{ Gesamtstimmenzahl: } & $\mathbf{8 7}$ \\
Mindeststimmenzahl für qualifizierte Mehrheit: & 62 \\
\hline
\end{tabular}

Quelle: Art. 148 (2) EGV.

${ }^{775} \mathrm{Vgl}$. Walthes (1996), S. 276. Hierzu ist auch die Umsetzung der Grundsatzentscheidungen des Europäischen Rates innerhalb der bestehenden Vertrăge zu rechnen (vgl. Jones (1996), S. 76).

776 Jedoch kann der Ministerrat die EK nach Art. 152 EGV dazu auffordern, in von ihm bestimmten Bereichen, Untersuchungen vorzunehmen und Vorschläge zu unterbreiten. Im Bereich der zweiten Säule - GASP - und der dritten Săule - ZBJI - besitzt der Ministerrat dariber hinaus ein umfassendes Initiativrecht.

777 Vgl. hierzu näher Abschnitt IV-2.2.2. zum Zusammenspiel der Organe im Entscheidungsprozeß. Über die Legislativkompetenzen hinaus nimmt der Ministerrat eine Reihe weiterer weniger zentraler Aufgabenfelder wahr. So hat er für die Abstimmung der Wirtschaftspolitik der Mitgliedstaaten zu sorgen (Art. 145 EGV), verfügt über Kontrollrechte (Art. 175 EGV), stellt einen Entwurf des Haushaltsplans auf (Art. 203 (3) EGV), schließt Abkommen mit dritten Staaten und internationalen Organisationen (Art. 228 u. $238 \mathrm{EGV}$ ) und ist für die Ernennung der Mitglieder des WSA (Art. 198a (3) EGV), des AdR (Art. 194 (2) EGV) und des EuRH (Art. 188b (3) EGV) verantwortlich (vgl. Borchardt (1996), S. 94 ff.; Weindl (1996), S. 29). 
Die Gesamtstimmenzahl beträgt bei qualifizierten Mehrheitsentscheidungen 87 Stimmen. Ein Beschluß kommt im Regelfall mit einer Mindeststimmenzahl von 62 zustande. Dies entspricht über 71 Prozent der Gesamtstimmenzahl. Sofern (ausnahmsweise) über Beschlüsse entschieden wird, die nicht auf Vorschlag der EK zur Abstimmung gestellt werden, ist über die Mindeststimmenzahl von 62 hinaus, zusätzlich die Zustimmung von mindestens zehn Mitgliedstaaten erforderlich. Die Stimmengewichtung bei qualifizierten Mehrheitsentscheidungen ,ist nur sehr grob an Unterschieden in Wirtschaftskraft und Bevölkerung orientiert."778 Damit wird den großen Mitgliedstaaten zwar ein größerer Einfluß auf den Entscheidungsausgang eingeräumt als bei Entscheidungen mit einfacher Mehrheit, doch verbleibt den kleineren Mitgliedstaaten relativ zu ihrer Wirtschaftskraft und Bevölkerungszahl eine überproportionale Abstimmungsmacht. ${ }^{779}$ „Der Bedarf an Zustimmung ist damit auch bei einer derartigen Mehrheitsabstimmung erheblich." ${ }^{780}$ Auch für Koalitionen kleinerer Mitgliedstaaten besteht die Möglichkeit, eine Sperrminorität zur Verhinderung unerwünschter Entscheidungen aufzubauen. $^{781}$

Seit dem Inkraftreten der Römischen Verträge 1957 wurde die Zahl der Aufgabenbereiche, die einstimmige Beschlüsse erfordern, beständig reduziert. ${ }^{782}$ Zuletzt wurde im Vertrag von Amsterdam die Zahl der Anwendungsgebiete erhöht, in denen Rechtsakte im Ministerrat mit qualifizierter Mehrheit verabschiedet werden können. ${ }^{783}$ Die Beschlußfassung wurde so im Vergleich zur Einstimmigkeitsregel erleichtert. Bei Entscheidungen in Aufgabenbereichen, die der EU-Ebene im Verlauf des Integrationsprozesses neu zugeordnet werden, herrscht hingegen zumeist (zunächst) das Einstimmigkeitsprinzip vor. Erst im Laufe weiterer Vertragsänderungen findet auch in diesen Bereichen (zum Teil) eine Lockerung der Abstimmungsregeln statt. Darüber hinaus ist „für Beschlüsse in besonders sensiblen Politikbereichen" ${ }^{\text {784 }}$ weiterhin die Einstimmigkeit vorgesehen. ${ }^{785}$ Unbestritten hat jedoch die Bedeutung der Mehrheitsentscheidungen im Zeitablauf erheblich zugenommen.

Dennoch verdeutlichen die Ausführungen insgesamt, daß die im Ministerrat geschaffenen Entscheidungs- und Verfahrensstrukturen die „konsensorientierte Entscheidungsfindung" ${ }^{786}$ in

\footnotetext{
778 Bohnet-Joschko (1996), S. 225.

779 Vgl. Bohnet-Joschko (1996), S. 225; Borchardt (1996), S. 99. So erhält Luxemburg eine Stimme je 200.000 Einwohner; Deutschland hingegen lediglich eine Stimme je acht Millionen Einwohner (vgl. Jones (1997), S. $77 \mathrm{f}$.).

780 Wessels (1996), S. 29.

781 Vgl. hierzu auch Scharpf(1996b), S. 115.

782 Vgl. Wilming (1995), S. 21 ff.; insb. S. 35.

${ }^{783}$ Vgl. hierzu bspw. Bundesrat (1997), S. 114; Thiel (1997).

784 Borchardt (1996), S. 100.

${ }^{785}$ Hierzu zăhlen bspw. das Steuerrecht sowie die Regional- u. Sozialfonds.

${ }^{786}$ Bohnet-Joschko (1996), S. 224; vgl. auch Jones (1996); S. 78.
} 
den Vordergrund stellen. Bereits die Entscheidungsvorbereitung im Rahmen des AStV zielt auf die Erarbeitung einer konsensfähigen Problemlösung ab. Zudem erfordert die eigentliche Abstimmung im Ministerrat entweder Einstimmigkeit oder eine Zustimmung von mindestens 71 Prozent der Gesamtstimmenzahl, so daß ein Beschlußfassung erst zur „erfolgreichen” Abstimmung gebracht werden kann, wenn die Zustimmung der meisten Mitgliedstaaten gesichert ist. Infolge dieser Entscheidungsstrukturen gab es in den vergangenen Jahren nur bei etwa 14 Prozent aller Beschlüsse des Ministerrates Enthaltungen oder Gegenstimmen. ${ }^{787}$

\section{IV-2.2.1.2.3 Das Europäische Parlament}

Das EP ist die Vertretung der in der EU zusammengeschlossenen Völker. ${ }^{788}$ Bis zum Jahr 1979 wurden diese Vertreter aus den Reihen der Abgeordneten der nationalen Parlamente ernannt und ins EP entsandt. Seit 1979 werden die Abgeordneten von den Bürgern der Mitgliedstaaten in direkter Wahl bestimmt. Die Abgeordneten sind weisungsunabhängig und nicht an Aufträge gebunden. Thre Amtsdauer beträgt fünf Jahre. ${ }^{789}$ Neben den Mitgliedern des Ministerrats sind sie die zweite Gruppe an staatlichen Entscheidungsträgern im Akteursgeflecht der EU.

Die Zahl der Abgeordneten des Parlaments beträgt nach Art. 138 (2) EGV derzeit 626 Mitglieder. ${ }^{790}$ Die Sitzverteilung im EP orientiert sich nur ansatzweise an der Bevölkerungsstärke der Mitgliedstaaten. Um eine angemessene Interessenvertretung aller Mitgliedstaaten in der Gemeinschaft zu gewährleisten, ${ }^{791}$ erhalten die kleineren Mitgliedstaaten eine größere Anzahl an Parlamentssitzen pro Bevölkerungseinheit als die größeren Mitgliedstaaten. So werden im EP ca. 826.000 deutsche Bürger durch einen Europa-Parlamentarier vertreten; hingegen vertritt ein luxemburgischer Europa-Abgeordneter lediglich ca. 67.000 Bewohner. Die Stimmengewichtung zugunsten der kleineren Mitgliedstaaten ist ein politischer Kompromiß, um die institutionelle Balance zwischen den größeren und kleineren Mitgliedstaaten zu erhalten: ${ }^{792}$

\footnotetext{
${ }^{787} \mathrm{Vgl}$. Jones (1996), S. 78.

788 Die vertraglichen Bestimmungen zum EP finden sich in den Art. 137-144 EGV.

789 Die Wahlen werden in allen Mitgliedstaaten in etwa zum gleichen Zeitpunkt durchgefuihrt. Die Wahlverfahren in den einzelnen Mitgliedstaaten sind jedoch nicht einheitlich. So wird bspw. im Vereinigten Königreich das Mehrheitswahlrecht angewendet, wohingegen in allen ubbrigen Mitgliedstaaten das Verhältniswahlrecht zur Geltung kommt. Das EP hat nach Art. 138 (3) die Aufgabe, bis zur năchsten Direktwahl im Jahr 1999 einen Entwurf furr Wahlen ,nach einem einheitlichen Verfahren in allen Mitgliedstaaten oder im Einklang mit den allen Mitgliedstaaten gemeinsamen Grundsätzen" auszuarbeiten (vgl. auch Borchardt (1996), S. 109).

${ }^{790}$ Durch den Amsterdamer Vertrag wurde die Anzahl der Mitglieder des EP auf maximal 700 Abgeordnete begrenzt. Auch infolge einer Erweiterung der $E U$ darf diese Anzahl nicht überschritten werden, um die Arbeitsfähigkeit der Versammlung sicherzustellen (vgl. Europäische Strukturkommission (1995), S. 44.).

791 Vgl. hierzu insb. Art. 138 (2) EGV in seiner durch den Amsterdamer Vertrag geänderten Fassung.

792 Vgl. Boldt (1995), S. 60; aber v.a. Neisser (1997), S. 198 ff., der betont, daß in einer langfristigen Perspektive „die Zahl der Abgeordneten jedes Mitgliedstaates .. in einer realistischen Beziehung zur demographischen Wirklichkeit stehen [muß]." (Neisser (1997), S. 200) Dies stellt eine Voraussetzung dafür dar, daß das EP im Integrationsprozeß zur „echten” Legislative der $E U$ weiterentwickelt werden kann.
} 
Die Befugnisse des EP sind stark eingeschränkt. Im Vergleich zu den Kompetenzen der mitgliedstaatlichen Parlamente besitzen zwei Aspekte besonderes Gewicht. Zum ersten wird die Gesetzgebungsfunktion auf der EU-Ebene weitgehend durch den Ministerrat ausgeübt. Zum zweiten besitzt das EP keine Verantwortung für die Wahl der Exekutive der EU. ${ }^{793}$ Allerdings wurden die Zuständigkeiten des EP im Laufe des Integrationsprozesses Schritt für Schritt erweitert; zuerst durch die EEA, dann durch die Verträge von Maastricht und zuletzt durch den Vertrag von Amsterdam. Zum heutigen Zeitpunkt umfassen die Kompetenzen des Parlaments die folgenden drei Aufgabenbereiche:

- Das EP besitzt die Kontrollfunktion bezüglich der exekutiven Tätigkeit der EU. Daher besitzt das EP gegenüber der EK und dem Ministerrat Kontrollbefugnisse. So müssen sich die Mitglieder der EK vor ihrem Amtsantritt dem Zustimmungsvotum des EP stellen und können durch ein Mißtrauensvotum des EP zum kollektiven Rücktritt gezwungen werden. Darüber hinaus überwacht das EP die Ausführung des EU-Haushalts durch die EK und beschließt über deren Entlastung. Sowohl die EK als auch der Ministerrat müssen dem EP verschiedener Berichte und Stellungnahmen zur Erörterung vorlegen. Besondere Bedeutung besitzen der jährliche Gesamtbericht der EK über die Tätigkeit der EU und der Bericht des Rats-Vorsitzenden über das Programm des Ministerrates, der stets zu Beginn und Ende der halbjährigen Amtszeit eines Vorsitzenden erstellt wird. ${ }^{794}$

- Das EP verfügt über weitreichende Haushaltsbefugnisse. Die Aufstellung des EUHaushalts ist eine gemeinsame Aufgabe von Ministerrat und EP, wobei die politische Strukturierung der Ausgabenansätze nach obligatorischen (OA) und nicht-obligatorischen Ausgaben (NOA) die entscheidende Bedeutung besitzt. ${ }^{795}$

Während der Ministerrat die Verantwortung für die OA trägt, entscheidet das EP innerhalb bestimmter Grenzen ${ }^{796}$ über die NOA und kann auf diese Weise die Höhe und Struktur der Ausgabetätigkeiten beeinflussen. Da zu den NOA sämtliche Ausgaben im Rahmen der strukturpolitischen Maßnahmen und aller internen Politikbereiche gehören, die annähernd 50 Prozent der Gesamtausgaben der EU umfassen und eine erhebliche Bedeutung für den

${ }^{793}$ Die Exekutivkompetenzen teilen sich die EK und der Ministerrat (vgl. hierzu die Abschnitte IV-2.2.1.2.1 u. 2). Vgl. auch Schmuck (1994a), S. 188; Beckmann (1995), S. 23.

794 Vgl. Europäische Kommission (1997b), S. 455.

795 Alle Ausgaben, ,die sich zwingend aus dem Vertrag oder den auf Grund des Vertrages erlassenen Rechtsakten ergeben" (Art. 203 (4 ) EGV) werden als OA bezeichnet. Alle übrigen Ausgaben sind NOA. Zu den NOA gehören insb. die Ausgaben im Bereich der Strukturmaßnahmen und der internen Politikbereiche. Der größte Posten der OA wird durch die Ausgaben im Rahmen des EAGFL, Abteilung Garantie verkörpert. Vgl. hierzu Europäische Kommission (1995a), S. $108 \mathrm{ff}$.

796 Vgl. zu diesen Grenzen Art. 203 (9) EGV. 
Integrationsprozeß besitzen, sichert die Verteilung der Haushaltsbefugnisse dem EP einen nicht zu vernachlässigenden Einfluß auf die Politikgestaltung. ${ }^{797}$

- Das EP nimmt an Rechtsetzungsverfahren der EU teil. Ursprünglich war das EP nicht direkt am Gesetzgebungsprozeß beteiligt, sondern übernahm nur eine Beratungsfunktion. Alle Rechtsakte wurden auf Initiative der EK hin vom Ministerrat verabschiedet. Nach und nach wurden dem EP jedoch substantielle Mitwirkungsrechte an der Gesetzgebung eingeräumt. Zum einen erfolgte die Einrichtung alternativer Rechtsetzungsverfahren, die dem EP unterschiedlich weitreichende Kompetenzen zuweisen. Zum anderen wurde im Zeitablauf der Anwendungsbereich derjenigen Rechtssetzungsverfahren ausgeweitet, die dem EP besonders ausgedehnte Kompetenzen zugestehen. Infolge dieser Entwicklungen kann das EP nunmehr in zahlreichen Aufgabenbereichen die Änderung von Rechtsakten erzwingen oder deren Verabschiedung sogar eigenständig beschließen. Allerdings beziehen sich diese Möglichkeiten in aller Regel auf Entscheidungen zur Durchführung konkreter Maßnahmen. Bei der Weiterentwicklung der rechtlich-organisatorischen Struktur der EU spielt das EP weiterhin nur eine nachgeordnete Rolle im Entscheidungsprozeß. ${ }^{798}$

Ein wichtiger Problemkreis im voranschreitenden Integrationsprozeß ist die Frage der demokratischen Legitimation der Entscheidungsfindung der EU. Das Parlament wird durch Wahlen direkt von den Bürgern bestimmt, so daß es als demokratisch legitimiert bezeichnet werden kann. Aus diesem Blickwinkel stellt die Ausweitung der Kompetenzen des EP eine Stärkung der Legitimation der gesamten Gesetzgebung auf der EU-Ebene dar.

Jedoch ist gegen diese Argumentation unter Berücksichtigung der heutigen institutionellen Strukturen und des momentanen Standes der Integration ${ }^{799}$ eine Reihe kritischer Anmerkungen vorzubringen. Zum ersten ist einzuwenden, daß die Parlamentswahlen nach national unterschiedlichen Verfahren erfolgen und die Kontingentierung der Mandate im Parlament unabhängig von der Bevölkerungszahl erfolgt. ${ }^{800}$ Zum zweiten ist die Ausrichtung der Rechtssetzungstätigkeit an den Bürgerpräferenzen für die europäischen Abgeordneten wegen der weiten „Entfernung” zum Wähler mit hohen Informationskosten verbunden; aus dem gleichen Grund sind die Informationskosten für die Wähler zur Kontrolle der Politiker sehr hoch. ${ }^{801}$ Als gravierendster Einwand ist zum dritten zu betonen, daß „die Völker der Mitgliedstaaten ..

\footnotetext{
797 Vgl. Europäische Kommission (1995a), S. 109; auch Borchardt (1996), S. $111 \mathrm{f}$.

${ }^{798} \mathrm{Vgl}$. Bohnet-Joschko (1996), S. 231 f.; Wessels (1996), S. 30. Vgl. auch die weitergehenden Ausfuhrungen in Abschnitt IV-2.2.2.

799 Vgl. hierzu Abschnitt IV-2.3 zum europäischen Integrationsprozeß in diesem Kapitel.

${ }^{800} \mathrm{Vgl}$. neben den Ausfuhrungen weiter oben in diesem Teilabschnitt auch Borchardt (1996), S. 109 und Walthes (1996), S. 274.

801 Vgl. Bohnet-Joschko (1996), S. 234 f.
} 
sich noch nicht als Teile eines europäischen Volkes, welches Ausgangspunkt einer umfassenden demokratischen Legitimation sein könnte, [verstehen]." ${ }^{802}$ Das EP besteht aus „Vertretern der Völker der in der Gemeinschaft zusammengeschlossenen Staaten”, ${ }^{803}$ und nicht aus Repräsentanten eines gemeinsamen europäischen Wahlvolkes. ${ }^{804}$

Diese Kritikpunkte stellen in Frage, ob durch eine Ausweitung der Kompetenzen des EP tatsächlich eine Verbesserung der demokratischen Legitimation der europäischen Entscheidungen vollzogen werden kann. So kommt der Wissenschaftliche Beirat beim Bundesministerium für Wirtschaft zu dem Schluß, daß die Stärkung der demokratischen Legitimation der EU zum gegenwärtigen Zeitpunkt nur sehr eingeschränkt durch das EP wahrgenommen werden kann und daher die Parlamente der einzelnen Mitgliedstaaten verstärkt in die Legitimationskette einzubeziehen sind. ${ }^{805}$

\section{IV-2.2.1.3 Die Nebenorgane der EU}

- Der $E u G H$ hat seinen Sitz in Luxemburg. ${ }^{806}$ Der Gerichtshof setzt sich derzeit aus 15 Richtern und neun Generalanwälten zusammen, die von den Regierungen der Mitgliedstaaten im gegenseitigen Einvernehmen für eine Amtszeit von sechs Jahren ernannt werden; eine Wiederbenennung ist zulässig. ${ }^{807}$

Nach Art. 164 EGV ist es die Aufgabe des EuGH, die Wahrung des gemeinschaftlichen Rechts bei der Auslegung und Anwendung der Verträge der EU zu sichern. ${ }^{808}$ Der Gerichtshof entscheidet nach dem Mehrheitsprinzip und folgt bei seinen Urteilen unabhängig

${ }^{802}$ Wissenschaftlicher Beirat (1994), S. 12. Vgl. auch Abschnitt IV-2.3.2.2 zur politischen Integration.

${ }^{803}$ Art. 137 EGV.

${ }^{804}$ Dies wird durch die Tatsache unterstrichen, daß bei den Wahlen zum EP bislang nur nationale Parteilisten bestehen (vgl. Walthes (1996), S. 274). Zwar grülndeten verschiedene Parteien bereits europäische Zusammenschlüsse, doch bleibt letztendlich die nationale Parteienliste entscheidendes Wahlkampfthema (vgl. Schmuck (1994b)). Allerdings hat die $E U$ erkannt, daß die politischen Parteien einen wichtigen Integrationsfaktor darstellen. Um der Entwicklung europäischer Parteistrukturen Schubkraft zu verleihen, betont Art. 138a EGV deshalb, daß diese entscheidend dazu beitragen, „ein europäisches Bewußtsein herauszubilden und den politischen Willen der Bürger der Union zum Ausdruck zu bringen."

${ }^{805}$ Vgl. Wissenschaftlicher Beirat (1994), S. 12 ff.; Beckmann (1995), S. 24; vgl. auch das Maastricht-Urteil des $B V \operatorname{erf} G$ (1993). Die Schlußfolgerungen sind jedoch umstritten. So argumentieren Schmuck (1994a), S. 193 u. Weindl (1996), S. 44 gerade entgegengesetzt und fordern, die Kompetenzen des EP deutlich auszudehnen, um so Schritte zur Demokratisierung der $E U$ einzuleiten. Eine einleuchtende Kompromißposition, die dem fortschreitenden Integrationsprozeß gerecht werden kann, entwickelt die Europäische Strukturkommission (1995), S. $38 \mathrm{ff}$. Sie fordert das Zusammenwirken unterschiedlicher Legitimationsquellen, die einerseits über die nationalen Parlamente und andererseits über europäische Formen der direkten Legitimation vermittelt werden. Auch Beck (1997b) folgert, daß das ,Insgesamt-Quantum einer europăischen Demokratie .. in dem $\mathrm{Maße}$ wachsen [würde], in dem die demokratische Zurechenbarkeit und Verantwortung auf den verschiedenen Ebenen [Hervorhebung nicht im Original] verbessert oder hergestellt wird."

${ }^{806}$ Die vertraglichen Bestimmungen zum EuGH finden sich in den Art. 164-188 EGV.

${ }^{807}$ Vgl. weiterfuhrend zum EuGH bspw. Klinke (1989).

${ }^{808}$ Die Zuständigkeit des $E u G H$ bezieht sich jedoch ausdrilcklich nicht auf die GASP, die ZJIP und die Gemeinsamen Bestimmungen des EUV; damit unterliegt auch die Tătigkeit des Europäischen Rates nicht der Kontrolle des EuGH (vgl. Wessels (1996), S. 34). 
von den Interessen der Mitgliedstaaten allein seiner eigenen Rechts- und Gerechtigkeitsauffassung. ${ }^{809}$ In Ausübung seiner juristischen Kontrollfunktion spielt der EuGH eine zentrale Rolle bei dem Aufbau einer europäischen Rechtsgemeinschaft und kann daher als ein „Integrationsfaktor erster Ordnung" ${ }^{\text {810 }}$ bezeichnet werden.

Diese Bedeutung wird v.a. bei der verfassungsrechtlichen Tätigkeit des Gerichtshof deutlich. $^{811}$ Zum ersten sorgt der EuGH in dieser Funktion für die Klärung der Rechte und Pflichten der Organe der EU untereinander sowie der Rechtsverhältnisse zwischen der EUEbene und den Mitgliedstaaten. Zum zweiten prüft der EuGH die Vereinbarkeit der sekundärrechtlichen Gesetzgebungstätigkeit des Ministerrats, der EK und des EP mit den Verträgen und allgemeinen Rechtsgrundsätzen der EU. Im bisherigen Verlauf des Integrationsprozesses hat der EuGH seine Autorität und Entscheidungsspielräume „durch gelegentlich kühn vorwärtsweisende Grundsatzentscheidungen”812 zu einer Stabilisierung und Ausdehnung der Kompetenzbereiche der zentralen EU-Ebene genutzt. ${ }^{813}$

- Der EuRH hat seinen Sitz in Luxemburg. ${ }^{814}$ Er setzt sich entsprechend der Anzahl der Mitgliedstaaten der EU aus 15 Mitgliedern zusammen, die vom Ministerrat nach Anhörung des EP für sechs Jahre ernannt werden; die Wiederernennung ist möglich. ${ }^{815}$

Der EuRH wirkt als Kontrollorgan zur Überwachung des Haushaltsgebarens der EU. „Der Rechnungshof prüft die Rechtmäßigkeit und Ordnungsmäßigkeit der Einnahmen und Ausgaben und überzeugt sich von der Wirtschaftlichkeit der Haushaltsführung." ${ }^{816}$ Diese Tätigkeiten führen die Mitglieder des EuRH in voller Unabhängigkeit aus. Da der EuRH über keine Rechtsmittel zur zwangsweisen Abstellung festgestellter Unregelmäßigkeiten verfügt, liegt die Bedeutung der Untersuchungen im politischen Bereich. Der EuRH faßt seine Untersuchungsergebnisse in einem Jahresbericht sowie einzelnen Sonderberichten zusammen, die der europäischen Öffentlichkeit Beanstandungen und Verbesserungsvorschläge zu den haushaltsrelevanten Aktivitäten der EU transparent vor Augen fuihren. In den vergangenen Jahren setzte sich der EuRH kritisch mit der Agrarpolitik und der Regionalpolitik der EU auseinander. Insgesamt entwickelte sich der EuRH im Laufe des Integrationsprozesses „zu einer unabhängigen und vielseitigen Prüfungsinstanz”, 817 die im Rahmen ihrer

\footnotetext{
$809 \mathrm{Vgl}$. Läufer (1994b), S. 217 f.

810 Weindl (1996), S. 49.

811 Vgl. zu den weiteren Tătigkeitsbereichen des EuGH Läufer (1994b), S. 218; Borchardt (1996), S. 124.

812 Oppermann (1991), S. 134.

813 Vgl. Oppermann (1991), S. 133 ff.; Häde (1996), S. 335; Wessels (1996), S. 34.

${ }^{814}$ Die vertraglichen Bestimmungen zum EuRH finden sich in den Art. 188a-188c EGV.

${ }^{815} \mathrm{Vgl}$. weiterführend zum EuRH bspw. Ehlermann (1976).

${ }^{816}$ Art. $188 \mathrm{c}$ (2) EGV.

${ }^{817}$ Läufer (1994c), S. 185.
} 
Kontrolltätigkeit auch ,ganze EU-Programme zur Diskussion stellt" ${ }^{818}$ und so eine erhebliche Bedeutung im institutionellen Gefüge der EU erlangt hat.

- Der $W S A^{819}$ gehört zu den ergänzenden organisatorischen Einrichtungen der EU, denen ausschließlich eine beratende Funktion im Entscheidungsprozeß der EU zukommt. In bestimmten vertraglich festgelegten Aufgabenbereichen ${ }^{820}$ sind der Ministerrat und die EK verpflichtet, eine Stellungnahme des WSA zu laufenden Rechtssetzungsverfahren einzuholen; in allen übrigen Fällen kann der Ausschuß gehört werden. Darüber hinaus ist der Ausschuß befugt aus eigener Initiative seine Meinung zu äußern. ${ }^{821}$ Die Mitglieder des WSA werden vom Ministerrat durch einstimmigen Beschluß für vier Jahre ernannt; eine Wiederernennung ist möglich. Das in Brüssel tagende Gremium umfaßt 222 Mitglieder, die ihre Tätigkeit weisungsungebunden und unabhängig ausüben.

„Der Ausschuß besteht aus Vertretern der verschiedenen Gruppen des wirtschaftlichen und sozialen Lebens", ${ }^{822}$ so daß Arbeitgeber, Arbeitnehmer und sonstige verschiedene Interessen ausgewogen repräsentiert werden. Hierin liegt die besondere Bedeutung des WSA. „Die Stellungnahmen des Ausschusses verkörpern eine Synthese von mitunter recht stark voneinander abweichenden Ausgangspositionen." ${ }^{823}$ Dem Ministerrat und der EK wird auf diese Weise unverbindlich ein möglicher Interessenausgleich als Lösungsvorschlag für umstrittene Rechtsakte signalisiert, der einen wesentlichen Beitrag zur konsensorientierten Entscheidungsfindung im Rahmen des Rechtssetzungsverfahrens der EU leisten kann. ${ }^{824}$

- Dem Ausschuß der Regionen (AdR) ${ }^{825}$ kommt wie dem WSA ausschließlich beratende Funktion zu. Die Mitglieder des AdR werden vom Ministerrat auf Vorschlag der jeweiligen Mitgliedstaaten durch einstimmigen Beschluß für einen Zeitraum von vier Jahren ernannt; eine Wiederernennung ist möglich. Analog zum WSA ist die Mitgliederzahl des AdR auf 222 festgesetzt, die ihre Tätigkeit weisungsungebunden und unabhängig ausüben.

Die Mitglieder des AdR sind Repräsentanten der regionalen und lokalen GKS der Mitgliedstaaten. Der AdR muß vom Ministerrat oder von der EK in einer Reihe vertraglich vorgesehener Fälle gehört werden. Hierzu gehören Fragen des wirtschaftlichen und sozialen Zusammenhalts, der transeuropäischen Netze, des Gesundheitswesens, der Bildung so-

\footnotetext{
${ }^{818}$ Walthes (1996), S. 281.

${ }^{819}$ Die vertraglichen Bestimmungen zum WSA finden sich in den Art. 193-198 EGV.

${ }^{820}$ Bspw. bei Rechtsakten zur Liberalisierung des Kapital- u. Dienstleistungsverkehrs oder bei der GAP.

821 Vgl. Oppermann (1991), S. 139.

822 Art. 193 (2) EGV.

${ }^{823}$ Borchardt (1996), S. 128.

${ }^{824}$ Als herausragendes Beispiel sei auf den Entwurf des WSA zur „Sozialcharta” der EU verwiesen, der schließlich von den entscheidungsbefugten Organen übernommen wurde. Vgl. Brüske (1994), S. 345.

${ }^{825}$ Die vertraglichen Bestimmungen zum AdR finden sich in den Art. 198a-198c EGV.
} 
wie der Jugend und Kultur; in allen anderen Fällen kann der Ausschuß angerufen werden. Zudem hat der AdR die Möglichkeit auf eigene Initiative hin Stellungnahmen abzugeben, sofern wichtige regionale Interessen berührt werden. ${ }^{826}$ Eine direkte Beteiligung an der Entscheidungsfindung bleibt den regionalen und lokalen politischen Instanzen zwar verwährt, doch gewinnen sie verstärkten Einfluß auf den Willensbildungsprozeß der europäischen Politik. Daher verkörpert der AdR ein Instrument gegen Zentralisierungstendenzen innerhalb der EU, da die Interessen der Regionen nun „, frühzeitiger und wirksamer als bisher geltend gemacht werden [können]." ${ }^{827}$

\section{IV-2.2.2 Das Zusammenwirken der Organe in den Entscheidungsprozessen der EU}

Im Laufe der europäsichen Einigung erfolgte eine beständige Veränderung des formalen Ablaufs der Entscheidungsprozesse. Die Reformschritte drücken das Bemühen aus, das institutionelle Gleichgewicht zwischen EP, EK und Ministerrat im Integrationsprozeß aufrechtzuerhalten. ${ }^{828}$ Die Etappen dieses Wandels werden anhand der verschiedenen Verfahrenstypen deutlich, die im Zeitablauf in das institutionelle Gefüge der EU eingefuihrt wurden:

- Die seit Beginn der europäischen Integration bestehende Grundlage für das allgemeine Rechtssetzungsverfahren der EU bildet das Anhörungsverfahren. ${ }^{829}$ Es kommt in allen Fällen zur Anwendung, in denen die vertraglichen Regelungen nicht explizit auf ein alternatives Entscheidungsverfahren verweisen. Der Entscheidungsproze $ß$ verläuft in drei Schritten. Zunächst erarbeitet die EK kraft ihres alleinigen Initiativrechts einen Vorschlag für einen Rechtsakt. Der Entwurf wird dem Ministerrat zugeleitet, der ihn wiederum an diejenigen Einrichtungen der EU weiterreicht, die beim betreffenden Rechtsakt ein vertragliches Anhörungsrecht besitzen. Hierzu gehört in jedem Fall das EP, ${ }^{830}$ darüber hinaus in bestimmten Fällen der WSA und der AdR. Diese Organisationen geben in Stellungnahmen ihrer Einschätzung des Rechtssetzungsvorhabens Ausdruck. Diese Positionen werden sowohl der EK als auch dem Ministerrat bekanntgegeben. Sie besitzen jedoch ausschließlich beratenden Charakter. Die EK besitzt die Möglichkeit, ihren ursprünglichen Vorschlag

${ }^{826}$ Vgl. Art. 198c EGV; auch Weindl (1996), S. 51.

${ }^{827}$ Weindl (1996), S. 51; vgl. auch Walthes (1996), S. 283.

${ }^{828} \mathrm{Vgl}$. Boldt (1995), S. 74; Neisser (1997), $193 \mathrm{f}$.

${ }^{829}$ Vgl. zum Anhörungsverfahren Läufer (1994d), S. 120 f.; Wilming (1995), S. 71; Borchardt (1996), S. 154 ff.

${ }^{830}$ Das EP besitzt bei allen politisch bedeutsamen Entscheidungen ein vertraglich zwingend vorgeschriebenes „obligatorisches" Anhörungsrecht. Eine Nichtbeachtung dieses Anhörungsrechts stellt einen schweren Formfehler im Rechtssetzungsverfahren der $E U$ dar, der die Nichtigkeit des betroffenen Rechtsakts zur Folge hat. In der Praxis wird dem EP darüber hinaus zu allen übrigen Rechtssetzungsvorhaben ein ,fakultatives” Anhörungsrecht eingeräumt. Die EK und der Ministerrat sind eine freiwillige Selbstverpflichtung eingegangen, das EP zur Abgabe von Stellungnahmen zu allen Rechtsakten der $E U$ aufzufordern (vgl. Läufer (1994d), S. 120; Borchardt (1996), S. 156). 
im Sinne der Stellungnahmen abzuändern. Der Ministerrat entscheidet schließlich unter Berücksichtigung des gesamten Anhörungsverfahrens über die Annahme der (unter Umständen geänderten) Rechtssetzungsvorlage. ${ }^{831}$ Der Annahmebeschluß des Ministerrates erfolgt gemäß der für den jeweiligen Entscheidungsinhalt vorgesehenen Regelung. Jedoch ist grundsätzlich ein einstimmiger Beschluß des Ministerrates erforderlich, um eigene Änderungen des Vorschlags der EK durchzusetzen. ${ }^{832}$

- Mit der EEA wurde im Jahr 1987 das Verfahren der Zusammenarbeit zwischen EP und Ministerrat unter Beteiligung der EK als neues Entscheidungsverfahren institutionalisiert. ${ }^{833}$ Es baut in seiner Struktur direkt auf das soeben geschilderte Anhörungsverfahren auf. Allerdings wird eine zweite Lesung im EP eingefügt, durch die dessen Mitwirkungskompetenzen im Entscheidungsprozeß gestärkt werden. Der Ministerrat entscheidet nunmehr auf Vorschlag der EK und unter Beachtung der abgegebenen Stellungnahmen in einem ersten Schritt nicht endgültig, sondern legt lediglich einen gemeinsamen Standpunkt des Ministerrates fest. Dieser gemeinsame Standpunkt bildet die Diskussionsgrundlage der zweiten Lesung im EP. Das EP besitzt daraufhin drei Handlungsoptionen, die einen jeweils abweichenden Abschluß des Rechtssetzungsverfahrens nach sich ziehen:

- Die Billigung des gemeinsamen Standpunkts durch das EP erlaubt es dem Ministerrat, das Rechtssetzungsvorhaben endgültig gemäß der für den jeweiligen Entscheidungsinhalt vorgesehenen Regelung zu verabschieden.

- Die Ablehnung des gemeinsamen Standpunkts durch die absolute Mehrheit des EP führt hingegen zu einer Änderung der Entscheidungsregel im Ministerrat. Dieser kann den gemeinsamen Standpunkt nun nur durch einstimmige Beschlußfassung durchsetzen; erfolgt keinerlei Beschluß, so bleibt das Rechtssetzungsvorhaben blockiert.

- Das EP besitzt die Möglichkeit, konkrete Änderungen des gemeinsamen Standpunkts des Ministerrates vorzuschlagen, über deren Aufnahme in den Rechtssetzungsentwurf die EK entscheidet. Übernimmt die EK die Änderungsvorschläge, so beschließt der Mi-

831 Seit 1975 existiert zudem die gemeinsame Erklärung von Ministerrat, EK u. EP zum sogenannten ,Konzertierungsverfahren” für gemeinschaftliche Rechtsakte „von allgemeiner Tragweite”, die ,ins Gewicht fallenden finanziellen Auswirkungen haben". (Europäisches Parlament/Rat/Kommission (1975), S. 1) Differieren die Rechtssetzungsstandpunkte des EP und des Ministerrats, so wird ein Konzertierungsausschuß aus Mitgliedern aller drei Organe gebildet, um auf dem Verhandlungsweg, Einvernehmen zwischen dem EP und dem Ministerrat herbeizufuhren. Da die Konzertierung bei finanziell bedeutsamen Rechtsakten erfolgt werden auf diese Weise die Rechtssetzungsbefugnisse im Rahmen des Anhorungsverfahrens und die Haushaltsbefugnisse des EP gestärkt. Die letzte Entscheidung verbleibt jedoch beim Ministerrat (vgl. hierzu auch Läufer (1994d), S. 125).

${ }^{832}$ Vgl. hierzu Art. 189a (1) EGV.

${ }^{833}$ Das Verfahren kommt immer dann zur Anwendung, wenn im Rahmen der Verträge explizit auf Art. 189c EGV zum Verfahren der Zusammenarbeit Bezug genommen wird. Vgl. hierzu Läufer (1994d), S. $121 \mathrm{ff}$; Wilming (1995), S. $38 \mathrm{ff}$; Borchardt (1996), S. $157 \mathrm{ff}$. 
nisterrat im normalen Abstimmungsverfahren und kann sich nur durch einstimmigen Beschluß über die geänderte Vorlage der EK hinwegsetzen. Akzeptiert die EK die Änderungswünsche hingegen nicht, so kann der Ministerrat die Vorschläge des EP nur durch einstimmigen Beschluß entgegen dem Entwurf der EK übernehmen.

Die letzte Entscheidungsinstanz bleibt aber in jedem Fall der Ministerrat, unabhängig von der Handlungsoption, die das EP im Rahmen der zweiten Lesung im Parlament gewählt hat; es ändert sich lediglich die Entscheidungsregel im Ministerrat. ${ }^{834}$

- In den Maastrichter-Verträgen wurde 1993 mit dem Mitentscheidungsverfahren ein drittes Gesetzgebungsverfahren eingeführt, das die Befugnisse des EP nochmals ausweitet, so daß Ministerrat und EP beinahe „als gleichwertige Partner”835 bei der Rechtssetzung auftreten. Im Grundsatz läuft der Entscheidungsprozeß bis zu der Festlegung des gemeinsamen Standpunkts durch den Ministerrat und der zweiten Lesung im EP analog zum Verfahren der Zusammenarbeit ab. Das EP besitzt die gleichen Handlungsoptionen zur Abstimmung über den gemeinsamen Standpunkt des Ministerrats. Deren jeweilige Auswirkung auf den Rechtssetzungsprozeß räumt dem EP jedoch über das Verfahren der Zusammenarbeit hinausgehend ,praktisch ein Vetorecht" ${ }^{\text {836 }}$ im Rechtssetzungsprozeß ein:

- Sofern das EP den gemeinsamen Standpunkt billigt oder die Beschlußfassung unterläßt, wird der jeweilige Rechtsakt entsprechend des gemeinsamen Standpunkts erlassen.

- Lehnt das EP den gemeinsamen Standpunkt mit der absoluten Mehrheit seiner Mitglieder ab, so gilt der entworfene Rechtsakt als gescheitert und endgültig nicht angenommen.

- Das EP kann mit der absoluten Mehrheit seiner Mitglieder Änderungen am gemeinsamen Standpunkt beschließen. Die geänderte Fassung des gemeinsamen Standpunkts wird der EK zur Stellungnahme ${ }^{837}$ und dem Ministerrat zur Abstimmung zugeleitet. Stimmt die EK dem Entwurf zu, kann der Ministerrat die Änderungen mit qualifizierter Mehrheit billigen und das Rechtssetzungsverfahren beenden. Änderungsvorschläge des EP, zu denen die EK eine ablehnende Haltung einnimmt, können vom Ministerrat nur einstimmig beschlossen werden. Akzeptiert der Ministerrat nicht alle Änderungsvorschläge des EP, so wird ein Vermittlungsausschuß eingerichtet, der auf Grundlage des

\footnotetext{
${ }^{834}$ Vgl. auch Oppermann (1991), S. 99; Leipold (1994a), S. 19.

835 Wilming (1995), S. 43.

${ }^{836}$ Borchardt (1996), S. 162.

837 Die $E K$ gibt eine Stellungnahme zu den Änderungen ab. Im Gegensatz zum Verfahren der Zusammenarbeit entscheidet sie jedoch nicht verbindlich darüber, ob die Vorschläge des $E P$ in die geänderte Fassung des Rechtsaktes aufgenommen werden.
} 
gemeinsamen Standpunkts des Ministerrats und der Änderungsvorschläge des EP einen Kompromißentwurf für den betreffenden Rechtsakt ausarbeiten soll, der sodann vom EP mit absoluter Mehrheit und vom Ministerrat mit qualifizierter Mehrheit erlassen werden kann. Die EK ist an der Tätigkeit des Ausschusses beteiligt, um unterstützend auf die Annäherung der abweichenden Standpunkte von Ministerrat und EP hinzuwirken. Gelingt es dem Vermittlungsausschuß nicht, einen gemeinsamen Kompromißentwurf zu formulieren oder nimmt eines der beiden Organe den vorgelegten Rechtsakt im „organinternen" Abstimmungsverfahren nicht an, kommt der Rechtsakt endgültig nicht zustande. Das EP kann das Zustandekommen eines Rechtsaktes im Mitentscheidungsverfahren folglich verhindern. Der Ministerrat verkörpert jedoch weiterhin das entscheidende Rechtsetzungsorgan. ${ }^{838}$

Neben diesen drei allgemeinen Rechtssetzungsverfahren bestimmen die gemeinschaftlichen Verträge weitere Sonderbereiche, in denen alternative Entscheidungsprozesse zur Anwendung gelangen. So ist in bestimmten Fällen die Entscheidungsfindung im Ministerrat an die Erteilung der Zustimmung durch die absolute Mehrheit des EP gebunden. Hierzu gehören die Entscheidungen über Abkommen mit dritten Staaten oder Organisationen sowie über den Beitritt neuer Mitgliedstaaten zur EU. ${ }^{839}$ Im Haushaltsverfahren entscheidet das EP über die Befugnisse der allgemeinen Rechtssetzungsverfahren hinausgehend ausnahmsweise eigenständig und endgültig. ${ }^{840}$ Zudem kann der Ministerrat ohne Entscheidungsbeteiligung der EK und des $\mathrm{EP}$ in einstimmiger Beschlußfassung die Zahl der Kommissionsmitglieder ändern und die Anzahl der Richter und Generalanwälte des EuGH erhöhen. ${ }^{841}$ Schließlich erfordern Beschlüsse über das System der Eigenmittel der $\mathrm{EU}^{842}$ sowie Änderungen der Unionsverträge ${ }^{843}$ alternative Rechtssetzungsverfahren, die wiederum die EK, den Ministerrat und das EP an den Entscheidungsprozessen beteiligen, aber darüber hinaus die Ratifizierung der Beschlüsse gemäß der verfassungsrechtlichen Vorschriften der Mitgliedstaaten fordern. Die Rolle des EP bleibt in diesen Fällen jedoch auf das Anhörungsrecht beschränkt.

\footnotetext{
${ }^{838}$ Vgl. Weindl (1996), S. 83.

${ }^{839}$ Vgl. zur vertraglichen Verankerung des Zustimmungsverfahrens Art. 138b EGV. Seit der jüngsten Reform des EUV durch den Amsterdamer Vertrag kommt das Zustimmungsverfahren im einzelnen im Rahmen der Art. 105 (6), Art. 106 (5), Art. 130d, Art. 138 (4) u. 228 (3) EGV sowie Art. Fa u. Art. O EUV zur Anwendung.

$840 \mathrm{Vgl}$. Art. 203 EGV.

841 Vgl. hierzu Art. 157 (1), Art. 165 (4) und Art. 166 (3) EGV.

${ }^{842} \mathrm{Vgl}$. Art. $201 \mathrm{EGV}$; vgl. hierzu insb. die näheren Ausführungen in Abschnitt IV-2.1.4.1.

${ }^{843}$ Vgl. Art. N EUV; vgl. zur Bedeutung dieser Verfahrensregel auch Abschnitt IV-2.2.1.1.
} 
Insgesamt verdeutlicht die Entwicklung der Rechtssetzungsverfahren die schrittweise Ausweitung der Mitwirkungskompetenzen des EP im Entscheidungsgefüge zwischen EK, Ministerrat und EP. Diese Entwicklung hat sich im Vertrag von Amsterdam durch die Ausweitung der Anwendungsbereiche des Mitbestimmungsverfahrens, die bislang gemäß des Anhörungsoder Zusammenarbeitsverfahrens entschieden wurden, fortgesetzt. ${ }^{844}$

Darüber hinaus zeigt sich, daß die „Vielfalt und Komplexität der Verfahren der EU” ${ }^{\text {845 }}$ ständig zugenommen hat. Die Entscheidungsverfahren zeichnet im Laufe des Integrationsprozesses eine zunehmende Intransparenz aus. Dies hat zur Folge, daß die Rechtssetzung für die Bürger kaum nachvollziehbar ist und eine legitimationsfördernde Kontrolle der Entscheidungsträger wesentlich erschwert wird. ${ }^{846}$ Zudem ergibt sich eine anwachsende Schwerfälligkeit und Langwierigkeit der Entscheidungsfindungsprozesse, wodurch die Problemlösungskapazität der EU-Ebene negativ beeinflußt wird. ${ }^{847}$ Der Vertrag von Amsterdam ist ein erster Schritt zur Vereinfachung. Erstens stellt die Ausdehnung des Mitentscheidungsverfahrens auf alle Bestimmungen, die bislang nach dem Verfahren der Zusammenarbeit entschieden wurden, praktisch die Abschaffung eines der drei allgemeinen Rechtssetzungsverfahren dar. ${ }^{848}$ Zweitens wurde der Ablauf des Mitentscheidungsverfahrens gestrafft und vereinfacht. ${ }^{849}$

Trotzdem fehlt eine systematische Strukturierung der Entscheidungsprozesse. Dem Nebeneinander der Vielzahl an allgemeinen und speziellen Entscheidungsverfahren liegt im EUV „keine rational nachvollziehbare Begründung" ${ }^{\text {850 }}$ zugrunde. V.a. unterbleibt eine klare Abgrenzung der Rechtssetzungsverfahren zwischen der Verfassungs- und die Bereitstellungsfunktion des öffentlichen Sektors. In beiden Bereichen bestimmen mit dem Ministerrat bzw. dem Europäischen Rat Vertreter der Regierungen der Mitgliedstaaten die Entscheidungsinhalte. Die Teilnahme der Mitgliedstaaten an der Verfassungsfunktion zur Fortentwicklung der rechtlichorganisatorischen Strukturen der EU - sei es innerhalb der bestehenden Verträge ${ }^{851}$ oder durch Vertragsänderungen ${ }^{852}$ - beschränkt sich auf den Ratifikationsvorbehalt der Entscheidungsinhalte gemäß der verfassungsrechtlichen Vorschriften der einzelnen Mitgliedstaaten. Die na-

\footnotetext{
844 Vgl. Bundesrat (1997), S. 107 ff.; Thiel (1997); Wisdorff (1997).

845 Wessels (1996), S. 36.

846 Vgl. Europäische Strukturkommission (1995), S. 41; Berg/Schmidt (1996), S. 135.

${ }^{847}$ Vgl. Läufer (1994d), S. 126; Boldt (1995), S. 74. Die Konferenz der Vertreter der Mitgliedstaaten betonte aus diesem Grund in einer Erklärung zum Vertragsentwurf von Amsterdam die besondere Bedeutung, „möglichst zigig" verlaufender Entscheidungsverfahren (vgl. Bundesrat (1997), S. 112).

${ }^{848}$ Lediglich im Bereich der WWU bleibt das Verfahren der Zusammenarbeit bestehen, um die betreffenden Bestimmungen nicht nochmals im Rahmen des Mitentscheidungsverfahrens neu verhandeln zu müssen (vgl. Bundesrat (1997), S. 106).

${ }^{849}$ Die Ausführungen zum Mitentscheidungsverfahren in diesem Abschnitt beziehen sich bereits auf das ,reformierte" Verfahren.

850 Europäische Strukturkommission (1995), S. 41; vgl. auch Boldt (1995), S. 74.

851 Vgl. bspw. das Verfahren der Eigenmittelbeschlüsse nach Art. 201 EGV.

852 Vgl. Art. N EUV.
} 
tionalen Parlamente und deren Wähler ,haben jedoch keine Möglichkeit, den Prozeß der Regelsetzung über dieses Vetorecht hinaus zu beeinflussen." ${ }^{853}$ Folglich besitzen die drei Hauptorgane der EU, die über die Bereitstellung europweiter öffentlicher Güter EU verfügen, zugleich die wesentlichen Kompetenzen zur Gestaltung des Ordnungsrahmens für diese Aktivitäten. ${ }^{854}$

\section{IV-2.3 Der europäische Integrationsprozeß}

Der europäische Integrationsprozeß weist unterschiedliche Dimensionen auf, deren jeweiliger Entwicklungsstand erhebliche Auswirkungen auf die ökonomischen, politischen, rechtlichen und sozio-kulturellen Handlungsgrundlagen der Staatstätigkeit besitzt und so die Steuerungsund Problemlösungskapazitäten der Mitgliedstaaten wesentlich mitbestimmt. Die Verdeutlichung struktureller Zusammenhänge zwischen verschiedenen Bereichen der Integration ermöglicht es, über eine kritische Bewertung des „status-quo” hinaus, Schlußfolgerungen zur notwendigen Fortentwicklung des Integrationsprozesses abzuleiten. Dies stellt einen weiteren Schritt zur Konkretisierung der Rahmenbedingungen dar, die der Ableitung eines rationalen Finanzausgleichsystems für die EU zugrundegelegt werden müssen.

Die EU stellt ein dynamisches System „sui generis” dar, dessen Ordnungsgefüge im Kontext des europäischen Integrationsprozesses einem beständigen Wandel unterliegt. Daher ist es fuir die Analyse zwischenstaatlicher FZ auf europäischer Ebene von entscheidender Bedeutung, „die Entwicklungslinien der europäischen Integration zu verstehen und sie durch geeignete organisatorische und verfahrensrechtliche Vorkehrungen zu begleiten und zu unterstützen." 855 Die Ableitung eines rationalen Finanzausgleichsystems für die EU darf sich nicht auf die Bestimmung eines Ausgleichsystems in bezug auf ein quasi am Reißbrett entworfenes „finales” Leitbild der europäischen Integration beschränken, sondern muß gerade die beständige Veränderung der Struktur der EU berücksichtigen und ,verarbeiten”, um die zielgerichtete Fortentwicklung des gesamten Integrationsprozesses zu fördern. ${ }^{856}$

${ }^{853} \mathrm{Berg} /$ Schmidt (1996), S. 134. Darüber hinaus besteht nach Art. 235 EGV die Möglichkeit, die rechtlichorganisatorische Struktur der $E U$ ohne explizite Änderung der Vertragsbestimmungen fortzuentwickeln (vgl. Abschnitt IV-2.1.1.2). In diesem Fall nehmen der Ministerrat, die $E K$ und das EP die Verfassungsfunktion unter Umgehung des Ratifizierungsvorbehalts der Mitgliedstaaten wahr. Da die Entscheidungsfindung nach Art. 235 das Anhörungsverfahren und die Einstimmigkeit im Ministerrat voraussetzt, ist lediglich der Konsens der Vertreter der Regierung der Mitgliedstaaten vonnöten (vgl. hierzu Berg/Schmidt (1996), S. 133).

${ }^{854} \mathrm{Vgl}$. Berg/Schmidt (1996), S. $133 \mathrm{ff}$.

${ }^{85 s}$ Schuppert (1994), S. 69.

${ }^{856}$ Vgl. hierzu Schuppert (1994), insb. S. 56 ff.; auch Folkers (1995), S. 108. 


\section{IV-2.3.1 Der Integrationsbegriff}

Unter Integration ist das Phänomen der Verbindung einzelner Elemente zu einer neuen Gesamtheit zu verstehen, wobei „die gewonnene Einheit mehr als die Summe der vereinigten Teile ist." ${ }^{857}$ Für die EU bedeutet Integration daher ,nicht Addition, Anschluß, sondern Bildung eines neuen Ganzen durch ein neues Zusammenspiel der bisher vereinzelten Glieder". 858 Die EU-Integration kann im Hinblick auf den heutigen Zustand, das finale Ziel sowie den andauernden Prozeß der Integration untersucht werden. ${ }^{859}$ Wie die einleitenden Ausführungen zu diesem Abschnitt verdeutlicht haben, können alle drei Ansätze einen wichtigen Beitrag zur Themenstellung dieser Arbeit leisten. Daher wird nachfolgend der Versuch unternommen, elementare Interdependenzen zwischen Zustand, finalem Ziel und Prozeß der EU-Integration herauszuarbeiten, um hieraus Teilaspekte der Rahmenbedingungen für ein EUFinanzausgleichsystem abzuleiten.

Es lassen sich zwei parallele Integrationsprozesse unterscheiden. ${ }^{860}$ Die informelle Integration umfaßt alle Annäherungen zwischen den Mitgliedstaaten, die nicht durch diskretionäre Entscheidungen der politischen Entscheidungsträger zustande kommen, sondern durch bestehende oder entstehende Interaktionsmuster zwischen den Mitgliedstaaten und deren Bewohnern. ${ }^{861}$ Sie stellt einen kontinuierlich verlaufenden Prozeß dar, der „fast unbemerkt und fast heimlich"862 durch unzählige Handlungen einzelner Akteure eine Zunahme der Verflechtungen der Mitgliedstaaten bewirkt. Die formale Integration hingegen vollzieht sich durch die bewußte Impulsgabe der politisch Handlungsberechtigten. Sie verläuft diskontinuierlich „Schritt für Schritt, Verhandlung für Verhandlung, Vertrag für Vertrag”. ${ }^{863}$ Zwischen formaler und informeller Integration besteht eine wechselseitige Abhängigkeitsbeziehung. ${ }^{864}$

${ }^{857}$ Murakami (1993), S. 24.

${ }^{858}$ Smend (1975), S. 1024. Jones betont, daß die Bildung einer neuen Einheit auf der EU-Ebene notwendigerweise uber eine bloße zwischenstaatliche Kooperation hinausgehen muß: „This implies that it [die Integration] goes beyond 'interstate co-operation' (where arguably there is no whole)". (Jones (1996), S. 33) So auch Staeck (1996), S. 13.

$859 \mathrm{Vgl}$. zu alternativen Untersuchungsansätzen verschiedener Integrationstheorien Puntscher Riekmann (1996), S. 291 ff. u. Harder (1997), S. 293 f. Aber auch schon Haas (1958).

860 Vgl. Wallace (1990), S. 9. Kritisch zum Zusammenspiel beider Integrationsmuster Schmitter (1995), $235 \mathrm{f}$.

${ }^{861}$ Schmitter (1995), S. 209 spricht von ,laufenden sozioökonomischen Integrationsprozessen auf informeller Ebene, die bei Privatpersonen, Unternehmen und lokalen Einrichtungen der Mitgliedsländer stattfinden." Die Entstehung solcher Austauschbeziehungen zwischen privaten Personen und Organisationen aller Mitgliedstaaten wird bspw. durch die Dynamik des gemeinsamen Binnenmarktes und den Aufbau europaweiter Kommunikations- und Verkehrsnetze gefördert (vgl. auch Wallace (1990), S. 9).

${ }^{862}$ Schmitter (1995), S. 236.

863 Wallace (1990), S. 9.

${ }^{864}$ So kann die politische Entscheidung für eine einheitliche Währung in der $E U$ - formaler Integrationsschritt einen wesentlichen (positiven) Einfluß auf die Entwicklung einer gemeinsamen europäischen Identität - informeller Integrationprozeß - besitzen. Vgl. auch Unger (1995), S. $250 \mathrm{f}$. 
In anderer Hinsicht ist zwischen negativer und positiver Integration $\mathrm{zu}$ unterscheiden. ${ }^{865} \mathrm{Als}$ negatives Integrationskonzept werden alle Maßnahmen bezeichnet, die Beschränkungen und Verzerrungen des Wettbewerbs innerhalb der EU beseitigen. Dies betrifft ganz wesentlich die Beseitigung von Handelsbarrieren zur Herstellung des freien Binnenmarktes. Demgegenüber verkörpern aktiv gestaltende Maßnahmen, die zu einer europaweiten Koordinierung weiterhin nationaler Aktivitäten beitragen oder zu einer Verlagerung der Wahrnehmung staatlicher Aktivitäten auf (neuzubildende oder bestehende) Organisationen der EU führen, das Konzept der positiven Integration. Wiederum bestehen weitreichende Interdependenzen zwischen beiden Integrationsformen. Daher können (zusätzliche) Handlungsnotwendigkeiten entstehen, wenn ein asymmetrischer Entwicklungsstand zwischen positiver und negativer Integration vorliegt.

\section{IV-2.3.2 Die Bereiche der Integration}

Integrationsprozesse gehen in verschiedenen, eng miteinander verknüpften Bereichen vonstatten. Es sind v.a. die Bereiche der legalen, der ökonomischen, der politischen und der sozialen Integration zu nennen. ${ }^{866}$ Im Folgenden erfolgt eine Analyse des Wechselspiels zwischen politischer und ökonomischer Integration, um den Fokus auf die grundlegenden (Ziel)Bereiche des europäischen Einigungsprozesses zu richten, denn, wie Vaubel ausführt, „[verbergen sich] hinter dem Ziel der europäischen Integration zwei völlig verschiedene Konzepte: die Integration der Märkte und die Integration der Politik." ${ }^{867}$ Die Handlungsmöglichkeiten und -spielräume aller am Wirtschaftsgeschehen beteiligten Akteure werden durch die Integration in diesen beiden Bereichen entscheidend beeinflußt.

\section{IV-2.3.2.1 Die ökonomische Integration in der EU}

Ökonomische Integration bezieht sich auf die Annäherung der nationalen Volkswirtschaften innerhalb der EU in Richtung einer einheitlichen Volkswirtschaft („Verschmelzung”). Dies impliziert den fortschreitenden Abbau aller Hemmnisse gegen den Austausch bzw. die Wanderung von Waren, Dienstleistungen, Arbeit und Kapital. Ausgehend von einem Zustand vollständiger Autarkie der Mitgliedstaaten werden einzelne Stufen der ökonomischen Integration unterschieden: ${ }^{868}$

\footnotetext{
${ }^{865}$ Vgl. Scharpf (1992a), S. 25; (1996a); Dent (1997), S. 28. Die Abgrenzung traf auch schon Tinbergen (1954).

${ }^{866}$ Vgl. hierzu näher Unger (1995), S. 244 ff.

${ }^{867}$ Vaubel (1992), S. 31. Entsprechend auch Fuest (1995), S. 3.

${ }^{868}$ In der Literatur findet sich eine Vielzahl voneinander abweichender Einteilungen der Stufen ökonomischer Integration. Vgl. zur folgenden Abgrenzung Wagner (1995), S. 20 f.; Sarrazin (1997), S. 60 f., m.w.N.; auch Dent (1997), S. 26 ff.
} 
- Freihandelszone: Es werden qualitative und quantitative Handelsbeschränkungen (Zölle und rein mengenmäßige Beschränkungen) zwischen den Mitgliedstaaten aufgehoben. Jeder Mitgliedstaat bleibt jedoch autonom in seinem Verhalten gegenüber Drittstaaten.

- Zollunion: Über die Bestimmungen der Freihandelszone hinaus erfolgt eine Einigung auf gemeinsame Zollbestimmungen gegenüber Drittstaaten.

- Gemeinsamer Markt (Binnenmarkt): Neben den tarifären werden auch alle nicht-tarifären Handelshemmnisse abgebaut, so daß vollständiger Freihandel zwischen den Mitgliedstaaten gewährleistet ist. Über den ungehinderten Fluß der Waren und Dienstleistungen hinaus wird auch die ungehinderte Mobilität der Produktionsfaktoren Arbeit und Kapital gewährleistet. $^{869}$

- Wirtschaftsunion: Ergänzend zur Harmonisierung der Außenhandels- und Zollpolitik findet eine gemeinschaftsweite Abstimmung der wirtschaftspolitischen Aktivitäten in weiteren Bereichen der Wirtschaftspolitik, so bspw. in ordnungspolitischen Fragen, statt. Die Koordination vollzieht sich v.a. in Form intergouvernementaler Kooperation kann jedoch auch durch die Einrichtung supranationaler Institutionen erfolgen.

- Wirtschafts- und Währungsunion („totale” Wirtschaftsunion): Auf dieser Integrationsstufe wird eine einheitliche Währung für alle Mitgliedstaaten eingeführt. Notwendigerweise erfolgt die Einrichtung supranationaler Institutionen, wie einer gemeinsamen Zentralbank, die die Kompetenz besitzen, autonome wirtschaftspolitische Entscheidungen im Namen aller Mitgliedstaaten zu treffen. Allgemein impliziert die Einrichtung einer WWU, ,that the countries involved must collaborate to a much closer degree on a variety of economic policies. ${ }^{, 870}$ Mit der Verwirklichung einer WWU ist eine vollständige ökonomische Integration erreicht.

Die beiden letzten wirtschaftlichen Integrationsschritte stellen einen bedeutenden Autonomieverlust für die nationalen Entscheidungsträger dar. Sie treten einzelstaatliche Regelungskompetenzen an die übergeordnete EU-Ebene ab. Dies verdeutlicht, daß die ökonomischen Integrationsschritte in enger Verbindung zur politischen Integration zu betrachten ist.

Mit dem EUV ist in der EU der letzte Integrationschritt zu einer WWU verbindlich festgelegt worden. Spätestens im Jahr 2002 wird dieser Integrationsschritt vollzogen sein. Aus rechtlicher Sicht kann die ökonomische Integration dann als abgeschlossen bezeichnet werden. Je-

\footnotetext{
${ }^{869}$ Dies kann ,Zwangsläufig schon eine gewisse Harmonisierung der Wirtschaftspolitik erzwing[en]”, (Wagner (1995), S. 20) um ungleichgewichtige Entwicklungen in bestimmten Regionen oder Mitgliedstaaten zu verhindern.

${ }^{870}$ Dent (1997), S. 28.
} 
doch ist fraglich ob infolgedessen bereits eine ,effektive ökonomische Integration”871 zu konstatieren ist. Es bestehen weiterhin eine Reihe integrationshemmender Faktoren, wie ZentrumPeripherie-Probleme, institutionelle Unvollkommenheiten ${ }^{872}$ und Sprachbarrieren, die verdeutlichen, daß eine tatsächliche völlige Freizügigkeit von Waren, Dienstleistungen, Arbeit und Kapital noch nicht besteht. ${ }^{873}$ Unterscheidet man zwischen formaler und informeller Integration her, so ist festzustellen, daß die formale ökonomische Integration 2002 weitgehend abgeschlossen sein wird, jedoch die parallelverlaufende informelle Integration noch andauert. Der gesamte ökonomische Integrationsprozeß nicht unabhängig von den anderen Integrationsbereichen. V.a. sind die Interdependenzen zur politischen Integration zu beachten.

\section{IV-2.3.2.2 Die politische Integration in der EU}

Entscheidendes Merkmal der politischen Integration ist ,die Zentralisierung und/oder Harmonisierung der Entscheidungs- und anderen Führungsfunktionen der Akteure auf der Gemeinschaftsebene, sei es durch eine Koordinierung der Politik der Regierungen, sei es durch die Übertragung gewisser Hoheitsrechte und Kompetenzen auf gemeinsame zentrale Institutionen." ${ }^{874}$ Wenngleich eine eindeutige Abgrenzung schwerfällt, lassen sich wiederum einzelne Stufen bestimmen, die den Stand der politischen Integration beschreiben: ${ }^{875}$

- Auf der niedrigsten Stufe politischer Integration treffen Nationalstaaten lose Vereinbarungen über die gemeinsame Erfüllung einzelner Funktionen (zwischenstaatliche Zweckverbände funktioneller Integration ${ }^{876}$ ). Es verbleibt jedem einzelnen Teilnehmerstaat eine Vetoposition im Rahmen des intergouvernementalen Abstimmungsprozesses (Einstimmigkeitsregel) oder die Möglichkeit, die (freiwillige) Teilnahme an der gemeinsamen Aufgabenerfüllung wieder zu kündigen. ${ }^{877}$

- Eine fortgeschrittenere Integrationsstufe wird erreicht, sobald Nationalstaaten eines fixen Territoriums abgegrenzte Aufgabengebiete in gemeinsamer Verantwortung zentral wahrnehmen (Staatenbund/Konföderation). Grundsätzlich verbleibt den Nationalstaaten aller-

\footnotetext{
871 Unger (1995), S. 246.

${ }^{872}$ Bspw. in bezug auf die einheitliche Anerkennung beruflicher Qualifikationen in allen Mitgliedstaaten, die als unabdingbare Voraussetzung einer ungehinderten Mobilităt des Produktionsfaktors Arbeit zu werten ist.

${ }^{873} \mathrm{Vgl}$. Unger (1995), S. $245 \mathrm{ff}$.

874 Saeter (1974), S. 15.

875 Die Unterscheidung erfolgt in Anlehnung an Unger (1995), S. 252 f.; Jones (1996), S. 34 ff. sowie Schmitter (1995), S. $213 \mathrm{ff}$. Da in der Literatur übereinstimmend davon ausgegangen wird, daß die (erfolgreiche) politische Integration der heterogenen Nationen auf dem europäischen Kontinent nur von foderativen Leitbildern geprägt sein kann (vgl. hierzu stellvertretend für viele Murakami (1993), S. 27 ff., m.w.N.), wird nachfolgend auf Integrationsstufen in Richtung eines zentralistischen EU-Staates nicht eingegangen.

876 Vgl. hierzu grundlegend Ipsen (1972).

877 Jones (1996), S. 35 bezeichnet diesen Integrationsstand als „loose intergovernmentalism”.
} 
dings weiterhin die Option, die Mitgliedschaft in den einzelnen Aufgabenbereichen aufzulösen: „Sovereignty has been 'lent rather than lost." ${ }^{878}$ Die Abstimmungsprozesse erfolgen zudem nach wie vor intergouvernemental. Wird bei diesen Abstimmungsprozessen von der Einstimmigkeitsregel auf Mehrheitsentscheidungen übergegangen, so stellt dies einen deutlichen Schritt in Richtung einer tieferen politischen Integration dar, da die nationalen Akteure nun gezwungen sind Mehrheitsentscheidungen zu akzeptieren. ${ }^{879}$

- Die höchste Stufe politischer Integration wird in einem Bundesstaat verwirklicht. Die territorialen Grenzen des Staatsgebietes werden endgültig festgelegt, so daß die einzelnen Nationalstaaten dem übergeordneten Bundesstaat unwiderruflich zugehören. In einer bundesstaatlichen Verfassung erfolgt die Aufteilung sämtlicher staatlicher Aufgabengebiete auf die supranationalen, nationalen und subnationalen Regierungseinheiten sowie die explizite Bestimmung der bei der Staatstätigkeit zu beachtenden Organisations- und Verfahrensregeln. Die Entscheidungsprozesse der zentralen Ebene vollziehen sich nicht länger in Form intergouvernementaler Verhandlungen, sondern innerhalb (neugeschaffener) autonomer supranationaler Institutionen. Letztendlich folgt, daß „the national sovereignty of member states is forgone and their peoples [are] obliged to adopt union citizenship."

Die Stufen der politischen Integration demonstrieren, daß die EU ,in ihrer gegenwärtigen Verfassung ... zwar mehr als ein Staatenbund, aber immer noch weit weniger als ein voll ausgebildeter Bundesstaat" ${ }^{\text {881 }}$ ist. Das entscheidende Kennzeichen des formalen Integrationsstandes ist das Ausmaß, in dem durch die gemeinsamen Verträge nationale Souveränität von den Mitgliedstaaten an die EU-Ebene abgetreten wurde. Wie die Ausführungen zu den MaastrichterVerträgen verdeutlichen, haben die Mitgliedstaaten bereits erhebliche Souveränitätsrechte an die EU übertragen, so daß der Integrationsstand über den eines bloßen Staatenbundes hinausgeht. $^{882}$ Zugleich zeigt das Vertragwerk aber auch, daß die nationale Souveränität keinesfalls gänzlich an die EU abgetreten wurde, wie es typisch für einen echten Bundesstaat wäre. ${ }^{883}$

878 Jones (1996), S. 35.

879 Jones (1996), S. 35 bezeichnet diesen Integrationsstand als „tight intergovernmentalism”.

${ }^{880}$ Dent (1997), S. 28.

${ }^{881}$ Scharpf(1991), S. 415. So auch Oppermann (1991), S. 304 f.

${ }^{882}$ So wurden auf der EU-Ebene bereits eine Reihe supranationaler Organisationen geschaffen, wie bspw. das $E P$, die an den zentralstaatlichen Entscheidungsprozessen beteiligt sind. Dabei zeigt sich je nach Politikbereich eine unterschiedliche ,politische Integrationsdichte". Während in den Aufgabengebieten der ersten EGSäule weitergehende Mitwirkungsrechte der supranationalen Institutionen bestehen, verlaufen die Entscheidungsprozesse im Rahmen der zweiten u. dritten Säule fast ausschließlich intergouvernemental. Vgl. hierzu Abschnitt IV.1.1; zur Frage unterschiedlicher Integrationsdichte auch Schuppert (1994), S. $61 \mathrm{ff}$.

${ }^{883} \mathrm{Vgl}$. Maihofer (1995), S. 62; sowie die deutlichen Ausfuhrungen des BVerfG (1993), S. 155 ff. An dieser Stelle könnte die grundsătzliche Frage gestellt werden, ob der politische Integrationsprozeß auf der EU-Ebene „mit der traditionellen Entgegensetzung von Staatenbund oder Bundesstaat" (Schuppert (1994), S. 56) überhaupt adăquat beschrieben werden kann. Es ist weithin akzeptierte Einsicht, daß sich eine ,qualitative neue" 
Über diese Analyse hinaus ist auch zur politischen Integration die Frage des Nebeneinander eines formalen und eines informellen Integrationsprozesses aufzuwerfen. Während die formale politische Integration anhand des Ausmaßes des nationalstaatlichen Souveränitätsverzichts beschrieben wurde, sind bei der informelle politische Integration zwei getrennte Aspekte zu beachten:

- Zum ersten ist die informelle politische Integration durch ,the shifting of the loyalities, expectations and activities of national political actors to a new centre" ${ }^{\mathbf{9 8 4}}$ charakterisiert. Erst wenn die nationalen politischen Eliten, wie Regierungen, führende Bürokraten, Parteien und Interessengruppen, ihre Handlungslogiken von der mitgliedstaatlichen zur gemeinschaftsweiten Ebene verlagern und ,ein integrationsorientiertes Verhalten an den Tag legen” ${ }^{, 885}$ entsteht nicht nur formal sondern ,tatsächlich"886 eine neue politische Einheit auf der EU-Ebene.

- Zum zweiten ,ist die Existenz eines auf Wir-Identität gestützten Gemeinwesens" als „strukturelle Voraussetzung" ${ }^{887}$ einer effektiven politischen Integration anzusehen. Eine fehlende Identifikation der Bürger mit der EU wirkt integrationshemmend und beschränkt faktisch die im Rahmen der formalen politischen Integration geschaffenen Handlungsmöglichkeiten der EU-Entscheidungsträger. ${ }^{88}$

Beide Kriterien einer fortgeschrittenen informellen politischen Integration sind derzeit auf der Ebene der EU nicht erfüllt. Die politischen Eliten sind in ihren Aktivitäten kaum von europäischen Interessen geleitet ${ }^{889}$ und „eine politisch belastbare Identität der Europäer als Europäer

(Streinz (1992), S. 33) politische Integration vollzieht, die sich nur schwer in das vorgegebene Schema von Staatenbund und Bundesstaat einfügen läßt, da sich „eine neuartige politische Superstruktur" (Oppermann (1991), S. 304) zwischen ,unabhängigen und souveränen Staaten” (Kirchhof (1995), S. 35) entwickelt. Auch im Maastricht-Urteil des $B V \operatorname{erf} G$ drückt sich diese Sichtweise aus, indem die $E U$ in Abgrenzung zu Staatenbund und Bundesstaat als „Staatenverbund” (BVerfG (1993), S. 155) qualifiziert wird. Für die vorliegende Untersuchung ist es jedoch weniger von Bedeutung, ein finales Leitbild der politischen Integration idealtypisch als Staatenbund oder Bundesstaat titulieren zu können, als vielmehr qualitative Aussagen zu Stand und Entwicklungsprozeß der (entstehenden) Entscheidungs- und Führungsfunktionen auf der Gemeinschaftsebene abzuleiten. In diesem Hinblick verkörpern die traditionellen Leitbilder eine geeignete didaktische Hilfsgröße.

884 Jones (1996), S. 33. Fast analog auch schon Haas (1958), S. 16. Vgl. auch Puntscher Riekmann (1996), S. 295 f. und Harder (1997), S. 297 ff., m.w.N.

${ }^{885}$ Puntscher Riekmann (1996), S. 295.

${ }^{886}$ Harder (1997), S. 299.

${ }_{887} \operatorname{Scharpf}(1993 \mathrm{~b})$, S. 31.

${ }^{888}$ Vgl. hierzu Scharpf (1993b), S. 26 f., der ausfuhrt: „Ohne diese Unterstützung durch Identifikation wäre der Kontroll- und Sanktionsaufwand effektiven kollektiven Handelns unter modernen Bedingungen prohibitiv. Umgekehrt bedeutet dies auch, daß politische Einheiten mit schwacher Identitätsbindung nur eine begrenzte Fähigkeit zur kollektiven Selbstbestimmung entwickeln können." Vgl. auch Kittel (1997), der die besondere Bedeutung der sozialen Integration für die Entwicklung des politischen Systems auf der EU-Ebene betont.

${ }^{889} \mathrm{Vgl}$. hierzu Graf Kielmansegg (1996), insb. S. 51 ff. So spielen bspw. europäische Themen bei nationalen Wahlen zumeist nur eine sehr untergeordnete Rolle. „Die Parlamentswahlen in den Mitgliedstaaten ... sind keine europäischen, keine auf Europa ausgerichteten Wahlen." (Graf Kielmansegg (1996), S. 52.) 
gibt es nicht". ${ }^{890}$ Insgesamt ist angesichts der stark eingeschränkten formalen sowie der praktisch fehlenden informellen Integration die Schlußfolgerung zu ziehen, daß „die politische Integration in der EU noch sehr wenig entwickelt [ist]."891

\section{IV-2.3.3 Der Zusammenhang zwischen ökonomischer und politischer Integration}

Ein Vergleich des Integrationsstandes im ökonomischen und politischen Bereich verdeutlicht, daß der europäische Integrationsprozeß von einer ,fundamentalen Asymmetrie"892 geprägt ist. Die weitgehende ökonomische Integration geht einher mit einer kaum vorangeschrittenen politischen Integration. Mit fortschreitender ökonomischer Integration schwinden jedoch in zunehmendem Maße die Handlungsspielräume der nationalen Entscheidungsträger. Insbesondere die vertragliche Garantie der vier Grundfreiheiten zur ungehinderten Mobilität von Waren, Dienstleistungen, Arbeit und Kapital schränkt das wirtschaftspolitische Instrumentarium der Nationalstaaten wesentlich ein. ${ }^{893}$ Darüber hinaus bewirken beschleunigte technologische und politische Globalisierungsprozesse in der Weltwirtschaft zusätzliche Handlungsrestriktionen, die die Chancen einer aktiv gestaltenden Wirtschaftspolitik der Nationalstaaten dramatisch verringern. ${ }^{894}$ Zugleich löst die Realisierung des negativen Integrationskonzepts im Rahmen des europäischen Binnenmarktes einen erheblichen zusätzlichen politischen Handlungsbedarf aus. „Die marktökonomische Integration erfolgt also keineswegs 'unpolitisch`. Sie impliziert vielmehr weittragende politische und sozialstrukturelle Wirkungen." ${ }^{895}$ Die einzelnen Mitgliedstaaten sind daher entscheidend darauf angewiesen, daß die auf nationaler Ebene verlorengegangenen Steuerungskompetenzen durch den Aufbau neuer Problemlösungskapazitäten auf der EU-Ebene kompensiert werden. Der Stand des politischen Einigungsprozesses verdeutlicht jedoch, daß eine entsprechende positive Integration noch nicht stattgefunden hat. Die

${ }^{890}$ Graf Kielmansegg (1995), S. 235. Analog auch Unger (1995), S. 253 und ausfuihrlicher Scharpf (1993b). Vgl. auch Immerfall/Sobisch (1997), die die wichtigsten Ergebnisse der europäischen Meinungsforschung dahingehend zusammenfassen, daß der einzelne Bürger heute nur dann seine Zustimmung zu Europa gibt, wenn dies mit materiellen Vorteilen für die eigene Person oder die Volkswirtschaft des eigenen Mitgliedstaates verbunden ist. Ein europäischer Identifikationsbezug existiert hingegen nicht. Für den weiteren Integrationsprozeß sind Immerfall/Sobisch allerdings durchaus optimistisch, da es „Ansätze[n] zur Entwicklung einer gemeinsamen Identität" gibt, "die der diffusen Unterstützung für das politische System der EU zugute kommt" und somit über rein wirtschaftliche Kosten/Nutzen Überlegungen hinausgeht.

891 Unger (1995), S. 252 f.

${ }^{892}$ Scharpf(1997b), S. 365.

${ }^{893}$ Vgl. hierzu bspw. Scharpf (1991); (1995); Böckenförde (1997).

${ }^{894}$ Dabei bleiben die Folgen der Globalisierung der Weltwirtschaft keineswegs auf den ökonomischen Bereich beschränkt. „Den eigentlichen Sprengstoff der Globalisierungsdebatte” (Ebert/Noll (1998), S. 23) bildet die politisch-gesellschaftliche Dimension. Vgl. für eine interessante Diskussion dieser Problematik Ebert/Noll (1997); Nowotny (1997a); (1997b) u. ausführlich Beck (1997a), insb. S. 259 ff.

895 Böckenförde (1997), S. 30. 
Handlungsfähigkeit der EU-Ebene zur Regelung der Folgeprobleme der ökonomischen Integration wurde bislang nur ungenügend gesteigert. ${ }^{896}$

Der Status-Quo zwischen ökonomischer und politischer Integration ist deshalb eine instabile Integrationskonstellation. Eine Gesamtschau aller gebietskörperschaftlichen Ebenen im gesamten Integrationsgebiet dokumentiert ein deutliches Mißverhältnis zwischen Handlungsnotwendigkeiten und Handlungkapazitäten. Bleiben diese staatlichen Problemlösungsdefizite längerfristig bestehen, so ergibt sich „die Gefahr einer regressiven Entwicklung”897 des gesamten Einigungsprozesses. Es sind in diesem Fall Rückschritte im Bereich der ökonomischen Integration zu erwarten, so daß letztlich eine sowohl in politischer wie auch ökonomischer Hinsicht lose Vereinigung der Mitgliedstaaten im europäischen Raum entstehen würde. Angesicht gegensätzlicher Interessen und heterogener Zielvorstellungen der einzelnen Mitgliedstaaten erscheint sogar eine Zersplitterung der EU in einzelne einander überlappende aber sowohl funktional als auch territorial unbestimmte regionale Zweckverbände nicht ausgeschlossen. ${ }^{898}$ Um diese unerwünschten Entwicklungsprozesse zu verhindern, muß daher die im Integrationsraum bestehende „Kompetenzlücke”899 geschlossen werden. Dies impliziert zum einen die Schaffung neuer Regelungskapazitäten auf der zentralen Ebene der EU; zum anderen bedarf es jedoch dort, wo es die Logik der Integrationsprozesse zuläßt, einer Erhaltung oder Wiederherstellung möglichst weitgehender autonomer Handlungsspielräume der nationalen und subnationalen Entscheidungsträger. ${ }^{900}$ Aus diesem Blickwinkel entspricht die momentane ,asymmetrische” Integration lediglich einem vorübergehenden Zustand - einem "Interregnum". 901 Indem im Laufe des weiteren Integrationsprozesses neben die ökonomische Integration auch eine zunehmende politische Integration tritt, erfolgt ein inkrementaler Übergang zu einer symmetrischen Integrationskonstellation und damit zu einer stabileren föderalen Balance. Unbestritten ist, daß bei dieser Vorgehensweise ,nicht der abschließende Entwurf ..

${ }^{896}$ Scharpf(1992a), S. 24 f.

897 Scharpf (1991), S. 417.

${ }^{898}$ Vgl. Schmitter (1995), S. 214 ff.; Unger (1995), S. 253 ff. Eine solcher Fortgang des Integrationsprozesses wird jedoch in der wissenschaftlichen Literatur sehr unterschiedlich bewertet. Einige Autoren sehen gerade im Wettbewerb staatlicher Einheiten, die sowohl funktional als auch territorial unbestimmt bleiben, ein neuartiges Integrationskonzept, das dem unbefriedigenden Status-Quo Abhilfe leisten könnte. So beschreibt Teutemann (1992) ein „System Europåischer Gemeinschaften”; Eichenberger (1995) und Frey, B. (1997) entwickeln ein Konzept der „Functional, Overlapping, Competing Jurisdictions”. Den Schlußfolgerungen dieser Autoren wird hier jedoch nicht gefolgt. In Anlehnung an Sinn (1995) u. (1997a) wird vielmehr davon ausgegangen, daß es nicht möglich ist, Analysen zur Effizienz des privatwirtschaftlichen Wettbewerbs gedanklich mit dem Systemwettbewerb zwischen Staaten gleichzusetzen. Diese Vorgehensweise greift daher auch zu kurz, um die Asymmetrie zwischen politischer und ökonomischer Integration im EU-Integrationsprozeß aufzulösen. Diese Überlegung besitzt insb. im Hinblick auf die Aufgaben des Sozialstaates exponierte Gültigkeit.

899 Scharpf (1992a), S. 27.

900 Vgl. bspw. Scharpf(1993a); (1997a), S. 81 ff.; (1997b).

901 Unger (1995), S. 254. 
gefragt [ist], sondern der realistische Schritt, der den Weg zu etwas, was man Endzustand nennen mag, offenhält." ${ }^{902}$ So vollzieht sich eine langfristige Entwicklung zu einer immer engeren Union der Völker Europas, die in der hier beschriebenen Vorgehensweise am ehesten mit der Annäherung an einen europäischen Bundesstaat beschrieben werden kann. ${ }^{903}$

\section{IV-2.4 Schlußfolgerungen für den weiteren Gang der Untersuchung}

In den Abschnitten IV-2.1 bis IV-2.3 wurden die Handlungsgrundlagen der Staatstätigkeit auf der EU-Ebene begutachtet. Es verdeutlicht sich die erhebliche Dynamik des gesamten Einigungsprozesses; zugleich zeigte sich aber auch die Langsamkeit der festzustellenden Veränderungsprozesse, da sich frühzeitig festgelegte Strukturen verfestigt haben. Die Fortentwicklung bestehender Strukturen bedarf deshalb eines sehr langfristigen und kontinuierlichen Gestaltungsprozesses. Die vergleichende Analyse der politischen und ökonomischen Integrationsintensität demonstriert die Notwendigkeit zur dynamischen Weiterentwicklung der rechtlichorganisatorischen Rahmenbedingungen. Nur so kann die Kontinuität des Einigungsprozesses sowie die Stabilität des bestehenden Gesamtsystems der EU gewährleistet werden.

Die Erörterungen identifizieren eine Reihe von allgemeinen Problembereichen, die bei jeder Entwicklungslinie des zukünftigen Integrationsprozesses eine besondere Bedeutung besitzen. Sie sind daher auch bei der Entwicklung eines rationalen Finanzausgleichsystems für die EU zu beachten. Darüber hinaus können spezielle Problembereiche abgeleitet werden, die bei der Vergabe zwischenstaatlicher FZ eine besondere Relevanz erlangen. Diese unterschiedlichen Problembereiche sollen nochmals knapp aufgezeigt werden:

- Die Analyse der Entscheidungsverfahren dokumentiert, daß der Willensbildungsprozeß innerhalb der EU durch die Theorie der Politikverflechtung zutreffend beschrieben wird. Zugleich verdeutlicht die fehlende informelle politische Integration, daß interkollektive Interessenkonflikte sehr wahrscheinlich sind. Die Konsensfindung wird hierdurch wesentlich erschwert und beeinträchtigt die Problemlösungsfähigkeit des Entscheidungssystems. Es besteht die Gefahr, daß die EU ,in einen Zustand der politischen Impotenz"904 verfällt und der Einigungsprozeß im Hinblick auf eine Vielzahl (politisch) umstrittener Einzelfragen in einem zunehmend probleminadäquaten Status-Quo verhaftet bleibt. Diese Aussage besitzt auch für das Gesamtsystem der FZ Gültigkeit.

\footnotetext{
902 Möschel (1996), S. 52.

903 So auch Joachimsen (1998), S. 198 ff. Zur Überlegung, daß es sich hierbei um einen Bundesstaat besonderer Prägung handeln muß, vgl. Fn 883 in Abschnitt IV-2.3.2.2 sowie auch Unger (1995), S. 257 f.

904 Scharpf(1992a), S. 26.
} 
Aus diesem Blickwinkel sind v.a. die bestehenden Ausgaben- und Einnahmestrukturen innerhalb der Finanzverfassung ein Problem. Auf der Ausgabenseite dominieren die traditionellen Ausgaben im Bereich des Agrarsektors. ${ }^{905}$ Auf der Einnahmeseite besitzt die EUEbene keine substantielle Einnahmeautonomie. Bleiben diese historisch entstandenen Strukturen wegen der den Status-Quo begünstigenden Entscheidungsregeln (fast) unverändert bestehen, so kann dies zu einer mangelnden Flexibilität des FZ-Vergabe fuihren, da die vorhandenen Strukturen des Finanzsystems den staatlichen Entscheidungsträgern nicht genügend Handlungsspielräume zur zieladäquaten Ausgestaltung der FZ einräumen.

- Lösungswege zur Erhöhung der Handlungsfähigkeit der EU-Ebene liegen im konsequenten Übergang zu Mehrheitsentscheidungen innerhalb der bestehenden Entscheidungsverfahren sowie in der zunehmenden Verlagerung der Entscheidungsbefugnisse auf das EP. Die Problemlösungsdefizite der konsensorientierten Entscheidungsfindung könnten auf diese Weise behoben werden. Die fehlende informelle politische Integration deutet jedoch daraufhin, daß hierdurch sehr hohe Präferenzkosten bei der majorisierten Minderheit ausgelöst würden. Die demokratische Legitimation der Entscheidungen auf der EU-Ebene kann so kaum gewährleistet werden. ${ }^{906}$ Denn diese „erfordert mehr als die Anwendung parlamentarischer Mehrheitsregeln. Sie verlangt, daß es der jeweils unterlegenen Minderheit mit guten Gründen zugemutet werden kann, die Mehrheitsentscheidungen ohne Widerstand als auch für sie gültig zu akzeptieren. ... Die Legitimationskraft des demokratischen Mehrheitsprinzips setzt die faktische politische Integration des Gemeinwesens voraus - wo diese fehlt, müßte seine Anwendung desintegrierend wirken." ${ }^{907}$ Diese Schlußfolgerung ist auch bei der FZVergabe zu beachten. Beim aktuellen Stand der informellen politischen Integration sind die Kosten der Eingriffe in die Präferenzen der Transferempfänger vergleichsweise hoch einzuschätzen.

- Die Dynamik der fortschreitenden Integrations- und Globalisierungprozesse löst eine andauernde Veränderung der ökonomischen Rahmenbedingungen des staatlichen Handelns aus. Diese bewirkt, daß bestimmte (wirtschafts-)politische Probleme im nationalen Rahmen nicht länger effektiv bewältigt werden können. Daher besteht die Notwendigkeit zur beständigen Überprüfung der Aufgabenverteilung zwischen der zentralen EU-Ebene und den dezentralen gebietskörperschaftlichen Ebenen. Es kann eine Übertragung bestimmter

${ }^{905}$ Einer sehr kritischen Beurteilung der dominanten Rolle der Agrarausgaben aus rein ökonomischer Sicht muß jedoch eine einschränkende Bemerkung zur Seite gestellt werden. In der Vergangenheit gingen von den Agrarausgaben positive ,spill-over"-Effekte auf andere Bereiche des europäischen Einigungsprozesses aus, die insgesamt eine integrationsfördernde Wirkung ausgelöst haben. Vgl. zu dieser ,neofunktionalistischen” Sichtweise bspw. Pfetsch (1997), S. 170 ff.; insb. S. 184 f.

906 Vgl. hierzu Abschnitt IV-2.2.1.2.3 zum EP.

907 Scharpf(1992b), S. 296. 
Aufgabenkompetenzen an die EU-Ebene angezeigt sein, um dort effektive Handlungskapazitäten zu schaffen. Eine aus diesem Grunde erfolgende Korrektur der Aufgabenverteilungsstruktur zugunsten der zentralen Ebene ist positiv zu bewerten. ${ }^{908}$ Wie die Ausführungen zur Entwicklung der Aufgabenverteilung zwischen den Mitgliedstaaten und der EU-Ebene sowie zur Eingriffsintensität der Rechtssetzungstätigkeiten der EU demonstrieren, besteht jedoch eine ernste Gefahr unerwünschter Zentralisierungstendenzen. Unter Beachtung polit-ökonomischer Überlegungen zu den Interessenlagen der EK, des Ministerrats und auch des EP zeichnet sich die Tendenz ab, daß bestehende Auslegungsspielräume bei der Kompetenzverteilung und -ausübung zur Expansion der Aufgabenzuständigkeiten der EU-Ebene genutzt werden.

Diese Befürchtungen zur übermäßigen Ausdehnung der zentralstaatlichen Gewalt in Richtung eines „Leviathan Europa"909 sind bei der Ableitung eines rationalen Finanzausgleichsystems zu berücksichtigen. Einerseits ist stets diejenige Ausgestaltungsform der FZ zu wählen, die den dezentralen GKS unter Beachtung der sachlichen Problemlösungfähigkeit, die größten autonomen Handlungsspielräume beläßt. ${ }^{910}$ Andererseits hat die Beendigung eines FZ-Programms zu erfolgen, sofern aufgrund dynamischer Entwicklungsprozesse der Begründungsansatz für die Vergabe der FZ entfällt. Beide Aspekte implizieren, daß das Subsidiaritätsprinzip als ein zentrales Strukturprinzip in den Mittelpunkt der Analyse des Finanzausgleichsystems gerückt wird. Jedoch nicht in seiner (eingeschränkten) Bedeutung basierend auf Art. 3b (2) des EGV, sondern in jener auf die Enzyklika „Quadragesimo Anno" zurückgehenden (umfassenden) positiven wie negativen Interpretation.

- Die institutionelle Struktur der EU zeichnet sich durch eine enorme Komplexität aus. Neben der umstrittenen Aufgaben- und Ausgabenverteilung tragen die komplizierten Entscheidungsverfahren $\mathrm{zu}$ einer weitgehenden Intransparenz und damit $\mathrm{zu}$ einer hohen Rechtsunklarheit und Verunsicherung aller von den Regelungen Betroffenen bei. Daher muß bei der Ableitung eines rationalen Finanzausgleichsystems für die EU die Transparenz der Regelungen besonders beachtet werden. So wird verhindert, daß der ohnehin erst allmählich entstehende europäischer Identifikationsbezug und die fragile Akzeptanz des europäischen Integrationsprozesses in der breiten Bevölkerung durch eine zusätzliche Verkomplizierung der institutionellen Strukturen gefährdet wird.

\footnotetext{
908 Vgl. auch Meyer (1998).

909 Vgl. zu dieser Fragestellung ausführlich die gleichnamige Arbeit von Bohnet-Joschko (1996).

910 So lassen sich bspw. Zentralisierungstendenzen vermeiden, sofern ,im Zweifelsfalle" auf eine Zweckbindung einer FZ zugunsten einer Pauschalzuweisung verzichtet wird.
} 
Steffen Meyer - 978-3-631-75269-2

Downloaded from PubFactory at 01/11/2019 06:28:10AM

via free access 


\section{Funktionen der Finanzzuweisungen im europäischen Integrationspro- zeß}

Die Zielsetzung des Kapitels V besteht darin, aus den umfangreichen theoretischen und empirischen Vorarbeiten der Kapitel II bis IV konkrete Gestaltungsaspekte eines rationalen Finanzausgleichsystem für die EU abzuleiten. Die Gliederung des Kapitels folgt den Zielen (Funktionen) der FZ (Abschnitte V-1 bis V-5). Da die einzelnen FZ-Programme in einem rationalen System letztendlich nicht isoliert voneinander betrachtet werden dürfen, stellt Abschnitt V-6 den Gesamtzusammenhang zwischen den einzelnen Funktionen her.

Die Abschnitte V-1 bis V-5 weisen jeweils zwei Analyseschwerpunkte auf.

Zum einen werden die unterschiedlichen Ansatzpunkte, die für die Vergabe zwischenstaatlicher FZ innerhalb der EU von Relevanz sind, systematisch herausgearbeitet. Als Abgrenzungkriterium werden die einzelnen Funktionen der FZ herangezogen, wie sie in Abschnitt III-3 eingeführt wurden, ${ }^{111}$ und unter Berücksichtigung des Zielsystems der EU auf ihre Relevanz hin untersucht. Dabei werden die wechselseitigen Zusammenhänge zwischen den einzelnen Funktionen und dem dynamischen europäischen Integrationsprozeß genau analysiert. Es zeigt sich, daß einige der zwischenstaatlichen FZ einen entscheidenden Einfluß auf den Ablauf des Integrationsprozesses besitzen aber auch der Ablauf des Integrationsprozesses die Relevanz der zwischenstaatlichen FZ determiniert. ${ }^{912}$ Zum anderen wird die Problemlösungsfähigkeit der europäischen Entscheidungsstrukturen in den Mittelpunkt gerückt. Ein zentrales Anliegen dieses Kapitels ist die Beantwortung der Frage, ob die bestehenden institutionellen Rahmenbedingungen die Verwirklichung eines rationalen FZ-Systems (überhaupt) ermöglichen. Deshalb wird untersucht, mit welcher Wahrscheinlichkeit in den einzelnen Problembereichen effiziente und effektive FZ-Maßnahmen beschlossen und durchgeführt werden können.

Bei jedem Ansatzpunkt zur Vergabe von FZ werden die folgenden Analyseschritte vollzogen: Zunächst erfolgt eine Überprüfung, ob überhaupt eine Handlungsnotwendigkeit für die Entscheidungsträger der zentralen EU-Ebene besteht. ${ }^{913}$ Für die Beurteilung dieser Frage spielt es eine entscheidende Rolle, welche Interdependenzen zwischen der Fortentwicklung des Inte-

911 Dabei zeigt sich, daß die trennscharfe Abgrenzung der Funktionen im Einzelfall sehr problematisch ist. Es besteht eine Reihe an Überschneidungen, die eine eindeutige Formulierung eines funktionalen Zielsystems erschweren. Um so wichtiger ist jedoch der Versuch, durch eine präzise Aufarbeitung dieser Problematik einen Beitrag zur Versachlichung der Diskussion zwischenstaatlicher FZ zu leisten.

912 FZ zum Ausgleich vertikaler fiskalischer Ungleichgewichte werden nicht thematisiert, da der Untersuchungsschwerpunkt dieser Arbeit auf die horizontale Dimension des europäischen Finanzausgleichs im engen Sinne gelegt wird (vgl. Abschnitt I-2).

913 Die Frage, welches der verschiedenen zur Verfügung stehenden staatlichen Instrumente zur Aufgabenerfüllung eingesetzt werden sollte, wird an dieser Stelle (noch) nicht thematisiert. 
grationsprozesses und den betrachteten Problemstrukturen existieren. Anschließend wird betrachtet, welche eigenen wirtschaftspolitischen Aktivitäten die EU-Ebene bereits zur Erfüllung der jeweiligen Funktion ergreift und wie diese Maßnahmen zu bewerten sind. Im nächsten Schritt wird den aktuell bestehenden Maßnahmen die theoretische Optimallösung ${ }^{914}$ unter Rückgriff auf das Instrument der zwischenstaatlichen FZ gegenübergestellt. Unter Bezug auf diesen Soll-Ist-Vergleich wird analysiert, inwieweit im politischen Entscheidungs- und Bereitstellungsprozeß die Durchsetzung einer effektiven und effizienten Problemlösung durch die Vergabe zwischenstaatlicher FZ aussichtsreich ist. In einem letzten Schritt werden jeweils abschließende Folgerungen gezogen.

In Abschnitt V-6 wird ausgehend von den Kritikpunkten an den bestehenden zwischenstaatlichen FZ in der EU ein Reformmodell vorgeschlagen, das die Ineffizienzen des Status-Quo wenn nicht $\mathrm{zu}$ vermeiden so doch deutlich abzumildern versucht. Anstelle der bestehenden „systemlosen” FZ wird ein funktionales System zwischenstaatlicher FZ vorgeschlagen.

\section{V-1 Räumliche externe Effekte zwischen den Mitgliedstaaten}

Die Struktur der GKS innerhalb der EU ist territorial bestimmt. Die EU selbst umspannt als zentrale Ebene den gesamten Raum. Es besteht in diesen Strukturen grundsätzlich die Möglichkeit, daß die Bereitstellung öffentlicher Güter durch die nationalen oder subnationalen GKS zu räumlichen externen Effekten zwischen den Mitgliedstaaten führt. Hieraus ergibt sich ein erster Ansatzpunkt für die Vergabe zwischenstaatlicher FZ. Sie können zur Kompensation grenzüberschreitender Spillover-Effekte eingesetzt werden, um für eine effiziente Versorgung der Bevölkerung der EU mit öffentlichen Gütern Sorge zu tragen. ${ }^{915}$

\section{V-1.1 Handlungsnotwendigkeit für die EU}

\section{V-1.1.1 Räumliche externe Effekte im Integrationsprozeß}

Die theoretische Analyse zeigte verschiedene Lösungswege zur Internalisierung räumlicher externer Effekte auf und verdeutlichte, daß eine abschließende Bewältigung der Externalitätenproblematik nur möglich ist, wenn die territoriale Ausdehnung der GKS so gestaltet wird, daß die Grenzen der GKS mit den räumlichen Wirkungskreisen der bereitzustellenden öffent-

\footnotetext{
914 Es zeigt sich jedoch, daß eine eindeutige Optimallösung zumeist nicht bestimmt werden kann.

915 Vgl. die theoretischen Überlegungen zu dieser Funktion der FZ in Abschnitt III-3.1.1.1.
} 
lichen Güter übereinstimmen. Um diesen Lösungsweg innerhalb der EU zu beschreiten, müßte für jedes öffentliche Gut mit einem spezifischen Nutzenradius eine monofunktionale Bereitstellungseinheit geschaffen werden. Dies impliziert den Übergang zu funktional bestimmten GKS. Diese Vorgehensweise ist aber aus theoretischer Sicht nicht optimal, da sie mit prohibitiv hohen Transaktionkosten zur Entscheidungsfindung und -durchführung innerhalb der vielzähligen monofunktionalen GKS verbunden wäre. ${ }^{916}$ Darüber hinaus ist diese Problemlösung aufgrund politisch-institutioneller Beschränkungen ausgeschlossen. Eine grundlegende Veränderung der gebietskörperschaftlichen Strukturen in der EU würde die Konsensfähigkeit der Entscheidungsgremien überfordern. Die erforderliche einstimmige Beschlußfassung durch die Vertreter der 15 Mitgliedstaaten im Europäischen Rat erscheint nicht erzielbar. Die Internalisierung grenzüberschreitender Spillover-Effekte ist deshalb eine langfristig bestehenbleibende Aufgabenstellung.

Um die Relevanz der räumlichen externen Effekte für die EU beurteilen zu können, muß berücksichtigt werden, daß die Spillover-Problematik in einer längerfristigen Sichtweise dynamischen Entwicklungsprozessen unterliegt. Im Zeitablauf tritt eine Veränderung der Wirkungskreise der bereitgestellten öffentlichen Güter ein. Für diese Entwicklung sind v.a. technologische und politische Globalisierungsprozesse verantwortlich. ${ }^{917}$ Infolge technischer Entwicklungen werden neuartige Informations-, Kommunikations- und Transportsysteme öffentlich bereitgestellt, die weiträumigere Spillover-Effekte auslösen als weniger leistungsfähige Technologien. Politische Datenänderungen unterstützen dieser Vorgänge. Durch den Abbau tarifärer wie nicht-tarifärer Handelshemmnisse wird die Verflechtung der nationalen Volkswirtschaften intensiver. Dieser Prozeß vollzieht sich in der EU durch die anhaltende Vertiefung der ökonomischen Integration zwischen den etablierten Mitgliedstaaten und durch die Aufnahme neuer Mitgliedstaaten. Die grenzüberschreitende Nutzung öffentlicher Güter wird infolgedessen in abnehmenden Maße durch politisch-jurisdiktionale Grenzen unterbunden. ${ }^{918}$ In Verbindung mit dem EU-Integrationsprozeß ergibt sich eine zweite wichtige Entwicklung. Denn mit dem Voranschreiten des Einigungsprozesses erhöht sich nicht nur die Reichweite, sondern auch das Ausmaß und die Häufigkeit der Spillover-Effekte, da eine zunehmende Anzahl an Interaktionen zwischen den Mitgliedstaaten stattfindet. ${ }^{919}$ Aus diesem

\footnotetext{
916 Vgl. hierzu insb. das Fusionsprinzip in Abschnitt II-2. Es zeigt die Notwendigkeit an, über das Kongruenzprinzip hinauszugehen.

917 Vgl. Thurow (1996), S. 169 ff; Die Gruppe von Lissabon (1997), S. 30 ff.

918 Vgl. Ebert/Noll (1998), S. 23 f. Insbesondere die anvisierte Erweiterung der EU nach Mittel- und Osteuropa läßt eine erhebliche Zunahme der Bedeutung der räumlichen externen Effekte erwarten.

919 Vgl. Costello (1993b), S. 374; auch Rompuy/Abraham/Heremans (1991), S. 132.
} 
Blickwinkel nimmt die Handlungsnotwendigkeit zur Internalisierung der externen Effekte im Zeitablauf der europäischen Integration beständig zu.

Einen hierzu gegenläufigen Effekt führt jedoch Peffekoven an. Er weist darauf hin, daß die externen Effekte zwischen GKS quantitativ umso geringer ausfallen, je homogener die öffentlichen Leistungsangebote der betrachteten GKS sind. Die Leistungsangebote fallen wiederum umso gleichartiger aus, je ähnlicher die Finanzkraft sowie die wirtschaftlichen Strukturen der GKS sind. ${ }^{920}$ Diese Argumentationslinie spricht dafür, daß die Bedeutung der räumlichen externen Effekte abnimmt, sofern sich im Rahmen des europäischen Zusammenwachsens homogenere gebietskörperschaftliche Strukturen herausbilden.

Insgesamt zeigt sich, daß die Handlungsnotwendigkeiten zur Internalisierung räumlicher externer Effekte sowohl mit Fortgang der Globalisierungsprozesse als auch der europäischen Einigungsprozesse wichtigen, in ihren Auswirkungen zum Teil gegenläufigen Veränderungen unterliegen. Die Bedeutung dieser Veränderungen variiert jedoch sehr stark, je nachdem, welcher Bereich öffentlicher Güterbereitstellung betrachtet wird. Im Folgenden wird deshalb analysiert, wie die Entstehung der räumlichen externen Effekte in den ausgewählten Bereichen zu erklären ist und welche Entwicklungen im Integrationsprozeß zu erwarten sind.

\section{V-1.1.2 Räumliche externe Effekte im Infrastrukturbereich}

Es existieren unterschiedliche Typen von Infrastruktur, die jeweils eine spezifische Dimension des Internalisierungsproblems aufweisen. Es sind vor allem die Bereiche der Verkehrsinfrastruktur, der Energietransportinfrastruktur sowie der Telekommunikationsnetze voneinander abzugrenzen. ${ }^{921}$ Die öffentliche Bereitstellung dieser Infrastruktur durch die Mitgliedstaaten rechtfertigt sich entweder aufgrund von steigenden Skalenerträgen bzw. hohen Fixkosten bei der Produktion dieser Güter (natürliches Monopol) oder aufgrund der Eigenschaften der Nicht-Rivalität bzw. Nicht-Ausschließbarkeit bei der Nutzung der Infrastrukturen. ${ }^{922}$

\footnotetext{
${ }^{920}$ Vgl. Peffekoven (1988), S. 627; knapp auch Costello (1993b), S. 374. Dieses Argument sei am Beispiel öffentlicher Bildungseinrichtungen verdeutlicht. Es wird davon ausgegangen, daß zwei GKS jeweils über die wirtschaftlichen Strukturen und ausreichende Finanzkraft verfügen, so daß die Einrichtung einer eigenen Universität lohnend und finanzierbar ist. In diesem Fall ist davon auszugehen, daß die Universität der einen GKS jeweils nur von wenigen Studenten der benachbarten GKS besucht wird. Anders jedoch für den Fall, in welchem eine der beiden GKS bspw. nicht die notwendige Finanzkraft zur Unterhaltung einer Universität besitzt. Nun ist damit zu rechnen, daß die Universität der benachbarten GKS von einer großen Zahl an Studenten der finanzschwachen GKS genutzt wird. Die GKS mit der Universität löst nun positive externe Effekte aus, die als Spillover-Effekte indirekter Natur bezeichnet werden, da sie erst durch die Mobilität der Wirtschaftssubjekte entstehen (vgl. hierzu Thomas (1997), S. 66).

$921 \mathrm{Vgl}$. zu diesen Bereichen näher Europäische Kommission (1994a), S. $99 \mathrm{ff}$.

${ }_{922}$ Vgl. bspw. Costello (1993b), S. 385.
} 
Im Zuge der Vollendung des europäischen Binnenmarkts steigt das Volumen der Transportleistungen und Informationsflüsse, die die Grenzen der Mitgliedstaaten überschreiten, deutlich an. Daher werden sich im Bereich der Verkehrsinfrastruktur sowie der Telekommunikationsnetze in zunehmenden Maße zwischenstaatliche Spillover-Effekte ergeben. ${ }^{923}$

Zudem begünstigen technologische Entwicklungen den Aufbau umfassender Infrastrukturnetze. Beispielhaft sei auf die technische Ermöglichung von Hochgeschwindigkeitstrecken im Eisenbahn- und Straßenverkehr (Verkehrsleitsysteme) hingewiesen, vor allem aber auf den Bereich der Telekommunikation, wo innovative Digitalisierungs- und Datenverarbeitungstechniken die problemlose Übertragung von Daten, Texten und Bildern im gesamten EURaum ermöglichen. ${ }^{924}$ Die Nutzungsintensität dieser Infrastruktureinrichtungen wird infolge der technischen Fortentwicklungen immer weniger von der geographischen Nähe zu den Einrichtungen bestimmt. Die räumliche Distanz wirkt daher weniger ausgeprägt „wie ein Exklusionsmechanismus gradueller Natur". ${ }^{95}$ Wenngleich eine begrenzte Anzahl benachbarter Mitgliedstaaten weiterhin den Großteil der Nutzen einer bestimmten Infrastrukturinvestition realisiert, partizipieren auch die übrigen Mitgliedstaaten zunehmend an den Nutzen der Maßnahmen. ${ }^{926}$ Die Bedeutung der Spillovers nimmt zu.

Allerdings verändern technologische Entwicklungen zugleich weitere Eigenschaften der öffentlich bereitgestellten Infrastruktureinrichtungen, die bewirken können, daß Marktversagenstatbestände nicht länger von entscheidender Relevanz für die Bereitstellung der Infrastrukturen sind. ${ }^{927}$ So hat die Bedeutung der (fixen) Kosten bei der Netzwerkerrichtung im Bereich der Telekommunikation stark abgenommen, so daß (möglicherweise) nicht länger ein natürliches Monopol vorliegt. Im Bereich der Verkehrsinfrastruktur bestehen zunehmend leistungsfähige Techniken zur Erhebung von Benutzungsgebühren, so daß die Ausschließbarkeit der Nutzung im Straßenverkehr nicht nur technisch möglich, sondern auch ökonomisch zweckmäßig wird. Vollziehen sich derartige Entwicklungen, verwandeln sich die öffentlichen Güter (tendenziell) in marktfähige Güter, deren Bereitstellung gemäß des Subsidiaritätsprinzips im Verantwortungsbereich des privaten Sektors liegen sollte. Daher ist die Entscheidung, ob das Infrastrukturangebot privat oder öffentlich vorzunehmen ist, eine im Einzelfall empirisch zu

\footnotetext{
923 Vgl. Europäische Kommission (1993a), S. 63; Laaser u.a. (1993), S. 79.

924 Vgl. Europäische Kommission (1994a), S. 99 f. u. 101 f.; Häring (1995), S. 237 f.

925 Thomas (1997), S. 200. Die Infrastruktureinrichtungen verlieren in bestimmten Ausmaß ihre Eigenschaften als Clubgüter; vgl. zur Theorie der Clubs grundlegend Buchanan (1965).

926 Ein anschauliches Beispiel ist der Transitverkehr im Bereich der Verkehrsinfrastruktur. Von den Investitionen eines Mitgliedstaates wie bspw. Deutschland, das geographisch im Zentrum der $E U$ liegt, profitieren die Transportunternehmen aller Mitgliedstaaten. Ein solcher Mitgliedstaat kann deshalb ,hohe Ansprüche auf Mitfinanzierung der Infrastrukturkosten anmelden." (Wissenschaftlicher Beirat (1994), S. 43) Vgl. auch Laaser u.a. (1993), S. 80; Baum (1995), S. 186 f.

927 Vgl. Costello (1993b), S. 386; Thomas (1997), S. 202; Ewers/Stackelberg (1998), S. 1167.
} 
entscheidende Frage. Je höher der Anteil der privaten Bereitstellung an den Infrastrukturen ausfällt, desto geringer wird die Bedeutung der Internalisierungsproblematik, da das Auftreten von Spillover-Effekten bei privaten Infrastrukturangebot ausgeschlossen ist. ${ }^{928}$

\section{V-1.1.3 Räumliche externe Effekte im Bereich Forschung und Entwicklung}

Im Bereich der Forschung und Entwicklung sind die Grundlagenforschung, die angewandte Forschung und die experimentelle Entwicklung voneinander abzugrenzen. ${ }^{929}$ Die Aktivitäten in diesen Teilbereichen weisen in unterschiedlichem Ausmaß Eigenschaften öffentlicher Güter auf. Je marktferner die Forschungs- und Entwicklungsvorhaben desto größer ist die Wahrscheinlichkeit, daß aus ökonomischen oder technischen Gründen die Nicht-Ausschließbarkeit von der Nutzung der Ergebnisse vorliegt. Private Unternehmen können die Erträge ihrer Forschungs- und Entwicklungsresultate dann nicht (vollständig) internalisieren. Sie werden daher v.a. Grundlagenforschung nur in einem suboptimalen Umfang betreiben. Denn dort besteht kaum die Möglichkeit, die Forschungsergebnisse durch Patente zu schützen. Zudem erfolgt die kommerzielle Nutzung der Forschungsergebnisse zumeist erst in zukünftigen Perioden und in unterschiedlichsten Anwendungsbereichen, die zu Beginn der Forschungsaktivitäten gar nicht absehbar waren. In den marktfernen Teilbereichen der Forschung und Entwicklung ist daher die öffentliche Förderung grundsätzlich gerechtfertigt, um zur Internalisierung der externen Erträge beizutragen. ${ }^{930}$

Entscheidend für die Bedeutung der Spillover-Problematik auf der EU-Ebene ist die räumliche Verteilung der Forschungserträge. Denn die Entscheidungsträger der einzelnen Mitgliedstaaten „werden kaum bereit sein, jene Erträge mitzufinanzieren, die in anderen Regionen anfallen." 931 Mit zunehmender Anzahl der Interaktionen zwischen allen (wirtschaftlichen) Akteuren der EU im voranschreitenden Integrationsprozeß ist zu erwarten, daß die sozialen Erträge der Forschungs- und Entwicklungsaktivitäten in zunehmenden Maße die Grenzen der Mitgliedstaaten überschreiten. ${ }^{932}$

Einschränkend weist jedoch Thomas darauf hin, daß selbst die marktferne Grundlagenforschung ,letztlich doch spezifische Erträge für jene Länder abwirft, die den Großteil der Forschungslasten tragen." 933 Die Begründung hierfür liegt in der Heterogenität der wirtschaftli-

\footnotetext{
${ }_{928}$ Vgl. Klodt u.a. (1992), S. 80; Europäische Kommission (1993a), S. 42; auch Thomas (1997), S. 202.

929 Vgl. zu dieser Abgrenzung Klodt u.a. (1992), S. 106 f., m.w.N.

${ }^{930}$ So übereinstimmend Klodt (1987), S. 108; Teutemann (1992), S. 234; Europäische Kommission (1993a),

S. 43; Hödl/Weida (1997), S. 302.

931 Klodt u.a. (1992), S. 107.

932 Vgl. Costello (1993b), S. 381.

933 Thomas (1997), S. 206.
} 
chen Strukturen der Mitgliedstaaten der EU. Die einzelnen Mitgliedstaaten besitzen unterschiedliche Prioritäten bezüglich der Durchführung ausgabenintensiver Forschungsvorhaben. Thomas bezieht sich exemplarisch auf die Grundlagenforschung Frankreichs im Bereich der Kerntechnologie. Da eine Reihe der Mitgliedstaaten über keine kerntechnischen Verwendungsmöglichkeiten verfügt, können diese Länder gar nicht von den Forschungsaktivitäten Frankreichs profitieren. Der Großteil der Forschungserträge wird deshalb von Frankreich internalisiert, da vor allem dort die wirtschaftlichen Strukturen zur Verwertung der Forschungsergebnisse bestehen. ${ }^{934}$

Es stellt sich jedoch die Frage, welche Entwicklung sich im europäischen Integrationsprozeß vollzieht. Es wurde argumentiert, daß sich die Spillover-Problematik entschärft, sofern im Laufe des Integrationsprozesses homogenere wirtschaftliche Strukturen sowie eine vergleichbare Finanzkraft und infolgedessen auch ähnlichere öffentliche Leistungsangebote in allen Mitgliedstaaten entstehen. Im Bereich der Forschung und Entwicklung muß sich diese Entwicklung nicht zwangsläufig ergeben, da die Grundlagenforschung mit enormen Kosten verbunden ist. Selbst Mitgliedstaaten, die eine ausreichende Finanzkraft erreichen, werden aufgrund von Kostenüberlegungen keine umfangreichen einzelstaatlichen (Grundlagen)Forschungen in solchen Bereichen starten, in denen bereits andere Mitgliedstaaten Aktivitäten entfalten. Dies ist auch ökonomisch sinnvoll, da so eine ressourcenverschwendende Doppelforschung vermieden wird. ${ }^{935}$ Mit zunehmender Homogenität der wirtschaftlichen Strukturen entsteht jedoch in einer steigenden Anzahl der Mitgliedstaaten die Voraussetzung zur Nutzung der Forschungsergebnisse einzelner Mitgliedstaaten. Die Erträge der Forschungsaktivitäten verbleiben daher immer weniger innerhalb der „forschenden” Mitgliedstaaten, da weitere Mitgliedstaaten die Forschungsergebnisse als Trittbrettfahrer verwerten. ${ }^{936}$ Vollziehen sich diese Entwicklungsprozesse so nimmt die Spillover-Problematik im Bereich der Forschung und Entwicklung im Integrationsprozeß zu.

\footnotetext{
934 Vgl. Thomas (1997), S. 206.

935 Jedoch weisen Hödl/Weida (1997), S. 302 darauf hin, daß die Abgrenzung zwischen „wettbewerblich sinnvoller Parallelforschung und ressourcenverschwendender Doppelforschung" nur sehr schwer vollzogen werden kann.

${ }^{936}$ Exemplarisch sei nochmals auf das Beispiel der Kernenergie zurückgegriffen. Es ist sehr wahrscheinlich, daß sich die wirtschaftlichen Strukturen der Mitgliedstaaten der $E U$ im Bereich der Energieversorgung im Zeitablauf angleichen. Zu dieser Homogenisierung trägt die sich im Rahmen des Integrationsprozesses vollziehende Liberalisierung der Strommärkte bei. Aufgrund dieser Entwicklung werden eine Reihe von Mitgliedstaaten verstärkt Kernenergie aus Frankreich nachfragen oder eigene Kernkraftwerke errichten. Im ersteren Fall nutzen diese Mitgliedstaaten die Kernforschungsergebnisse Frankreichs indirekt, im letzteren Fall sogar direkt. In beiden Fällen werden durch Frankreich verstärkt positive Spillover-Effekte ausgelöst.
} 


\section{V-1.1.4 Räumliche externe Effekte im Umweltbereich}

Verschiedene Güter im Umweltbereich besitzen Eigenschaften, mit denen Marktunvollkommenheiten verbunden sind. Als typische Beispiele seien das Landschaftsbild oder die Luftund Wasserqualität genannt. Der Nutzungsausschluß dieser Umweltgüter ist aus technischen, ökonomischen oder auch meritorischen Gründen nicht durchführbar. Zugleich besteht zumeist Rivalität im Konsum. Insb. die depositive Nutzung der Umweltgüter durch Schadstoffemissionen führt in der Regel zu Schädigungen der Qualität der Umweltgüter, die die Nutzungsmöglichkeiten für alle anderen Wirtschaftssubjekte beeinträchtigen. Es entstehen negative Externalitäten, die jedoch wegen der Nicht-Ausschließbarkeit nicht vom Preismechanismus erfaßt werden. Die Umweltgüter sind daher öffentliche Güter. ${ }^{937}$

Der Handlungsbedarf zur Internalisierung von Spillover-Effekten entsteht erst unter Berücksichtigung der räumlichen Dimension der negativen externen Effekte der Umweltnutzung. Die Schadstoffemissionen besitzen sehr unterschiedliche Diffusionseigenschaften. Daher kann bei der vorgegebenen Struktur der GKS keine Übereinstimmung zwischen den räumlichen Wirkungskreisen der Emissionen und den geographischen Grenzen der GKS erzielt werden. Für die EU-Ebene ergibt sich eine Spillover-Problematik, wenn auf der nationalen oder subnationalen Ebene Umweltschutzmaßnahmen zur Beseitigung von Emissionsbelastungen ergriffen werden, die grenzüberschreitend positive externe Effekte in anderen Mitgliedstaaten auslösen. Zumeist bleiben die Wirkungen der Schadstoffemissionen und damit auch der Umweltschutzmaßnahmen jedoch lokal oder regional begrenzt. Dies ist bspw. in bezug auf stehende Gewässer, den Boden, lokale oder regionale Öko-Systeme und Lärmbelästigungen der Fall. Werden die mitgliedstaatlichen Grenzen überschritten, so sind in aller Regel nur wenige Mitgliedstaaten betroffen. ${ }^{938}$ Lediglich „,bei großräumlichen Luftbelastungen dürfte sich der Kreis der Verhandlungspartner auf zahlreiche Mitgliedstaaten erstrecken."

Eine dynamische Veränderung der Wirkungskreise der Spillover-Effekte im Umweltbereich erfolgt durch den voranschreitenden Integrationsprozeß nicht. Jedoch wird sich parallel mit einer Zunahme der wirtschaftlichen Aktivitäten auch ein quantitativer Anstieg der Schadstof-

\footnotetext{
937 Vgl. hierzu stellvertretend für viele Brunton/Meyer (1996), S. 290 ff. oder Karl (1998), S. 1017 ff.

${ }^{938}$ So sind bspw. im Hinblick auf die Schadstoffbelastung des Rheins die Anliegerstaaten Niederlande, Deutschland, Frankreich sowie die Schweiz betroffen. An diesem Beispiel, das mit der Schweiz einen NichtMitgliedstaat der $E U$ umfaßt, verdeutlicht sich, daß die räumlichen externen Effekte im Umweltbereich selbstverständlich nicht an den Außengrenzen der $E U$ halt machen.

939 Karl (1998), S. 1034; vgl. auch Klodt u.a. (1992), S. 164 f.; Hoeller/Louppe/Vergriete (1996), S. 34.
} 
femissionen durch die Unternehmen innerhalb der EU einstellen, wodurch die SpilloverProblematik an Bedeutung gewinnt.

\section{V-1.1.5 Räumliche externe Effekte im Bildungsbereich}

Die Bildungsausgaben in der EU erfolgen weitgehend durch die nationalen bzw. subnationalen GKS. Zur Rechtfertigung der öffentlichen Bereitstellung des Guts Bildung werden zwei Argumente vorgebracht. Zum einen soll allen Bürgern eines Gemeinwesens der Zugang zu Bildungseinrichtungen ermöglicht werden, da die Bildung und Ausbildung ,in einer arbeitsteiligen Gesellschaft eine überragende Stellung"940 einnimmt. Zum anderen wird davon ausgegangen, daß die ausgebildeten Bürger durch ihren besonderen Sachverstand positive externe Effekte für die gesamte Wirtschaft eines Gemeinwesens auslösen. Die Internalisierung dieser externen Effekte erfolgt durch die öffentliche Bildungsförderung. ${ }^{941}$

Die Ausgaben im Bildungsbereich lösen positive räumliche externe Effekte aus, sofern wegen der Mobilität der Individuen die öffentlichen Investitionen in Humankapital nicht denjenigen GKS zugute kommen, die die Investitionen finanziert haben. Diese Situation entsteht, wenn die Bildungseinrichtungen einer GKS auch von gebietskörperschafts-externen Auszubildenden genutzt werden oder wenn qualifizierte Arbeitskräfte nach der Ausbildung in andere GKS abwandern. ${ }^{942}$

Da mit zunehmendem Aggregationsgrad von der lokalen über die regionale auf die mitgliedstaatliche Ebene die Bildungseinrichtungen einer GKS immer seltener auch von gebietskörperschafts-externen Auszubildenden genutzt werden, ist die Bedeutung der Mobilität der Schüler und Studenten für das Auftreten positiver externer Effekte auf der zentralen EUEbene stark begrenzt - sie nimmt allerdings im Integrationsprozeß zu. Diese Entwicklung ergibt sich v.a. aufgrund der aktiven Förderung des grenzüberschreitenden Austauschs von Auszubildenden durch die EU. Diese Förderungsmaßnahmen bestehen in der Schul- und Hochschulausbildung und dienen einem politischen Ziel. Sie sollen zur Überwindung bestehender kultureller Barrieren im Binnenmarkt beitragen. Die Spillover-Effekte sind daher ein Nebeneffekt des Versuchs, den informellen Integrationsprozeß in der EU voranzutreiben. ${ }^{943}$

Angesichts der marginalen Arbeitskräftemobilität zwischen den Mitgliedstaaten der $\mathrm{EU}^{944}$ werden auch durch Wanderungen qualifizierter Arbeitskräfte nur in geringem Ausmaß positi-

\footnotetext{
940 Teutemann (1992), S. 86.

941 Vgl. Teutemann (1992), S. 86 ff.; Europäische Kommission (1993a), S. 43; Häring (1995), S. 237.

942 So v.a. Teutemann (1992), S. 89.

943 Vgl. Europäische Kommission (1993a), S. 43.

944 Vgl. zu dieser Aussage bspw. die Untersuchungen von Mayes (1994).
} 
ve externe Effekte ausgelöst. Für die absehbare Zukunft ist davon auszugehen, daß der Großteil der Nutzen der öffentlichen Bildungsausgaben innerhalb der Grenzen der Mitgliedstaaten anfallen wird. Wenngleich durch die formale Vollendung der ökonomischen Integration eine Reihe institutioneller Mobilitätshemmnisse beseitigt wurde, bleiben enorme kulturelle und sprachliche Barrieren bestehen. Diese verhindern, daß die zwischenstaatliche Mobilität der Arbeitskräfte in der EU entscheidend zunimmt. ${ }^{945}$ Eine Ausnahmesituation besteht jedoch im Fall Irlands, „where continued emigration is leading to significant educational investment losses." ${ }^{946}$ Dort besteht eine hohe Bereitschaft qualifizierter Arbeitskräfte zur Abwanderung in das benachbarte Vereinigte Königreich sowie die USA. Da zudem zwischen diesen Staaten keine sprachlichen und nur geringe kulturelle Barrieren bestehen, ergibt sich eine sehr hohe Arbeitskräftemobilität zu Lasten des irischen Arbeitsmarktes.

\section{V-1.1.6 Die Bedeutung der FZ zur Internalisierung räumlicher externer Effekte}

Die Teilabschnitte V-1.1.1 bis 5 verdeutlichen, daß es nicht möglich ist, allgemeingültige Handlungsempfehlungen zur Lösung der Internalisierungsproblematik in der EU abzuleiten. Die Auswahl des wirtschaftspolitischen Instruments muß sich auf den jeweiligen Einzelfall beziehen. Dennoch können Tendenzaussagen zur Geeignetheit der alternativen theoretischen Lösungsansätze zur Kompensation der räumlichen externen Effekte getroffen werden:

Mit ansteigender Reichweite der Spillover-Effekte besteht die Notwendigkeit, eine größere Anzahl der Mitgliedstaaten in die Lösung eines einzelnen räumlichen Externalitätenproblems zu integrieren. Hierdurch verringert sich die Wahrscheinlichkeit, durch ein „,bargaining” der direkt betroffenen Mitgliedstaaten eine effiziente Problemlösung zu erzielen, da der Handlungsspielraum für strategische Verhaltensweisen (Trittbrettfahrerverhalten) zunimmt. Darüber hinaus steigen die Kosten zur Einrichtung und Durchfuihrung der dezentralen Verhandlungen stark an, weil diese nicht auf wenige Mitgliedstaaten zu begrenzen sind.

Die Frage der Verhandlungskosten tritt noch stärker in den Vordergrund, wenn im Ablauf des Integrationsprozesses die Häufigkeit von Spillover-Effekten zunimmt. Es ist dann eine entsprechende Vielzahl spezifischer Problemlösungen mit unterschiedlichsten Verhandlungskonstellationen zu organisieren. Die Verlagerung der Problemlösung auf die zentrale Ebene, wo bereits leistungsfähige Organisationen bestehen, die die Entscheidungsfindung für eine Vielzahl von Einzelfällen vollziehen können, spart deshalb in wesentlichem Umfang Transaktionskosten ein.

\footnotetext{
945 Vgl. hierzu Europäische Kommission (1993a), S. 43; Mayes (1994), S. 440 ff.; Nerlich (1996), S. 88 ff.

946 Costello (1993b), S. 392; vgl. auch Mayes (1994), S. 442.
} 
Aufgrund der dynamischen Veränderungen im Integrationsprozeß folgern Rompuy/Abraham/Heremans, daß die Lösung der Internalisierungsprobleme in abnehmenden Maße durch den Coaseschen Verhandlungsmechanismus zu realisieren ist und sich konsequenterweise eine zunehmende Rolle für zwischenstaatliche Internalisierungszuweisungen durch die EU-Ebene ergibt: „As the scope of the transnational programmmes increases, a bargaining solution will not be achieved. This leads to a role for the Community as the appropriate intermediary level and as the agency that organizes the compensatory transfers by means of conditional matching grants." 947

\section{V-1.2 Bestehende Aktivitäten der EU zur Internalisierung räumlicher externer Ef- fekte}

Die EU entfaltet in allen der angesprochenen Bereiche, die durch das Auftreten räumlicher externer Effekte gekennzeichnet sind, ausgabewirksame wirtschaftspolitische Aktivitäten. So ermöglicht der EGV gemäß Art. 129 b und c für den Auf- und Ausbau transeuropäischer Netze im Infrastrukturbereich, gemäß Art. 130 f und g zur Förderung von Forschung und technologischer Entwicklung, gemäß Art. $130 \mathrm{r}$ und s im Bereich der Umwelt sowie gemäß Art. 126 und 127 zur Entwicklung der allgemeinen und beruflichen Bildung die finanzielle Beteiligung der EU an den durch Mitgliedstaaten durchgeführten Aktionen. ${ }^{948}$ Die zunehmende Bedeutung dieser zwischenstaatlichen FZ der EU spiegelt sich durch Ausgabensteigerungen im Rahmen der Strukturfonds, des Kohäsionsfonds sowie der internen Politikbereiche wider. ${ }^{949}$

Die Analyse der Ausgabetätigkeiten zeigt jedoch, daß das staatliche Handeln der EU in den einzelnen Bereichen jeweils eine Reihe sehr unterschiedlicher Zielsetzungen verfolgt. ${ }^{950}$ Es bestehen keine eigenständigen Ausgabetätigkeiten, die explizit der Internalisierung räumlicher externer Effekte zugeordnet sind. Ob die EU mit ihrem Ausgabegebaren auch einen Beitrag zur Lösung der Spillover-Problematik zwischen den Mitgliedstaaten anstrebt, kann daher lediglich implizit aufgrund der konkreten Ausgabenstrukturen innerhalb der einzelnen Bereiche

947 Rompuy/Abraham/Heremans (1991), S. 132. Vgl. zu dieser Argumentation aber auch Klodt u.a. (1992), S. 133 f. u. Thomas (1997), S. 200 f. Die Autoren gelangen zu der entgegengesetzten Schlußfolgerung, daß bilaterale wie auch multilaterale Kooperationen zwischen einer weiterhin begrenzten Anzahl unmittelbar betroffener Mitgliedstaaten $\mathrm{zu}$ befriedigenden Verhandlungslösungen führen. Beispielhaft belegt wird diese Aussage anhand des Verkehrswegebaus, wo die dezentrale Kooperation in jüngerer Zeit funktioniert hat. Dies, so Klodt u.a. (1992), S. 134, ,dürfte daran deutlich werden, daß kein Fall bekannt ist, in dem in einem Mitgliedsland eine Autobahn zur Grenze gefürt wurde, die im angrenzenden Mitgliedsland als Feldweg weiterführte."

948 Vgl. hierzu Europäische Kommission (1997a).

949 Vgl. hierzu Abschnitt IV-2.1.3.2.

950 Vgl. hierzu den jüngsten Gesamtbericht über die Tätigkeit der EU: Europäische Kommission (1998). 
beurteilt werden. Eine eingehendere Analyse zeigt, daß zumeist andere Zielsetzungen als die Kompensation von Spillover-Effekten im Mittelpunkt der Ausgabetätigkeit stehen.

So erfolgt die Vergabe der FZ an die Mitgliedstaaten im Bereich der Infrastrukturmaßnahmen zum Auf- und Ausbau transeuropäischer Netze aus den Strukturfonds bzw. dem Kohäsionsfonds. Mit diesen Fonds wird aber in erster Linie die Förderung des wirtschaftlichen und sozialen Zusammenhalts angestrebt und nicht die Kompensation räumlicher externer Effekte. ${ }^{951}$ Auch im Umweltbereich werden „benachteiligte” Mitgliedstaaten zur Berücksichtigung von Umweltbelangen aus den Strukturfonds und dem Kohäsionsfonds finanziell unterstützt. ${ }^{952}$ V.a. aber werden gemeinschaftliche Aktionsprogramme, Einzelprojekte und Demonstrationsvorhaben unterschiedlicher umweltpolitischer Zielvorhaben (mit)finanziert. ${ }^{953} \mathrm{Im}$ Bereich der Forschung und Entwicklung stellt die Ausgabetätigkeit „eine der Säulen der Industriepolitik der EU"954 durch die sektorale Subventionierung marktnaher Forschungsaktivitäten einzelner Industrien dar. ${ }^{955}$ Bei den Bildungsausgaben steht mit Unterstützung der (informellen) Integration ein politisches Kalkül im Mittelpunkt der Fördermaßnahmen (vgl. weiter oben in Abschnitt V-1.1.5).

\section{V-1.3 Die Internalisierung räumlicher externer Effekte durch FZ}

Die Vermischung unterschiedlicher Zielsetzungen beeinträchtigt die Effizienz der Ausgabetätigkeiten im Hinblick auf die Internalisierung räumlicher externer Effekte. Die Vergabe von FZ an die Mitgliedstaaten entspricht nicht den theoretischen Anforderungen, die eine effiziente Lösung der Spillover-Problematik ermöglichen. Dies ergibt sich zwangsläufig, da die Entscheidungsträger versuchen, mit Hilfe eines wirtschaftspolitischen Instruments ${ }^{956}$ eine Mehrzahl an wirtschaftspolitischen Zielen zu verfolgen, die zum Teil in Zielkonflikt zueinander stehen. Dies führt zu der wichtigen Erkenntnis, daß die effiziente Kompensation räumlicher externer Effekte nur zu realisieren ist, wenn für diese Funktion ein eigenständiger Aufgabenbereich geschaffen wird. Welche konkreten Kritikpunkte an den bestehenden zwischenstaatlichen FZ bei dieser Entflechtung der Funktionen der FZ zu beachten sind, wird im nächsten Schritt verdeutlicht.

\footnotetext{
951 Vgl. Teutemann (1992), S. 248 f.; zu den Strukturfonds und dem Kohäsionsfonds Abschnitt V-2.3.

952 Die Vermischung unterschiedlicher Zielsetzungen im Umweltbereich betont Grossekettler (1996), S. 22.

$953 \mathrm{Vgl}$. Hödl/Weida (1997), S. 366 ff. u. 374 ff.; Europäische Kommission (1998), S. 196 ff. insb. 206 f.

954 Hödl/Weida (1997), S. 298.

955 Vgl. Teutemann (1992), S. 234 ff.; Hödl/Weida (1997), S. 311.

${ }^{956}$ Nămlich der Vergabe einer zwischenstaatlichen FZ einer bestimmten Ausgestaltungsform.
} 


\section{V-1.3.1 Zur Ausgestaltung der FZ aus rein ökonomischer Sicht}

Die theoretisch abgeleitete Ausgestaltung der FZ zur Kompensation räumlicher externer Effekte erfährt zur Problemlösung auf der Ebene der EU keine Abwandlung. Die FZ sollten zweckgebunden, mit einer Eigenleistung verknüpft und betragsmäßig unbegrenzt vergeben werden. Zudem ist $\mathrm{zu}$ fordern, daß die Mittel von jenen Mitgliedstaaten aufgebracht werden, die von der Leistungsbereitstellung der FZ-Empfänger profitieren. ${ }^{957}$

Aufgrund dieser Überlegungen ist zu kritisieren, daß die FZ-Vergabe stets betraglich begrenzt erfolgt. Die finanzielle Vorausschau der EU bestimmt bereits vor Beginn der Mittelvergabe den Gesamtbetrag der FZ, der dann gemäß eines festgelegten Verteilungsschlüssels auf die Empfängerstaaten verteilt wird (Repartitionsprinzip). Die zieladäquate Ausgestaltung der Transfers hingegen erfordert, daß sich das Gesamtvolumen erst ex-post aus dem Ausgabeverhalten der Mitgliedstaaten ergibt, die positive Spillovers auslösen (Quotitätsprinzip) ${ }^{958}$

Die Vergabe der FZ ist immer mit einer Eigenleistung der Transferempfänger verbunden. Dies ist aus ökonomischer Sicht positiv zu bewerten. Die Höhe der Eigenleistung ist hingegen zumeist willkürlich oder aufgrund von verteilungspolitischen Erfordernissen bestimmt. ${ }^{959}$ Sie entspricht daher allenfalls zufällig dem Anteil des Gesamtnutzens einer angebotenen öffentlichen Leistung, der in der bereitstellenden Jurisdiktion anfällt. Zumeist ist der Finanzierungsanteil der EU-Ebene zu hoch, so daß die Gefahr einer Ausweitung des Bereitstellungsniveaus über den „socially optimal point” hinaus besteht. Bspw. ist nicht davon auszugehen, daß bei einer FZ aus den Strukturfonds bzw. dem Kohäsionsfonds im Infrastruktur- und Umweltbereich bis zu 85 Prozent der Nutzen außerhalb der geförderten Mitgliedstaaten anfallen. Ähnliches gilt für den Bereich der Forschung und Entwicklung, wo der Finanzierungsanteil der EUEbene einheitlich auf 50 Prozent festgelegt ist. Aus rein allokationstheoretischer Sicht ${ }^{960}$ ist in diesen Bereichen eine flexiblere Staffelung der Eigenbeteiligung der transferempfangenden Mitgliedstaaten zu fordern, die sich stärker an der regionalen Verteilung des Gesamtnutzens der bereitgestellten öffentlichen Güter orientiert. Entsprechend dieser Verteilung sind von Mitgliedstaat zu Mitgliedstaat unterschiedliche Eigenbeteiligungsanteile festzulegen. ${ }^{961}$

Kritisch sind die Empfangsauflagen zu bewerten, mit welchen die FZ-Vergabe in den meisten Fällen verbunden wird. Exemplarisch sei auf die unterschiedlichen Empfangsauflagen verwie-

\footnotetext{
957 Vgl. Abschnitt III-3.1.1.1.

958 Vgl. auch Costello (1993a), S. 113.

959 Vgl. Diekmann/Breier (1993), S. 264; Walsh (1993), S. 41.

${ }_{960}$ Verteilungspolitische Aspekte, wie bspw. zur Leistungsfähigkeit der Mitgliedstaaten werden an dieser Stelle nicht berücksichtigt.

961 Vgl. Walsh (1993), S. 41 f.; auch Europäische Kommission (1994a), S. 114.
} 
sen, die mit den FZ im Infrastruktur- und Umweltbereich aus den Strukturfonds und dem Kohäsionsfonds verknüpft werden. ${ }^{962}$ Sofern die Bereitstellung einer öffentlichen Leistung durch Mitgliedstaaten positive räumliche Spillover-Effekte auslöst, führt die Formulierung spezifischer Empfangskriterien, durch die einzelne Mitgliedstaaten von der Transfervergabe ausgeschlossen werden, zu einem aus Sicht des Gesamtkollektivs ineffizienten Bereitstellungsniveau der betreffenden öffentlichen Leistung. Unter der Zielsetzung der Internalisierungszuweisungen besteht keine Rechtfertigung zur Eingrenzung des Empfängerkreises der FZ. Die einzige zulässige Empfangsauflage stellt das Auftreten positiver Spillover-Effekte dar. ${ }^{963}$

Die EU-Ebene verbindet die Vergabe der FZ in den genannten Bereichen der Bereitstellung öffentlicher Güter stets mit einer Zweckbindung. ${ }^{964}$ Die Formulierung dieser Verwendungsauflagen ist theoretisch begründet und daher grundsätzlich zu befürworten. Allerdings greift die EU-Ebene in vielen Fällen sehr stark in die konkrete Maßnahmengestaltung ein. Es besteht die Gefahr, daß die nationalen und subnationalen Entscheidungsträger mitgliedstaatliche $\mathrm{Be}$ sonderheiten nicht ausreichend zur Geltung bringen können. Die Zentralisierung der wirtschaftspolitischen Zuständigkeit bleibt in dieser Situation nicht auf den Spillover-Aspekt des öffentlichen Tätigkeitsbereichs beschränkt. Stattdessen wird ein erheblicher Schritt zur Zentralisierung der (gesamten) Aufgabenerfüllung vollzogen. Diese Kompetenzzentralisierung ist jedoch unerwünscht. ${ }^{965}$ Daher sollte die EU bei der Internalisierung externer Effekte „die konkrete Programmgestaltung sowie die Abwicklung der Förderverfahren"966 den Mitgliedstaaten überlassen.

\section{V-1.3.2 Die Umsetzung der effizienten Problemlösung im politischen Entscheidungs- prozeß}

Ausgangspunkt der Analyse ist die besondere Verhandlungskonstellation auf der EU-Ebene. Der Politikgestaltungsprozeß vollzieht sich - wie in Abschnitt IV-2.2 gezeigt - in einem komplexen Verbundsystem von Transfergebern und -empfängern. Dabei sind alle Mitgliedstaaten durch den Ministerrat an den Verhandlungen zur FZ-Vergabe beteiligt. Darüber hinaus nimmt die EK als Planungs- und Koordinierungsstelle an der Entscheidungsfindung teil. Dies ver-

\footnotetext{
962 Vgl. zu den Empfangsauflagen der Fonds ausführlich Abschnitt V-2.3.2.

963 Vgl. hierzu Costello (1993a), S. 110 u. 113.

964 Vgl. Costello (1993a), S. 113.

${ }^{965}$ In den Mitgliedstaaten entstehen Präferenzkosten. Der Eingriff in die Präferenzen der Mitgliedstaaten ist zudem nicht durch meritorisches Verhalten der Transfergeber zu rechtfertigen. Vielmehr sollen die FZ den Präferenzen der Transferempfänger zur Durchsetzung verhelfen (vgl. Abschnitt III-2.4 sowie Fn 423 in Abschnitt III-3.1.1.1).

${ }^{966}$ Klodt u.a. (1992), S. 111; vgl. auch Europäische Kommission (1993a), S. 42 ff. u. Teutemann (1992),
} S. $234 \mathrm{ff}$. 
deutlicht, daß die dezentralen Verhandlungen zwischen den direkt betroffenen Mitgliedstaaten im Rahmen der Coaseschen Verhandlungslösung im Fall der Vergabe zentraler Internalisierungszuweisungen durch Verhandlungen im europäischen Verbundsystem ersetzt werden. Es entscheidet also kein monolithischer Entscheidungsträger über die Höhe und Ausgestaltung der Internalisierungstransfers. Auf Basis dieser rechtlich-organisatorischen Rahmenbedingungen wird die Durchsetzbarkeit effizienter Internalisierungszuweisungen im Vergleich zu dezentralen Verhandlungen beurteilt. ${ }^{967}$

\section{V-1.3.2.1 Die Gewinnung der entscheidungsrelevanten Informationen}

Die effiziente Internalisierung von Spillover-Effekten setzt ein hohes Maß an Informationen voraus. Einerseits in quantitativer Hinsicht, da eine Vielzahl an Einzelfällen räumlicher externer Effekte besteht und eine Pauschalierung zu einem einheitlichen FZ-Paket keine problemadäquate Lösung zuläßt. Andererseits in qualitativer Hinsicht, da es große Probleme bereitet, das Ausmaß der Spillover-Effekte zwischen den Mitgliedstaaten zu berechnen und ein interjurisdiktionaler Nutzenvergleich angestellt werden muß, um effiziente Finanzierungsanteile bestimmen zu können. ${ }^{968}$

Dies spricht dafür, die Internalisierung den dezentralen Verhandlungen der direkt betroffenen Mitgliedstaaten zu überlassen. Wegen der geographischen Nähe der dortigen Entscheidungsträger zu den Problemfällen ist damit zu rechnen, daß diese bereits in der Ausgangssituation einen hohen Informationsstand der Spillover-Probleme besitzen. Zudem können zusätzliche Informationen aufgrund kurzer Kommunikationswege zu (relativ) geringen Transaktionskosten beschafft werden. Die Entscheidungsträger der EU sind hingegen auf eine effektive Weiterleitung der entscheidungsrelevanten Informationen von der dezentralen zur EU-Ebene angewiesen. Aufgrund der Länge dieses Kommunikationswegs kann jedoch nicht ausgeschlossen werden, daß wichtige Informationen verfälscht werden oder gänzlich abhanden kommen. ${ }^{969}$

${ }^{967}$ Dabei wird auch darauf eingegangen, ob dezentrale Verhandlungen zwischen den direkt betroffenen Mitgliedstaaten „effizienter" $F Z$ ergeben würden.

968 Allerdings muß eine differenzierte Sichtweise einzelner Internalisierungsprobleme eingenommen werden. So weist Baum (1995) darauf hin, daß im Verkehrsbereich die Fahrleistungen von Inländern und Ausländer sehr einfach festzustellen sind. Aufgrund dieser Nutzungen kann auch eine adăquate Verteilung der Finanzierungslasten der Infrastrukturinvestitionen erfolgen. Vor kaum zu lösenden Informationsproblemen steht hingegen bspw. der Versuch im Bereich der Grundlagenforschung mitgliedstaatliche Spillover-Quoten berechnen zu wollen. Hier existiert kein Indikator, der einen gesicherten Aufschluß über die Nutzungen der einzelnen Mitgliedstaaten gibt (vgl. Berthold/Hilpert (1996), S. 85 f.; Thomas (1997), S. 206).

969 Vgl. hierzu grundsätzlich Picot (1982). Zudem Jensen/Meckling (1992), S. 252 ff. 
Nimmt jedoch mit der Vertiefung und Erweiterung des Integrationsprozesses die Reichweite der Spillover-Effekte zu, so erscheint die Vergabe von FZ seitens EU-Ebene vorteilhafter. Denn es gewinnen nun gesamtsystem-spezifische Informationen an Bedeutung, da aufgrund der räumlichen Dimension der Spillover-Effekte wechselseitige Auswirkungen und Rückkoppelungen zwischen den Bereitstellungsaktivitäten der einzelnen Mitgliedstaaten einen immer stärkeren Einfluß gewinnen. Diese müssen in einen übergeordneten (EU-weiten) Problemzusammenhang eingeordnet werden. Deshalb tritt neben die reine Finanzierungsfunktion der FZ zunehmend eine Koordinationsfunktion zur Abstimmung des Bereitstellungverhaltens der einzelnen Mitgliedstaaten. Zur Übernahme dieser Koordinationsfunktion ist ein horizontal und vertikal organisiertes Verbundsystem besonders geeignet, da dort die Voraussetzungen zur Generierung gesamtsystem-spezifische Informationen vorliegen. ${ }^{970}$ Ein solches Verbundsystem besteht auf der EU-Ebene beim Zusammenspiel zwischen der EK und dem Ministerrat. Die Arbeit dieser Organisationen wird durch verschiedene Ausschüsse unterstützt, die auf einen Interessenausgleich zwischen allen Mitgliedstaaten hinwirken. ${ }^{971}$ Sie bieten das Forum zur Artikulation der Problemwahrnehmung durch die einzelnen Mitgliedstaaten. Da diese organisatorischen Strukturen langfristig bestehen bleiben, besitzen die Verhandlungsteilnehmer - insb. im Vergleich zu einer isolierten Einzelentscheidung gemäß der Coaseschen Verhandlungslösung - geringe Anreize, entscheidungsrelevante Informationen strategisch zurückzuhalten. Im Laufe der vielzähligen Verhandlungsrunden kann eine gemeinsame Vertrauensbasis aufgebaut werden. Es besteht die Möglichkeit, eine hohe Kommunikations-Effektivität innerhalb des Verbundsystems zu entwickeln, die auch solche Informationen erfaßbar macht, die innerhalb von Einzelverhandlungen unverfügbar bleiben.

Die Informationsproblematik erfordert daher eine Bewertung im Einzelfall. In solchen Bereichen, in denen nur wenige Mitgliedstaaten von einer Spillover-Problematik betroffen sind, können die entscheidungsrelevanten Informationen im Rahmen dezentraler Verhandlungen zu geringeren Kosten bereitgestellt werden. Mit steigender Anzahl der beteiligten Mitgliedstaaten und zunehmender Bedeutung komplexer Gesamtzusammenhänge ist hingegen tendenziell die zentrale Vergabe von FZ angezeigt, um diejenigen Informationen zu gewinnen, die es erlauben, die Erfullung der Finanzierungsfunktion mit jener der Koordinationsfunktion zu verbinden.

${ }^{970}$ Vgl. Abschnitt III-2.3.2.

971 Vgl. hierzu năher Abschnitt IV-2.2.1. Insbesondere die Ausführungen zum $A S t V$. 


\section{V-1.3.2.2 Die Fragen der Konfliktregelung und Konsensfindung}

Es stellt sich die Frage, ob auf Basis dieser Informationen eine problemadäquate Entscheidungsfindung über die FZ-Vergabe im Verbundsystem der EU-Ebene zu erwarten ist.

In einem ersten Schritt ist der Konsensbedarf der Verhandlungen zu analysieren, wobei die besondere Komplexität der Problemstellung für einen hohen Konsensbedarf spricht. Denn es besteht sowohl ein Koordinations- als auch ein Verteilungsproblem (,mixed-motive-game”). Das Koordinationsproblem besteht darin, ein aus gesamtwirtschaftlicher Sicht ineffizientes Versorgungsniveau der Bevölkerung mit einem öffentlichen Gut auf ein effizientes Niveau anzuheben. Das Verteilungsproblem ergibt sich aus der Frage, welchen Anteil die einzelnen Mitgliedstaaten an der Finanzierung dieses effizienten Versorgungsniveaus tragen.

Zudem weisen die großen Schwierigkeiten, gesicherte Erkenntnisse über das Ausmaß bestehender Spillover-Effekte zu erlangen, auf einen hohen Konsensbedarf hin. Es bleiben Unsicherheiten über die Verhandlungspositionen der einzelnen Mitgliedstaaten bestehen, wodurch sich Handlungsspielräume für strategische Verhaltensweisen eröffnen. Die Kenntnis dieser prekären Situation wiederum erschwert die Einigung im Verhandlungsprozeß. ${ }^{972}$ An dieser Stelle eröffnet sich Interessengruppen die Möglichkeit auf die Entscheidungsfindung Einfluß zu nehmen, indem sie den Entscheidungsträgern relevante Informationen vermitteln. Da die externen Effekte in vielen Fällen durch die Produktionstätigkeiten von Unternehmen ausgelöst werden, verfügen deren sektorale Interessenvertretungen über einen besonderen Informationsstand der jeweiligen Internalisierungsproblematik. ${ }^{973}$ Durch die Weitergabe dieser Informationen wird ein wichtiger Beitrag zur Konsensfindung geleistet, da die Unsicherheit über die Verhandlungspositionen der einzelnen Mitgliedstaaten reduziert wird. Die Interessenvertretungen bemühen sich mit der Informationsweitergabe jedoch zugleich darum, spezifische Sonderinteressen ihrer Unternehmen auf Kosten anderer gesellschaftlicher Gruppen in den politischen Entscheidungsprozeß einzubringen. Da sich die Interessen relativ kleiner und homogener Produzentengruppen gut organisieren lassen, besteht eine große Wahrscheinlichkeit, daß sie hierbei erfolgreich sind und so zu einer Verzerrung ökonomisch effizienter Internalisierungszuweisungen beitragen. ${ }^{974}$

972 Es zeigt sich die Bedeutung gesicherter Erkenntnisse uber die Spillover-Quoten der Bereitstellung offentlicher Güter. Nicht nur hängt die Effizienz der Mittelzuweisungen von diesem Wissen ab, sondern auch die Möglichkeiten zur Konsensbildung im Entscheidungsprozeß. Dies rechtfertigt eingehende Untersuchungen der Spillover-Quoten (vgl. auch Walsh (1993), S. 41).

973 Dieses Argument bezieht sich weniger auf den Bildungsbereich; jedoch sehr stark auf den Bereich der Forschung- und Entwicklung, der Infrastruktur und auch des Umweltschutzes.

974 Ausdruck dieser Verzerrungen wäre ein erfolgreiches ,rent-seeking” dieser Interessengruppen, das sich in Subventionszahlungen wiederspiegelt, die über die Kompensation positiver externer Effekte hinausgehen. 
Auch führt die Einstimmigkeitsregel - bzw. die Abstimmungsregel der qualifizierten Mehrheit - im Ministerrat grundsätzlich zu einem hohen Konsensbedarf, da sie einen weitgehenden Konsens zwischen allen Verhandlungsbeteiligten erfordert. Diese Aussage erhält jedoch eine Einschränkung, da sich im Hinblick auf die Internalisierung eines Spillover-Effekts drei Gruppen von Mitgliedstaaten mit gleichartigen Interessenpositionen voneinander abgrenzen lassen. Zum ersten eine Anzahl an Mitgliedstaaten, die zwar an den Verhandlungen im Ministerrat beteiligt ist, aber weder das betreffende öffentliche Gut bereitstellt noch innerhalb des räumlichen Wirkungskreises des betreffenden öffentlichen Gutes liegt. Zum zweiten jene Mitgliedstaaten, die das betreffende öffentliche Gut nicht bereitstellen, aber aufgrund der Spillover-Effekte Nutzenzugewinne realisieren. Und zum dritten derjenige Mitgliedstaat, der für die Bereitstellung des betreffenden öffentlichen Gutes Sorge trägt. Die Anzahl der Entscheidungsträger, die unabhängig voneinander berücksichtigt werden müssen, reduziert sich hierdurch und somit auch der Konsensbedarf der Verhandlungen.

Dieser Aspekt leitet über zur Frage, ob in den Verhandlungen strategische Maßnahmen ergriffen werden können, die aktiv zu einer Konsensfindung beitragen, indem die Zustimmungswahrscheinlichkeit einzelner Verhandlungspartner zur effizienten Problemlösung erhöht wird. Ein aussichtsreicher Ansatzpunkt ergibt sich, weil es zu jedem Verhandlungszeitpunkt eine Vielzahl an Internalisierungsproblemen gibt. Es ist zu erwarten, daß in vielen Fällen sehr ähnliche Problemstrukturen existieren, die sich aber dadurch unterscheiden, daß die einzelnen Mitgliedstaaten jeweils einer anderen der drei Gruppen mit gleichartigen Interessen angehören. Dies eröffnet die Möglichkeit, die Konsensbildung durch die Zusammenfuihrung der zahlreichen Einzelfälle zu einem Verhandlungspaket (Koppelgeschäft) zu fördern. Denn solange die einzelnen Mitgliedstaaten den einzelnen Interessenkoalitionen in einem weitgehend ausgewogenem Verhältnis angehören, wird die Paketlösung für alle Verhandlungsteilnehmer insgesamt vorteilhaft sein. Um die Nutzenzugewinne des Gesamtpakets nicht zu gefährden, besteht daher eine große Wahrscheinlichkeit, daß die einzelnen Entscheidungsträger nicht nur eine Finanzierungsbeteiligung der anderen Mitgliedstaaten fordern, wenn der eigene Mitgliedstaat positive externe Effekte auslöst, sondern auch eine angemessene Finanzierungsbeteiligung des eigenen Mitgliedstaates akzeptieren, wenn dieser von der Leistungsbereitstellung anderer Mitgliedstaaten profitiert. Die Gültigkeit dieser Argumentation ist in einer dynamische Perspektive noch wahrscheinlicher. Da die Internalisierung externer Effekte eine langfristig bestehenbleibende Aufgabe ist, verspricht der Verzicht auf strategische Verhaltensweisen eine kooperative Dauerbeziehung und somit die Realisierung wesentlicher Nutzenzugewinne auch in zukünftigen Perioden. 
Allerdings spricht ein entscheidendes Argument gegen diese optimistische Einschätzung zur Realisierung effizienzfördernder Koppelgeschäfte. Unter Berücksichtigung des enormen Gefälles des wirtschaftlichen Entwicklungsstandes in der EU ist nicht davon auszugehen, daß die einzelnen Mitgliedstaaten in einem ausgewogenen Verhältnis den drei Interessengruppen angehören. ${ }^{975} \mathrm{Da}$ die wohlhabenderen Mitgliedstaaten in allen Bereichen der Bereitstellung öffentlicher Güter tendenziell ein höheres Ausgabevolumen aufweisen, werden sie in überwiegendem Maße die grenzüberschreitenden positive externe Effekte auslösen. ${ }^{976}$ Die weniger wohlhabenden Mitgliedstaaten hingegen befinden sich unausgewogen häufig in jener Gruppe der Mitgliedstaaten, die von der Bereitstellung öffentlicher Güter anderer Mitgliedstaaten profitiert und daher im Rahmen der Verhandlungen Finanzierungsbeiträgen zustimmen soll. Sie besitzen daher auch in einer längerfristigen Betrachtung kaum Anreize, einen Verhandlungskonsens zu ermöglichen, da jener sie beständig in eine Zahlerposition drängen würde. Diese Konstellation begünstigt zudem die Entstehung einer „cross-cutting-cleavage”, da die Verhandlungen beständig zwischen der Front der „reichen” und der „armen” Mitgliedstaaten geführt werden. Dies löst unter Umständen eine kompetitive Interaktionsorientierung der Akteure aus und erschwert so die Konsensfindung.

Diese Argumente sprechen dafür, daß die Konsensfindung durch Strategien zur Minimierung des Konsensbedarfs unterstützt werden muß. Dies kann eine effiziente Problemlösung blokkieren, wenn die Mitgliedstaaten durch die formelle Gleichbehandlung aller Verhandlungsteilnehmer eine einvernehmliche Entscheidungsfindung realisieren. Denn wie die theoretische Analyse zeigt, basiert die effiziente Internalisierung der räumlichen externen Effekte gerade auf einer von Fall zu Fall differenzierten und flexiblen FZ-Vergabe. Es ist erforderlich, daß auf Seiten des Transferempfängers in jedem Einzelfall spezifische Eigenfinanzierungsanteile festgesetzt werden und auf Seiten der Transfergeber eine differenzierte Verteilung der Finanzierungslasten auf diejenige Mitgliedstaaten erfolgt, die Nutznießer der Bereitstellung der öffentlichen Güter sind. Eine horizontale Verteilung der Finanzierungslasten ist aber ausgeschlossen, wenn alle Mitgliedstaaten gleich behandelt werden sollen und folglich einen einheitlichen Beitrag zur Finanzierung der Transfers leisten. Und auch auf der Seite der Transferempfänger werden unter dem Aspekt der Gleichbehandlung einheitliche Eigenfinanzierunganteile bestimmt. Es erfolgt dann aber keine zieladäquate Ausgestaltung der Transfers, die in

\footnotetext{
${ }_{975} \mathrm{Vgl}$. hierzu mit besonderem Bezug zur Infrastruktur auch Welfens (1996), S. $163 \mathrm{ff}$.

976 So können sich die finanzkräftigeren Mitgliedstaaten weitgehendere Umweltschutzmaßnahmen „leisten”. Sie besitzen zudem aufgrund der bereits stärker auf den sekundären und tertiären Bereich ausgerichteten Wirtschaftsstrukturen besonders leistungsfähige Infrastruktur- und Bildungseinrichtungen sowie umfangreiche Forschungsvorhaben mit Bezug zu den bestehenden Sektoren ihrer Industrieunternehmen.
} 
jedem Einzelfall den Einklang zwischen Grenzkosten und sozialem Grenznutzen der Güterversorgung herzustellen versucht.

\section{V-1.3.2.3 Die Frage der Implementation}

Selbst wenn man davon ausgeht, daß der Entscheidungsfindungsprozeß im Verbundsystem zu einer effizienten Problemlösung geführt hat, ist zu überprüfen, ob im Rahmen der Implementation der Entscheidung Ineffizienzen zu erwarten sind.

Hier steht zunächst die EK im Mittelpunkt. Als Exekutivorgan hat die EK für die Umsetzung der Entscheidungen der EU Sorge zu tragen. Zu diesem Zweck ist die EK befugt, Durchfuihrungsvorschriften zu erlassen. Unter Berücksichtigung der Eigeninteressen der Akteure der EK besteht hier eine mögliche Quelle für zentrales Politikversagen. Es ist zu befürchten, daß die europäische Bürokratie ihre Kompetenzen dazu nutzt, die eigenen Handlungsspielräume auf Kosten der Mitgliedstaaten auszuweiten. Da diese Entwicklung bei einer Vielzahl an Einzelfällen möglich wird, können in der Summe merkliche Zentralisierungstendenzen resultieren, die in den Mitgliedstaaten hohe Präferenzkosten auslösen. Es ist deshalb die Rolle der EK bei der Durchführung der FZ-Vergabe strikt auf die Abwicklung der Mittelvergabe und Kontrolle der Mittelverwendung zu beschränken.

Aus der Vielzahl der Einzelfälle entsteht ein weitere Begründungsansatz möglicher Ineffizienzen bei der Entscheidungsdurchführung. Die Kontrolle der ordnungsgemäßen Mittelverwendung in jedem Einzelfall würde die administrativen Kapazitäten der EU-Ebene bei weitem überfordern und zudem enorme Kosten auslösen. ${ }^{977}$ „Realistischerweise” können von der EK daher nur fallweise Kontrollen durchgeführt werden. Da die Transferempfänger Kenntnis dieser Kontrollproblematik besitzen, ergeben sich für die Bürokratie in den einzelnen Mitgliedstaaten erhebliche Spielräume zur Verausgabung der FZ-Mittel nach eigenen Vorstellungen. Die Entstehung von Sickerverlusten kann folglich nicht ausgeschlossen werden, wenn die Preiselastizitäten der Nachfrage nach den bereitgestellten öffentlichen Gütern innerhalb der Mitgliedstaaten dem „Normalfall” entsprechen. ${ }^{978}$

\footnotetext{
977 Da mit den Internalisierungszuweisungen keine allgemeinen Programme sondern konkrete Projekte zur Bereitstellung öffentlicher Güter gefördert werden, scheint die Überprüfung, ob der festgesetzte Finanzierungsanteil durch den transferempfangenden Mitgliedstaat eingehalten wurde, bei vertretbarem Kontrollaufwand durchführbar. Es bleibt aber praktisch ausgeschlossen, in jedem Einzelfall zu kontrollieren, ob es tatsächlich zur gewünschten Ausdehnung des Bereitstellungsniveaus der geförderten öffentlichen Leistung gekommen ist, weil die Überprüfung diesbezüglicher, aussagefähiger Indikatoren einen enormen Kontrollaufwand auslösen würde.

978 Vgl. hierzu Abschnitt III-2.2.3 insb. Fn 169.
} 
Je höher der Finanzierungsanteil der FZ-Mittel, desto größer ist zudem tendenziell die Gefahr von Ineffizienzen bei der Produktion der öffentlichen Güter auf dezentraler Ebene. Denn der Anreiz für die Transferempfänger, die Effizienz der Mittelverausgabung zu kontrollieren sinkt, da deren Anteil an der Finanzierung abnimmt. Dies spricht dafür, verstärkte Kontrollen durch die EU-Ebene einzurichten, wenn solche Projekte gefördert werden, die von einer hohen Spillover-Quote gekennzeichnet sind.

\section{V-1.4 Schlußfolgerungen und finanzielle Dimension}

Um die angestellten Überlegungen beurteilen zu können, ist es wichtig, einen Eindruck von der quantitativen Bedeutung der Spillover-Problematik zu vermitteln. Die EK hat im Jahr 1993 empirische Untersuchungen angestellt, ob ein „stärkeres Engagement der Gemeinschaft

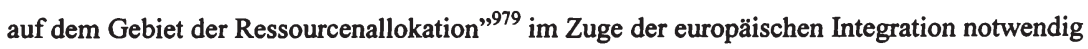
wird. Sie schätzte in zwei Studien den jährlichen Ausgabenbedarf zur Internalisierung von Spillover-Effekten zwischen den Mitgliedstaaten bis 1998 ab, der sich „bei einer systematischen Anwendung des Subsidiaritätsprinzips" ${ }^{\text {980 }}$ ergeben würde. Dabei gelangte Costello ${ }^{981}$ in einer der beiden Analysen zu dem Ergebnis, daß ,no overwhelming case for other than modest increases" 982 dieser Ausgabenkategorie für die EU-Ebene besteht. Den jährlichen zusätzlichen Ausgabenbedarf bezifferte er auf 0,1 bis 0,2 Prozent des BSP der Mitgliedstaaten. Für das Jahr 1997 bedeutet dies immerhin ein Ausgabevolumen von ca. 7 bis 14 Mrd. ECU und damit Ausgabensteigerungen im Vergleich zur gültigen finanziellen Vorausschau von ca. 7,8 bis 15,5 Prozent. In der zweiten Studie gelangte die $\mathrm{EK}^{983} \mathrm{zu}$ einer etwas geringeren finanziellen Dimension. Für das Jahr 1997 resultiert gemäß dieser Untersuchung ein zusätzlicher Ausgabenbedarf von ca. 4,8 Mrd. ECU. ${ }^{984}$ Dies entspricht einer Veränderung der Haushaltsansätze für 1997 von ca. 5,3 Prozent. Unter Berücksichtigung der bestehenden fixen Eigenmittelobergrenze als Begrenzung der Ausgabetätigkeit der EU sowie der starren Ausgabenstrukturen des EU-Haushalts ist aber selbst das zusätzliche Ausgabevolumen der zweiten Studie sehr wohl als beträchtlich zu bezeichnen.

979 Europäische Kommission (1993a), S. 61.

980 Europäische Kommission (1993a), S. 61.

981 Vgl. Costello (1993b).

982 Costello (1993b), S. 372.

983 Vgl. Europäische Kommission (1993a), S. 61 ff. Die nachfolgenden Zahlenangaben basieren auf eigenen Berechnungen, die auf Grundlage der Studie der $E K$ angestellt wurden.

984 Der Bedarf zur Leistung zusätzlicher Kompensationen wird in dieser Untersuchung insb. im Bereich der Forschung und Entwicklung gesehen (zusätzlicher Ausgabenbedarf ca. 3,6 Mrd. ECU). Daruber hinaus werden zusätzliche Ausgaben im Infrastruktur- und Bildungsbereich als notwendig erachtet (jeweils ca. 0,6 Mrd. ECU), wohingegen im Umweltbereich kein zusätzlicher Mittelbedarf erkannt wird. 
Welche Schlußfolgerungen können aus Abschnitt V-1 gezogen werden? Es wird evident, daß sich die Bedeutung der Internalisierungsproblematik für die EU in Abhängigkeit vom Entwicklungsstand der europäischen Integration verändert. Jedoch besitzt die Erfüllung dieser Funktion umgekehrt keine entscheidende Bedeutung als Triebkraft für die Fortsetzung und die Stabilität des gesamten europäischen Einigungsprozesses. Denn bei der Internalisierung externer Effekte stehen statische Effizienzgewinne und nicht dynamische Integrationsfortschritte im Zentrum.

Es ist daher gerechtfertigt, der Gefahr zentralen Politikversagens bei einer abwägenden Beurteilung der unterschiedlichen Lösungsmöglichkeiten der Internalisierungproblematik ein besonderes Gewicht beizumessen. Aus diesem Blickwinkel sollte dort, wo nur eine begrenzte Anzahl an Mitgliedstaaten von einer Spillover-Problematik betroffen ist, dezentralen Verhandlungslösungen der Vorrang eingeräumt werden. Hierdurch wird ausgeschlossen, daß durch unerwünschte Zentralisierungstendenzen hohe Präferenzkosten in den einzelnen Mitgliedstaaten ausgelöst werden. ${ }^{985}$ Die Vergabe zwischenstaatlicher FZ durch die EU-Ebene ist hingegen effizient, sofern eine Vielzahl der Mitgliedstaaten von den räumlichen externen Effekten betroffen ist. ${ }^{986}$ Durch die Nutzung der bestehenden EU-Organisationen können nun in relevanten Ausmaß Transaktionskosten eingespart werden. Das entscheidende Argument ist aber die Möglichkeit im Entscheidungsprozeß des europäischen Verbundsystems, die Internalisierung der Spillover-Effekte mit der zunehmend bedeutsamen Lösung von Koordinationsproblemen bei der Bereitstellung öffentlicher Güter zu verbinden. Daher ergibt sich v.a. im Bereich der Forschung und Entwicklung sowie der Infrastrukturbereitstellung eine Rechtfertigung für die Vergabe von Internalisierungszuweisungen. In beiden Bereichen nimmt die Anzahl der Mitgliedstaaten, die von Spillover-Effekten betroffen werden, im Integrationsprozeß zu. Zudem besitzt in beiden Bereichen die Koordination der Bereitstellungsaktivitäten der Mitgliedstaaten eine große Bedeutung. Im Bereich der Forschung und Entwicklung, um ineffiziente Doppelforschungen der Mitgliedstaaten in der Grundlagenforschung zu verhindern; im Bereich der Infrastrukturbereitstellung, um technische Unvereinbarkeiten und Lücken in den Infrastrukturnetzen der EU zu vermeiden bzw. zu beseitigen. ${ }^{987}$

\footnotetext{
${ }^{985}$ Dies entspricht der Einschätzung, wie sie in der wissenschaftlichen Literatur fast übereinstimmend wiedergegeben wird; vgl. bspw. Klodt u.a. (1992), insb. S. 190 ff; Teutemann (1992), S. 55 ff. u. S. 207 ff.; Laaser u.a. (1993), S. 20 ff.; Thomas (1997), S. 198 ff.

${ }^{986}$ Es stellt sich jedoch ein Abgrenzungsproblem. Viele öffentliche Güter lösen positive räumliche externe Effekte aus, die zwar zum Großteil wenigen Mitgliedstaaten zugute kommen, aber in geringem Umfang auch einer größeren Anzahl weiterer Mitgliedstaaten. Es stellt sich die Frage, ab welcher Spillover-Quote von der Betroffenheit eines bestimmten Mitgliedstaats zu sprechen ist und es konsequenterweise in den (dezentralen) Verhandlungsproze $ß$ aufzunehmen ist.

${ }^{987}$ So auch Costello (1993b).
} 


\section{V-2 Die Kohäsionsproblematik}

\section{V-2.1 Das Kohäsionsziel}

Die EU besitzt nach Art. 2 EGV die Aufgabe, zur Stärkung des wirtschaftlichen und sozialen Zusammenhalts (Kohäsion) in der Gemeinschaft beizutragen. Diese Zielsetzung stellt einen unbestimmten Rechtsbegriff dar. ${ }^{988}$ Eine Einschätzung, ob die Kohäsionsproblematik einen möglichen Ansatzpunkt für die FZ-Vergabe zwischen den Mitgliedstaaten darstellt, erfordert daher eine inhaltliche Präzisierung des Kohäsionsbegriffs. Der EGV bestimmt in Art. 130a, daß die Verwirklichung der Kohäsion „eine harmonische Entwicklung der Gemeinschaft als Ganzes” ermöglichen und „die Unterschiede im Entwicklungsstand der verschiedenen Regionen und den Rückstand der am stärksten benachteiligten Gebiete” verringern soll.

Diese Formulierungen deuten auf zwei grundlegende Aspekte hin. Zum ersten besitzt die Problematik eine realwirtschaftliche Dimension in räumlicher Hinsicht. Dem Kohäsionsgedanken liegt das Verständnis zugrunde, daß große Disparitäten zwischen geographischen Teileinheiten ,in einer Gemeinschaft nicht toleriert werden können, wenn der Begriff der Gemeinschaft einen Sinn haben soll." 989 Die Aggregationsstufe dieser Betrachtung ist unterhalb der Ebene der Mitgliedstaaten anzusetzen. ${ }^{990}$ Kohäsion zielt auf die reale Konvergenz aller Regionen in Richtung der Wirtschaftsleistungen der entwickelteren Regionen ab. ${ }^{991}$ Die Schlüsselgröße zur Bewertung dieser Disparitäten ist das Pro-Kopf-Einkommen. ${ }^{992}$

Zum zweiten ist diese raumwirtschaftliche Angleichung der Lebensverhältnisse in der EU nicht durch eine „bloße” Umverteilung von Einkommensteilen zwischen den Mitgliedstaaten zu verwirklichen. Entgegen dieser „nachträglichen” Korrektur geht es im Sinne eines ausgewogenen Einigungsprozesses darum, in allen Regionen eigenständige Einkommenserzielungsmöglichkeiten zu schaffen. ${ }^{993}$ Denn ,cohesion would be a less compelling goal if the EU were to be conceived only as a free-market area where economic forces alone determine the

${ }_{988}^{989}$ Vgl. hierzu auch Abschnitt IV-1.

989 Europäische Kommission (1996), S. 13. Diesen Aspekt betont Wasmayr (1997), S. 44.

990 Vgl. Franzmeyer (1996a), S. 117 f. Eine gegensätzliche Meinung vertritt Wasmayr (1997), S. 49 f. Er stellt die relative Wohlfahrtsposition ganzer Mitgliedstaaten in den Mittelpunkt des Kohäsionsziels.

991 Die EU besitzt seit 1971 ein dreistufiges System zur Regionenabgrenzung unterhalb der Ebene der Mitgliedstaaten, das sich an den administrativen Gebietsabgrenzungen der Mitgliedstaaten orientiert. Es wird als „Niveaux d'Unités Territoriales Statistiques" (NUTS) bezeichnet. NUTS 1 bezieht sich auf die höchste, NUTS 2 auf die mittlere und NUTS 3 auf die unterste Aggregationsstufe (vgl. hierzu Europäische Kommission (1994b), S. 172 ff.).

992 Vgl. Klodt u.a. (1992), S. 33 f.

993 Vgl. Franzmeyer (1994), S. 209; Europäische Kommission (1996), S. 100. Diese Überlegung verdeutlicht, daß die geeignete Aggregationsstufe zur Beurteilung des kohäsionspolitischen Handlungsbedarfs Arbeitsmarktregionen sind, denn diese kőnnen „die sozioökonomische Lage von Gebieten unverzerrt widerspiegeln" (Waniek (1994), S. 47). Die bestehende Regionenabgrenzung nach administrativen GKS ist aus diesem Blickwinkel als unzureichend zu bezeichnen. 
flow of investments, the structure of production, the distribution of purchasing power and the level of consumption, and where no higher political goals are posited." ${ }^{994}$ Es ist ein zentrales Anliegen des Kohäsionskonzepts, ,einen größeren Anteil der Bevölkerung zum wirtschaftlichen Wachstum beitragen" ${ }^{995}$ zu lassen. Unter Berücksichtigung der Kohäsionszielsetzung steht nicht ein maximales Wachstum für den Gesamtraum der EU im Mittelpunkt, sondern das Bemühen, daß alle Regionen einen ausgewogenen Beitrag zum Wachstum in der Gemeinschaft leisten. In den benachteiligten Regionen sind daher die strukturellen Voraussetzungen für ein zukünftiges selbsttragendes Wachstum zu schaffen. ${ }^{996}$ Die Erfüllung dieser Aufgabe fällt dem Subsidiaritätsprinzip gemäß in den Verantwortungsbereich der betroffenen Regionen und Mitgliedstaaten. Wenn die entsprechenden gebietskörperschaftlichen Ebenen jedoch aus eigener Initiative nicht zur Aufgabenerfüllung in der Lage sind, ist es die Pflicht der (nächsthöheren) EU-Ebene, Maßnahmen zu ergreifen, die die Startchancen der Teileinheiten einander annähern. ${ }^{997}$ So erst wird die Voraussetzung geschaffen, daß die benachteiligten Regionen einen (produktiven) Wettstreit mit den weiterentwickelten Regionen bestehen können. ${ }^{998}$ Es wird erhoff, daß diese Vorgehensweise langfristig ${ }^{999}$ auch für die EU als Ganzes wohlfahrtssteigernd wirkt und hierdurch der Zielkonflikt zwischen „unbalanced"- und „balanced"growth ${ }^{1000}$ gemildert wird.

Die Operationalisierung des Kohäsionsbegriffs verdeutlicht, daß der wirtschaftliche und soziale Zusammenhalt einen Ansatzpunkt für die Vergabe zwischenstaatlicher FZ im Dienst der Regionalpolitik bietet. Die EU kann die regionalen Wirtschaftsstrukturen innerhalb der gesamten EU im Sinne einer allokativ orientierten Ausgleichspolitik beeinflussen, um Spielräume für einen eigenständigen Aufholprozeß in den benachteiligten Regionen zu schaffen. ${ }^{1001}$

\footnotetext{
994 Leonardi (1995), S. 2.

995 Europäische Kommission (1996), S. 115. Dieses Argument zielt zum einen darauf ab, in allen Regionen eigenständige Einkommenserzielungsmöglichkeiten zu schaffen. Zum anderen bezieht sich die Zielsetzung aber auch auf die Lebenschancen für den einzelnen Bürger einer beliebigen Region der EU. Der Zugang zu Beschäftigung bildet den zentralen Faktor zur Förderung des Zusammenhalts in der gesamten Gemeinschaft. Aus diesem Grund stellt die Arbeitslosenquote die zweite Schlüsselgröße zur Bewertung der Disparitäten zwischen den Teileinheiten der $E U$ dar.

996 Vgl. Leonardi (1995), S. 1 ff.; Europäische Kommission (1996), S. 13 ff.

997 Vgl. Klodt u.a. (1992), S. 34; Postlep (1993), S. 84. Pointiert verdeutlicht die Europäische Kommission (1993a), S. 51 den Unterschied zwischen dem Konzept der Kohăsion und einer bloßen Umverteilung: „Verkürzt kann man sagen, daß es beim Zusammenhalt um Gleichheit der Chancen, bei der Verteilungsgerechtigkeit dagegen um Gleichheit der Ergebnisse geht."

998 Vgl. zum hier angedeuteten „System konkurrierender Regionen” bspw. Klemmer (1998), S. 464 f.

999 Vgl. zur „Langfristigkeit” der Kohäsionspolitik De La Dehesa/Krugman (1992), S. 3; Jaggi (1996), S. 42; Wasmayr (1997), S. 44 ff. u. 206.

${ }^{1000}$ Die Relevanz dieses Zielkonflikts zeigt sich auch im Weißbuch der Europäischen Kommission, worin die Voraussetzungen für Wachstum, Wettbewerbsfähigkeit und Beschăftigung in der $E U$ im direkten Vergleich zu anderen Regionen oder Nationen analysiert werden; vgl. Europäische Kommission (1994a).

${ }^{1001}$ Vgl. zu dieser „allokativ orientierten Ausgleichspolitik” die Ausfuhrungen zum Potentialfaktoransatz in Abschnitt III-3.1.1.2.
} 


\section{V-2.2 Handlungsnotwendigkeit für die EU}

Die Frage, ob für die EU-Ebene zum heutigen Zeitpunkt eine Handlungsnotwendigkeit zur Vergabe von kohäsionspolitischen FZ besteht, erfordert zwei Untersuchungsschritte. Zum ersten gilt es in einer Situationsanalyse zu überprüfen, ob es im Status-Quo überhaupt Teileinheiten gibt, die durch einen deutlichen Entwicklungsrückstand gekennzeichnet sind. Zugleich muß im Rahmen dieser Situationsanalyse geprüft werden, ob die „zurückliegenden” Regionen strukturelle Benachteiligungen aufweisen, die durch staatliche Eingriffe beseitigt werden können. Nur in diesem Fall leisten die FZ einen Beitrag zur Schaffung der Voraussetzungen für ein eigenständiges Wachstum in den Teileinheiten. ${ }^{1002}$ Darüber hinaus ist zum zweiten die Entwicklungsperspektive der EU im Hinblick auf das Kohäsionsziel zu beleuchten. In einer längerfristigen Perspektive gilt es zu analysieren, wie sich der fortschreitende Integrationsprozeß auf die zurückliegenden Regionen auswirken wird. Gelangt diese Prognose zu dem Resultat, daß sich die Entwicklungsunterschiede innerhalb der EU infolge des Integrationsprozesses automatisch - d.h. ohne staatliche Intervention - in einer akzeptablen Zeitspanne verringern, so besteht selbst dann kein wirtschaftspolitischer Handlungsbedarf, wenn die Situationsanalyse eine Abweichung von der gewünschten kohäsionspolitischen SollSituation ergeben hat.

\section{V-2.2.1 Situationsbeschreibung und -erklärung}

Zur Beschreibung des Entwicklungsstandes der Teileinheiten innerhalb der EU werden im Folgenden das pro Kopf $\mathrm{BIP}^{1003}$ sowie die Arbeitslosenquote herangezogen. ${ }^{1004}$ Die Abbildungen V-1 und V-2 weisen diese Schlüsselgrößen der Disparitätenanalyse für die Ebene der Mitgliedstaaten im Jahr 1997 aus. Der regionale Vergleich wird also zunächst auf der höchstmöglichen Aggregationsstufe angestellt:

\footnotetext{
${ }^{1002}$ Vgl. hierzu nochmals die Ausführungen zum Potentialfaktoransatz in Abschnitt III-3.1.1.2.

${ }^{1003} \mathrm{Da}$ das Einkommen als ein Wohlstandsmaß angesehen wird, ist es sinnvoll den Vergleich zwischen den Mitgliedstaaten in Kaufkraftstandards anzustellen; vgl. hierzu bspw. Stähling (1994), S. 108 f.

${ }^{1004}$ Eine umfassende Analyse der räumlichen Disparităten in der $E U$ nimmt der ,Erste Bericht über den wirtschaftlichen und sozialen Zusammenahlt 1996" vor. Vgl. Europäische Kommission (1996); vgl. aber auch die vorhergehenden periodischen Berichte zur sozio-ökonomischen Lage und Entwicklung in der Regionen in der EU: Europäische Kommission (1987); (1991); (1994b).
} 
Abb. V-1: BIP pro Kopf, KKS, 1997, in Prozent, EUR 15=100

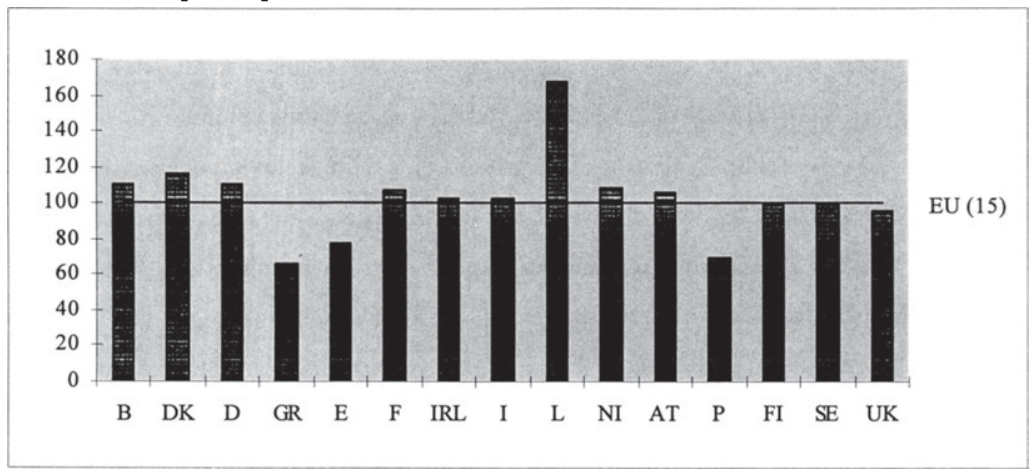

Quelle: Europäische Kommission (1997c), S. 94 f.

Beide Abbildungen verdeutlichen erhebliche räumliche Disparitäten. Es zeigt sich, daß der Entwicklungsstand dreier Mitgliedstaaten deutlich nach unten abweicht. Das Pro-KopfEinkommen der beiden schwächsten Mitgliedstaaten erreicht im Jahr 1997 weniger als 70 Prozent des Durchschnitts aller EU-Mitgliedstaaten (Griechenland 66 Prozent; Portugal 69 Prozent). Zudem bleibt Spanien mit 78 Prozent deutlich hinter dem EU-Durchschnitt zurück. Luxemburg hingegen ist als einkommenstärkster Mitgliedstaat mit einem Pro-KopfEinkommen ausgestattet, das den Durchschnitt um fast 70 Prozent übertrifft (vgl. Abb. V-1). Ein ähnliches Bild ergibt sich bei den Arbeitslosenquoten. Dort weist Spanien mit 21,3 Prozent die bei weitem höchste Rate auf, die mehr als doppelt so hoch ausfällt wie die durchschnittliche Arbeitslosenquote der gesamten EU von 10,6 Prozent. Demgegenüber betragen die Arbeitslosenquoten in Luxemburg und Österreich lediglich 3,3 bzw. 4,2 Prozent. In diesen beiden Mitgliedstaaten sind 69 bzw. 60 Prozent weniger Erwerbstätige ohne Beschäftigung als im EU-Durchschnitt (vgl. Abb. V-2). 
Abb. V-2: Arbeitslosenquoten in den Mitgliedstaaten, 1997, in Prozent

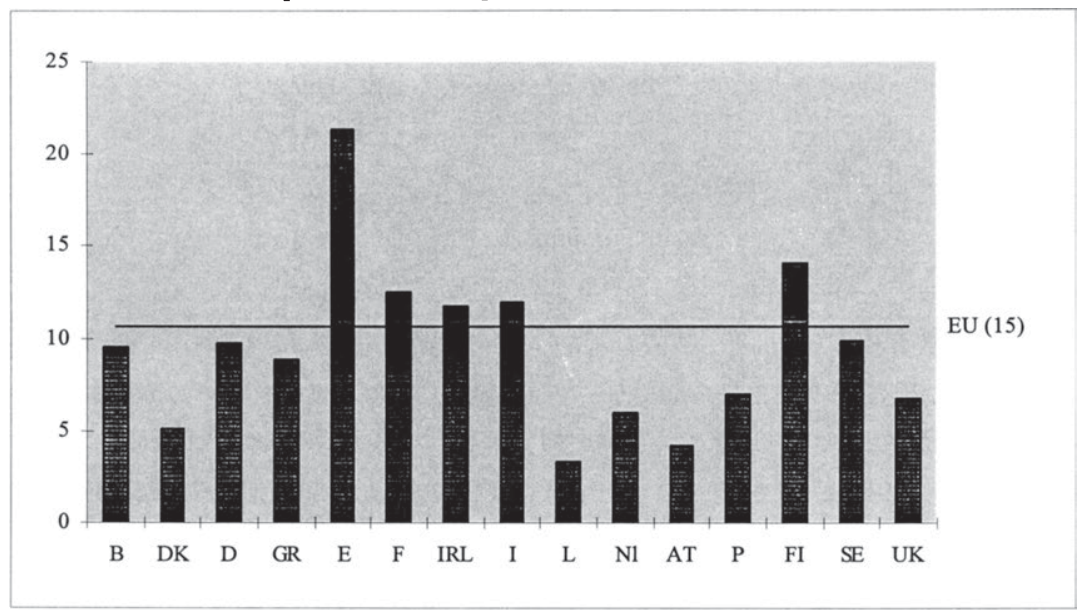

Quelle: Europäische Kommission (1997c), S. 82 f.

Die räumlichen Disparitäten fallen sehr viel höher aus, wenn der Vergleich nicht auf die Ebene der Mitgliedstaaten, sondern der Regionen bezogen wird. Die Abb. V-3 verdeutlicht dies für das Jahr 1993 bzw. 1995 anhand der Standardabweichung der beiden Schlüsselgrößen zwischen den Regionen ${ }^{1005}$ einerseits und den Mitgliedstaaten andererseits:

Abb. V-3: Disparitäten in Europa, (Standardabweichung, EUR 15=100)

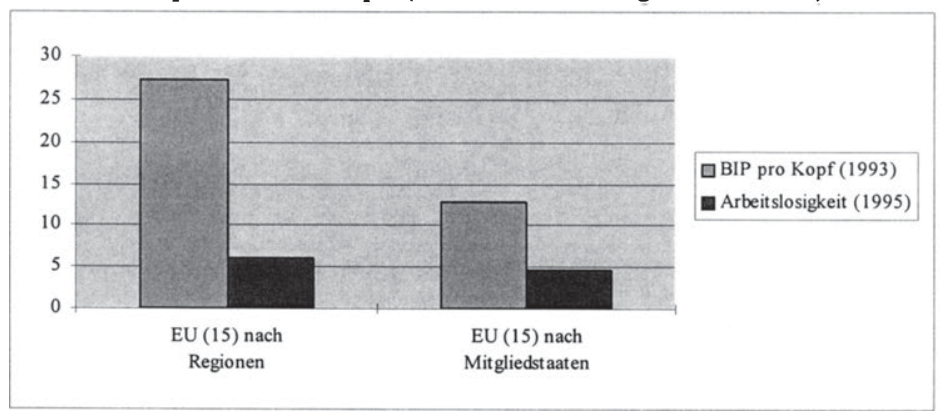

Quelle: Europäische Kommission (1996), S. 135 u. 137.

V.a. im Hinblick auf das Pro-Kopf-Einkommen zeigt sich sehr deutlich, daß die Streuung der Daten zwischen den Regionen (Standardabweichung 27,2) viel höher ist, als zwischen den Mitgliedstaaten (Standardabweichung 12,8). Exemplarisch sei auf Hamburg als die reichste

\footnotetext{
${ }^{1005}$ Hierbei erfolgt die Bezugnahme auf die NUTS 2 Ebene.
} 
Region verwiesen, die 1993 über ein Pro-Kopf-Einkommen von 189 Prozent des EUDurchschnitts verfügt. Am anderen Ende der Skala steht das französische Guadeloupe mit einem Pro-Kopf-Einkommen von lediglich 37 Prozent des EU-Durchschnitts. ${ }^{1006}$ Damit erhöht sich die Spanne zwischen der „ärmsten” und der „reichsten” Teileinheit, die für die Mitgliedstaaten den Faktor 2,5 beträgt, beim Vergleich der Regionen auf 4,5.

Auch die Streuung der Arbeitslosenraten nimmt bei dem Übergang zum Regionenvergleich zu. Die Standardabweichung steigt von 4,6 auf 6,0. Die am wenigsten von Arbeitslosigkeit betroffene Region ist 1995 Luxemburg ${ }^{1007}$ mit einer Quote von 2,9 Prozent. In der Region Andalucia in Spanien sind hingegen 33,2 Prozent der Erwerbsbevölkerung ohne Beschäftigung. Die Spanne zwischen der Teileinheit mit der niedrigsten und der höchsten Arbeitslosenquote, die für die Mitgliedstaaten den Faktor 7,9 beträgt, erhöht sich beim Regionenvergleich auf 11,5 .

Im zweiten Schritt dieser Situationsanalyse ist zu überprüfen, ob die „zurückliegenden” Regionen durch strukturelle Benachteiligungen gekennzeichnet sind, die durch staatliche Interventionen behoben werden könnten. Zu diesem Zweck ist es notwendig, einen Überblick über die Disparitäten in der Infrastrukturausstattung zu gewinnen. ${ }^{1008}$ Biehl hat für die Jahre um 1985 einen produktivitätsorientierten Infrastrukturgesamtindikator für die Regionen (NUTS 2 Ebene) der EU erstellt, der mit der Verkehrsinfrastruktur, der Telekommunikation, dem Energiebereich und den (berufsausbildungsorientierten) Bildungseinrichtungen alle produktionsrelevanten Infrastrukturkategorien berücksichtigt. ${ }^{1009}$ Die Querschnittsanalyse demonstriert erhebliche regionale Disparitäten in der Infrastrukturausstattung. Dabei zeigt sich, daß gerade die Regionen der sogenannten Kohäsionsländer ${ }^{1010}$ Irland, Spanien, Portugal und Griechenland gravierende Rückstände in den verschiedenen Infrastrukturkategorien aufweisen. ${ }^{1011}$ Die Infrastrukturdefizite bestehen also insb. in jenen Mitgliedstaaten, die im Hinblick auf das BIP einen Entwicklungsrückstand aufweisen. Abbildung V-4 verdeutlicht diesen Zusammenhang graphisch:

\footnotetext{
${ }^{1006}$ Die zehn ärmsten Regionen erreichen im Schnitt nur 48 Prozent des durchschnittlichen Pro-KopfEinkommens der $E U$.

${ }^{1007}$ Luxemburg wird innerhalb der EU-Systematik als eine Region innerhalb der NUTS 2 Ebene gewertet.

${ }^{1008}$ Zur Problematik der Ermittlung von Infrastrukturindikatoren vgl. Stähling (1994), S. 7 ff.

${ }^{1009} \mathrm{Vgl}$. zur nachfolgenden Analyse Biehl (1995b).

${ }^{1010}$ Als Kohäsionsländer werden diejenigen Mitgliedstaaten der EU bezeichnet, deren Pro-Kopf-BSP (in KKS) zum Zeitpunkt des Abschlusses der Maastrichter Verträge im Jahr 1993 weniger als 90 Prozent des EUDurchschnitts betragen hat. Vgl. hierzu näher S. 243 in Abschnitt V-2.3.2.

${ }^{1011} \mathrm{Vgl}$. zu den Disparitäten in den einzelnen Infrastrukturkategorien auch Meyer (1996), m.w.N.
} 
Abb. V-4: Die Infrastrukturausstattung in den Kohäsionsländern

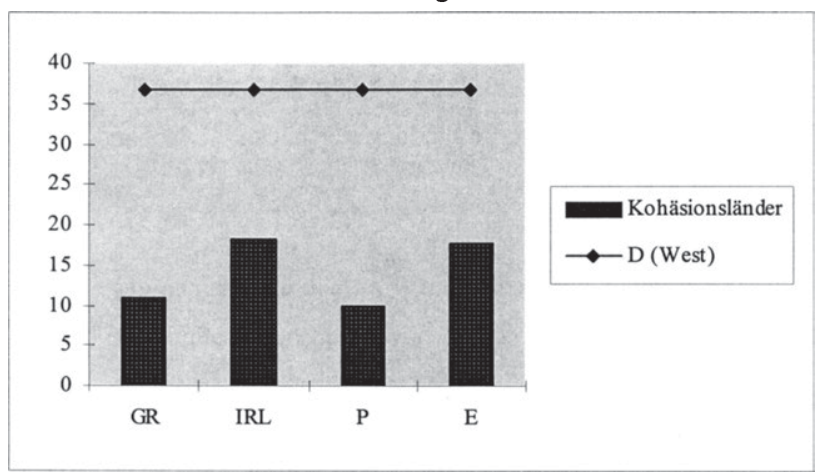

Quelle: Biehl (1995b), S. 69 ff.; eigene Berechnungen.

Die Abbildung zeigt den Gesamtindikatorwert für die vier Kohäsionsländer, der als der Durchschnitt der Einzelwerte aller Regionen des jeweiligen Staates berechnet wurde. Dieser Wert wird als Prozentsatz der bestausgestatteten Region Hamburg wiedergegeben, deren Gesamtindikatorwert auf 100 normiert wurde. Als Vergleichsgröße ist der durchschnittliche Gesamtindikatorwert der Regionen (Regierungsbezirke) in den alten Bundesländern Deutschlands ausgewiesen. Dieser Wert beträgt 36,8 Prozent der Infrastrukturausstattung Hamburgs. Es zeigt sich der deutliche Rückstand der vier Kohäsionsländer: Irland weist einen Gesamtindikatorwert von 18,2 Prozent, Spanien von 17,8 Prozent auf; Griechenland und Portugal, die den größten Entwicklungsrückstand beim Pro-Kopf-Einkommen besitzen, verzeichnen sogar nur Werte von 10,9 Prozent bzw. 9,9 Prozent. ${ }^{1012}$

\section{V-2.2.2 Prognose der zukünftigen Entwicklung}

In einer längerfristigen Perspektive ist zu überprüfen, wie sich der fortschreitende Integrationsprozeß mit der Vollendung der Wirtschafts- und Währungsunion auf die zurückliegenden Mitgliedstaaten bzw. Regionen auswirken wird. In der Literatur werden ganz unterschiedliche Ansätze über vermutete Zusammenhänge vorgetragen. Dementsprechend unterschiedlich bis gegensätzlich sind die abgeleiteten Ergebnisse über zu erwartende räumliche Entwicklun-

\footnotetext{
${ }^{1012} \mathrm{Zu}$ einem vergleichbaren Ergebnis gelangte auch Stähling für das Jahr 1989. Er entwickelte in einer Querschnittsanalyse ebenfalls einen Gesamtindikator für das produktive Infrastrukturkapital in der $E U$. Allerdings berechnete Stähling die Indikatorenwerte für die Ebene der Mitgliedstaaten. Zudem berücksichtigte er keine Subkategorie zur Infrastruktur im Bildungsbereich. Dennoch bestätigt das Ergebnis die Ergebnisse von Biehl auch für das Jahr 1989. Die Kohäsionsländer weisen eine deutlich schlechtere Infrastrukturausstattung auf, als die übrigen Mitgliedstaaten der EU; vgl. hierzu Stähling (1994), insb. S. 84 ff.
} 
gen. ${ }^{1013}$ Der eine Pol wird durch die sogenannte Konvergenzschule vertreten und basiert auf der klassischen Außenhandelstheorie ${ }^{1014}$ sowie der neoklassischen Wachstumstheorie. ${ }^{1015}$ Der andere Pol wird als Divergenzschule bezeichnet. In deren Mittelpunkt steht die Theorie der kumulativen Entwicklung, ${ }^{1016}$ die in einer engen Verbindung zur neuen Außenhandelstheorie $^{1017}$ und zur neuen Wachstumstheorie steht. ${ }^{1018}$

Den klassischen und neoklassischen Theorieansätzen gemäß werden im Rahmen des europäischen Integrationsprozesses alle Disparitäten zwischen den Mitgliedstaaten eliminiert: ${ }^{1019}$

- Ausgangspunkt der Überlegung ist eine unterschiedliche Anfangsausstattung der Mitgliedstaaten mit Produktionsfaktoren. Diese stellt die Ursache für Unterschiede in den ProKopf-Einkommen der einzelnen Mitgliedstaaten dar. Unter der Annahme identischer Produktionsfunktionen weisen in dieser Situation diejenigen Mitgliedstaaten mit einer hohen Kapitalintensität einen höheren Reallohn, aber eine niedrigere Grenzproduktivität des Kapitals im Vergleich zu denjenigen Mitgliedstaaten mit niedriger Kapitalintensität auf. Ausgehend davon, daß die Vollendung des Integrationsprozesses die vollständige Mobilität der Produktionsfaktoren Arbeit und Kapital garantiert, werden diese Disparitäten durch Wanderungen der Produktionsfaktoren ausgeglichen.

Arbeit wird von Mitgliedstaaten mit niedriger Entlohnung zu Mitgliedstaaten mit hoher Entlohnung wandern. Damit entsteht ein Druck zu Lohnsteigerungen in den Mitgliedstaaten, aus denen Arbeit abwandert. Gleichzeitig entsteht ein Druck zu Lohnsenkungen in den Staaten, die Zuwanderung von Arbeitskrätten zu verzeichnen haben, so daß sich die Entlohnung des Faktors Arbeit insgesamt angleicht. Zugleich wird der Produktionsfaktor Kapital von niedrigen Löhnen und reichem Arbeitskraftangebot in den weniger entwickelten Regionen angezogen. So kommt es auch zu einer Angleichung der Kapitalrendite in den Mitgliedstaaten der EU. Solange der Handel zwischen den Mitgliedstaaten innerhalb der

\footnotetext{
${ }^{1013}$ Einen hervorragenden Überblick über die unterschiedlichen älteren und neueren Erklärungsansätze geben Krieger-Boden (1995) sowie die Aufsatzsammlung von Peschel (1997). Vgl. aber auch Bode (1996).

${ }^{1014}$ Die Grundlagen der traditionellen Außenhandelstheorie legten Ricardo (1817) sowie Heckscher (1919) und Ohlin (1931).

${ }^{1015}$ Ausgangspunkt der neoklassischen Wachstumstheorie ist das Modell von Solow (1956).

${ }^{1016}$ Diese Modelle werden auch als Teufelskreis-Modelle bezeichnet. Sie gehen zurück auf Myrdal (1957), aber auch Hirschman (1958) und Kaldor (1970).

${ }^{1017}$ Den Durchbruch der neuen Außenhandelstheorie reprăsentiert Krugman (1991).

${ }^{1018}$ Die ersten Ansätze der neuen Wachstumstheorie gehen auf Romer (1986); (1990) u. Lucas (1988) zurück. Das Hauptanliegen der neuen Wachstumstheorie ist die modellendogene Erklärung des technischen Fortschritts und damit eines langfristigen wirtschaftlichen Wachstums. In der traditionellen Wachstumstheorie wird langfristiges Wachstum ausschließlich mit exogenem technischem Fortschritt erklärt (vgl. bspw. Bode (1996), S. 4 ff.).

${ }^{1019}$ Vgl. zum Folgenden auch Prud'homme (1993); Santos (1993); Beckmann (1995), S. 60 ff. u. Werner (1996), S. $76 \mathrm{ff}$.
} 
europäischen Wirtschaftsunion unbeschränkt ist, stellt sich ein analoges Ergebnis auch dann ein, wenn die Produktionsfaktoren nicht vollständig mobil sind.

Die beschriebenen Faktorwanderungen erlauben es den weniger entwickelten Mitgliedstaaten, höhere Wachstumsraten des Einkommens zu realisieren, als den entwickelteren Mitgliedstaaten. Denn durch den Kapitalzufluß in die benachteiligten Mitgliedstaaten erhöht sich dort die Produktivität im Vergleich zu den entwickelterten Mitgliedstaaten. So kommt es zu einer quasi-automatischen (marktinduzierten) Konvergenz der Pro-KopfEinkommen. Eine Aussage über den Zeitraum des Angleichungsprozesses erfolgt in der klassischen bzw. neoklassischen Analyse jedoch nicht. ${ }^{1020}$

Entsprechend der Divergenzschule ergibt sich hingegen eine entgegengesetzte Entwicklung. Im Mittelpunkt deren Theorieansätze stehen „economies of scale” und positive externe Effekte, die sich selbst verstärkende Konzentrationsprozesse auslösen. Wegen dieser zirkulären (kumulativen) Verursachungen werden sich bestehende regionale Disparitäten im Integrationsprozeß noch vergrößern:

- Aufgrund von unternehmensinternen „economies of scale” können Produzenten, die bereits auf einem bestimmten Markt präsent sind, in besonderem Maße von einer Vergrößerung der Absatzmärkte im Zuge der Vollendung des europäischen Binnenmarktes profitieren. Durch eine Produktionsausweitung in vergrößerten Betriebseinheiten realisieren diese Unternehmen Effizienzgewinne und können so ihre Produktionskosten senken. ${ }^{1021}$ Es ist daher lohnend die Produktion dieser Güter auf wenige Standorte zu konzentrieren und von dort aus die Güter auf die umliegenden Regionen zu verteilen. ${ }^{1022}$ Im Status-Quo sind die Produktionsstandorte überwiegend innerhalb der weiterentwickelten, stärker industrialisierten Mitgliedstaaten lokalisiert. Daher wird es für weniger entwickelte Mitgliedstaaten im Laufe des Integrationsprozesses zunehmend schwieriger, den Marktzutritt neuer Unternehmen im eigenen Mitgliedstaat zu ermöglichen, da die Größenvorteile der etablierten Unternehmen mit der ökonomischen Integration eher noch ansteigen. Es vollzieht sich ein Prozeß der kumulativen Verursachung, der die Einleitung eines wirtschaftlichen Aufholprozesses in den benachteiligten Teileinheiten fortlaufend erschwert.

\footnotetext{
${ }^{1020}$ Vgl. auch Häring (1995), S. 96 f.

${ }^{1021}$ Diese „economies of scale” treten bspw. dann auf, wenn bei der Produktion Unteilbarkeiten des Kapitaleinsatzes vorliegen (statische Skalenerträge). Es sind aber auch dynamische Skalenerträge möglich, die durch Lerneffekte im Produktionsprozeß entstehen; vgl. Klodt (1992), S. 6 f.

${ }^{1022} \mathrm{Je}$ niedriger die Transportkosten im Vergleich zu den „economies of scale” ausfallen, desto weiter wird die Konzentration der Produktion fortschreiten. Vgl. Krieger-Boden (1995), S. $49 \mathrm{ff}$.
} 
- Die entwickelten Regionen können geographische positive externe Effekte ausnutzen, die räumlich begrenzt den Kerngebieten zugute kommen. Sie werden als Agglomerationsvorteile des Zentrums bezeichnet. So sind in wirtschaftlichen Kernregionen bspw. Transportsowie Informationskosten niedriger und qualifizierte Arbeitskräfte sowie spezialisierte $\mathrm{Zu}$ lieferer in größerem Umfang vorhanden als in weniger entwickelten Regionen. Darüber hinaus bestehen dort Fühlungsvorteile durch die stärkere Präsenz von anderen Unternehmen der gleichen Branche sowie öffentlicher Einrichtungen und Behörden. Erneut ergibt sich ein Teufelskreis. Je deutlicher der Entwicklungsvorsprung der begünstigten Regionen, desto stärker fallen die Nachteile der peripheren Regionen ins Gewicht. ${ }^{1023}$

- Schließlich zeigen die Modelle der neuen Wachstumstheorie unter der Berücksichtigung von ,economies of scale"1024 in den Produktionstechnologien, daß sich die Wachstumsraten zweier Regionen auch langfristig unterscheiden können. Wenn die Regionen in der Ausgangssituation unterschiedliche „Strukturparameter” ${ }^{1025}$ aufweisen und zudem „Wissen interregional nur eingeschränkt mobil ist, so daß die Geschwindigkeit des technischen Fortschritts interregional variieren kann", ${ }^{1026}$ gelangen die Modelle zu dem Resultat, daß sich bestehende Pro-Kopf-Einkommensunterschiede zwischen den Regionen im fortschreitenden Integrationsprozeß sogar noch verstärken (Pfadabhängigkeit). So entwickeln Grossman und Helpman ${ }^{1027}$ bspw. ein Modell mit zwei Regionen, die sich in ihrer Humankapitalausstattung unterscheiden. Es werden in der Modellwelt High-tech-Güter, die den umfangreichen Einsatz von Humankapital erfordern, und Low-tech-Güter, die nur wenig Humankapitaleinsatz erfordern, hergestellt. Endogenes Wachstum wird dadurch ausgelöst, daß das technische Wissen mit konstanten Grenzerträgen in die Produktion der High-tech-Güter einfließt. Dieser Sektor verzeichnet daher höhere Wachstumsraten als der Low-tech-Sektor, der keine Skalenerträge ausnutzen kann. Erfolgt nun ausgehend von einer Situation der Autarkie ein ökonomischer Integrationsprozeß, so werden sich die beiden Regionen gemäß ihrer komparativen Vorteile spezialisieren. In der humankapitalarmen Region werden v.a. die Low-tech-Güter und in der humankapitalreichen Region v.a. die

\footnotetext{
${ }^{1023}$ Zudem ist darauf zu verweisen, daß die soziale Kosten der Agglomeration in ökonomischen Kernregionen, wie bspw. die negativen externen Effekte im Bereich der Umweltverschmutzung, nur zum Teil von den Verursachern der Kosten getragen werden. Dies bedeutet einen zusätzlichen Kostennachteil für die benachteiligten Regionen (vgl. bspw. Thomas (1994), S. 478).

${ }^{1024}$ Konstante oder steigende Skalenerträge werden in den Modellen der neuen Wachstumstheorie durch die Annahme ermöglicht, daß die Grenzerträge zumindest eines der akkumulierbaren Produktionsfaktoren nicht sinken. In Verbindung mit weiteren (nicht akkumulierbaren) Produktionsfaktoren sind daher konstante oder steigende Skalenerträge erzielbar. Im Gegensatz hierzu wird in der traditionellen Wachstumstheorie stets von abnehmenden Grenzerträgen aller eingesetzten Produktionsfaktoren ausgegangen (vgl. Häring (1995), S. 97 f.).

${ }^{1025}$ Klodt u.a. (1992), S. 42.

${ }^{1026}$ Bode (1996), S. 63.

${ }^{1027}$ Vgl. Grossman/Helpman (1991); vgl. auch die Darstellung des Ansatzes bei Bode (1996), S. $48 \mathrm{ff}$.
} 
High-tech-Güter produziert. Da jedoch der High-tech-Sektor schneller wächst, kann die humankapitalreiche Region höhere Steigerungsraten der Pro-Kopf-Einkommen realisieren. Langfristig erhöhen sich auf diese Weise die Disparitäten zwischen den Regionen.

Die verschiedenen Theorieansätze konnten an dieser Stelle nur in ihren Grundaussagen skizziert werden. Die Ausführungen verdeutlichen aber einen Dualismus widersprüchlicher Theorien, die dem europäischen Integrationsprozeß eine konvergenzfördernde oder aber eine divergenzfördernde Wirkung zusprechen. ${ }^{1028}$ Dies demonstriert, daß keine empirisch gehaltvolle monokausale Erklärung der komplexen Gesamtzusammenhänge innerhalb eines Theoriegebäudes möglich ist. Die Ergebnisse der einzelnen Modelle hängen entscheidend von den getroffenen Annahmen und dem ausgewählten Schwerpunkt des Untersuchungsgegenstandes ab. Es werden in den einzelnen Modellen ganz unterschiedliche theoretische Zusammenhänge in den Mittelpunkt der Diagnose und Prognose der zu erwartenden räumlichen Entwicklungsprozesse gestellt. So zeigt sich, daß die neue Wachstumstheorie „keineswegs ausschließlich Konzentrationsprozesse, sondern ebensogut Dekonzentrationsprozesse erklären kann."1029 Findet im Modell von Grossman und Helpman ein Wissensaustausch zwischen den Regionen statt, so resultieren im Modell nicht länger divergierende, sondern einheitliche Wachstumsraten in den betrachteten Regionen.

Es ist daher entscheidend, Realitätsbezug durch empirische Überprüfung der Annahmen und Hypothesen herzustellen. ${ }^{1030}$ Barro/Sala-i-Martin haben in diesem Zusammenhang eine Reihe von Untersuchungen durchgeführt. ${ }^{1031}$ Die Autoren überprüfen u.a. eine Auswahl von Regionen innerhalb der EU für den Zeitraum von 1950 bis 1985. Die Autoren gelangen zum Ergebnis einer Einkommenskonvergenz. Ihre Schätzungen bestätigen daher grundsätzlich das neoklassische Wachstumsmodell. Dieser Konvergenzprozeß nimmt jedoch einen sehr langen Zeitraum in Anspruch. Die Schätzungen ergaben, daß allein eine Halbierung der existierenden Disparitäten der Pro-Kopf-Einkommen zwischen 25 und 35 Jahren benötigen wird.

Auf der Ebene der Mitgliedstaaten werden diese Ergebnisse durch die tatsächliche Entwicklung der Disparitäten der Pro-Kopf-Einkommen gestützt. Abbildung V-5 bildet die Entwicklung seit 1960 für die vier Kohäsionsländer ab. Griechenland konnte in den vergangenen 37 Jahren 40 Prozent des Rückstands im Pro-Kopf-Einkommen zum EU-Durchschnitt aufholen, Portugal 48 Prozent und Spanien 49 Prozent. Irland stellt einen deutlichen Ausnahmefall dar.

\footnotetext{
${ }^{1028}$ Vgl. hierzu bspw. Europäische Kommission (1990), S. 237 f.; Klemmer (1998), S. 489.

${ }^{1029}$ Bode (1996), S. 6.

${ }^{1030}$ So auch Krieger-Boden (1995), S. 78.

${ }^{1031}$ Vgl. bspw. Barro/Sala-i-Martin (1991); (1992) und auch (1998), S. $443 \mathrm{ff}$.
} 
Nachdem das Land von 1960 bis 1990 ähnlich wie die übrigen Kohäsionsländer ca. 28 Prozent des Rückstands im Pro-Kopf-Einkommen aufholte, gelang es ihm in den letzten Jahren sehr schnell zum EU-Durchschnitt aufzuschließen.

Abb. V-5: BIP pro Kopf in den Kohäsionsländern, KKS, in Prozent, EUR 15=100

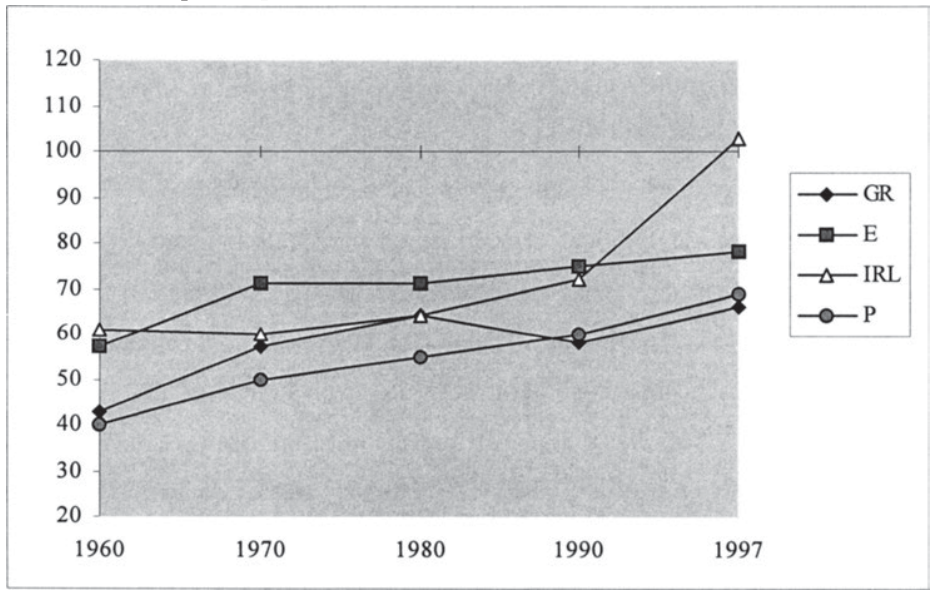

Quelle: Europäische Kommission (1997c), S. 94 f.

Der empirische Nachweis einer Konvergenz der Pro-Kopf-Einkommen bleibt jedoch aus, wenn man die Betrachtung auf der Ebene der Regionen anstellt. Abbildung V-6 zeigt die Standardabweichung der Pro-Kopf-Einkommen im Hinblick auf die Regionen und die Mitgliedstaaten. Es verdeutlicht sich nicht nur, daß die Disparitäten zwischen den Regionen deutlich höher ausfallen, sondern auch, daß auf dort im Unterschied zur mitgliedstaatlichen Ebene im Betrachtungszeitraum von 1983 bis 1993 keine Verringerung der Disparitäten stattgefunden hat. Vielmehr hat die Standardabweichung in diesem Zeitraum von 26,8 auf 27,2 zugenommen. ${ }^{1032}$

\footnotetext{
${ }^{1032}$ Auf der mitgliedstaatlichen Ebene hat die Standardabweichung in diesem Zeitraum von 17,2 auf 12,8 abgenommen.
} 
Abb. V-6: Disparitäten beim BIP pro Kopf in KKS (Standardabweichung, EUR 15=100)

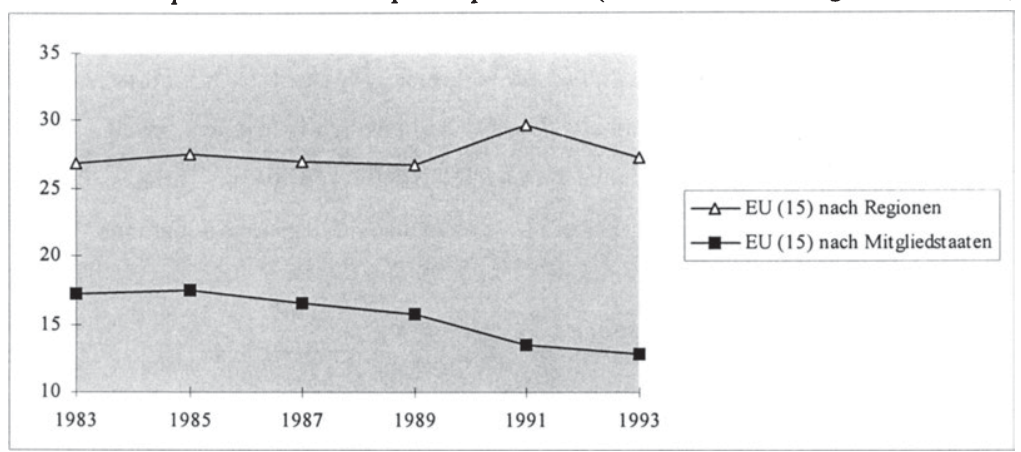

Quelle: Europäische Kommission (1996), S. 135.

Insgesamt erlaubt die Lageanalyse der vergangenen beiden Teilabschnitte daher die folgenden Schlußfolgerungen:

- Die Situationsbeschreibung verdeutlicht, daß zum heutigen Zeitpunkt tatsächlich erhebliche räumliche Disparitäten zwischen den Mitgliedstaaten und insb. zwischen den Regionen der EU bestehen. Zudem besitzen gerade jene Mitgliedstaaten, die einen Entwicklungsrückstand im Hinblick auf das BIP besitzen, zugleich die größten Infrastrukturdefizite. Aus Sicht der Situationsanalyse besteht daher eine Handlungsnotwendigkeit und auch eine Handlungsmöglichkeit zur Verwirklichung der Kohäsionszielsetzung.

- Die theoretische Analyse der Auswirkungen des Integrationsprozesses auf die weitere Entwicklung der Disparitäten innerhalb der EU läßt keine eindeutigen Schlußfolgerungen zu. $\mathrm{Ob}$ ohne staatliche Eingriffe letztendlich konvergenz- oder divergenzfördernde Faktoren das größere Gewicht besitzen kann nicht abschließend beurteilt werden. Jedoch gelangen selbst empirische Schätzungen, die die Konvergenzhypothese grundsätzlich unterstützen, $\mathrm{zu}$ dem Fazit, daß „Konvergenzprozesse mit einem großen Zeitaufwand verbunden sind." 1033

Ein Zeitbedarf von mehr als 25 Jahren zur Halbierung bestehender Disparitäten erscheint aufgrund politischer Abwägungskalküle nicht akzeptabel. Es besteht daher ein wirtschaftspolitischer Handlungsbedarf, um die Zeitspanne zur Verwirklichung des Kohäsionsziels durch den Einsatz staatlicher Instrumente zu verringern. ${ }^{1034}$

\footnotetext{
${ }^{1033}$ Klemmer (1998), S. 489.

${ }^{1034}$ Diese Schlußfolgerung betont Jaggi (1996).
} 


\section{V-2.3 Bestehende Aktivitäten der EU - die Regionalpolitik der EU}

Die EU-Ebene ergreift zum heutigen Zeitpunkt umfangreiche Maßnahmen zur Förderung des wirtschaftlichen und sozialen Zusammenhalts. Die EU bedient sich hierbei v.a. zweier Finanzierungsinstrumente. Der Darlehensvergabe durch die $\mathrm{EIB}^{1035}$ und als „wichtigstes Instrument" ${ }^{\text {1036 }}$ der Ausgabetätigkeit im Rahmen von Strukturfonds und des Kohäsionsfonds. ${ }^{1037}$

\section{V-2.3.1 Die Europäische Investitionsbank}

Die EIB finanziert sich weitgehend auf dem Kapitalmarkt und vergibt Darlehen, die mit den wirtschaftspolitischen Zielen der EU im Einklang stehen. Im Jahr 1995 zahlte die EIB Darlehen in Höhe von 18,6 Mrd. ECU aus. Über 65 Prozent dieses Kreditvolumens diente der Förderung der Regionalentwicklung in den Mitgliedstaaten. ${ }^{1038}$ Der Großteil dieser Mittel wiederum wurde an benachteiligte Regionen mit einem beträchtlichem Entwicklungsrückstand vergeben (ca. 50 Prozent). Die Bonität der Mitgliedstaaten spielt bei der Bestimmung des Kreditzinses keine Rolle, so daß die (weniger kreditwürdigen) Mitgliedstaaten mit beträchtlichem Entwicklungsrückstand von einer ,impliziten Zinssubvention”1039 profitieren können. Die EIB ist daher im wesentlichen als Instrument der EG-Regionalpolitik zu betrachten, mit dessen Hilfe das Kohäsionsziel verfolgt wird. Daher werden die Darlehen überwiegend für Infrastrukturinvestitionen im Verkehrsbereich, im Energiesektor und in der Telekommunikation vergeben. Darüber hinaus erfolgt die Unterstützung von Umweltschutzmaßnahmen. ${ }^{1040}$

\section{V-2.3.2 Die Fondswirtschaft der EU}

Die Anfänge der Fondswirtschaft der EU gehen auf die 60er und 70er Jahre zurück. In diesem Zeitraum wurden mehrere Fonds zur Durchführung regionalpolitischer Ziele der EU gegründet. Die Grundlage der heutigen Kohäsionspolitik legte jedoch die EEA im Jahr 1987. Es wurde eine umfassende Reform der Regionalpolitik durch die Zusammenfassung der bis dahin unabhängig nebeneinanderstehenden regional- und sozialpolitischen Ziele zu dem gleichgerichteten Zielbündel „wirtschaftlicher und sozialer Zusammenhalt” vollzogen. Im Jahr 1993

\footnotetext{
${ }^{1035}$ In sektoraler Hinsicht sind zudem die Kredite der EGKS und der $E A G$ zu berücksichtigen; vgl. hierzu auch Abschnitt IV-2.1.2.

${ }^{1036}$ Thomas (1994), S. 472.

${ }^{1037}$ Vgl. hierzu Art. 130b EGV.

${ }^{1038} \mathrm{Zu}$ den weiteren Feldern der Darlehensvergabe der EIB vgl. auch Abschnitt IV-2.1.2. Insgesamt werden zu über 95 Prozent Vorhaben innerhalb der Mitgliedstaaten der $E U$ unterstützt.

${ }^{1039}$ Heinemann (1993), S. 100

${ }^{1040}$ Vgl. Hillenbrand (1994), S. 161; Europäische Kommission (1996), S. 92.
} 
erfolgte eine erneute Revision des kohäsionspolitischen Instrumentariums zur Festlegung der Kohäsionspolitik für den Zeitraum von 1994 bis 1999. Nachfolgend werden die qualitativen und quantitativen Merkmale dieser Bestimmungen erläutert.

Ein zentrales Element der Reformschritte ist die Ausrichtung der finanziellen Interventionen auf eine begrenzte Anzahl, klar definierter Ziele. Zum heutigen Zeitpunkt konzentrieren sich die Maßnahmen auf folgende sechs Ziele: ${ }^{1041}$

- Ziel 1: Förderung der Entwicklung und Strukturanpassung von Regionen mit beträchtlichem Entwicklungsrückstand (Förderkriterium: Regionen der NUTS II-Ebene mit einem BIP-Pro-Kopf in KKS unter oder nahe bei $75 \%$ des EU-Durchschnitts); in diesen Regionen lebt ein Anteil von 26,6 Prozent der EU-Gesamtbevölkerung;

- Ziel 2: Förderung von Regionen der NUTS III-Ebene mit stark rückläufiger industrieller Entwicklung (Förderkriterium: Arbeitslosenquote im Schnitt über dem EU-Durchschnitt; rückläufige Beschäftigung in der Industrie); in diesen Regionen lebt ein Anteil von 16,4 Prozent der Gesamtbevölkerung;

- Ziel 3: Bekämpfung der Langzeitarbeitslosigkeit sowie Eingliederung der Jugendlichen und der vom Ausschluß aus dem Arbeitsmarkt bedrohten Personen in das Erwerbsleben (Förderkriterium: Arbeitsplatzsuchende unter 25 Jahren bzw. Arbeitnehmer über 25 Jahre, die länger als 12 Monate ohne Arbeit sind);

- Ziel 4: Unterstützung der Anpassung der Arbeitskräfte an die industriellen Wandlungsprozesse und an Veränderungen der Produktionssysteme durch die Finanzierung von Ausund Weiterbildungsmaßnahmen, von Beschäftigungsbeihilfen sowie der Entwicklung der Ausbildungssysteme;

- Ziel 5: Förderung der Entwicklung des ländlichen Raums;

- Ziel 5a: Beschleunigte Anpassung der Erzeugungs-, Verarbeitungs- und Vermarktungsstrukturen in der Land- und Forstwirtschaft sowie der Fischerei;

- Ziel 5b: Förderung der Entwicklung und Strukturanpassung von Agrarregionen (Förderkriterium: Regionen mit niedriger Bruttowertschöpfung je landwirtschaftlicher Arbeitskraft und niedrigem Pro-Kopf-Einkommen sowie hohen Erwerbstätigenanteil im Agrarsektor); ca. 8,8 Prozent der EU-Bevölkerungen leben in diesen Regionen;

- Ziel 6: Förderung der Entwicklung und Strukturanpassung von sehr dünn besiedelten Gebieten (Förderkriterium: Regionen, die weniger als acht Einwohner pro Quadratkilometer

\footnotetext{
${ }^{1041} \mathrm{Vgl.} \mathrm{Europäische} \mathrm{Kommission} \mathrm{(1996),} \mathrm{S.} 89$ ff.; Cuny (1997), S. 227 f.
} 
aufweisen); dieses Kriterium wird nur in Regionen Finnlands und Schwedens erfüllt; insgesamt leben dort ca. 0,4 Prozent der EU-Gesamtbevölkerung.

Einen ausdrücklich räumlichen Bezug haben nur die Ziele 1, 2, 5 b und 6. Sie stellen den Kern der Regionalpolitik dar, auf den ca. 85 Prozent der Fördermittel konzentriert werden. Dabei wird die Mittelvergabe nur bei Ziel 1 aufgrund der Schlüsselgröße zur Beurteilung des Kohäsionsziels - dem Pro-Kopf-Einkommen - bestimmt. Die Ziele 3, 4 und 5a beziehen sich auf das gesamte Gebiet der EU. Dennoch sind diese Ziele „regionalpolitisch bedeutsam”. ${ }^{1042}$

Mit der Vergabe der Finanzmittel werden drei große Interventionsbereiche abgedeckt. Es werden ca. 30 Prozent der Mittel zur Förderung der öffentlichen Infrastruktur bereitgestellt; weitere 30 Prozent der Mittel dienen der Bildung von Humankapital durch die Unterstützung der mitgliedstaatlichen Bildungssysteme und der mitgliedstaatlichen Arbeitsmarktpolitik. Ca. 40 Prozent der Mittel werden zur direkten unternehmensbezogenen Förderung produktiver Investitionen eingesetzt. Der letzte Bereich ist „mittlerweile der wichtigste Interventionsbereich in den Ziel-1-Regionen", ${ }^{1043}$ dessen Bedeutung in der Zukunft noch weiter ausgebaut werden soll. ${ }^{1044}$

Der größte Teil (ca. 90 Prozent) der finanziellen Mittel zur Verfolgung der sechs Ziele wird über vier Strukturfonds bereitgestellt:

- Der Europäischer Fonds für regionale Entwicklung (EFRE) soll selbsttragendes Wachstum und dauerhafte Beschäftigung in den Regionen ermöglichen. Er fördert produktive gewerbliche Investitionen mit Arbeitsplatzeffekten, Infrastrukturinvestitionen sowie Maßnahmen zur Erschließung des endogenen Entwicklungspotentials in den Regionen.

- Der Europäische Sozialfonds (ESF) konzentriert seine Unterstützungsleistungen auf die Beschäftigungspolitik zur Finanzierung von beruflichen Qualifizierungsaktionen, Existenzgründungen und Maßnahmen zur allgemeinen Verbesserung der Ausbildungssysteme.

- Der Europäische Ausrichtungs- und Garantiefonds (EAGFL) - Abteilung Ausrichtung erleichtert die strukturelle Anpassung von Agrarregionen. Hierzu sind auch Flächenstillegungen und Umweltschutzmaßnahmen zu rechnen.

- Das Finanzinstrument für die Ausrichtung der Fischerei (FIAF) fördert die strukturelle Anpassung in Fischereiregionen.

\footnotetext{
${ }^{1042}$ Klemmer (1998), S. 496; vgl. auch Friedmann (1996), S. $56 \mathrm{f}$.

${ }^{1043}$ Europäische Kommission (1996), S. 93.

${ }^{1044} \mathrm{Vgl}$. Europäische Kommission (1996), S. 92 f.; Häring (1995), S. 274; Wasmayr (1997), S. 154.
} 
Die kohäsionspolitischen Maßnahmen der Strukturfonds werden in einem dreistufigen Verfahren umgesetzt: ${ }^{1045}$

- Im ersten Schritt entwickeln die verantwortlichen GKS der Mitgliedstaaten drei- bis fünfjährige Entwicklungspläne, die den regionalpolitischen Handlungsbedarf in den Regionen des betreffenden Mitgliedstaates bestimmen.

- Im zweiten Schritt erstellt die EK auf Grundlage dieser Entwicklungspläne in einem Verhandlungsprozeß mit den betroffenen GKS sogenannte Gemeinschaftliche Förderkonzepte, die die Förderschwerpunkte, Interventionsmethoden, Förderhöchstsätze und Finanzpläne für die Fondsmittel festlegen.

- Im dritten Schritt werden auf Antrag hin Fördermittel für konkrete Maßnahmen vergeben. Diese Mittel werden stets als FZ mit Eigenbeteiligung der Mitgliedstaaten ausgezahlt.

Die zur Verfügung stehenden Transfermittel werden bereits vor Beginn des eigentlichen Programmplanungsverfahrens für den gesamten Programmplanungszeitraum auf die einzelnen Mitgliedstaaten und die verschiedenen Zielbereiche aufgeteilt. ${ }^{1046}$ Dies soll den Mitgliedstaaten eine gesicherte Planungsgrundlage für die Ausarbeitung der Entwicklungspläne schaffen. Allerdings bewirkt diese indikative Mittelaufteilung auch, „daß die Qualität der Entwicklungspläne für die Mittelverteilung auf die Mitgliedstaaten keine größere Rolle mehr spielt." 1047

Darüber hinaus besteht ein eigenständiger regionalpolitischer Handlungsspielraum für die EUEbene in Form der sogenannten Gemeinschaftsinitiativen. Diese Initiativen erlauben der EK den Einsatz von Fördermitteln außerhalb der Gemeinschaftlichen Förderkonzepte. Die EK kann so ein eigenes regionalpolitisches Zielsystem verfolgen, da die Gemeinschaftsinitiativen ,ausschließlich kommissionsintern erarbeitet"1048 werden. Hierzu werden immerhin fast 10 Prozent der Strukturfondsmittel reserviert. „Mittlerweile existiert eine schier unübersehbare Anzahl von Gemeinschaftsinitiativen mit den Schwerpunkten Strukturwandel in altindustriellen Regionen, Aufbau regionaler Kooperationsnetze und Technologietransfer."1049

\footnotetext{
${ }^{1045}$ Vgl. bspw. Waniek (1994), S. 44.

${ }^{1046}$ Vgl. zu den Einzelheiten der Mittelaufteilung im laufenden Planungszeitraum von 1994-1999 Europäische Kommission (1996), S. 145.

${ }^{1047}$ Wasmayr (1997), S. 93.

${ }^{1048}$ Wasmayr (1997), S. 74.

${ }^{1049}$ Waniek (1994), S. 44; vgl. auch Franzmeyer (1996a), S. 124 und kritisch Stahl (1997), S. 205.
} 
Mit diesen Ausführungen wurde die institutionelle Ausgestaltung der Kohäsionspolitik beschrieben. Darüber hinaus ist auf die Prinzipien der Zusammenarbeit zwischen den Mitgliedstaaten und der EU-Ebene einzugehen, „die sozusagen den philosophischen Hintergrund der Gemeinschaftsinterventionen ausleuchten:" ${ }^{1050}$ Partnerschaft, Subsidiarität, Kohärenz und Additionalität bilden seit der Reform von 1987 die konzeptionelle Grundlage der Kohäsionspolitik. Die Befolgung dieser Prinzipien wird als elementare Voraussetzung angesehen, um die Effektivität und die Akzeptanz (in den betroffenen Mitgliedstaaten und Regionen) der durchgeführten Maßnahmen gewährleisten zu können: ${ }^{1051}$

- Das Prinzip der Partnerschaft zielt auf eine enge Zusammenarbeit von EU-Ebene, Mitgliedstaaten und Regionen ab, durch die eine ,sinnvolle Konzertierung der Motivation, Initiative, Kenntnisse, Fertigkeiten"1052 aller beteiligten Akteure ermöglicht werden soll. Das Prinzip erstreckt sich auf den gesamten Ablauf einer Fördermaßnahme von der ersten Planung bis hin zur nachträglichen Kontrolle der Mittelverwendung. ${ }^{1053}$

- Das Subsidiaritätsprinzip steht in enger Verbindung zum Prinzip der Partnerschaft. Es soll in allen Fällen verhindert werden, daß die EK die kohäsionspolitischen Maßnahmen ohne Beteiligung der betroffen Mitgliedstaaten und Regionen ergreift. Die EU-Ebene darf sich erst dann in die Aktivitäten der Mitgliedstaaten und Regionen einschalten, wenn diese in ihrer Leistungsfähigkeit überfordert sind, sei es finanziell oder bei der Planung, Durchführung und Kontrolle der Maßnahmen.

- Das Prinzip der Kohärenz erfordert eine Kohäsionspolitik, die in ihrer Gesamtheit konsistent und widerspruchsfrei ausgestaltet ist. Diese Forderung wird erfüllt, wenn sich bestehende Einzelmaßnahmen sinnvoll ergänzen und nicht gegenseitig konterkarieren. Dies impliziert die bewußte Abstimmung zwischen den verschiedenen Interventionen der Strukturfonds sowie den übrigen Politikbereichen der EU; darüber hinaus aber auch die „Verzahnung" 1054 der EU-Kohäsionspolitik mit den wirtschaftspolitischen Maßnahmen der Mitgliedstaaten.

- Die Einfuhhrung des Prinzips der Additionalität verfolgt das Ziel, einen größtmöglichen Gesamteffekt der Interventionen zu gewährleisten. Daher sollen die Finanzmittel der EUStrukturfonds nationale Eigenanstrengungen nicht ersetzen, sondern zusätzliche Ausgaben in den Mitgliedstaaten auslösen. Um die Durchsetzung des Additionalitäts-Prinzips zu un-

\footnotetext{
${ }^{1050}$ Franzmeyer (1993), S. 89.

${ }^{1051} \mathrm{Vgl}$. hierzu Europäische Kommission (1989); Franzmeyer (1993), S. 89 f.

${ }^{1052}$ Franzmeyer (1993), S. 89.

${ }^{1053} \mathrm{Vgl}$. auch Hilligweg (1994), S. $19 \mathrm{ff}$.

${ }^{1054}$ Wasmayr (1997), S. 77.
} 
terstützen werden die EU-Mittel deshalb ausschließlich als Kofinanzierungsmittel mitgliedstaatlicher Förderprogramme gewährt.

Diese Prinzipien stellen noch heute die wesentlichen Strukturparameter der Kohäsionspolitik dar, auch wenn die „(kleine) Reform”1055 im Jahr 1993 einige wichtige Modifikationen der kohäsionspolitischen Rahmenbedingungen brachte. Diese wurden vorgenommen, um die Effektivität der Fonds auch nach dem Abschluß der Maastrichter Verträge zur Einführung des EURO aufrechterhalten zu können:

- Es wurde mit der Einrichtung eines weiteren Fonds ein zusätzliches strukturpolitisches Instrument geschaffen. ${ }^{1056}$ Der Kohäsionsfonds stellt Finanzmittel zur Förderung grenzüberschreitender Verkehrsinfrastruktur- und Umweltschutzmaßnahmen zur Verfügung. Als förderungswürdig gelten jene Mitgliedstaaten, deren Pro-Kopf-BSP (in KKS) weniger als 90 Prozent des EU-Durchschnitts beträgt. Im Rahmen des Kohäsionsfonds wird hiermit ein Wandel vollzogen. Die Auswahl der Fördergebiete bezieht sich nicht wie in den Strukturfonds auf die regionale Ebene, sondern auf die Mitgliedstaaten. Innerhalb des ersten Planungszeitraums von 1994 bis 1999 erhalten Griechenland, Spanien, Portugal und Irland Transfers. Die geförderten Mitgliedstaaten müssen ein Konvergenzprogramm zur Vermeidung übermäßiger Defizite vorweisen, das langfristig die Teilnahmevoraussetzungen an der WWU sichert. Hierdurch wird die Zuweisung von strukturpolitischen Fördermitteln ,erstmalig mit einer makroökonomischen Konditionalität verknüpft." ${ }^{1057}$ Diese Empfangsauflage verdeutlicht zugleich die eigentliche Begründung für die Einrichtung des Kohäsionsfonds. Es soll verhindert werden, daß die benachteiligten Mitgliedstaaten „unabdingbare Infrastrukturverbesserungen" 1058 unterlassen, nur um die Konvergenzkriterien des Maastrichter Vertragswerks zu erfüllen. Um die finanzpolitischen Spielräume nicht erneut zu beschneiden, verzichtet die EU beim Kohäsionsfonds deshalb auch auf das Prinzip der Additionalität. Allerdings ist dieser Verzicht mit der Zusage der betroffenen Mitgliedstaaten verbunden, ihren Investitionsaufwand in den geförderten Bereichen zumindest nicht zu verringern. $^{1059}$

- Es erfolgte eine erhebliche Aufstockung der Strukturfondsmittel. Während die Interventionen der EU in den Jahren vor der Reform (1989-1993) durchschnittlich 0,29 Prozent des

\footnotetext{
${ }^{1055}$ Frick/Van der Beek/Hünger (1996), S. 357.

${ }^{1056} \mathrm{Vgl}$. zum Kohäsionsfonds ausführlich Diekmann/Breier (1993); Binder/Walthes (1995).

${ }^{1057}$ Wasmayr (1997), S. 84.

${ }^{1058}$ Frick/Van der Beek/Hünger (1996), S. 358.

${ }^{1059} \mathrm{Vgl}$. Diekmann/Breier (1993), S. 264 f.
} 
BIP aller Mitgliedstaaten betrugen, erhöht sich dieser Anteil für den Zeitraum von 19941999 auf über 0,45 Prozent. ${ }^{1060}$ Die absoluten Ausgaben für die Strukturmaßnahmen steigen von 22,2 Mrd. ECU im Jahr 1993 auf weit über $36 \mathrm{Mrd}$. ECU im Jahr 1999. Der Ausgabenanteil an den Gesamtausgaben der EU erhöht sich bis 1999 auf annähernd 33 Prozent. Insgesamt stehen für den Zeitraum 1994-1999 ca. 180 Mrd. ECU zur Verfügung. ${ }^{1061}$

- Die Fördermittel werden zunehmend auf jene Regionen bzw. Mitgliedstaaten konzentriert, die über ein unterdurchschnittliches Pro-Kopf-Einkommen verfügen. So werden im Förderzeitraum von 1994-1999 ca. 68 Prozent der Mittel der vier Strukturfonds zur Verfolgung des Ziels 1 eingesetzt. Dabei steigt der Anteil von Ziel 1-Mitteln kontinuierlich von ca. 65 Prozent im Jahr 1994 auf über 70 Prozent im Jahr 1999 an. Unter Berücksichtigung des Kohäsionsfonds erhöht sich diese ausgeprägte Konzentration im gesamten Förderzeitraum auf 71 Prozent. In absoluten Zahlen ausgedrückt kommen diesen Teileinheiten von den gesamten Strukturmaßnahmen (180 Mrd. ECU) des Zeitraums 1994-1999 mehr als 127 Mrd. ECU (Strukturfonds-Ziel 1: 112,1 Mrd. ECU; Kohäsionsfonds 15,1 Mrd. ECU) zugute. $^{1062}$

Die Mittelkonzentration zeigt sich nicht nur bei den Förderzielen, sondern auch bei Intensität der Förderung. Die Finanzierungsbeteiligung der EU kann in Ziel 1-Gebieten bis zu 75 Prozent der Gesamtkosten betragen, in den übrigen Regionen nur bis zu 50 Prozent. Im Rahmen des Kohäsionsfonds kann sich die Gemeinschaftsbeteiligung sogar auf 80 Prozent belaufen; in Gebieten mit äußerst peripherer Lage sogar auf 85 Prozent. Dabei werden die konkreten Interventionssätze ,je nach Grad der regionalen Probleme, nach der Finanzkraft des betreffenden Mitgliedstaates sowie nach gemeinschaftlichen, nationalen und regionalen Interesse an der jeweiligen Maßnahme differenziert." 1063

\section{V-2.3.3 Problemfelder der bestehenden Regionalpolitik}

Die aktive Regionalpolitik der EU sieht sich in der wissenschaftlichen Literatur einer beständigen Kritik ausgesetzt. ${ }^{1064}$ Die Stellungnahmen der Autoren setzen an einer Vielzahl von Einzelaspekten an, die entweder die kohäsionspolitische Effektivität (mangelhafter Zielerrei-

\footnotetext{
${ }^{1060}$ Vgl. hierzu Europäische Kommission (1996), S. 9 u. 144.

${ }^{1061}$ Vgl. hierzu Abschnitt IV-2.1.3.2.

${ }^{1062}$ Die Zahlenangaben sind eigene Berechnungen auf Basis von Europäische Kommission (1996), S. 145; Europäische Kommission (1997a), S. 66. Die Angaben beziehen sich auf die jeweiligen Preise. Für 1999 Preise des Jahres 1998. Vgl. auch Wasmayr (1997), S. 86 ff.

${ }^{1063}$ Waniek (1994), S. 45; vgl. auch Wasmayr (1997), S. 66.

${ }^{1064} \mathrm{Da}$ die Fondswirtschaft den Kern der finanziellen Interventionen darstellt, wird die nachfolgende Analyse auf diesen Bereich beschränkt. Der Ressourcentransfer an die Mitgliedstaaten über die Darlehenstätigkeit der $E U$ bleibt ausgeklammert; vgl. aber die kritische Einschätzung der Darlehensvergabe bei Heinemann (1993).
} 
chungsgrad) oder die prozeßpolitische Effizienz (überhöhte Ressourcenkosten) der Maßnahmen bemängeln. Darüber hinaus werden grundsätzliche ordnungspolitische Einwände (Entstehung von Präferenzkosten) erhoben. Es zeigt sich jedoch, daß auch die ordnungspolitisch motivierte Kritik in enger Verbindung $\mathrm{zu}$ den weiteren Beanstandungen steht, so daß eine deutliche Abgrenzung zumeist nicht möglich ist. Dennoch können die folgenden Kritikpunkte der einzelnen Autoren „gesammelt” werden, wobei (ausschließlich) das Kohäsionsziel zur Beurteilung der Regionalpolitik herangezogen wird:

- Das Förderkonzept in seiner Gesamtheit ist zu kompliziert und intransparent. ${ }^{1065}$ Dieser zentrale Kritikpunkt ist das Ergebnis eines längerfristigen Entwicklungsprozesses der Fondswirtschaft, der durch das Bemühen der EK geprägt ist, für jedes regionale Entwicklungsproblem ein eigenständiges Förderungsinstrument einzurichten. Die EK besitzt die Vorstellung, daß durch diese Vorgehensweise eine flexible und problemadäquate Intervention realisierbar ist. „Mit steigender Zahl der Akteure und der Förderangebote steigt jedoch der Koordinierungsaufwand, und die Abstimmung der Beteiligten wird zum Alibi." ${ }^{1066}$ Die Neigung der EK ,zu einem extremen Ausdifferenzieren vorhandener Förderinstrumente", ${ }^{1067}$ um jedem Einzelfall gerecht zu werden, verhindert so global betrachtet die erfolgreiche Abstimmung der kohäsionspolitischen Maßnahmen. Im Zeitablauf ist ein ineffizientes System zahlreicher Ziele und Fonds entstanden, „die kreuz und quer miteinander verbunden sind." 1068 Aufgrund dieser allgemeinen Analyse ergeben sich eine Reihe konkreter Beanstandungen:

(1) Das komplizierte Förderkonzept verhindert die Kohärenz der Fondsinterventionen. Die Vielzahl der heterogenen Haupt-, Neben- und Unterziele der Fonds löst eine Zielüberfrachtung der Regionalpolitik aus. Die Fülle der Gemeinschaftsinitiativen verstärkt diese Tendenz. Die Entstehung von Widersprüchlichkeiten beim Einsatz der finanziellen Mittel ist daher fast unvermeidlich. So wird bspw. in den Ziel-5b-Regionen zugleich die Schaffung nicht-landwirtschaftlicher Arbeitsplätze und die Niederlassung von Junglandwirten gefördert. $^{1069}$

Die Zielüberfrachtung wird dadurch erhöht, „daß die europäische Regionalpolitik als Verhandlungsmasse zur Realisierung anderer Ziele eingesetzt wird."1070 Die Fondsmittel fun-

\footnotetext{
${ }^{1065}$ Vgl. hierzu Waniek (1994), S. 46; Gornig u.a. (1996), S. 96 u. 117; Reichenbach/Beck (1997), S. 142; Wasmayr (1997), S. $180 \mathrm{ff}$.

${ }^{1066}$ Gornig u.a. (1996), S. 96.

${ }^{1067}$ Wasmayr (1997), S. 180.

${ }^{1068}$ Schäfers (1993), S. 189 f.

${ }^{1069} \mathrm{Vgl}$. Waniek (1994), S. 46; Friedmann (1996), S. 61.

${ }^{1070}$ Binder/Walthes (1995), S. 306.
} 
gieren als Kompensationszahlungen, um die Entscheidungsfindung der EU bei Integrationschritten zu ermöglichen. ${ }^{1071}$

Im Zentrum der Mittelvergabe stehen daher nur zu einem Teil die strukturellen Probleme der Regionen mit Entwicklungsrückstand. Um die Konterkarierung der kohäsionspolitischen Maßnahmen durch die Vielzahl weiterer regionalpolitischer und allgemeinpolitischer Ziele auszuschließen, ist die Förderung auf den Aufholprozeß der benachteiligten Regionen (Ziel-1 Regionen) zu beschränken. ${ }^{1072}$

(2) Es bestehen weitere Gemeinschaftspolitiken, die im Widerspruch zu den kohäsionspolitischen Ausgaben der Fonds stehen. Insbesondere die Stützung der Agrarpreise (EAGFLAbteilung Garantie), die fast 50 Prozent der Gesamtausgaben der EU umfaßt, sowie die Ausgaben für Forschung und Entwicklung und die sektoralen Beihilfen der EGKS kommen überwiegend wirtschaftsstarken Mitgliedstaaten zugute. ${ }^{1073}$ Die Verteilungswirkungen dieser Politiken stehen im Gegensatz zur Kohäsionszielsetzung.

(3) Die Verzahnung der Regionalpolitik der EU-Ebene mit jener der Mitgliedstaaten ist inkonsistent. „Die Zielsetzungen der nationalen und gemeinschaftlichen Strukturpolitiken [sind] teilweise inkompatibel." ${ }^{1074}$ Dieser Kritikpunkt gewinnt seit der letzten Reform der Strukturfonds zunehmende Bedeutung, da die EK verstärkt dazu übergegangen ist, eigenständige Fördergebiete und Fördermaßnahmen zu formulieren. Die Fördersysteme der Mitgliedstaaten und der EU-Ebene treten deshalb „verstärkt zueinander in Konkurrenz”"1075 mit dem Ergebnis einer „insgesamt geringeren Lenkungseffizienz der Regionalpolitik." 1076

(4) Die Intransparenz des gesamten Förderkonzepts behindert die Akzeptanz der Regelungen in der Bevölkerung, die weder die Zielsetzungen noch den Ablauf der Fördermaßnahmen nachvollziehen kann. Eine demokratische Kontrolle der Maßnahmen ist praktisch ausgeschlossen, da die Verantwortungsbereiche der Entscheidungsträger der mitgliedstaatlichen und der EU-Ebene nicht voneinander abgrenzbar sind. ${ }^{1077}$ Die Entscheidungsträger der transferleistenden Mitgliedstaaten vermögen daher kaum eine breite Zustimmung für die Zahlungen in der Bevölkerung herzustellen.

\footnotetext{
${ }^{1071}$ Vgl. Wissenschaftliche Beirat (1994), S. 56 f.; Binder/Walthes (1995), S. 306 f.; auch schon Noé (1983), S. 17 f.; vgl. zu diesen Zielüberschneidungen näher Abschnitt V-5.2.

${ }^{1072}$ Vgl. bspw. Europäische Kommission (1993a), S. 68; Waniek (1994), S. 43; Franzmeyer (1996a), S. 135 f.; Harder (1997), S. 218 f.

${ }^{1073}$ Vgl. Franzmeyer (1993), S. 94 ff.; Gornig u.a. (1996), S. 109 ff.; Wasmayr (1997), S. 135 f. Diese FZ besitzen primär eine wachstums- bzw. verteilungspolitische Zielsetzung.

${ }^{1074}$ Friedmann (1996), S. 61; so auch Waniek (1994), S. 46 f.; Franzmeyer (1996a), S. 128 f.

${ }^{1075}$ Franzmeyer (1996a), S. 129.

${ }^{1076}$ Waniek (1994), S. 47.

${ }^{1077}$ Vgl. Gornig u.a. (1996), S. 96; Wasmayr (1997), S. $186 \mathrm{ff}$.
} 
(5) Zugleich löst das aufwendige Verfahren mit der „mittlerweile außerordentlich hohen Regelungsdichte"1078 einen extremen Verwaltungsaufwand sowohl auf der Seite der EK als auch der transferempfangenden Mitgliedstaaten aus. Hier muß „das Verhältnis zwischen Förderbetrag und Verwaltungsaufwand optimiert werden." ${ }^{1079}$ Denn die Einhaltung der komplizierten Verfahrensprozeduren stellt insb. bei finanziell unbedeutenden Programmen einen nicht zu rechtfertigenden Ressourcenaufwand dar. ${ }^{1080}$

(6) Die Dauerhaftigkeit der Mittelvergabe kann zu unerwünschten Gewöhnungseffekten führen (,rent-seeking-Mentalität”). Die kurzfristige Herstellung gleichwertigerer Lebensverhältnisse geht dann ,zulasten der Kraft einer Region .., auf längere Frist selber für den Anschluß zu sorgen."1081

(7) Die Additionalität der Mittelvergabe kann nicht garantiert werden, weil eine ex-post Kontrolle praktisch ausgeschlossen ist. „Da nur unvollständige Informationen darüber vorliegen, welche Maßnahmen der betreffende Mitgliedstaat in Abwesenheit von Gemeinschaftshilfen getroffen hätte", ${ }^{1082}$ sind Mitnahmeeffekte der Transferempfänger nicht auszuschließen. ${ }^{1083}$ Diese besitzen dann besonders negative Auswirkungen, wenn es zur Umlenkung von Investitionsmitteln in konsumtive Verwendungen kommt. ${ }^{1084}$ Noé, argumentiert jedoch, daß die EK bei der Durchsetzung des Additionalitätsprinzips nur unzureichende Maßnahmen ergreift. Die Mitgliedstaaten, so Noé, könnten durch die EK sehr wohl dazu verpflichtet werden, die eigenen regionalpolitischen Ausgaben für ein Basisjahr zu quantifizieren. Anhand dieser Angaben könnte die Zusätzlichkeit der Mittel in den Folgejahren beurteilt werden. ${ }^{1085}$

(8) Es bestehen Probleme der Absorption der Transfers in den Empfängerregionen. Diese treten insbesondere in den „wenig erschlossenen Regionen"1086 auf, auf welche die kohäsionspolitischen Maßnahmen sich gerade konzentrieren sollten.

Zum ersten sind für die Absorptionsproblematik Defizite in der öffentlichen Verwaltung verantwortlich. Der Aufbau funktionierender Institutionen in den Empfängerregionen bil-

\footnotetext{
${ }^{1078}$ Wasmayr (1997), S. 186.

${ }^{1079}$ Stahl (1997), S. 205.

${ }^{1080} \mathrm{Vgl}$. Waniek (1994), S. 48; Funkschmidt (1997), S. 220 f. Diese Aussage behält auch nach der letzten Reform der Strukturfonds Gültigkeit, obwohl dort erste Schritte zu Verfahrensvereinfachungen durchgeführt wurden; vgl. hierzu Cuny (1997), S. 233.

${ }^{1081}$ Franzmeyer (1996a), S. 131. Vgl. auch Gornig u.a. (1996), S.98.

${ }^{1082}$ Europäische Kommission (1993a), S. 72.

${ }^{1083} \mathrm{Vgl}$. Diekmann/Breier (1993), S. 264 f.; Europäische Kommission (1993a), S. 72 f.; Beckmann (1995), S. $165 \mathrm{ff}$. Vgl. zu den bestehenden Kontrollaktivitäten Europäische Kommission (1997d), S. $115 \mathrm{ff}$.

${ }^{1084}$ Vgl. Franzmeyer (1996a), S. 131.

${ }^{1085}$ Vgl. Noé (1983), S. 17. Auch Franzmeyer (1996a), S. 135 und Reichenbach/Beck (1997), S. 140 betonen, daß sich die Effizienz der Mittelvergabe durch strengere Finanzkontrollen steigern ließe.

${ }^{1086}$ Franzmeyer (1993), S. 94.
} 
det deshalb „ein (bisher vernachlässigtes) Aufgabengebiet einer ursachengerechten EGRegionalpolitik". ${ }^{1087}$

Zum zweiten ist dafür die Verteilung der Transfers auf die Interventionsbereiche öffentliche Infrastruktur und Humankapital einerseits sowie unternehmensbezogene Beihilfen andererseits verantwortlich. Solange in den Empfängerregionen eine mangelnde Ressourcenausstattung mit den (öffentlichen) Potentialfaktoren zu konstatieren ist, ${ }^{1088}$ bestehen nur sehr begrenzte Möglichkeiten, unternehmensbezogene Transfermittel in effiziente Verwendungsformen für direkt produktive Investitionen lenken zu können. Werden die Finanzmittel dennoch absorbiert, ${ }^{1089}$ entsteht die Gefahr der Förderung unproduktiver „Investitionsruinen", ${ }^{1090}$ die keinen längerfristigen Beitrag zum Aufholprozeß der benachteiligten Regionen leisten. Das erklärte Ziel der Reformen der Strukturfonds von 1988, die Mittel verstärkt für produktive Investitionen und weniger für den Infrastrukturausbau einzusetzen, ist aus diesem Blickwinkel ,eine bedenkliche Entwicklung”. 1091

Zum dritten entsteht ein Absorptionsproblem, wenn die mangelnde finanzielle Leistungsfähigkeit es den Empfängerregionen unmöglich macht, die Kofinanzierungsmittel aufzubringen. ${ }^{1092}$ Dies verweist auf die Problematik der Eigenbeteiligung und spricht für hohe Mitfinanzierungssätze der EU. Sie sind jedoch „ein zweischneidiges Schwert.”" ${ }^{093}$ Denn Beteiligungssätze der EU bis zu 85 Prozent der Gesamtkosten einer Maßnahme gefährden die Akzeptanz der Transfervergabe in den Geberstaaten und begünstigen in den Empfängerstaaten eine ineffiziente Programmauswahl, um möglichst umfangreiche Finanzmittel zu erhalten. ${ }^{1094}$

- Die vorgetragenen acht Kritikpunkte führen in ihrer Gesamtbetrachtung zu der grundsätzlichen ordnungspolitischen Infragestellung der bestehenden Kompetenzverteilung innerhalb der Regionalpolitik zwischen der EU-Ebene und den dezentralen gebietskörperschaftlichen Ebenen. Es wird von der Mehrzahl der Autoren eine Überzentralisierung der Kompetenzen

\footnotetext{
${ }^{1087}$ Waniek (1994), S. 48; Vgl. auch Friedmann (1996), S. 61.

${ }^{1088}$ Vgl. hierzu Abschnitt III-3.1.1.2; insb. S. 105.

${ }^{1089}$ Franzmeyer (1993), S. 94 weist daraufhin, daß „die Kompliziertheit und die Trägheit der Verfahren” dazu beitragen, daß die Gelder häufig trotz nicht ausreichender Absorptionfähigkeit von den Regionen abgerufen werden können.

${ }^{1090}$ Wasmayr (1997), S. 143.

${ }^{1091}$ Häring (1995), S. 274; vgl. auch Waniek (1994), S. 47 f. Wasmayr (1997), S. 142 f. weist daraufhin, daß es zu einem „crowding-out” privater Investitionen kommen kann, wenn die regionale Investitionsgüterindustrie bereits in der Ausgangssituation - ohne Transfers der EU-Ebene - weitgehend ausgelastet ist.

${ }^{1092} \mathrm{Vgl}$. Jochimsen (1998), S. 217, m.w.N.

${ }^{1093}$ Diekmann/Breier (1993), S. 264.

${ }^{1094}$ Vgl. Diekmann/Breier (1993), S. 264; Gornig u.a. (1996), S. 98 f.
} 
konstatiert. ${ }^{1095}$ Dabei wird argumentiert, daß der Versuch der EU-Ebene, eine Einschätzung der unterschiedlichen regionalen Besonderheiten zur gemeinschaftsweiten Selektion förderungswürdiger Regionen vorzunehmen, „,bereits an unlösbaren Problemen der Informationsbeschaffung und -verarbeitung, bei der Regionalanalyse und -diagnose" ${ }^{1096}$ scheitert. Es ist demnach auf der EU-Ebene „schlechthin nicht zu prognostizieren, welches ('endogene') Entwicklungspotential die jeweiligen Regionen der EU konkret aufweisen." 1097

Aus diesem Blickwinkel sind v.a. die eigenständigen Interventionen der EU im Rahmen der Gemeinschaftsinitiativen nicht zu rechtfertigen. Zudem ist die zunehmende Konzentration der Eingriffe auf die Finanzierung unternehmensbezogener Beihilfen für produktive Investitionen als eine ordnungspolitische Fehlentwicklung zu bezeichnen. Die EU-Ebene steht bei der selektiven Unternehmensförderung mehr noch als die Mitgliedstaaten vor einem unlösbaren Prognoseproblem im Hinblick auf die als wachstumsträchtig anzusehenden Sektoren. Es besteht daher die Gefahr „daß die Kohäsionspolitik vermehrt zu einer industriepolitisch motivierten (Ko-)Finanzierung der jeweiligen nationalen sektoralen Strukturpolitik degeneriert", ${ }^{1098}$ statt die allgemeinen Entwicklungschancen der benachteiligten Regionen in einer langfristigen Perspektive zu verbessern. ${ }^{1099}$

Bei der Kompetenzverteilung in der Regionalpolitik sollte deshalb das Subsidiaritätsprinzip ins Zentrum gerückt werden. Demnach besitzen grundsätzlich die Mitgliedstaaten die Verantwortung zu einer eigenständigen Regionalpolitik. Die EU-Ebene besitzt aber die Verpflichtung, denjenigen Mitgliedstaaten Hilfe zu gewähren, die in ihrer Leistungsfähigkeit überfordert sind. Die EU-Ebene sollte dann die Regionalpolitik des betreffenden Mitgliedstaates durch die Vergabe gezielter FZ solange unterstützen, bis der Mitgliedstaat in die Lage versetzt worden ist, die Aufgabe (wieder) eigenverantwortlich zu erfüllen. Die EU-Ebene leistet eine temporäre Hilfe zur Selbsthilfe. ${ }^{1100}$ Es stellt sich nun die Frage, wie diese FZ aus ökonomischer Sicht ausgestaltet sein sollten, um eine problemadäquate Alternative zu einer autonomen Regionalpolitik der EU-Ebene darzustellen. ${ }^{1101}$

${ }^{1095}$ Vgl. bspw. Spiekermann (1988), S. 30 ff.; Klodt u.a. (1992), S. 85 ff.; Schäfers (1993), S. 190 ff.; Hilligweg (1994), S. 36 ff.; Wissenschaftlicher Beirat (1994), S. 56; Beckmann (1995), S. 211 ff.; Walthes (1996), S. 78 f.; Wasmayr (1997), S. 189. Eine gegensätzliche Meinung vertritt hingegen bspw. Cuny (1997), der die Strukturfondsverordnungen bezüglich der Programmdurchführung unter ordnungspolitischen Gesichtspunkten ,als vorbildlich" (Cuny (1997), S. 229) betrachtet.

${ }^{1096}$ Spiekermann (1988), S. 31.

${ }^{1097}$ Wasmayr (1997), S. 149. Vgl. auch Schäfers (1993), S. 190 f.; Hilligweg (1994), S. 40 f.

${ }^{1098}$ Wasmayr (1997), S. 154.

${ }^{1099}$ Vgl. hierzu Schäfers (1993), S. 190; Biehl (1995b), S. 65; Häring (1995), S. 274 f.; Wasmayr (1997), S. $149 \mathrm{ff}$.

${ }^{1100} \mathrm{Vgl}$. hierzu prägnant Waniek (1994), S. $48 \mathrm{f}$.

${ }^{1101}$ Die Prinzipien der kohäsionspolitischen Interventionen der EU-Ebene - Partnerschaft, Subsidiarităt, Kohärenz und Additionalität - werden durch den Alternativvorschlag nicht in Frage gestellt. Das Ziel der Reformbemühungen ist es vielmehr, Fehlentwicklungen der bisherigen Kohäsionspolitik zu korrigieren, die verhindern, 


\section{V-2.4 Die Erfüllung der Kohäsionsfunktion durch FZ}

\section{V-2.4.1 Zur Ausgestaltung der FZ aus rein ökonomischer Sicht}

Aus der mikroökonomischen Indifferenzkurvenanalyse leiten sich eindeutige Ausgestaltungsempfehlungen für FZ mit der Zielsetzung einer allokativ orientierten Ausgleichspolitik ab. ${ }^{1102}$ Die Formulierung konkreter FZ-Programme wird jedoch sehr stark erschwert, wenn die Ressourcenkosten zur Durchführung und Kontrolle der FZ-Vergabe sowie Effizienzverluste und Präferenzkosten, die auftreten, wenn die Transfers nicht den Besonderheiten der Transferempfängerregionen entsprechen, in die Erörterungen eingeschlossen werden. Zumeist sind dann keine eindeutigen Aussagen mehr möglich. Vielmehr hat stets eine Abwägung der Bedeutung der unterschiedlichen Kostenkategorien zu erfolgen. Die konkrete Ausgestaltungsentscheidung muß eine Reihe von Zielkonflikte im Hinblick auf die Einzelkriterien lösen. Die folgenden Aspekte sind zu beachten: ${ }^{1103}$

\section{- Die Zweckbindung der FZ-Vergabe:}

Um die gewünschten Strukturveränderungen in den benachteiligten Regionen mit einem möglichst geringen FZ-Volumen realisieren zu können, sind die FZ zweckgebunden zu vergeben. Denn bei Pauschalzuweisungen besteht ,die Gefahr, daß nur die mangelnde Finanzkraft der schwachen Mitgliedstaaten, also eine Symptom, beseitigt würde, nicht aber die eigentliche Ursache, nämlich die Strukturschwäche." 1104

Die Verwendung der Finanzmittel muß auf diejenigen Interventionsbereiche beschränkt werden, die die strukturellen Voraussetzungen für eigenständige Einkommenserzielungsmöglichkeiten in den benachteiligten Regionen herstellen. Den Zweck der FZ stellen daher Investitionen in die verschiedenen Bereiche der öffentlichen Infrastruktur dar und nicht direkte Beihilfen für produktive Investitionen einzelner Unternehmen oder Sektoren.

daß die angestrebten Prinzipien tatsăchlich zur Umsetzung gelangen. Hierzu wird das Subsidiaritätsprinzip in den Mittelpunkt gestellt, dessen konsequente Beachtung einen entscheidenden Beitrag zur Erfüllung der weiteren Prinzipien leistet.

${ }^{1102} \mathrm{Vgl}$. hierzu das Effizienzkonzept der Indifferenzkurvenanalyse (Abschnitt III-2.2) sowie die Erörterung zu den Funktionen der FZ in Abschnitt III-3.1.1.2.

${ }^{1103}$ Frick/Van der Beek/Hünger (1996) greifen die kontroverse Diskussion um die „effiziente” Ausgestaltung der kohäsionspolitischen FZ auf sehr interessante Art auf. Sie verweisen auf die Existenz unterschiedlicher Föderalismus- und Integrationsideale, die den Analysen der verschiedenen Autoren zugrunde liegen. Am einen Ende des Spektrums liegt das Ideal des kompetitiven Föderalismus, am anderen Ende dasjenige des kooperativen Föderalismus. Je nachdem durch welches Ideal ein Autor seine Vorschläge zur Ausgestaltung der kohäsionspolitischen Maßnahmen kofundiert, wird er eine spezifische Wertung der entstehenden Nutzen und Kosten vornehmen. Eine „objektive” Bewertung der unterschiedlichen Kostenkategorien (vgl. auch Kapitel II) ist nicht möglich. Hierdurch ergibt sich eine Erklärung für unterschiedliche theoretische Ergebnisse zu den Ausgestaltungsempfehlungen der FZ.

${ }^{1104}$ Peffekoven (1994), S. 109. So auch Spiekermann (1988), S. 42; Cuny (1997), S. 230. 
Zugleich dürfen die Verwendungsauflagen jedoch nicht zu restriktiv formuliert werden. Den dezentralen Entscheidungsträgern müssen weitreichende Handlungsspielräume verbleiben, um ihre überlegenen Informationen zu den Besonderheiten der regionalen Entwicklungspotentiale der eigenen GKS ausnützen zu können. Einige Autoren fordern daher, ausschließlich ungebundene Pauschalzuweisungen an die Mitgliedstaaten zu vergeben. ${ }^{1105}$ Jedoch spricht die Akzeptanz der Transferzahlungen in den transferleistenden Mitgliedstaaten gegen einen völligen Verzicht auf die Zweckbindung. ${ }^{1106}$ Daher erscheint es sinnvoll, daß die EU-Ebene einen allgemeinen Rahmen zur Verwendung der Transfers vorgibt, die konkrete Planung und Umsetzung der Investitionsprogramme jedoch im eigenständigen Verantwortungsbereich der Transferempfänger bleibt. Dies entspricht weitgehend einer Umkehrung der heutigen Verfahrensabläufe, in deren Rahmen „das Gros der Abläufe zentral vorgegeben” wird, da die EK in ,allen Phasen der Fondsinterventionen gestaltend ein[greift]." 1107 Die empfohlene Vorgehensweise ist dem Subsidiaritätsprinzip adäquat, denn als Hilfe zur Selbsthilfe kann die zeitlich begrenzte Vergabe und Zweckbindung von Finanzmitteln zur Nutzbarmachung endogener Entwicklungspotentiale sehr wohl gerechtfertigt werden. ${ }^{108}$

Gegen eine detaillierte Zweckbindung der Mittel spricht zudem, daß auch durch sie Sickerverluste nicht ausgeschlossen werden können. Bei einem geringen Transfervolumen treten bei zweckgebundenen FZ und Pauschalzuweisungen stets identische „leakage”-Effekte auf, da die Substitution eigener Finanzmittel der transferempfangenden Mitgliedstaaten nicht unterbunden werden kann. Erst wenn die Transferempfänger sämtliche eigenen Ressourcen aus der Finanzierung der geförderten Investitionen abgezogen haben, verhindert die Zweckbindung weitere Sickerverluste im Vergleich zur Pauschalzuweisung. ${ }^{1109}$ Eine besondere Rechtferti-

\footnotetext{
${ }^{1105}$ So bspw. Lammers (1993); Hilligweg (1994), S. 246 ff.; Frick/Van der Beek/Hünger (1996), S. 370.

${ }^{1106} \mathrm{Vgl}$. Wissenschaftlicher Beirat (1994), S. $55 \mathrm{f}$.

${ }^{1107}$ Wasmayr (1997), S. 180; vgl. auch S. 212 ff. sowie Gornig u.a. (1996), S. 117 ff. Dies entspricht weiterhin dem Prinzip der Partnerschaft jedoch in einem umgekehrten Verhältnis. Während bislang die EU-Ebene die Verfahrensabläufe bestimmte, übernehmen diese Aufgabe nun die dezentralen GKS. So werden deren Informationsvorsprünge ausgenutzt. Zugleich werden Frustrationskosten innerhalb der Mitgliedstaaten verringert. Der Verwaltungsaufwand kann für die Transfergeber und -nehmer entscheidend abgebaut werden. Die EUEbene kann die ,innerhalb der 'operativen' Kohäsionspolitik freigesetzten Steuerungskapazitäten” (Wasmayr (1997), S. 223) dazu nutzen, eine verstärkte ex-post Kontrolle der ordnungsgemäßen und effizienten Durchfuihrung der Projekte vorzunehmen.

${ }^{1108} \mathrm{Vgl}$. Noé (1983); auch Gornig u.a. (1996), S. 117. Lammers (1993) kritisiert diese Zweckbindung. Er konstatiert Effizienzverluste aufgrund einer Vermischung von allokativen und distributiven Zielsetzungen. Dem liegt jedoch die Auffassung zugrunde, daß die Fondsmittel der reinen Umverteilung dienen würden. An dieser Stelle wird jedoch dementgegengesetzt von einer allokativ orientierten Ausgleichszielsetzung ausgegangen, die sich gerade nicht auf eine reine Umverteilung beschränkt, sondern langfristige Entwicklungsmöglichkeiten eröffnen soll. Der von Lammers geforderte Standortwettbewerb, um herauszufinden, welche Maßnahmen in den Regionen beschleunigte Aufholprozesse erlauben, soll durch die Vergabe der strukturpolitischen Mittel erst ermöglicht werden (vgl. hierzu ausfuhrlich Leonardi (1995)).

${ }^{1109} \mathrm{Vgl}$. hierzu auch Beckmann (1995), S. $135 \mathrm{ff}$. Die Tatsache, daß die Strukturmaßnahmen selbst in den vier Kohäsionsländern in der laufenden Programmperiode nicht mehr als 14 Prozent der gesamten Investitionen der Empfängerstaaten betragen (vgl. Europäische Kommission (1996), S. 98 f.), spricht dafür, daß die zweck-
} 
gung für Verwendungsauflagen ergibt sich aus dieser Sicht in solchen Bereichen der öffentlichen Infrastruktur, die ,innovativen” Charakter besitzen, so daß diese Ausgabenbereiche bislang von den transferempfangenden GKS noch gar nicht abgedeckt wurden. ${ }^{1110}$ In den übrigen Bereichen besteht eine große Wahrscheinlichkeit, daß durch die EU-Ebene erhebliche Ressourcen zur Einrichtung und Kontrolle der Verwendungsauflagen aufgewendet werden, ohne hierdurch eine stimulierende Wirkung auf den Umfang der Infrastrukturinvestitionen auszulösen. Eine effektive ex-post Kontrolle der Mittelverwendung ist außerdem nur möglich, wenn eine detaillierte Spezifizierung der Verwendungsauflagen erfolgt. Eben solche Vorschriften sollen jedoch vermieden werden, um den dezentralen GKS die Durchführung einer eigenständigen Regionalpolitik zu ermöglichen.

\section{- Die Eigenbeteiligung der Transferempfänger:}

Eine Eigenbeteiligung der Transferempfänger ist aus Effizienzüberlegungen angebracht. Zum einen treten bei dieser Ausgestaltungsform die geringsten Sickerverluste auf, da gewährleistet wird, daß die eigenen Mittel der Transferempfänger nicht vollständig substituiert werden können. Zum anderen stellt eine Eigenbeteiligung sicher, daß sich die Transferempfänger nur um solche FZ bemühen werden, die tatsächlich einen gesamtwirtschaftlichen Nutzen spenden. Aus dem Blickwinkel dieser Effizienzüberlegungen sollte die EU-Ebene einen möglichst niedrigen Finanzierungsanteil übernehmen. Allerdings muß die Finanzkraft der Transferempfänger berücksichtigt werden, um zu gewährleisten, daß die Kofinanzierungsmittel von den Transferempfängern tatsächlich erbracht werden können. Daher ist eine Staffelung der Eigenbeteiligungssätze gemäß der Finanzkraft der Transferempfänger zu befürworten, wie sie bereits im Rahmen der Fondswirtschaft vorgenommen wird. Die Höhe der Finanzierungsbeteiligung bis zu 85 Prozent der Gesamtkosten einer Investition muß jedoch einer kritischen Überprüfung unterzogen werden. Sie bildet einen erheblichen Anreiz für die staatlichen Entscheidungsträger der transferempfangenden GKS, Projekte in Angriff zu nehmen, ,die gesamtwirtschaftlich von zweifelhaftem Nutzen sind, wohl aber etwa beschäftigungspolitisch kurzfristig positiv gesehen werden oder einem politischen Aktivitätsnachweis dienen."1111

gebundene Mittelvergabe keine Sickerverluste verhindern kann. Eine gesicherte Beurteilung erfordert jedoch eine genaue Untersuchung der Einkommens- und Preiselastizităten in den Empfängerstaaten sowie des Verhältnisses zwischen Zuweisungen der EU und eigenen Investitionen der Empfängerstaaten in den einzelnen geförderten Teilbereichen.

${ }^{1110}$ Dies erscheint bspw. denkbar bei neuen Entwicklungen in der Telekommunikation.

${ }^{1111}$ Diekmann/Breier (1993), S. 264. Es bestehen aber weitere Anreize, wie bspw. die notwendige Finanzierung der Folgekosten der Investitionen, die wiederum dafür sprechen, daß die Transferempfänger nur ökonomisch „sinnvolle” Projekte ausfuihren. Notwendig ist eine umfassende Gesamtschau aller Anreizargumente. 
- Die betragliche Begrenzung des Transfervolumens:

Das Gesamttransfervolumen der FZ kann betraglich begrenzt werden, da lediglich eine bestimmte Infrastrukturausstattung in allen Mitgliedstaaten gewährleistet werden soll. Angesichts der großen Rückstände der benachteiligten Mitgliedstaaten mit öffentlichen Infrastruktureinrichtungen kann das notwendige FZ-Volumen jedoch nicht innerhalb einer Periode, sondern nur innerhalb eines längerfristigen Zeitraums bereitgestellt werden. ${ }^{112}$ In welchem konkreten Zeitraum der Aufholprozeß ermöglicht werden soll, verbleibt eine politische Entscheidung. Hierbei ist eine Überlastung der transferleistenden Mitgliedstaaten in ihrer Bereitschaft zur Vergabe der strukturpolitischen Transfers zu vermeiden, zugleich aber eine verläßliche Perspektive für den Aufholprozeß der benachteiligten Regionen zu schaffen. ${ }^{1113}$

\section{- Die Formulierung von Empfangsauflagen:}

Anhand konkreter Empfangsauflagen sind die benachteiligten GKS zu bestimmen, die sich für den Erhalt der allokativ orientierten Transfers qualifizieren. Die Empfangsauflagen sollten eine möglichst objektive Auswahl der Transferempfänger ermöglichen, um die Mittelvergabe aus wiederholten politischen Willensbildungsprozessen herauszuhalten. Denn verbleiben weitgehende diskretionäre Entscheidungsspielräume so ist zu befürchten, „daß den nationalen Interessen über Gebühr Rechnung getragen wird"1114 und die zentrale Ebene starken Einfluß auf die Programmgestaltung gewinnt.

Um jene Mitgliedstaaten zu definieren, die gemäß des Subsidiaritätsprinzips für einen begrenzten Zeitraum eine finanzielle Hilfe zur Selbsthilfe durch die zentrale EU-Ebene erhalten, müssen zwei Empfangsauflagen eingeführt werden:

Zum einen die Höhe des Pro-Kopf-Einkommens. Dieser Indikator bestimmt, welche Mitgliedstaaten wegen mangelnder ökonomischer Leistungsfähigkeit finanzielle Unterstützung zur Durchführung einer eigenständigen Regionalpolitik benötigen. Finanzstarke Mitgliedstaaten können die benachteiligten Regionen ihres Staates ohne die Hilfestellung der übergeordneten EU-Ebene autonom unterstützen. ${ }^{1115}$ Bei welcher Höhe des durchschnittlichen Pro-KopfEinkommens diese Förderbedürftigkeit als gegeben anzusehen ist, läßt sich nicht wissen-

\footnotetext{
${ }^{1112}$ Vgl. zur finanziellen Dimension der notwendigen Transfers Abschnitt V-2.5.

${ }^{1113}$ Stahl (1997), S. 204 spricht davon, daß ,die politische Sensibilität dieses Vorhabens .. von allen Beteiligten viel Fingerspitzengefühl verlangen [wird]." Vgl. auch Scharmer (1997), S. 262.

${ }^{1114}$ Gornig u.a. (1996), S. 107. Schäfers (1993), S. 196 fordert die „Entpolitisierung” der FZ-Vergabe.

${ }^{1115}$ Vgl. Spiekermann (1988), S. 49; Franzmeyer/Weise (1997), S. 322 f. Franzmeyer (1996a), S. 135 f. weist darauf hin, daß in diesem Fall die Kontrolle der autonomen Regionalpolitik der Mitgliedstaaten durch die $E K$ umso strikter durchgefuhrt werden muß, um zu verhindern, daß ,unter regionalpolitischem Deckmantel nationale Industriepolitik betrieben wird, die den innergemeinschaftlichen Wettbewerb verfälscht." Folglich rückt die Beihilfenkontrolle verstärkt in den Mittelpunkt (vgl. auch Gornig u.a. (1996), S. 107 ff.).
} 
schaftlich bestimmen. Es ist daher eine politische Entscheidung zu treffen. Z.B. kann die Fördergrenze der Ziel-1-Regionen der Strukturfonds von 75 Prozent des durchschnittlichen ProKopf-Einkommens der EU beibehalten und nun auf die Mitgliedstaaten bezogen werden.

Zum anderen ist ein Indikator über die bestehende öffentliche Infrastrukturausstattung in den Regionen der benachteiligten Mitgliedstaaten zu erstellen, um zu ermitteln, ob das (öffentlich direkt beeinflußbare) endogene Entwicklungspotential in den Regionen bereits vorhanden ist oder erst noch mit Hilfe der Transfers geschaffen werden muß. Denn besteht bereits eine angemessene öffentliche Infrastrukturausstattung, so liegt aus Sicht der allokativ orientierten Ausgleichszielsetzung kein Handlungsbedarf zur Vergabe weiterer FZ vor.

Beide Empfangsauflagen sind geeignete Indikatoren zur Bestimmung der Förderbedürftigkeit, da sie die Problemlage anzeigen, einen EU-weiten Vergleich zulassen und zudem relativ objektiv sind, da sie (weitgehend) quantitativ spezifiziert werden können.

Die Festlegung dieser Empfangsauflagen gewährleistet, daß die FZ nur temporär begrenzt vergeben werden. Sofern die angestrebte öffentliche Infrastrukturausstattung geschaffen wurde oder die transferempfangenden Mitgliedstaaten die festgelegte Grenze des Pro-KopfEinkommens überschritten haben, besitzt die EU-Ebene die Verpflichtung den Eingriff in den Verantwortungsbereich der mitgliedstaatlichen Regionalpolitik zu beenden. Die Gefahr von Gewöhnungseffekten bei den Transferempfängern wird auf diese Weise unterbunden. Sie erhalten aufgrund der objektiven Indikatoren eine langfristige, transparente und stabile Perspektive für den Erhalt der FZ, zugleich aber eine politisch nicht verhandelbare Situationsbeschreibung für die Beendigung der Unterstützungsleistungen. ${ }^{116}$

Eine Reihe von Autoren fordert weitere Empfangsauflagen, um die Effizienz der Mittelvergabe zu steigern. Hier steht zum ersten die Frage im Mittelpunkt, ob in den benachteiligten Mitgliedstaaten funktionierende Verwaltungsstrukturen bestehen, die eine effiziente Ausführung und Kontrolle der kohäsionspolitischen Maßnahmen erlauben. Problematisch ist vor allem „die vielfach noch wenig entwickelte Kultur des Dialogs zwischen den Ebenen, so daß eine Partizipation von Regionen und Kommunen nicht gewährleistet ist und die Geberländer der zweckgerichteten Verwendung der von ihnen aufgebrachten Mittel mißtrauen werden." ${ }^{1117}$ In solchen Mitgliedstaaten, die wenig leistungsfähige Verwaltungseinrichtungen besitzen, soll

\footnotetext{
${ }^{1116}$ Vgl. auch Lammers (1993), S. 197; Leonardi (1995), S. 3; Grossekettler (1996), S. 27 f.

${ }^{1117}$ Franzmeyer (1996a), S. 133.
} 
die FZ-Vergabe an die Empfangsauflage geknüpft werden, einen schlüssigen Entwicklungsplan zum Aufbau effizienter Finanzverwaltungsstrukturen vorzulegen. ${ }^{1118}$

Zum zweiten wird die Additionalität der Mittelvergabe als Empfangsauflage verlangt. Hierzu wurden weiter oben bereits Überlegungen angestellt. ${ }^{1119}$ Wie bei den Verwendungsauflagen besteht die Möglichkeit, daß die Verwaltungs- und Kontrollkosten zur Implementierung und Durchsetzung der „Zusätzlichkeit” des Mitteleinsatzes prohibitiv hoch ausfallen.

Zum dritten wird angesichts der entscheidenden Bedeutung der allgemeinen Wirtschaftspolitik der Empfängerstaaten für den Erfolg kohäsionspolitischer Transfers die Koppelung der Mittelvergabe an nationale makroökonomische Indikatoren gefordert. ${ }^{120}$ Die Autoren plädieren für die Schaffung eines Systems von Anreizen und Sanktionen, d.h. für Schritte weg von dem Förderkriterium der „Bedürftigkeit” hin zu jenem der „Output-Performance”. ${ }^{1121}$ Eine Transfergarantie, wie sie zum heutigen Zeitpunkt durch die indikative Mittelaufteilung vorgenommen wird, würde es dann nicht mehr geben, selbst wenn die beiden oben beschriebenen Empfangsauflagen erfüllt werden. ${ }^{1122}$ So erachtet Schäfers ${ }^{1123}$ es als notwendig, daß die EUEbene ,in einem gewissen Maße Einfluß auf die Wirtschaftspolitik der peripheren Mitgliedstaaten” ${ }^{1124}$ ausübt. Er nennt insb. die „Steuergesetzgebung, die Lohn- und Infrastrukturpolitik sowie eine Stabilitätsausrichtung in der gesamten Wirtschaftspolitik." ${ }^{1125}$ Indem als Indikator für die Mittelvergabe die Wachstumsrate des nationalen BIP herangezogen wird, erhofft sich Schäfers einen fruchtbaren Wettbewerb der Mitgliedstaaten um die Kohäsionsmittel. Nach der Argumentation von Schäfers werden diejenigen Mitgliedstaaten, die die Vorgaben der EUEbene beachten, überdurchschnittliche Wachstumsraten erzielen können und erhalten hierfür durch zusätzliche Transferleistungen eine Belohnung. Auch Wasmayr ${ }^{1126}$ sieht die Notwendigkeit zur Einflußnahme auf die Wirtschaftspolitik der Transferempfänger. Er plädiert dafür, die Transferzahlungen von der gesamtwirtschaftlichen Investitionsquote der Mitgliedstaaten

\footnotetext{
${ }^{1118}$ Vgl. Waniek (1994), S. 48; Thomas (1994), S. 486; Gornig u.a. (1996), S. 124. Wasmayr (1997), S. 226 argumentiert, daß nur in sechs der 15 Mitgliedstaaten zum heutigen Zeitpunkt Verwaltungsstrukturen bestehen, „die eine dezentrale Wahrnehmung kohäsionspolitischer Aufgaben erlauben."

${ }^{1119} \mathrm{Vgl}$. Abschnitt V-2.3.3.

${ }^{1120}$ Vgl. Padoa-Schioppa (1988), S. 99 f.; Schäfers (1993), S. 192 ff.; Peffekoven (1994), S. 110. Vgl. auch Laaser (1997), der die Bedeutung des wirtschaftspolitischen Ordnungsrahmens für die Effektivität der Kohäsionspolitik am Beispiel Griechenlands, Portugals und Spaniens untersucht. Er gelangt zu dem Resultat, daß „Erfolg oder Mißerfolg einer Integration - im Sinne einkommensmäßigen Aufholens oder Zurückbleibens entscheidend von der eigenen Wirtschaftspolitik abhängen" (Laaser (1997), S. 144).

${ }^{1121}$ Vgl. bspw. Costello (1993a), S. 118; Franzmeyer (1996a), S. 135; Reichenbach/Beck (1997), S. 140 f.

${ }^{1122} \mathrm{Vgl}$. Europäische Kommission (1993a), S. 73 f.; Wasmayr (1997), S. $141 \mathrm{f}$.

${ }^{1123}$ Vgl. Schäfers (1993), S. $192 \mathrm{ff}$.

${ }^{1124}$ Schäfers (1993), S. 195.

${ }^{1125}$ Schäfers (1993), S. 193.

${ }^{1126} \mathrm{Vgl}$. Wasmayr (1997), S. $228 \mathrm{ff}$.
} 
und von der Einhaltung der haushaltswirtschaftlichen Konvergenzkriterien des EUV abhängig zu machen.

Im Hinblick auf beide Vorschläge ist aber zu fragen, ob sich die EU-Ebene bei der Formulierung dieser Empfangsauflagen nicht ein Wissen über die dezentralen Besonderheiten der Mitgliedstaaten - und damit über die ,richtige” Wirtschaftspolitik - anmaßt, das mit dem Subsidiaritätsprinzip gerade nicht zu vereinbaren ist. Zudem ist es unmöglich, objektiv festzustellen, ob einen Mitgliedstaat ein eigenständiges Verschulden für eine unterdurchschnittliche Wachstumsrate oder Investitionsquote triff, selbst wenn in erheblichem Umfang Kosten zur Sammlung von Informationen aufgewendet werden. Daher sind Konflikte im politischen Entscheidungsprozeß vorprogrammiert. ${ }^{1127}$ Vor allem aber entsteht die Gefahr eines ökonomischen Teufelskreises, da auch solche benachteiligten Mitgliedstaaten, deren Entwicklungsrückstand unverschuldet ist, Mittelkürzungen hinnehmen müssen und damit deren Möglichkeiten, einen tragfähigen Entwicklungsprozeß einzuleiten, weiter verschlechtert werden.

Insgesamt demonstrieren die Ausfuhrungen deutlich die Problematik, die mit der Formulierung von Empfangsauflagen verbunden ist. Im Einzelfall erscheinen die Forderungen plausibel und ökonomisch begründet. In ihrer Gesamtheit jedoch erzeugen sie ein intransparentes und kompliziertes Verflechtungssystem, durch das eine effektive Kohäsionspolitik gefährdet werden kann (ökonomischer Aspekt). Es ergeben sich diskretionäre Handlungsspielräume für politisch motivierte Entscheidungen, da kein objektives Urteil über die angestrebten (qualitativen) Empfangsauflagen möglich ist (politischer bzw. polit-ökonomischer Aspekt). Es besteht daher im Zeitablauf eine recht hohe Wahrscheinlichkeit, daß sich diejenigen Fehlentwicklungen wiederholen, die den Anlaß für die Reformüberlegungen darstellen. An dieser Stelle wird daher dafür plädiert, nur die beiden erstgenannten elementaren (und quantifizierbaren) Indikatoren zur Festlegung der Mittelvergabe heranzuziehen. Es wird eine konsequente Konsolidierung und Vereinfachung der kohäsionspolitischen Maßnahmen der EU angestrebt.

\section{V-2.4.2 Die Umsetzung der effizienten Problemlösung im politischen Entscheidungs- prozeß}

Die Vergabe zwischenstaatlicher FZ im Dienst der Regionalpolitik erfordert eine weitgehende Reform der bisherigen kohäsionspolitischen Maßnahmen der EU-Ebene. Die Aussicht, die angestrebten Veränderungen innerhalb des europäischen Politikgestaltungsprozesses verwirklichen zu können, bildet daher den Kern der nachfolgenden Überlegungen.

${ }^{1127} \mathrm{Vgl}$. hierzu auch Scharmer (1997), S. $281 \mathrm{ff}$. 
V-2.4.2.1 Die Gewinnung der entscheidungsrelevanten Informationen

Die spezifischen Besonderheiten der zurückliegenden Regionen sind die entscheidungsrelevanten Informationen zur Vergabe von FZ mit einer allokativ orientierten Ausgleichszielsetzung. Die zur Gewinnung dieser Informationen notwendigen Kenntnisse über die grundsätzlichen Entwicklungschancen, die bestehenden Standortdefizite und die hieraus resultierenden konkreten Fördernotwendigkeiten besitzen die staatlichen Entscheidungsträger innerhalb dieser Regionen. Eine weitaus geringere Bedeutung für die Einleitung eines eigenständigen Entwicklungsprozesses einer benachteiligten Region nehmen demgegenüber wechselseitige Beziehungen zu den Handlungsalternativen und Entscheidungen der weiteren GKS der EU ein. Denn die „Maßnahmen kommen im allgemeinen ... nur der betreffenden Arbeitsmarktregion zugute."1128 Spillover-Effekte stehen also nicht im Zentrum der Überlegungen. ${ }^{1129}$ Daher besitzt die besondere Eignung des Verbundsystems zur Generierung gesamtsystem-spezifischer Informationen nur eine untergeordnete Bedeutung.

Von zentraler Bedeutung ist vielmehr die Nutzung des Informationspotentials der dezentralen Jurisdiktionen. Es ist deshalb elementar, daß deren staatliche Entscheidungsträger die vorhandenen Informationen vollständig und unverfälscht in den Willensbildungsprozeß des EUVerbundsystems einbringen. Hierzu besteht allerdings kein Anreiz, wenn durch die strategische Zurückhaltung oder Veränderung von Informationen zusätzliche Transfers in die eigene GKS gelenkt werden können.

Die bestehende Fondswirtschaft eröffnet jedoch zunehmend die Möglichkeit zu strategischen Verhaltensweisen, da die zentrale Ebene immer detailliertere Förderkonzepte vorgibt und verstärkt eigenständige Gemeinschaftsinitiativen entwickelt. ${ }^{1130}$ Die dezentralen Entscheidungsträger werden nur solche Programmvorschläge an die EU-Ebene weiterleiten, die in Einklang mit den zentral vorgegebenen Konzeptionen gebracht wurden. Die Abstimmung der Vorschläge auf die dezentralen Problemstrukturen steht nicht im Mittelpunkt, da hierdurch Fördermittel verloren gehen können. ${ }^{1131}$ Dies spricht dafür, wie für die Vergabe der FZ vorgeschlagen, die gesamte Programmplanung den betroffenen Mitgliedstaaten zu überlassen und zentral nur einen weitgefaßten Rahmen für förderungswürdige Vorhaben abzustecken. Der

\footnotetext{
${ }^{1128}$ Klodt u.a. (1992), S. 87.

${ }^{1129}$ Vgl. Klodt u.a. (1992), S. 85 ff; auch Lammers (1993), S. 196.

${ }^{1130}$ Um diese Förderprogramme zieladäquat formulieren zu können, müßte die EU-Ebene bereits die Kenntnisse der spezifischen Problemstrukturen der benachteiligten Regionen besitzen. Es entsteht ein gravierendes Informationsproblem.

${ }^{1131}$ Die Bürokraten verhalten sich zugleich „nach dem Gesetz des geringsten Aufwandes” (Schäfers (1993), S. 75) und unterlassen eine für sie „aufwendige, komplizierte” (Schäfers, (1993), S. 75) Analyse der regionalen Problemstrukturen.
} 
Anspruch an die EU-Ebene zur Gewinnung der entscheidungsrelevanten Informationen wird hierdurch deutlich reduziert. Die transferempfangenden Mitgliedstaaten entwickeln eigenständig, regionale Entwicklungskonzeptionen, die von der EU-Ebene daraufhin überprüft werden, ob sie den Rahmenanforderungen genügen. Darüber hinaus jedoch sind die Mittelverwendungen, wie sie dezentral geplant werden, verbindlich. Da die Höhe der Transfervergabe nun unabhängig von der Einhaltung konkreter inhaltlicher Vorgaben der EU-Ebene erfolgt, existieren in den Mitgliedstaaten keine (Fehl-)Anreize, wesentliche entscheidungsrelevante Informationen bei der Ausarbeitung der Entwicklungspläne zurückzuhalten oder zu verfälschen. ${ }^{1132}$

Insgesamt ist hieraus die Schlußfolgerung zu ziehen, daß das kohäsionspolitische Informationsproblem der EU-Ebene beim Übergang von der aktiven, interventionistisch-selektiven Regionalpolitik zu einer Vergabe von zwischenstaatlichen $\mathrm{FZ}$ deutlich verringert wird.

\section{V-2.4.2.2 Die Fragen der Konfliktregelung und Konsensfindung}

Die Konfliktregelung und Konsensfindung bilden die Haupthindernisse bei der Verwirklichung der in den vergangenen Abschnitten entwickelten Kohäsionspolitik. Dabei sind zwei Aspekte zu beachten. Die grundsätzlichen Interessenkonflikte und Koordinationsprobleme zwischen den Verhandlungspartnern bezüglich der angestrebten gemeinsamen Problemlösung und die besondere Problematik, die sich ergibt, weil der kohäsionspolitische Instrumenteinsatz der EU grundlegend verändert werden soll.

Die Problemstellung, die bei der Einrichtung einer geeigneten Kohäsionspolitik erfaßt werden muß, hat eine hohe Komplexität. Denn die potentiellen Auswirkungen der möglichen Verhandlungslösungen für die Mitgliedstaaten sind sehr schwer einzuschätzen. Dies ergibt sich zum einen aufgrund der langfristigen Perspektive der kohäsionspolitischen Aktivitäten. Zum anderen, weil die (ökonomische) Theorie keine eindeutigen Schlußfolgerungen über die Wirkungsweise der kohäsionspolitischen Maßnahmen erlaubt. ${ }^{1133}$ Daher besteht eine erhebliche Unsicherheit über die Wohlfahrtspositionen der verhandelnden Mitgliedstaaten. Ob eine bestimmte Problemlösung langfristig einen positiven oder negativen Gesamtnutzen für einen bestimmten Verhandlungspartner bedeutet, kann nicht sicher beantwortet werden.

\footnotetext{
${ }^{1132} \mathrm{Vgl}$. zu den hier skizzierten Überlegungen ausführlicher Gornig u.a. (1996), S. $139 \mathrm{ff}$. Es muß allerdings darauf hingewiesen werden, daß weiterhin bestimmte Fehlanreize bestehen bleiben. So besitzen die Mitgliedstaaten sehr wohl Anreize, die bestehende Infrastrukturausstattung der Problemregionen sowie die Finanzkraft des Gesamtmitgliedstaates zu unterzeichnen, um die Zuweisung der Finanzmittel zu sichern. Da die Informationen zu diesen beiden elementaren Empfangsauflagen jedoch (weitgehend) quantifizierbar sind, können sie relativ leicht einer Überprüfung durch die EU-Ebene unterzogen werden.

${ }^{1133} \mathrm{Vgl}$. hierzu Abschnitt V-2.2.2.
} 
Zudem besteht eine Vermischung von Koordinationsproblemen und Verteilungfragen. Das Koordinationsproblem besteht darin, in den peripheren Regionen Wachstumspotentiale auszuschöpfen, die ohne ein koordiniertes Vorgehen unerschlossen bleiben würden. In einer längerfristige Perspektive ermöglicht dies eine harmonische Entwicklung aller Teilregionen der EU, wodurch alle Mitgliedstaaten Nutzenzugewinne realisieren können (integrative Problemstellung). ${ }^{1134}$ Die Aufbringung der Finanzmittel zur Vergabe der kohäsionspolitischen FZ führt hingegen zu einem Verteilungskonflikt. Die Akteure müssen anhand des Indikators „ProKopf-Einkommen" zu einer Einigung darüber gelangen, welche Mitgliedstaaten als Transferempfänger FZ erhalten (müssen) und welche als Transferzahler die Mittel zur Finanzierung der öffentlichen Infrastrukturausstattung in den benachteiligten Regionen aufbringen (können). ${ }^{1135}$ Die Vergabe der kohäsionspolitischen FZ stellt also ein ,mixed-motive-game” dar, wodurch die einvernehmliche Problemlösung erschwert wird.

Der Verteilungskonflikt demonstriert, daß nur zwei Interessenlagen existieren: das Interesse der Nettotransferzahler, die den Umfang der Transfers begrenzen möchten, und das Interesse der Nettotransferempfänger, die für eine Ausweitung der Transfers plädieren. Hierdurch scheint sich der Konsensbedarf der Verhandlungssituation deutlich zu verringern, da nur zwei Interessenpositionen miteinander in Einklang gebracht werden müssen. Jedoch besteht die gravierende Gefahr, daß eine „cross-cutting-cleavage” entlang der Linie der Nettotransferzahler und -empfänger auftritt. Es stehen sich die strukturschwachen, benachteiligten Mitgliedstaaten und die strukturstarken, weiterentwickelten Mitgliedstaaten gegenüber. Dies verdeutlicht die zentrale Bedeutung der kohäsionspolitischen Maßnahmen für den gesamten Integrationsprozeß. ${ }^{1136}$ Sofern die Mittel erfolgreich dazu beitragen, daß in allen Mitgliedstaaten eigenständige Entwicklungsmöglichkeiten entstehen, werden im Zeitablauf sich selbstverstärkende Effekte ausgelöst: Die Polarisierung zwischen „reichen” und „armen” Mitgliedstaaten löst sich dann zunehmend auf. Es stehen sich nun weniger gegensätzliche Interessenpositionen gegenüber, da die Verteilungspositionen der einzelnen Mitgliedstaaten einander näher gerückt sind. Dies erleichtert die Einigung auf integrative Problemlösungen, wodurch wiederum die

\footnotetext{
${ }^{1134}$ Sei es indirekt dadurch, daß Fortschritte des Integrationsprozesses ermöglicht werden, die positive Entwicklung in politischer, sozio-kultureller und ökonomischer Hinsicht erlauben oder aber direkt in ökonomischer Hinsicht dadurch, daß das Wachstum in den peripheren Regionen allen anderen Mitgliedstaaten zugute kommt, bspw. über zusätzliche Exporte.

${ }^{1135}$ Die Frage, ob die FZ vertikal oder horizontal vergeben werden sollten, bleibt an dieser Stelle ausgeklammert. Es wird davon ausgegangen, daß die $\mathrm{FZ}$ aus dem allgemeinen EU-Haushalt bestritten werden, der von allen Mitgliedstaaten finanziert wird. Daher tragen auch die transferempfangenden Mitgliedstaaten zur Finanzierung der kohäsionspolitischen FZ bei. Deshalb muß korrekterweise von Netto-Transferempfängern und NettoTransferzahlern gesprochen werden.

${ }^{1136} \mathrm{Vgl}$. hierzu auch die Abschnitt V-1.3.2.2 und V-3.3.3. Auch dort wird jeweils eine Konfliktlinie zwischen den weiterentwickelten und den benachteiligten Mitgliedstaaten festgestellt.
} 
Entwicklungsperspektiven aller Mitgliedstaaten verbessert werden. Langfristig ist es denkbar, daß ein homogener Gesamtraum entsteht, in dem die Mitgliedstaaten je nach Fragestellung völlig unterschiedliche Koalitionen bilden. Es ist in dieser Situation auch möglich, verstärkt zu Mehrheitsentscheidungen überzugehen, da die Präferenzkosten in den überstimmten Mitgliedstaaten nicht mehr prohibitiv hoch ausfallen. Damit wird die EU-Ebene insgesamt handlungsfähiger. ${ }^{1137}$

Die Kohäsionsprobleme besitzen, wie dargestellt, wegen der Langfristigkeit der Zielsetzung und der Vielschichtigkeit der Entwicklungsmöglichkeiten, einen hohen Konsensbedarf. Diese Komplexität weist jedoch zugleich auf einen wichtigen Ansatzpunkt hin, um in den Verhandlungen aktiv auf die Herstellung des notwendigen Konsenses hinzuarbeiten. ${ }^{1138}$ Die EK hat die Möglichkeit, durch eine offensive Informationsstrategie gezielt entscheidungsrelevante Informationen an die Transferempfänger und -geber zu vermitteln, die deren Zustimmungswahrscheinlichkeit zu der angestrebten Problemlösung erhöhen. Die EK fungiert als Moderator, der den Verhandlungsprozeß begleitet und so Einfluß auf die Verhandlungsergebnisse gewinnt.

Auf der Seite der transferzahlenden Mitgliedstaaten erscheint es erfolgsversprechend, auf die dynamische Perspektive der kohäsionspolitischen Problemlösungsstrategie hinzuweisen. Es ist denkbar, daß die Transferzahler im Rahmen ihrer Willensbildung die (kurzfristigen) Zahlungsströme überbewerten, wohingegen die langfristigen Nutzen des Abbaus der wirtschaftlichen und sozialen Disparitäten in der EU unterbewertet werden. Es ist den Transferzahlern zu verdeutlichen, daß eine alleinige Betrachtung der Netto-Transferzahlerposition ,in vielfacher Hinsicht unzureichend ist." ${ }^{1139}$ So wird demonstriert, daß langfristig eine Mehrzahl ökonomischer und außer-ökonomischer Faktoren die Wohlfahrtsposition des transferleistenden Mitgliedstaates bestimmt, so daß in einer Gesamtbetrachtung auch für die Transferzahler Nutzenzugewinne aus der Gewährung kohäsionspolitischer Transfers resultieren.

Auf der Seite der Transferempfänger kann die EK gegenüber Entscheidungsträgern und Wählern gezielt auf die große Bedeutung der gewählten Zweckbestimmung der FZ für investive Zwecke aufmerksam machen. Gelingt es der EK, das Verständnis der Wähler für die

\footnotetext{
${ }^{1137}$ Frick/Van der Beek/Hünger (1996), S. 360 f. sehen die Abkehr vom Einstimmigkeitsprinzip sogar als die entscheidende Voraussetzung an, um eine konsistente Kohäsionspolitik durchfuhren zu können. Einzelne Mitgliedstaaten verfügen sodann über keine Vetoposition mehr, um kohäsionspolitisch sinnvolle Maßnahmen zu blockieren, die für die eigene Verteilungsposition mit Nachteilen verbunden sind.

${ }^{1138}$ Die Analyse der Strategien zur aktiven Konsensbildung stellt den zweiten Schritt bei der Untersuchung der Wahrscheinlichkeit einer einvernehmlichen Problemlősung im Verbundsystem dar.

${ }^{1139}$ Caesar (1996a), S. 261.
} 
Wichtigkeit der Investitionen in öffentliche Infrastruktur zu steigern, ${ }^{140}$ so erhöht sich der politische Druck auf die Politiker und die Verwaltung der transferempfangenden Mitgliedstaaten, für eine zweckgerechte Verwendung der FZ Sorge zu tragen. Der Handlungsspielraum der Akteure, die Transfers in kurzfristige, konsumtive Verwendungen zu lenken, sinkt.

Gelingt es trotz dieser Vorgehensweise nicht, eine einvernehmliche Problemlösung zu finden, können Maßnahmen zur Minimierung des Konsensbedarfs ergriffen werden. ${ }^{1141}$ Langfristig bietet sich die Änderung der Entscheidungsregeln im Ministerrat sowie beim Zusammenwirken von EK, EP und Ministerrat an. Es besteht aber erneut eine Wechselwirkung mit dem Erfolg der kohäsionspolitischen Maßnahmen. Angesichts der momentan bestehenden Heterogenität der Mitgliedstaaten würde der Übergang von der Einstimmigkeitsregel zu einer Form der Mehrheitsregel erhebliche Präferenzkosten auslösen. Entwickeln sich durch die Kohäsionsmaßnahmen jedoch homogenere Präferenzstrukturen in der gesamten EU, so vermindert sich die Bedeutung der Präferenzkosten und die Verringerung des Konsensbedarfs durch eine Änderung der Entscheidungsregel stellt eine zunehmend effiziente Vorgehensweise dar.

Bereits zum heutigen Zeitpunkt bietet sich die Möglichkeit an, die komplexe Verhandlungsproblematik in mehrere Teilprobleme geringerer Komplexität aufzuspalten. So können bei der FZ-Vergabe zunächst die transferberechtigten Mitgliedstaaten bestimmt, in einem zweiten Schritt über das jährliche Gesamtvolumen der Finanzmittel entschieden und schließlich die Art der Zweckbindung festgelegt werden. Die Anforderungen an die Konsensfindungskapazitäten des Entscheidungssystems wird bei jeder Teilentscheidung im Vergleich zur Verhandlung der Gesamtproblematik reduziert. ${ }^{1142}$

Im Vordergrund der konsensbedarfminimierenden Maßnahmen steht die Anwendung konfliktminimierender Entscheidungsregeln. Diese Strategien gefährden aber die Realisierung einer effizienten Lösung der Kohäsionsproblematik und lassen die Wahrscheinlichkeit, daß es zu wesentlichen Veränderungen der bestehenden kohäsionspolitischen Maßnahmen kommt, gering erscheinen.

Es kann die Zustimmung aller Mitgliedstaaten zu den kohäsionspolitischen Transfers durch eine Gleichbehandlung aller Verhandlungspartner hergestellt werden. Dies bedeutet, daß alle Mitgliedstaaten in einem bestimmten Umfang kohäsionspolitische Finanzmittel erhalten. Diese Vorgehensweise ist kohäsionspolitisch ineffektiv. Denn wenn ,alle Regionen - ob stark

\footnotetext{
${ }^{1140} \mathrm{Vgl}$. zur Bedeutung der offentlichen Infrastruktur nochmals die Ausführungen zum Potentialfaktoransatz in Abschnitt III-3.1.1.2.

${ }^{1141}$ Der dritte Schritt zur Untersuchung der Wahrscheinlichkeit einer einvernehmlichen Problemlösung.

${ }^{1142}$ Allerdings besteht der Nachteil, daß die Verhandlungen insgesamt einen längeren Zeitaum beanspruchen und hierdurch zusătzliche Verhandlungskosten ausgelöst werden.
} 
oder schwach - annähernd gleichermaßen gefördert werden, ist nichts gewonnen, die Abstände zwischen den Regionen werden nicht geringer, nur das Umverteilungsvolumen ist gewachsen." 1143 Die benachteiligten Regionen müssen relativ zu den weiterentwickelten Regionen bessergestellt werden, um die Kohäsionszielsetzung zu verwirklichen. ${ }^{1144}$

Diese Feststellung leitet direkt über zur Strategie der Besitzstandswahrung. Sie erlaubt es, eine Ungleichbehandlung der verschiedenen Akteure einzuführen. Die benachteiligten Regionen erhalten in diesem Fall vom Status-Quo ausgehend zusätzliche Finanzmittel, um die Realisierung der Kohäsionszielsetzung zu ermöglichen. Zugleich wird aber gewährleistet, daß sich die absolute Höhe der FZ, die an die weiterentwickelten Mitgliedstaaten fließen, nicht verringert. Unter dieser Voraussetzung wird die Wahrscheinlichkeit erhöht, daß deren Entscheidungsträger der relativen Besserstellung der benachteiligten Regionen zustimmen. Das Transfervolumen ufert auf diese Weise jedoch aus. Es entsteht zunehmend die Gefahr, daß Mitnahmeeffekte auftreten und die Finanzmittel zur Errichtung von Investitionsruinen genutzt werden, da die Absorptionsfähigkeit der Regionen überfordert wird. ${ }^{1145}$ Zudem erscheint es unter diesen Voraussetzungen aussichtslos, die temporäre Begrenzung der FZ-Vergabe glaubhaft durchzusetzen. So kann nicht nur in den benachteiligten, sondern in allen Mitgliedstaaten eine Subventionsmentalität entstehen. Hierfür spricht auch der Einfluß von Interessengruppen. Diese werden erheblichen Widerstand leisten, wenn die Besitzstände abgebaut werden sollen, die ihren partikularen Interessen durch die FZ an den „eigenen” Mitgliedstaat zugeflossen sind. Dies gilt in sektoraler Hinsicht für die angestrebte Beendigung der FZ für direkt produktive Investitionen einzelner Unternehmen oder Branchen, ${ }^{1146}$ in räumlicher Hinsicht für die strikte Beschränkung der FZ auf die Mitgliedstaaten mit unterdurchschnittlichem Pro-KopfEinkommen. ${ }^{1147}$ Und auch die EK wird die Beschneidung ihrer diskretionären Entscheidungs-

\footnotetext{
${ }^{1143}$ Frick/Van der Beek/Hünger (1996), S. 361.

${ }^{1144}$ Die Fehlentwicklung der Gleichbehandlung ist auch im Rahmen der bestehenden Strukturfonds festzustellen. So hat sich der Anteil der in geforderten Regionen lebenden Bevölkerung der $E U$ von 43 Prozent im Jahr 1989 auf fast 51 Prozent im Jahr 1995 erhöht. Infolge der Norderweiterung der EU wurde das Ziel-6 der Strukturfonds eingefuhrt, um auch diesen Mitgliedstaaten eine angemessene Gleichbehandlung bei der Mittelvergabe garantieren zu können (vgl. Reichenbach/Beck (1997), S. 141; Stahl (1997), S. 204).

${ }^{1145}$ Das Phänomen der Besitzstandswahrung begleitet auch die Fondswirtschaft der EU. Bei den Strukturfonds kommt es von 1992 bis 1999 real zu einer Verdoppelung der FZ an die Ziel-1-Regionen, ohne die Besitzstände der übrigen Zielregionen anzutasten (vgl. Wasmayr (1997), S. 86 ff.). Die Einrichtung des Kohäsionsfonds für die Zeit von 1994 bis 1999 weist den Mitgliedstaaten mit niedrigem Pro-Kopf-Einkommen zusätzlich FZ $\mathrm{zu}$, ohne Veränderungen im Hinblick auf die bereits bestehenden Transfers an die übrigen weiterentwickelten Mitgliedstaaten vorzunehmen. Konsequenterweise steigt das Gesamttransfervolumen beständig an (vgl. hierzu auch Abschnitt V-2.3.2).

${ }^{1146}$ In sektoraler Hinsicht wird zudem ein großer Widerstand von der Agrarlobby zu erwarten sein, wenn in diesem Bereich der Versuch unternommen wird, durch Ausgabenkürzungen finanzielle Handlungsspielräume für die kohäsionspolitischen Maßnahmen zu gewinnen und die Kohärenz der kohäsionspolitischen Maßnahmen zu verbessern.

${ }^{1147}$ Aus dieser Sicht muß. die Vergabe der kohäsionspolitischen FZ an Irland beendet werden. Da dieser Mitgliedstaat mittlerweile sogar ein überdurchschnittliches Pro-Kopf-Einkommen erreicht hat (vgl. hierzu
} 
befugnisse durch die Reform der Kohäsionspolitik „nur bei einer expansiven Lösung”1148 mittragen, die den eigenen politischen Einflußbereich zumindest quantitativ gewährleistet.

In enger Verknüpfung hierzu steht die Strategie der Konfliktvertagung. Es ist zu vermuten, daß die Entscheidung besonders konfliktträchtiger Teilprobleme in die Zukunft verschoben wird, um eine einvernehmliche Problemlösung zum heutigen Zeitpunkt nicht zu gefährden. Daher können die angestrebten strukturellen Veränderungen der kohäsionspolitischen Maßnahmen der EU-Ebene nur in einem sehr langfristigen Prozeß in das Entscheidungssystem eingebracht werden, um den Konsensbedarf einzelner Verhandlungsrunden nicht zu überfrachten. Erfolgt in diesem Zeitraum jedoch eine dynamische Veränderung der Problemstrukturen, so vergrößert sich die Diskrepanz zwischen der bestehenden Kohäsionspolitik und der aus theoretischer Sicht effizienten Problemlösung. ${ }^{1149}$

\section{V-2.4.2.3 Die Frage der Implementation}

Bei der Implementation sind die kohäsionspolitischen Aktivitäten der EK zu beleuchten. Die EK muß eine Einschränkung ihrer Kompetenzen zur konkreten Ausgestaltung der regionalpolitischen Maßnahmen hinnehmen. Es ist daher darauf zu achten, daß es im Zeitablauf nicht (erneut) ${ }^{1150}$ zu einer kontinuierlichen Ausweitung der Kompetenzausübung durch die europäische Bürokratie kommt, indem bestehende Handlungsspielräume von der EK interventionistisch ausgefüllt werden. Hier müssen die verschiedenen Organisationen der EU eine Kontrollfunktion ausüben. Neben der Rechtsprechung des EuGH ist hierzu der AdR besonders geeignet. ${ }^{1151}$ So werden die Kompetenzspielräume der Regionen geschützt und eine zunehmende Intransparenz der kohäsionspolitischen Maßnahmen verhindert. Die Kapazitäten der EK sind auf die ex-ante Evaluierung der Entwicklungspläne der Mitgliedstaaten und die expost Kontrolle der Mittelverwendung durch die Mitgliedstaaten zu konzentrieren.

Für die Kontrollaktivitäten gilt jedoch - wie schon bei den externen Effekten -, daß sie nicht in jedem Einzelfall durchführbar sind. Es würden prohibitive Kontrollkosten entstehen. Es ver-

Abb. V-5) erfüllt Irland nicht mehr die Empfangsauflage, um im kommenden Planungszeitraum weiterhin FZ zu erhalten.

${ }^{1148}$ Franzmeyer (1996a), S. 134.

${ }^{1149} \mathrm{Als}$ markantes Beispiel sei in diesem Zusammenhang die Osterweiterung der $E U$ genannt. Obwohl seit geraumer Zeit feststeht, daß die bestehende Fondswirtschaft angesichts des enormen Entwicklungsrückstandes der Beitrittskandidaten ein erhebliches Erweiterungshindernis darstellt, ist es bislang nicht gelungen, eine Entwicklungsstrategie der Strukturmaßnahmen für die potentiellen neuen Mitgliedstaaten zu entwerfen. Gelingt bis zum Beitritt der osteuropäischen Länder keine umfassende Reform der heutigen Kohäsionspolitik, so wird der Handlungsbedarf entscheidend ansteigen.

${ }^{1150} \mathrm{Vgl}$. hierzu die Kritik an dem allmählichen Zentralisierungsprozeß in der bestehenden Fondswirtschaft in Abschnitt V-2.3.3.

${ }^{1151} \mathrm{Vgl}$. zum $A d R$ Abschnitt IV-2.2.1.3. 
bleiben daher Handlungsspielräume bei der Verwendung der FZ in den Empfängerregionen. Verhalten sich die dortigen Politiker und Bürokraten eigennutzorientiert, sind Ineffizienzen durch die Zweckentfremdung der Mittelverwendung (allokative Ineffizienz) und überhöhte Bereitstellungskosten (technische Ineffizienz) nicht auszuschließen. Aus polit-ökonomischer Gründen ist die Fehlleitung von FZ insb. dann dankbar, wenn die politischen Entscheidungsträger aus wahltaktischen Überlegungen heraus kurz- bis mittelfristige Zielsetzungen verwirklichen möchten, um Wählergruppen mit spürbaren Vergünstigungen zu bedienen. ${ }^{1152}$

\section{V-2.5 Schlußfolgerungen und finanzielle Dimension}

Die Ausfuihrungen dieses Abschnitts zeigten zunächst den wirtschaftspolitischen Handlungsbedarf zur Durchfuihrung kohäsionspolitischer Maßnahmen auf. Es bestehen zum heutigen Zeitpunkt erhebliche wirtschaftliche und soziale Disparitäten in der EU, die (auch) auf einen Rückstand der betroffenen Mitgliedstaaten in der öffentlichen Infrastruktur zurückgeführt werden können. Der europäische Integrationsprozeß übt einen erheblichen Einfluß auf die Entwicklung der bestehenden Disparitäten aus. Allerdings erlauben theoretische wie auch empirische Analysen keine eindeutigen Schlußfolgerungen, ob hierdurch „insgesamt" eine Konvergenz oder Divergenz des Entwicklungsstandes der Mitgliedstaaten und Regionen ausgelöst wird.

Entsprechend der kohäsionspolitischen Zielsetzung besitzen die Transfers der EU als allokativ orientierte Ausgleichszuweisungen einen vorübergehenden Charakter. Sofern sie „erfolgreich" sind, stellen sie die Voraussetzungen für einen eigenständigen Aufholprozeß in den benachteiligten Mitgliedstaaten her und machen sich so im Laufe der Zeit selbst überflüssig. ${ }^{1153}$ Im Kohäsionsland Irland ist diese Situation bereits eingetreten. 1997 verfuigt Irland erstmals über ein Pro-Kopf-Einkommen, das den Durchschnitt der EUR 15 übertrifft. Daher benötigt dieser Mitgliedstaat selbst dann keine weiteren kohäsionspolitischen FZ der übergeordneten Ebene mehr, wenn einzelne Teilregionen erhebliche Defizite der öffentlichen Infrastruktur aufweisen. ${ }^{1154}$ Irland verfügt heute über eine ausreichende wirtschaftliche Leistungsfähigkeit, um den Aufholprozeß der betreffenden Teilregionen eigenständig zu finanzieren.

\footnotetext{
${ }^{11152}$ Vgl. Schäfers (1993), S. 75 f.; Beckmann (1995), S. 145 ff.; auch Spiess (1973), S. 78 u. 87 f.

${ }^{1153}$ Vgl. auch Hesse, H. (1993), S. 48. Die Vergabe der FZ ermöglicht dynamische Entwicklungsprozesse.

${ }^{1154}$ Vgl. hierzu S. 230 f. mit Abb. V-4 in Abschnitt V-2.2.1, wo ein erheblicher Rückstand Irlands in der Infrastrukturausstattung aufgezeigt wird. Allerdings stammen die jüngsten Daten aus dem Jahr 1989. Beachtet man, daß der dynamische Aufholprozeß Irlands im Hinblick auf das Pro-Kopf-Einkommen erst in den 90er Jahren stattgefunden hat, so ist zu vermuten, daß in diesem Zeitraum auch die Defizite im Infrastrukturbereich verringert werden konnten.
} 
Eine enorme Bedeutung besitzen die kohäsionspolitischen Transfers für den gesamten europäischen Integrationsprozeß. Sie ermöglichen dynamische Integrationsfortschritte. Die kohäsionspolitischen Maßnahmen erlauben es den benachteiligten Mitgliedstaaten, leistungs- und zukunftsfähige Strukturen aufzubauen, die jenen der weiterentwickelten, „erfolgreichen”1155 Mitgliedstaaten ähneln. ${ }^{1156}$ Findet auf diese Weise eine Homogenisierung innerhalb der EU statt, lösen sich Konfliktlinien zwischen benachteiligten und weiterentwickelten Mitgliedstaaten auf, die bislang als „cross-cutting-cleavage” unterschiedlichste Problemstellungen betroffen haben. Das Gesamtsystem der EU wird hierdurch stabiler. Dies bedeutet jedoch nicht, daß kein Wandel stattfindet. Vielmehr werden die notwendigen Entwicklungsprozesse erst ermöglicht, weil die Entscheidungsfindung auf der EU-Ebene nicht länger durch unüberwindbare Interessengegensätze blockiert wird (Stabilität im Wandel). „Damit kommt der Kohäsionspolitik nicht nur eine große wirtschaftliche, sondern auch eine überragende politische Bedeutung zu." 1157

Insgesamt zeigt sich ein interdependentes Verhältnis zwischen dem wirtschaftlichen und sozialen Zusammenhalt und dem Integrationsprozeß. Einerseits beeinflußt der Integrationsprozeß die Entwicklung der Kohäsion innerhalb der EU. Andererseits hängt der Fortgang des Integrationsprozesses entscheidend von dem Stand der Kohäsion ab.

Daher besitzt die Kohäsionspolitik eine zentrale Bedeutung für die EU. Eine effiziente und effektive Kohäsionspolitik, so demonstrieren die Analysen dieses Abschnitts, ist aber nur in einem kooperierenden Miteinander von transferempfangenden und transferleistenden Mitgliedstaaten sowie der EU-Ebene möglich. ${ }^{1158}$ Dies erfordert es, der EU-Ebene eine neue Rolle im Bereich der Kohäsionspolitik zuzuweisen. Statt den Mitgliedstaaten und Regionen konkrete regionalpolitische Programme vorzuschreiben, muß die zentrale Ebene „zum Moderator und Impulsgeber für die regionale Selbstorganisation des Strukturwandels aufgrund möglichst breit getragenen Konsenses werden." ${ }^{1159}$ Die EU-Ebene sollte deshalb das Forum zur Konsensfindung über eine gemeinschaftliche Entwicklungsstrategie bieten ${ }^{1160}$ und als Partner der dezentralen GKS eine Moderationsfunktion bei der Umsetzung der Verhandlungs-

\footnotetext{
${ }^{1155}$ Waniek (1995), S. 26.

${ }^{1156}$ Vgl. bspw. Waniek (1995), der diesen Prozeß im Hinblick auf die Sektoralstrukturen in weiterentwickelten und benachteiligten Regionen analysiert.

${ }^{1157}$ Schäfers (1993), S. 16.

${ }^{1158}$ Vgl. Spiekermann (1988), S. 18 f. und jüngst Jochimsen (1998), S. $220 \mathrm{ff}$. Vgl. auch das Resümee von Schäfers (1993), S. $182 \mathrm{f}$.

${ }^{1159}$ Jochimsen (1995), S. 497.

${ }^{1160}$ Auf der EU-Ebene wird die Willensbildung der Mitgliedstaaten im Ministerrat mit der Problemwahrnehmung der $E K$ und des $E P$ koordiniert.
} 
ergebnisse in den jeweiligen Mitgliedstaaten ausfuillen, um die Zielsetzung der FZ-Vergabe verständlich zu machen.

Die unabdingbare Notwendigkeit zur Erhöhung der Wirksamkeit der kohäsionspolitischen Maßnahmen wird angesichts der finanziellen Dimension der bevorstehenden Herausforderungen augenscheinlich. So schätzt die EK, daß im Zeitraum von 1994-2010 jährliche Investitionen von ca. $30 \mathrm{Mrd}$. ECU erforderlich sind, um in den benachteiligten Ziel-1-Regionen des bestehenden Gesamtgebietes der EU eine öffentliche Infrastrukturausstattung zu schaffen, die dem Durchschnitt der EU entspricht. ${ }^{1161}$ Unter Berücksichtigung der bevorstehenden Erweiterung der EU nach Osten wird das Finanzierungsproblem noch deutlicher. Die räumlichen Disparitäten in der EU werden sich durch diesen Integrationsschritt stark erhöhen und so einen zusätzlichen Finanzbedarf auslösen. Allein der Beitritt der vier Visegrad-Länder - Polen, Tschechische Republik, Slowakei und Ungarn - bedeutet im Rahmen der bestehenden Strukturfonds einen Anstieg der Transferleistungen um jährlich etwa 26 Mrd. ECU. „Kämen die Balkanstaaten und die baltischen Republiken hinzu, würde sich dieser Zuwachs im Prinzip auf etwa 54 Mrd. ECU ... verdoppeln."1162 Der Vergleich mit den gesamten Strukturmaßnahmen der EU im Jahr 1998 von ca. 33,5 Mrd. ECU verdeutlicht die enorme finanzielle Dimension dieser Ausgaben.

Deutlich von der Entscheidung über die Vergabe der kohäsionspolitischen $\mathrm{FZ}$ zu trennen ist die Frage, wie die EU mit jenen Entwicklungsunterschieden zwischen den Mitgliedstaaten verfährt, die bestehen bleiben, obwohl die Voraussetzungen zur Ausschöpfung der Entwicklungspotentiale der einzelnen Regionen mit Unterstützung der kohäsionspolitischen FZ geschaffen wurden. Die Gründe für die bestehenbleibenden Entwicklungsrückstände liegen dann in natürlichen und klimatische Bedingungen sowie soziokulturellen Einflüssen, die aber mit Hilfe zwischenstaatlicher FZ nicht beeinflußt werden können. ${ }^{1163}$ Es steht dann nicht mehr eine allokativ orientierte Ausgleichszielsetzung im Mittelpunkt, sondern eine ,reine” Umverteilung. Dieser Problemkreis steht im Zentrum des nachfolgenden Abschnittes.

\footnotetext{
${ }^{1161}$ Vgl. Europäische Kommission (1992b), S. 32. Die Angabe bezieht sich auf Preise des Jahres 1997.

${ }^{1162}$ Europäische Kommission (1993a), S. 123; vgl. auch Baldwin (1994), S. 155 ff. u. Achten (1996), S. 161 ff.; Mallosek (1996). Allgemein verschärfen sich durch die Osterweiterung die Probleme der Kohäsionspolitik. Neben der Höhe des Transfervolumens stellt v.a. die Fähigkeit zur Absorptions der Transfers eine enorme Schwierigkeit dar. Eine Lösungsmöglichkeit besteht darin, die Transfervergabe zunächst zu beschränken und nach und nach ein „wirtschaftlich vernüntiges Phasing-in” (Reichenbach/Beck (1997), S. 144) der neuen Mitgliedstaaten in die Kohäsionspolitik zu vollziehen (vgl. auch Franzmeyer/Weise (1997), S. 325 f.).

${ }^{1163} \mathrm{Vgl}$. hierzu Wagner (1993), S. 33 ff. Die soziokulturellen Einflüsse beziehen „sich einmal auf zu hohe Zeitpräferenzen und zum anderen auf wachstumshinderliche Verteilungspräferenzen". (Wagner (1993), S. 65 f.) Liegen diese Begründungsansătze vor, so spricht man von freiwilligen Entwicklungsrückstănden.
} 


\section{V-3 Horizontale fiskalische Ungleichgewichte}

\section{V-3.1 Handlungsnotwendigkeit für die EU - zum Begriff der Solidarität}

Art. 2 EGV zählt zu den Aufgaben der EU, die „Solidarität zwischen den Mitgliedstaaten zu fördern." Dieses grundlegende Prinzip des Integrationsprozesses ist den unbestimmten Rechtsbegriffen des Maastrichter-Vertragswerks zuzuordnen, da die weiteren Vertragsbestimmungen keine Konkretisierung vornehmen, welche exakte Bedeutung der „Solidarität” im Sinne des Vertrages zukommt. ${ }^{1164}$ Dies entspricht auch der Intention des Vertragswerks. Mit dem Begriff ,Solidarität” wird ein allgemeiner Wertmaßstab in das Primärrecht eingefuihrt, der bei allen Entscheidungen zu berücksichtigen ist. Hieraus ist mit Heinemann die Schlußfolgerung erlaubt, daß die EU „eindeutig auch ein Umverteilungsziel ähnlich dem Grundsatz der 'Einheitlichkeit der Lebensverhältnisse' in der deutschen Finanzverfassung"1165 zuläßt.

Die konkrete Umsetzung dieser Zielsetzung überlassen die Autoren des Vertragswerks bewußt der freien politischen Auseinandersetzung der staatlichen Entscheidungsträger aller Mitgliedstaaten. Diese Vorgehensweise ist akzeptabel, da die Begründung von EU-weiten Umverteilungsmaßnahmen auf subjektiven Werturteilen der betroffenen Akteure beruht und daher „nicht ökonomisch-rational nachprüfbar"1166 ist. Die Ergebnisse der politischen Abstimmungsprozesse spiegeln das bestehende Ausmaß der Solidarität innerhalb der Gemeinschaft wider. $^{1167}$

Die Umverteilungszielsetzung steht in einen systematischen Zusammenhang zum Kohäsionsziel. Denn in einer längerfristigen Betrachtungsweise bezieht sich die Frage der horizontalen Umverteilung auf jene räumlichen Unterschiede der Lebensverhältnisse zwischen den Mitgliedstaaten, die bestehen bleiben, obwohl in den einzelnen Mitgliedstaaten die vorhandenen Entwicklungspotentiale erfolgreich ausgeschöpft werden. Darin wird deutlich, daß die „reinen" Redistributionsmaßnahmen subsidiär zu den allokativen Ausgleichsmaßnahmen (Stärkung der Kohäsion) zu erfolgen haben. Die vorrangige Aufgabe der EU besteht darin, die strukturellen Voraussetzungen für die eigenständige Erzielung von Einkommen in den benachteiligten Mitgliedstaaten zu schaffen.

\footnotetext{
${ }^{1164}$ Vgl. hierzu Abschnitt IV-1.

${ }^{1165}$ Heinemann (1995), S. 15.

${ }^{1166}$ Fischer-Menshausen (1988), S. 656.

${ }^{1167} \mathrm{Vgl}$. Fischer-Menshausen (1988), S. 656.
} 
Darüber hinaus muß die EU-Ebene aber einen Konsens finden, ob und wenn ja in welcher Art und Intensität Maßnahmen zur Reduktion der verbleibenden Entwicklungsunterschiede ergriffen werden sollen. ${ }^{1168}$ Die Solidarität zum Ausgleich von Unterschieden der Lebensverhältnisse steht wiederum in einer engen Verbindung zum Stand der Kohäsion. Denn die Bürger der einzelnen Mitgliedstaaten „feel a stronger sense of distributive justice regarding the members of their own constituent unit than regarding members of the federation at large. The stronger is the sense of cohesion within the federation, the more will the problem of distribution be viewed in .. federation-wide terms; and the less it is, the more will distribution be viewed within the context of the member jurisdiction only." 169 Daher ist im Integrationsprozeß eine Zunahme der Solidarität zu erwarten, sofern die Bürger verstärkt einen europäischen Identifikationsbezug aufweisen. $\mathrm{Zu}$ dieser Entwicklung tragen die Maßnahmen zur Förderung der wirtschaftlichen und sozialen Zusammenhalts entscheidend bei. Sie bilden daher eine Voraussetzung für Bereitschaft zur reinen Umverteilung innerhalb der EU.

Allerdings müssen die europäischen Entscheidungsträger beachten, ob nicht die aktuelle Heterogenität der Lebensverhältnisse in der EU die Stabilität des Integrationsprozesses gefährdet. So ist denkbar, daß durch die Einführung der gemeinsamen Währung die bestehenden Einkommensunterschiede zwischen den Mitgliedstaaten deutlicher hervortreten und hierdurch in den Mitgliedstaaten mit geringerem Einkommensniveau die Akzeptanz für die EU schwindet. Sofern diese Überlegung zutrifft und der Erfolg der kohäsionspolitischen Maßnahmen (wie zu erwarten) einen sehr langen Zeitraum in Anspruch nimmt, ${ }^{1170}$ besteht schon heute eine Handlungsnotwendigkeit zur Ergreifung „rein” umverteilender Maßnahmen, um den Integrationsprozeß aufrechtzuerhalten. ${ }^{1171}$ Die umverteilungspolitischen Aktivitäten liegen dann auch im Eigeninteresse derjenigen Mitgliedstaaten, die keine FZ erhalten und erfolgen unabhängig vom Ausmaß der Solidarität in der EU. ${ }^{1172}$

\footnotetext{
${ }^{1168}$ Dieser Konsens knüpft an das Prinzip gerechter Lastenverteilung an (vgl. Abschnitt II-2). Vgl. auch FischerMenshausen (1988), S. 656 f. und Seidel (1992), S. 243.

${ }^{1169}$ Musgrave/Musgrave (1984), S. 514. Tendenziell ist die Solidarität zwischen den Teileinheiten einer Gemeinschaft umso weniger ausgeprägt, je größer und heterogener die bestehende Gemeinschaft ist. Daher wird die Ost-Erweiterung der $E U$ das Ausmaß der Solidarität fur den Gesamtraum der $E U$ verringern.

${ }^{1170} \mathrm{Vgl}$. hierzu Abschnitt V-2.2.2.

${ }^{1171}$ Diese FZ wirken als „Integrationskraft und Integrationsverstärker” (Feldsieper/Prokop (1996), S. 43).

${ }^{1172}$ Vgl. Peffekoven (1994), S. 105; vgl. hierzu auch Abschnitt III-3.1.2.2.1. Die Aufrechterhaltung des Integrationsprozesses ist eng mit der Kompensationsfunktion der FZ verbunden (vgl. hierzu Abschnitt V-5). Es besteht jedoch ein wichtiger Unterschied. Während an dieser Stelle Gerechtigkeitsüberlegungen mit Bezug zur gegenwärtigen Ist-Situation im Zentrum stehen, wird mit der Kompensationsfunktion die Sicherung von Kooperationsgewinnen angestrebt, die in der Zukunft anfallen werden.
} 


\section{V-3.2 Bestehende Aktivitäten der EU}

„Es gibt keinen rein horizontalen, expliziten und ungebundenen Finanzausgleich, der Finanzkraftunterschiede zwischen den Mitgliedsländern ausgleicht und dem ein einheitlicher Umverteilungsgedanke von reich zu arm zugrunde liegt." ${ }^{1173}$ Ein Ausgleich horizontaler fiskalischer Ungleichgewichte durch die zentrale EU-Ebene kann aber nicht nur über einen eigenständigen Finanzhilfemechanismus, sondern auch ausgabenseitig und/oder einnahmenseitig durchgeführt werden.

Auf der Einnahmenseite des EU-Haushalts hat das Finanzierungssystem der EU in der Vergangenheit regressive Züge aufgewiesen und erst in den letzten Jahren wurden Reformschritte eingeleitet, die zur Verwirklichung einer proportionalen Verteilung der Finanzierungslasten beitragen. Eine horizontale Umverteilung über die Einnahmenseite des EU-Haushalts findet folglich momentan nicht statt. ${ }^{1174}$

Demgegenüber werden auf der Ausgabenseite erhebliche horizontale Umverteilungswirkungen ausgelöst. Hierbei stehen aber die unterschiedlichen Aufgabenbereiche der EU im Mittelpunkt. Der Ausgleich horizontaler fiskalischer Ungleichgewichte bildet „nicht das Hauptziel dieser Tätigkeit”. ${ }^{1175}$ Die horizontalen Verteilungswirkungen der einzelnen Ausgabetätigkeiten summieren sich zu einem „,impliziten Finanzausgleich i.e.S.”, ${ }^{1176}$ dessen Gesamteinflußnahme auf die horizontalen fiskalischen Ungleichgewichte ,in hohem Maße intransparent"1177 bleibt.

Es zeigt sich daher, daß die EU-Ebene zum heutigen Zeitpunkt keine expliziten Maßnahmen zur ,reinen” Umverteilung finanzieller Mittel zwischen den Mitgliedstaaten durchführt.

\section{V-3.3 Der Ausgleich horizontaler fiskalischer Ungleichgewichte durch FZ}

\section{V-3.3.1 Zur Ausgestaltung der FZ aus rein ökonomischer Sicht}

Die Ergebnisse der theoretischen Analyse zur Ausgestaltung der FZ, die einen Ausgleich horizontaler fiskalischer Ungleichgewichte bezwecken, besitzen auch für die EU-Ebene Gültigkeit. Da keine Beeinflussung des Ausgabeverhaltens der transferempfangenden Mitgliedstaa-

\footnotetext{
${ }^{1173}$ Frick/Van der Beek/Hünger (1996), S. 360. So auch Seidel (1992), S. 243; Peffekoven (1994), S. 106 oder Häde (1996), S. 481.

${ }^{1174}$ Vgl. hierzu Abschnitt IV-2.1.4.1. So auch Franzmeyer (1996a), S. 133 f. und Häde (1996), S. 482 ff.

${ }^{1175}$ Postlep (1993), S. 90. Vgl. auch die Ausführungen zu den Problemfeldern der Regionalpolitik, die den hier angesprochenen Aspekt der Verteilungswirkungen der Ausgaben bereits aufgreifen (Abschnitt V-2.3.3).

${ }^{1176}$ Seidel (1992), S. 250; so auch Frick/Van der Beek/Hünger (1996), S. 360.

${ }^{1177}$ Frick/Van der Beek/Hünger (1996), S. 360; so auch Feldsieper/Prokop (1996), S. 45.
} 
ten angestrebt wird, sind die FZ als Pauschalzuweisungen ohne Verwendungsauflagen und ohne Eigenbeteiligung zu vergeben. ${ }^{1178}$

Die Ausgestaltungsprobleme der FZ liegen bei der Festlegung geeigneter Indikatoren zur Messung der Finanzkraft und des Finanzbedarfs der Mitgliedstaaten sowie der anzustrebenden Ausgleichsintensität:

- Die Bestimmung der Finanzkraft ist problematisch, weil die einzelnen Mitgliedstaaten über eine weitgehend uneingeschränkte Autonomie zur Gestaltung der Einnahmenseite der nationalen Finanzverfassungen verfügen. ${ }^{1179}$ Infolge dieser Gestaltungsfreiheit bestehen in der EU fünfzehn heterogene mitgliedstaatliche Einnahmensysteme. So erheben die Mitgliedstaaten unterschiedliche Steuerarten und die Ermittlung der Steuerschuld der einzelnen Steuern basiert auf stark voneinander abweichenden Steuerbemessungsgrundlagen und Steuersätzen. Die Finanzierung der Sozialversicherungen erfolgt in einigen Mitgliedstaaten über Steuereinnahmen, wohingegen die Mehrzahl der Mitgliedstaaten eigenständige Sozialversicherungsbeiträge erhebt. ${ }^{1180}$ Außerdem ist darauf $\mathrm{zu}$ verweisen, daß es keinesfalls allen Mitgliedstaaten gelingt das bestehende nationale Steuerrecht „mit dem gleichen Erfolg durchzusetzen." 1181 Die Ermittlung der Finanzkraft darf daher nicht auf die Erfassung der tatsächlichen Steuereinnahmen der Mitgliedstaaten beschränkt bleiben. ${ }^{1182}$ Vielmehr ist es notwendig, eine Normierung vorzunehmen, um diejenigen Faktoren der Einnahmeerzielung auszuschließen, die von den Mitgliedstaaten autonom zu verantworten sind. Allerdings ist es wegen der enormen Heterogenität der nationalen Einnahmensysteme sehr diffizil, die Vergleichbarkeit der Einnahmen herzustellen. ${ }^{1183}$

Bei den nachfolgenden Modellrechnungen werden zwei Schritte ausgeführt, um eine homogene Bemessungsgrundlage für den Vergleich der mitgliedstaatlichen Finanzkraft zu schaffen. ${ }^{1184}$ Zum ersten werden der Finanzkraftermittlung die gesamten laufenden Einnahmen der Mitgliedstaaten zugrunde gelegt, zu denen neben den direkten Steuern, den indirekten Steuern und den übrigen laufenden Einnahmen auch die von den Mitgliedstaaten

${ }^{1178} \mathrm{Vgl}$. hierzu Abschnitt III-3.1.2.2.2.

${ }^{1179}$ Vgl. hierzu auch Abschnitt IV-2.1.4.

${ }^{1180}$ Diese Bemerkung trifft insb. für Dänemark zu. Dort wird das gesamte System der sozialen Sicherung aus allgemeinen Steuereinnahmen finanziert.

${ }^{1181}$ Peffekoven (1994), S. 108.

${ }^{1182} \mathrm{Vgl}$. hierzu auch nochmals Abschnitt III-3.1.2.2.3.

${ }^{1183}$ So auch Postlep (1993), S. 90.

${ }^{1184} \mathrm{Zu}$ beiden Normierungsschritten wurden bereits im MacDougall-Bericht Überlegungen angestellt (vgl. Europäische Kommission (1977b), S. 457 ff.). Zur Ermittlung der durchschnittlichen Steueranstrengung vgl. auch Feldsieper/Prokop (1996), S. $46 \mathrm{ff}$. 
empfangenen Sozialversicherungsbeiträge zählen. ${ }^{1185}$ Durch diese umfassende Berücksichtigung der mitgliedstaatlichen Einnahmen wird verhindert, daß die Finanzkraftrelationen dadurch verzerrt werden, daß die Mitgliedstaaten ganz unterschiedliche Einnahmequellen zur Finanzierung ihrer Aufgaben heranziehen. ${ }^{186}$ Zum zweiten wird die volkswirtschaftliche Einnahmenquote ${ }^{1187}$ der einzelnen Mitgliedstaaten als ein (einfaches) Maß für den Anspannungsgrad der Besteuerung in den jeweiligen Mitgliedstaaten gebildet. Durch den Vergleich mit der durchschnittlichen Einnahmenquote in der EUR 15 wird ein Anhaltspunkt gewonnen, ob ein Mitgliedstaat überdurchschnittliche oder unterschiedliche Anstrengungen unternimmt, seine Einnahmekraft auszuschöpfen. Um auszuschließen, daß der von den Mitgliedstaaten autonom zu verantwortende Handlungsparameter des „tax-effort” in die Berechnung der Finanzausgleichsleistungen einfließt, werden deshalb bei der Bestimmung der Finanzkraft nicht die tatsächlichen Einnahmen eines Mitgliedstaates berücksichtigt, sondern jene Einnahmen, die sich ergeben hätten, sofern die mitgliedstaatliche Einnahmenquote dem durchschnittlichen Anspannungsgrad der Besteuerung der EUR 15 entsprochen hätte. Auf diese Weise wird die den Berechnungen zugrundezulegende Finanzkraft derjenigen Mitgliedstaaten, die besondere Anstrengungen zur Ausschöpfung der eigenen Einnahmequellen unternehmen, gesenkt; hingegen wird die Finanzkraft solcher Mitgliedstaaten, die nur einen geringen „tax-effort” aufweisen, nach oben revidiert.

- Bei der Ermittlung des Finanzbedarfs sind politische Entscheidungen unabdingbar, da es nicht möglich ist, objektiv zu bestimmen, welche Einnahmenausstattung die einzelnen Mitgliedstaaten zur Erfüllung der ihnen zugewiesenen Aufgaben benötigen. ${ }^{1188}$ Daher bietet es sich aus theoretischer Sicht an, auf eine zwischen den Mitgliedstaaten differenzierende Bestimmung des Finanzbedarfs zu verzichten und vereinfachend davon auszugehen, daß der Finanzbedarf in jedem Mitgliedstaat pro-Kopf gleich hoch sei. Für diese Vorgehensweise spricht auch, daß im Rahmen eines funktionalen Finanzausgleichsystem der EU weitere zwischenstaatliche Transfermechanismen bestehen, durch die spezifische Sonderlasten einzelner Mitgliedstaaten abgegolten werden. Dies gilt fuir Sonderbedarfe infolge positiver externer Effekte ${ }^{1189}$ und struktureller Benachteiligungen. ${ }^{1190}$

\footnotetext{
${ }^{1185} \mathrm{Vgl}$. hierzu Europäische Kommission (1997c), S. $188 \mathrm{ff}$.

${ }^{1186}$ Die Möglichkeit dieser Verzerrung dokumentiert sich am deutlichsten im Hinblick auf die sozialen Sicherungssysteme. Allerdings ist die umfassende Erfassung aller Einnahmen auch der Kritik ausgesetzt, da erhebliche ,technische Probleme der Abgrenzung und Bewertung” (Walthes (1996), S. 250) bestehen, die wiederum zu einer Verzerrung der ermittelten Finanzkraft führen können.

${ }^{1187} \mathrm{Die}$ volkswirtschaftliche Einnahmenquote berechnet sich aus dem Quotienten der gesamten laufenden Einnahmen und des BIP eines Mitgliedstaates.

${ }^{1188} \mathrm{Vgl}$. hierzu Abschnitt III-3.1.2.2.4 zur Bestimmung des Finanzbedarfs. Prägnant auch Postlep (1993), S. 90.

${ }^{1189} \mathrm{Vgl}$. Abschnitt V-1.

${ }^{1190} \mathrm{Vgl}$. Abschnitt V-2.
} 
- Die Frage, in welchem Ausmaß die bestehenden Differenzen zwischen dem Finanzbedarf und der Finanzkraft der einzelnen Mitgliedstaaten ausgeglichen werden sollen (Ausgleichsintensität), muß in politischer Auseinandersetzung bestimmt werden. Hierbei sind auch allokative Aspekte zu berücksichtigen, da eine sehr weitgehende Nivellierung der Finanzkraft, die Anreize der transferempfangenden Mitgliedstaaten beeinträchtigen kann, ausreichende Vorsorge für die eigenständigen Einnahmenquellen zu treffen. ${ }^{1191}$ Im Vordergrund stehen angesichts der enormen Entwicklungsunterschiede zwischen den Mitgliedstaaten jedoch verteilungspolitische Überlegungen zur horizontalen Gerechtigkeit. ${ }^{192}$

Sobald die staatlichen Entscheidungsträger Einigung über die Bestimmung der Finanzkraft und des Finanzbedarfs sowie die anzustrebende Ausgleichsintensität gefunden haben, liegen alle Faktoren fest, die anzeigen, welche Mitgliedstaaten sich in einer bestimmten Periode für den Erhalt von FZ qualifizieren. Die Vergabe der FZ folgt daher im Einzelfall einem Automatismus. Die staatlichen Entscheidungsträger besitzen keine diskretionären Ermessenspielräume, einzelne Mitgliedstaaten bei der Zuweisungsvergabe ein- oder auszuschließen.

\section{V-3.3.2 Die finanzielle Dimension}

Dieser Teilabschnitt vermittelt einen Eindruck von der finanziellen Dimension der Transfers, die ein Ausgleich horizontaler fiskalischer Ungleichgewichte zwischen den Mitgliedstaaten der EU zum heutigen Zeitpunkt auslösen würde. Abbildung V-7 liefert die Basisdaten für die Berechnung der FZ im Jahr 1997.

Die Spalten I-VI enthalten die Daten zur Ableitung der Finanzkraft der Mitgliedstaaten, die durch die Finanzkraftmeßzahl (FKM) ausgedrückt wird. Spalte IV gibt die gesamten laufenden Einnahmen der Mitgliedstaaten wieder. Dieses absolute Finanzaufkommen der Mitgliedstaaten entspricht der unnormierten FKM. Durch die Berücksichtigung der durchschnittlichen Einnahmequote der EUR 15 an Stelle der tatsächlichen Einnahmequote der einzelnen Mitgliedstaaten (vgl. Spalte III) wird die Normierung der FKM durchgeführt. Spalte V quantifiziert das absolute Finanzaufkommen der Mitgliedstaaten in Mrd. ECU, das der Ermittlung der Ausgleichszahlungen zugrundegelegt wird. Es zeigt sich, daß insb. für Irland, das Vereinigte Königreich und Griechenland durch die Normierung eine deutliche Revidierung der Finanz-

\footnotetext{
${ }^{1191} \mathrm{Vgl}$. Abschnitt III-3.1.2.2.5.

${ }^{1192}$ Hinsichtlich dieser Feststellung besteht eine Analogie zum horizontalen Länderfinanzausgleich in Deutschland. Auch dort müssen wegen der gravierenden Finanzschwäche der neuen Länder nach der Wiedervereinigung eindeutig verteilungspolitische Aspekte in das Zentrum der Finanzausgleichsregelungen gestellt werden; vgl. hierzu Ebert/Meyer (1998b); (1999); Lenk/Teichmann (1998).
} 
kraft nach oben erfolgt, wohingegen die Finanzkraft Schwedens und Dänemarks deutlich nach unten korrigiert wird.

Die Spalte VII bildet die Ausgleichsmeßzahl (AMZ) als Maß für den absoluten Finanzbedarf der Mitgliedstaaten ab. Es wird angenommen, daß der Finanzbedarf in jedem Mitgliedstaat pro-Kopf gleich hoch ist. Zudem wird vereinfachend davon ausgegangen, daß die exakte Höhe des Pro-Kopf-Finanzbedarfs durch die durchschnittliche Pro-Kopf-Finanzkraft innerhalb der EUR 15 (vgl. Spalte VI) zutreffend wiedergegeben wird. ${ }^{1193}$ Damit ergibt sich der absolute Finanzbedarf eines Mitgliedstaates durch die Multiplikation der durchschnittlichen FKMPro-Kopf der EUR 15, die im Jahr 1997 ca. 8700 ECU beträgt, mit der Bevölkerungszahl des jeweiligen Mitgliedstaates.

Durch die Gegenüberstellung der AMZ und FKM (vgl. Spalte VIII) läßt sich für jeden Mitgliedstaat sein Status beim Ausgleich horizontaler Ungleichgewichte ermitteln. Mitgliedstaaten, deren FKM die AMZ übersteigt (AMZ - FKM < 0; überdurchschnittliche Deckungsrelation) sind ausgleichspflichtig (AP; vgl. Spalte XI). ${ }^{1194}$ Mitgliedstaaten, deren FKM ihre AMZ nicht erreicht (AMZ - FKM > 0; unterdurchschnittliche Deckungsrelation) sind grundsätzlich ausgleichsberechtigt (AB; vgl. Spalte XI). ${ }^{1195}$ Der Quotient aus der FKM und der AMZ gibt Aufschluß über die relative Stärke der Finanzkraft der Mitgliedstaaten (vgl. Spalte DX). Aufgrund dieses Indikators läßt sich die Finanzkraftreihenfolge aller Mitgliedstaaten vor der Vergabe der FZ bilden (vgl. Spalte X). Luxemburg nimmt den Spitzenplatz ein (Finanzkraft: ca. 186 Prozent des europaweiten Durchschnitts). Mit großem Abstand folgt Dänemark auf Platz zwei mit einer relativen Finanzkraft von ca. 142 Prozent. Drei Mitgliedstaaten sind weit abgeschlagen: Portugal mit 46,2 Prozent, Griechenland mit 52,5 Prozent und Spanien mit 62,8 Prozent der durchschnittlichen Finanzkraft.

\footnotetext{
${ }^{1193}$ Vgl. hierzu Zimmermann/Henke (1994), S. 193.

${ }^{1194}$ Bei der Bestimmung der zu leistenden Transferzahlung wird davon ausgegangen, daß jeder ausgleichspflichtige Mitgliedstaat einen einheitlichen Prozentsatz seiner überdurchschnittlichen Finanzausstattung abtreten muß. Dieser Prozentsatz wird so bestimmt, daß exakt die notwendige Summe der Ausgleichsleistungen erreicht wird. Es erfolgt aber mit zunehmender überdurchschnittlicher Finanzkraft keine progressive Staffelung des abzutretenden Finanzmittel. Es wird ein linearer Tarif angewendet (vgl. zu diesem Vorgehen auch Feldsieper/Prokop (1996), S. 49).

${ }^{1195} \mathrm{Ob}$ ein ausgleichsberechtigter Mitgliedstaat tatsächlich $\mathrm{FZ}$ erhält hängt jedoch von der konkreten Ausgleichsvariante ab. Vgl. hierzu die nachfolgende Diskussion unterschiedlicher Ausgleichsmodelle.
} 
Abb. V-7: Die Basisdaten zum Ausgleich horizontaler fiskalischer Ungleichgewichte im Jahr 1997

\begin{tabular}{|c|c|c|c|c|c|c|c|c|c|c|c|}
\hline & I & II & III & IV & $\mathrm{V}$ & VI & VII & VIII & IX & $\mathrm{X}$ & XI \\
\hline EU-Staat & BZ in Mio. & $\begin{array}{l}\text { BIP in Mrd. } \\
\text { ECU }\end{array}$ & $\begin{array}{l}\text { Einnahmen- } \\
\text { quote }\end{array}$ & $\begin{array}{c}\text { FKM in Mrd. } \\
\text { ECU } \\
\text { (unnormiert) }\end{array}$ & $\begin{array}{c}\text { FKM in Mrd. } \\
\text { ECU } \\
\text { (normiert) }\end{array}$ & $\begin{array}{c}\text { FKM pro } \\
\text { Kopf (Tsd. } \\
\text { ECU) } \\
\text { (normiert) }\end{array}$ & $\begin{array}{c}\mathrm{AMZ} \text { in } \mathrm{Mrd} . \\
\mathrm{ECU}\end{array}$ & \begin{tabular}{|c|} 
AMZ-FKM \\
in Mrd. \\
ECU \\
(normiert) \\
\end{tabular} & $\begin{array}{c}\text { relative FK } \\
\text { pro Kopf } \\
\text { (normiert) }\end{array}$ & $\begin{array}{c}\text { FK- } \\
\text { Reihenfolge } \\
\text { (Rang) }\end{array}$ & Status \\
\hline B & 10,2 & 211,2 & 49,9 & 105,4 & 97,2 & 9,5 & 89,0 & $-8,1$ & $109,1 \%$ & 7 & AP \\
\hline DK & 5,3 & 142,9 & 58,1 & 83,0 & 65,7 & 12,4 & 46,3 & $-19,5$ & $142,1 \%$ & 2 & AP \\
\hline D & 82,1 & 1872,7 & 45,5 & 852,1 & 861,4 & 10,5 & 716,6 & $-144,9$ & $120,2 \%$ & 3 & AP \\
\hline E & 39,3 & 468,1 & 40,9 & 191,5 & 215,3 & 5,5 & 343,0 & 127,7 & $62,8 \%$ & 13 & $\mathrm{AB}$ \\
\hline F & 58,6 & 1242,1 & 50,4 & 626,0 & 571,4 & 9,8 & 511,5 & $-59,9$ & $111,7 \%$ & 6 & AP \\
\hline IRL & 3,6 & 64,7 & 34,7 & 22,5 & 29,8 & 8,3 & 31,4 & 1,7 & $94,7 \%$ & 11 & $\mathrm{AB}$ \\
\hline I & 57,5 & 1007,6 & 46,9 & 472,6 & 463,5 & 8,1 & 501,9 & 38,4 & $92,4 \%$ & 12 & $\mathrm{AB}$ \\
\hline $\mathbf{L}$ & 0,4 & 14,1 & 44,9 & 6,3 & 6,5 & 16,2 & 3,5 & $-3,0$ & $185,8 \%$ & 1 & AP \\
\hline NI & 15,6 & 316,1 & 47,8 & 151,1 & 145,4 & 9,3 & 136,2 & $-9,3$ & $106,8 \%$ & 8 & AP \\
\hline AT & 8,1 & 175,0 & 49,0 & 85,8 & 80,5 & 9,9 & 70,7 & $-9,8$ & $113,9 \%$ & 5 & AP \\
\hline FI & 5,1 & 102,2 & 54,7 & 55,9 & 47,0 & 9,2 & 44,5 & $-2,5$ & $105,6 \%$ & 9 & AP \\
\hline SE & 8,9 & 199,5 & 61,5 & 122,7 & 91,8 & 10,3 & 77,7 & $-14,1$ & $118,1 \%$ & 4 & AP \\
\hline UK & 59,0 & 1093,3 & 37,9 & 414,4 & 502,9 & 8,5 & 514,9 & 12,0 & $97,7 \%$ & 10 & $\mathrm{AB}$ \\
\hline EUR 15 & 374,3 & 7101,8 & 46,0 & 3266,8 & 3266,8 & 8,7 & 3266,8 & & & & \\
\hline
\end{tabular}

Quelle: eigene Berechnungen basierend auf Europäische Kommission (1997c), Tabelle 1, 5 u. 58-62. 
Abb. V-8: Fünf Varianten zum Ausgleich horizontaler fiskalischer Ungleichgewichte im Jahr 1997; Transfervolumen in Mrd. ECU

\begin{tabular}{|c|c|c|c|c|c|c|c|c|c|c|c|}
\hline & $\mathrm{I}$ & II & III & IV & $\mathrm{V}$ & VI & VII & VIII & IX & $\mathrm{X}$ & $\mathrm{XI}$ \\
\hline EU-Staat & $\begin{array}{c}\text { relative FK } \\
\text { vor Aus- } \\
\text { gleich }\end{array}$ & $\begin{array}{c}\text { Voll- } \\
\text { ausgleich }\end{array}$ & $\begin{array}{c}\text { relative FK } \\
\text { nach Voll- } \\
\text { ausgleich }\end{array}$ & $\begin{array}{c}50 \% \\
\text { Ausgleichs- } \\
\text { intensität }\end{array}$ & \begin{tabular}{|c|}
$\begin{array}{c}\text { relative FK } \\
\text { nach } 50 \% \\
\text { Ausgleichs- } \\
\text { intensität }\end{array}$ \\
\end{tabular} & $\begin{array}{c}75 \% \\
\text { Auffüllung }\end{array}$ & $\begin{array}{l}\text { relative FK } \\
\text { nach } 75 \% \\
\text { Auffüllung }\end{array}$ & $\begin{array}{c}90 \% \\
\text { Auffüllung }\end{array}$ & $\begin{array}{l}\text { relative FK } \\
\text { nach } 90 \% \\
\text { Auffüllung }\end{array}$ & $\begin{array}{l}\text { Plafonds- } \\
\text { lösung }\end{array}$ & $\begin{array}{c}\text { relative FK } \\
\text { nach } \\
\text { Plafonds- } \\
\text { lösung } \\
\end{array}$ \\
\hline B & $109,1 \%$ & $-8,1$ & $100,0 \%$ & $-4,1$ & $104,6 \%$ & $-2,6$ & $106,2 \%$ & $-5,0$ & $103,5 \%$ & $-0,9$ & $108,1 \%$ \\
\hline DK & $142,1 \%$ & $-19,5$ & $100,0 \%$ & $-9,7$ & $121,1 \%$ & $-6,3$ & $128,4 \%$ & $-12,0$ & $116,2 \%$ & $-2,3$ & $137,2 \%$ \\
\hline D & $120,2 \%$ & $-144,9$ & $100,0 \%$ & $-72,4$ & $110,1 \%$ & $-47,0$ & $113,7 \%$ & $-89,0$ & $107,8 \%$ & $-16,8$ & $117,9 \%$ \\
\hline GR & $52,5 \%$ & 44,0 & $100,0 \%$ & 22,0 & $76,2 \%$ & 20,9 & $75,0 \%$ & 34,7 & $90,0 \%$ & 5,1 & $58,0 \%$ \\
\hline $\mathbf{E}$ & $62,8 \%$ & 127,7 & $100,0 \%$ & 63,8 & $81,4 \%$ & 41,9 & $75,0 \%$ & 93,4 & $90,0 \%$ & 14,8 & $67,1 \%$ \\
\hline $\mathbf{F}$ & $111,7 \%$ & $-59,9$ & $100,0 \%$ & $-30,0$ & $105,9 \%$ & $-19,4$ & $107,9 \%$ & $-36,8$ & $104,5 \%$ & $-7,0$ & $110,4 \%$ \\
\hline IRL & $94,7 \%$ & 1,7 & $100,0 \%$ & 0,8 & $97,4 \%$ & 0,0 & $94,7 \%$ & 0,0 & $94,7 \%$ & 0,2 & $95,3 \%$ \\
\hline I & $92,4 \%$ & 38,4 & $100,0 \%$ & 19,2 & $96,2 \%$ & 0,0 & $92,4 \%$ & 0,0 & $92,4 \%$ & 4,5 & $93,2 \%$ \\
\hline $\mathbf{L}$ & $185,8 \%$ & $-3,0$ & $100,0 \%$ & $-1,5$ & $142,9 \%$ & $-1,0$ & $158,0 \%$ & $-1,8$ & $133,1 \%$ & $-0,3$ & $175,8 \%$ \\
\hline NI & $106,8 \%$ & $-9,3$ & $100,0 \%$ & $-4,6$ & $103,4 \%$ & $-3,0$ & $104,6 \%$ & $-5,7$ & $102,6 \%$ & $-1,1$ & $106,0 \%$ \\
\hline AT & $113,9 \%$ & $-9,8$ & $100,0 \%$ & $-4,9$ & $106,9 \%$ & $-3,2$ & $109,4 \%$ & $-6,0$ & $105,4 \%$ & $-1,1$ & $112,3 \%$ \\
\hline $\mathbf{P}$ & $46,2 \%$ & 46,5 & $100,0 \%$ & 23,2 & $73,1 \%$ & 24,9 & $75,0 \%$ & 37,8 & $90,0 \%$ & 5,4 & $52,5 \%$ \\
\hline FI & $105,6 \%$ & $-2,5$ & $100,0 \%$ & $-1,3$ & $102,8 \%$ & $-0,8$ & $103,8 \%$ & $-1,5$ & $102,2 \%$ & $-0,3$ & $105,0 \%$ \\
\hline SE & $118,1 \%$ & $-14,1$ & $100,0 \%$ & $-7,0$ & $109,1 \%$ & $-4,6$ & $112,3 \%$ & $-8,7$ & $107,0 \%$ & $-1,6$ & $116,0 \%$ \\
\hline UK & $97,7 \%$ & 12,0 & $100,0 \%$ & 6,0 & $98,8 \%$ & 0,0 & $97,7 \%$ & 0,0 & $97,7 \%$ & 1,4 & $97,9 \%$ \\
\hline Gesamtes FZ-Volumen & & 270,2 & & 135,5 & & 87,7 & & 165,9 & & 31,4 & \\
\hline
\end{tabular}

Quelle: eigene Berechnungen basierend auf Europäische Kommission (1997c), Tabelle 1, 5 u. 58-62. 
Auf der Basis dieser Daten können verschiedene Ausgleichsvarianten simuliert werden, die in unterschiedlichem Ausmaß für eine Beseitigung der bestehenden Differenzen zwischen dem Finanzbedarf und der Finanzkraft der einzelnen Mitgliedstaaten Sorge tragen. Abbildung V-8 demonstriert die Ergebnisse der Modellrechnungen für das Jahr 1997:

- Die erste Modellvariante verdeutlicht das maximal mögliche Transfervolumen (vgl. Spalte II). Die Differenz zwischen Finanzbedarf und -kraft (AMZ-FKM) aller Mitgliedstaaten wird vollständig ausgeglichen (Vollausgleich; Ausgleichsintensität 100 Prozent). Nach Durchführung des Vollausgleichs weisen alle Mitgliedstaaten eine relative Finanzkraft von 100 Prozent auf (vgl. Spalte III). Das zur Durchführung des Vollausgleichs erforderliche Finanzvolumen beträgt ca. 270 Mrd. ECU. ${ }^{1196}$ Dies entspricht mehr als dem Dreifachen des gesamten EU-Haushalts für das betreffende Jahr 1997. Eine vollkommene Nivellierung der Finanzkraft würde daher den finanziellen Rahmen der EU bei weitem sprengen.

Spanien profitiert durch die Zuweisung von 127,7 Mrd. ECU in absoluter Betrachtung am stärksten. In Relation zum BIP Spaniens hingegen entspricht dies „nur” 27,3 Prozent. In dieser Hinsicht sind Griechenland und Portugal die Hauptnutznießer der FZ: dort erreichen die Transfers 42,7 Prozent bzw. 53,5 Prozent des BIP. Insgesamt sind sechs Mitgliedstaaten ausgleichsberechtigt. Spanien, Portugal und Griechenland erhalten zusammen jedoch über 80 Prozent der Transfers. Der Hauptzahler ist in absoluter Betrachtung Deutschland, das ca. $120 \mathrm{Mrd}$. ECU zum Finanzvolumen beisteuern muß. Dies entspricht fast 45 Prozent des Gesamtvolumens. In Relation zum BIP Deutschlands beträgt dies 7,7 Prozent. In dieser Hinsicht wird Deutschland jedoch von Luxemburg und Dänemark deutlich übertroffen. Diese beiden Mitgliedstaaten sind verpflichtet 21,2 Prozent bzw. 13,6 Prozent ihres BIP zu transferieren.

- Aufgrund dieses Finanzierungsvolumens ist es evident, daß lediglich ein geringer Nivellierungsgrad realisierbar ist. Doch selbst ein Teilausgleich mit 50 Prozent Ausgleichsintensität $^{1197}$ (Modellvariante zwei) führt zu einem Transfervolumen von über $135 \mathrm{Mrd}$. ECU (vgl. Spalte IV).

- Aus diesem Grund könnten sich die politischen Entscheidungsträger dafür entscheiden, jedem Mitgliedstaat lediglich eine bestimmte relative Mindestfinanzkraft zu garantieren. In

\footnotetext{
${ }^{1196}$ Preise des Jahres 1997.

${ }^{1197}$ Jeder Mitgliedstaat mit einer unterdurchschnittlichen FK erhält eine FZ, die 50 Prozent der Differenz zwischen der AMZ und der FKM entspricht. Die ausgleichspflichtigen Mitgliedstaaten müssen 50 Prozent ihrer überdurchschnittlichen Finanzkraft zum Ausgleich horizontaler Ungleichgewichte abgeben. Diese Modellvariante ähnelt den Überlegungen zur ,hälftigen Abschöpfung”, die als Reformkonzept für den deutschen Länderfinanzausgleich diskutiert wird; vgl. hierzu Huber/Lichtblau (1997); (1998).
} 
diesem Fall erhalten nicht alle Mitgliedstaaten, bei denen die Differenz zwischen AMZ und FKM negativ ausfällt, Transferzahlungen, sondern nur diejenigen Mitgliedstaaten, deren relative Finanzkraft eine bestimmte Schwelle unterschreitet. In diesem Hinblick wurden zwei Modellvarianten in die Abbildung V-8 aufgenommen: die eine Variante garantiert allen Mitgliedstaaten mindestens 75 Prozent der durchschnittlichen Finanzkraft aller Mitgliedstaaten (vgl. Spalte VI); die andere Variante geht von einer Mindestfinanzkraft von 90 Prozent aus (vgl. Spalte VII). ${ }^{1198}$

Es zeigt sich, daß auch diese Modellvarianten die Finanzierungsproblematik nicht entscheidend entschärfen können. Zwar verbleiben bei beiden Varianten lediglich drei ausgleichsberechtigte Mitgliedstaaten doch müssen sie selbst bei der 75 Prozent Auffüllung enorme Transfermittel erhalten, um die Mindestausstattung zu erreichen. Das Finanzierungsvolumen beträgt bei dieser Variante $87,7 \mathrm{Mrd}$. ECU und übertrifft trotz der geringen Mindestauffüllung das gesamte EU-Haushaltsvolumen. Die ausgleichspflichtigen Mitgliedstaaten müssen 32,4 Prozent ihrer überdurchschnittlichen Finanzausstattung zur Finanzierung der Transfers abtreten. Die Auffüllung auf 90 Prozent der durchschnittlichen Finanzkraft erhöht das Ausgleichsvolumen auf 135,5 Mrd. ECU. ${ }^{1199}$ Diese Größenordnungen verdeutlichen den enormen Entwicklungsunterschied zwischen den drei finanzschwächsten und allen übrigen Mitgliedstaaten. Italien als Mitgliedstaat mit der viertschwächsten Finanzkraft weist eine relative Finanzkraft von 92,4 Prozent auf. Die Lücke zu Spanien, dem Mitgliedstaat mit der drittschwächsten relativen FK, beträgt annähernd 30 Prozent. $^{1200}$

- Bei der Vergabe von FZ zum Ausgleich horizontaler fiskalischer Ungleichgewichte ist es daher zum heutigen Zeitpunkt unumgänglich, eine betragliche Begrenzung des Transfervolumens zu bestimmen. ${ }^{1201}$ Diese Vorgehensweise wird durch die fünfte Modellvariante simuliert (vgl. Spalte X und XI). Dabei wird als Plafonds der Umfang der Mittel gewählt, der im Jahr 1997 durch die Strukturmaßnahmen der EU den Mitgliedstaaten zugewiesen wurde. Dies entspricht ca. 31,4 Mrd. ECU und kann aus dem Blickwinkel der finanziellen Beschränkungen der öffentlichen Haushalte der Mitgliedstaaten und der EU-Ebene als ein

\footnotetext{
${ }^{1198}$ Die Festlegung dieser Schwellenwerte kann nicht ökonomisch begründet werden. Hier wurden diese beiden Werte gewählt, da sie von der EU-Ebene bei den kohäsionspolitischen Maßnahmen die Schwellenwerte für die Vergabe von FZ im Rahmen der Strukturfonds (75 Prozent des BIP-Pro-Kopf) bzw. im Rahmen des Kohäsionsfonds (90 Prozent des BSP-Pro-Kopf) darstellen (vgl. näher Abschnitt V-2.3).

${ }^{1199}$ Die ausgleichspflichtigen Mitgliedstaaten müssen in diesem Fall 61,4 Prozent ihrer überdurchschnittlichen Finanzausstattung abtreten.

${ }^{1200}$ An dieser Stelle zeigt sich die enge (positive) Korrelation zwischen der Finanzkraft eines Mitgliedstaates und der Höhe seines BIP. Denn Spanien, Portugal und Griechenland wurden bereits im Rahmen der Überlegungen zur Kohäsionsproblematik als diejenigen Mitgliedstaaten identifiziert, die einen erheblichen Rückstand im Pro-Kopf-Einkommen zu den übrigen Mitgliedstaaten aufweisen (vgl. Abschnitt V-2.2.1).

${ }^{1201}$ So auch Grüske/Walthes (1994), S. 379 u. Walthes (1996), S. 319.
} 
realistisches Transfervolumen bezeichnet werden. Allerdings verdeutlicht Abbildung V-8, daß mit diesem FZ-Volumen nur eine sehr geringe Nivellierung der horizontalen fiskalischen Ungleichgewichte gewährleistet wird. Da die Zuweisungen nicht der Verwirklichung einer Mindestausstattung dienen, sind bei dieser Modellvariante alle sechs Mitgliedstaaten mit unterdurchschnittlicher relativer Finanzkraft ausgleichsberechtigt. Die Mittel genügen lediglich zur Realisierung einer Ausgleichsintensität von 11,6 Prozent. ${ }^{1202}$ Damit erzielt aber Portugal als das finanzschwächste aller Mitgliedstaaten auch nach Vergabe der FZ nur eine relative Finanzkraft von 52,5 Prozent des Durchschnitts der EUR 15.

Insgesamt belegen die Modellrechnungen das enorme Transfervolumen, das zum heutigen Zeitpunkt mit einem „merklichen” Ausgleich der zwischen den Mitgliedstaaten der EU bestehenden horizontalen fiskalischen Ungleichgewichte verbunden wäre. Diese Feststellung entspricht den Ergebnissen jüngerer Studien anderer Autoren, die analoge Modellrechnungen für die Jahre $1991,{ }^{1203} 1993^{1204}$ und $1995^{1205}$ durchgefuihrt haben. Allerdings gelangen die Studien sehr wohl zu deutlich voneinander abweichenden absoluten Transferbedarfen. Die Begründung hierfür liegt in der Heterogenität der Einnahmesysteme der Mitgliedstaaten, die es - wie bereits ausgeführt - nicht erlaubt, die tatsächlichen Steuereinnahmen der Mitgliedstaaten als Finanzkraft-Indikator heranzuziehen. Die einzelnen Studien unternehmen aber sehr unterschiedliche Anpassungsschritte zur Erfassung der Finanzkraft. ${ }^{1206}$ In Abhängigkeit von der gewählten Berechnungsvariante schwankt das Volumen der Finanzkraft, das der Bestimmung der Ausgleichsleistungen zugrunde gelegt wird, sehr stark. Hierdurch wird in der Folge auch das berechnete Finanzvolumen der Ausgleichszahlungen deutlich beeinflußt. ${ }^{1207}$

\footnotetext{
${ }^{1202}$ Alle ausgleichsberechtigten Mitgliedstaaten erhalten 11,6 Prozent der Differenz zwischen AMZ und FKM.

${ }^{1203} \mathrm{Vgl}$. Grüske/Walthes (1994).

${ }^{1204}$ Vgl. Feldsieper/Prokop (1996), Walthes (1996), S. $330 \mathrm{ff}$.

${ }^{1205}$ Vgl. Meyer (1996); Kraff(1997), S. 530 ff.; m.E. auch Scharmer (1997), S. 285 ff.

${ }^{1206}$ Es sind zwei Vorgehensweisen voneinander abzugrenzen. Einerseits werden die tatsächlichen Steuereinnahmen als Ausgangspunkt der Berechnungen verwendet; es werden aber einzelne Normierungsschritte vorgenommen, um die Vergleichbarkeit der Ist-Einnahmen der einzelnen Mitgliedstaaten herzustellen. So wird bspw. im Rahmen dieser Arbeit verfahren; ăhnlich gehen Feldsieper/Prokop (1996) und auch schon Europäische Kommission (1977a) vor. Andererseits werden alternative Bemessungsgrundlagen als Basis der Berechnungen benutzt. So legt Walthes (1996) der Ermittlung der Finanzkraft ausschließlich die MwSt.-Einnahmen der Mitgliedstaaten zugrunde. Hierfirr spricht, daß die MwSt.-Bemessungsgrundlage EU-weit harmonisiert und damit vergleichbar ist. Allerdings ist die MwSt. ein schlechter Indikator für die Leistungsfahigkeit eines Mitgliedstaates. Dies spricht dafur, direkt das BIP der Mitgliedstaaten als alternative Bemessungsgrundlage der Finanzkraft heranzuziehen (so wiederum Walthes (1996); auch Kraff (1997)). Diese Vorgehensweise hat jedoch den Nachteil, daß die einheitliche Erfassung des BIP in der $E U$ (noch) nicht zufriedenstellend erfolgt (vgl. zu dieser Problematik Hilber (1974), S. 119 ff. und knapp Prud'homme (1993), S. 348 f.).

${ }^{1207}$ Prägnant zeigt sich dieser Sachverhalt bei den Modellrechnungen von Walthes (1996). Auf Basis der MwSt.Bemessungsgrundlage berechnet Walthes im Jahr 1993 für die EUR 12 ein maximales Transfervolumen von 199,2 Mrd. ECU; auf Basis der BIP-Bemessungsgrundlage hingegen von 429,3 Mrd. ECU. Dabei ist unmittelbar einleuchtend, daß das Transfervolumen bei der zweiten Modellvariante stark überzeichnet wird, wenn der Finanzkraft der Mitgliedstaaten - wie bei diesen Berechnungen geschehen - ohne weitere Normierungsschritte das (gesamte) BIP zugrundegelegt wird (vgl. auch Kraff (1997), S. $541 \mathrm{ff}$.). Die hohe Variabilität der
} 


\section{V-3.3.3 Die Umsetzung der effizienten Problemlösung im politischen Entscheidungs- prozeß}

Die Erörterungen konzentrieren sich auf die Konfliktregelung und Konsensfindung bei der Institutionalisierung des Finanzhilfemechanismus. Die Anzahl der bei der Abstimmung zu berücksichtigenden Verhandlungspartner spricht für einen hohen Konsensbedarf, denn die Einrichtung eines neuen Finanzhilfemechanismus erfordert eine Veränderung der EUVerträge, die von den 15 Mitgliedstaaten nur durch einen einstimmigen Beschluß verabschiedet werden kann. Der Übergang zu einer Entscheidung mit qualifizierter Mehrheit ist bei dieser „Verfassungsentscheidung” ausgeschlossen. Möglicherweise reduziert sich die Anzahl der unabhängig voneinander zu berücksichtigenden Entscheidungsträger jedoch durch die Bildung von Interessenkoalitionen. Letztendlich stehen sich mit den ausgleichspflichtigen Mitgliedstaaten und den ausgleichsberechtigten Mitgliedstaaten nur zwei Gruppen gegenüber, die jeweils gleichgerichtete Interessen im Hinblick auf das Verhandlungsergebnis besitzen. Hierdurch verringert sich die Wahrscheinlichkeit eines Scheiterns der Verhandlungen. Allerdings führt die Bildung der Interessenkoalitionen zugleich zu einer expliziten Katalogisierung der Mitgliedstaaten in finanzstarke und finanzschwache Teileinheiten. „Cross-cutting-cleavages” können daher das Entscheidungsverhalten der Gruppen dominieren. ${ }^{1208}$

Demgegenüber spricht die geringe Komplexität der Verhandlungssituation für einen begrenzten Konsensbedarf. Aufgrund der rein distributiven Fragestellung besteht nicht die Notwendigkeit zur Lösung komplizierter Koordinationsprobleme. Die Sicherheit über die möglichen Wohlfahrtspositionen fördert die Wahrscheinlichkeit einer einvernehmlichen Verhandlungslösung, weil sich keine Spielräume für strategische Vorgehensweisen der Akteure ergeben.

Allerdings könnte sich bei reinen Verteilungsfragen gerade wegen dieser sicheren Kenntnis der Wohlfahrtspositionen die Konfliktwahrscheinlichkeit auch erhöhen. ${ }^{1209}$ Unter der Annah-

Modellergebnisse in Abhängigkeit von der Art der Finanzkraftermittlung verdeutlicht sich aber auch in dieser Arbeit. Sofern man die Normierung der gesamten laufenden Einnahmen gemäß der durchschnittlichen Einnahmenquote der EUR 15 unterläßt, erhöht sich das maximale Transfervolumen (ganz erheblich) von 270,2 Mrd. ECU auf 392,8 Mrd. ECU. Zusammenfassend betrachtet verweisen diese Ausfihrungen auf einen großen Forschungsbedarf, um eine leistungsfähige Systematik zum Vergleich der Finanzkraft heterogener Einnahmensysteme zu entwickeln.

${ }^{1208}$ Die Möglichkeit, daß es zur Ausformung dieser kompetitiven oder sogar feindseligen Interaktionsorientierung zwischen den Mitgliedstaaten kommt, wurde bereits im Hinblick auf die Internalisierung externer Effekte und die Vergabe kohäsionspolitischer FZ festgestellt (vgl. Abschnitt V-1.3.2.2 und V-2.4.2.2). Die Gefahr ihrer Entstehung ist bei der Vergabe ,rein" umverteilender FZ jedoch am größten, da in diesem Fall die Verteilungseffekte der FZ nicht durch die Verwirklichung einer gemeinsamen integrativen Problemlosung ,überdeckt” werden können, wie dies bei den ,mixed-motive-games” zur Internalisierung externer Effekte und zur Vergabe kohäsionspolitischer FZ der Fall ist.

${ }^{1209}$ Und zwar über die bereits angesprochene Gefahr hinaus, daß es zur Entstehung einer „cross-cutting-cleavage” und damit zur Ausbildung einer kompetitiven oder sogar feindseligen Interaktionsorientierung kommt. Die Konfliktwahrscheinlichkeit erhöht sich, obwohl die Verhandlungspartner sich „nur” egoistisch-rational verhalten. 
me einer egoistisch-rationalen Verhaltensweise werden potentielle Zahlerländer der Einrichtung des Finanzhilfemechanismus die Zustimmung verweigern. Zumindest entstehen bei der Festlegung der Regeln zur Ermittlung der Finanzkraft und des Finanzbedarfs Konflikte, da jeder Mitgliedstaat egoistisch-rational nur solche Bestimmungen akzeptiert, die die Nutzenposition des eigenen Mitgliedstaates verbessern. ${ }^{1210}$ Eine Einigung ist nur möglich, wenn die subjektive Interaktionsorientierung der ausgleichspflichtigen Mitgliedstaaten nicht ausschließlich egoistisch-rational orientiert ist, sondern auch kooperative Züge aufweist. Das Ausmaß einer kooperativen Interaktionsorientierung kann als ein Synonym für das Ausmaß der bestehenden Solidarität angesehen werden. Allerdings ist beim heutigen Stand des europäischen Integrationsprozesses allenfalls die Einigung auf einen Finanzhilfemechanismus zur „reinen” Umverteilung denkbar, der ein sehr geringes Transfervolumen aufweist (Modellvariante fünf).

Diese Einschätzung ändert sich erst dann wieder, wenn die Finanzkraftunterschiede so enorm sind, daß durch sie die (soziale) Stabilität des gesamten Integrationsprozesses gefährdet wird. ${ }^{1211}$ Die Blockade des Finanzhilfemechanismus wird dann selbst in den ausgleichspflichtigen Mitgliedstaaten Wohlfahrtsverluste auslösen. Aufgrund der positiven Auswirkungen der Transfers auf die Stabilität des Integrationsprozesses besitzen deshalb auch die ausgleichspflichtigen Mitgliedstaaten - selbst bei egoistisch-rationaler Verhaltensorientierung ein (eingeschränktes) Eigeninteresse an der Vergabe der FZ. ${ }^{1212}$ Dieses Eigeninteresse bezieht sich insb. auf die Verbesserung der Finanzausstattung derjenigen Mitgliedstaaten, deren relative Finanzkraft besonders weit hinter dem Durchschnitt der EU zurückliegt. Dies spricht dafür, daß schon heute die einvernehmliche Einigung auf einen Finanzhilfemechanismus möglich ist, der allen Mitgliedstaaten eine bestimmte Mindest-Finanzkraftausstattung garantiert. $^{1213}$

Auch durch eine Informationsstrategie ist es möglich, aktiv zur Konsensfindung zwischen den Verhandlungspartnern beizutragen. ${ }^{1214}$ Die EK kann als Moderator auf mögliche Gefahren für den Integrationsprozeß hinweisen, die sich wegen der bestehenden Finanzkraftunterschiede

\footnotetext{
${ }^{1210}$ Vgl. prägnant Postlep (1993), S. 90.

${ }^{1211}$ Im Extremfall sind Seperationsbewegungen derjenigen Mitgliedstaaten denkbar, die auf Dauer einen erheblichen Rückstand in ihrer Finanzkraft im Vergleich zu den übrigen Mitgliedstaaten akzeptieren müssen.

${ }^{1212}$ Der Nutzenzugewinn durch die Stabilität des Integrationsprozesses erlaubt es den ausgleichspflichtigen Mitgliedstaaten, zusätzliche Transfers zu leisten und dennoch einen positiven Nettonutzen aus der Einrichtung des Finanzhilfemechanismus zu ziehen. Vgl. hierzu auch Fischer-Menshausen (1988), S. 655.

${ }^{1213} \mathrm{Vgl}$. hierzu die Modellvarianten zwei bzw. drei in Abb. V-8. Es zeigt sich jedoch, daß schon eine relative moderate Mindestausstattung ein erhebliches Finanzienungsvolumen auslöst.

${ }^{1214}$ Die Analyse der Strategien zur aktiven Konsensbildung stellt den zweiten Schritt zur Analyse der Einigungswahrscheinlichkeit dar.
} 
ergeben, um die Wahrnehmung der Risiken bei den ausgleichspflichtigen Mitgliedstaaten zu beeinflussen. $^{1215}$

Langfristig sind zudem die Bemühungen der EU-Ebene, die Entwicklung eines europäischen Identifikationsbezugs innerhalb der einzelnen Mitgliedstaaten aktiv zu unterstützen (Überzeugungsstrategie), von elementarer Bedeutung. Den Kern dieser Strategie bilden die kohäsionspolitischen Maßnahmen. ${ }^{1216}$ Kurzfristig leisten diese Aktivitäten allerdings kaum einen Beitrag zur Deckung des Konsensbedarfs. Sie fördern vielmehr einen allmählichen Wandel der Interaktionsorientierung sowohl der staatlichen Entscheidungsträger als auch der einzelnen Bürger der Mitgliedstaaten, mit dem eine graduelle Zunahme der Solidarität innerhalb der EU verbunden ist. ${ }^{1217}$

In der kurzen Frist ist zusätzlich eine Form der Durchsetzungsstrategie gangbar. Durch den Übergang von Pauschalzuweisungen zur zweckgebundenen Vergabe der FZ kann die Nutzenposition der ausgleichspflichtigen Mitgliedstaaten aktiv verbessert werden. Da die Auflagenbindung gewährleistet, daß die Transfers nur für solche Zwecke verwendet werden, die von den transfergebenden Mitgliedstaaten als sinnvoll erachtet werden, erhöht sich deren Bereitschaft, Finanzmittel zum Ausgleich der horizontalen fiskalischen Ungleichgewichte bereitzustellen. ${ }^{1218}$ Zugleich löst die Zweckbindung Präferenzkosten bei den ausgleichsberechtigten und Ressourcenkosten zur Kontrolle der Zweckbindung bei den ausgleichspflichtigen Mitgliedstaaten aus. Es bleibt bei Beachtung aller Kostenkategorien fraglich, ob durch die Zweckbindung tatsächlich ein positiver Gesamtnutzen für beide Verhandlungsparteien realisiert wird, der die Voraussetzung für eine einvernehmliche Problemlösung zur FZ-Vergabe bildet.

Schließlich ist zu überprüfen, ob den Verhandlungspartnern Handlungsmöglichkeiten zur Verringerung des ursprünglichen Konsensbedarf verbleiben.

Im Hinblick auf die Festlegung der Regeln zur Bestimmung der Finanzkraft und des Finanzbedarfs wird die einvernehmliche Problemlösung durch die Gleichbehandlung aller Verhand-

\footnotetext{
${ }^{1215} \mathrm{Da}$ die $\mathrm{FZ}$ als Pauschalzuweisungen zwischen den Mitgliedstaaten vergeben werden, besteht bei dieser Rolle der $E K$ keine Gefahr zentralen Politikversagens. Denn die $E K$ besitzt keine Möglichkeit, ihren Kompetenzbereich durch die Befürwortung von $\mathrm{FZ}$ zum Ausgleich horizontaler fiskalischer Ungleichgewichte auszuweiten. Daher besteht für die $E K$ kein Anreiz, aus bloßem bürokratischem Eigeninteresse für eine FZ-Vergabe zu "werben" und so unerwünschte Zentralisierungstendenzen auszulösen.

${ }^{1216}$ Vgl. hierzu Abschnitt V-2 und weiter oben in diesem Abschnitt den Teilabschnitt V-3.3.1.

${ }^{1217}$ Dies spricht dafü, die Frage der Einrichtung eines ,rein" umverteilenden Finanzhilfemechanismus in bestimmten Zeitabständen immer wieder in das Verhandlungssystem der $E U$ einzubringen, selbst wenn zum heutigen Zeitpunkt eine einvernehmliche Problemlösung scheitert. Denn die Bewertungen der potentiellen Verhandlungslösungen ändern sich mit der Fortentwicklung des Integrationsprozesses und somit auch die Wahrscheinlichkeit eine einstimmige Problemlösung finden zu können.

${ }^{1218}$ Die Zweckbindung kann als eine Koppelgeschäft zugunsten der Transfergeber interpretiert werden. Vgl. hierzu auch Biehl (1988b), S. 77.
} 
lungspartner gefördert. Dies spricht dafür, weder bei der Bestimmung der Finanzkraft noch des Finanzbedarfs länderspezifische Sondertatbestände zuzulassen, sondern allgemeine Hilfsgrößen als Indikatoren heranzuziehen, die für alle Mitgliedstaaten gleiche Gültigkeit besitzen. Die Zustimmungswahrscheinlichkeit der Verhandlungspartner erhöht sich, wenn sie die Gewißheit gewinnen, im Vergleich zu den übrigen Mitgliedstaaten keine ungerechtfertigte Benachteiligung hinnehmen zu müssen. Denn besondere Bedarfssituationen für einzelne Mitgliedstaaten lassen sich nicht objektiv begründen und es bleibt zumeist unklar, ob die Grundlage der Sondertatbestände durch ein Eigenverschulden der betroffenen Mitgliedstaaten ausgelöst wurde oder nicht. ${ }^{1219}$

Die Zustimmungswahrscheinlichkeit der ausgleichspflichtigen Mitgliedstaaten kann auch dadurch erhöht werden, daß ihnen eine Garantie bestehender Besitzstände gegeben wird. Wie die Ausfuihrungen zu den Gemeinschaftspolitiken verdeutlichen, unternimmt die EU-Ebene zum heutigen Zeitpunkt eine Reihe ausgabenintensiver Aktivitäten, deren Verteilungswirkungen auch den finanzkräftigen Mitgliedstaaten zugute kommen. ${ }^{1220}$ Wird den ausgleichspflichtigen Mitgliedstaaten zugesichert, daß die absolute Höhe dieser Besitzstände erhalten bleibt, so werden sie eher einem Finanzausgleichsmechanismus zustimmen, dessen Einrichtung für sie eine Benachteiligung darstellt. Aus dieser Konsensfindungsstrategie resultiert jedoch eine Aufblähung des Finanzierungsvolumen. Darüber hinaus „zementiert” die Vorgehensweise bestehende Strukturen langfristig und blockiert so Veränderungen gerade in jenen Bereichen, die im Hinblick auf die Vertiefung und Erweiterung des Integrationsprozesses besonders reformbedürftig sind. ${ }^{1221}$

\section{V-3.4 Schlußfolgerungen}

Die einleitenden Ausfuihrungen des Teilabschnitts V-3.1 legen dar, daß die primärrechtlichen Bestimmungen der EU einen Ansatzpunkt für die Vergabe verteilungspolitischer FZ bieten. Für das Instrument der FZ spricht dessen Ausgestaltung als expliziter Finanzhilfemechanismus zur ,reinen” Umverteilung. Im Vergleich zu einer impliziten Umverteilung über das Finanzierungssystem der EU (Einnahmenseite) oder die verschiedenen Ausgabentätigkeiten der EU gewährleistet dies eine hohe Transparenz. Hierdurch werden die Handlungsspielräume der

\footnotetext{
${ }^{1219}$ Vgl. hierzu nochmals Abschnitt III-3.1.2.2.3 u. 4 zur Bestimmung der Finanzkraft und des Finanzbedarfs der GKS.

${ }^{1220} \mathrm{Vgl}$. hierzu die Ausführungen zu den bestehenden Aktivitäten der EU in den Abschnitten V-2.3.3 und V-3.2.

${ }^{1221} \mathrm{Vgl}$. hierzu auch Abschnitt IV-2.1.3.2. Hierin liegt jedoch der besondere Anreiz für die ausgleichspflichtigen Mitgliedstaaten. Denn die finanzstärkeren Mitgliedstaaten müssen im weiteren Integrationsprozeß in besonders hohem Ausmaß den Verlust von Zuweisungen der zentralen EU-Ebene „befürchten”. Daher besteht für sie die Aussicht, durch die Koppelung der Einrichtung des expliziten Finanzhilfemechanismus an die Garantie bestehender Besitzstände, insgesamt einen Netto-Nutzenzugewinn zu realisieren.
} 
staatlichen Entscheidungsträger verringert, Umverteilungsmaßnahmen entgegen der Wünsche der Bürger auszuführen. Langfristig wird hierdurch die Akzeptanz der Vorhaben in der Bevölkerung gefördert. ${ }^{1222}$

Angesichts der Ausgestaltung der Transfers als Pauschalzuweisungen können mit der Einrichtung des Finanzhilfemechanismus Zentralisierungsgefahren unterbunden werden. Denn der zentralen Ebene erschließen sich in diesem Fall keine Ansatzpunkte zur Einflußnahme auf die politischen Handlungsspielräume der transferempfangenden Mitgliedstaaten, wie dies bei einer auflagengebundenen Vergabe der FZ oder auch bei der Durchführung der umverteilungspolitischen Maßnahmen über die Einnahmen- oder Ausgabenseite des zentralen EUHaushalts möglich ist. Die Entstehung von Präferenzkosten bei den Transferempfängern ist daher ausgeschlossen.

Die Vergabe der FZ löst nur geringe politische Transaktionskosten aus. Denn sobald die staatlichen Entscheidungsträger Einigung über die Einrichtung des Finanzhilfemechanismus gefunden haben, folgt die Vergabe der FZ einem Automatismus. Eine Kontrolle der Mittelvergabe ist nicht durchzuführen, da die Zuweisungen nicht mit Auflagen verbunden sind. Daher fallen bei der jährlichen Ausführung des Ausgleichs keine Verhandlungs- und Kontrollkosten an. Erhebliche Verhandlungskosten entstehen nur einmalig im Rahmen des Entscheidungsprozesses zur Einrichtung der FZ.

Die Einrichtung eines FZ-Mechanismus zur ,reinen” Umverteilung würde zum heutigen Zeitpunkt jedoch mit hoher Wahrscheinlichkeit an der extremen Heterogenität der Mitgliedstaaten scheitern. Denn angesichts der großen (ökonomischen) Entwicklungsdifferenzen bestehen enorme Finanzkraftunterschiede zwischen den Mitgliedstaaten. Gleichzeitig stehen die erheblichen (ökonomischen wie auch sozio-kulturellen) Unterschiede der Entstehung einer weitergehenden Solidarität zwischen den Mitgliedstaaten im Wege, da ein enges Beziehungsgefüge zwischen dem Stand der Kohäsion und dem Ausmaß der Solidarität besteht. Der Versuch einen ,merklichen” Ausgleich der horizontalen fiskalischen Ungleichgewichte herbeizufuihren, würde daher rasch die Bereitschaft zur Unterstützung umverteilungspolitischer Maßnahmen überstrapazieren. Bereits sehr geringe, aus allokativen Gründen unbedenkliche Nivellierungsgrade führen zu einem extrem hohen Konsensbedarf im Rahmen der Abstimmungsprozesse

\footnotetext{
${ }^{1222}$ Kurzfristig ist es möglich, durch eine weniger transparente Ausführung der Umverteilungsmaßnahmen - bspw. über eine progressive Gestaltung der Finanzierungsbeiträge zur $E U-$, das Transfervolumen zu steigern. Jedoch müssen die Maßnahmen dann nicht den Wünschen der Bürger entsprechen. Es entstehen Präferenzkosten. Langfristig kann hierdurch die Akzeptanz der Maßnahmen gefahrdet werden, wenn die Bürger die Vorgehensweise der staatlichen Entscheidungsträger im Zeitablauf durchschauen (vgl. hierzu auch Franzmeyer (1996a), S. 134).
} 
zur Einrichtung eines expliziten Finanzhilfemechanismus und schließen praktisch jede Möglichkeit zur einvernehmlichen Entscheidungsfindung aus. ${ }^{1223}$

Die Abbildung V-9 skizziert in dieser Hinsicht ein ernüchterndes Bild des bisherigen Verlaufs des Integrationsprozesses. Sie verdeutlicht, daß innerhalb der EU in den vergangenen Jahren kaum Entwicklungsprozesse stattgefunden haben, die zu einer Verringerung des Transfervolumens beim Ausgleich horizontaler fiskalischer Ungleichgewichte beigetragen hätten:

Abb. V-9: Die Entwicklung des Transfervolumens in Mrd. ECU, ausgewählte Jahre 1975-97, Preise des Jahres 1997

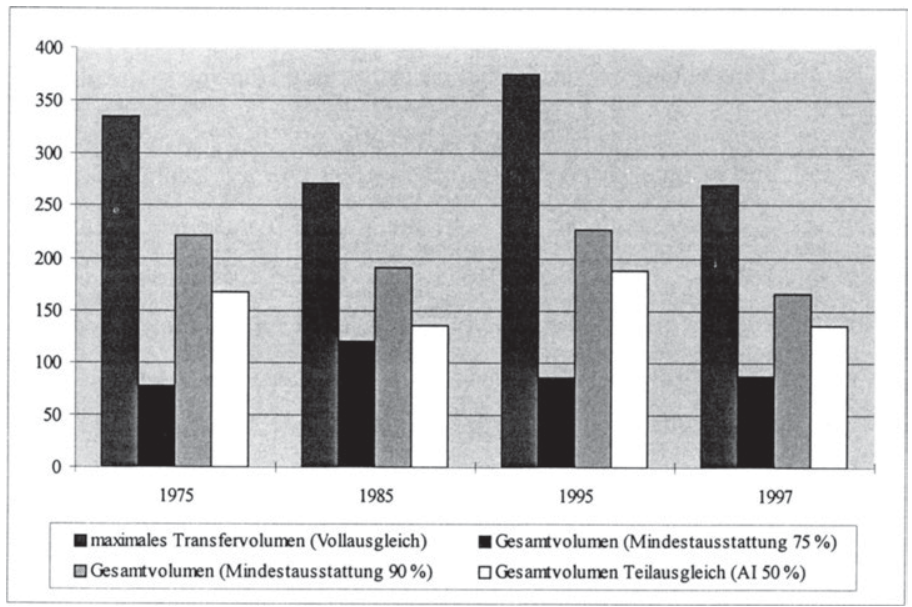

Quelle: eigene Darstellung.

Die Abbildung veranschaulicht die Ergebnisse der in Abschnitt V-3.3.2 angestellten Modellrechnungen nicht nur für das Jahr 1997, sondern auch für die Jahre 1975, 1985 und 1995. ${ }^{1224}$ Thr ist zu entnehmen, daß sich das Gesamtvolumen der FZ, um eine vorgegebene Ausgleichsintensität zu gewährleisten, in den vergangenen beiden Dekaden nicht für alle Modellvarianten entscheidend verringert hat. In der Abbildung sind die Finanzvolumina jeweils in Preisen des Jahres 1997 erfaßt und daher direkt vergleichbar. Ein Vollausgleich hätte im Jahr 1975

\footnotetext{
${ }^{1223}$ So auch Grüske/Walthes (1994), S. 379. Die Gesamtkonstellation zwischen dem Stand der Kohäsion, der Solidarität und der mitgliedstaatlichen Finanzkraftunterschiede stellt eine Dilemmasituation dar. Zum heutigen Zeitpunkt, zu dem enorme mitgliedstaatliche Unterschiede in den Lebensstandards bestehen, läßt die vorhandene EU-weite Solidarităt nur in geringem Ausmaß ,reine” Umverteilungsmaßnahmen zu. Zu einem zukünftigen Zeitpunkt, zu dem die Kohäsion deutlich weiter fortgeschritten sein wird und die einzelnen Mitgliedstaaten (auch dank der kohäsionspolitischen Maßnahmen) eigenständige Einkommenserzielungsmöglichkeiten entwickelt haben werden, die die Unterschiede in den Lebensstandards verringern, besteht hingegen eine höhere Solidarität, die auch verstärkt ,reine” Umverteilungsmaßnahmen zuläßt. Dann besteht aber eine geringere Handlungsnotwendigkeit zur Vergabe der horizontalen FZ.

${ }^{1224}$ Es sind vier Modellvariationen abgebildet. Lediglich die Plafondlösung bleibt ausgeklammert. Sie liefert keine Aussage, da dort das Gesamtvolumen ohnehin auf einen vorgegebenen Betrag normiert ist.
} 
Transfers in Höhe von 334,8 Mrd. ECU absorbiert. Im Hinblick auf diese Modellvariante hat sich das benötigte Transfervolumen bis zum Jahr 1997 (270,2 Mrd. ECU) um fast 20 Prozent verringert. Die Gewährleistung einer Mindestfinanzkraftausstattung von 75 Prozent hätte 1975 hingegen mit 78,2 Mrd. ECU und damit mit weniger als 90 Prozent des im Jahr 1997 benötigten Transfervolumens (87,7 Mrd. ECU) bewerkstelligt werden können. Eine kontinuierliche Abnahme der Ausgleichszahlungen kann daher im bisherigen Integrationsverlauf nicht festgestellt werden, so daß die Einrichtung eines „rein” umverteilenden Finanzhilfemechanismus aus finanziellen Gründen für die absehbare Zukunft ausgeschlossen bleibt.

Das langfristig äußerst beharrliche Finanzierungsvolumen zur Garantie einer Mindestausstattung (von 75 oder 90 Prozent) für die Mitgliedstaaten mit unterdurchschnittlicher Finanzkraft könnte dahingehend interpretiert werden, daß diese Mitgliedstaaten ihre Entwicklungspotentiale bereits ausschöpfen und die Höhe der Transferzahlungen auch in der Zukunft bestehen bleiben werden. Eine dauerhafte Steigerung der autonomen Finanzkraft der finanzschwachen Mitgliedstaaten durch die Vergabe kohäsionspolitischer FZ wäre in diesem Fall nicht mehr möglich. Die Ergebnisse des Abschnitts V-2 zur Kohäsionsproblematik sprechen jedoch dafür, daß die besonders finanzschwachen Mitgliedstaaten Portugal, Griechenland und Spanien noch erhebliche strukturelle Benachteiligungen aufweisen, die das hohe Transfervolumen (mit)verursachen. Es bestehen dort weiterhin erhebliche ungenutzte Entwicklungspotentiale, deren Ausschöpfung durch allokative Unterstützungszahlungen verbessert werden kann. Die Abbildung V-9 demonstriert daher eher die Tatsache, daß die kohäsionspolitischen Maßnahmen der EU in der Vergangenheit nur einen geringen Zielerreichungsgrad besessen haben. Entsprechend dem subsidiären Charakter der „reinen” Redistributionsmaßnahmen in Relation zu allokativen Maßnahmen muß deshalb zum heutigen Zeitpunkt den Maßnahmen zum strukturellen Ausgleich Vorrang eingeräumt werden: entwickelt sich in den transfergebenden Mitgliedstaaten die Bereitschaft, zusätzliche Transferleistungen für die benachteiligten Mitgliedstaaten zu erbringen, sollten diese nicht zur ,reinen” Umverteilung, sondern für allokative Ausgleichszahlungen verwendet werden. 


\section{V-4.1 Handlungsnotwendigkeit für die EU}

Eine der zentralen Zielvorgaben des Maastricht Vertrags ist die Einführung einer einheitlichen Währung. ${ }^{1225}$ Im Mai 1998 entschied der Europäische Rat, daß der Start der Währungsunion am 1. Januar 1999 mit elf Mitgliedstaaten erfolgt. Durch diese große Währungsunion ergeben sich ,einschneidende Veränderungen der ökonomischen Rahmenbedingungen in Europa”. ${ }^{226}$ Der stabilitätspolitische Handlungsspielraum der Teilnehmerstaaten zur Reaktion auf konjunkturelle Schwankungen wird deutlich eingeschränkt. ${ }^{1227}$ Die Teilnehmerstaaten treten ihre Souveränität zur Durchfuihrung einer autonomen Geldpolitik an die EZB ab. Der finanzpolitische Handlungsspielraum der öffentlichen Haushalte zur Verfolgung einer antizyklischen Fiskalpolitik wird beschnitten, da die Mitgliedstaaten zur Vermeidung übermäßiger öffentlicher Defizite verpflichtet sind. ${ }^{1228}$ Außerdem entfält der Wechselkurs als eigenständiges wirtschaftspolitisches Instrument. ${ }^{1229}$ Daher werden durch die Währungsunion die Problemlösungskapazitäten der Mitgliedstaaten zum Ausgleich kurz- bis mittelfristiger Schwankungen im Auslastungsgrad der Produktionsfaktoren deutlich reduziert.

Da die Schwankungen im allgemeinen ,eine relativ starke und relativ rasche Änderung des Angebots und/oder der Nachfrage"1230 darstellen und den Beschäftigungsstand in den Mitgliedstaaten beeinflussen, werden sie als reale Schocks bezeichnet. Sie werden zumeist durch externe Einflußfaktoren verursacht (exogene oder nicht-selbstverschuldete Schocks), wie bspw. neue Produktionstechnologien, veränderte Kundenpräferenzen (Modeerscheinungen), Lieferengpässe und gravierende Preisveränderungen bei Rohstoffen (Ölkrise), Naturkatastro-

\footnotetext{
${ }^{1225}$ Vgl. hierzu Abschnitt IV-1.

${ }^{1226}$ Krupp/Cabos (1998), S. 331. Scharrer (1998), S. 194 bezeichnet die Währungsunion als „ordnungspolitischen Quantensprung".

${ }^{1227}$ Vgl. unter vielen ausführlich Scharmer (1997), S. 220 ff.; knapp Francke (1993); S. 3 ff.; Nowotny (1997c), S. 111 f.; Wohlers (1997), S. 81 f.

${ }^{1228}$ Die Mitgliedstaaten mulssen das nominelle (fiskalische) Defizitkriterium, das zunächst nur als Qualifikationskriterium zur Teilnahme an der Währungsunion eingerichtet wurde, auch nach Beginn der Währungsunion einhalten. Das öffentliche Budgetdefizit aller GKS einschließlich der Sozialversicherungen darf höchstens drei Prozent des BIP betragen. Zur Sicherstellung dieser Haushaltsdisziplin wurde der Stabilităts- und Wachstumspakt in den Amsterdamer Vertrag aufgenommen (vgl. hierzu Callies (1997); zu den Konsequenzen für die Stabilisierungsbemühungen der Mitgliedstaaten knapp Francke (1993), S. 8 f. u. Hoeller/Louppe/Vegriete (1996), S. 17 f.; sehr kritisch Dumke (1996), S. 221).

${ }^{1229}$ Der Wechselkurs ist als Stabilisierungsinstrument allerdings umstritten: einerseits, weil durch eine Wechselkursanpassung undifferenziert alle Preise und nicht nur die relativen Preise derjenigen Sektoren, die von einem Schock betroffen sind, verändern werden (vgl. Teutemann (1992), S. 174); andererseits, weil der überwiegende Teil des Devisenhandels auf (monetäre) Finanztransaktionen und nicht auf den (realen) Güterhandel entfällt (vgl. Sinn (1997b), S. 218). Aus dieser Sicht kann der Wegfall des Wechselkursinstruments den stabilisierungspolitischen Handlungsbedarf sogar verringern.

${ }^{1230}$ Schmidt/Straubhaar (1995), S. 438, Fn 13.
} 
phen oder erhebliche Störungen im Produktionsablauf (Streiks). Sie können ihren Ursprung aber auch in der internen Wirtschafts- und Lohnpolitik eines Mitgliedstaates finden (endogene oder selbstverschuldete Schocks), wie bspw. bei einem Politik- oder Regierungswechsel. ${ }^{1231}$

Eine weitergehende Aufschlüsselung der Charakteristika möglicher Schocks demonstriert, in welcher Hinsicht ein stabilitätspolitischer Handlungsbedarf durch die Währungsunion entstehen kann:

- Zum einen ist die Unterscheidung zwischen symmetrischen und asymmetrischen Schocks zu vollziehen. Symmetrische Schocks, die das Einkommen und die Arbeitslosigkeit aller Mitgliedstaaten in ähnlicher Weise beeinflussen, stellen nur ein untergeordnetes Problem dar, da auf sie auch innerhalb der Währungsunion mit einer einheitlichen Geldpolitik der EZB und dem gemeinsamen Wechselkurs der Teilnehmerstaaten angemessen reagiert werden kann. ${ }^{1232}$ Das Problem bilden vielmehr asymmetrische Schocks, die die einzelnen Mitgliedstaaten unterschiedlich treffen und so Ungleichgewichte zwischen den Mitgliedstaaten auslösen. Sie erfordern eine differenzierte Problemlösung. In diesem Fall kann der Stabilisierungsbedarf weder durch den gemeinsamen Wechselkurs noch durch eine einheitliche Geldpolitik gedeckt werden. ${ }^{1233}$

- Zum anderen sind transitorische (konjunkturelle) Schocks von permanenten (strukturellen) Schocks abzugrenzen. Im zweiten Fall stellen kurz- bis mittelfristige stabilisierungspolitische Maßnahmen keine „ursachenadäquate Therapie”1234 dar. Es sind langfristig ausgerichtete Programme durchzuführen, die die Anpassungskapazität der Mitgliedstaaten dauerhaft erhöhen. ${ }^{1235}$ Im ersten Fall hingegen ,reicht es aus, wenn die wirtschaftlichen Akteure in der Lage sind, die eingetretenen Ungleichgewichte solange zu finanzieren, bis sich die adversen Schocks wieder zurückgebildet haben."1236

Damit steht in den folgenden Ausführungen die Frage im Mittelpunkt, wie innerhalb der Währungsunion auf reale Schocks reagiert werden kann, die die Teilnehmerstaaten asymmetrisch (länderspezifisch) und transitorisch (temporär) treffen. ${ }^{1237}$

\footnotetext{
${ }^{1231}$ Vgl. hierzu Schmidt/Straubhaar (1995), S. 438; Wohlers (1997), S. 79 f.

${ }^{1232}$ "Konzertierte Stabilisierungspolitik der EU-Staaten" (Grossekettler (1996), S. 17).

${ }^{1233}$ Vgl. bspw. Heinemann (1995), S. 35; Grossekettler (1996), S. 17; Schmidt, C. (1997), S.79.

${ }^{1234}$ Berthold (1997), S. 34.

${ }^{1235}$ Hierzu gehören bspw. die strukturpolitischen Maßnahmen; vgl. Abschnitt V-2. Werden dauerhaft, kurzfristige Maßnahmen zur Heilung langfristiger Probleme ergriffen besteht für den öffentlichen Sektor zudem die Gefahr einer zunehmenden Verschuldungsdynamik (vgl. Schweickert (1996), S. 188 f.).

${ }^{1236}$ Berthold (1997), S. 34; vgl. auch Grossekettler (1997), S. 121 und die kritischen Äußerungen bei Wohlers (1997), S. $80 \mathrm{f}$.

${ }^{1237}$ Diese Abgrenzung ist aber kaum trennscharf einzuhalten, „weil schwer zwischen temporären und dauerhaften Schocks zu unterscheiden ist" (Berthold (1997), S. 35) und weil Schocks, die zunächst alle Mitgliedstaaten symmetrisch treffen, asymmetrische Wirkungen hervorrufen können, wenn die einzelnen Mitgliedstaaten über unterschiedliche Anpassungskapazitäten zur Verarbeitung von Schocks verfügen.
} 
Empirische Untersuchungen kommen zu der Schlußfolgerung, daß asymmetrischen, temporären Schocks innerhalb der EU eine erhebliche Bedeutung zukommt. ${ }^{1238}$ Zumeist zeigen die Studien ein deutliches Gefälle zwischen dem Kern und der Peripherie der EU. „Im 'Kern', der Deutschland, die Benelux-Staaten, Frankreich, Österreich und - mit einigen Abstrichen - Dänemark umfaßt, haben asymmetrische Schocks eine erheblich geringere Bedeutung als in den anderen EU-Ländern”. ${ }^{1239}$ Für die große Währungsunion von elf Mitgliedstaaten sind asymmetrische Stabilisierungsprobleme daher äußerst relevant. Dabei fallen die Anpassungslasten in den peripheren Mitgliedstaaten besonders hoch aus. ${ }^{1240}$

Allerdings übt die dynamische Fortentwicklung der Integration einen wesentlichen Einfluß auf das Auftreten der asymmetrischen Schocks aus. In der wissenschaftlichen Literatur wird übereinstimmend davon ausgegangen, daß die durch die mitgliedstaatlichen Politik induzierten (endogenen) Schocks im Laufe des Integrationsprozesses abnehmen werden. ${ }^{1241}$ Durch die Vereinheitlichung der Geldpolitik und die immer engere Verflechtung aller Politikbereiche innerhalb der WWU werden die Spielräume für destabilisierende nationale Politikmaßnahmen eingeengt. „Die Wirtschafts- und Währungsunion kann in gewisser Weise als Veranstaltung zur künftigen Verhinderung solcher Schocks bezeichnet werden." ${ }^{\text {"1242 }}$ Weniger eindeutig ist der Zusammenhang zwischen dem Integrationsprozeß und den exogenen Schocks. Dabei ist unbestritten, daß sich durch die Vollendung des Binnenmarktes und die Einführung einer einheitlichen Währung der Austausch von Waren und Dienstleistungen in der EU erhöhen wird. Es bleibt jedoch ein wissenschaftlicher Streitpunkt, „ob sich damit die Produktion in den Mitgliedsländern der Europäischen Union stärker diversifiziert oder eher spezialisiert."1243 Führt die Vertiefung der Integration zu einer zunehmenden inter-industriellen Spezialisierung und regionalen Konzentration der Produktion, werden die einzelnen Mitgliedstaaten in zunehmenden Maße von unerwarteten Änderungen der Angebots- und Nachfragebedingungen betroffen. Die Bedeutung (exogener) asymmetrischer Schocks nimmt zu. ${ }^{1244}$ Erfolgt hingegen mit fort-

\footnotetext{
${ }^{1238}$ So bspw. Eichengreen (1990); Bayoumi/Eichengreen (1992); Kempa (1996); Auria (1997); Feldstein (1997); Knoppik (1997). Einen Überblick geben Heinemann (1995), S. 64 ff. und Willms (1998).

${ }^{1239}$ Wohlers (1997), S. 104. Vgl. auch Schmidt, C. (1997), S. 59 ff. Den Studien stellt sich jedoch das Problem, „daß die tieferen Ursachen von Schwankungen der wirtschaftlichen Aktivität ganz unterschiedlicher Natur sein können und oftmals nicht direkt beobachtbar sind" (Heinemann (1995), S. 65). Deshalb gelangen die Untersuchungen keinesfalls zu eindeutigen oder völlig übereinstimmenden Ergebnissen (vgl. auch Wohlers (1997), S. 82 f.).

${ }^{1240}$ So auch Heinemann (1995), S. 70 f. und Nerlich (1996), S. 16 f.

${ }^{1241}$ Vgl. bspw. Matthes (1997), S. 45 f.; Nowotmy (1997c), S. 113; Wohlers (1997), S. 80 ff. Zurückhaltender äußern sich jedoch Hagen/Hammond (1997), S. 199.

${ }^{1242}$ Matthes (1997), S. 45.

${ }^{1243}$ Berthold (1997), S. 19. Einen guten und aktuellen Überblick über die zum Teil sehr kontroverse und widersprüchliche Debatte gibt die Veröffentlichung von Mayer/Scharrer (1997).

${ }^{1244}$ Hiervon gehen bspw. Feldstein (1992), S. 20; Tichy (1993), S. 233; Peffekoven (1994), S. 105; Grossekettler (1997), S. 120; Knoppik (1997), S. 180 und Nowotny (1997c), S. 113 aus.
} 
schreitender Integrationstiefe ein verstärkter intra-industrieller Handel zwischen den Mitgliedstaaten, löst dies im Zeitablauf eine Diversifikation der Produktionsstrukturen der einzelnen Volkswirtschaften aus. Ein bestimmter Mitgliedstaat wird nun von Schwankungen in bezug auf eine spezifische Gütergruppe gesamtwirtschaftlich weniger stark betroffen, als eine hochspezialisierte Volkswirtschaft. Zudem werden (anfänglich) asymmetrische Schocks durch den intra-industriellen Handel „symmetrisch weitergereicht”. ${ }^{1245}$ Die Bedeutung der (exogenen) asymmetrischen Schocks nimmt aus diesem (theoretischen) Blickwinkel daher im Integrationsprozeß $a b .{ }^{1246}$ Allerdings wird diese Entwicklung von der anstehenden Ost-Erweiterung der EU beträchtlich verlängert, da wegen enormer Unterschiede der Produktionsstrukturen zwischen den neuen und alten Mitgliedstaaten „der inter-industrielle Handel noch lange Zeit bedeutend bleiben wird."1247

In diesem Zusammenhang zeigt sich erneut die zentrale Bedeutung des strukturellen Ausgleichs innerhalb der EU. Werden mit Hilfe der Kohäsionsmaßnahmen, in allen Mitgliedstaaten leistungsfähige Produktionsstrukturen und eine polyzentrische Raumstruktur mit jeweils spezifischen Entwicklungsmöglichkeiten aufgebaut, so diversifiziert sich die Wirtschaftstätigkeit der Mitgliedstaaten. Daher nimmt die Bedeutung asymmetrischer Schocks in der WWU infolge einer „erfolgreichen” Kohäsionspolitik ab. Die am allokativen Ausgleichsziel orientierten FZ stellen daher eine wesentliche Voraussetzung für die Vertiefung der Integration durch die WWU dar. ${ }^{1248}$

Die Theorie optimaler Währungsräume $e^{1249}$ nennt zwei mögliche marktliche Anpassungsmechanismen. ${ }^{1250}$ Zum einen die Flexibilität von Preisen und Löhnen (preisgesteuerte Koordination). Sie wird in einer Marktwirtschaft als „das First-best-Anpassungsinstrument bei jeglicher

\footnotetext{
${ }^{1245}$ Heise (1997), S. 84.

${ }^{1246}$ Diese Entwicklung erwarten bspw. Europäische Kommission (1990), S. 158 ff.; Franzmeyer (1996b), S. 515; Auria (1997), S. 235.

${ }^{1247}$ Berthold (1997), S. 20.

${ }^{1248}$ Vgl. auch Schmidt/Straubhaar (1995), insb. S. 439.

${ }^{1249}$ Die Theorie optimaler Währungräume stellt einen Vergleich der ökonomischen Kosten eines fixen Wechselkurssystems mit jenen eines festen Wechselkurssystems an (vgl. hierzu grundlegend Mundell (1961); McKinnon (1963) und Kenen (1969)). Den entscheidenden Kostenfaktor eines fixen Wechselkurssystems bildet der Verzicht auf das Instrument der Wechselkursanpassung an einen exogenen Schock. Die Höhe der hiermit verbundenen Kosten hängt von den alternativen Anpassungsmechanismen ab, die das Wechselkursinstrument ersetzen können. Im föderativen Referenzsystem (vgl. Kapitel II) sind die möglichen Anpassungsmechanismen unterschiedlich zu bewerten. Daher kann ,in normativer Hinsicht" (Lammers (1993), S. 190) nach dem optimalen alternativen Anpassungsmechanismus gesucht werden.

${ }^{1250}$ Berthold (1993c), S. 166 nennt die Verschuldung der Mitgliedstaaten auf den europäischen Kapitalmärkten als eine dritte marktliche Lösung des Stabilisierungsproblems. Mitgliedstaaten, die von positiven Schocks betroffen sind, stellen demnach Mitgliedstaaten, die von negativen Schocks betroffen sind, finanzielle Mittel zur Verfügung. Dieser Weg ist jedoch wegen der Defizitgrenzen des Stabilitäts- und Wachstumspakts des Amsterdamer Vertrages nur eingeschränkt gangbar.
} 
Art von Schwankungen auf der Angebots- und Nachfrageseite"1251 bezeichnet. In der EU verhindern zum heutigen Zeitpunkt jedoch unvollkommene Güter- und Faktormärkte den raschen Abbau exogener Schocks über diesen Mechanismus. „Reallohnsenkungen werden erfahrungsgemäß weder von den Gewerkschaften noch von den Politikern und der Bevölkerung in ausreichendem Maße akzeptiert," ${ }^{1252}$ und die Güterpreise geben nicht nach unten nach. ${ }^{1253}$ Zum anderen kann die Mobilität der Produktionsfaktoren, insb. der Arbeit, die Anpassungslasten übernehmen (mengengesteuerte Koordination). Wie weiter oben bereits ausgeführt, bestehen in der EU aber kulturelle und sprachliche Barrieren, die zu einer sehr geringen Arbeitskräftemobilität führen. Daher können die exogenen Schocks beim momentanen Integrationsstand durch keinen der beiden marktlichen Koordinationsmechanismen aufgefangen werden. ${ }^{1254}$ Eine differenzierte Analyse veranschaulicht zudem, daß die einzelnen Mitgliedstaaten sehr unterschiedliche Anpassungskapazitäten dieser marktlichen Instrumente besitzen. Mit dieser Feststellung wird die Konvergenz-Problematik innerhalb der EU thematisiert. Unter Konvergenz ist die Fähigkeit der einzelnen Mitgliedstaaten zu verstehen, ,eine gleichgerichtet stabilitätsorientierte makroökonomische Wirtschaftspolitik zu betreiben”. ${ }^{1255}$ Diese Fähigkeit wird von der "Qualität, Solidität und Stetigkeit nationaler wirtschaftspolitischer Prozeßsteuerung, vor allem auf dem Gebiet der öffentlichen Finanzen” sowie der „Qualität nationaler Rahmenbedingungen für effizientes Wirtschaften" ${ }^{1256}$ bestimmt, die wesentlich von der Flexibilität der Güter- und Faktormärkte und der regionalen Arbeitsmobilität abhängt. ${ }^{1257}$ Die diesbezüglichen Kapazitätsunterschiede deuten darauf hin, daß eine weitergehende Konvergenz der Mitgliedstaaten noch nicht stattgefunden hat. ${ }^{1258}$ Hierdurch wird der Problemdruck bei der Schockabsorption nochmals erhöht. Denn die unterschiedlichen Anpassungskapazitäten führen dazu, daß sich temporäre, asymmetrische Schocks in den Mitgliedstaaten unterschiedlich

${ }^{1251}$ Heinemann (1995), S. 41.

${ }^{1252}$ Grossekettler (1996), S. 18.

${ }^{1253} \mathrm{Vgl}$. auch Siebert (1996), S. $345 \mathrm{ff}$.

${ }^{1254}$ So auch Berthold (1993c), S. 151; Lammers (1993), S. 190; Heinemann (1995), S. 31 f.; Feldstein (1997), S. $21 \mathrm{ff}$. Unter Berïcksichtigung sozio-ökonomischer und distributiver Argumente ist es allerdings fraglich, ob die marktlichen Anpassungsinstrumente überhaupt die First-best-Instrumente darstellen. Die kritische Erorterung dieser Thematik wilrde jedoch den Rahmen der Arbeit sprengen; vgl. hierzu aber Ebert (1999), S. $179 \mathrm{ff}$.

${ }^{1255}$ Franzmeyer (1994), S. 206.

${ }^{1256}$ Franzmeyer (1994), S. 207 f.

${ }^{1257} \mathrm{Vgl}$. auch Schmidt/Straubhaar (1995), S. 441 f. und Walthes (1996), S. $79 \mathrm{ff}$.

${ }^{1258}$ Aus diesem Blickwinkel sind die Konvergenzkriterien des Maastricht Vertrags kritisch zu bewerten. Die $\mathrm{Zu}-$ lassung eines Mitgliedstaates zur Währungsunion wurde ausschließlich von nominellen (monetären und fiskalischen) Konvergenzkriterien abhängig gemacht. Dies führte zu dem Start der Währungsunion mit einem großen Teilnehmerkreis, der sich durch nominelle Konvergenz auszeichnet. Reale Konvergenzkriterien, so bspw. zur Flexibilität der Güter- und Faktormärkte oder zur allgemeinen Wettbewerbsfähigkeit der Mitgliedstaaten, wurden als Eintrittsbedingung nicht berücksichtigt. Daher startete die Währungsunion auch mit jenen Mitgliedstaaten, die aufgrund der realwirtschaftlichen Sphäre nur eine geringe Fähigkeit zu einer eigenständigen stabilitătsorientierten Wirtschaftspolitik besitzen (vgl. Schmidt/Straubhaar (1995); Franzmeyer (1996b)). 
stark auswirken und daß selbst temporäre, symmetrische Schocks in den Mitgliedstaaten mit besonders geringer Anpassungskapazität asymmetrische „Spuren hinterlassen”. 1259

Insgesamt ist zu folgern, daß für die zentrale Ebene eine Handlungsnotwendigkeit aus stabilisierungspolitischen Erwägungen besteht. Auf sie wird die „Hauptlast im Anpassungsprozeß zukommen." 1260 Diese Aussage gewinnt an Gewicht, wenn die Hysteresis-Effekte auf dem Arbeitsmarkt berücksichtigt werden. Denn ,wenn es nicht gelingt, die nach adversen Schocks eingetretenen Ungleichgewichte möglichst schnell wieder zu beseitigen, besteht die Gefahr, daß sie sich später kaum oder nur sehr schwer wieder beseitigen lassen." ${ }^{261}$ Es ist dann eine zunehmende Entwertung des Humankapital zu befürchten, wodurch sich die Arbeitsmarktprobleme verfestigen würden. Daher sind auf der zentralen Ebene stabilisierungspolitische Maßnahmen zu befürworten, auch wenn sie aus Sicht der Theorie optimaler Währungsräume „allenfalls eine Second- oder Third-best-Lösung”1262 darstellen.

\section{V-4.2 Bestehende Aktivitäten der EU-Ebene}

Zur Einrichtung eines Stabilisierungsmechanismus auf der zentralen Ebene sind zwei Wege beschreitbar. Der Ausgleich über die Einnahmenseite des EU-Haushalts durch das Wirken automatischer Stabilisatoren, die die Beitrgasverpflichtungen der Mitgliedstaaten beeinflussen, oder über die Ausgabenseite des EU-Haushalts durch die Etablierung eines expliziten Finanzhilfemechanismus mit zwischenstaatlichen FZ. Beide Instrumente bestehen zum heutigen Zeitpunkt auf der EU-Ebene (praktisch) nicht. ${ }^{1263}$

Ein System automatischer Stabilisatoren setzt eine weitgehende fiskalische Integration auf der Gemeinschaftsebene voraus. Es ist ein umfangreicher zentraler Haushalt erforderlich, durch den interregionale Einkommensumverteilungen ausgelöst und so regionenspezifische Konjunkturschwankungen ausgeglichen werden. Die automatischen Stabilisatoren wirken über

\footnotetext{
${ }^{1259}$ Wohlers (1997), S. 82; vgl. auch Nerlich (1996), S. 10 ff.

${ }^{1260}$ Peffekoven (1994), S. 105; so auch Feldstein (1992), S. 21; Ohr (1996), S. 221; Siebert (1996), S. 347; Grossekettler (1997), S. 120; Nowotny (1997c), S. 113; Scharmer (1997), S. 220 ff.

${ }^{1261}$ Berthold (1993c), S. 151. Vgl. zum Hysteresis-Problem Berthold (1993c), S. 159 ff.; (1997), S. 13 f.; Michaelis (1997), S. 163.

${ }^{1262}$ Lammers (1993), S. 190.

${ }^{1263}$ So auch Papaspyrou (1993), S. 483. Einen Ansatzpunkt zur Entwicklung eines expliziten Stabilisierungsmechanismus auf der zentralen Ebene bietet allerdings Art. 103a (2) EGV. Er bestimmt, daß einem Mitgliedstaat finanzieller Beistand geleistet werden kann, wenn er ,aufgrund außergewöhnlicher Ereignisse, die sich seiner Kontrolle entziehen, von Schwierigkeiten betroffen oder von gravierenden Schwierigkeiten ernsthaft bedroht" ist. Bislang wurde aber noch keine Überlegungen angestellt, auf Basis dieser primărrechtlichen Bestimmung einen konkreten Stabilisierungsmechanismus zu erarbeiten (vgl. Papaspyrou (1993); Thomas (1997), S. 231).
} 
eine progressive Einkommensbesteuerung durch den Zentralhaushalt und/oder über eine zentrale Sozial- und Arbeitslosenversicherung. ${ }^{1264}$ Empirische Studien verdeutlichen, daß automatische Stabilisatoren in anderen Ländern eine erhebliche stabilisierende Wirkung auslösen. So werden bspw. in den USA ca. 35 bis 44 Prozent einer regionalen Einkommensänderung durch automatische Stabilisatoren auf zentraler Ebene absorbiert. ${ }^{1265}$ Durch den bestehenden EU-Haushalt hingegen werden Schätzungen zufolge „Einkommenseinbußen in einem Mitgliedsland zu nicht mehr als $1 \%$ durch niedrigere Zahlungen an die Gemeinschaft ausgeglichen". ${ }^{1266}$ Die institutionellen Voraussetzungen für das Wirken automatischer Stabilisatoren sind zum heutigen Zeitpunkt nicht durchsetzbar. Weder die Vergabe der Einkommensteuer an den EU-Haushalt, noch die Einrichtung einer europaweiten Arbeits- und Sozialversicherung stehen auf der politischen Tagesordnung. Zudem scheitert das Vorhaben an dem Umfang des zentralen Haushalts, der heute ca. 1,27 Prozent des BIP beträgt. Um eine Wirkung als automatischer Stabilisator zu entfalten, müßte er ,sich in der Größenordnung zweistelliger Prozentsätze des BIP"1267 bewegen. Eine solch dramatische Erhöhung des Haushaltsvolumens ist auf absehbare Zeit politisch nicht zu verwirklichen. ${ }^{1268}$ Damit rückt die Frage ins Zentrum, ob die Einrichtung eines expliziten Finanzhilfemechanismus einen Lösungsweg für die Abfederung realer, temporärer, asymmetrischer Schocks darstellt.

\section{V-4.3 Der Ausgleich asymmetrischer Schocks durch FZ}

\section{V-4.3.1 Zur Ausgestaltung der FZ aus rein ökonomischer Sicht}

Zwischenstaatliche FZ durch die EU finden ihren Niederschlag auf der Ausgabenseite des EUHaushalts; sie dienen aber der Verstetigung der Einnahmen der Mitgliedstaaten. Hierzu bieten sich grundsätzlich zwei Wege an. ${ }^{1269}$ Erstens könnte eine antizyklische Variation bereits bestehender Ausgabenprogramme der EU mit horizontalen Wirkungen erfolgen. Es bestünde die Möglichkeit, die Ausgaben der Strukturfonds für stabilisierungspolitische Zwecke zu instrumentalisieren. Diese Lösungsvariante ist aber „,nicht sachgerecht”, ${ }^{1270}$ da es zu einer (zusätzli-

\footnotetext{
${ }^{1264} \mathrm{Vgl}$. zu diesen Überlegungen auch Nerlich (1996), S. $161 \mathrm{ff}$.

${ }^{1265}$ Vgl. Sachs/Sala-i-Martin (1992); für einen guten Überblick über diese und weitere Studien vgl. Goodhart/Smith (1993).

${ }^{1266}$ Europäische Kommission (1990), S. 186, m.w.N.

${ }^{1267}$ Harder (1997), S. 230. Die MacDougall-Gruppe vertrat 1977 in einem Gutachten allerdings die Meinung, daß bereits ein zentraler EU-Hauhalt von 5-7 Prozent eine angemessene Stabilisierungswirkung erlaubt, „doch würde die technische Gestaltung der betreffenden Haushaltsinstrumente kräftig und explizit auf diese Zielsetzungen hin zugeschnitten werden müssen." (Europäische Kommission (1977a), S. 78)

${ }^{1268}$ So auch Goodhart/Smith (1993), S. 425 ff.; Majocchi/Rey (1993), S. 478 und Wasmayr (1997), S. 204 f.

${ }^{1269}$ Vgl. hierzu Abschnitt III-3.1.3.1.

${ }^{1270}$ Wasmayr (1997), S. 239.
} 
chen) Vermischung unterschiedlicher Zielsetzungen käme und die Intransparenz der europäischen Fondswirtschaft (weiter) erhöht werden würde. ${ }^{1271}$

Dies spricht für die zweite Möglichkeit: der Einrichtung autonomer Verstetigungszuweisungen. Ein solcher Stabilisierungsmechanismus kann als eine Versicherung der Mitgliedstaaten gegen temporäre, länderspezifische Schocks interpretiert werden: „Eine faire Versicherung impliziert, daß es nicht zu einer systematischen Umverteilung zwischen den Versicherten kommt. Je nach Art der auftretenden Schocks können einmal die reicheren und ein anderes Mal die ärmeren Länder in den Genuß von fiskalischen Nettotransfers kommen. Gemessen am Erwartungswert würden sich diese Zahlungsströme in einem reinen Stabilisierungssystem aber in etwa die Waage halten." 1272

Diese Beschreibung des Stabilisierungsmechanismus als Versicherung verweist (indirekt) auf eine Reihe von Problemfeldern, die im Hinblick auf eine zieladäquate Ausgestaltung der zwischenstaatlichen FZ berücksichtigt werden müssen. Zwar liefern die theoretischen Überlegungen des Kapitel III Anhaltspunkte, sie lassen aber keine konkreten Aussagen in der Situation von Zielkonflikten zu: ${ }^{1273}$

(1) Der Empfängerkreis der FZ muß durch die Formulierung gezielter Empfangsauflagen auf problemadäquate Weise eingrenzt werden:

Von entscheidender Bedeutung ist, daß die Empfangsauflagen eine Trennung der kurz- bis mittelfristigen Konjunkturphänomene von langfristigen strukturellen Problemen und von verteilungspolitischen Maßnahmen erlauben.

Die Abgrenzung zu langfristigen strukturellen Problemen ist erforderlich, weil die stabilisierungspolitischen $\mathrm{FZ}$ nur temporär begrenzt zugewiesen werden dürfen. Deshalb muß die Empfangsauflage garantieren, daß die FZ an einen Mitgliedstaat nur vergeben werden, während eine negative Veränderung der Wirtschaftstätigkeit vonstatten geht. Ihr Einsatz wird jedoch gestoppt, ,sobald keine weiteren Veränderungen mehr eintreten, gleichgültig, auf welchem Niveau sich die Wirtschaft wieder stabilisiert hat."1274

Um die Trennung zu verteilungspolitischen Maßnahmen zu gewährleisten, ist ein Indikator als Empfangsauflage heranzuziehen, der an den Veränderungsraten und nicht an dem absoluten Niveau der Wirtschaftstätigkeit anknüpft. Denn „differences in the level of fiscal variables

\footnotetext{
${ }^{1271} \mathrm{Vgl}$. hierzu die Kritik an der bestehenden Regionalpolitik der EU in Abschnitt V-2.3.3.

${ }^{1272}$ Heinemann (1995), S. 52. So auch Hagen/Hammond (1997), S. 200. Heinemann (1995), S. 51 unterscheidet in diesem Zusammenhang die „Versicherungssolidarităt” im Rahmen der Stabilisierungsfunktion von der „Umverteilungssolidarität” im Rahmen der Distributionsfunktion.

${ }^{1273}$ Dies verdeutlichte schon Abschnitt III-3.1.3.1. Vgl. auch Hagen/Hammond (1997), S. 212.

${ }^{1274}$ Europäische Kommission (1993a), S. 77.
} 
that are functions of the level of economic activity are essential redistributive, whilst differences in fiscal variables that are a function of the rate of change of economic activity constitute stabilization."1275

Zugleich muß der Indikator anzeigen, ob die Veränderung der wirtschaftlichen Aktivität symmetrisch die gesamte EU betrifft oder aber asymmetrisch (länderspezifisch) nur einen oder mehrere Mitgliedstaaten. Nur im letzteren Fall können sich Teilnehmer am Versicherungsmechanismus für FZ qualifizieren. Um diese Abgrenzung treffen zu können, muß die Empfangsauflage die Veränderung der Wirtschaftslage der einzelnen Mitgliedstaaten relativ zur Wirtschaftstätigkeit der gesamten EU erfassen.

Italianer/Vanheukelen schlagen einen Indikator auf der Grundlage der Arbeitslosenraten vor, der eine Abgrenzung der Konjunkturphänomene von strukturellen und verteilungspolitischen Problemen erlaubt und anzeigt, ob ein symmetrischer oder asymmetrischer Schock vorliegt. ${ }^{1276}$ Ein Mitgliedstaat kann demnach FZ erhalten, wenn die monatliche Veränderung seiner Arbeitslosenrate im Jahresvergleich ${ }^{1277}$ positiv ist und von der durchschnittlichen Veränderung der Arbeitslosenrate der anderen Mitgliedstaaten nach oben abweicht. Für jeden Monatszeitraum erfolgt im Fall der Transferberechtigung eine einmalige Transferzuweisung. ${ }^{1278}$

Der Indikator von Italianer/Vanheukelen ist in allen Mitgliedstaaten (exakt) quantifizierbar, so daß eine objektive Bestimmung der transferberechtigten Mitgliedstaaten durchführbar ist. Damit ist es grundsätzlich möglich, die FZ „ohne weitere diskretionäre Prüfung durch Gemeinschaftsinstitutionen" ${ }^{1279}$ zuzuweisen. Für diese Vorgehensweise spricht der Zeithorizont der Konjunkturphänomene. „The periods when incomes are declining tend to be short, and policy must thus act rapidly if it is to have a stabilizing impact." ${ }^{1280}$ Eine zeitintensive, diskretionäre Einschätzung der FZ-Vergabe durch die EU-Ebene kann deshalb die Effizienz der Transfers beeinträchtigen oder sogar zu unerwünschten pro-zyklischen Wirkungen führen. ${ }^{1281}$

\footnotetext{
${ }^{1275}$ Goodhart/Smith (1993), S.419.

${ }^{1276}$ Grundsätzlich würde die Veränderung des BIP der Mitgliedstaaten den geeigneten Indikator zu Erfassung der Schwankungen der Wirtschaftstätigkeit der Mitgliedstaaten darstellen. Jedoch stehen die BIP-Daten nicht kurzfristig zur Verfügung. Daher würden die ,time-lags” zur Vergabe der FZ zu lang. Dies spricht dafür, die mitgliedstaatlichen Arbeitslosenraten als Indikator zu verwenden. Die entsprechenden Daten stehen kurzfristig zur Verfügung und können darüber hinaus innerhalb der gesamten EU, ,hochgradig einheitlich" (Europäische Kommission (1993a), S. 78) erhoben werden (vgl. hierzu Italianer/Vanheukelen (1993), S. 496 f.; Hagen/Hammond (1997), S. 207).

${ }^{1277}$ Der Jahresvergleich der monatlichen Daten wird herangezogen, um saisonale Schwankungen zu eliminieren.

${ }^{1278} \mathrm{Vgl}$. Italianer/Vanheukelen (1993), S. 496. Im jeweiligen Folgemonat qualifiziert sich ein Mitgliedstaat nur dann fulr eine Transferzahlung, wenn erneut eine Veränderung der Wirtschaftslage des einzelnen Mitgliedstaates relativ zur Wirtschaftstätigkeit der gesamten $E U$ erfolgte.

${ }^{1279}$ Wasmayr (1997), S. 241.

${ }^{1280}$ Goodhart/Smith (1993), S. 419.

${ }^{1281}$ Vgl. zur Zeitproblematik der Stabilisierungspolitik grundsätzlich Friedman (1948).
} 
Majocchi/Rey hingegen argumentieren, daß eine diskretionäre Überprüfung der FZ-Vergabe notwendig ist. „In order to minimize the chances of such assistance giving rise to perverse incentives, the provision of aid should be preceded by a careful examination of whether the shock in question could be reasonably considered as 'exogenous". ${ }^{1282}$ Sofern die Mitgliedstaaten die Einkommensverluste oder Beschäftigungsprobleme selbst verschuldet haben (endogene Schocks) werden keine FZ geleistet. Mit dieser Überprüfung soll das Problem des Moral-Hazard eingedämmt werden. Denn die Tatsache, daß die Lasten eines länderspezifischen Schocks von allen Mitgliedstaaten der EU getragen werden, kann die einzelnen Mitgliedstaaten bei einer automatischen Transfervergabe dazu verleiten, einen ,allzu sorglosen Umgang mit der versicherten Gefahr" ${ }^{1283}$ zu pflegen. ${ }^{1284}$

Allerdings ist in der Realität eine Abgrenzung von exogenen und endogenen Ursachen konjunktureller Schwankungen praktisch ausgeschlossen. ${ }^{1285}$ Eine politische Durchsetzung der Zurückhaltung der FZ wird unter diesen Umständen stets äußerst umstritten bleiben. ${ }^{1286} \mathrm{Zu}$ dem erfordert das diskretionäre Prüfungsverfahren Ressourcenkosten. Außerdem sollte das Moral-Hazard Problem im Rahmen der von Italianer/Vanheukelen vorgeschlagenen Empfangsauflagen nur eine untergeordnete Rolle spielen. Da der Stabilisierungsmechanismus bei einer negativen Veränderung des Indikators nur eine einmalige FZ gewährt, fällt der Anreiz, den Indikator bewußt zu manipulieren oder mit Absicht einen Rückgang der mitgliedstaatlichen Wirtschaftstätigkeit auszulösen, lediglich gering aus. Darüber hinaus kann das MoralHazard-Verhalten eines Mitgliedstaates durch die Entwicklung der Wirtschaftstätigkeit in den übrigen EU-Staaten „durchkreuzt” ${ }^{1287}$ werden. Da ein Abschwung der Wirtschaftstätigkeit nur dann zu FZ führt, wenn dieser relativ zu den übrigen Mitgliedstaaten erfolgt, bleiben die Transferzahlungen völlig aus, sofern die gesamte EU (symmetrisch) von einem Rückgang der Wirtschaftstätigkeit betroffen ist. ${ }^{1288}$

Majocchi/Rey fordern über die diskretionäre Prüfung der Moral-Hazard-Problematik hinaus weitere Empfangsauflagen, die sich auf die reale Konvergenz der transferempfangenden Mitgliedstaaten beziehen. Demnach erhalten solche Mitgliedstaaten, deren Anpassungskapazitäten an temporäre, asymmetrische Schocks von der zentralen Ebene als gering eingeschätzt werden, nur dann Finanzmittel zugewiesen, wenn sie Fortschritte beim Aufbau stabilisie-

\footnotetext{
${ }^{1282}$ Majocchi/Rey (1993), S. 476.

${ }^{1283} \operatorname{Sinn}(1997 \mathrm{~b})$, S. 216.

${ }^{1284}$ Die Moral-Hazard-Gefahr betonen eine Reihe an Autoren, so neben Majocchi/Rey (1993) und Sinn (1997b) auch Mélitz/Vori (1992), Lammers (1993); Heinemann (1995); Berthold (1997) und schon Peeters (1977).

${ }^{1285}$ Vgl. hierzu auch die Problematik der Informationsbeschaffung (Abschnitt V-4.3.2.1).

${ }^{1286}$ Vgl. hierzu den nachfolgenden Abschnitt V-4.3.2; vgl. auch Harder (1997), S. 228.

${ }^{1287}$ Europäische Kommission (1993a), S. 79.

${ }^{1288} \mathrm{Vgl}$. Europäische Kommission (1993a), S. 79; Wasmayr (1997), S. 241.
} 
rungspolitischer Anpassungskapazitäten innerhalb des eigenen Mitgliedstaates nachweisen können. ${ }^{1289}$

(2) Der zweite Ausgestaltungsaspekt betrifft die Frage, ob die Vergabe der FZ mit Verwendungsauflagen verbunden werden sollte. Für eine Zweckbindung an öffentliche Investitionen spricht die Möglichkeit, daß mit diesen Ausgaben besonders hohe Einkommens- und Beschäftigungseffekte ausgelöst werden und die Mitgliedstaaten diese Ausgaben flexibel variieren können. Allerdings zeigte die mikroökonomische Indifferenzkurvenanalyse, daß eine Zweckbindung bei einem relativ geringen Transfervolumen keine zusätzlichen Lenkungseffekte im Vergleich zu einer Pauschalzuweisung auslöst. Da die stabilisierungspolitischen FZ der EU zeitlich und betraglich begrenzt sowie subsidiär zu den mitgliedstaatlichen Stabilisierungsaktivitäten vergeben werden, spricht das zu erwartende Transfervolumen ${ }^{1290}$ tendenziell gegen eine Zweckbindung. ${ }^{1291}$ In einer längerfristigen Perspektive können zudem Konflikte zu den allokativen Zielen der Struktur- und Kohäsionsfonds auftreten. Im Rahmen der Fondswirtschaft soll den Mitgliedstaaten gerade eine langfristige Planungsgrundlage vermittelt werden. ${ }^{1292} \mathrm{Zu}$ beachten ist auch, daß die Formulierung der Verwendungsauflagen durch die EU-Ebene sowie die Beachtung der Verwendungsauflagen in den Transferempfängerstaaten einen „time-lag” auslöst, der die stabilisierungspolitische Effizienz der FZ beeinträchtigen kann. ${ }^{1293}$ Daher erscheint es insgesamt angezeigt, die Vergabe ungebundener Pauschalzuweisungen zu empfehlen. ${ }^{1294}$

(3) Um einen ,angemessenen” Ausgleich der konjunkturellen Schwankungen zu gewährleisten, muß eine betragliche Begrenzung der Mittelvergabe vorgeschrieben werden. Welches Ausmaß der Versicherung gegen temporäre asymmetrische Schocks als ,angemessen” angesehen wird, ist dabei eine politische Entscheidung. Sie ist Ausdruck „,der politischen Präferenzen, die die Risikoeinstellung widerspiegeln."1295 Je risikoaverser die Mitgliedstaaten sind, desto höher wird die Stabilisierungskraft der Finanzhilfemechanismus festgelegt.

\footnotetext{
${ }^{1289}$ Vgl. Majocchi/Rey (1993), S. 476. Der Vorschlag eröffnet der zentralen Ebene erhebliche diskretionäre Handlungsspielräume zur Formulierung und Überwachung der Empfangsauflagen.

${ }^{1290} \mathrm{Vgl}$. hierzu auch den nachfolgenden Absatz zur betraglichen Begrenzung der Mittelvergabe sowie die Ausführungen zur finanziellen Dimension des Finanzhilfemechanismus in Abschnitt V-4.4.

${ }^{1291}$ Die gleiche Aussage trifft für eine Eigenbeteiligung der Transferempfänger zu, die mit der Zweckbindung der FZ verbunden werden kann, um zusätzliche Lenkungseffekte auszulösen.

${ }^{1292} \mathrm{Vgl}$. Abschnitt V-2.3.3. Vgl. aber auch die abweichende Meinung von Majocchi/Rey (1993), S. 476.

${ }^{1293}$ Dieses Argument sehen auch Majocchi/Rey (1993), S. 476.

${ }^{1294}$ Diese Vorgehensweise steht zudem im Einklang mit der automatischen Vergabe der FZ. Sofern auf eine diskretionäre Überprüfung der FZ-Vergabe verzichtet wird, um den Zeitbedarf der Mittelvergabe zu verkürzen, wäre die Formulierung der Verwendungsauflagen kontraproduktiv; vgl. auch Wasmayr (1997), S. 242 f.

${ }^{1295}$ Europäische Kommission (1993a), S. 80.
} 
Die betragliche Begrenzung der Mittelvergabe wird von drei Gestaltungsparametern bestimmt. Bei der Frage einer Untergrenze zur Aktivierung des Stabilisierungsmechanismus wird festgeschrieben, ob jeder asymmetrische Schock zur Vergabe von FZ führt oder ob eine bestimmte Schwelle besteht, unterhalb derer ein wirtschaftlicher Abschwung eigenständig vom betroffenen Mitgliedstaat aufgefangen werden muß. Zum zweiten ist eine Einigung über die Höhe der Ausgleichszahlungen (Ausgleichsintensität) zu finden. Ein Tarif muß einer gegebenen relativen negativen Veränderung der Wirtschaftstätigkeit ein entsprechendes Volumen der FZ zuordnen. Zum dritten ist zu klären, ob eine Obergrenze der FZ-Zahlungen eingeführt wird, die pro Periode an einen Mitgliedstaat erfolgen kann, oder ob jeder Mitgliedstaat einen betragsmäßig unbegrenzten Anspruch auf die Stabilisierungstransfers besitzt. ${ }^{1296}$

Die Begrenzung der Mittelvergabe kann einen entscheidenden Beitrag zur Verringerung der Moral-Hazard Problematik leisten. So bewirkt die Einführung einer Untergrenze, daß „nur gravierende regionale oder sektorale Schocks mit deutlich meßbaren Rückwirkungen auf die verwendeten makroökonomischen Indikatoren .. zum Einsatz des Mechanismus führen."1297 Wird außerdem bei Überschreiten dieser Untergrenze nur ein teilweiser Ausgleich der Einkommenseinbußen des betroffenen Mitgliedstaates gewährt (begrenzte Ausgleichsintensität), so verbleibt für die Akteure kaum ein Anreiz, den „Versicherungsfall” durch bewußtes Fehlverhalten herbeizuführen.

(4) Schließlich ist auf die Frage einzugehen, welche GKS an der FZ-Vergabe zu beteiligen sind. Der Stabilisierungsmechanismus sollte nach Möglichkeit keine Ausweitung des EUHaushalts nach sich ziehen. „Ideally, payments into the system would equal payments out of the system in each period." ${ }^{1298}$ Dies würde einer horizontalen FZ-Vergabe von jenen Mitgliedstaaten, die einen positiven asymmetrischen Schock erfahren, an jene Mitgliedstaaten, die von einem negativen asymmetrischen Schock betroffen sind, entsprechen. ${ }^{1299}$ Es besteht jedoch die Gefahr, daß die horizontale Vergabe der FZ an der konkreten Ausgestaltung des Finanzmechanismus scheitert. ${ }^{1300}$ Als Alternative bietet es sich daher an, die Mittel für den Sta-

\footnotetext{
${ }^{1296}$ Vgl. Italianer/Vanheukelen (1993), S. 495 ff.; Wasmayr (1997), S. 245.

${ }^{1297}$ Wasmayr (1997), S. 242.

${ }^{1298}$ Hagen/Hammond (1997), S. 201.

${ }^{1299} \mathrm{Vgl}$. Hagen/Hammond (1997), S. 201. Eine Ausweitung des Volumens des EU-Haushalts ist angesichts der bestehenden Zentralisierungsbefürchtungen innerhalb der Mitgliedstaaten der $E U$ kritisch zu beurteilen. Scharmer (1997), S. 280 f. sieht darüber hinaus die Möglichkeit, daß eine Verschuldungsdynamik entstehen könnte, wenn die FZ nicht ,jeweils zeitgleich mit dem eingetretenen 'Versicherungsfall' erhoben" (Scharmer (1997), S. 280) und horizontal vergeben werden.

${ }^{1300}$ Es sei darauf verwiesen, daß der Finanzhilfemechanismus auf die relative Veränderung der Wirtschaftstätigkeit der einzelnen Mitgliedstaaten abstellt. Bei einer horizontalen Vergabe der FZ wären daher Fälle denkbar, in denen Mitgliedstaaten, die selbst einen Konjunkturabschwung durchlaufen, der aber relativ schwächer verläuft als in anderen Mitgliedstaaten, Transfers leisten müßten. Hierdurch würde jedoch die Wirtschaftslage des betreffenden Mitgliedstaates zusätzlich destabilisiert.
} 
bilisierungsmechanismus als Reserve in den EU-Haushalt einzusetzen und anschließend vertikal an die transferberechtigten Mitgliedstaaten zuzuweisen. Die einzelnen Mitgliedstaaten tragen zur Bildung dieser Reserve entsprechend ihres Anteils am BIP der EU bei. ${ }^{1301}$

Diese Verteilung der Finanzierungslasten verstößt jedoch gegen den Versicherungscharakter der FZ, wenn nicht alle Mitgliedstaaten mit gleicher Wahrscheinlichkeit die Versicherung in Anspruch nehmen. Um den Versicherungscharakter der FZ aufrechtzuerhalten, schlägt Wasmayr deshalb eine Abänderung der Verteilung der Finanzierungslasten zur Bildung der Stabilisierungsreserve vor. ${ }^{1302}$ Im Zeitablauf ist eine Äquivalenz zwischen dem Finanzierungsbeitrag und der „Schadenswahrscheinlichkeit”"1303 der einzelnen Mitgliedstaaten herzustellen. Diejenigen Mitgliedstaaten, die den Finanzhilfemechanismus relativ häufig in Anspruch nehmen, müssen einen erhöhten Beitrag zur Finanzierung der Stabilisierungsreserve leisten. So wird verhindert, daß sich der Stabilisierungsmechanismus nach und nach zu einem Umverteilungsinstrument fortentwickelt. Diese Vorgehensweise besitzt im Hinblick auf die große Währungsunion eine erhebliche Bedeutung. Denn wie die empirischen Studien verdeutlichen, werden die peripheren Mitgliedstaaten aller Voraussicht nach häufiger von asymmetrischen Schocks betroffen sein als die Kernländer der Währungsunion. ${ }^{1304}$ Zugleich kann „die Einführung gestaffelter Schadens- bzw. Beitragsklassen .. als Anreiz interpretiert werden, die Anpassungskapazität der jeweiligen nationalen Volkswirtschaft in bezug auf reale Schocks zu erhöhen." ${ }^{1305}$ Die Wahrscheinlichkeit, daß langfristig notwendige Strukturanpassungen in den Mitgliedstaaten wegen des (automatischen) Stabilisierungsmechanismus verzögert und hierdurch die Anpassungskosten auf die EU überwälzt werden, verringert sich. ${ }^{1306}$ Gegen diesen Vorschlag spricht allerdings, daß der Finanzhilfemechanismus zusätzlich verkompliziert wird. Zudem eröffnen sich Spielräume für politische Einflußnahmen, sofern es nicht gelingt, die Berechnung der Beitragshöhe objektiv zu quantifizieren. ${ }^{1307}$

\footnotetext{
${ }^{1301}$ Vgl. Europäische Kommission (1993a), S. 82; auch Mélitz/Vori (1992), S. 6 ff. Da der Haushaltsausgleich der $E U$ nicht durch die Aufnahme von Krediten hergestellt werden darf (vgl. Abschnitt IV-2.1.2) sollte der Gesamtumfang "dem theoretischen Höchstbetrag der Zahlungen entsprechen" (Europäische Kommission (1993a), S. 82). Dieser ergibt sich aufgrund der Regelungen zur betraglichen Begrenzung der FZ.

${ }^{1302}$ Vgl. Wasmayr (1997), S. 251.

${ }^{1303}$ Wasmayr (1997), S. 251.

${ }^{1304} \mathrm{Vgl}$. hierzu Abschnitt V-4.1.

${ }^{1305}$ Wasmayr (1997), S. 251.

${ }^{1306}$ Dieses Argument wird bspw. von Berthold (1997), S. $33 \mathrm{ff}$. und Feldstein (1997), S. 28 f. angeführt. Sie betonen, daß die Arbeitsmarktprobleme in der $E U$ fast ausschließlich strukturelle und nicht konjunkturelle Ursachen besitzen. Dies kann sich sowohl auf nicht-selbstverschuldete langfristige, strukturelle Anpassungsprobleme beziehen als auch auf selbstverschuldete wirtschafts- und lohnpolitische Anpassungsprobleme. Vgl. in diesem Zusammenhang aber Fn 1254 und die Einsicht, daß eine Abgrenzung selbstverschuldeter und nichtselbstverschuldeter Ursachen annähernd unmöglich ist.

${ }^{1307} \mathrm{~V}$ gl. Mélitz (1994).
} 
Die Diskussion der ökonomischen Ausgestaltung der FZ zum Ausgleich konjunktureller Schwankungen offenbart einen Zielkonflikt. Das Zeitproblem stabilisierungspolitischer Maßnahmen spricht eindeutig für die zweckungebundene, automatische Vergabe der FZ. ${ }^{1308}$ Hierdurch werden zudem (erhebliche) Ressourcenkosten eingespart. Jedoch sind maßgebliche Abgrenzungsprobleme und polit-ökonomische Überlegungen zu berücksichtigen. Es besteht die Gefahr, daß bei einer zweckungebundenen und automatischen Vergabe der FZ temporäre Schocks nicht (immer) von permanenten abgegrenzt werden können und die staatlichen Entscheidungsträger der transferempfangenden Mitgliedstaaten Moral-Hazard betreiben. Aus dieser Sicht ist eine diskretionäre, an restriktive Empfangsauflagen geknüpfte Vergabe der FZ zu befürworten. Nachfolgend wird die Durchsetzbarkeit der beiden Problemlösungsvarianten im politischen Entscheidungsprozeß analysiert. ${ }^{1309}$ Es wird untersucht, ob sich der Zielkonflikt hierdurch auflösen läßt: Besitzt eine der beiden Varianten eine größere Wahrscheinlichkeit im Rahmen des Willensbildungsprozesses effektiv umgesetzt werden zu können, so ist diese Ausgestaltungsvariante zu befürworten.

\section{V-4.3.2 Die Umsetzung der effizienten Problemlösung im politischen Entscheidungs- prozeß}

\section{V-4.3.2.1 Die Gewinnung der entscheidungsrelevanten Informationen}

Die Gewinnung der entscheidungsrelevanten Information stellt bei der automatischen FZVergabe keine Restriktion für die Problemlösungsfähigkeit im Entscheidungssystem dar. Entscheidungsrelevant sind in diesem Fall ausschließlich die monatlichen Arbeitslosenraten. Diese Informationen sind quantifizierbar und können für alle Mitgliedstaaten einheitlich erhoben werden. Diese Aufgabe übernimmt die europäische Statistikbehörde Eurostat. Damit ist auch ausgeschlossen, daß bei der Übermittlung der Informationen von den Mitgliedstaaten zur EUEbene ein Verlust oder eine Verfälschung der Daten erfolgt.

Ein anderes Bild ergibt sich bei der diskretionären FZ-Vergabe. In diesem Fall werden zur Entscheidungsfindung über die rein quantitativen Arbeitslosendaten hinaus eine Reihe qualitativer Informationen über die (potentiell) transferberechtigten Mitgliedstaaten benötigt. ${ }^{1310}$ Es muß eine Aussage getroffen werden, ob die bestehenden Empfangsauflagen eingehalten und ob die festgestellten asymmetrischen Schocks von den betreffenden Mitgliedstaaten selbstver-

\footnotetext{
${ }^{1308}$ Unumstritten ist die betragliche Begrenzung der Transfers.

${ }^{1309}$ Zur einfachen Unterscheidung der beiden Ausgestaltungsvarianten, wird im weiteren von der ,automatischen" FZ-Vergabe einerseits und der, ,diskretionären” FZ-Vergabe andererseits gesprochen.

${ }^{1310}$ Vgl. hierzu auch Majocchi/Rey (1993), S. 476.
} 
schuldet wurden (endogener Schock). Die zentrale Ebene ist zur Gewinnung dieser Kenntnisse wesentlich auf das Informationspotential der dezentralen Jurisdiktionen angewiesen. ${ }^{1311} \mathrm{Da}$ die einzelnen Teilsysteme des EU-Verflechtungssystems aber gegensätzliche Interessenlagen besitzen, ${ }^{1312}$ ist nicht mit einem kooperativen Zusammenspiel der Akteure zu rechnen. Gerade jene Mitgliedstaaten, die den Verlust von FZ befürchten müssen, werden die Informationen nicht unverzerrt und vollständig an die zentrale EU-Ebene weitergeben. Die diskretionäre FZVergabe steht daher vor einem erheblichen Informationsproblem. ${ }^{1313}$

\section{V-4.3.2.2 Die Fragen der Konfliktregelung und Konsensfindung}

\section{- Die automatische FZ-Vergabe}

Sofern sich die EU-Entscheidungsträger im Rahmen ihrer Verfassungsfunktion auf den automatischen Finanzhilfemechanismus geeinigt haben, stellt sich die Problematik der Konsensfindung und Konfliktregelung im Einzelfall nicht mehr. Zeigt der (exakt quantifizierbare) Arbeitslosenratenindikator einen Transfer an, erfolgt die Vergabe der FZ ohne weitere Prüfung. Daher rückt die Frage in den Mittelpunkt, welche Wahrscheinlichkeit besteht, daß die Mitgliedstaaten Einvernehmen über die Institutionalisierung dieses Vergabemechanismus finden.

Da die Einrichtung eines neuen Finanzhilfemechanismus eine Änderung der EU-Verträge nach sich zieht, muß die Entscheidung in jedem Fall einstimmig durch alle 15 Mitgliedstaaten getroffen werden. Es besteht außerdem kaum die Möglichkeit, Interessenskoalitionen zu bilden, da die einzelnen Mitgliedstaaten sehr unterschiedliche Präferenzen und Anpassungskapazitäten im Hinblick auf stabilisierungspolitische Fragen besitzen. ${ }^{1314}$ Die (große) Anzahl der Verhandlungsbeteiligten, die bei der Entscheidungsfindung unabhängig voneinander zu berücksichtigen ist, spricht deshalb für einen hohen Konsensbedarf.

${ }^{1311}$ Es ist unbestritten, daß bei den zu treffenden Entscheidungen in jedem Fall Auslegungsspielräume verbleiben. Die Fragestellungen sind nicht objektiv zu beantworten.

${ }^{1312}$ Die zentrale Ebene bemüht sich darum, Mitgliedstaaten, die die Empfangsauflagen nicht erfüllen, von den Zuweisungen auszuschließen. Diese Mitgliedstaaten hingegen versuchen, die FZ-Vergabe zu sichern.

${ }^{1313}$ Läßt man die Bedeutung der Ressourcenkosten außer acht, so kann der angestellte Vergleich zur Gewinnung der entscheidungsrelevanten Informationen als tautologisch bezeichnet werden. Denn im Fall der automatischen FZ-Vergabe wird das Problem, das bei der diskretionären FZ-Vergabe gelöst werden soll, ganz einfach ausgeklammert. Der relevante Gesichtspunkt ist jedoch, daß es bei der diskretionären FZ-Vergabe zur Aufwendung von Ressourcen zur Informationsgewinnung kommt, ohne daß eine (realistische) Aussicht besteht, die Problemlösung entscheidend verbessern zu können. Aus dieser Perspektive kann die automatische FZVergabe befüwortet werden.

${ }^{1314}$ Exemplarisch sei auf die Auseinandersetzung zwischen Deutschland und Frankreich um eine stärker beschäftigungswirksame Ausrichtung des Stabilitäts- und Wachstumspaktes verwiesen (vgl. Wolter/Hasse (1997)). Es zeigt sich, daß selbst zwei Mitgliedstaaten, die dem Kern der Währungsunion angehören, aufgrund unterschiedlicher Präferenzen keine gemeinsame stabilitätspolitische Interessenkoalition bilden können. 
Demgegenüber deutet die zu lösende Verhandlungsproblematik auf einen weniger hohen Konsensbedarf hin. Wenngleich die technische Ausgestaltung des Finanzhilfemechanismus komplizierte Details umfaßt, ${ }^{1315}$ ist die eigentlich Problematik des Ausgleichs konjunktureller Schwankungen relativ leicht zu erfassen, weil kurzfristige Phänomene im Zentrum der Überlegungen stehen. Diese lassen sich isoliert von einer Vielzahl langfristiger Entwicklungsprozesse verhandeln, deren Berücksichtigung eine undurchsichtige Gemengenlage gemeinsamer und gegensätzlicher Interessen der Mitgliedstaaten auslösen würde.

Der entscheidende Gesichtspunkt aber liegt in der Ausgestaltung des Finanzhilfemechanismus als ein Versicherungssystem gegen unvorhersehbare länderspezifische (exogene) Schocks. Die Unsicherheit der Mitgliedstaaten über die eigene Verhandlungsposition, die bei anderen Entscheidungssituationen den Konsensbedarf der Verhandlungen wesentlich erhöht, wird hier zum entscheidenden Faktor, der eine Einigung ermöglicht. Unterliegen die Mitgliedstaaten einem „Schleier der Unsicherheit”, ${ }^{1316}$ welche Mitgliedstaaten im Zeitablauf von den asymmetrischen Schocks betroffen sein werden, so wird die Teilnahme an der Versicherung attraktiv. Bereits bei geringer Risikoaversität verzeichnen langfristig alle Mitgliedstaaten einen Nutzenzugewinn. Dann erscheint eine einvernehmliche Einigung auf die Einführung der stabilisierungspolitischen FZ möglich.

Wie gezeigt bestehen jedoch Abgrenzungsschwierigkeiten zwischen temporären und permanenten Schocks. Zudem besitzen die Mitgliedstaaten unterschiedliche Anpassungskapazitäten und es existieren Spielräume für strategische Verhaltensweisen. Dies läßt darauf schließen, daß die einzelnen Mitgliedstaaten mit großer Wahrscheinlichkeit unterschiedlich häufig von asymmetrischen Schocks getroffen werden. Da dies den Entscheidungsträgern bekannt ist, besteht kein (ausreichender) Schleier der Unwissenheit. Einige Mitgliedstaaten werden davon ausgehen, daß der Finanzhilfemechanismus für sie keinen Nutzenzugewinn bedeutet. Aus diesem Blickwinkel erscheint die Einigung innerhalb des europäischen Verflechtungssystems auf einen reinen Automatismus bei der FZ-Vergabe unwahrscheinlich.

Es ist jedoch möglich, Strategien der aktiven Konsensbildung anzuwenden. ${ }^{1317}$ So kann der Vorschlag von Wasmayr zur Finanzierung des Finanzhilfemechanismus als (ex-post) Leistung von Kompensationszahlungen verstanden werden. Im Zeitablauf werden diejenigen Mitgliedstaaten zu höheren Beiträgen herangezogen, die in besonderem Maße von der FZ-Vergabe

\footnotetext{
${ }^{1315} \mathrm{Vgl}$. hierzu näher Italianer/Vanheukelen (1993) oder auch Hagen/Hammond (1997).

${ }^{1316}$ Vgl. hierzu Buchanan/Tullock (1962), S. 31 ff. Die Akteure sind nicht in der Lage zukünftige Ereignisse zu antizipieren. Im Extremfall besteht ein „Schleier der Unwissenheit”, bei dem die Akteure zusätzlich keine Kenntnisse über die Eigenschaften der anderen Akteure besitzen; vgl. hierzu grundlegend Rawls (1971).

${ }^{1317}$ Der zweite Schritt bei der Analyse der Einigungswahrscheinlichkeit.
} 
profitiert haben. Sie entlasten damit jene Mitgliedstaaten, die den Versicherungsmechanismus nur in geringem Umfang in Anspruch genommen haben. Damit verbessert sich die Nutzenposition derjenigen Mitgliedstaaten, die erwarten nur (relativ) selten von dem Finanzhilfemechanismus zu profitieren, und ihre Zustimmung zur angestrebten Verhandlungslösung wird wahrscheinlicher.

Insgesamt ist bei der automatischen FZ-Vergabe, wegen der spezifischen Problemstruktur bei der Einrichtung des stabilisierungspolitischen Finanzhilfemechanismus, mit einer hohen Intensität der Verhandlungen im Verflechtungssystem zu rechnen. Die Wahrscheinlichkeit des Scheiterns der Verhandlungen ist erheblich. Einigen sich die Akteure jedoch auf die Institutionalisierung der automatischen FZ-Vergabe, so fallen anschließend bei der (monatlichen) Vergabe der FZ keine (weiteren) Verhandlungs- und Entscheidungskosten an.

\section{- Die diskretionäre FZ-Vergabe}

Bei der diskretionären FZ-Vergabe ergibt sich ein gegensätzliches Bild. In diesem Fall ist die Wahrscheinlichkeit groß, daß sich die 15 Mitgliedstaaten auf die Einrichtung des Finanzhilfemechanismus einigen können. Denn es bleibt jedem Mitgliedstaat im verflochtenen Entscheidungssystem ein Einfluß auf die Vergabe der FZ im Einzelfall erhalten, selbst wenn der Indikator auf Grundlage der Arbeitslosenrate eine Transferberechtigung ,anzeigt”. Daher werden auch jene Mitgliedstaaten dem Finanzhilfemechanismus zustimmen, die bei der automatischen FZ-Vergabe „fürchten”, auch dann zur Leistung von Finanzbeiträgen herangezogen zu werden, wenn die asymmetrischen Schocks von den transferempfangenden Mitgliedstaaten selbstverschuldet wurden oder es sich um permanente Schocks handelt. Diese Einigung wird durch eine Konfliktvertagung ermöglicht. Die entscheidende und daher konfliktträchtige Beurteilung, wann es zur Vergabe einer FZ kommt, wird in die Zukunft verlegt. Lediglich die Festlegung der Beurteilungskriterien (Empfangsauflagen) erfolgt mit der Einrichtung des Finanzhilfemechanismus. Dies hat jedoch zur Folge, daß auch die Gefahr des Scheiterns einer einvernehmlichen Problemlösung auf die Einzelfallentscheidungen verschoben wird.

Die Notwendigkeit, ein Urteil über die Erfüllung der Empfangsauflagen und das Eigenverschulden für das Entstehen der Schocks zu fällen, erhöht die Komplexität der Verhandlungssituationen erheblich. Die Analyse dieser Problemstellungen schafft eine komplizierte Gemengenlage unterschiedlicher Interessen, da neben den kurzfristigen stabilisierungspolitischen Problemen auch langfristige Aspekte in die Entscheidungsfindung einbezogen werden. In den Mitgliedstaaten werden durch die Annahme der FZ nunmehr vielzählige Handlungsalternativen betroffen, da die Einhaltung der Empfangsauflagen bei den nationalen Politikmaßnahmen 
beachtet werden muß. Hierdurch können Präferenzkosten ausgelöst werden. ${ }^{1318}$ Zudem unterliegen die transferempfangenden Mitgliedstaaten einer größeren Unsicherheit hinsichtlich der Netto-Wohlfahrtseffekte, die sich durch die Annahme der FZ ergeben.

Solange die Einstimmigkeitsregel gilt, ist daher stets mit einem Scheitern der Verhandlungen zu rechnen, wenn die Vergabe der FZ an einen bestimmten Mitgliedstaat verweigert werden soll. Derjenige Mitgliedstaat, dem die Zurückhaltung einer stabilisierungspolitischen FZ droht, wird stets von seinem (faktischen) Veto-Recht Gebrauch machen und die einvernehmliche Entscheidungsfindung blockieren.

In dieser Situation ist es aussichtslos, die Zustimmung des betroffenen Mitgliedstaates durch die Verfolgung einer Informations- oder Überzeugungsstrategie aktiv gewinnen zu wollen. Selbst wenn es im Laufe der Verhandlungen gelingt, die staatlichen Akteure durch die Beseitigung bestehender Informationsdefizite von der Notwendigkeit der Empfangsauflagen bspw. zur Durchfuihrung langfristiger Strukturreformen - zu überzeugen, besteht kein Anlaß für die Entscheidungsträger des betreffenden Mitgliedstaates, „freiwillig” der Zurückhaltung der Transfers zuzustimmen. Die strategischen Reformen können auch durchgeführt werden, ohne auf die FZ zu verzichten. Die Blockade des Entscheidungssystems ist daher nur zu verhindern, wenn durch die Änderung der Entscheidungsregel der Konsensbedarf der Entscheidungssituation gesenkt wird. Dies kann entweder unter Beibehaltung der Einstimmigkeitsregel erfolgen, wenn der jeweils betroffene Mitgliedstaat von der Abstimmung im Ministerrat ausgeschlossen wird oder durch den Übergang von der Einstimmigkeitsregel zu einer Form der Mehrheitsentscheidung. ${ }^{1319}$

Allerdings bleibt es auch in diesem Fall unsicher, ob die aus Sicht des Gemeinwohls erwünschte Problemlösung realisiert wird. Denn es besteht eine hohe Wahrscheinlichkeit, daß diejenigen Verhandlungspartner, die befürchten, von den Sanktionen (relativ häufig) betroffen zu sein, ihr Abstimmungsverhalten absprechen. Sie einigen sich auf eine Konfliktminimierung durch gegenseitige formelle Gleichbehandlung. ${ }^{1320} \mathrm{Da}$ eine objektive Entscheidung über ein Selbstverschulden oder eine Einhaltung der Empfangsauflagen nicht möglich ist, müssen in

\footnotetext{
${ }^{1318}$ Dies ist bspw. dann der Fall, wenn die Empfangsauflagen ein bestimmtes tarif- oder wirtschaftspolitisches Verhalten vorschreiben, das nicht den Wertvorstellungen der betroffenen Bürger entspricht.

${ }^{1319}$ Grundsätzlich ist als dritte Alternative ein Verlagerung der Entscheidungskompetenz auf die $E K$ denkbar. Diese könnte als neutrale Instanz das übergeordnete Interesse der Gesamtheit der $E U$ vertreten. $\mathrm{Da}$ aber die $E K$ demokratisch nicht direkt legitimiert ist, bleibt diese Lösung aus politischen Gründen ausgeschlossen. Sie würde der vertikalen Gewaltenteilung gemäß der erweiterten Distributionsfunktion widersprechen (vgl. Abschnitt II-1).

${ }^{132}$ Hierbei ist nicht notwendigerweise eine explizite Vereinbarung der betroffenen Mitgliedstaaten angesprochen. Die Grundlage zur Verständigung ergibt sich (implizit) aufgrund der Problemstrukturen innerhalb der Verhandlungs- und Entscheidungsprozesse.
} 
einer langfristigen Perspektive eine Reihe der Mitgliedstaaten damit rechnen, von der Zurückhaltung der stabilisierungspolitischen FZ betroffen zu sein. In dieser unsicheren Entscheidungssituation können risikoaverse Verhandlungspartner einen Nutzengewinn realisieren, indem sie der Verhängung von Sanktionen gegen andere Mitgliedstaaten keine Zustimmung erteilen. Dieses Abstimmungsverhalten ist mit der Erwartung verknüpft, daß sich die übrigen Verhandlungspartner analog verhalten werden, wenn der eigene Mitgliedstaat von der $\mathrm{Zu}-$ rückhaltung der stabilisierungspolitischen FZ „bedroht” wird. Besitzen diese (risikoaversen) Mitgliedstaaten eine zur Beschlußfassung ausreichende Mehrheit, so kann die Koalition dieser Mitgliedstaaten das Verhandlungsergebnis bestimmen. ${ }^{1321}$ Infolgedessen würde auf die Verhängung der Sanktionen gänzlich verzichtet. Die Mitgliedstaaten, die an der strengen Beachtung der Empfangsauflagen interessiert sind, unterliegen im Abstimmungsprozeß. Es resultiert eine formelle Gleichbehandlung aller Mitgliedstaaten, da nur der quantitative Arbeitslosenratenindikator zur Vergabeentscheidung herangezogen wird. ${ }^{1322}$

Insgesamt zeigt sich, daß bei der diskretionären Vergabe der stabilisierungspolitischen FZ in jedem Fall mit einer erheblichen zeitlichen Ausdehnung der Verhandlungen zu rechnen ist. Diese Entscheidungsverzögerung (,time-lag”) stellt die stabilisierungspolitische Effektivität der gesamten Maßnahme in Frage. Dies spricht für die Beschleunigung des Willensbildungsprozesses durch die Änderung der Entscheidungsregel, wodurch aber die (endogene) Entwicklung konfliktminimierender Entscheidungsregeln ausgelöst werden kann, die zu Lasten einer differenzierten, flexiblen und aus ökonomischer Sicht problemadäquaten Verhandlungslösung geht. Kommt es zu der beschriebenen Gleichbehandlung aller Akteure, so ist der intendierte Sanktionsmechanismus gar nicht wirksam. ${ }^{1323}$ Die aufgewendeten Verhandlungsund Entscheidungskosten stellen dann einen unnötigen Ressourcenaufwand dar.

\section{V-4.3.2.3 Die Frage der Implementation}

Im Hinblick auf die Implementation ist auf die grundsätzlichen Probleme der Durchfuihrung konjunkturpolitischer Maßnahmen zu verweisen. ${ }^{1324}$ Hierzu gehört die Frage der Auswahl

\footnotetext{
${ }^{1321}$ In jedem Fall kann die Koalition dieser Mitgliedstaaten die Entscheidungsfindung durch die übrigen Mitgliedstaaten blockieren.

${ }^{1322}$ Dies ist eine politische „Verzerrung” des Einsatzes der stabilisierungspolitischen FZ. Denn die Gleichbehandlung wird von den Mitgliedstaaten wegen strategischer Überlegungen zum politischen Abstimmungsprozeß präferiert. Die ökonomische Notwendigkeit zur Ungleichbehandlung der einzelnen Mitgliedstaaten, die durch die Empfangsauflagen durchgesetzt werden soll, geht nicht in das Entscheidungskalkül ein; vgl. hierzu auch Nowotny (1996), S. 611.

${ }^{1323}$ Dies bedeutet, daß die befürchteten Anpassungsverzögerungen bei permanenten Schocks sowie die MoralHazard Problematik unverändert bestehen bleiben.

${ }^{1324}$ Vgl. hierzu Nowotny (1996), S. 609 ff.
} 
geeigneter Einzelmaßnahmen mit hoher „Stabilisierungseffizienz" ${ }^{1325}$ beim Einsatz der FZMittel in den Mitgliedstaaten. Es ist zu beachten, daß Verzögerungen auftreten, bis die Maßnahmen ihre ausgleichenden Wirkungen auslösen. Zudem wird die Wirksamkeit stabilisierungspolitischer Interventionen durch die von Lucas entwickelte Theorie der rationalen Erwartungen ${ }^{1326}$ grundsätzlich in Frage gestellt. Diese Einwände gegen stabilisierungspolitische FZ besitzen eine erhebliche Bedeutung, doch stehen sie nicht in einer direkten Verbindung zur konkreten Ausgestaltung des Finanzhilfemechanismus der EU. Die Problembereiche besitzen sowohl für die automatische als auch die diskretionäre FZ-Vergabe gleiche Gültigkeit. Daher wird auf diese Überlegungen an dieser Stelle nicht näher eingegangen.

\section{V-4.4 Schlußfolgerungen und finanzielle Dimension}

Die Einführung eines expliziten Finanzhilfemechanismus zum Ausgleich länderspezifischer konjunktureller Schwankungen besitzt eine erhebliche Relevanz für die EU. Da die elf Teilnehmerstaaten mit dem Beginn der großen Währungsunion verschiedene stabilisierungspolitische Instrumente aufgeben und empirische Untersuchungen die Bedeutung asymmetrischer, temporärer Schocks in der EU bestätigen, ist es geboten, alternative stabilisierungspolitische Anpassungsmechanismen zu nutzen. Im Status-Quo entfalten die verfügbaren Instrumente aber keine ausreichende Wirkung. Unvollkommenheiten auf den Güter- und Faktormärkten sowie die geringe Mobilität der Arbeitskräfte verhindern, daß die Anpassungslasten durch marktliche Koordinationsmechanismen verteilt werden können und die Größenordnung des EU-Haushalts von nur 1,27 Prozent des BIP läßt es nicht zu, daß automatische Stabilisatoren auf zentraler Ebene eine merkliche Wirkung entfalten.

Daher verbleibt (kurzfristig) als einziges Instrument die Vergabe von FZ. Dem raschen Ausbau stabilisierungspolitischer Steuerungskapazitäten kommt vor dem Hintergrund der erheblichen Arbeitslosenproblematik in der EU eine vordringliche Bedeutung zu. Lösen länderspezifische, temporäre Schocks gravierende Einkommens- und Beschäftigungseinbrüche aus, „so gilt es den Anpassungsprozeß an das neue Gleichgewicht zu beschleunigen, denn andernfalls droht über das Greifen der einschlägigen Hysterese- und Persistenz-Mechanismen eine Verfestigung der Arbeitslosigkeit." ${ }^{\text {"1327 }}$ Daher ist die Einrichtung eines stabilisierungspolitischen Finanzhilfemechanismus infolge der Währungsunion grundsätzlich sinnvoll.

\footnotetext{
${ }^{1325}$ Nowotny (1996), S. 612.

${ }^{1326}$ Vgl. hierzu grundlegend Lucas (1976).

${ }^{1327}$ Michaelis (1997), S. 163.
} 
Für die Vergabe der stabilisierungsorientierten FZ spricht, daß sie explizit auf den Ausgleich der konjunkturellen Schwankungen konzentriert werden. So wird eine Überschneidung mit distributiven oder allokativen Vorhaben verhindert, bei der Zielkonflikte nie vollständig ausgeschlossen werden können. ${ }^{1328}$ Deshalb besitzen die FZ eine hohe stabilisierungspolitische Effizienz. Mit einem niedrigen Transfervolumen kann ein relativ hoher Grad an Stabilisierung herbeigefuihrt werden. Die finanzielle Dimension verdeutlichen Modellrechnungen von Italianer/Vanheukelen. ${ }^{1329}$ Sie kommen für den Beobachtungszeitraum von 1984 bis $1991 \mathrm{zu}$ dem Ergebnis, daß mit einem durchschnittlichen jährlichen Transfervolumen von ca. 10 bis 11 Mrd. ECU ${ }^{1330}$ die mitgliedstaatlichen Verluste in der realen Wirtschaftsleistung zu knapp 20 Prozent ausgeglichen werden. Dies bedeutet, daß mit einem Finanzvolumen von nur ca. 0,22 Prozent des BIP der EU eine Stabilisierungswirkung erzielt werden kann, die weitgehend jener der automatischen Stabilisatoren in entwickelten Bundesstaaten entspricht. ${ }^{1331}$

Längerfristig sind erhebliche dynamische Entwicklungen zu berücksichtigen, da die Bedeutung der temporären, asymmetrischen Schocks in einer direkten Wechselwirkung zum Verlauf des europäischen Integrationsprozesses steht.

Durch die Vollendung des Binnenmarktes und die Einführung der einheitlichen Währung verändern sich die Anpassungslasten. Es kann keine eindeutige Aussage getroffen werden, ob sich die Handlungsnotwendigkeit durch diese Vertiefung der Integration erhöht oder verringert. Es bleibt umstritten, ob temporäre, asymmetrische Schocks mit fortschreitender Integration häufiger oder seltener auftreten werden. Die kohäsionspolitischen Aktivitäten der EU sprechen jedoch dafür, daß die Anpassungslasten im Zeitablauf zurückgehen. Sofern die Maßnahmen erfolgreich durchgeführt werden, resultiert eine (allmähliche) Angleichung der wirtschaftlichen und sozialen Strukturen innerhalb aller Mitgliedstaaten, so daß asymmetrische Schocks nur noch seltener und weniger ausgeprägt auftreten.

Der fortschreitende Integrationsprozeß beeinflußt die Anpassungskapazitäten. So wird sich die Mobilität der Arbeitskräfte im Zeitablauf erhöhen. ${ }^{1332}$ Durch die Integrationsvertiefung entsteht ein zunehmender Wettbewerbsdruck, der Reformen auf den nationalen Güter- und Faktormärkten auslösen kann, die zu flexibleren Löhnen und Preisen führen. Zudem ist es denkbar, daß sich die staatlichen Entscheidungsträger schrittweise auf eine Ausweitung des

\footnotetext{
${ }^{1328}$ Eine Vermischung von Zielsetzungen erfolgt bspw., wenn die progressive Einkommensteuer als automatischer Stabilisator genutzt wird oder die Finanzmittel des Kohäsions- und Strukturfonds antizyklisch variiert werden.

${ }^{1329}$ Vgl. Italianer/Vanheukelen (1993).

${ }^{1330}$ Preise des Jahres 1990.

${ }^{1331} \mathrm{Vgl}$. hierzu den Überblick über empirische Untersuchungen bei der Europäische Kommission (1993a), S. 31 ff., insb. Tabelle 9 und S. 79 ff.

${ }^{1332} \mathrm{Vgl}$. aber einschränkend Abschnitt V-1.1.5.
} 
EU-Haushalts verständigen, um in unterschiedlichen Politikbereichen Handlungskapazitäten auf der EU-Ebene aufzubauen. Hierdurch entstünde die Möglichkeit, automatische Stabilisatoren auf der zentralen Ebene wirken zu lassen.

Bei abnehmenden Anpassungslasten und zunehmenden Anpassungskapazitäten ist es im Laufe des Integrationsprozesses möglich, nach und nach auf alternative stabilisierungspolitische Anpassungsinstrumente zurückzugreifen. Damit ist das folgende Übergangsszenario vorstellbar: Die explizite Vergabe stabilisierungspolitischer FZ wird mit der Einführung der einheitlichen Währung eingerichtet. Da dieser Finanzhilfemechanismus lediglich ein second-bestInstrument darstellt, wird er temporär befristet. Sobald eine reale Konvergenz innerhalb der EU stattgefunden hat ${ }^{1333}$ oder der EU-Haushalt aufgrund seines Volumens eine ausreichende automatische Stabilisierung garantiert, wird der explizite stabilisierungspolitische Finanzhilfemechanismus wieder abgeschaff. ${ }^{1334}$

Die Gesamtschau der Teilabschnitte V-3.3.1 u 2 verdeutlicht, daß konkrete Ausgestaltung der FZ zwei zentrale Anforderungen erfüllen muß, die zueinander im Zielkonflikt stehen können: die Aufrechterhaltung des Charakters der FZ-Vergabe als stabilisierungsorientierte Versicherung und die stabilisierungspolitische Effektivität der FZ-Vergabe durch die rasche Zuweisung der Mittel.

Die erste Bedingung spricht für die diskretionäre Überprüfung der monatlichen FZ-Vergabe anhand von Empfangsauflagen, die über den quantifizierbaren Indikator zur Arbeitslosenrate hinausgehen. Hierdurch wird unterbunden, daß einzelne Mitgliedstaaten den Versicherungsmechanismus systematisch ausbeuten (Moral-Hazard) oder auch dann FZ erhalten, wenn keine temporären, konjunkturellen sondern permanente, strukturelle Schocks auftreten. Die Kontrolle der Empfangsauflagen unterliegt aber einem gravierenden Informationsproblem und führt zu weiteren Kosten. In den Transferempfängerstaaten werden Präferenzkosten ausgelöst. ${ }^{1335}$ Im Entscheidungsprozeß entstehen hohe politische Transaktionskosten, da die Verhandlungen einen erheblichen Konsensbedarf aufweisen. Hieraus ergibt sich auch der wichtigste Einwand gegen die diskretionäre FZ-Vergabe: der hohe Konsensbedarf löst zeitintensive

\footnotetext{
${ }^{1333}$ Dies impliziert, daß die einzelnen Mitgliedstaaten die Anpassungskapazitäten entwickelt haben, um auch ohne Wechselkurs, ohne Geldpolitik und ohne übermäßige Defizite einen eigenständigen Ausgleich der Konjunkturschwankungen herbeizuführen (vgl. Abschnitt V-4.1).

${ }^{1334} \mathrm{Vgl}$ Van Rompuy/Abraham/Heremans (1991), S. 133; Majocchi/Rey (1993), S. 478; auch Francke (1993) u. (1994); kritisch Nerlich (1996), S. 170 f.

${ }^{1335} \mathrm{Da}$ die Empfangsauflagen darauf abzielen, das Entscheidungsverhalten der Transferempfänger innerhalb ganzer Politikfelder zu beeinflussen, können diese Präferenzkosten sehr hoch ausfallen. Daher ist zu prüfen, ob eine stichhaltige meritorische Begründung für diese Präferenzeingriffe besteht, wie bspw. ein unzureichender Informationsstand der mitgliedstaatlichen Entscheidungsträger. In jenem Fall ist jedoch eine aktive Informationsstrategie als ein alternatives Instrument mit geringerer Eingriffsintensität zu berücksichtigen (vgl. hierzu Abschnitt III-2.4).
} 
Verhandlungen aus, die die Effektivität der monatlichen Mittelvergabe entscheidend beeinträchtigen können.

Dies spricht für die automatische FZ-Vergabe, um die monatliche Zuweisung der Finanzmittel nicht durch politische Entscheidungsprozesse zu verzögern. Zudem zeigt die Analyse, daß auch die automatische FZ-Vergabe über eine Anzahl an Gestaltungskriterien verfügt, deren problemadäquate Nutzung verhindern kann, daß der Versicherungscharakter der stabilisierungspolitischen $\mathrm{FZ}$ nach und nach verloren geht. ${ }^{1336}$

Zwei weitere Faktoren sprechen für die automatische Vergabe der FZ. Erstens ist die Transparenz des automatischen Finanzhilfemechanismus deutlich höher, als die des diskretionären Finanzhilfemechanismus, der beständige Einzelentscheidungen durch die staatlichen Entscheidungsträger erfordert. Zweitens eröffnet die diskretionäre FZ-Vergabe den Akteuren der zentralen Ebene erhebliche Handlungsspielräume zum Eingriff in die autonomen Entscheidungsbereiche der dezentralen GKS. Je weiter diese Handlungsspielräume ausgenutzt werden, desto stärker verlagert sich Aufgabenerfüllung auf die zentrale Ebene. Solche (unerwünschten) Zentralisierungstendenzen sind bei einer automatischen FZ-Vergabe ausgeschlossen. Die Transparenz der Regelungen und die Gefahr von Zentralisierungstendenzen wurden bei der Analyse der institutionellen Rahmenbedingungen der EU als besonders sensible Problembereiche in den Vordergrund gerückt und geben daher im Zweifelsfalle den Ausschlag für den automatischen Finanzhilfemechanismus.

Den entscheidenden Problemkreis stellt bei der automatischen FZ-Vergabe die Schwierigkeit dar, ein Einvernehmen über die Institutionalisierung des Vergabemechanismus zu finden. Ein Ansatz zur Entschärfung dieses Problems eröffnet sich, wenn die Vergabe der FZ nur als eine zeitlich befristete Übergangslösung institutionalisiert wird. Wird bereits bei der Einrichtung des Stabilisierungsmechanismus ein konkreter Zeitpunkt festgelegt, zu dem die Zuweisungen durch den Finanzhilfemechanismus beendet werden, so kann die Zustimmungswahrscheinlichkeit derjenigen Mitgliedstaaten erhöht werden, die bislang fürchten, daß sich die Transfervergabe langfristig verfestigen könnte. Zum Beendigungszeitpunkt erfolgt eine Überprüfung, ob mittlerweile andere stabilisierungspolitische Instrumente die Anpassungslasten an die temporären, asymmetrischen Schocks tragen können. Nur für den Fall, daß die bevorzugten (firstbest-) Instrumente die Anpassungslasten weiterhin nicht übernehmen können, wird die Exi-

\footnotetext{
${ }^{1336}$ Es sei daran erinnert, daß nur eine einmalige Stabilisierungszuweisung erfolgt und eine betragliche Begrenzung der FZ anhand der Untergrenze, der Ausgleichsintensität und der Obergrenze ermöglicht wird. Darüber hinaus erlaubt der Vorschlag von Wasmayr die Verteilung der Finanzierungslasten gemäß der „Schadenswahrscheinlicheit". Dieser Vorschlag ist jedoch nur als Gestaltungsparameter der automatischen FZ-Vergabe anzusehen, wenn die Festlegung der Finanzierungslasten ex-ante quantifizierbar bleibt (vgl. Abschnitt V4.3.1).
} 
stenz des expliziten Finanzhilfemechanismus verlängert. ${ }^{1337}$ Der entscheidende Aspekt ist, daß nicht die Beendigung des Mechanismus im politischen Entscheidungsprozeß durchgesetzt werden muß, sondern dessen Weiterführung. Dieser Beschluß hat im Zusammenwirken der Organe der EU einstimmig zu erfolgen. Damit ist ausgeschlossen, daß sich eine Koalition von Mitgliedstaaten bilden kann, die sich auf eine gemeinsame Strategie der Besitzstandswahrung einigt und so die Beendigung des Transfermechanismus blockiert.

\section{V-5 Die Kompensationsfunktion im Integrationsprozeß}

Die bislang analysierten Ansatzpunkte für die Vergabe zwischenstaatlicher FZ bezogen sich auf ökonomische Funktionen im Bereich der Allokation, der Distribution und der Stabilisierung. Es zeigt sich, daß die Transfers darüber hinaus eine wichtige polit-ökonomische Funktion im Integrationsprozeß zur Beeinflussung des Abstimmungsverhaltens der staatlichen Entscheidungsträger ausfüllen.

\section{V-5.1 Handlungsnotwendigkeit für die EU}

Art. A des EUV stellt klar, daß die Mitgliedstaaten der EU die „Verwirklichung einer immer engeren Union der Völker Europas” anstreben. Wenngleich keine Einigkeit zwischen den Akteuren über die anzustrebende finale Gestalt des Zusammenschlusses der Mitgliedstaaten besteht, läßt sich aus dieser Formulierung die Zielsetzung ableiten, daß der Integrationsprozeß langfristig aufrechterhalten und kontinuierlich fortentwickelt werden soll.

Der Entwicklungsverlauf des Integrationsprozesses umfaßt zwei Dimensionen. Die Vertiefung der Integration, indem nach und nach weitere Stufen der ökonomischen oder politischen Integration beschritten werden ${ }^{1338}$ und die Erweiterung der Integration durch die Aufnahme neuer Mitgliedstaaten. Mit dem Einigungsprozeß sind Wohlfahrtssteigerungen für die Gesamtheit der Mitgliedstaaten verbunden. Jedoch demonstrieren die Ausführungen in den vergangenen Abschnitten dieses Kapitels, daß die Nutzenzugewinne spezifischer Integrationsschritte keinesfalls gleichmäßig verteilt sein müssen. Es ist möglich, daß einzelne Mitgliedstaaten relativ zu anderen Mitgliedstaaten nur sehr geringe Nutzenzugewinne verbuchen können oder sogar

\footnotetext{
${ }^{1337}$ Diese Verhandlungen lösen politische Transaktionskosten aus. Dies spricht dafür, die zeitliche Begrenzung des Finanzhilfemechanismus nicht zu kurz zu wählen. Je länger das System besteht, desto stärker verteilen sich die fixen Kosten zur Institutionalisierung des Mechanismus auf eine Vielzahl monatlicher Vergabeentscheidungen. Auf der Ebene der $E U$ bietet sich bspw. der Planungszeitraum der Finanziellen Vorausschau an. Die nächste Finanzielle Vorausschau gilt für den Zeitraum von 2000-2006.

${ }^{1338}$ Vgl. hierzu Abschnitt IV-2.3.
} 
absolute Wohlfahrtsverluste hinnehmen müssen. Zugleich verlangen die Abstimmungsverfahren der EU für alle integrationspolitisch bedeutsamen Entscheidungen eine einstimmige Beschlußfassung. Schritte zur Vertiefung oder Erweiterung der EU können nur im Konsens aller Verhandlungsbeteiligten vollzogen werden. ${ }^{1339}$ Einzelne Mitgliedstaaten werden daher die Fortentwicklung des Integrationsprozesses bei egoistisch-rationaler Verhaltensweise blockieren, sofern Nutzeneinbußen für die eigene Nation zu erwarten sind. Aus Sicht der Gesamtheit stellt dies einen Wohlfahrtsverlust dar, da Nutzenzugewinne, die durch eine kooperative Verwirklichung der Integrationsschritte realisiert werden könnten, ungenutzt bleiben.

Aufgrund dieser Konstellation ergibt sich eine große Bedeutung für die Vergabe von Kompensationsleistungen. Sie besitzen „eine allokative Funktion dynamischer Art, die jenseits traditioneller Allokationsaufgaben in der Schaffung der Bedingungen für Integrationsmaßnahmen besteht." 1340 Sie tragen dafür Sorge, daß die Gesamtwirkung eines Integrationsschrittes für alle Verhandlungsbeteiligten einen Nutzenzugewinn bedeutet und ermöglichen so das einvernehmliche Übereinkommen der Akteure. „Normative Bezugsgröße sind dabei die marginalen Wohlfahrtseffekte der Integration." ${ }^{1341}$ Es stehen nicht die zum heutigen Zeitpunkt bereits bestehenden Effizienz- und Verteilungswirkungen der Integration im Mittelpunkt, sondern die zusätzlichen Effekte der anstehenden Integrationsschritte. Die Kompensationsfunktion ist in die Zukunft gerichtet. ${ }^{1342}$

$\mathrm{Zu}$ diesen Wohlfahrtseffekten sind die (rein ökonomischen) Effizienzwirkungen zu rechnen, die durch einen spezifischen Integrationsschritt in den einzelnen Mitgliedstaaten ausgelöst werden. Es sind aber zusätzlich Frustrations- bzw. Präferenzkosten zu beachten. ${ }^{1343}$ Da der nationale wirtschaftspolitische Handlungsspielraum der einzelnen Mitgliedstaaten durch einen spezifischen Integrationsschritt mit unterschiedlicher Stärke beeinflußt und der Eingriff in die autonomen Souveränitätsbereiche mit ungleicher Intensität bewertet wird, entstehen durch den Verzicht auf die Ausübung nationaler Kompetenzen in differierendem Ausmaß Präferenzkosten in den Mitgliedstaaten. ${ }^{1344}$ Die Gesamtwirkung einer Integrationsmaßnahme ergibt sich für einen Mitgliedstaat aus der Berücksichtigung beider Faktoren. Der Gesamtwohlfahrtseffekt

\footnotetext{
${ }^{1339} \mathrm{Vgl}$. hierzu näher die Ausführungen zu den Organen und Entscheidungsverfahren der $E U$ in Abschnitt IV-2.2.

${ }^{1340}$ Folkers (1995), S. 93.

${ }^{1341}$ Folkers (1995), S. 101.

${ }^{1342} \mathrm{Vgl}$. hierzu auch Fn 1172 in Abschnitt V-3.1.

${ }^{1343} \mathrm{Vgl}$. auch Thomas (1994), S. $479 \mathrm{f}$.

${ }^{1344}$ Beispielhaft sei auf den Verzicht einer autonomen Geldpolitik im Rahmen der Verwirklichung der Währungsunion verwiesen. Hier tritt der Mitgliedstaat Deutschland, der bislang die Geldpolitik innerhalb der $E U$ durch die Bundesbank weitgehend bestimmte, in weit größerem Ausmaß autonome Handlungsspielräume an die EU-Ebene ab, als andere Mitgliedstaaten, die schon in der Vergangenheit ihre Geldpolitik an den Vorgaben der Bundesbank ausgerichtet haben.
} 
muß durch die Kompensationsleistung für jeden Mitgliedstaat positiv gestaltet werden. Dann ist eine einstimmige Problemlösung auch bei egoistisch-rationaler Interaktionsorientierung aller Akteure zu erwarten. ${ }^{1345}$

Bei der Durchführung der Kompensation ist die zeitliche Perspektive der Auswirkungen des Integrationsschrittes zu berücksichtigen. Einerseits gibt es Integrationsschritte, durch die die Wohlfahrtsposition einzelner Mitgliedstaaten - unter sonst unveränderten Rahmenbedingungen - dauerhaft verschlechtert wird, so daß entsprechende dauerhafte Kompensationsleistungen erforderlich sind. Andererseits können Integrationsschritte aber lediglich einmalige oder zeitlich begrenzte Anpassungslasten auslösen, wofür auch nur ein singulärer oder temporär begrenzter Ausgleich zu gewähren ist. ${ }^{1346}$

Insgesamt trägt die Kompensationsfunktion entscheidend dazu bei, in der EU ein dynamisches institutionelles Gleichgewicht aufrechtzuerhalten. Da sich die ökonomischen, politischen und sozio-kulturellen Rahmenbedingungen des Integrationsprozesses beständig verändern, darf der Einigungsprozeß nicht im Status-Quo verhaften bleiben. Im Fall eines Integrationsstillstandes würde die Balance zwischen Handlungsnotwendigkeiten und Handlungskapazitäten zunehmend verloren gehen. ${ }^{1347}$ Die Kompensationsfunktion gewährleistet auf diese Weise die Festigung der unterschiedlichen Teilsysteme der EU im Sinne der erweiterten Stabilisierungsfunktion.

Der Stellenwert der Kompensationsfunktion steht über diese grundsätzliche Einschätzung hinaus in mehrfacher Hinsicht in einer engen Verbindung zum Stand des Integrationsprozesses:

- Je weiter der Integrationsprozeß voranschreitet, desto mehr nimmt die Bedeutung der Kompensationsfunktion bei neuen Integrationsschritten ab. Denn mit zunehmender Inte-

${ }^{1345}$ Diese Ausführungen demonstrieren, daß die reinen Zahlungsströme des EU-Haushalts keine Aussage über die Netto-Wohlfahrtspositionen der einzelnen Mitgliedstaaten im Integrationsprozeß zulassen (vgl. auch Folkers (1995), S. 101). Eine reine „Nettozahler-Diskussion”, wie sie bspw. jüngst vom Bundesministerium der Finanzen aufgegriffen wurde (vgl. Bundeministerium der Finanzen (1998), S. 31 ff.) wird daher der zu lösenden Problemstellung nicht gerecht. Dabei bleibt unbestritten, daß die Erfassung und der Vergleich der verschiedenen Nutzen und Kosten eines Integrationsschrittes sehr problematisch ist (vgl. hierzu Abschnitt II-1, insb. Fn 50).

${ }^{1346}$ Unter Berücksichtigung der Zeitpräferenzrate der Mitgliedstaaten könnten die negativen Wohlfahrtseffekte grundsätzlich mit einer einmaligen Zahlung abgegolten werden. Jedoch ist dieser Lösungsvorschlag, selbst wenn man von den theoretischen Problemen zur Ermittlung der Zeitpräferenzrate eines Mitgliedstaates absieht (vgl. hierzu bspw. Musgrave/Musgrave/Kullmer (1990), S. 196 ff.), nicht praktikabel, da eine einmalige Zahlung bei vielen Integrationsschritten den Rahmen des EU-Haushaltes sprengen würde.

${ }^{1347} \mathrm{Vgl}$. hierzu die Ausfuihrungen zur Asymmetrie zwischen politischer und ökonomischer Integration in Abschnitt IV-2.3.3. 
grationstiefe verringern sich die Strukturveränderungen, die durch einen zusätzlichen Vertiefungsschritt ausgelöst werden. Während die Einrichtung des Binnenmarktes oder die Einführung der einheitlichen Währung elementare Integrationschritte verkörpern, die gravierende Wohlfahrtseffekte auslösen, verringern sich die Wohlfahrtswirkungen bei weiter fortgeschrittenem Integrationsstand. Die entscheidenden institutionellen Rahmenbedingungen bleiben fortan stabil. Die EU erlangt mit ansteigendem Integrationsniveau ein institutionelles Gleichgewicht, das nur noch in kleineren Schritten fortentwickelt werden muß. ${ }^{1348}$ Das Volumen der Kompensationsleistungen reduziert sich folglich mit zunehmender Vollendung der Integration.

Diese Aussage gilt nicht bei Erweiterungsschritten der EU. Hier besitzt die Kompensationsfunktion stets eine enorme Bedeutung, da die Wohlfahrtspositionen der einzelnen Mitgliedstaaten und der Aufnahmekandidaten in einer Vielzahl ökonomischer und soziokultureller Bereiche beeinflußt werden. ${ }^{1349}$ Die bei den einzelnen Verhandlungspartnern entstehenden Wohlfahrtseffekte sind deshalb sehr schwer abzuschätzen; sie können aber ein hohes Ausmaß annehmen und zudem von Staat zu Staat weit voneinander abweichen. $^{1350}$

- Es besteht ein enger Zusammenhang zu den Maßnahmen zur Förderung des wirtschaftlichen und sozialen Zusammenhalts. Diese Aktivitäten tragen langfristig zur Verringerung der Heterogenität der Wirtschaftsstrukturen der Mitgliedstaaten bei, so daß sich die Effizienzwirkungen anstehender Integrationsschritte symmetrischer auf die Mitgliedstaaten verteilen. Sie begünstigen außerdem die Entwicklung eines europäischen Identifikationsbezugs. Hierdurch kommt es zu einer Annäherung der Präferenzstrukturen der Bürger der einzelnen Mitgliedstaaten. Dann entstehen bei der Durchführung neuer Integrationsschritte geringere Frustrationskosten. ${ }^{1351}$ Erfolgreiche Kohäsionsmaßnahmen verringern daher das Volumen der Kompensationsleistungen, das zur Realisierung eines vorgegebenen Integrationsschrittes vonnöten ist.

- Zugleich besitzt die Kohäsionspolitik einen wichtigen Einfluß auf das bestehende Gesamtvolumen der Kompensationsleistungen. Mit Zunahme des wirtschaftlichen und sozialen

\footnotetext{
${ }^{1348}$ Vgl. hierzu auch Berg/Schmidt (1997), S. 174 und Franzmeyer/Weise (1997), S. $324 \mathrm{ff}$.

${ }^{1349}$ Bei einer Erweiterung sind nicht nur die Wohlfahrtspositionen der alten Mitglieder, sondern auch die der Aufnahmekandidaten zu berücksichtigen, um eine einvernehmliche Problemlösung zu ermöglichen.

${ }^{1350}$ Einen wichtigen Einflußfaktor stellt in diesem Zusammenhang bspw. die räumliche Dimension dar. So ist davon auszugehen, daß der Mitgliedstaat Deutschland aufgrund der geographischen Năhe zu den Beitrittskandidaten in Osteuropa in besonderem Maß von der Schaffung eines Binnenmarktes mit diesen Nationen profitieren kann.

${ }^{1351}$ Hier zeigt sich die große Bedeutung der informellen Integration für die (tatsächliche) Vollendung der formalen Integrationsschritte (vgl. Abschnitt IV-2.3.2).
} 
Zusammenhalt in der EU, verändern sich die von Periode zu Periode entstehenden Wohlfahrtswirkungen bestimmter Integrationsschritte, die in der Vergangenheit vollzogen wurden. Insbesondere im Bereich des europäischen Binnenmarktes kann eine effiziente Kohäsionspolitik dazu führen, daß Mitgliedstaaten, die bislang durch den Abbau von Handelsschranken Wohlfahrtsverluste hinnehmen mußten, nunmehr Wohlfahrtszugewinne realisieren können. ${ }^{1352}$ Dann entfällt die Grundlage für die Vergabe von Kompensationsleistungen, die den betreffenden Mitgliedstaaten ursprünglich dauerhaft zugesprochen wurden. Sie können ersatzlos gestrichen werden, wodurch das Gesamtvolumen der Kompensationsleistungen reduziert wird.

- Im Laufe des Integrationsprozesses verändert sich die Art, in der mit den Wohlfahrtseffekten eines Integrationsschritts verfahren wird. ${ }^{1353}$ Die einzelnen Mitgliedstaaten können im Rahmen der Entscheidungsstrukturen der EU im Zeitablauf die Reputation einer kooperativen Verhaltensorientierung aufbauen. Die Verhandlungspartner entwickeln hierdurch nach und nach eine wechselseitige Vertrauensbasis. Wenn die Auswirkungen einzelner Integrationschritte keine extremen Wohlfahrtsverluste auslösen, kann in dieser Situation auf die Kompensation im Einzelfall verzichtet werden und dennoch eine einvernehmliche Einigung gefunden werden. Denn da die EU auf Dauer angelegt ist, verlassen sich die Akteure darauf, daß die Wohlfahrtseffekte langfristig ,gerecht" aufgeteilt werden.

Eng hiermit verbunden ist die Überlegung, daß sich im Laufe des Integrationsprozesses ein zunehmend belastbarer europäischer Identifikationsbezug der Bürger der einzelnen Mitgliedstaaten entwickelt. Dies legitimiert zumindest bei weniger bedeutenden Integrationsschritten den Übergang zu Mehrheitsentscheidungen, da es nun einer Minderheit der Bürger zugemutet werden kann, Entscheidungen auch gegen ihren Willen zu akzeptieren. ${ }^{1354}$ Dann ist die Kompensation im Einzelfall nicht mehr notwendig, um eine Entscheidungsfindung zu ermöglichen.

\footnotetext{
${ }^{1352} \mathrm{~V}$ gl. hierzu ausfuhrlich die Konvergenz-Divergenz-Diskussion in Abschnitt V-2.2.

${ }^{1353}$ Nachfolgend steht nicht wie bei den vorhergehenden Aspekten im Mittelpunkt, ob sich die Streuung der Wohlfahrtseffekte zwischen den Mitgliedstaaten im Integrationsprozeß verringert. Es wird stattdessen betrachtet, auf welche Weise vorgegebene Wohlfahrtseffekte im Rahmen des politischen und sozio-kulturellen Gesamtsystems verarbeitet werden können.

${ }^{1354} \mathrm{Vgl}$. hierzu Abschnitt IV-2.3.3.
} 


\section{V-5.2 Bestehende Aktivitäten der EU zur Kompensation einzelner Mitgliedstaaten}

Die Kompensation der Mitgliedstaaten kann grundsätzlich über die Einnahmen- und Ausgabenseite des EU-Haushalts oder durch die Vergabe zwischenstaatlicher FZ vollzogen werden. ${ }^{1355}$ Es zeigt sich, daß zum heutigen Zeitpunkt alle drei Varianten genutzt werden. Dabei vergibt die EU sowohl dauerhafte als auch zeitliche begrenzte Kompensationsleistungen.

Eine extreme Position bezieht Folkers. ${ }^{1356}$ Er argumentiert, daß der gesamte EU-Haushalt ausschließlich der Kompensation der Mitgliedstaaten zum Zwecke der Fortentwicklung des Integrationsprozesses dient. Der Haushalt erfüllt diese Funktion „dadurch, daß er Projekte in geeigneter Verteilung zwischen den Mitgliedstaaten ausweist, die einen Konsens über insgesamt wohlfahrtssteigernde Maßnahmen der Integration herbeifuhren."1357

Im Vordergrund der Aktivitäten steht die Ausgabenseite des EU-Haushalts. Die Mitgliedstaaten einigen sich auf die gemeinschaftliche Finanzierung von Ausgabenprogrammen, „wobei mit den allokativen Maßnahmen die distributiven Ziele der Kompensationsleistungen realisiert werden." ${ }^{1358}$ Als augenscheinliche Beispiele sind der Kohäsionsfonds sowie die Strukturfonds anzufuihren. So wurde die Zustimmung der Kohäsionsländer Spanien, Portugal, Griechenland und Irland zur Vollendung der WWU durch die Einrichtung des Kohäsionsfonds „erkauft”. Im Zuge der Norderweiterung der EU erfolgte die Einfuihrung des (neuen) Ziels 6 innerhalb der Strukturfonds. Dies ermöglicht die dauerhafte Vergabe von Kompensationszahlungen an die beiden skandinavischen Länder Schweden und Finnland zur Entwicklung von Regionen mit geringer Bevölkerungsdichte. ${ }^{1359}$

Allerdings wird auch auf der Einnahmenseite eine Kompensationsmaßnahme ausgeführt. Der Beitrag des Vereinigten Königreichs zum EU-Haushalt wird gemindert. Diese Sonderregelung wurde im Jahr 1985 beschlossen, um dem Vereinigten Königreich eine Kompensation dafür zukommen zu lassen, daß es nur in relativ geringem Ausmaß von den Agrarausgaben der EU profitiert. $^{1360}$

Eine direkte kompensatorische FZ fließt an die Beitrittsländer der Norderweiterung Schweden, Österreich und Finnland. Sie erhalten zeitlich befristet von 1995-1999 vertikale Pauschalzuweisungen aus dem EU-Haushalt. Diese Kompensationszahlungen werden geleistet,

\footnotetext{
${ }^{1355} \mathrm{Vgl}$. Hackenbroch (1983), S. 35.

${ }^{1356}$ Vgl. Folkers (1994); (1995).

${ }^{1357}$ Folkers (1994), S. 26.

${ }^{1358}$ Folkers (1994), S. 25.

${ }^{1359}$ Vgl. Franzmeyer/Weise (1997), S. 327. Vgl. zu den Fonds näher Abschnitt V-2.3.2.

${ }^{1360}$ Bereits von 1976 bis 1985 bestanden alternative Kompensationsmechanismen zugunsten des Vereinigten Königreichs, die jedoch längerfristig keinen Konsens zwischen den Mitgliedstaaten fanden und daher modifiziert wurden. Der momentane Kompensationsmechanismus wurde auf dem Europäischen Rat in Fontainebleau im Juni 1984 ausgehandelt. Vgl. hierzu näher Europäische Kommission (1995a), S. 18 f.
} 
um den neuen Mitgliedstaaten einen Ausgleich für die Anpassungslasten zu gewähren, die durch den Beitritt innerhalb des Agrarsektors dieser Staaten ausgelöst werden. ${ }^{1361}$

\section{V-5.3 Die Kompensation einzelner Mitgliedstaaten durch FZ}

Die Vergabe der kompensatorischen FZ ist aus ökonomischer Sicht als reine Pauschalzuweisung auszugestalten. Denn die Zielsetzung der FZ-Vergabe ist es, die Wohlfahrtsposition des transferempfangenden Mitgliedstaates in möglichst starkem Umfang zu verbessern, so daß dieser einem anstehenden Integrationsschritt die Zustimmung erteilt. Es wird nicht beabsichtigt, das Ausgabeverhalten des Transferempfängers zu beeinflussen. Jede Verknüpfung der FZ mit einer Empfangs- oder Verwendungsauflage stellt einen Eingriff in die Präferenzen des Transferempfängers dar und beeinträchtigt dessen Wohlfahrtsposition in Relation zur Vergabe einer Pauschalzuweisung. Um einen vorgegebenen Nutzenzugewinn auszulösen, müßte dann eine FZ eines höheren Volumens vergeben werden. ${ }^{1362}$

\section{V-5.4 Die Umsetzung der effizienten Problemlösung im politischen Entscheidungs- prozeß}

Die Vergabe der kompensatorischen FZ stellt eine rein distributive Verhandlungssituation dar. Es wird davon ausgegangen, daß die Wohlfahrtswirkung, die ein anstehender Integrationsschritt für die Gesamtheit des Verflechtungssystems und für die einzelnen Mitgliedstaaten auslösen wird, allen Verhandlungspartnern bekannt ist. Es stellt sich ausschließlich das Verhandlungsproblem, den Gesamt-Nutzenzugewinn auf die einzelnen Akteure zu verteilen. Deshalb werden (ex-ante) kompensatorische FZ geleistet. Diese müssen sicherstellen, daß sich die Wohlfahrtsposition für jeden Mitgliedstaat im Vergleich zum Status-Quo zumindest nicht verschlechtert. In welchem Ausmaß die einzelnen Mitgliedstaaten einen NettoNutzenzugewinn realisieren können, ist darüber hinaus eine Frage der Verhandlungsmacht der einzelnen Akteure. ${ }^{1363}$

Diese Schlußfolgerung ist jedoch nur zutreffend, wenn die Wohlfahrtseffekte des Integrationsschrittes mit großer Sicherheit bestimmbar sind. Die Aussicht, daß es zur Durchsetzung der kompensatorischen Pauschalzuweisungen im politischen Entscheidungsprozeß kommt, hängt

\footnotetext{
${ }^{1361} \mathrm{Vgl}$. hierzu auch Abschnitt IV-2.1.3.2, m.w.N.

${ }^{1362} \mathrm{Vgl}$. hierzu die mikroőkonomische Indifferenzkurvenanalyse in Abschnitt III-2.2; so auch Oates (1977), S. 313 u. 330 und Folkers (1995), S. 93 u. 96.

${ }^{1363} \mathrm{Vgl}$. Thomas (1994), S. 480; Binder/Walthes (1995), S. 306; vgl. hierzu auch Abb. III-11 in Abschnitt III2.3.2.2.3.
} 
daher entscheidend von der Problemstruktur des anstehenden Integrationsschrittes ab. Dabei sind große Schritte zur Vertiefung der Integration, wie die Vollendung des Binnenmarktes oder die Einfuihrung der gemeinsamen Währung, von einer enormen Komplexität geprägt. Es ist praktisch unmöglich, deren Wohlfahrtswirkungen zu prognostizieren. ${ }^{1364}$ Daher ist die distributive Verhandlungssituation von einer hohen Unsicherheit über die Verhandlungspositionen der einzelnen Mitgliedstaaten geprägt. Es eröffnen sich Spielräume für strategische Verhaltensweisen. Die Akteure können durch die gezielte Weitergabe oder Zurückhaltung von Informationen versuchen, besonders hohe Kompensationsleistungen „herauszuschlagen” bzw. die Leistung von Transfers zu verhindern. Der Konsensbedarf der distributiven Verhandlungssituation zur Vergabe der Pauschalzuweisungen erhöht sich hierdurch. Dies zeigt, daß die Wahrscheinlichkeit des Scheiterns der Verhandlungen gerade bei bedeutenden Integrationsschritten hoch ausfällt.

Allerdings besteht bei diesen komplexen Integrationsvorhaben wiederum die Gelegenheit für die EK, als Moderator des Verhandlungsprozesses zu einem Abbau von Informationsdefiziten bei den einzelnen Verhandlungspartnern beizutragen. Durch diese Informationsstrategie kann ein aktiver Beitrag zur Konsensbildung geleistet werden. Die Vermittlung entscheidungsrelevanter Informationen durch die EK besitzt eine hohe Glaubwürdigkeit, da die mitgliedstaatlichen Akteure nicht befürchten müssen, daß die EK strategisch die Interessenposition eines bestimmten Mitgliedstaates unterstützt. Die Begleitung des Verhandlungsprozesses durch die EK erhöht daher nicht nur den Informationsstand der Akteure, sondern ersetzt auch die Ungewißheit über den Wert bestehender Informationen durch Gewißheit. Insgesamt ermöglicht die EK die Stabilisierung des Verhandlungsprozesses.

Selbst wenn die politischen Entscheidungsträger zu einer Einigung über die Höhe der zu vergebenden Pauschalzuweisungen gelangen, kann die Vergabe der ungebundenen Zuweisungen an der fehlenden Akzeptanz in der (Wahl-)Bevölkerung der transferleistenden Mitgliedstaaten scheitern. Zur Überwindung dieser intrakollektiven ,politischen Widerstände”1365 besteht die Möglichkeit, die Informationsstrategie gezielt auf die Bevölkerung der betreffenden Mitgliedstaaten auszudehnen. So wird der Eindruck der Bürger zerstreut, daß die Mittelzuweisungen eine Form „der politischen Bestechung"1366 darstellen.

\footnotetext{
${ }^{1364}$ Bereits bei der Gewinnung der entscheidungsrelevanten Informationen werden bei diesen Integrationschritten erhebliche Defizite bestehen bleiben, die sich auf die Konsensfindungsproblematik im eigentlichen Entscheidungsprozeß übertragen.

${ }^{1365}$ Folkers (1994), S. 25.

${ }^{1366}$ Folkers (1994), S. 25.
} 
Scheitert diese Informationsstrategie, kann als alternative Handlungsoption von der problemadäquaten Ausgestaltung der FZ als Pauschalzuweisungen abgewichen werden. Durch die Zweckbindung der FZ wird die Nutzenposition der Transfergeber aktiv verbessert (Durchsetzungsstrategie), da die Bevölkerung der transfergebenden Mitgliedstaaten hierdurch überzeugt wird, daß die Mittel für „sinnvolle” Programmvorhaben verwendet werden. ${ }^{1367}$ Durch diese Ausgestaltungsform werden jedoch Ineffizienzen ausgelöst. Es muß ein höheres Transfervolumen aufgewendet werden, um die Kompensationsfunktion auszufüllen. Zudem entstehen Ressourcenkosten zur administrativen Durchführung der Zweckbindung sowie zur Kontrolle der Mittelverwendung.

\section{V-5.5 Schlußfolgerungen}

Der Kompensationsfunktion fällt angesichts der restriktiven Entscheidungsstrukturen der EU eine erhebliche Bedeutung für den Einigungsprozeß in Europa zu: sie ermöglicht es, Integrationsschritte im Einvernehmen aller staatlichen Entscheidungsträger zu vollziehen. Die bevorstehenden Integrationsvorhaben zur Einführung der einheitlichen Währung und zur EUErweiterung demonstrieren, daß die Kompensationsfunktion in der absehbaren Zukunft eine außerordentliche Tragweite behalten wird. ${ }^{1368}$ Der rechtlich-organisatorische Rahmen der EU muß in vielzähligen Bereichen durch substantielle Integrationsschritte fortentwickelt werden, um problemadäquate Steuerungsleistungen erbringen zu können. ${ }^{1369}$ Die EU ist weit von dem „Endzustand eines institutionellen Gleichgewichts"1370 entfernt, der es rechtfertigen würde, das bestehenden Integrationsniveau langfristig (statisch) aufrechtzuerhalten. Es muß vielmehr ein beständiger dynamischer Wandel vollzogen werden. Solange die EU-Entscheidungsstrukturen bei institutionellen Fragen die Einstimmigkeit als Abstimmungsregel vorschreiben, wird dieser Wandel durch die Leistung von Kompensationen entscheidend unterstützt.

Zum heutigen Zeitpunkt bestehen erhebliche Aktivitäten zur Erfüllung der Kompensationsfunktion. Während die finanzielle Dimension der expliziten Kompensationsleistungen auf der Einnahmenseite und der Vergabe expliziter kompensatorischer FZ eng begrenzt bleibt, kann im Extrem die gesamte Ausgabetätigkeit der EU als Ausübung der Kompensationsfunktion interpretiert werden. ${ }^{1371}$ Die Ausgaben spiegeln entsprechend dieser Auffassung Kompensati-

\footnotetext{
${ }^{1367} \mathrm{Vgl}$. hierzu auch die analoge Argumentation zur Zweckbindung bei der Vergabe von FZ zum Ausgleich horizontaler fiskalischer Ungleichgewichte in Abschnitt V-3.3.3.

${ }^{1368}$ So auch Berg/Schmidt (1997), S. 174 und Folkers (1994), S. 31 f.

${ }^{1369} \mathrm{Vgl}$. hierzu insb. Kapitel IV-2.

${ }^{1370}$ Folkers (1995), S. 108.

${ }^{1371}$ So eben Folkers (1994); (1995); auch Thomas (1994), insb. S. 479 f.
} 
onsmuster wider, die im Ablauf des bisherigen Integrationsprozesses ausgehandelt wurden. Mit zunehmender Anzahl der Integrationsvertiefungs- und -erweiterungsschritte ergab sich ein immer weiter ansteigendes Gesamtvolumen, da die meisten Ausgleichsleistungen dauerhaft installiert wurden. ${ }^{1372}$ Realistischerweise ist jedoch eine Abgrenzung, welcher Anteil der Ausgabetätigkeiten der politischen Kompensationsfunktion zuzurechnen ist und welcher der Erfüllung ökonomischer Funktionen dient, nicht möglich. Es bestehen zahlreiche Überschneidungen, Vermischungen und Interdependenzen zwischen diesen Funktionen. Das tatsächliche Volumen der Kompensationsleistungen auf der Ausgabenseite ist deshalb kaum abzuschätzen. Die Zielsetzung der jeweiligen Ausgabetätigkeiten bleibt intransparent. Es kann lediglich die Schlußfolgerung gezogen werden, daß die Bedeutung der Kompensationszahlungen hoch ist.

Einen wichtigen Erklärungsansatz für die extreme Funktionsvermischung liefert die Konsensfindungsproblematik (Teilabschnitt V-5.1.4): die Vergabe umfangreicher (expliziter) kompensatorischer FZ scheitert am politischen Widerstand in den transferleistenden Mitgliedstaaten, sofern die Mittel in problemadäquater Weise als reine Pauschalzuweisungen ausgestaltet werden. Erst die „Verschleierung” der Kompensationsleistungen durch die Verknüpfung mit ökonomisch begründeten Ausgabeprogrammen ermöglicht die Durchführung des Kompensationsgeschäfts und folglich die Konsensfindung für einen anstehenden Integrationsschritt.

Diese Vorgehensweise besitzt, so Folkers, eine hohe „Wirksamkeit im Hinblick auf ein Konzept der Integrationseffizienz". ${ }^{1373}$ Dieses Konzept rückt allein die Fortentwicklung des Integrationsprozesses in den Mittelpunkt der politischen Entscheidungen. Es ist jedoch aus zwei Blickwinkeln kritisch zu sehen:

- Es stellt sich die Frage, in welchem Ausmaß in der Bevölkerung Präferenzkosten ausgelöst werden. Da die Zustimmung der Bürger zur Fortentwicklung des Integrationsprozesses nur durch die Erzeugung einer Ausgabenillusion möglich wird, wird das Integrationsniveau über das von der Bevölkerung, gewünschte” Ausmaß hinaus fortgetrieben. Die staatlichen Entscheidungsträger greifen bewußt in die Präferenzen der Bürger ein. Dieser Eingriff kann nur mit Hinweis auf einen unzureichenden bzw. fälschlichen Informationsstand der Bürger bezüglich der Nutzen des europäischen Einigungsprozesses gerechtfertigt werden (Meritorisierung). ${ }^{1374}$ In diesem Fall sollten die staatlichen Entscheidungsträger

\footnotetext{
${ }^{1372}$ Exemplarisch sei auf die Verwirklichung des EU-Binnenmarktes verwiesen. Da die Befürchtung bestand, da $\beta$ von diesem Integrationsschritt unter sonst gleichen Bedingungen vor allem die Kernregionen der $E U$ profitieren werden, wurden die Strukturfonds eingerichtet bzw. ausgeweitet. Hiermit wurde eine dauerhafie Kompensation für die Benachteiligung der peripheren Regionen geschaffen (vgl. auch Folkers (1995), S. 82 f.).

${ }^{1373}$ Folkers (1995), S. 96.

${ }^{1374} \mathrm{Vgl}$. hierzu Abschnitt III-2.4.
} 
eine aktive Informationsstrategie verfolgen, um den Bürgern eine „rationale” Beurteilung der Integrationsvorhaben zu ermöglichen. Die Verschleierung der Auswirkungen der Integrationsschritte ist negativ zu bewerten. In einer langfristigen Perspektive kann die Akzeptanz der Bevölkerung für den Integrationsprozeß nur gewonnen bzw. aufrecht erhalten werden, wenn die Vorgehensweise der staatlichen Akteure von einer hohen Transparenz geprägt ist. Die Bürger dürfen vom Tempo der Integration nicht überfordert werden, selbst wenn aus Sicht der staatlichen Entscheidungsträger rein ökonomische Effizienzgewinne für zusätzliche Integrationsschritte sprechen. ${ }^{1375}$ Dem Referenzsystem des Kapitels II entsprechend sind stets die Frustrationskosten mit in die Beurteilung einzubeziehen.

- Es muß beachtet werden, daß durch die Vermischung der ökonomischen mit der politischen (kompensatorischen) Zielsetzung, die Effizienz und Effektivität der allokativ, distributiv oder stabilisierungspolitisch begründeten Ausgabenprogramme der EU beeinträchtigt werden kann. Es entstehen Wohlfahrtsverluste in diesen Tätigkeitsbereichen der EU. Diese Erwägung besitzt eine besonders große Bedeutung im Bereich des wirtschaftlichen und sozialen Zusammenhalts, da durch eine „erfolgreiche” Kohäsionspolitik sich selbstverstärkende Prozesse eingeleitet werden, die im Zeitablauf die Vergabe der kompensatorischen FZ obsolet werden lassen. ${ }^{1376}$

Diese Argumente sprechen dafür, eine deutliche Trennung der politischen und der ökonomischen Zielsetzung zu vollziehen. Die Kompensationszahlungen sollten explizit ausgewiesen und hierdurch transparent gemacht werden. Dieses Vorhaben kann entweder durch kompensatorische Korrekturen auf der Einnahmenseite des EU-Haushalts oder durch die Vergabe eigenständiger Kompensationszuweisungen verwirklicht werden.

Im Laufe des weiteren Einigungsprozesses ist der unterschiedlichen Bedeutung der Kompensationsfunktion in den verschiedenen Funktionsbereichen des öffentlichen Sektors Rechnung zu tragen. Deshalb sollte eine systematische Strukturierung der Entscheidungsprozesse erfolgen, um die Bereitstellungsfunktion des öffentlichen Sektors klar von seiner Verfassungsfunktion abzugrenzen. ${ }^{1377}$ Mit zunehmendem wirtschaftlichem und sozialem Zusammenhalt inner-

\footnotetext{
${ }^{1375}$ Vgl. auch Francke (1993), S. 20 f.; Kraff(1997), S. 438.

${ }^{1376} \mathrm{Vgl}$. prägnant Binder/Walthes (1995), S. 306 f.; zudem Abschnitt V-5.1. Vgl. aber auch Biehl (1991b), S. 180, der darauf verweist, daß bei dieser Zielvermischung auch eine Zielharmonie zwischen der Kompensationsfunktion und den okonomischen Funktionen der $E U$ bestehen kann. Dies ist dann der Fall, wenn das politische „bargaining”-Ergebnis zur Vergabe von Kompensationszahlungen an jene Mitgliedstaaten führt, die auch aus ökonomischer Sicht zweckgebundene Unterstützungsleistungen erhalten sollten. Diese Sichtweise trifft im Fall der Ausweitung der Kohäsionsmaßnahmen zu.

${ }^{1377} \mathrm{Vgl}$. zu dieser Forderung Abschnitt IV-2.2.2.
} 
halb der EU kann bei Abstimmungen, die der Erfüllung der Bereitstellungsfunktion dienen, völlig von Kompensationsleistungen abgesehen werden. ${ }^{1378}$ Bei der Erfüllung der Verfassungsfunktion hingegen besitzen die Kompensationsleistungen auch langfristig eine elementare Rolle, um den Integrationsprozeß aufrecht zu erhalten und so die Verwirklichung der Zielsetzung „einer immer engeren Union der Völker Europas”" ${ }^{1379}$ zu unterstützen. In diesem Bereich fällt das Ausmaß der entstehenden Wohlfahrtseffekte so hoch aus, daß auf eine Kompensation der relativen oder absoluten Verlierer nicht verzichtet werden kann. Die Tragfähigkeit des europaweiten Zusammengehörigkeitsgefühls würde sonst überfordert werden. ${ }^{1380}$

\section{V-6 Das Gesamtsystem zwischenstaatlicher FZ in der EU}

Im Kapitel V wurden bislang diejenigen Probleme der EU untersucht, zu deren Lösung die Vergabe von FZ zwischen den Mitgliedstaaten als (finanz-)politisches Instrument einen Beitrag leisten kann. Zudem wurde jeweils die aufgabenadäquate Ausgestaltung der FZ analysiert. In der theoretischen Idealvorstellung resultiert insgesamt ein effizientes System monofunktionaler zwischenstaatlicher FZ. In der Realität stehen die einzelnen FZ jedoch nicht unverbunden nebeneinander. Deshalb stellt sich die Aufgabe, systematisch die Zusammenhänge zwischen den FZ zu beleuchten, um zu einem rationalen Gesamtsystem zu gelangen. ${ }^{1381}$

Zunächst werden die in Abschnitts III-4 formulierten Beurteilungskriterien eines Systems zwischenstaatlicher FZ herangezogen, um die zum heutigen Zeitpunkt bestehenden FZ aus dem Blickwinkel eines rationalen Gesamtsystems zu bewerten. Es ergibt sich eine Reihe von Kritikpunkten, die zu einem großen Teil schon in den einzelnen Teilabschnitten des Kapitels V erkannt wurden. Sie sollen aber an dieser Stelle nochmals deutlich herausgearbeitet und zusammenhängend dargestellt werden (Abschnitt V-6.1). Im Anschluß hieran wird ein Reformvorschlag gemacht, um den Weg zu einer rationaleren Ausgestaltung der zwischenstaatlichen FZ in der EU aufzuzeigen (Abschnitt V-6.2).

\section{V-6.1 Zum Status-Quo der zwischenstaatlichen FZ in der EU}

Die bestehenden FZ zwischen den Mitgliedstaaten der EU bilden kein bewußt erstelltes Gesamtsystem. Der Status-Quo ist im Integrationsprozeß nach und nach historisch gewachsen

\footnotetext{
${ }^{1378}$ Diese Überlegung entspricht der Forderung im Rahmen der Bereitstellungsfunktion konsequent von der Einstimmigkeitsregel zu einer Form der Mehrheitsregel uberzugehen. Die Leistung von Kompensationen kann dann nicht mehr durch Veto-Positionen erzwungen werden (vgl. auch Folkers (1994), S. 27 f.).

${ }^{1379}$ Art. A EUV.

${ }^{1380}$ So auch Berg/Schmidt (1997), S. 174.

${ }^{1381} \mathrm{Vgl}$. hierzu die theoretischen Grundlagen in Abschnitt III-4.
} 
und damit Ausdruck der politischen Entscheidungsprozesse unterschiedlicher Epochen der europäischen Einigung. ${ }^{1382}$

Wie die Ausführungen der einzelnen Teilabschnitte dieses Kapitels zeigen, stehen bei den FZ zum heutigen Zeitpunkt die Kohäsionsfunktion sowie die Kompensationsfunktion im Vordergrund. Nur als „Nebenprodukt” tragen die FZ zur Lösung der Spillover-Problematik bei und auch ,rein” umverteilende Wirkungen werden durch die FZ mehr zufällig und unsystematisch ausgelöst. FZ zur Ausfüllung der Stabilisierungsfunktion existieren nicht. Es bestehen folglich „Lücken” im System der FZ-Vergabe der EU. Die Beurteilung dieser Lücken erfordert eine differenzierte Betrachtung. Es muß der Stand des Integrationsprozesses und das Vorhandensein alternativer Instrumente zur Erfüllung der in Frage stehenden Funktionen berücksichtigt werden. So gesehen ist die Bedeutung der bestehenden Lücken unterschiedlich gravierend: Im Hinblick auf einen ,rein” umverteilenden Finanzkraftausgleich kann unter Berücksichtigung des unzureichenden Stands des Integrationsprozesses argumentiert werden, daß die SchlieBung dieser Lücke im System der FZ verfrüht wäre. Bei der Internalisierung positiver externer Effekte kann auf die Problemlösung durch dezentrale Verhandlungen verwiesen werden, die unter Beachtung aller Einflußfaktoren möglicherweise besser zur Erfüllung der Internalisierungsfunktion geeignet ist. Die Lücke mit Bezug zur Stabilisierungsfunktion hingegen ist gravierend, da die Einführung der einheitlichen Währung einen wirtschaftspolitischen Handlungsbedarf auslöst und zugleich (auf absehbare Zeit) keine alternativen Instrumente zur Verfügung stehen. Entscheidend für die Beurteilung der Lücken im System der FZ ist die Frage, ob diese Lücken von den staatlichen Entscheidungsträgern mit Rücksicht auf den Integrationsprozeß und/oder die Existenz alternativer Instrumente ${ }^{1383}$ bewußt offen gelassen wurden $^{1384}$ oder ob sie bestehen, weil im Entscheidungsprozeß keine Einigung gefunden werden konnte oder die Fragestellung erst gar nicht in den Abstimmungsprozeß eingebracht wurde.

Es treten bei der FZ-Vergabe eine Reihe an Widersprüchlichkeiten auf. Es bestehen sachliche Überschneidungen zwischen verschiedenen FZ-Programmen bzw. zwischen FZ-Programmen und anderen Ausgabenprogrammen, die sich in ihren Wirkungen gegenseitig konterkarieren. Dies gilt in extremen Maße für die Ausgabenprogramme des EAGFL - Abteilung Garantie

\footnotetext{
${ }^{1382}$ In Abgrenzung zu einem rationalen kann daher von einem historischen System der FZ gesprochen werden.

${ }^{1383}$ Hierunter ist auch der Fall zu subsumieren, daß die zentrale EU-Ebene gar nicht in die Aufgabenerfüllung eingreifen muß, die die Mitgliedstaaten autonom wahrnehmen können.

${ }^{1384}$ Unter der Annahme, daß die staatlichen Entscheidungstrăger sichere Kenntnis der Wohlfahrtseffekte der FZProgramme besitzen, entstehen in diesem Fall durch die Lücke im FZ-System keine Wohlfahrtsverluste, da die Lulcke auf Basis einer rationalen Entscheidung offen gelassen wird, die Ausdruck der wohlfahrtsmaximierenden Problemlosung ist.
} 
(sektorale Umverteilung), die zu einem großen Teil im Widerspruch zu der kohäsionspolitischen Zielsetzung der Strukturfonds stehen. Auch die Transfers im Bereich der Forschung und Entwicklung (wachstumspolitische Zielsetzung) sowie die Beihilfen der EGKS (sektorale Umverteilung) wirken den wirtschaftlichen Aufholprozessen der Kohäsionsländer mitunter entgegen. Außerdem ist eine Zielüberfrachtung einzelner FZ-Programme zu konstatieren, die ebenfalls zu Widersprüchlichkeiten führt. So erschweren FZ im Rahmen der Strukturfonds die Erreichung der Kohäsionszielsetzung, wenn sie an wirtschaftsstarke Mitgliedstaaten geleistet werden, um dort einen Beitrag zur Kompensationsfunktion zu leisten. Dies ist bspw. bei den Transfers des Ziels 6 der Strukturfonds an Schweden und Finnland der Fall. ${ }^{1385}$

Es sind stets zwei Formen der Widersprüchlichkeiten qualitativ voneinander abzugrenzen. Zum einen bestehen Widersprüchlichkeiten, denen keine (ökonomischen) Zielkonflikte zugrunde liegen. Hier ist die Ursache der Inkonsistenzen der Einzelnormen auf fehlerhafte politische Steuerungsleistungen zurückzuführen. ${ }^{1386}$ Diese Widersprüchlichkeiten können grundsätzlich beseitigt werden, ohne die Verwirklichung eines der angestrebten Ziele aufgeben zu müssen. Zum anderen sind Widersprüchlichkeiten präsent, die Ausdruck unauflösbarer (ökonomischer) Zielkonflikte sind. ${ }^{1387}$ In diesem Fall ist es notwendig, durch eine politische Entscheidung die Klärung der Zielprioritäten der EU herbeizuführen. Im Anschluß hieran können die Widersprüchlichkeiten entsprechend der politischen Zielhierarchie aufgelöst werden. Dies hat jedoch zwingend zur Folge, daß auf die Verwirklichung des Zieles, dem die geringere Priorität eingeräumt wird, zugunsten des „wichtigeren” Zieles verzichtet wird.

Sehr eng mit dem zuvor angesprochenen Kritikpunkt im Zusammenhang stehen die Praktikabilität und die Transparenz des FZ-Systems. Diese beide Grundsätze gehen aufgrund der bestehenden sachlichen Überschneidungen und der Zielüberfrachtung weitgehend verloren. ${ }^{1388}$ Diese gilt insb. für die Fondswirtschaft der EU. Die vielzähligen Regelungen sind für die staatlichen Verwaltungstellen kaum noch korrekt handhabbar (Impraktikabilität). Hierdurch wird die effiziente Ausfuihrung der FZ-Programme in Frage gestellt. Darüber hinaus sind die komplizierten Maßnahmen für die Bevölkerung ohne erklärende Hilfestellung kaum durchschaubar (Intransparenz). Sofern die komplexen Bestimmungen sachlich geboten sind, müssen die Vorhaben den Bürgern deshalb durch eine intensive, bürgernahe Informationspolitik

\footnotetext{
${ }^{1385}$ Vgl. auch Frick/Van der Beek/Hünger (1996), S. 360; Nowotny (1997c), S. 134.

${ }^{1386}$ Entweder bringt der Konsensfindungsprozeß im Verflechtungssystem keine problemadăquate Lösung hervor oder die einzelnen Akteure oder Akteursgruppen lösen durch ihr (polit-ð̌konomisch begründetes) Eigennutzverhalten unnötige Inkonsistenzen aus.

${ }^{1387}$ Vgl. hierzu Streit (1991), S. 236 ff.; den klassischen Zielkonflikt zwischen Wachstum und Verteilung stellt Zimmermann (1996), insb. S. $131 \mathrm{ff}$. ausführlich dar.
} 
verständlich gemacht werden. Dies hat einen großen Einfluß auf das Volumen der Transfers, das für das Gesamtsystem einvernehmlich durchgesetzt werden kann. Denn langfristig können die politischen Entscheidungsträger keine Akzeptanz für Vergabe der unterschiedlichen FZ in den transferleistenden Mitgliedstaaten erwarten, wenn die Bürger weder über das angestrebte Zielsystem noch über die eingesetzten Instrumente ausreichend informiert sind. ${ }^{1389}$

\section{V-6.2 Reformvorschlag - ein funktionales System zwischenstaatlicher FZ}

Die verschiedenen Kritikpunkte an der Gesamtheit der bestehenden FZ zwischen den Mitgliedstaaten finden ihren gemeinsamen Ausgangspunkt darin, daß bislang noch zu keinem Zeitpunkt im Integrationsprozeß ein (umfassender) Versuch unternommen wurde, ein rationales System zwischenstaatlicher FZ zu installieren. ${ }^{1390}$

Diese Feststellung ist nicht als eine grundsätzliche Kritik an dem bisherigen Vorgehen der EU-Entscheidungsträger zu verstehen, denn die Konsensfindungskapazität des europäischen Verflechtungssystems wäre mit Sicherheit überfordert worden, wenn man den Versuch unternommen hätte, bereits sehr frühzeitig im Integrationsprozeß ein umfassendes rationales System zwischenstaatlicher FZ einzuführen. Die Mehrzahl der Entscheidungen, die aus heutiger Sicht eindeutig als Auslöser von Widersprüchlichkeiten im System der FZ erkannt werden, entstanden im Kontext komplexer rechtlich-organisatorischer, politischer, ökonomischer und sozio-kultureller Zwänge und Notwendigkeiten, so daß sie in der historischen Entscheidungssituation in vielen Fällen gar nicht zu vermeiden gewesen sind und durchaus rationale (Einzel)Maßnahmen darstellten. ${ }^{1391}$

Im dynamischen Umfeld des Integrationsprozesses entwickeln sich jedoch nach und nach in zunehmenden Maße sachliche Überschneidungen sowie Zielüberfrachtungen. Zugleich gewinnt die Tragweite der Lücken des bestehenden FZ-Systems auf der EU-Ebene beständig an Bedeutung, da die fortschreitenden Globalisierungsprozesse die eigenständigen Handlungsspielräume der Mitgliedstaaten beständig vermindern. Außerdem steht der Integrationsprozeß

\footnotetext{
${ }^{1388}$ Ebenfalls eng hiermit verbunden ist die deutliche Kritik am Verwaltungsaufwand, der mit der Vergabe und Inanspruchnahme der Transfers in der $E U$ verbunden ist (vgl. Abschnitt V-2.3.3).

${ }^{1389}$ So zeigt sich im Rahmen der Diskussionen zur Ost-Erweiterung der $E U$, daß eine Ausweitung des Gesamtvolumens der bestehenden Transfers politisch kaum durchzusetzen ist (vgl. bspw. Franzmeyer/Weise (1997)). Es kann in diesem Zusammenhang die Hypothese aufgestellt werden, daß eine frühzeitige Aufklärung der Bevölkerung über die enorme wirtschaftliche und politische Bedeutung dieses Integrationschrittes die Bereitschaft zur Leistung zusătzlicher Transfers erhöht hătte.

${ }^{1390}$ Vgl. hierzu Grossekettler (1997) oder auch Francke (1993); (1994).

${ }^{1391}$ So standen zu Beginn des Integrationsprozesses nach Beendigung des zweiten Weltkrieges eindeutig politische Überlegungen im Mittelpunkt der zu treffenden Entscheidungen, die die Konsensfindungskapazitäten des Entscheidungssystems bereits bis auf das äußerste ausschöpften (vgl. hierzu Pfetsch (1997), S. 15 ff.).
} 
angesichts der Einführung der einheitlichen Währung und der Osterweiterung an einem besonders kritischen Punkt. Diese Faktoren lösen eine hohe Dringlichkeit aus, die bestehende Systemlosigkeit der FZ nunmehr im politischen Entscheidungsprozeß aufzugreifen und zu beenden.

Das entscheidende Fundament, um eine systematische Ordnung zu schaffen, ist die explizite Trennung der FZ gemäß der einzelnen ökonomischen und nicht-ökonomischen Ansatzpunkte zu ihrer Vergabe. Es wird ein nach den einzelnen Funktionen aufgebautes funktionales System zwischenstaatlicher FZ angestrebt. Mit einem solchen Trenn-System sind eine Reihe von Vorteilen für das Gesamtsystem der FZ verbunden, die die zum heutigen Zeitpunkt bestehenden Ineffizienzen (zum Teil) beseitigen können. Es müssen jedoch auch Nachteile bzw. Zielkonflikte beachtet werden. Nachfolgend werden die verschiedenen Aspekte gegeinander abgewogen. Auf diese Weise kann eingeschätzt werden, ob die vorgetragene Reformüberlegung auch unter Beachtung der in Kapitel III-4 formulierten Anforderungen an das Gesamtsystem der zwischenstaatlichen FZ Bestand hat.

\section{V-6.2.1 Zur Widerspruchsfreiheit und Vollständigkeit eines funktionalen Gesamtsy- stems}

Die Widerspruchsfreiheit und Vollständigkeit des FZ-Systems bilden das Hauptziel, das mit dem Übergang vom bestehenden unsystematischen System zu einem funktionalen TrennSystem zwischenstaatlicher FZ verwirklicht werden soll. Da sich die Vergabe der einzelnen FZ im funktionalen Gesamtsystem getrennt nach der jeweils $\mathrm{zu}$ erfüllenden Funktion bestimmt, werden sowohl sachliche Überschneidungen als auch Zielüberfrachtungen vermieden. So wird automatisch ein widerspruchsfreies FZ-System gebildet. ${ }^{1392}$ Sofern die politischen Entscheidungsträger über alle im Rahmen der theoretischen Analyse ermittelten funktionalen Ansatzpunkte der FZ beraten und zu einer (sachgerechten) Einigung im Abstimmungsprozeß gelangen, wird die Vollständigkeit des FZ-Systems gewährleistet.

Die Chancen, innerhalb der EU ein entsprechendes vollständiges und widerspruchfreies System zu realisieren, müssen differenziert beurteilt werden.

Einerseits besteht in Europa in einzelnen Politikbereichen, in denen FZ als finanzpolitisches Instrument zum Einsatz kommen können, eine Art ,grüne Wiese”, die es erlaubt, die Vergabe der FZ (ökonomisch) rational einzurichten. Es müssen in diesen Bereichen nicht die Systemwidrigkeiten eines langfristig bestehenden historischen Instrumenteneinsatzes durch ein-

\footnotetext{
${ }^{1392}$ Vgl. zur Definition eines widerspruchsfreien FZ-Systems nochmals Abschnitt III-4.1.
} 
schneidende Reformschritte beseitigt werden. Die Vergabe der FZ kann funktional getrennt von anderen Zuweisungsschienen erfolgen. Eine solche „grüne Wiese” besteht bspw. im Hinblick auf die Realisierung eines expliziten stabilisierungspolitischen FZ-Mechanismus. Die Aussage trifft auch auf die Vergabe ,rein” umverteilender FZ zum Finanzkraftausgleich zwischen den Mitgliedstaaten zu.

Andererseits stehen die vorhandenen ,traditionellen” Interessenpositionen der (negativ) betroffenen Mitgliedstaaten mit hoher Wahrscheinlichkeit der Beseitigung bereits bestehender Widersprüchlichkeiten im Wege. Die Durchführung von Reformschritten zu einem rationalen FZ-System scheitert an dem Verhalten der Entscheidungsberechtigten im Verflechtungssystem, sofern diese sich auf Strategien zur Minimierung des Konsensbedarfs - wie der Konfliktvertagung und der Besitzstandswahrung - verständigen. Die Entscheidungsstrukturen der EU, die zumeist die Einstimmigkeit aller Verhandlungspartner vorschreiben, fördern diese Verhaltensweise. Daher besteht bspw. nur eine sehr geringe Aussicht, daß die Trennung der Kompensationsfunktion von den anderen Funktionen der FZ, insb. der Kohäsionsfunktion, vollzogen wird. Diese Zielüberfrachtung wird voraussichtlich fortbestehen, obwohl eine funktionale Trennung der FZ sachlich möglich ist. ${ }^{1393}$

Allerdings wird die Dynamik des europäischen Integrationsprozesses im Zeitablauf einen ansteigenden Reformdruck auslösen, der langfristig den Übergang zu einem funktionalen System begünstigt. Denn die Integrationsdynamik führt zu massiven Veränderungen der ökonomischen und sozio-kulturellen Rahmenbedingungen des Zusammenlebens der Mitgliedstaaten der EU. Diese zwingen die staatlichen Entscheidungsträger, in bestimmten Zeitabständen grundlegende Veränderungen des historisch überkommenen Systems der FZ vorzunehmen, soll nicht die Existenz des gesamten europäischen Einigungsprozesses gefährdet werden. ${ }^{1394}$ Solche Situationen können zur Beseitigung von Widersprüchlichkeiten und Unvollständigkeiten des bestehenden FZ-Systems genutzt werden. ${ }^{1395}$

Bei dem Aufbau des funktionalen Gesamtsystems besitzt das Verhalten der EK eine wesentliche Bedeutung. Das Gelingen der Reform erfordert von der zentralen EU-Ebene ein neues Rollenverständnis. Sie darf nicht hierarchisch-interventionistisch Entscheidungsinhalte bestimmen, sondern muß als gleichgeordneter Partner der Mitgliedstaaten die Verwirklichung kooperativer Problemlösungen unterstützen. Diese Rolle der EK leitet sich aus den bestehenden komplexen aber zugleich mit einem hohen Problemlösungspotential ausgestatteten recht-

\footnotetext{
${ }^{1393}$ Vgl. hierzu Abschnitt V-5.3.

${ }^{1394}$ An dieser Stelle sei nochmals auf die Einfuhrung einer einheitlichen Währung und die Osterweiterung der $E U$ verwiesen. Vgl. aber auch Abschnitt IV-2.3.

${ }^{1395}$ Vgl. hierzu mit Bezugnahme auf ein rationales Steuersystem Nowotny (1996), S. 263 f.
} 
lich-organisatorischen Entscheidungsstrukturen der EU ab. ${ }^{1396}$ Das Verbundsystem zwischen den Mitgliedstaaten und der zentralen Ebene kann zur Verwirklichung der theoretischen Idealvorstellung eines funktionalen FZ-Systems in geeigneter Weise instrumentalisiert werden:

Die EK muß dafür Sorge tragen, daß die Aussagen der Theorie der Finanzzuweisungen in die Entscheidungsprozesse zwischen den Mitgliedstaaten im Ministerrat eingebracht werden. Die EK fungiert zunächst als Impulsgeber, der den Anstoß zur Verhandlung über eine bestimmte Funktion der FZ gibt und sodann als Moderator, der die Bedeutung der jeweiligen Funktion erläutert. Erfüllt die EK diese Aufgabe im Hinblick auf jede der potentiellen Funktionen der FZ, so wird insgesamt die Vollständigkeit und Widerspruchsfreiheit des Gesamtsystems ermöglicht.

Das funktionale System der FZ ist bewußt in die Gesamtheit der Finanzverfassung der EU einzuordnen, so daß unter Beachtung der Aufgabenverteilung zwischen der EU und den Mitgliedstaaten sowie der zur Verfügung stehenden alternativen Instrumente, die geeignetsten Maßnahmen durch die staatlichen Entscheidungsträger ergriffen und durchgefuihrt werden. Auch dieser Vorgang kann von der EK begleitet und unterstützt werden.

Hierbei sind Interdependenzen zwischen den getrennten FZ-Programmen zu berücksichtigen. Denn zwischen den spezifischen Funktionen der FZ besteht in vielen Fällen keine Zielneutralität. Die Verfolgung eines Ziels durch ein FZ-Programm läßt die anderen Ziele des Gesamtsystems der FZ zumeist nicht unberührt.

Es besteht eine Reihe an Zielharmonien. Dies gilt erstens für die FZ zur ,reinen” Umverteilung, die auch einen Beitrag zur Erreichung der Stabilisierungsfunktion leisten. Da die Finanzkraft eines Mitgliedstaates, der von einem länderspezifischen negativen (positiven) Schock getroffen wird, absinkt (ansteigt), erhöht (verringert) sich dessen Anspruch auf FZ im Rahmen des Finanzausgleichs zur ,reinen” Umverteilung. So wird eine stabilisierende Wirkung auf die Finanzsituation des betreffenden Mitgliedstaates ausgelöst. ${ }^{1397}$ Zweitens existiert ein zielharmonischer Zusammenhang zwischen den Kohäsionszuweisungen und der „reinen” Umverteilung. Mit den kohäsionspolitisch motivierten Infrastrukturinvestitionen in Sach- und Humankapital, die eine Vorleistung für die Unternehmen darstellen, werden in vielen Fällen

\footnotetext{
${ }^{1396} \mathrm{Vgl}$. hierzu die Ausführungen zu den Entscheidungsstrukturen der EU in Abschnitt IV-2.2 in Verbindung mit den theoretischen Voruberlegungen in Abschnitt III-2.3.2.

${ }^{1397}$ Vgl. hierzu auch Kraff(1997), S. $591 \mathrm{f}$.
} 
zugleich konsumtiven Nutzungen für die Bürger der betroffenen Regionen ermöglicht. ${ }^{1398}$ Hierdurch erfolgt ein Beitrag zur Verwirklichung gleichwertiger Lebensverhältnisse, unabhängig von der Auswirkung der FZ auf das wirtschaftliche Entwicklungspotential der transferempfangenden Mitgliedstaaten. Drittens tragen die Kohäsionstransfers zugleich zur Internalisierung externer Effekte bei, da deren FZ in vielen Fällen gerade die Ausgabetätigkeiten in jenen Bereiche stimulieren, die durch positive Spillovers zwischen den Mitgliedstaaten geprägt sind. ${ }^{1399}$ Diese positiven Nebenwirkungen der FZ-Programme müssen bei der Vergabe der FZ in den einzelnen Funktionsbereichen in Rechnung gestellt werden. Der Umfang der FZ kann entsprechend abgesenkt werden. ${ }^{1400}$

Die EK muß gleichzeitig darauf dringen, daß die bestehenden unwiderruflichen Zielkonflikte zwischen den Funktionen der FZ einer politischen Lösung zugeführt werden, indem sie die fraglichen Problemstellungen in die Entscheidungsprozesse einbringt und hierbei das Verständnis für die vorliegenden Zielkonflikte entsprechend der Intention der Vertragsinhalte fördert. Im Mittelpunkt steht der Zielkonflikt zwischen „,balanced”-growth und „unbalanced”growth. ${ }^{1401}$ Wie im Rahmen dieses Kapitels herausgearbeitet wurde, sprechen eine Reihe von Faktoren dafür, der ausgewogenen Entwicklung im Gesamtraum der EU und damit dem wirtschaftlichen und sozialen Zusammenhang die höchste Priorität einzuräumen. Denn die Effizienz der FZ mit allokativer Ausgleichsorientierung besitzt eine elementare Bedeutung, um eine Vielzahl der zwischenstaatlichen Problembereiche innerhalb der EU quasi automatisch einer Lösung zuzuführen. ${ }^{1402}$

Insgesamt füllt die EK in dem Zusammenspiel zwischen der EU-Ebene und den Mitgliedstaaten die Rolle eines dritten Partners aus, der im Interesse der Gesamtheit der EU auf eine kooperative Verhandlungslösung hinwirkt. ${ }^{1403}$

\footnotetext{
${ }^{1398}$ Als markantes Beispiel sei auf den Schienen- und Straßenbau verwiesen, der einerseits den Transport von Gütern ermöglicht, andererseits aber den privaten Bürgern die Gelegenheit für Individual- und Freizeitverkehr bietet.

${ }^{1399}$ Vgl. hierzu näher Abschnitt V-1.2; vgl. auch Jochimsen (1995), S. 497.

${ }^{1400}$ Diese Überlegung gilt analog auch für den Einsatz alternativer Instrumente zur Erreichung einer bestimmten Zielsetzung, die in Zielharmonie zu einer anderen Funktion der FZ steht. Im Extremfall ist es sogar denkbar, daß auf ein bestimmtes funktionales FZ-Programm vollständig verzichtet wird, wenn dessen Zielerreichung bereits durch ein anderes (zielharmonisches) FZ-Programm in befriedigendem Ausmaß sichergestellt wird.

${ }^{1401}$ Vgl. hierzu Abschnitt V-2.1.

${ }^{1402}$ Vgl. hierzu insb. die Abschnitte V-3 und V-4; aber auch Abschnitt V-5.

${ }^{1403}$ Das Bild des „dritten Partners" ist der Analyse von Böhret (1993) zum funktionalen Staat entnommen. Seine Überlegungen zum Staat als katalysatorischer dritter Partner im multilateralen Verhandlungs- und Koordinierungssystem der privaten Akteure wird hier auf den offentlichen Sektor übertragen: die zentrale EU-Ebene kann keine hierarchisch-interventionistischen Entscheidungen über die Köpfe der Mitgliedstaaten hinweg fällen; sie besitzt aber eine wichtige Handlungsberechtigung als Partner im Verflechtungssystem, der kooperativ an der Verwirklichung von Verhandlungslösungen zwischen den Mitgliedstaaten beteiligt ist (vgl. hierzu năher Böhret (1993), insb. S. 13 ff.).
} 


\section{V-6.2.2 Zur Transparenz und Praktikabilität eines funktionalen Gesamtsystems}

Auch die Anforderungen von Transparenz und Praktikabilität der einzelnen FZ sprechen für die Einführung eines funktionalen Systems zwischenstaatlicher FZ. Durch die sachliche Trennung der FZ nach Funktionen können die einzelnen Transferprogramme eindeutig auf eine Zielsetzung hin formuliert werden.

Dies erhöht die Wahrscheinlichkeit, daß es bei den Transfergebern und -nehmern zu einer korrekten Handhabung der FZ kommt. Die Zuweisungsregelungen fallen weniger kompliziert aus, als im Fall von „multifunktionalen” FZ. Infolge dieser Erhöhung der Praktikabilität des FZ-Systems können Ineffizienzen vermieden werden.

Durch das funktionale FZ-System wird eine hohe Transparenz der Zielsetzungen geschaffen, die mit der jeweiligen FZ-Vergabe verbunden sind. Dies verbessert die Möglichkeiten der (Wahl-)Bürger zu Kontrolle der politisch Verantwortlichen und verringert deren autonomen Handlungsspielraum zur Verfolgung von Eigeninteressen. Hierdurch können sachliche Ineffizienzen vermieden werden. Zudem entstehen geringere Frustrationskosten, da die politischen Akteure nunmehr gezwungen sind, ihre Entscheidungen stärker an den Präferenzen der Bürger auszurichten. $^{1404}$

Allerdings kann die Ausgestaltung der einzelnen FZ-Programme nach wie vor sehr differenziert erfolgen, um die problemadäquate Erfüllung der spezifischen Funktion zu ermöglichen. Diese Aussage trifft bspw. auf die Internalisierung externer Effekte ${ }^{1405}$ oder auch den stabilisierungspolitischen Finanzhilfemechanismus zu. „An optimal system of transfers might appear on the surface to be as complex, diverse, and apparently arbitrary", ${ }^{1406}$ wie das historisch gegebene System an FZ. Da diese Gestaltungsmerkmale jedoch sachlich geboten sind, werden im Vergleich zu einem FZ-System, das im Verlauf einer Vielzahl politischer Kompromisse sowie historischer Zufälligkeiten zunehmend an Komplexität gewonnen und Transparenz verloren hat, Effizienz- und Effektivitätsgewinne realisiert. ${ }^{1407}$

\footnotetext{
${ }^{1404} \mathrm{Vgl}$. auch Grossekettler (1997), S. $132 \mathrm{f}$.

${ }^{1405}$ Bei den FZ zur Internalisierung positiver externer Effekte triff diese Aussage in besonderem Maße zu, da hier eine Vielzahl spezifischer $\mathrm{FZ}$ vergeben werden muß, um eine effektive Ausfuhrung der Funktion zu garantieren. Denn eine Konsolidierung der einzelnen $\mathrm{FZ}$ zwischen den Mitgliedstaaten würde zu einem suboptimalem Angebot bei allen betroffenen öffentlichen Gütern führen (vgl. Peffekoven (1988), S. 627; Brümmerhoff (1996), S. 499).

${ }^{1406}$ Bird (1993), S. 221.

${ }^{1407}$ Vgl. hierzu Bird (1993).
} 


\section{V-6.2.3 Zum Verwaltungsaufwand eines funktionalen Gesamtsystems}

Der Verwaltungsaufwand steigt beim Übergang zu einem funktionalen System zwischenstaatlicher FZ im Vergleich zum bestehenden System an, weil jede einzelne Funktion der FZ getrennt voneinander ausgeführt wird und deshalb einen eigenständigen Verwaltungsapperat benötigt. Dies stellt einen Nachteil des funktionalen FZ-Systems dar. Es entstehen zusätzliche Ressourcenkosten. ${ }^{1408}$

Um diesen Nachteil zu verringern, sind durch eine Zusammenlegung funktional getrennter FZ-Programme Skalenerträge bei den mit der FZ-Vergabe verbundenen Verwaltungsabläufen zu realisieren, ohne die Effektivität der FZ-Vergabe zu beeinträchtigen.

Diese Möglichkeit besteht immer dann, wenn die theoretische Analyse zu einer äquivalenten Ausgestaltungsempfehlung der FZ für zwei unterschiedliche Funktionen gelangt. Hier zeigt sich eine entscheidende Schwierigkeit dieser Vorgehensweise, denn eindeutige Ausgestaltungsempfehlungen können schon aus rein ökonomischer Sicht kaum abgeleitet werden. Die Unbestimmtheit der theoretischen Analyseergebnisse erhöht sich nochmals, wenn man die Unberechenbarkeiten der Konsensfindungsprozesse bei der politischen Entscheidungsfindung in die Betrachtung integriert. Mit Blick auf die Funktionen zur Vergabe von FZ innerhalb der EU erfolgt lediglich zwischen der Funktion zur „reinen” Umverteilung sowie der (politischen) Kompensationsfunktion eine äquivalente Ausgestaltungsempfehlung. Beide Ansatzpunkte erfordern reine Pauschalzuweisungen. Das Nebeneinander dieser beiden FZ-Programme in einem funktionalen FZ-System könnte daher durch die Zusammenlegung beider Programme beendet werden. Prinzipiell läßt sich auch der Stabilisierungsmechanismus in diesen Verwaltungsapperat integrieren, sofern unter Abwägung aller Argumente für eine pauschale Vergabe der FZ votiert wird. ${ }^{1409}$ Der administrative Ressourcenaufwand zur Bestimmung der jeweils empfangsberechtigten Mitgliedstaaten kann durch diese Konsolidierung allerdings nicht verringert werden, da nur die differenzierte Analyse der unterschiedlichen Empfangsauflagen der einzelnen Funktionen die Effektivität der Transfers gewährleistet. Im Hinblick auf die FZ zur

\footnotetext{
${ }^{1408}$ Im Rahmen jeder einzelnen Funktion wird der Verwaltungsaufwand durch die sachlichen Zwänge der problemadäquaten FZ-Ausgestaltung vorgegeben. Im Bereich der Strukturfonds der $E U$ wird der Verwaltungsaufwand, der mit der Vergabe der FZ verbunden ist, deutlich kritisiert (vgl. Abschnitt V-2.3.3). Diese funktionsinterne Kritik steht an dieser Stelle jedoch nicht im Mittelpunkt. Vielmehr werden Überlegungen angestellt, ob Einsparpotentiale im Verwaltungsbereich durch die Zusammenlegung verschiedener FZ-Programme bestehen.

${ }^{1409}$ Man kann sich in diesem Zusammenhang ein Finanzausgleichsmodell in Analogie zum bundesdeutschen Finanzausgleich vorstellen. Die, ,reine" Umverteilung durch den Finanzkraftausgleich wird durch Sonderbedarfe einzelner Mitgliedstaaten zur Abgeltung von Kompensations- oder Stabilisierungszahlungen ergånzt. Die Zahlungen dieser drei Schienen kőnnten auf diese Weise in einem Ausgleichsinstrument zusammengefaßt werden.
} 
Internalisierung der externen Effekte sowie zur Förderung der Kohäsion ist eine verwaltungstechnische Zusammenlegung der FZ-Vergabe wegen der differenzierten Zweckbindung der Transfers praktisch ausgeschlossen. ${ }^{1410}$

\section{V-6.2.4 Zur Stetigkeit und Flexibilität eines funktionalen Gesamtsystems}

Die Stetigkeit des FZ-Systems soll die Rationalität des Gesamtsystems sichern. ${ }^{1411}$ Im Mittelpunkt steht die Vorstellung, daß sich im Zeitablauf ein sinnvolles Gleichgewicht im Zusammenspiel der einzelnen FZ und der weiteren (alternativen) wirtschaftspolitischen Maßnahmen eingestellt hat. Andauernde oder abrupte Änderungen würden zu zahlreichen Haupt- und Nebenwirkungen führen, deren Bedeutung für das bestehende Gleichgewicht von den staatlichen Entscheidungsträgern kaum abgeschätzt werden kann. ${ }^{1412}$ Aus diesem Blickwinkel ist ein (stetiges) funktionales System zwischenstaatlicher FZ positiv zu bewerten. Denn im funktionalen System bietet die bewußte Formulierung der einzelnen Ziele der FZ und die transparente Abgrenzung der einzelnen FZ-Programme Gewähr dafür, daß kurzsichtige und undurchdachte Einzelmaßnahmen unterbleiben. Erneut fällt der EK eine wichtige Rolle zu. Hier als Kontrollinstanz, die im Rahmen der politischen Entscheidungsfindungsprozesse auf entstehende Problembereiche frühzeitig aufmerksam machen kann und damit einen Beitrag zur langfristigen Kontinuität des Gesamtsystems leistet.

Der Gesichtspunkt der Stetigkeit weist darauf hin, daß der Übergang von der bestehenden wenig systemhaften Vergabe der FZ zu einem funktionalen Gesamtsystem nur in kleinen Reformschritten mit langfristigen Übergangszeiten erfolgen sollte. Hierdurch wird sichergestellt, daß die Fortentwicklung für die staatlichen Entscheidungsträger überschaubar und beherrschbar bleibt. Auf unerwartete Auswirkungen marginaler Reformschritte kann flexibel reagiert werden, ohne elementare Störungen des Integrationsprozesses auszulösen. Für diese inkrementale Vorgehensweise sprechen zudem die Entscheidungsstrukturen der EU. Die Konsensfähigkeit des Verflechtungssystems würde bei gravierenden Reformschritten sehr rasch überfordert werden, so daß entweder sachlich ineffiziente Problemlösungen realisiert würden

\footnotetext{
${ }^{1410}$ Deutlich von dem Vorhaben, FZ-Programme verwaltungstechnisch zusammenzulegen, das das Volumen der FZ-Vergabe unberührt läßt, ist die Frage der Konsolidierungsmöglichkeiten im Gesamtsystem der FZ abzugrenzen. Dort steht die Frage im Mittelpunkt, ob aufgrund bestehender Zielharmonien eine Reduzierung des Volumens einzelner FZ-Programme - oder im Extremfall sogar die Abschaffung einzelner FZ-Programme erfolgen kann (vgl. hierzu weiter oben in diesem Abschnitt).

${ }^{1411}$ Vgl. hierzu Abschnitt III-4.4.

${ }^{1412}$ Es soll v.a. verhindert werden, daß zunehmend Widersprulchlichkeiten Eingang in die Regelungen finden.
} 
oder eine Einigung gänzlich unterbleiben würde, mit der Konsequenz, daß das System der FZ im unbefriedigenden Status-Quo verweilt. ${ }^{1413}$

Die Stetigkeit der FZ-Regelungen stellt damit zugleich eine elementare Voraussetzung für die Flexibilität des Gesamtsystems dar. Stetigkeit und Flexibilität stehen auf der EU-Ebene keinesfalls in Widerspruch zueinander.

Die Flexibilität der FZ hat für die EU eine enorme Relevanz. Denn die Regelungen der einzelnen FZ-Programme müssen systematisch den sich verändernden Rahmenbedingungen angepaßt werden, um langfristig effektive Problemlösungen generieren zu können. Diese Rahmenbedingungen unterliegen schon in gewachsenen Einzelstaaten, die über ein stabiles rechtlich-organisatorisches Gleichgewicht verfügen, zunehmend heftigen Veränderungen (Globalisierungsprozesse). Die Dynamik dieser Entwicklungen erhöht sich auf der EU-Ebene wegen des (ökonomischen und politischen) Integrationsprozesses nochmals erheblich. ${ }^{1414}$

Es ist sinnvoll, innerhalb der einzelnen Funktionsbereiche jeweils eine automatische Flexibilität der FZ-Regelungen zu gewährleisten. Dies bedeutet, daß nach Möglichkeit objektive, quantifizierbare Kriterien zur Berechnung der Transferleistungen bestimmt werden, so daß veränderte Rahmenbedingungen automatisch zu einer problemadäquaten Variation der Transferströme führen. Damit wird ausgeschlossen, daß die Entscheidung über ein bestimmtes FZProgramm beständig in das politische Entscheidungssystem eingebracht werden muß. Dies ist auf der EU-Ebene besonders positiv zu bewerten, weil die angestrebte Flexibilität sonst durch die langwierigen Abstimmungsprozesse gefährdet wird.

Die automatische Flexibilität der Regelungen ist bei den Ausgestaltungsvorschlägen dieser Arbeit im Hinblick auf die FZ zur „reinen” Umverteilung und den stabilisierungspolitischen Finanzhilfemechanismus weitgehend erfüllt. Bei den allokativ orientierten Ausgleichszuweisungen (Kohäsionsfunktion) erfolgt durch die Infrastrukturindikatoren zumindest eine partielle „Objektivierung” der FZ-Vergabe. Mit Bezug auf die Internalisierung externer Effekte und die Kompensationsfunktion ist eine automatische FZ-Vergabe hingegen ausgeschlossen. Die besonderen Problemstrukturen dieser Funktionen erfordern in jedem Fall einen politischen Willensbildungsprozeß.

Wegen der Dynamik des Integrationsprozesses ist allerdings in bestimmten Zeitabständen eine politische Neubewertung aller Elemente des funktionalen Gesamtsystems unabdingbar. Die

\footnotetext{
${ }^{1413}$ Vgl. hierzu auch Francke (1994), S. 18 ff. Es kommt eine Strategie der Konfliktminimierung zur Anwendung: der komplexe Gesamtzusammenhang wird in einzelne Teil-Probleme geringerer Komplexităt aufgeteilt. ${ }^{1414} \mathrm{Die}$ EU-Ebene ist von einem rechtlich-organisatorischen Gleichgewicht (noch) weit entfernt.
} 
Ausgestaltung der FZ muß an grundlegende strukturelle Veränderungen der Rahmenbedingungen angepaßt werden, die durch die automatische Flexibilität nicht aufgefangen werden können. ${ }^{1415}$ Außerdem ändern sich im Laufe des Integrationsprozesses die politischen Wertschätzungen in den einzelnen Mitgliedstaaten, ${ }^{1416}$ die durch die automatische Flexibilität nicht erfaßt werden können. Veränderte Wertschätzungen finden ihren Ausdruck in einer Reformulierung der Zielhierarchie des FZ-Systems in den intergouvernementalen Abstimmungsprozessen auf der EU-Ebene. Diese Reformulierung kann erfordern, daß die Ausgestaltung und das Volumen der einzelnen FZ-Programme verändert wird oder auch, daß neue Funktionen der FZ in das bestehende Gesamtsystem integriert werden, die bislang bewußt nicht berücksichtigt wurden. ${ }^{1417}$

\footnotetext{
${ }^{1415}$ Dies gilt bspw. im Hinblick auf die anstehende Ost-Erweiterung der $E U$.

${ }^{1416}$ Es kommt zu einer Verănderung der Prăferenzkosten, die mit der Vergabe der $\mathrm{FZ}$ verbunden sind.

${ }^{1417}$ Dies ist bspw. denkbar mit Bezug zur ,reinen” Umverteilung. Entwickelt sich im Zeitablauf eine zunehmende Solidarităt zwischen den Mitgliedstaaten, so kann ein Konsens aller Mitgliedstaaten entstehen, die bestehende Lücke im FZ-System bezüglich eines mitgliedstaatlichen Finanzkraftausgleichs zu schließen.
} 


\section{Schlußbetrachtungen}

Das Erkenntnisinteresse dieser Arbeit galt der Notwendigkeit und Geeignetheit der Vergabe von $\mathrm{FZ}$ zwischen den Mitgliedstaaten der EU als wirtschaftspolitisches Instrument. Es wurde der Frage nachgegangen, welche Netto-Wohlfahrtseffekte durch einzelne FZ-Programme und insgesamt durch die Einrichtung eines europäischen Finanzausgleichsystems im engen Sinne ausgelöst werden. Dabei nehmen die FZ im Zusammenspiel mit dem Integrationsprozeß vielgestaltigen Einfluß auf die sozio-ökonomische Lebenslage der Bevölkerung in den Mitgliedstaaten. Diese Effekte der Transfers besitzen eine elementare Bedeutung für die Beurteilung der FZ. Deshalb durfte die Untersuchung nicht auf die rein ökonomischen Auswirkungen der FZ-Vergabe beschränkt werden. Aufbauend auf die ökonomische Theorie des Föderalismus wurde ein normativer Referenzrahmen entworfen, der es erlaubte, über ökonomische Kriterien hinaus auch sozio-kulturelle, rechtliche und politische Abwägungskalküle zur Bewertung der FZ heranzuziehen (vgl. Kapitel II).

In Kapitel III erfolgte eine umfassende Erörterung der Gesamtproblematik aus theoretischer Sicht.

Zunächst wurden die möglichen Ausgestaltungeformen der Transfers diskutiert, wobei die Unterscheidung von allgemeinen und auflagengebundenen Zuweisungen für die Praxis der FZ-Vergabe besonders wichtig ist. Anschließend wurde die Wirkungsweise der unterschiedlichen Ausgestaltungsformen der FZ mit Hilfe einer mikroökonomischen Indifferenzkurvenanalyse analysiert. Es zeigte sich, daß die stimulierende Wirkung auf das Bereitstellungsniveau einer geförderten öffentlichen Leistung bei einer zweckgebundenen FZ, die zusätzlich mit einer Eigenbeteiligung verbunden wird, am höchsten ist. Aufbauend auf die Einsichten dieser Untersuchung ließ sich bestimmen, welche Formen der FZ besonders geeignet sind, um die unterschiedlichen Ziele der Vergabe von FZ zu erreichen. Während distributionspolitische Ziele am besten mit allgemeinen Zuweisungen zu verwirklichen sind, stehen unter allokativen und wachstumspolitischen Aspekten zweckgebundene FZ im Vordergrund.

Allerdings verdeutlichte die theoretische Analyse auch, daß bei der Vergabe von FZ aufgrund von Unvollkommenheiten der politischen Märkte oder der rechtlich-organisatorischen Rahmenbedingungen Fehlentwicklungen möglich sind, durch die sachliche Ineffizienzen, Ressourcenkosten oder Präferenzkosten ausgelöst werden. So sind in den transferempfangenden GKS ein Mißbrauch auflagengebundener Transfers und Mitnahmeeffekte auch dann nicht auszuschließen, wenn erhebliche Kontrollkosten aufgewendet werden (Sickerverluste). Den Transfergebern verbleiben in aller Regel Handlungsspielräume bei der Durchführung der $\mathrm{Zu}$ - 
weisungsprogramme, die zu einer wohlfahrtsmindernden Zentralisierung von Entscheidungskompetenzen ausgenutzt werden können. Im Entscheidungsprozeß zur Vergabe der FZ können zusätzlich Handlungsblockaden von den beteiligten Akteuren errichtet werden, die sich zwar durch konfliktminimierende Entscheidungsregeln abbauen lassen, aber Ineffizienzen bei der Ausgestaltung der Transfers begünstigen.

Ein Urteil über den Netto-Wohlfahrtseffekt der Vergabe einer zwischenstaatlichen FZ macht daher eine differenzierte (Einzelfall-)Analyse erforderlich, bei der die Pro- und Kontraargumente gegeneinander abgewogen werden. Da die zahlreichen Nutzen- und Kostenaspekte nicht objektiv erfaßt werden können, hängt ein Gesamturteil entscheidend von der Gewichtung der einzelnen Argumente durch den Politiker oder wissenschaftlichen Politikberater ab.

Das empirisch-deskriptive Kapitel IV verdeutlichte die Schwierigkeit, ein konkretes Zielbündel für die Vergabe von FZ auf der EU-Ebene abzuleiten, da zwischen den Mitgliedstaaten in vielen Fällen ein Dissens bezüglich der Einzelziele besteht. Allerdings bestimmt der Maastrichter-Vertrag die Währungsunion, die Vollendung des Binnenmarktes und die Erweiterung der EU als unwiderrufliche Zielvorgaben des weiteren Integrationsprozesses.

Die Analyse der rechtlich-organisatorischen Rahmenbedingungen des Integrationsprozesses wies vor allem auf zwei Aspekte hin, die bei der Gestaltung eines Finanzausgleichsystems besonders zu beachten sind. Um eine stabile Fortführung des Integrationsprozesses zu unterstützen, die eine breite Akzeptanz in der Bevölkerung findet, sollten die FZ-Regelungen möglichst transparent ausgestaltet werden und ausschließen, daß es zu einer übermäßigen Ausdehnung der Kompetenzen der zentralen EU-Ebene kommt.

In Kapitel V wurden die theoretischen und empirisch-institutionellen Analyseergebnisse auf die Ebene der EU übertragen, um nun konkret die Notwendigkeit und die Geeignetheit der Vergabe von FZ zwischen den Mitgliedstaaten zu ermitteln:

\section{- Zur Notwendigkeit der FZ für die EU:}

Die Untersuchung demonstriert, daß es berechtigte Argumente für einen europäischen Finanzausgleich im engen Sinne gibt, die sich systematisch an der Realisierung von Gemeinwohlzielen orientieren. Aus den Zielvorgaben der Maastrichter-Verträge ergibt sich in unterschiedlichen Aufgabenbereichen ein zwischenstaatlicher Handlungsbedarf, der grundsätzlich durch die Vergabe von FZ gedeckt werden kann. Dabei ist die Bedeutung der einzelnen Funktionen der FZ entscheidend mit dem Stand des Integrationsprozesses verknüpft. 
Im Rahmen der Untersuchung kristallisiert sich die Aufrechterhaltung und Förderung des Integrationsprozesses als zentraler Kern der Vergabe von FZ heraus. Denn die fortschreitende Integration der Mitgliedstaaten ist unbedingt notwendig, um eine Vielzahl der Probleme lösen zu können, mit denen die Mitgliedstaaten konfrontiert sind. Da sich aber die ökonomischen, politischen und sozio-kulturellen Rahmenbedingungen des Integrationsprozesses beständig verändern, ${ }^{1418}$ darf der Stand der Integration nicht im Status-Quo verhaftet bleiben.

Aus diesem Grund sind Kompensationszahlungen von großer Relevanz. Sie ermöglichen die einvernehmliche Einigung aller Verhandlungspartner zur Durchführung anstehender Integrationsschritte, indem die Integrationsverlierer finanziell kompensiert werden. Solange die Abstimmungsregeln der EU nur eine einstimmige Beschlußfassung bei integrationspolitisch bedeutsamen Entscheidungen zulassen, kann auf die Leistung kompensatorischer FZ deshalb nicht verzichtet werden. Die Kompensationszahlungen leisten einen wichtigen Beitrag, ein dynamisches institutionelles Gleichgewicht in der EU aufrechtzuerhalten. Allerdings werden diese Kompensationen in der EU zumeist unter dem Deckmantel verschiedener Fachpolitiken vergeben, um die Akzeptanz in der Bevölkerung der betroffenen Mitgliedstaaten zu sichern. Bei dieser Verfahrensweise besteht jedoch die Gefahr, daß die politischen Entscheidungsträger ein Integrationstempo vorgeben, das die Einwohner überfordert. Langfristig kann dies dazu führen, daß die Bevölkerung ihre Zustimmung zu weiteren Integrationschritten in Frage stellt oder sogar dem gesamten Integrationsprozeß die politische Unterstützung entzieht. Daraus leitet sich die Forderung ab, die Kompensationszahlungen explizit auszuweisen und transparent zu machen. Die Geschwindigkeit des Integrationsprozesses kann dann weniger leicht über die Köpfe der betroffenen Bürger hinweg von den politischen Akteuren bestimmt werden.

Die zentrale Bedeutung für die Fortentwicklung des Einigungsprozesses besitzt aber die Vergabe von FZ zur Förderung des wirtschaftlichen und sozialen Zusammenhalts. Denn erfolgreiche kohäsionspolitische Maßnahmen ermöglichen dynamische Integrationsfortschritte. Indem mit diesen zweckgebundenen Unterstützungsleistungen in den benachteiligten Mitgliedstaaten zukunftsfähige Wirtschaftsstrukturen aufgebaut werden, lösen sich vielfältige Konfliktlinien zwischen benachteiligten und weiterentwickelten Mitgliedstaaten auf, die bislang die einvernehmliche Entscheidungsfindung im Rahmen der Abstimmungsprozesse auf

\footnotetext{
${ }^{1418} \mathrm{Vgl}$. hierzu năher den Abschnitt IV-2.3 zum europăischen Integrationsprozeß.
} 
der EU-Ebene blockieren. Zudem tragen die kohäsionspolitischen FZ dazu bei, daß die Dimension der Probleme in einer Reihe anderer Politikbereiche verringert wird.

Dies gilt z.B. für das Auftreten asymmetrischer Schocks in den einzelnen Mitgliedstaaten. In dieser Hinsicht besteht infolge der Währungsunion die Notwendigkeit, durch die Einfuihrung expliziter stabilisierungspolitischer FZ die Entstehung gravierender Einkommens- und Beschäftigungseinbrüche zu verhindern, solange keine alternativen Instrumente verfügbar sind, die „besser” geeignet sind, die konjunkturellen Schwankungen aufzufangen. Diese Problematik entschärft sich allerdings, wenn durch die kohäsionspolitischen Maßnahmen eine Diversifikation der Wirtschaftstätigkeit in der gesamten EU eingeleitet wird, und in der Folge die Bedeutung asymmetrischer Schocks in der WWU insgesamt abnimmt.

Die kohäsionspolitischen Maßnahmen erhöhen zudem die Realisierungschancen von FZ zur „reinen" Umverteilung. Denn die Nivellierung von Finanzkraftunterschieden scheitert zum heutigen Zeitpunkt an der extremen Heterogenität der Mitgliedstaaten. Sie führt dazu, daß ein merklicher Ausgleich der horizontalen fiskalischen Ungleichgewichte ein enormes Transfervolumen auslösen würde, und verhindert zugleich, daß die Bürger der einzelnen Mitgliedstaaten einen belastbaren europäischen Identifikationsbezug entwickeln. Erst wenn in den Mitgliedstaaten mit Unterstützung der Kohäsionsmaßnahmen homogenere Wirtschaftsstrukturen und eine weitergehende europaweite Solidarität entstanden sein werden, sind verstärkt „reine” Umverteilungsmaßnahmen möglich. Da die Mitgliedstaaten dann jedoch ohnehin weniger gravierende Finanzkraftunterschiede aufweisen und deshalb nur noch eine geringere Handlungsnotwendigkeit zur Vergabe derartiger horizontaler FZ besteht als zum heutigen Zeitpunkt, ergibt sich aus der Abhängigkeit der ,reinen” Umverteilung von den kohäsionspolitischen Maßnahmen eine Dilemmasituation.

Insgesamt zeigte sich, daß der Entwicklungsprozeß der europäischen Integration von einer Vielzahl an Interdependenzen, Abhängigkeiten und historischen Zufälligkeiten geprägt wird. Die hier angestellten Betrachtungen zu den Funktionen der FZ in der EU stellen deshalb keinen Entwurf für die ferne Zukunft dar, sondern besitzen bereits heute entscheidende Relevanz. Die Voraussetzungen zur stabilen und (möglichst) friktionsfreien Fortfuihrung des Integrationsprozesses müssen so früh wie möglich geschaffen werden, da ansonsten in vielen Bereichen erhebliche Fehlentwicklungen nicht auszuschließen sind und Entwicklungschancen im Integrationsprozeß verpaßt werden, die später gar nicht mehr wahrgenommen werden können 
(Pfadabhängigkeit). ${ }^{1419}$ Zur Schaffung dieser Voraussetzungen leistet ein rationales Finanzausgleichsystem einen wichtigen Beitrag.

\section{- Zur Geeignetheit der FZ für die EU:}

Um die Geeignetheit der FZ als wirtschaftspolitisches Instrument zu prüfen, erfolgte eine eingehende Analyse der Politikgestaltungsprozesse auf der europäischen Ebene, die die potentiellen Fehlentwicklungen bei der FZ-Vergabe und dadurch bedingte Wohlfahrtsverluste aufzeigt. Es rückte das europäische Verbundsystem, an dem der Ministerrat, die EK und das EP als Konsenspartner beteiligt sind, in den Mittelpunkt der Untersuchung. In diesem Zusammenhang wurde vor allem die eigenständige Regionalpolitik der EU deutlich kritisiert. Die Neigung der EK zur extremen (interventionistischen) Ausdifferenzierung der Einzelmaßnahmen führt insgesamt zu einem komplizierten und intransparenten Förderkonzept, das zu einer ungenügenden Effektivität und Effizienz der kohäsionspolitischen Maßnahmen in den Mitgliedstaaten beiträgt. Die EU sollte sich auf eine temporäre Hilfe zur Selbsthilfe durch die Vergabe zweckgebundener FZ beschränken.

Grundsätzlich jedoch besitzt das verflochtene Entscheidungssystem der EU ein besonderes Steuerungspotential, das es erlaubt, Wohlfahrtsgewinne zu realisieren, die innerhalb 15 dezentraler Entscheidungssysteme auf mitgliedstaatlicher Ebene nicht ausgeschöpft werden können. Die Verflechtungsstrukturen bieten die Möglichkeit, kooperative Problemlösungen für in horizontaler wie vertikaler Sichtweise komplexe Gesamtzusammenhänge auszuhandeln. Allerdings besteht unter Berücksichtigung des Einstimmigkeitsprinzips im Ministerrat die Möglichkeit von Entscheidungsblockaden, die eine einvernehmliche Problemlösung verhindern und so den (zunehmend probleminadäquaten) Status-Quo zementieren. Diese Gefahr ist dann besonders groß, wenn erhebliche Unsicherheiten über die Wohlfahrtswirkungen der FZVergabe bestehen oder wenn ausschließlich Verteilungsfragen zur Entscheidung anstehen. Eine einstimmige Entscheidungsfindung zwischen den 15 Mitgliedstaaten wird in diesen Situationen zumeist nur durch die Anwendung konfliktminimierender Entscheidungsregeln möglich, die aber zu einer probleminadäquaten Ausgestaltung der FZ führt und deshalb Wohlfahrtsverluste zur Folge hat.

\footnotetext{
${ }^{1419}$ Als Beispiel sei auf die Währungsunion verwiesen. Die vorübergehende Einrichtung eines expliziten Finanzhilfemechanismus kann entscheidend zum Gelingen der Währungsunion beitragen. Wird es verpaßt die Funktionsvoraussetzungen der WWU herzustellen, sind Fehlentwicklungen, wie bspw. ein weiterer Anstieg der Arbeitslosenzahlen in den Mitgliedstaaten, nicht ausgeschlossen, die möglicherweise die Akzeptanz des Integrationsprozesses nachhaltig und unumkehrbar beeinträchtigen.
} 
Eine optimistischere Sichtweise der Politikgestaltungsprozesse auf der EU-Ebene ergibt sich, wenn es der EK gelingt, die Rolle eines katalysatorischen „dritten Partners” im Verhandlungssystem der EU zu übernehmen. Entscheidend ist, daß die EK im Zeitablauf eine hohe Reputation in dieser Rolle erwirbt, die von den am Verhandlungsprozeß beteiligten Mitgliedstaaten nicht in Frage gestellt wird. Die EK vertritt dann die langfristigen Interessenpositionen der Gesamtheit und hilft als Impulsgeber und Moderator der Verhandlungsprozesse, innovative Einigungsmöglichkeiten zu erschließen. Die Anstöße der EK würden in diesem Fall eine hohe Glaubwürdigkeit im strategischen Abwägungskalkül der mitgliedstaatlichen Entscheidungsträger und damit eine hohe einigungsfördernde Wirkung besitzen, da nicht zu befürchten wäre, daß einseitig der Interessenposition einer bestimmten Koalition an Mitgliedstaaten zu Durchsetzung verholfen wird. Auf diese Weise würde langfristig ein Interessensausgleich hergestellt, und das Problemlösungspotential des Verflechtungssystems optimal ausgeschöpft.

Diesem Vorschlag zur Organisation des Politikgestaltungsprozesses liegt die These zugrunde, daß die Kooperation zwischen den Mitgliedstaaten und die Ausübung der Steuerungsfunktion durch die EU-Ebene nicht grundsätzlich an polit-ökonomisch begründeteten Staatsversagenstatbeständen scheitern müssen. Allerdings ist dies eine Frage, die empirische Untersuchungen darüber erfordert, ob die tatsächlich vorherrschenden Verhaltensmuster der Politiker und Bürokraten eher eigennutz- oder gemeinwohlorientiert sind. Wenn es nicht gelingt, das kooperative Element im Rahmen der EU-Verhandlungsprozesse zu stärken, bleiben in jedem Fall wesentliche Wohlfahrtsgewinne ungenutzt, die bei der Vergabe von FZ nur in einem kooperativen Miteinander aller Entscheidungsträger realisiert werden können. Wird davon ausgegangen, daß die Akteure die im Rahmen der europäischen Willensbildungsprozesse bestehenden Handlungsspielräume stets eigennützig auf Kosten der Gesamtheit ausnutzen, ${ }^{1420}$ so bleibt als Ausweg nur der Rückschritt zu der vielfach vorgeschlagenen ,europäischen Minimalgemeinschaft", ${ }^{1421}$ die an das kooperative Verhalten der politischen Entscheidungsträger nur geringe Anforderungen stellt.

Die dargelegten Schlußfolgerungen besitzen nicht nur für den Teilbereich der FZ eine große Bedeutung, sondern für die gesamte Aufgabenerfüllung innerhalb der EU. Wie in Abschnitt IV-2 verdeutlicht wurde, entwickelte sich im Zeitablauf eine gravierende Asymmetrie zwischen der ökonomischen und der politischen Integration. Der ökonomische Integrationsprozeß mit dem fortschreitenden Abbau von Handelsbarrieren im Binnenmarkt (negative Integration) ist aber mit dramatischen Auswirkungen auf die politisch-gesellschaftliche Dimension ver-

\footnotetext{
${ }^{1420}$ So bspw. Vaubel (1992) u. (1994).

${ }^{1421}$ Möschel (1994), S. 129; vgl. auch Möschel (1993) u. Mussler/Streit (1996).
} 
bunden. Die Lebenslagen der Bevölkerung in den einzelnen Mitgliedstaaten werden hierdurch entscheidend geprägt. Es ist zu konstatieren, daß den Nationen im Prozeß der ökonomischen Integration - der zudem von der politischen und technologischen Globalisierung der Wirtschaft verstärkt wird - in zahlreichen Politikbereichen die Fähigkeit abhanden kommt, dem staatlichen Handlungsbedarf im nationalen Rahmen gerecht zu werden. Hierdurch entsteht die Erfordernis, durch die Fortentwicklung der EU-Ebene neue Problemlösungskapazitäten zu erschließen. Dabei geht es keineswegs darum, daß die Regelungsinhalte der einzelnen Politikbereiche auf der zentralen Ebene entschieden werden. Vielmehr stellt die zentrale Ebene ein umfassendes Forum bereit, das die Suche nach kooperativen Problemlösungen im Sinne des Gemeinwohls der gesamten EU ermöglicht. Die negative (ökonomische) Integration wird auf diese Weise durch eine positive (politische) Integration ergänzt und vervollständigt. Eine elementare Handlungsberechtigung erhält die EU-Ebene damit aufgrund eines alternativen Verständnisses der Politikgestaltung, das den Problemstrukturen in einer globalisierten Welt Rechnung trägt. Die zentrale Aufgabe der EU ist es nach dieser Auffassung, die Kommunikation zwischen den Verhandlungspartnern zu fördern sowie bislang verkannte Handlungsoptionen aufzuzeigen und hierdurch neue Kompromißmöglichkeiten zwischen den divergierenden (mitglied)staatlichen und privaten Interessenpositionen $\mathrm{zu}$ erschließen. Viel seltener besteht die Notwendigkeit, daß die EU in Politikbereichen eigenständig entscheidet und damit Politikinhalte (interventionistisch) ausgestaltet.

Wird der europäische Integrationsprozeß diesem Verständnis entsprechend konsequent fortgeführt, ergibt sich langfristig der Übergang zu einem Bundesstaat Europa. Dessen wichtigstes Charakteristikum ist nicht die Verlagerung von Aufgabenkompetenzen, sondern die Moderation des Politikgestaltungsprozesses auf der zentralen Ebene, wodurch das konzertierte gemeinwohlorientierte Vorgehen aller betroffenen Teileinheiten gefördert und stabilisiert wird. ${ }^{1422}$ Die Fortentwicklung zu einem derartigen Bundesstaat ist erstrebenswert, wenn bei den Bürgern der EU im Zeitablauf eine europäische Identität entsteht, so daß die Präferenzkosten, die mit der Verlagerung von Souveränitätsrechten auf die zentrale Ebene verbunden sind, nach und nach geringer werden. Zum heutigen Zeitpunkt löst eine Verlagerung von Verfassungsfunktionen auf die EU-Ebene noch so hohe Präferenzkosten aus, daß diese Option in vielen Bereichen ausgeschlossen bleibt. Die bestehende europäische Politikverflechtung zwischen den Mitgliedstaaten und der zentralen Ebene ist deshalb ein notwendiges Resultat der Entwicklungsgeschichte der EU und bei dem momentanen (geringen) europäischen Identifikationsniveau eine effiziente Form der Willensbildung, die prohibitiv hohe Präferenzkosten

\footnotetext{
${ }^{1422}$ In ähnlicher Weise argumentiert Ebert (1999) für die nationalstaatliche Ebene.
} 
vermeidet. Entwickelt sich jedoch ein belastbares europäisches Bewußtsein, so wird es zunehmend effizient, zu supranationalen institutionellen Arrangements überzugehen, um so die Problemlösungskapazitäten des politischen Gesamtsystems der EU zu erhöhen.

Diese abschließenden Bemerkungen verdeutlichen nochmals die Komplexität des Integrationsprozesses. Die ökonomischen, politischen, rechtlichen und sozio-kulturellen Aspekte des Untersuchungsgegenstandes „,europäische Integration” sind in der Realität untrennbar miteinander verbunden. Um diesen Interdependenzen bei der Ausgestaltung der FZ in der EU gerecht zu werden, wurde der Versuch unternommen, nicht ausschließlich ökonomisch zu argumentieren. Die zur Ableitung der Ergebnisse dieser Arbeit herangezogenen (wohlfahrtstheoretischen) Ansätze stoßen jedoch recht schnell an ihre Grenzen, weil ihr Erklärungsgehalt im Hinblick auf die politischen, rechtlichen und sozio-kulturellen Gesichtspunkte der Wirklichkeit eng begrenzt ist. Eine umfassende, alle relevanten Blickwinkel integrierende Theorie besteht jedoch momentan nicht und es erscheint ausgeschlossen, daß es zukünftig gelingen könnte, die zahllosen Einflußfaktoren im Rahmen einer einheitlichen Theorie zu erfassen. Deshalb bleibt für die Behandlung des Themas nichts anderes übrig, als unterschiedliche theoretische Ansätze heranzuziehen, die jeweils empirisch bedeutsame Teilaspekte der Gesamtproblematik aufgreifen. Nach diesem methodischen Ansatz wurde in dieser Arbeit verfahren. Dabei wurde jedoch nur eine Teilstrecke auf dem Weg zu einem tiefergehenden Verständnis des europäischen Integrationsprozesses und der Wirkungsweise zwischenstaatlicher FZ zurückgelegt. Die Analyse blieb ausschließlich auf wohlfahrtstheoretische Ansätze beschränkt, wobei mit der mikroökonomischen Indifferenzkurvenanalyse die (rein) ökonomische Dimension und mit der ökonomischen Theorie der Politik sowie der Theorie der Politikverflechtung die politisch-institutionelle Dimension berücksichtigt und in einen gemeinsamen Bewertungsrahmen zusammengeführt wurde. Ausgehend von der grundlegenden Einsicht, daß die Theorienvielfalt für die Wissenschaft fruchtbar ist, müssen zahlreiche alternative Forschungsansätze beachtet werden. Denn „disziplinäre Scheuklappen sind keine Tugend."1423 So stellen eine Institutionenanalyse aus evolutorischer Perspektive oder stärker politikwissenschaftlich (Integrationstheorie) und soziologisch (Systemtheorie) ausgerichtete Forschungsansätze vielversprechende neuere Ansatzpunkte für die Untersuchung zwischenstaatlicher FZ im dynamischen Einigungsprozeß Europas dar. Die Entwicklung dieser theoretischen Denkmodelle und der Versuch, die Erkenntnisse der heterogenen Arbeiten sinnvoll miteinander zu verknüpfen, ist eine anspruchsvolle Forschungsarbeit, die in der Zukunft noch zu leisten ist.

\footnotetext{
${ }^{1423}$ Prisching (1996), S. 13.
} 


\section{Literaturverzeichnis}

Abromeit, Heidrun (1993): Förderalismus: Modelle für Europa, in: Österreichische Zeitschrift für Politikwissenschaft, 22. Jg., Heft 2, S. 207-220.

Abromeit, Heidrun (1997): Direkte Demokratie und Föderalismus in der Europäischen Union, in: Eugen Antalovsky/ Josef Melchior/ Sonja Puntscher Riekmann (Hrsg.): Integration durch Demokratie - Neue Impulse für die Europäische Union, Marburg, S. 207-221.

Achten, Peter (1996): Die Osterweiterung der Europäischen Union - Beitritts- und Erweiterungshindernisse im Spiegel ökonomischer Kritik, Bergisch Gladbach/ Köln.

ACIR (Advisory Commission on Intergovernmental Relations) (1991): Interjurisdictional Tax and Policy Competition - Good or Bad for the Federal System?, Washington.

Ahrns, Hans-Jürgen/ Feser, Hans-Dieter (1987): Wirtschaftspolitik - Problemorientierte Einführung, 5. Aufl., München/ Wien.

Albers, Willi (1977): Ziele und Bestimmungsgründe der Finanzpolitik, in: Fritz Neumark (Hrsg.): Handbuch der Finanzwissenschaft, Bd. I, 3. Aufl., Tübingen, S. 123-163.

Allais, Maurice (1992): Aufbau Europas als Herausforderung der Gegenwart, in: Schweizer Monatshefte für Politik, Wissenschaft, Kultur, 72. Jg., Heft 9, S. 697-708.

Andel, Norbert (1969): Zur Diskussion über Musgraves Begriff der 'merit wants', in: Finanzarchiv, N.F., Bd. 28, S. 209-213.

Andel, Norbert (1983): Finanzwirtschaftliche Aspekte regionaler wirtschaftlicher Zusammenschlüsse - Europäische Gemeinschaften, in: Fritz Neumark (Hrsg.): Handbuch der Finanzwissenschaft, Bd. IV, 3. Aufl., Tübingen, S. 311-364.

Andel, Norbert (1984): Zum Konzept der meritorischen Güter, in: Finanzarchiv, N.F., Bd. 42, S. 630-648.

Andel, Norbert (1992): Finanzwissenschaft, 3. Aufl., Tübingen.

Arnold, Volker (1992): Theorie der Kollektivgüter, München.

Arrow, Kenneth J. (1963): Social Choice and Individual Values, 2. Aufl., New York.

Auria, Laura (1997): Ist Europa ein optimaler Währungsraum? Eine theoretische und empirische Analyse auf der Grundlage von Nachfrage- und Angebotsschocks, Frankfurt am Main u.a.

Axelrod, Robert (1987): Die Evolution der Kooperation, München.

Baldwin, Richard E. (1994): Towards an Integrated Europe, Centre for Economic Policy Research.

Barro, Robert J./ Sala-i-Martin, Xavier (1991): Convergence across States and Regions, in: Brookings Papers on Economic Activity, Nr. 1, S. 107-182. 
Barro, Robert J./ Sala-i-Martin, Xavier (1992): Convergence, in: Journal of Political Economy, Vol. 100, Nr. 2, S. 223-251.

Barro, Robert J./ Sala-i-Martin, Xavier (1998): Wirtschaftswachstum, München/ Wien.

Basu, Kaushik (1975/1976): Retrospective Choice and Merit Goods, in Finanzarchiv, N.F., Bd. 34, S. 220-225.

Baum, Herbert (1995): Europäische Integration durch Ausbau der Verkehrsnetze?, in: Helmut Karl/ Wilhelm Henrichsmeyer (Hrsg.): Regionalentwicklung im Prozess der Europäischen Integration, Bonn, S. 185-195.

Bayoumi, Tamim/ Eichengreen, Barry (1992): Shocking Aspects of European Monetary Unification, Centre for Economic Policy Research, Diskussionspapier, Nr. 643, London.

Beck, Ulrich (1997a): Was ist Globalisierung? Irrtümer des Globalismus - Antworten auf Globalisierung, Frankfurt am Main.

Beck, Ulrich (1997b): Mißverständnisse sind nicht stets von Übel - Über einige übersehene Schwierigkeiten bei der Europäischen Einigung, in: Süddeutsche Zeitung, Montag, 24.11.1997, S. 13.

Beckmann, Karin (1995): Probleme der Regionalpolitik im Zuge der Vollendung des Europäischen Binnenmarktes, Frankfurt am Main u.a.

Benkert, Wolfgang (1984a): Die Theorie der Zuweisungen, in: Wirtschaftsstudium (WISU), Nr. 1, S. 43-49.

Benkert, Wolfgang (1984b): Die Theorie der Zuweisungen (II), in: Wirtschaftsstudium (WISU), Nr. 2, S. 93-97.

Benz, Arthur (1994): Kooperative Verwaltung - Funktionen, Voraussetzungen und Folgen, Baden-Baden.

Berg, Hartmut/ Schmidt, Frank (1996): Reformnotwendigkeiten und Reformmöglichkeiten der Gemeinschaftsinstitutionen und ihres Zusammenwirkens - Einige Folgerungen aus der Theorie der Verfassung, in: Werner Zohlnhöfer (Hrsg.): Europa auf dem Wege zur Politischen Union? - Probleme und Perspektiven der europäischen Integration vor „Maastricht II“, Berlin, S. 113-143.

Berg, Hartmut/ Schmidt, Frank (1997): Vorschläge zur institutionellen Reform einer erweiterten Europäischen Union, in: Wirtschaftswissenschaftliches Studium (WiSt), Heft 4, S. 170-174.

Berthold, Norbert (1993a): Europa nach Maastricht - Die Skepsis bleibt, in: Aus Politik und Zeitgeschichte, Beilage zur Wochenzeitschrift „Das Parlament“, B 28/93, S. 29-38.

Berthold, Norbert (1993b): Sozialunion in Europa - Notwendig oder überflüssig?, in: Wirtschaftsdienst, Heft 8, S. 414-418. 
Berthold, Norbert (1993c): 'Fiscal Federalism' in Europa: Voraussetzung für eine erfolgreiche Wirtschafts- und Währungsunion? in: Helmut Gröner/ Alfred Schüller (Hrsg.): Die europäische Integration als ordnungspolitische Aufgabe, Schriften zum Vergleich von Wirtschaftsordnungen, Bd. 43, Stuttgart, S. 147-171.

Berthold, Norbert (1997): Die Europäische Währungsunion - ein weiterer Schock für Europa?, in: Otto G. Mayer/ Hans-Eckart Scharrer (Hrsg.): Schocks und Schockverarbeitung in der Europäischen Währungsunion, Baden-Baden, S. 11-44.

Berthold, Norbert/ Hilpert, Jörg (1996): Wettbewerbspolitik, Industriepolitik und Handelspolitik in der EU, in: Renate Ohr (Hrsg.): Europäische Integration, Stuttgart/ Berlin/ Köln, S. 77-109.

Bieber, Roland (1991): Verfassungsentwicklung und Verfassungsgebung in der Europäischen Gemeinschaft, in: Rudolf Wildenmann (Hrsg.): Staatswerdung Europas? Optionen für eine Europäische Union, Baden-Baden, S. 393-414.

Biehl, Dieter (1979): Dezentralisierung als Chance für größere Effizienz und mehr soziale Gerechtigkeit, in: Franz Schuster (Hrsg.): Dezentralisierung des politischen Handelns (II) Konzeption und Positionen, Forschungsbericht 4 des Instituts für Kommunalwissenschaften, hrsg. im Auftrag der Konrad-Adenauer-Stiftung, St. Augustin, S. 85-132.

Biehl, Dieter (1983): Die Entwicklung des Finanzausgleichs in ausgewählten Bundesstaaten Bundesrepublik Deutschland, in: Fritz Neumark (Hrsg.): Handbuch der Finanzwissenschaft, Bd. IV, 3. Aufl., Tübingen, S. 69-122.

Biehl, Dieter (1988a): Finanzausgleich IV. - Internationaler Finanzausgleich, in: Willi Albers (Hrsg.): Handwörterbuch der Wirtschaftswissenschaft (HdWW), Bd. 2, Stuttgart u.a., S. 689-713.

Biehl, Dieter (1988b): Die Reform der EG-Finanzverfassung aus der Sicht der ökonomischen Theorie des Föderalismus, in: Manfred E. Streit (Hrsg.): Wirtschaftspolitik zwischen ökonomischer und politischer Rationalität, Wiesbaden, S. 63-84.

Biehl, Dieter (1989): Optimal Decentralization - a Conceptual Approach to the Reform of German Federalism, in: Environment and Planning C: Government and Policy, Vol. 7, S. 375-383.

Biehl, Dieter (1991a): Die EG-Finanzverfassung: Struktur, Mängel und Reformmöglichkeiten, in: Rudolf Wildenmann (Hrsg.): Staatswerdung Europas? Optionen für eine Europäische Union, Baden-Baden, S. 355-391.

Biehl, Dieter (1991b): Regionalpolitik und Finanzausgleich in der förderativen ZwölferGemeinschaft, in: Fritz Franzmeyer (Hrsg.): Die Auswirkungen des Binnenmarktes auf die Entwicklung der Regionen der Europäischen Gemeinschaft, Deutsches Institut für Wirtschaftsforschung, Sonderheft 146, Berlin, S. 159-194.

Biehl, Dieter (1994a): Zur ökonomischen Theorie des Förderalismus: Grundelemente und ihre Anwendung auf eine EU-Finanzunion, in: Heinrich Schneider/Wolfgang Wessels (Hrsg.): Förderale Union - Europas Zukunft?, München, S. 99-122.

Biehl, Dieter (1994b): Fiscal Federalism in Germany, in: Anne Mullins/ Cheryl Saunders (Hrsg.): Economic Union in Federal Systems, Sydney, S. 151-193. 
Biehl, Dieter (1994c): The Public Finances of The Union, in: Andrew Duft/ John Pinder/ Roy Pryce (Hrsg.): Maastricht and Beyond, London/ New York, S. 140-153.

Biehl, Dieter (1995a): Wechselspiel zwischen Prozeß und Institutionalisierung im Zuge der europäischen Integration, in: Bertram Schefold (Hrsg.): Wandlungsprozesse in den Wirtschaftssystemen Westeuropas, Marburg, S. 109-152.

Biehl, Dieter (1995b): Infrastruktur als Bestimmungsfaktor regionaler Entwicklungspotentiale in der Europäischen Union, in: Helmut Karl/ Wilhelm Henrichsmeyer (Hrsg.): Regionalentwicklung im Prozess der Europäischen Integration, Bonn, S. 53-86.

Biehl, Dieter/ Mans, Angela (1995): Europäische Integration, in: Akademie für Raumforschung und Landesplanung: Handwörterbuch der Raumordnung, Hannover, S. 250-257.

Binder, Klaus Georg / Walthes, Frank (1995): Der europäische Kohäsionsfonds, in: Wirtschaftswissenschaftliches Studium (WiSt), Heft 6, S. 306-309.

Bird, Richard M. (1993): Threading the Fiscal Labyrinth - Some Issues in Fiscal Decentralization, in: National Tax Journal, Vol. 46, S.207-227.

Bitterlich, Joachim (1995a): Der Vertrag von Maastricht aus deutscher Perspektive, in: Werner Weidenfeld (Hrsg.): Reform der Europäischen Union - Materialien zur Revision des Maastrichter Vertrages 1996, Gütersloh, S. 127-132.

Bitterlich, Joachim (1995b): Die Verankerung des Subsidiaritätsprinzips und seine operative Umsetzung, in: Werner Weidenfeld (Hrsg.): Reform der Europäischen Union - Materialien zur Revision des Maastrichter Vertrages 1996, S. 177-189.

Bock, Sibylle (1985): Instrumente des Finanzausgleichs im Dienste der regionalen Einkommensangleichung in der EG, Frankfurt am Main/ Bern/ New York.

Böckenförde, Ernst Wolfgang (1997): Wenn der europäische Stier vom goldenen Kalb überholt wird, in: Frankfurter Allgemeine Zeitung, Donnerstag, 24. Juli 1997, S. 30.

Bode, Eckhardt (1996): Ursachen regionaler Wachstumsunterschiede - Wachstumstheoretische Erklärungsansätze, Kieler Arbeitspapiere, Nr. 740, Kiel.

Bohnet-Joschko, Sabine (1996): Leviathan Europa? Föderalistische und institutionelle Aspekte der Staatswerdung Europas, Marburg.

Böhret, Carl (1993): Funktionaler Staat - Ein Konzept für die Jahrhundertwende?, Frankfurt am Main u.a.

Boldt, Hans (1995): Die Europäische Union - Geschichte, Struktur, Politik, Mannheim u.a.

Borchardt, Klaus-Dieter (1996): Die rechtlichen Grundlagen der Europäischen Union, Heidelberg.

Bös, Dieter (1978): Zur Theorie des Finanzausgleichs, in: Wilhelmine Dreißig (Hrsg.): Probleme des Finanzausgleichs I, Schriften des Vereins für Socialpolitik, Gesellschaft für Wirtschafts- und Sozialwissenschaften, N.F., Bd. 96/I, S. 45-133.

Böventer, Edwin von/ Illing, Gerhard (1995): Einführung in die Mikroökonomie, 8. Aufl., München/ Wien. 
Bradford, David F./ Oates, Wallace E. (1971a): The Analysis of Revenue Sharing in a New Approach to Collective Fiscal Decisions, in: Quarterly Journal of Economics, Vol. 85, S. 416-439.

Bradford, David F./ Oates, Wallace E. (1971b): Towards a Predictive Theory of Intergovernmental Grants, in: American Economic Review, Vol. 61, S. 440-448.

Break, George F. (1980): Financing Government in a Federal System, Washington, D.C.

Brecht, Arnold (1932): Internationaler Vergleich der öffentlichen Ausgaben, Leibzig/ Berlin.

Brennan,Geoffrey H./ Lomasky, Loren (1983): Institutional Aspects of „Merit Goods“ Analysis, in: Finanzarchiv, N.F., Bd. 41, Heft 2, S. 183-206.

Breton, Albert (1974): The Economic Theory of Representative Government, Chicago.

Breton, Albert/Scott, Anthony (1978): The Economic Constitution of Federal States, Toronto/ Buffalo/ London.

Brok, Elmar (1997): Kein Papiertiger - der Vertrag von Amsterdam, in: Wirtschaftsdienst, Heft 7, S. 375-378.

Brümmerhoff, Dieter (1996): Finanzwissenschaft, 7. Aufl., München/ Wien.

Brunton, William/ Meyer, Steffen (1996): Ökologisierung kommunaler Abgaben, in: Eva Lang/ Willam Brunton/ Werner Ebert (Hrsg.): Kommunen vor neuen Herausforderungen, Festschrift für Werner Noll zum 65. Geburtstag, Berlin, S. 289-343.

Brüske, Hans-Günther (1994): Wirtschafts- und Sozialausschuß, in: Werner Weidenfeld/ Wolfgang Wessels (Hrsg.): Europa von A - Z, Taschenbuch der europäischen Integration, 3. Aufl., Bonn, S. 343-345.

Buchanan, James M. (1950): Federalism and Fiscal Equity, in: American Economic Review,Vol. 40, S. 583-599.

Buchanan, James M. (1965): An Economic Theory of Clubs, in: Economica, Vol. 32, S. 1-14.

Buchanan, James M. (1970): The Public Finances, 3. Aufl., Homewood/ Georgetown.

Buchanan, James M./ Tullock, Gordon (1962): The Calculus of Consent - Logical Foundations of Constitutional Democracy, Ann Arbor.

Buhl, Hans-Ulrich/ Pfingsten, Andreas (1986): Eigenschaften und Verfahren für einen angemessenen Länderfinanzausgleich in der Bundesrepublik Deutschland, in: Finanzarchiv, N.F., Bd. 44, Heft 1, S. 98-109.

Bulmer, Simon/ Burch, Martin (1997): Maastricht II und danach - Großbritannien doch am Herzen Europas?, in: Wirtschaftsdienst, Heft 7, S. 381-385.

Bundesministerium der Finanzen (BMF) (1998): Symmetrische Finanzpolitik 2010 - Reformen: National entscheiden und international mitgestalten, August, Bonn.

Bundesrat (1997): Unterrichtung durch die Bundesregierung - Vertragsentwurf der Regierungskonfenrenz - Entwurf des Vertrags von Amsterdam, Drucksache 450/97, 16.06.97, Bonn. 
Bundesverfassungsgericht (BVerfG) (1993): Maastricht-Vertrag, Urteil vom 12. Oktober 1993 (2 BvR 2134, 2159/92), zit. nach: Mitglieder des Bundesverfassungsgerichts (Hrsg.): Entscheidungen des Bundesverfassungsgerichts, 89. Bd., Tübingen: 1994, S. 155-213.

Butterwegge, Stephan (1993): Wirtschaftliche Integrationsprozesse aus evolutorischer Sicht eine modelltheoretische Untersuchung unter besonderer Berücksichtigung von Schwankungen im Integrationsverlauf, Bergisch Gladbach.

Caesar, Rolf (1996a): Finanzordnung der EU, in: Renate Ohr (Hrsg.): Europäische Integration, Stuttgart/ Berlin/ Köln, S. 235-264.

Caesar, Rolf (1996b): Zur Reform des Einnahmensystems der Europäischen Union, in: Werner Zohlnhöfer (Hrsg.): Europa auf dem Wege zur Politischen Union? - Probleme und Perspektiven der europäischen Integration vor „Maastricht II“, Berlin, S. 145-174.

Callies, Patricia (1997): Der Stabilitäts- und Wachstumspakt - ein Pakt für mehr Glaubwürdigkeit, in: Wirtschaftsdienst, Heft 3, S. 153-158.

Carl, Dieter (1995): Bund-Länder-Finanzausgleich im Verfassungsstaat, Baden-Baden.

Club von Florenz (Hrsg.) (1996): Europa - Der unmögliche Status quo, Baden-Baden.

Coase, Ronald H. (1960): The Problem of Social Cost, in: The Journal of Law and Economics, Vol. 3, S. 1-44.

Costello, Declan (1993a): Intergovernmental Grants - What Role for the European Community?, in: Europäische Kommission (Hrsg.): The Economics of Community Public Finance, European Economy, Reports and Studies, No 5, Brussels/ Luxembourg, S. 101119.

Costello, Declan (1993b): The Spatial Implications of Economic and Monetary Union, in: Europäische Kommission (Hrsg.): The Economics of Community Public Finance, European Economy, Reports and Studies, No 5, Brussels/ Luxembourg, S. 369-393.

Cuny, Reinhard H. (1997): Reform der Europäischen Strukturfonds, in: Wirtschaftsdienst, Heft 4, S. 227-233.

Dams, Theodor/ Heide, Hans-Jürgen von der (1995): Subsidiaritätsprinzip, in: Akademie für Raumforschung und Landesplanung: Handwörterbuch der Raumordnung, Hannover, S. 937-945.

Davis, Otto A./ Dempster, Michael A.H./ Wildavsky, Aaron (1974): Towards a Predictive Theory of Government Expenditure - US Domestic Appropriations, in: British Journal of Political Science, Vol. 4, S. 419-452.

De la Dehesa, Guillermo/ Krugman, Paul (1992): EMU and the Regions, Washington, D.C.

Delors-Bericht (1989): Bericht zur Wirtschafts- und Währungsunion der EG, vorgelegt vom Ausschuß zur Prüfung der Wirtschafts- und Währungsunion am 12. April 1989, in: Henry Krägenaw Wolfgang Wetter (1993): Europäische Wirtschafts- und Währungsunion - vom Werner-Plan zum Vertrag von Maastricht. Analysen und Dokumentationen, Baden-Baden, S. 146-157. 
Dent, Christopher M. (1997): The European Economy - The Global Context, London/ New York.

Die Gruppe von Lissabon (1997): Grenzen des Wettbewerbs - Die Globalisierung der Wirtschaft und die Zukunft der Menschheit, München.

Diekmann, Berend/Breier, Siegfried (1993): Der Kohäsionsfonds - ein notwendiges Gemeinschaftsinstrument?, in: Wirtschaftsdienst, Heft 5, S. 258-265.

Dixit, Avinash K. (1997): The Making of Economic Policy - A Transaction-Cost Politics Perspective, Cambridge, Ma./ London.

Döring, Thomas (1994): Subsidiaritätsprinzip, in: Wirtschaftswissenschaftliches Studium (WiSt), Heft 5, S. 243-246.

Downs, Anthony (1968): Ökonomische Theorie der Demokratie, Tübingen.

Dumke, Rolf H. (1996): Historische Erfahrung und theoretische Erkenntnisse zur Frage einer Harmonisierung der Finanz- und Lohnpolitik und eines europaweiten Finanzausgleichs in der europäischen Währungsunion: Korreferat zu Rainer Schweickert, in: Maastricht II Entwicklungschancen und Risiken der EU: Erweiterung, Vertiefung oder Stagnation?, Beihefte zur Konjunkturpolitik - Zeitschrift für angewandte Wirtschaftsforschung, Heft 44, Berlin, S. 213-237.

Dye, Robert A. (1990): American Federalism - Competition Among Governments, Massachusetts/ Toronto.

Ebert, Werner (1999): Wirtschaftspolitik aus evolutorischer Perspektive - ein konzeptioneller Beitrag unter Berücksichtigung kommunaler Aufgabenwahrnehmung, Hamburg.

Ebert, Werner/ Meyer, Steffen (1998a): Das Anreizsystem des LFA - besteht Reformbedarf?, Universität Würzburg, Wirtschaftswissenschaftliche Beiträge des Volkswirtschaftlichen Instituts, Würzburg.

Ebert, Werner/ Meyer, Steffen (1998b): Reform der föderalen Finanzbeziehungen - einige weiterführende Überlegungen, Stellungnahme zum Länderbericht Deutschland 1998 der OECD, Universität Würzburg, Wirtschaftswissenschaftliche Beiträge des Volkswirtschaftlichen Instituts, Würzburg.

Ebert, Werner/ Meyer, Steffen (1999): Die Anreizwirkungen des Finanzausgleichs, in: Wirtschaftsdienst, Heft 2, S. 106-114.

Ebert, Werner/ Noll, Werner (1997): Globalisierung, Standortwettbewerb und die Rolle des Staates in systemischer Sicht, Universität Würzburg, Wirtschaftswissenschaftliche Beiträge des Volkswirtschaftlichen Instituts, Würzburg.

Ebert, Werner/ Noll, Werner (1998): Globalisierung - Neue Anforderungen an öffentliche Unternehmen im Standortwettbewerb, in Zeitschrift für öffentliche und gemeinwirtschaftliche Unternehmen (ZögU), Bd. 21, Heft 1, S. 21-40.

Ehlermann, Claus-Dieter (1976): Der Europäische Rechnungshof - Haushaltskontrolle in der Gemeinschaft, Baden-Baden. 
Eichenberger, Reiner (1995): FOCJ für Europa: Die fünfte Freiheit schafft politischen Wettbewerb, Diskussionspapier präsentiert bei der fünften Jahrestagung des Vereins für Socialpolitik, Linz.

Eichengreen, Barry (1990): Is Europe an Optimum Currency Area?, Centre for Economic Policy Research, Diskussionspapier, Nr. 478, London.

Ensthaler, Jürgen (1995): Auf dem Weg vom Binnenmarkt zur Europäischen Union, in: Jürgen Ensthaler (Hrsg.): Vom Binnenmarkt zur Europäischen Union - Die Gemeinschaft zwischen Zweckverband und neuer Staatlichkeit, Berlin, S. 9-32.

Eucken, Walter (1990): Grundsätze der Wirtschaftspolitik, 6. Aufl., Tübingen.

Europäische Kommission (Hrsg.) (1977a): Bericht der Sachverständigengruppe zur Untersuchung der Rolle der öffentlichen Finanzen bei der europäischen Integration, Bd. I, Generalbericht, Brüssel.

Europäische Kommission (Hrsg.) (1977b): Bericht der Sachverständigengruppe zur Untersuchung der Rolle der öffentlichen Finanzen bei der europäischen Integration, Bd. II, Einzelbeiträge und Arbeitsunterlagen, Brüssel.

Europäische Kommission (Hrsg.) (1978): Finanzierung des Gemeinschaftshaushalts - künftige Methode, Beilage zum Bulletin der EG, Nr. 8, Brüssel.

Europäische Kommission (Hrsg.) (1987): Die Regionen der erweiterten Gemeinschaft. Dritter periodischer Bericht über die sozio-ökonomische Lage und Entwicklung der Regionen der Gemeinschaft, Brüssel/ Luxemburg.

Europäische Kommission (Hrsg.) (1989): Leitfaden zur Reform der Strukturfonds der Gemeinschaft, Luxemburg.

Europäische Kommission (Hrsg.) (1990): Ein Markt, eine Währung - Potentielle Nutzen und Kosten der Errichtung einer Wirtschafts- und Währungsunion - eine Bewertung, Europäische Wirtschaft, Nr. 44, Brüssel.

Europäische Kommission (Hrsg.) (1991): The Regions in the 1990s. Fourth periodic report on the social and economic situation and development of the regions of the Community, Brussels/ Luxembourg.

Europäische Kommission (Hrsg.) (1992a): Das Subsidiaritätsprinzip - Mitteilung der Kommission an den Rat und an das Europäische Parlament, (SEK(92)1990), Brüssel.

Europäische Kommission (Hrsg.) (1992b): Die gemeinschaftlichen Strukturpolitiken - Bilanz und Perspektiven, KOM(92) 84 endg., Brüssel.

Europäische Kommission (Hrsg.) (1993a): Stabiles Geld - solide Finanzen. Die öffentlichen Finanzen der Gemeinschaft im Hinblick auf die WWU, Europäische Wirtschaft, Nr. 53, Brüssel/ Luxemburg.

Europäische Kommission (Hrsg.) (1993b): Bericht der Europäischen Kommission an den Europäischen Rat über die Anpassung der geltenden Rechtsvorschriften an das Subsidiaritätsprinzip vom 24. November 1993, KOM(93) 545, endg., Brüssel, zitiert nach Werner Weidenfeld (Hrsg.)(1995): Reform der Europäischen Union - Materialien zur Revision des Maastrichter Vertrages 1996, Gütersloh, S. 378-388. 
Europäische Kommission (Hrsg.) (1994a): Wachstum, Wettbewerbsfähigkeit, Beschäftigung Herausforderungen der Gegenwart und Wege ins 21. Jahrhundert - Weißbuch, Brüssel/ Luxemburg.

Europäische Kommission (Hrsg.) (1994b): Wettbewerbsfähigkeit und Kohäsion - Tendenzen in den Regionen. Fünfter periodischer Bericht über die sozioökonomische Lage und Entwicklung der Regionen der Gemeinschaft, Brüssel/ Luxemburg.

Europäische Kommission (Hrsg.) (1995a): Die Finanzverfassung der Europäischen Union Merkmale, Regeln, Funktionsweise, Luxemburg.

Europäische Kommission (Hrsg.) (1995b): Haushaltsvademekum 1995, Luxemburg.

Europäische Kommission (Hrsg.) (1996): Erster Bericht über den wirtschaftlichen und sozialen Zusammenhalt 1996, Brüssel/ Luxemburg.

Europäische Kommission (Hrsg.) (1997a): Haushaltsvademekum 1997, Luxemburg.

Europäische Kommission (Hrsg.) (1997b): Gesamtbericht über die Tätigkeit der Europäischen Union 1996, Luxemburg.

Europäische Kommission (Hrsg.) (1997c): Grundzüge der Wirtschaftspolitik 1997 - Das Ergebnis des Europäischen Rates in Amsterdam bezüglich Stabilität, Wachstum und Beschäftigung, Europäische Wirtschaft, Nr. 64, Brüssel/ Luxemburg.

Europäische Kommission (Hrsg.) (1997d): Die Strukturfonds in 1996 - achter Jahresbericht, Luxemburg.

Europäische Kommission (Hrsg.) (1997e): Towards a Common Agricultural and Rural Policy for Europe, European Economy, Reports and Studies, No 5, Brussels.

Europäische Kommission (Hrsg.) (1998): Gesamtbericht über die Tätigkeit der Europäischen Union 1997, Luxemburg.

Europäische Strukturkommission (Hrsg.) (1995): Europa '96 - Reformprogramm für die Europäische Union, in: Werner Weidenfeld (Hrsg.): Reform der Europäischen Union - Materialien zur Revision des Maastrichter Vertrages 1996, Gütersloh, S. 11-55.

Europäischer Rat in Edinburgh (Hrsg.) (1992): Gesamtkonzept für die Anwendung des Subsidiaritätsprinzips und des Artikels $3 b$ des Vertrags über die Europäische Union durch den Rat, in: Presse- und Informationsamt der Bundesregierung (Hrsg.): Bulletin, Nr. 140 vom 28. Dezember 1992, S. 1280-1284.

Europäisches Parlament (Hrsg.) (1994): Bericht des Institutionellen Ausschusses des Europäischen Parlaments zur Verfassung der Europäischen Union vom 10. Februar 1994 (Bericht Herman), in: Deutscher Bundestag, 12. Wahlperiode, Drucksache 12/7074 vom 10. März 1994, zitiert nach Werner Weidenfeld (Hrsg.): Reform der Europäischen Union Materialien zur Revision des Maastrichter Vertrages 1996, Gütersloh S. 389-410.

Europäisches Parlament/ Rat/ Kommission (Hrsg.) (1975): Gemeinsame Erklärung des Europäischen Parlaments, des Rates und der Kommission, in: Amtsblatt der Europäischen Gemeinschaften, Nr. C 89 vom 22.4.1975, S. 1-2. 
Everling, Ulrich (1995): Kompetenzordnung und Subsidiarität, in: Werner Weidenfeld (Hrsg.): Reform der Europäischen Union - Materialien zur Revision des Maastrichter Vertrages 1996, Gütersloh, S. 166-176.

Ewers, Hans-Jürgen/ Stackelberg, Friedrich v. (1998): Verkehrspolitik, in Paul Klemmer (Hrsg.): Handbuch Europäische Wirtschaftspolitik, München, S. 1151-1192.

Feldman, Allan M. (1980): Welfare Economics and Social Choice Theory, Boston.

Feldsieper, Manfred/ Prokop, Marc (1996): Dimensionen eines Europäischen Finanzausgleichs, in: Staatswissenschaften und Staatspraxis, Bd. 7, Heft 1, S. 43-62.

Feldstein, Martin (1992): Europe's Monetary System - The Case against EMU, in: The Economist, London, Vol. 7763 vom 13.06.1992, S. 19-22.

Feldstein, Martin (1997): The Political Economy of the European Economic and Monetary Union - Political Sources of an Economic Liability, National Bureau of Economic Research, Working Paper 6150, August, Cambridge, Ma.

Fischer, Helmut (1984): Zur Problematik von Finanzzuweisungen, in: Wirtschaftswissenschaftliches Studium (WiSt), Heft 5, S. 229-234.

Fischer, Helmut (1988): Finanzzuweisungen - Theoretische Grundlagen und praktische Ausgestaltung im bundesstaatlichen Finanzausgleich Australiens und der Bundesrepublik Deutschland, Berlin.

Fischer-Menshausen, Herbert (1978): Unbestimmte Rechtsbegriffe in der bundesstaatlichen Finanzverfassung, in: Wilhelmine Dreißig (Hrsg.): Probleme des Finanzausgleichs I, Schriften des Vereins für Socialpolitik, Gesellschaft für Wirtschafts- und Sozialwissenschaften, N.F., Bd. 96/I, S. 135-163.

Fischer-Menshausen, Herbert (1988): Finanzausgleich II - Grundzüge des Finanzausgleichsrechts, in: Willi Albers (Hrsg.): Handwörterbuch der Wirtschaftswissenschaft (HdWW), Bd. 2, Stuttgart u.a., S. 636-662.

Flatters, Frank R./ Henderson, V./ Mieszkowski, Peter M. (1974): Public Goods, Efficiency and Regional Fiscal Equalization, in: Journal of Public Economics, Bd. 3, Vol. 2, S. 99112.

Folkers, Cay (1974): Meritorische Güter als Problem einer normativen Theorie öffentlicher Ausgaben, Jahrbuch für Sozialwissenschaft, Bd. 25, S. 1-29.

Folkers, Cay (1994): Die Kompensationsfunktion des Europäischen Haushalts - Zur ökonomischen Analyse de EU-Finanzen im Integrationsprozeß, in: Institut für Europäische Wirtschaft, Ruhr-Universität Bochum (Hrsg.): Diskussionsbeiträge - Nr.4, Bochum.

Folkers, Cay (1995): Welches Finanzausgleichssystem braucht Europa?, in: Helmut Karl/ Wilhelm Henrichsmeyer (Hrsg.): Regionalentwicklung im Prozess der Europäischen Integration, Bonn, S. 87-108.

Forte, Francesco (1977): Grundsätze der Zuordnung öffentlicher ökonomischer Funktionen im Rahmen von Gebietskörperschaften, in: Europäische Kommission (Hrsg.): Bericht der Sachverständigengruppe zur Untersuchung der Rolle der öffentlichen Finanzen bei der europäischen Integration, Bd. II, Einzelbeiträge und Arbeitsunterlagen, Brüssel, S. 333-376. 
Francke, Hans-Hermann (1993): Zukunftsprobleme der europäischen Integration - von Maastricht zu einem europäischen Finanzausgleichssystem?, Diskussionsbeiträge des Instituts für Finanzwissenschaft der Albert-Ludwigs-Universität Freiburg im Breisgau, 22/93.

Francke, Hans-Hermann (1994): The European Currency Area and the European Financial Equalisation System, Diskussionsbeiträge des Instituts für Finanzwissenschaft der AlbertLudwigs-Universität Freiburg im Breisgau, 36/94.

Franke, Siegfried F. (1989): Der Finanzausgleich: Problembereich im Spannungsfeld ökonomischer Rationalität und politischer Kompromißbildung, in: Hamburger Jahrbuch für Wirtschafts- und Gesellschaftspolitik, 34. Jg., S. 65-80.

Franke, Siegfried F. (1993): Steuerpolitik in der Demokratie - Das Beispiel der Bundesrepublik Deutschland, Berlin.

Franzmeyer, Franz (1993): Aufgaben und Funktionsweise der EG-Strukturfonds: Kritische Würdigung eines Reformkonzepts, in: Wulfdiether Zippel (Hrsg.): Ökonomische Grundlagen der europäischen Integration, München, S. 83-98.

Franzmeyer, Fritz (1994): Zum Zusammenhang von Konvergenz und Kohäsion, in: Fritz Franzmeyer (Hrsg.): Das Kovergenzproblem - Wirtschaftspolitik im Europa von Maastricht, Deutsches Institut für Wirtschaftsforschung, Sonderheft 151, Berlin, S. 206-236.

Franzmeyer, Fritz (1996a): Europäische Struktur- und Regionalpolitik, in: Renate Ohr (Hrsg.): Europäische Integration, Stuttgart/ Berlin/ Köln, S. 111-140.

Franzmeyer, Fritz (1996b): Europäische Währungsunion - Reale Konvergenz unentbehrlich, in: Deutsches Institut für Wirtschaftsforschung (Hrsg.): Wochenbericht 31/ 96, 63. Jg., 1. August, Berlin, S. 515-524.

Franzmeyer, Fritz/ Weise, Christian (1997): Agenda 2000 - Strukturfonds - künftige Aufgaben und Reformbedarf, in: Rolf Hrbek (Hrsg.): Die Reform der Europäischen Union - Positionen und Perspektiven anläßlich der Regierungskonferenz, Baden-Baden, S. 321-329.

Frey, Bruno S. (1988): Ökonomische Theorie der Politik, in: Willi Albers (Hrsg.): Handwörterbuch der Wirtschaftswissenschaft (HdWW), Bd. 5, Stuttgart u.a., S. 658-667.

Frey, Bruno S. (1997): Ein neuer Föderalismus für Europa: Die Idee der FOCJ, Tübingen.

Frey, Bruno S./ Heggli, Beat (1993): Außermarktliche Ökonomie, in: Gabler Wirtschaftslexikon, 13. Aufl., Bd. A-BH, Wiesbaden, S. 305-311.

Frey, Bruno S./ Kirchgässner, Gebhard (1994): Demokratische Wirtschaftspolitik - Theorie und Anwendung, München.

Frey, René L. (1977): Zwischen Föderalismus und Zentralismus - Ein volkswirtschaftliches Konzept des schweizerischen Bundesstaates, Bern/ Frankfurt am Main.

Frick, Siegfried/Van der Beek, Gregor/ Hünger, Franklin (1996): Die Regionalpolitik der EU - Reformperspektiven aus finanzwissenschaftlicher Sicht, in: List Forum für Wirtschaftsund Finanzpolitik, Bd. 22, Heft 4, S. 354-376.

Friedman, Milton (1948): A Monetary and Fiscal Framework for Economic Stability, in: American Economic Review, Vol. 38, S. 245-264. 
Friedmann, Bernhard (1996): Die Strukturfonds der Europäischen Union; in: Bernhard Friedmann (Hrsg.): Evaluierungsansätze zu ausgewählten Politikbereichen der Europäischen Union; Bonn, Europa Union Verlag, S. 53- 67.

Fuest, Clemens (1995): Eine Fiskalverfassung für Europa, Köln.

Funkschmidt, Gerhard (1997): Die EU-Strukturpolitik - Zielorientierungen, Wirkungen, Effizienz, in: Rolf Caesar (Hrsg.): Zur Reform der Finanzverfassung und Strukturpolitik der EU, Baden-Baden, S. 209-221.

Galbraith, John K. (1952): American Capitalism - The Concept of Countervailing Power, Boston.

Genser, Bernd (1995): Auf der Suche nach einer föderativen Finanzverfassung für Europa, Diskussionsbeiträge der Universität Konstanz, Sonderforschungsbereich 178 „Internationalisierung der Wirtschaft“, Serie II - Nr. 290, Dezember, Konstanz.

Gerken, Lüder (1993): Politische und ökonomische Integration in Europa, in: Lüder Gerken (Hrsg.): Europa 2000 - Perspektive wohin? - Die europäische Integration nach Maastricht, Freiburg i. Br., S. 13-38.

Geske, Otto-Erich (1988): Einleitung, in: Volker Arnold/ Otto-Erich Geske (Hrsg.): Öffentliche Finanzwirtschaft, München, S. 1-10.

Geske, Otto-Erich (1996): Empfehlen sich Maßnahmen, um in der Finanzverfassung Aufgaben- und Ausgabenverantwortung von Bund, Ländern und Gemeinden stärker zusammenzuführen - Referat anläßlich des einundsechzigsten deutschen Juristentages, in: Ständige Deputation des deutschen Juristentages (Hrsg.): Verhandlungen des einundsechzigsten deutschen Juristentages, Karlsruhe, Bd. II/1 (Sitzungsberichte - Referate und Beschlüsse) Teil M, München, S. M9-M33.

Geske, Otto-Erich (1998): Eine neue Finanzverfassung zur Wiederherstellung eines strikten Konnexitätsprinzips?, in: Wirtschaftsdienst, Heft 9, S. 556-564.

Gläser, Martin (1981): Die staatlichen Finanzzuweisungen an die Gemeinden - Gestaltungskriterien, Effektivität, Reform, Thun/ Frankfurt am Main.

Goodhart, Charles A.E./ Smith, Stephen (1993): Stabilization, in: Europäische Kommission (Hrsg.): The Economics of Community Public Finance, European Economy, Reports and Studies, No 5, Brussels/ Luxembourg, S. 417-455.

Gornig, Martin u.a. (1996): Regionale Strukturpolitik unter den veränderten Rahmenbedingungen der 90er Jahre, Deutsches Institut für Wirtschaftsforschung (Hrsg.), Sonderheft 157 , Berlin.

Graf Kielmansegg, Peter (1995): Läßt sich die Europäische Union demokratisch verfassen?, in: Werner Weidenfeld (Hrsg.): Reform der Europäischen Union - Materialien zur Revision des Maastrichter Vertrages 1996, Gütersloh, S. 229-242.

Graf Kielmansegg, Peter (1996): Integration und Demokratie, in: Markus Jachtenfuchs/ Beate Kohler-Koch (Hrsg.): Europäische Integration, Opladen, S. 47-71. 
Gramlich, Edward E. (1977): Intergovernmental Grants - A Review of the Empirical Literature, in: Wallace E. Oates (Hrsg.): The Political Economy of Fiscal Federalism, Lexington, S. 219-239.

Gramlich, Edward E. (1993): A Policymaker's Guide to Fiscal Decentralization, in: National Tax Journal, Vol. 46, S. 229-235.

Grande, Edgar (1995): Regieren in verflochtenen Verhandlungssystemen, in: Renate Mayntz/ Fritz W. Scharpf (Hrsg.): Gesellschaftliche Selbstregelung und politische Steuerung, Frankfurt am Main/ New York, S. 327-368.

Grimm, Dieter u.a. (Hrsg.) (1997): Zur Neuordnung der Europäischen Union: Die Regierungskonferenz 1996/97, Baden-Baden.

Groenewegen, Peter (1988): Taxation And Decentralisation - A Reconsideration Of The Costs And Benefits Of A Decentralised Tax System, in: Department of Economics (University of Sydney, Australia) (Hrsg): Working Papers in Economics, Nr. 104 (März), Sydney, S. 1-37.

Grossekettler, Heinz (1995): Öffentliche Finanzen, in: Vahlens Kompendium der Wirtschaftstheorie und Wirtschaftspolitik, Bd. 1, 6. Aufl., München, S. 483-669.

Grossekettler, Heinz (1996): Koordinationsprobleme in der Europäischen Finanzpolitik - das Pro und Kontra eines Europäischen Finanzausgleichs, in: Helmut Karl (Hrsg.): Die Koordination der Finanz-, Währungs- und Strukturpolitik in der EU, Bonn, S. 15-31.

Grossekettler, Heinz (1997): Finanzausgleich über den EU-Haushalt: Rechtfertigung und Größenordnungen, in: Rolf Caesar (Hrsg.): Zur Reform der Finanzverfassung und Strukturpolitik der EU, Baden-Baden, S. 111-140.

Grossman, Gene M./ Helpman, Elhanan (1991): Innovation and Growth in the Global Economy, Cambridge, Ma.

Grüske, Karl-Dieter/ Walthes, Frank (1994): Europäischer Finanzausgleich zwischen EUMitgliedstaaten - Determinaten und finanzielle Dimensionen, in: Raumforschung und Raumordnung, Jg. 52, Heft 6, S. 373-382.

Haas, Ernst B. (1958): The Uniting of Europe. Political, Social and Economical Forces 19501957, London.

Hackenbroch, Inge (1983): Zur Theorie und Politik eines supranationalen Finanzausgleichs Gestaltungsprobleme und Gestaltungsansätze unter besonderer Berücksichtigung der EG, München/ Köln/ London.

Häde, Ulrich (1996): Finanzausgleich - Die Verteilung der Aufgaben, Ausgaben und Einnahmen im Recht der Bundesrepublik Deutschland und der Europäischen Union, Tübingen.

Hagen, Jürgen von/ Hammond, George W. (1997): Coping With Asymmetric Shocks in EMU - The Insurance Approach, in: Otto G. Mayer/ Hans-Eckart Scharrer (Hrsg.): Schocks und Schockverarbeitung in der Europäischen Währungsunion, Baden-Baden, S. 197-214.

Haller, Heinz (1972): Finanzpolitik - Grundlagen und Hauptprobleme, 5. Aufl., Tübingen. 
Haller, Heinz (1981): Die Steuern - Grundlinien eines rationalen Systems öffentlicher Abgaben, 3. Aufl., Tübingen.

Hansmeyer, Karl-Heinrich (1970): Zweckzuweisungen an Gemeinden als Mittel der Wirtschaftspolitik?, in: Heinz Haller u.a. (Hrsg.): Theorie und Praxis des finanzpolitischen Interventionismus, Fritz Neumark zum 70. Geburtstag, Tübingen, S. 431-450.

Hansmeyer, Karl-Heinrich (1977): Transferzahlungen an Unternehmen (Subventionen), in: Fritz Neumark (Hrsg.): Handbuch der Finanzwissenschaft, Bd. I, 3. Aufl., Tübingen, S. 959-996.

Harder, Bettina von (1997): Die Interdependenzen zwischen Währungsunion und Politischer Union in der Europäischen Union des Maastrichter Vertrages, Frankfurt am Main.

Häring, Norbert (1995): Regionalpolitik und Finanzverfassung in einem probabilistischen Modell des politischen Wettbewerbs, Frankfurt am Main u.a.

Head, John G. (1966): On Merit Goods, in: Finanzarchiv, N.F., Bd. 25, S. 1-29.

Head, John G. (1988): On Merit Wants, in: Finanzarchiv, N.F., Bd. 46, S. 1-37.

Heckscher, Eli F. (1919): The Effect of Foreign Trade on the Distribution of Income, in: Economisk Tidskrift, Vol. 21, S. 497-512.

Heinemann, Friedrich (1993): Europäische Investitionsbank - Subsidiärer Finanzintermediär oder Umverteilungsinstrument?, in: Wirtschaftsdienst, Heft 2, S. 98-103.

Heinemann, Friedrich (1995): Die Finanzverfassung und Kompetenzausstattung der Europäischen Union nach Maastricht - Eine finanzwissenschaftliche Soll-Ist-Analyse, BadenBaden.

Heise, Arne (1997): Grundlagen der Europäischen Währungsunion: Theorie - Institutionen Politik, Wiesbaden.

Henke, Klaus-Dirk (1997): Die Finanzierung der EU, in: Wirtschaftsdienst, Heft 1, S. 45-49.

Herder-Dorneich, Philipp (1992): Neue Politische Ökonomie. Eine kurzgefaßte Hinführung. Rückblick - Anwendung - Ausblick, Baden-Baden.

Hesse, Helmut (1993): Finanzausgleich im Bundesstaat - Implikationen für Europa, in: Staatswissenschaften und Staatspraxis, Bd. 4, Heft 1, S. 43-55.

Hesse, Joachim Jens (1997): Institutioneller Wandel in Europa als Bestandssicherung und Konsolidierung, in: Dieter Grimm u.a.( Hrsg.): Zur Neuordnung der Europäischen Union: Die Regierungskonferenz 1996/97, Baden-Baden, S. 93-119.

Hilber, Günther (1974): Horizontale Finanzbeziehungen zwischen Nationalstaaten, Frankfurt am Main.

Hildebrand, Bruno (1848): Die Nationalökonomie der Gegenwart und Zukunft, in: Heinrich Waentig (Hrsg.) (1922): Sammlung sozialwissenschaftlicher Meister, Bd. 22, Jena.

Hildebrandt, Ariane (1995): Politisch-ökonomische Ursachen und ökonomisch-institutionelle Restriktionen der Entwicklung öffentlicher Finanzen, Frankfurt am Main u.a. 
Hillenbrand, Olaf (1994): Europäische Investitionsbank, in: Werner Weidenfeld/Wolfgang Wessels (Hrsg.): Europa von A - Z, Taschenbuch der europäischen Integration, 3. Aufl., Bonn, S. 160-161.

Hilligweg, Gerd (1994): Beurteilung der Regionalpolitik der Europäischen Gemeinschaft und möglicher Weiterentwicklungskonzepte unter besonderer Berücksichtigung des Reformmodells einer finanzausgleichsorientierten Neugestaltung des Systems der EGRegionalfonds, Bochum.

Hines, James R. Jr./ Thaler, Richard H. (1995): Anomalies - The Flypaper Effect, in: Journal of Economic Perspectives, Vol. 9, Nr. 4, S. 217-226.

Hirschman, Albert O. (1958): The Strategy of Economic Development, New Haven.

Hirte, Georg (1996): Effizienzwirkungen von Finanzausgleichsregelungen - Eine Empirische Allgemeine Gleichgewichtsanalyse für die Bundesrepublik Deutschland, Frankfurt am Main u.a.

Hödl, Erich/ Weida, Andreas (1997): Die Strukturpolitik der Europäischen Union: eine Untersuchung ihrer Konsistenz im Hinblick auf die Verwirklichung einer Wirtschafts- und Währungsunion, Frankfurt am Main u.a.

Hoeller, Peter/ Louppe, Marie-Odile/ Vergriete, Patrice (1996): Fiscal Relations Within the European Union, OECD - Economic Department Working Papers, Nr. 163, Paris.

Holler, Manfred J./ Illing, Gerhard (1996): Einführung in die Spieltheorie, 3. Aufl., Berlin u.a.

Homann, Karl/ Kirchner, Christian (1995): Das Subsidiaritätsprinzip in der Katholischen Soziallehre und in der Ökonomik, in: Lüder Gerken (Hrsg.): Europa zwischen Ordnungswettbewerb und Harmonisierung - Europäische Ordnungspolitik im Zeichen der Subsidiarität, Berlin u.a., S. 45-69.

Homburg, Stefan (1993): Eine Theorie des Länderfinanzausgleichs - Finanzausgleich und Produktionseffizienz, in: Finanzarchiv, N.F., Bd. 50, S. 458-486.

Homburg, Stefan (1994): Anreizwirkungen des deutschen Finanzausgleichs, in: Finanzarchiv, N.F., Bd. 51, S. 312-330.

Homburg, Stefan (1997): Ursachen und Wirkungen eines zwischenstaatlichen Finanzausgleichs, in: Alois Oberhauser (Hrsg.): Fiskalföderalismus in Europa, Schriften des Vereins für Socialpolitik, Gesellschaft für Wirtschafts- und Sozialwissenschaften, N.F., Bd. 253, Berlin, S. 61-95.

Hrbek, Rudolf (1992a): Das Vertragswerk von Maastricht: Die EG auf dem Weg zur Europäischen Union, in: Wirtschaftsdienst, Heft 3, S. 131-137.

Hrbek, Rudolf (1992b): Kontroversen und Manifeste zum Vertrag von Maastricht: Zur Einführung, in: Integration, Beilage zur Europäischen Zeitung, Jg. 15, Nr. 1, S. 225-235.

Hrbek, Rudolf (1993): Entstehung und Weiterentwicklung der EG, in: Wulfdiether Zippel (Hrsg.): Ökonomische Grundlagen der europäischen Integration, München, S. 1-23. 
Hrbek, Rudolf (Hrsg.) (1997a): Die Reform der Europäischen Union - Positionen und Perspektiven anläßlich der Regierungskonferenz, Baden-Baden.

Hrbek, Rudolf (1997b): Der Vertrag von Amsterdam - eine neue Etappe im EUIntegrationsprozeß, in: Wirtschaftsdienst, Heft 7, S. 378-381.

Hrbek, Rudolf/ Läufer, Thomas (1986): Die Einheitliche Europäische Akte. Das Luxemburger Reformpaket - eine neue Etappe im Integrationsprozeß, in: Europa-Archiv 1986, S. 173184.

Huber, Bernd/ Lichtblau, Karl (1997): Systemschwächen des Finanzausgleichs - eine Reformskizze, in: IW-Trends - Quartalshefte zur empirischen Wirtschaftsforschung, hrsg. vom Institut der deutschen Wirtschaft Köln, 24. Jg., Heft 4, S. 24-45.

Huber, Bernd/ Lichtblau, Karl (1998): Konfiskatorischer Finanzausgleich verlangt eine Reform, in: Wirtschaftsdienst, Heft 3, S. 142-147.

Hünger, Fränklin (1996): Notwendigkeit eines europäischen Finanzausgleichs und Möglichkeiten seiner institutionellen Gestaltung, Volkswirtschaftliche Diplomarbeit, Duisburg.

Hüther, Michael (1993): Reform des Finanzausgleichs - Handlungsbedarf und Lösungsvorschläge, in: Wirtschaftsdienst, Heft 1, S. 43-52.

Illing, Gerhard (1995): Spieltheorie in den Wirtschaftswissenschaften, in: Wirtschaftswissenschaftliches Studium (WiSt), Heft 10, S. 509-516.

Immerfall, Stefan/ Sorbisch, Andreas (1997): Europäische Integration und europäische Identität - Die Europäische Union im Bewußtsein ihrer Bürger, in: Aus Politik und Zeitgeschichte, Beilage 10, 28. Feb. 1997, S. 25-37.

Institut der deutschen Wirtschaft Köln (Hrsg.) (1997): Zahlen zur wirtschaftlichen Entwicklung der Bundesrepublik Deutschland, Köln.

Ipsen, Hans Peter (1972): Europäisches Gemeinschaftsrecht, Tübingen.

Italianer, Alexander/Vanheukelen, Marc (1993): Proposals for Community Stabilization Mechanisms - Some Histrorical Applications, in: Europäische Kommission (Hrsg.): The Economics of Community Public Finance, European Economy, Reports and Studies, No 5; Brussels/ Luxembourg, S. 493-510.

Jaggi, Arvind (1996): Cohesion in a Stratified EU: Development Under Integration, in: Christos C. Paraskevopulos/ Ricardo Grinspun/ Theodore Georgakopoulos (Hrsg.): Economic Integration and Public Policy in the European Union, Cheltenham/ Brookfield, S. 33-46.

Janning, Josef (1994): Leitbilder der europäischen Integration, in: Werner Weidenfeld/Wolfgang Wessels (Hrsg.): Europa von A - Z, Taschenbuch der europäischen Integration, 3. Aufl., Bonn, S. 266-269.

Jochimsen, Reimut (1995): Infrastruktur, in: Akademie für Raumforschung und Landesplanung: Handwörterbuch der Raumordnung, Hannover, S. 490-498.

Jochimsen, Reimut (1998): Perspektiven der europäischen Wirtschafts- und Währungsunion, 2. Aufl., Baden-Baden. 
Jones, Robert A. (1996): The Politics and Economics of the European Union, Cheltenham/ Brookfield.

Kaldor, Nicholas (1970): The Case for Regional Policies, in: Scottish Journal of Political Economy, Vol. 17, Nr. 3, S. 337-348.

Karl, Helmut (1998): Umweltpolitik, in Paul Klemmer (Hrsg.): Handbuch Europäische Wirtschaftspolitik, München, S. 1001-1149.

Keller, Theo (1961): Finanzausgleich (I) - Allgemeines, in: Erwin v. Beckerath u.a. (Hrsg.): Handwörterbuch der Sozialwissenschaften, Bd. 3, Stuttgart/ Tübingen/ Göttingen, S. 541547.

Kempa, Bernd (1996): Industry- Versus Nation- Specific Shocks in the EU: Evidence from Industry Data, in: Christos Paraskevopoulos/ Ricardo Grinspun/ Theodore Georgakopoulos (Hrsg.): Economic Integration and Public Policy in the European Union, Cheltenham/ Brookfield, S. 123-132.

Kenen, Peter (1969): The Theory of Optimum Currency Areas - An Eclectic View, in: Robert A. Mundell/ Alexander K. Swoboda (Hrsg.): Monetary Problems of the International Economy, Chicago, S. 40-60.

King, David (1984): Fiscal Tiers - The Economics of Multi-Level Government, London u.a.

Kirchgässner, Gebhard (1991): Homo Oeconomicus - das ökonomische Modell individuellen Verhaltens und seine Anwendung in den Wirtschafts- und Sozialwissenschaften, Tübingen.

Kirchhof, Paul (1995): Das Maastricht-Urteil des Bundesverfassungsgerichts, in: Jürgen Ensthaler (Hrsg.): Vom Binnenmarkt zur Europäischen Union - Die Gemeinschaft zwischen Zweckverband und neuer Staatlichkeit, Berlin, S. 33-49.

Kirsch, Guy (1978): Föderalismus - Die Wahl zwischen intrakollektiver Konsenssuche und interkollektiver Auseinandersetzung, in: Wilhelmine Dreißig (Hrsg.): Probleme des Finanzausgleichs I, Schriften des Vereins für Socialpolitik, Gesellschaft für Wirtschafts- und Sozialwissenschaften, N.F., Bd. 96/I, S. 9-43.

Kittel, Bernhard (1997): Der Nationalstaat zwischen Sozial- und Systemintegration - Anmerkungen zur „Nationalisierung“ der Europäischen Union, in: Beigewum (Beirat für gesellschafts-, wirtschafts- und umweltpolitische Alternativen) (Hrsg.): Wege zu einem anderen Europa - Perspektiven der Europäischen Integration, Köln, S. 34-59.

Kleinewerfers, Henner/ Jans, Armin (1983): Einführung in die volkswirtschaftliche und wirtschaftspolitische Modellbildung, München.

Klemmer, Paul (1998): Regionalpolitik, in Paul Klemmer (Hrsg.): Handbuch Europäische Wirtschaftspolitik, München, S. 457-517.

Klinke, Ulrich (1989): Der Gerichtshof der Europäischen Gemeinschaften - Aufbau und Arbeitsweise, Baden-Baden.

Klodt, Henning (1987): Wettlauf um die Zukunft - Technologiepolitik im internationalen Vergleich, Kieler Studien, Nr. 206, Tübingen. 
Klodt, Henning (1992): Theorie der strategischen Handelspolitik und neue Wachstumstheorie als Grundlage für eine Industrie- und Technologiepolitik?, Kieler Arbeitspapiere, Nr. 533, Kiel.

Klodt, Henning u.a. (1992): Die Strukturpolitik der EG, Kieler Studien, Nr. 249, Tübingen.

Knoppik, Christoph (1997): Stabilitätseinbußen durch die Europäische Währungsunion Theoretische und empirische Untersuchungen, Frankfurt am Main u.a.

Kops, Manfred (1984): Formen und Grundprinzipien des Finanzausgleichs (III): Der ergänzende aktive Finanzausgleich, in: Wirtschaftsstudium (WISU), Heft 7, S. 341-345.

Kops, Manfred (1989): Möglichkeiten und Restriktionen einer Berücksichtigung von Sonderbedarfen im Länderfinanzausgleich, Opladen.

Kops, Manfred (1997): Grundstrukturen einer Europäischen Finanzverfassung, in: Rolf Caesar (Hrsg.): Zur Reform der Finanzverfassung und Strukturpolitik der EU, BadenBaden, S. 23-53.

Korioth, Stefan (1997): Der Finanzausgleich zwischen Bund und Ländern, Tübingen.

Kraff, Manfred (1997): Der Finanzausgleich in der Europäischen Union - Theorie, Praxis und Perspektiven, Bonn.

Krägenau, Henry/ Wetter, Wolfgang (1993): Europäische Wirtschafts- und Währungsunion Vom Werner-Plan zum Vertrag von Maastricht. Analysen und Dokumentationen, BadenBaden.

Krägenau, Henry/ Wetter, Wolfgang (1995): Maastricht II - Europäische Integration auf dem Prüfstand, in: Wirtschaftsdienst, Heft 10, S. 525-532.

Krieger-Boden, Christiane (1995): Die räumliche Dimension in der Wirtschaftstheorie - Ältere und neuere Erklärungsansätze, Kiel.

Krugman, Paul (1991): Geography and Trade, Leuven/ Cambridge/ London.

Krupp, Hans-Jürgen/ Cabos, Karen (1998): Die Aufgaben der Geldpolitik in der Interimsphase bis zum Beginn der EWU, in: Wirtschaftsdienst, Heft 6, S. 331-337.

Külp, Bernhard (1988): Wohlfahrtsökonomik I - Grundlagen, in: Willi Albers (Hrsg.): Handwörterbuch der Wirtschaftswissenschaften (HdWW), Bd. 9, Stuttgart u.a., S. 469-486.

Laaser, Claus-Friedrich (1997): Ordnungspolitik und Strukturpolitik im Integrationsprozeß Das Beispiel Griechenlands, Portugals und Spaniens, Tübingen.

Laaser, Claus-Friedrich u.a. (1993): Europäische Integration und nationale Wirtschaftspolitik, Tübingen.

Lammers, Konrad (1993): Braucht die EG einen Finanzausgleich?, in: Arbeitsgemeinschaft deutscher wirtschaftswissenschaftlicher Forschungsinstitute (Hrsg.): Probleme des Finanzausgleich in nationaler und internationaler Sicht, Tagungsband zur Jahreshauptversammlung im Mai 1993 in Bonn, Beihefte der Konjunkturpolitik, Heft 41, Berlin, S. 189200. 
Laufer, Heinz (1995): Kriterien der Kompetenzabgrenzung, in: Werner Weidenfeld (Hrsg.): Reform der Europäischen Union - Materialien zur Revision des Maastrichter Vertrages 1996, Gütersloh, S. 201-213.

Laufer, Heinz/ Arens, Uwe (1995): Die kontinuierliche Ausweitung der EG-Kompetenzen, in: Werner Weidenfeld (Hrsg.): Reform der Europäischen Union - Materialien zur Revision des Maastrichter Vertrages 1996, Gütersloh, S. 193-200.

Laufer, Heinz/ Fischer, Thomas (1995): Zur Kompetenzverteilung zwischen Europäischer Union und den Mitgliedstaaten, in: Werner Weidenfeld (Hrsg.): Reform der Europäischen Union - Materialien zur Revision des Maastrichter Vertrages 1996, Gütersloh, S. 214-225.

Läufer, Thomas (1993): Europäische Gemeinschaft, Europäische Union - Die Vertragstexte von Maastricht mit den deutschen Begleitgesetzen, 2. Aufl., Bonn.

Läufer, Thomas (1994a): Einheitliche Europäische Akte, in: Werner Weidenfeld/ Wolfgang Wessels (Hrsg.): Europa von A - Z, Taschenbuch der europäischen Integration, 3. Aufl., Bonn, S. 107-110.

Läufer, Thomas (1994b): Gerichtshof der EG, in: Werner Weidenfeld/Wolfgang Wessels (Hrsg.): Europa von A - Z, Taschenbuch der europäischen Integration, 3. Aufl., Bonn, S. $217-220$.

Läufer, Thomas (1994c): Europäischer Rechnungshof, in: Werner Weidenfeld/Wolfgang Wessels (Hrsg.): Europa von A - Z, Taschenbuch der europäischen Integration, 3. Aufl., Bonn, S. 184-185.

Läufer, Thomas (1994d): Entscheidungsverfahren, in: Werner Weidenfeld/ Wolfgang Wessels (Hrsg.): Europa von A - Z, Taschenbuch der europäischen Integration, Bonn, 3. Aufl., S. 118-126.

Läufer, Thomas (Hrsg.) (1998): Vertrag von Amsterdam - Texte des EU-Vertrages und des EG-Vertrages, Bonn.

Lehner, Dionys (1971): Der Finanzausgleich zwischen Bund und Kantonen im Hinblick auf eine Bundesfinanzreform, Bern/ Stuttgart.

Leipold, Helmut (1994a): Die EG im Spannungsverhältnis zwischen Konsens und Effizienz, in: Helmut Leibold (Hrsg.), Ordnungsprobleme Europas: Die Europäische Union zwischen Vertiefung und Erweiterung, Marburger Gesellschaft für Ordnungsfragen der Wirtschaft e.V., Arbeitsbericht Nr. 18, Marburg, S. 1-38.

Leipold, Helmut (1994b): Die EU im Spannungsverhältnis zwischen Vertiefung und Erweiterung, in: Helmut Leipold (Hrsg.), Ordnungsprobleme Europas: Die Europäische Union zwischen Vertiefung und Erweiterung, Marburger Gesellschaft für Ordnungsfragen der Wirtschaft e.V., Arbeitsbericht Nr. 18, Marburg, S. 39-78.

Lenk, Thomas (1992): Anforderungen an eine gesetzliche Regelung des Länderfinanzausgleichs in der Bundesrepublik Deutschland, Technische Hochschule Darmstadt - Institut für Volkswirtschaftslehre - Arbeitspapier Nr. 65, Juli, Darmstadt.

Lenk, Thomas (1993): Reformbedarf und Reformmöglichkeiten des deutschen Finanzausgleichs - Eine Simulationsstudie, Baden-Baden. 
Lenk, Thomas/ Teichmann, Volkmar (1998): Bei der Reform der Finanzverfassung die neuen Bundesländer nicht vergessen!, Universität Leipzig, Wirtschaftswissenschaftliche Fakultät, Diskussionsbeiträge, Nr. 2, Oktober, Leibzig.

Leonardi, Robert (1995): Convergence, Cohesion and Integration in the European Union, New York.

Levaggi, Rosella/ Smith, Peter (1994): On the Intergovernmental Fiscal Game, in: Public Finance, Vol. 49, Nr. 1, S. 72-86.

Leyendecker, Michael (1994): Justiz und Inneres, in: Werner Weidenfeld/ Wolfgang Wessels (Hrsg.): Europa von A - Z, Taschenbuch der europäischen Integration, 3. Aufl., Bonn, S. 243-248.

Lucas, Robert E. Jr. (1976): Econometric Policy Evaluation - A Critique, in: Karl Brunner/ Alan H. Meltzer (Hrsg.): The Phillips Curve and Labor Markets, Carnegie-Rochester Conference Series on Public Policy, Vol. 1, Amsterdam, S. 19-46.

Lucas, Robert E. Jr. (1988): On the Mechanics of Economic Development, in: Journal of Monetary Economics, Vol. 22, S. 3-42.

Maihofer, Werner (1995): Föderativverfassung und Kompetenzverteilung einer Europäischen Union, in: Werner Weidenfeld (Hrsg.): Reform der Europäischen Union - Materialien zur Revision des Maastrichter Vertrages 1996, Gütersloh, S. 61-74.

Majocchi, Alberto/ Rey, Mario (1993): A Special Financial Support Scheme in Economic amd Monetary Union - Need and Nature, in: Europäische Kommission (Hrsg.): The Economics of Community Public Finance, European Economy, Reports and Studies, No 5, Brussels/ Luxembourg, S. 457-480.

Mallossek, Jörg (1996): Entwicklung einer Finanzkonzeption der Europäischen Union im Hinblick auf eine Aufnahme von mittel- und osteuropäischen Staaten, in: Zeitschrift für Wirtschaftspolitik, Jg. 45, Heft 3, S. 274-302.

Mathews, Russel (1977): Finanzausgleichmechanismen in einer zusammenwachsenden Europäischen Gemeinschaft, in: Europäische Kommission (Hrsg.): Bericht der Sachverständigengruppe zur Untersuchung der Rolle der öffentlichen Finanzen bei der europäischen Integration, Bd. II, Einzelbeiträge und Arbeitsunterlagen, Brüssel, S. 421-452.

Matthes, Heinrich (1997): Asymmetrische Schocks in der Währungsunion - Korreferat zu Norbert Berthold, in: Otto G. Mayer/ Hans-Eckart Scharrer (Hrsg.): Schocks und Schockverarbeitung in der Europäischen Währungsunion, Baden-Baden, S. 45-51.

Mayer, Otto G./ Scharrer, Hans-Eckart (Hrsg.) (1997): Schocks und Schockverarbeitung in der Europäischen Währungsunion, Baden-Baden.

Mayes, David G. (1994): Factor Mobility, in: Ali M. El-Agraa (Hrsg.): The Economics of the European Community, 4. Aufl., New York u.a., S. 421-448.

Mayntz, Renate (1995): Föderalismus und die Gesellschaft der Gegenwart, in: Karlheinz Bentele/ Bernd Reissert/ Roland Schettkat (Hrsg.): Die Reformfähigkeit von Industriegesellschaften - Fritz W. Scharpf - Festschrift zu seinem 60. Geburtstag, Frankfurt am Main/ New York, S. 131-144. 
McKinnon, Ronald I. (1963): Optimum Currency Areas, in: American Economic Review, Vol. 53, S. 717-725.

McLure, Charles E. (1968): Merit Wants - a Normatively Empty Box, in: Finanzarchiv, N.F., Bd. 27, S. 474-483.

Mélitz, Jaques (1994): Is there a Need for Communitywide Insurance against Cyclical Disparities?, in: Économie Et Statistique - Special Issue, S. 99-106.

Mélitz, Jaques/ Vori, Silvia (1992): National Insurance against Unevenly Distributed Shocks in a European Monetary Union, Institut National De La Statistique Et Des Etudes Economiques - Série Des Documents De Travail Du CREST Et Du Département De La Recherche, Oktober, Nr. 9219.

Messal, Rüdiger/ Klein, Armin (1993): Finanzlasten und Eigenmittelstruktur der Europäischen Gemeinschaft, in: Wirtschaftsdienst, Heft 7, S. 375-383.

Meyer, Steffen (1996): Redistribution Through Intergovernmental Transfers - the German 'Laenderfinanzausgleich' as a Model for the European Union?, Universität Würzburg, Wirtschaftswissenschaftliche Beiträge des Volkswirtschaftlichen Instituts, Würzburg.

Meyer, Steffen (1998): Popitz „Gesetz der Anziehungskraft des zentralen Etats“ - Erklärungsansatz für Zentralisierungstendenzen im europäischen Integrationsprozeß?, in: Wirtschaftswissenschaftliches Studium (WiSt), Heft 4, S. 197-200.

Michaelis, Jochen (1997): Schockverarbeitung durch nationale Fiskalpolitiken - Effizienz nationaler Instrumente in einer Wirtschafts- und Währungsunion, in: Otto G. Mayer/ Hans-Eckart Scharrer (Hrsg.): Schocks und Schockverarbeitung in der Europäischen Währungsunion, Baden-Baden, S. 159-187.

Migué, Jean-Luc/ Bélanger, Gerard (1974): Toward a General Theory of Managerial Discretion, in: Public Choice, Vol. 17, S. 27-43.

Möller, Alex (Hrsg.) (1969): Kommentar zum Gesetz zur Förderung der Stabilität und des Wachstums der Wirtschaft, 2. Aufl., Hannover.

Monnet, Jean (1988): Erinnerungen eines Europäers, Baden-Baden.

Möschel, Wernhard (1993): Konturen einer politischen Union. Plädoyer für eine europäische Minimalgemeinschaft, in: Erhard Kantzenbach/ Otto G. Mayer (Hrsg.): Europäische Gemeinschaft - Bestandsaufnahme und Perspektiven, Schriften des Vereins für Socialpolitik, Gesellschaft für Wirtschafts- und Sozialwissenschaften, N.F., Bd. 225, Berlin, S. 23-39.

Möschel, Wernhard (1994): Europäische Integration am Wendepunkt? - Perspektiven nach Maastricht, in: Wirtschaftswissenschaftliches Studium (WiSt), Heft 3, S. 123-131.

Möschel, Wernhard (1995): Subsidiaritätsprinzip im Zwielicht, in: Wirtschaftswissenschaftliches Studium (WiSt), Heft 5, S. 232-236.

Möschel, Wernhard (1996): Zur Verfassungsdebatte in Europa, in: Felix A. Zimmermann u.a. (Hrsg.): Ordnungspolitische Aspekte der europäischen Integration - Freiburgs Botschaft für ein offenes Europa, Baden-Baden, S. 51-55. 
Mueller, Dennis C. (1989): Public Choice II - A revised edition of Public Choice, Cambridge u.a.

Müller-Armack, Alfred (1956): Soziale Marktwirtschaft, in: Erwin v. Beckerath u.a. (Hrsg.): Handwörterbuch der Sozialwissenschaften, Bd. 9, Stuttgart/ Tübingen/ Göttingen, S. 390392.

Mundell, Robert (1961): A Theory of Optimum Currency Areas, in: American Economic Review, Vol. 51, S. 509-516.

Murakami, Thomas (1993): EG-Kohäsionspolitik und der Finanzausgleich der Schweiz, Münster/ Hamburg.

Musgrave, Richard A. (1957): A Multible Theory of Budget Determination, in: Finanzarchiv, N.F., Bd. 17, Heft 3, S. 333-343.

Musgrave, Richard A. (1959): The Theory of Public Finance - A Study in Public Economy, New York u.a.

Musgrave, Richard A. (1961): Approaches to A Fiscal Theory of Political Federalism, in: National Bureau of Economic Research (Hrsg.): Public Finances - Needs, Sources and Utilization, Princeton, S. 97-133.

Musgrave, Richard A. (1969): Finanztheorie, ins Deutsche übertragen von Lore Kullmer unter Mitarbeit von Hans Fechner, 2. Aufl., Tübingen.

Musgrave, Richard A. (1987): Merit Goods, in: John Eatwell/ Murray Milgate/ Peter Newman (Hrsg.): The New Palgrave Dictionary of Money and Finance \# 3, London/ New York, S. 452-453.

Musgrave, Richard A./ Musgrave, Peggy B. (1973): Public Finance in Theory and Practice, Tokyo u.a.

Musgrave, Richard A./ Musgrave, Peggy B. (1984): Public Finance in Theory and Practice, 4. Aufl., New York u.a..

Musgrave, Richard A./ Musgrave, Peggy B./Kullmer, Lore (1990): Die Öffentlichen Finanzen in Theorie und Praxis, 1. Bd., 5. Aufl., Tübingen.

Musgrave, Richard A./ Musgrave, Peggy B./ Kullmer, Lore (1992): Die Öffentlichen Finanzen in Theorie und Praxis, 3. Bd., 4. Aufl., Tübingen.

Mussler, Werner/ Streit, Manfred E. (1996): Integrationspolitische Strategien in der EU, in: Renate Ohr (Hrsg.): Europäische Integration, Stuttgart/ Berlin/ Köln, S. 265-292.

Myrdal, Gunnar (1957): Economic Theory and Under-developed Regions, London.

Neisser, Heinrich (1997): Optionen der Parlamentarisierung der Europäischen Union, in: Eugen Antalovsky/ Josef Melchior/ Sonja Puntscher Riekmann (Hrsg.): Integration durch Demokratie - Neue Impulse für die Europäische Union, Marburg, S. 193-204.

Nell-Breuning, Oswald von (1962): Subsidiaritätsprinzip, in: Staatslexikon, Bd. 7, S. 826-834.

Nerlich, Carolin (1996): Zur wirtschaftlichen Stabilität in einer Währungsunion unter Bedingungen realer Schocks, Köln. 
Neumark, Fritz (1970): Grundsätze gerechter und ökonomisch rationaler Steuerpolitik, Tübingen.

Nicolaysen, Gert (1995): Funktionalität und Kontrolle der Subsidiarität, in: Werner Weidenfeld (Hrsg.): Reform der Europäischen Union - Materialien zur Revision des Maastrichter Vertrages 1996, Gütersloh, S. 156-165.

Niskanen, William A. (1971): Bureaucracy and Representativ Government, Chicago/ New York.

Noé, Claus (1983): Wo sind 19,5 Milliarden geblieben?, in: Raumforschung und Raumordnung, 41. Jg., Heft 1-2, S. 15-20.

Noll, Werner (1979): Finanzwissenschaft, München.

Noll, Werner (1983): Kommunale Stabilisierungspolitik, in: Wirtschaftswissenschaftliches Studium (WiSt), Heft 12, S. 610-616.

Noll, Werner (1992): Vom Fonds Deutsche Einheit zu einer aufgabenadäquaten Gestaltung des horizontalen Finanzausgleichs zwischen den Bundesländern?, Universität Würzburg, Wirtschaftswissenschaftliche Beiträge des Volkswirtschaftlichen Instituts, Würzburg.

Noll, Werner (1993): Finanztransfer und Finanzausgleich zwischen den Gebietskörperschaften in Ost- und Westdeutschland - Zustand und Ausblick, in: Peter Eichhorn (Hrsg.): Finanzierung und Organisation der Infrastruktur in den neuen Bundesländern, Schriftenreihe der Gesellschaft für öffentliche Wirtschaft, Bd. 34, Baden-Baden, S. 79-92.

Noll, Werner (1994): Wirtschaftsförderung durch öffentliche Unternehmen, in: Peter Eichhorn u.a. (Hrsg.): Standortbestimmung öffentlicher Unternehmen in der Marktwirtschaft. Gedenkschrift für Theo Thiemeyer, Schriftenreihe der Gesellschaft für öffentliche Wirtschaft, Bd. 35, Baden-Baden, S. 117-131.

Noll, Werner/ Hildebrandt, Ariane (1996): Finanzwissenschaftliche Grundlagen, in: Helmut W. Jenkis (Hrsg.): Raumordnung und Raumordnungspolitik, München/ Wien, S. 95-117.

Nordhaus, William D. (1975): The Political Business Cycle, in: Review of Economic Studies, Vol. 42, S. 169-190.

North, Douglas C. (1992): Institutionen, institutioneller Wandel und Wirtschaftsleistung, Tübingen.

Nowotny, Ewald (1996): Der öffentliche Sektor - Einfuhrung in die Finanzwissenschaft, 3. Aufl., Berlin u.a.

Nowotny, Ewald (1997a): Konsequenzen einer Globalisierung der Weltwirtschaft für unsere Gesellschaft, Vienna University of Economics and Business Administration, Working Paper No. 44, Wien.

Nowotny, Ewald (1997b): Ein Ordnungsrahmen für den globalen Wettbewerb, in: Internationale Politik und Gesellschaft, Nr. 3, S. 229-236. 
Nowotny, Ewald (1997c): Zur regionalen Dimension der Finanzverfassung der EU - gegenwärtiger Stand und Perspektiven, in: Alois Oberhauser (Hrsg.): Fiskalföderalismus in Europa, Schriften des Vereins für Socialpolitik, Gesellschaft für Wirtschafts- und Sozialwissenschaften, N.F., Bd. 253, Berlin, S. 97-145.

Oates, Wallace E. (1968): The Theory of Public Finance in a Federal System, in: Canadian Journal of Economics, Vol. 1, S. 37-54.

Oates, Wallace E. (1972): Fiscal Federalism, New York u.a.

Oates, Wallace E. (1977): „Finanz-Föderalismus“ (Fiscal Federalism) in Theorie und Praxis Lehren für die Europäische Gemeinschaft, in: Europäische Kommission (Hrsg.) (1977): Bericht der Sachverständigengruppe zur Untersuchung der Rolle der öffentlichen Finanzen bei der europäischen Integration, Bd. II, Einzelbeiträge und Arbeitsunterlagen, Brüssel, S. 291-331.

Oates, Wallace E. (1990): Decentralization of the Public Sector - An Overview, in: Robert J. Bennett (Hrsg.): Decentralization, Local Governments and Markets, Oxford, S. 43-58.

Ohlin, Bertil (1931): Die Beziehung zwischen internationalem Handel und internationalen Bewegungen von Kapital und Arbeit, in: Zeitschrift für Nationalökonomie, Vol. 2, S. 161199.

Ohr, Renate (1996): Europäische Währungsunion - eine Gefahr für Europa, in: Rolf Caesar/ Renate Ohr (Hrsg.): Maastricht und Maastricht II - Vision oder Abenteuer?, Baden Baden, S. 239-250.

Olson, Mancur Jr. (1968): Die Logik des kollektiven Handelns - Kollektivgüter und die Theorie der Gruppen, Tübingen.

Olson, Mancur Jr. (1969): The Principle of 'Fiscal Equivalence' - The Division of Responsabilities among different Levels of Government, in: American Economic Review, Vol. 59, S. 479-487.

Oppermann, Thomas (1991): Europarecht, München.

Osman, Jack W. (1966): The Dual Impact of Federal Aid on State and Local Government Expenditures, in: National Tax Journal, Vol. 19, S. 362-372.

o.V. (1997): Vertrag von Amsterdam zur Änderung des Vertrags über die Europäische Union, der Verträge zur Gründung der Europäischen Gemeinschaften sowie einiger damit zusammenhängender Rechtsakte, vom 2. Oktober 1997, in: Presse- und Informationsamt der Bundesregierung (Hrsg.): Bulletin, Nr. 94 vom 27. November 1997, S. 1089-1216.

Padoa-Schioppa, Tommaso (1988): Effizienz, Stabilität und Verteilungsgerechtigkeit - Eine Entwicklungsstrategie für das Wirtschaftssystem der Europäischen Gemeinschaft, Wiesbaden.

Papaspyrou, Theodoros (1993): Stabilization Policy in Economic and Monetary Union in the Light of the Maastricht Treaty Provisions Concerning Financial Assistance, in: Europäische Kommission (Hrsg.): The Economics of Community Public Finance, European Economy, Reports and Studies, No 5, Brussels/ Luxembourg, S. 481-491. . 
Peeters, Theo (1977): Stabilitätsorientierte Finanzpolitik in der Gemeinschaft sowie Währungs- und Wechselkurspolitik, in: MacDougall-Bericht, S. 485-503.

Peffekoven, Rolf (1983): Probleme der internationalen Finanzordnung, in: Fritz Neumark (Hrsg.): Handbuch der Finanzwissenschaft, Bd. IV, 3. Aufl., Tübingen, S. 219-268.

Peffekoven, Rolf (1988): Finanzausgleich I - Wirtschaftstheoretische Grundlagen, in: Willi Albers (Hrsg.): Handwörterbuch der Wirtschaftswissenschaft (HdWW), Bd. 2, Stuttgart u.a., S. 608-636.

Peffekoven, Rolf (1990): Finanzausgleich und Sonderbedarfe - Thema und vier Variationen, in: Franz Xaver Bea/ Wolfgang Kitterer (Hrsg.): Finanzwissenschaft im Dienste der Wirtschaftspolitik - Dieter Pohmer zum 65. Geburtstag, Tübingen, S. 323-341.

Peffekoven, Rolf(1994): Die Finanzen der Europäischen Union, Mannheim u.a.

Pennock, Ronald J. (1959): Federal and Unitary Government - Disharmony and Frustration, in: Behavioral Science, Bd. 4, S. 147-157.

Peschel, Karin (Hrsg.) (1997): Regional Growth and Regional Policy Within the Framework of European Integration, Heidelberg.

Pfetsch, Frank R. (1997): Die Europäische Union - Geschichte, Institutionen, Prozesse, München.

Pfingsten, Andreas/ Wagener, Andreas (1995): Fiskalischer Föderalismus als Anwendungsgebiet der Spieltheorie, in: Manfred J. Holler (Hrsg.): Ein halbes Jahrhundert Spieltheorie, Homo Oeconomicus, Bd. 12, München, S. 223-249.

Picot, Arnold (1982): Transaktionskostenansatz in der Organisationstheorie - Stand der Diskussion und Aussagewert, in: Die Betriebswirtschaft (DBW), Vol. 42, S. 267-284.

Pigou, Arthur C. (1932): The Economics of Welfare, 4. Aufl., Reprint 1962, London/ New York.

Pitlik, Hans (1997): Politische Ökonomie des Föderalismus, Frankfurt am Main u.a.

Popitz, Johannes (1927): Der Finanzausgleich, in: Wilhelm Gerloff/ Franz Meisel (Hrsg.): Handbuch der Finanzwissenschaft, Bd. II, S. 338-375.

Postlep, Rolf-Dieter (1993): Möglichkeiten eines horizontalen Finanzausgleichs zwischen den Mitgliedstaaten der Europaeischen Gemeinschaft, in: Günter Mertins (Hrsg.): Vorstellungen der Bundesrepublik Deutschland zu einem europäischen Raumordnungskonzept, Marburg/ Lahn, S. 83-93.

Priddat, Briger P. (1992): Zur Ökonomie der Gemeinschaftsbedürfnisse - Neuere Versuche einer ethischen Begründung der Theorie meritorischer Güter: in: Zeitschrift für Wirtschafts- und Sozialwissenschaften (ZWS), 112. Jg., S. 239-259.

Prisching, Manfred (1996): Bilder des Wohlfahrtsstaates, Marburg. 
Prud'homme, Rémy (1993): The Potential Role of the EC Budget in the Reduction of Spatial Disparities in a European Economic and Monetary Union, in: Europäische Kommission (Hrsg.): The Economics of Community Public Finance, European Economy, Reports and Studies, No 5, Brussels/ Luxembourg, S. 317-351.

Puntscher Riekmann, Sonja (1996): Integration und Desintegration in Europa, in: Sylvia Pintaris: Macht, Demokratie und Regionen in Europa - Analysen und Szenarien der Integration und Desintegration. Mit einem Beitrag von Sonja Puntscher Riekmann, Marburg, S. 289-361.

Rabushka, Alvin/ Shepsle, Kenneth A. (1972): Politics in Plural Societies - A Theory of Democratic Instability, Columbus, Ohio.

Rambow, Gerhard (1996): Die Regierungskonferenz 1996 - Wirtschaftspolitische Fragen, in: List-Forum für Wirtschafts- und Finanzpolitik, Bd. 22, Heft 3, S. 243-252.

Rawls, John (1971): A Theory of Justice, Cambridge.

Regelsberger, Elfriede (1994): Außenbeziehungen, in: Werner Weidenfeld/Wolfgang Wessels (Hrsg.): Europa von A - Z, Taschenbuch der europäischen Integration, 3. Aufl., Bonn, S. 75-78.

Reichenbach, Horst (1992): Ausgewählte Probleme der Europäischen Finanzverfassung, Universität des Saarlandes - Europa-Institut, Vorträge, Reden und Berichte aus dem EuropaInstitut - Sektion Rechtswissenschaft - Nr. 287, hrsg. von Georg Ress/ Torsten Stein, Saarbrücken.

Reichenbach, Horst/ Beck, Hans-Ulrich (1997): Die Regionalpolitik der Europäischen Union - Auf dem Wege zu verbesserter Kohäsion, in: Hans-Jürgen Vosgerau (Hrsg.): Zentrum und Peripherie - Zur Entwicklung der Arbeitsteilung in Europa, Schriften des Vereins für Socialpolitik, Gesellschaft für Wirtschafts- und Sozialwissenschaften, N.F., Bd. 250, Berlin, S. 129-145.

Reuter, Norbert (1994): Der Institutionalismus - Geschichte und Theorie der evolutionären Ökonomie, Marburg.

Ricardo, David (1817): On the Principles of Political Economy and Taxation, London.

Richter, Rudolf/ Furubotn, Eirik (1996): Neue Institutionenökonomik - Eine Einführung und kritische Würdigung, Tübingen.

Richter, Wolfram F./ Weimann, Joachim (1991): Meritorik, Verteilung und sozialer Grenznutzen vom Einkommen, in: Jahrbuch für Sozialwissenschaft, 42 Jg., S. 118-130.

Romer, Paul M. (1986): Increasing Returns and Long-Run Growth, in: Journal of Political Economy, Vol. 94, Nr. 5, S. 1002-1037.

Romer, Paul M. (1990): Endogenous Technological Change, in: Journal of Political Economy, Vol. 98, Nr. 5, S. 71-102.

Romer, Thomas/ Rosenthal, Howard (1980): An Institutional Theory of the Effects of Intergovernmental Grants, in: National Tax Journal, Vol. 33, S. 451-458. 
Rompuy, Paul Van/ Abraham, Filip/ Heremans, Dirk (1991): Economic Federalism and the EMU, in: Europäische Kommission (Hrsg.): The Economics of EMU - Background Studies for European Economy No 44 'One Market, One Money', Special Edition No 1, Brüssel, S. 109-135.

Rothschild, Kurt W. (1992): Ethik und Wirtschaftstheorie, Tübingen.

Saeter, Martin (1974): Europa politisch - Alternativen, Modelle und Motive der Integrationspolitik, Berlin.

Santos, Pedro (1993): The Spatial Implications of Economic and Monetary Union, in: Europäische Kommission (Hrsg.): The Economics of Community Public Finance, European Economy, Reports and Studies, No 5, Brussels/ Luxembourg, S. 353-368.

Sarrazin, Thilo (1997): Der EURO - Chance oder Abenteuer?, Bonn.

Schäfers, Manfred (1993): Die Kohäsionspolitik der Europäischen Gemeinschaft - Integrationspolitische Einordnung, Darstellung und Erfolgskontrolle, Baden-Baden.

Scharmer, Marco (1997): Europäische Währungsunion und die Implikationen ökonomischer Disparitäten - Stabilitätspolitische Risiken und finanzwissenschaftliche Konsequenzen der Europäischen Währungsunion, Frankfurt am Main u.a.

Scharpf, Fritz W. (1973): Komplexität als Schranke der politischen Planung, in: Fritz W. Scharpf (Hrsg.): Planung als politischer Prozeß - Aufsätze zur Theorie der planenden Demokratie, Frankfurt am Main, S. 73-113.

Scharpf, Fritz W. (1976): Theorie der Politikverflechtung, in: Fritz W. Scharpf/ Bernd Reissert/ Fritz Schnabel: Politikverflechtung - Theorie und Empirie des kooperativen Föderalismus in der Bundesrepublik, Kronberg/Ts., S. 13-70.

Scharpf, Fitz W. (1978): Die Theorie der Politikverflechtung - ein kurzgefaßter Leitfaden, in: Joachim Jens Hesse (Hrsg.): Politikverflechtung im föderativen Staat - Studien zum Planungs- und Finanzierungsverbund zwischen Bund, Ländern und Gemeinden, BadenBaden, S. 21-31.

Scharpf, Fritz W. (1991): Kann es in Europa eine stabile föderale Balance geben?, in: Rudolf Wildenmann (Hrsg.): Staatswerdung Europas? Optionen für eine Europäische Union, Baden-Baden, S. 415-428.

Scharpf, Fritz W. (1992a): Wege aus der Sackgasse - Europa: Zentralisierung und Dezentralisierung, in: WZB-Mitteilungen, Nr. 56, S. 24-28.

Scharpf, Fritz W. (1992b): Europäisches Demokratiedefizit und deutscher Föderalismus, in: Staatswissenschaften und Staatspraxis, Bd. 3, Heft 3, S. 293-306.

Scharpf, Fritz W. (1992c): Einführung - zur Theorie von Verhandlungssystemen, in: Arthur Benz/ Fritz W. Scharpf/ Reinhard Zintl: Horizontale Politikverflechtung - zur Theorie von Verhandlungssystemen, Frankfurt am Main, S. 11-27.

Scharpf, Fritz W. (1992d): Koordination durch Verhandlungssysteme: Analytische Konzepte und institutionelle Lösungen, in: Arthur Benz/ Fritz W. Scharpf/ Reinhard Zintl (Hrsg.): Horizontale Politikverflechtung - Zur Theorie von Verhandlungssystemen, Frankfurt am Main/ New York, S. 51-96. 
Scharpf, Fritz W. (1992e): Die Handlungsfähigkeit des Staates am Ende des Zwanzigsten Jahrhunderts, , in: Beate Kohler-Koch (Hrsg.): Staat und Demokratie in Europa, Opladen, S. 93-115.

Scharpf, Fritz W. (1993a): Autonomieschonend und gemeinschaftsverträglich - Zur Logik der europäischen Mehrebenenpolitik, Max-Planck-Institut für Gesellschaftsforschung, Diskussionspapier 93/9, Köln.

Scharpf, Fritz W. (1993b): Versuch über Demokratie im verhandelnden Staat, in: Roland Czada/ Manfred G. Schmidt (Hrsg.): Verhandlungsdemokratie, Interessenvermittlung, Regierbarkeit, Opladen, S. 25-50.

Scharpf, Fritz W. (1993c): Coordination in Hierarchies and Networks, in: Fritz W. Scharpf (Hrsg.): Games in Hierarchies and Networks - Analytical and Empirical Approaches to the Study of Governance Institutions, Frankfurt am Main/ Boulder, Colorado, S. 125-165.

Scharpf, Fritz W. (1994a): Politiknetzwerke als Steuerungssubjekte, in: Hans-Ulrich Derlien/ Uta Gerhardt/ Fritz W. Scharpf (Hrsg.): Systemrationalität und Partialinteresse, BadenBaden, S. 381-407.

Scharpf, Fritz W. (1994b): Die Politikverflechtungsfalle - Europäische Integration und deutscher Föderalismus im Vergleich, in: Fritz W. Scharpf: Optionen des Föderalismus in Deutschland und Europa, Frankfurt am Main/ New York, S. 11-44.

Scharpf, Fritz W. (1995): Europa nach Maastricht: Markt ohne Demokratie?, in: Wirtschaftsdienst, Heft 2, S. 85-93.

Scharpf, Fritz W. (1996a): Positive und negative Koordination in Verhandlungssystemen, in: Patrick Kenis/ Volker Schneider (Hrsg.): Organisation und Netzwerk - Institutionelle Steuerung in Wirtschaft und Politik, Frankfurt am Main/ New York, S. 497-534.

Scharpf, Fritz W. (1996b): Politische Optionen im vollendeten Binnenmarkt, in: Markus Jachtenfuchs/ Beate Kohler-Koch (Hrsg.): Europäische Integration, Opladen, S. 109-140.

Scharpf, Fritz W. (1997a): Demokratische Politik in Europa, in: Dieter Grimm u.a.( Hrsg.): Zur Neuordnung der Europäischen Union: Die Regierungskonferenz 1996/97, BadenBaden, S. 65-91.

Scharpf, Fritz W. (1997b): Wege zur Zivilisierung des Eurokapitalismus, in: Eugen Antalovsky/ Josef Melchior/Sonja Puntscher Riekmann (Hrsg.): Integration durch Demokratie - Neue Impulse für die Europäische Union, Marburg, S. 365-375.

Scharrer, Hans-Eckart (1998): Aufgaben für die Währungsunion der Elf, in: Wirtschaftsdienst, Heft 4, S. 194-195.

Schauer, Hans (1997): Nationale und europäische Identität - Die unterschiedlichen Auffassungen in Deutschland, Frankreich und Großbritannien, in: Aus Politik und Zeitgeschichte, Beilage 10, 28. Februar 1997, S. 3-13.

Schmidt, Christian (1997): Real Convergence in the European Union - An Empirical Analysis, Frankfurt am Main u.a.

Schmidt, Christian/ Straubhaar, Thomas (1995). Maastricht II - Bedarf es realer Konvergenzkriterien?, in: Wirtschaftsdienst, Heft 8, S. 434-442. 
Schmidt, Kurt (1964): Zur Geschichte der Lehre von den Kollektivbedürfnissen, in: Norbert Kloten u.a. (Hrsg.): Systeme und Methoden in den Wirtschafts- und Sozialwissenschaften, Erwin von Beckerath zum 75. Geburtstag, Tübingen.

Schmidt, Kurt (1970): Kollektivbedürfnisse und Staatstätigkeit, in: Heinz Haller u.a. (Hrsg.): Theorie und Praxis des finanzpolitischen Interventionismus. Fritz Neumark zum 70. Geburtstag, Tübingen, S. 3-27.

Schmidt, Kurt (1988): Mehr zur Meritorik - Kritisches und Alternatives zu der Lehre von den öffentlichen Gütern, in: Zeitschrift für Wirtschafts- u. Sozialwissenschaften (ZWS), 108 Jg., S. 383-403.

Schmitt, Günther (1998): Agrarpolitik, in: Paul Klemmer (Hrsg.): Handbuch Europäische Wirtschaftspolitik, München, S. 141-218.

Schmitter, Philippe C. (1995): Die Zukunft Europas - Zwischen Integration und Zerfall, in: Karl S. Althaler u.a. (Hrsg.): Sozioökonomische Forschungsansätze - Historische Genese, Methoden, Anwendungsgebiete, Marburg, S. 207-241.

Schmölders, Günter (1965): „Finanzstarke“ und „finanzschwache“ Gemeinden. Zur Frage der Typisierung kommunaler Gebilde nach finanzwirtschaftlichen Strukturmerkmalen, in: Archiv für Kommunalwissenschaften, 4. Jg., S. 30-46.

Schmuck, Otto (1994a): Europäisches Parlament, in: Werner Weidenfeld/ Wolfgang Wessels (Hrsg.): Europa von A - Z, Taschenbuch der europäischen Integration, 3. Aufl., Bonn, S. 186-193.

Schmuck, Otto (1994b): Europäische Parteienzusammenschlüsse, in: Werner Weidenfeld/ Wolfgang Wessels (Hrsg.): Europa von A - Z, Taschenbuch der europäischen Integration, 3. Aufl., Bonn, S. 162-165.

Schönfelder, Wilhelm/ Thiel, Elke (1996): Ein Markt - eine Währung - Die Verhandlungen zur Europäischen Wirtschafts- und Währungsunion, 2. Aufl., Baden-Baden.

Schulz-Nieswandt, Frank (1996): Regionale Wohlstandsunterschiede als Problem einer sozialpolitisch relevanten regionalen Entwicklungspolitik in der EG - ein Überblick über die aktuelle Debatte, in: Soziale Integration in Europa, Bd. 2, S. 189-254.

Schumpeter, Joseph A. (1950): Kapitalismus, Sozialismus und Demokratie, München.

Schuppert, Gunnar Folke (1994): Zur Staatswerdung Europas - Überlegungen zu Bedingungsfaktoren und Perspektiven der europäischen Verfassungsentwicklung, in: Staatswissenschaften und Staatspraxis, Bd. 5, Heft 1, S. 35-76.

Schweickert, Rainer (1996): Harmonisierung versus institutioneller Wettbewerb zur Sicherung realwirtschaftlicher Anpassung und monetärer Stabilität in der Europäischen Währungsunion, in: Maastricht II - Entwicklungschancen und Risiken der EU: Erweiterung, Vertiefung oder Stagnation?, Beihefte zur Konjunkturpolitik - Zeitschrift für angewandte Wirtschaftsforschung, Heft 44, Berlin, S. 181-212.

Scott, Anthony D. (1952): The Evaluation of Federal Grants, in: Economica, Vol. 19, S. $377-$ 394. 
Scott, Anthony D. (1964): The Economic Goals of Federal Finance, in: Public Finance, Vol. 19, S. 241-288.

Seidel, Barbara (1992): Die Einbindung der Bundesrepublik Deutschland in die Europäischen Gemeinschaften als Problem des Finanzausgleichs, Frankfurt am Main u.a.

Seiler, Gerhard (1980): Ziele und Mittel des kommunalen Finanzausgleichs - Ein Rahmenkonzept für einen aufgabenbezogenen kommunalen Finanzausgleich, in: Dieter Pohmer (Hrsg.): Probleme des Finanzausgleichs II, Schriften des Vereins für Socialpolitik, Gesellschaft für Wirtschafts- und Sozialwissenschaften, N.F., Bd. 96/II, S. 11-82.

Siebert, Horst (1996): Zum Transferbedarf in einer Währungsunion, in: Die Weltwirtschaft, Heft 4, S. 345-353.

Siebert, Horst/ Koop, Michael J. (1993): Institutional Competition Versus Centralization Quo Vadis Europe?, Kieler Arbeitspapiere, Nr. 548, Kiel.

Sinn, Hans-Werner (1995): Implikationen der vier Grundfreiheiten für eine nationale Fiskalpolitik, in: Wirtschaftsdienst, Heft 5, S. 240-249.

Sinn, Hans-Werner (1997a): Das Selektionsprinzip und der Systemwettbewerb, in: Alois Oberhauser (Hrsg.): Fiskalföderalismus in Europa, Schriften des Vereins für Socialpolitik, Gesellschaft für Wirtschafts- und Sozialwissenschaften, N.F., Bd. 253, Berlin, S. 9-60.

Sinn, Hans-Werner (1997b): Verlangt der Euro einen Finanzausgleich? - Korreferat zu Jürgen von Hagen und George W. Hammond, in: Otto G. Mayer/ Hans-Eckart Scharrer (Hrsg.): Schocks und Schockverarbeitung in der Europäischen Währungsunion, Baden-Baden, S. 215-219.

Smekal, Christian (1980): Transfers zwischen Gebietskörperschaften (TG) - Ziele und Gestaltungsprobleme, in: Dieter Pohmer (Hrsg.): Probleme des Finanzausgleichs II, Schriften des Vereins für Socialpolitik, Gesellschaft für Wirtschafts- und Socialwissenschaften, N.F., Bd. 96/II, S. 151-220.

Smend, Rudolf (1975): Integration, in: Herman Kunst u.a. (Hrsg.): Evangelisches Staatslexikon, 2. Aufl., Stuttgart, S. 1024-1027.

Solow, Robert M. (1956): A Contribution to the Theory of Economic Growth, in: Quarterly Journal of Economics, Vol. 70, S. 65-94.

Spahn, Bernd (1993a): The Design of Federal Fiscal Constitutions in Theory and Practice, in: Europäische Kommission (Hrsg.): The Economics of Community Public Finance, European Economy, Reports and Studies, No 5, Brussels/ Luxembourg, S. 63-99.

Spahn, Bernd (1993b): The Consequences of Economic and Monetary Union for Fiscal Federal Relations in the Community and the Financing of the Community Budget, in: Europäische Kommission (Hrsg.): The Economics of Community Public Finance, European Economy, Reports and Studies, No 5, Brussels/ Luxembourg, S. 541-584.

Spiekermann, Bernd u.a. (1988): Europäische Regionalpolitik - Empfehlungen zur Weiterentwicklung, Köln u.a. 
Spiess, Lukas (1973): Der Finanzausgleich im Lichte volkswirtschaftlicher Ziele - Ansätze zu einer Theorie des Finanzausgleichs als wirtschaftspolitisches Steuerungsinstrument im Bundesstaate, Freiburg i. Br.

Staeck, Nicola (1996): Politikprozesse im Mehrebenensystem der Europäischen Union - Eine Policy-Netzwerkanalyse der europäischen Strukturfondspolitik dargestellt am Bundesland Niedersachsen, Hannover.

Stahl, Gerhard (1997): Die EU-Stukturpolitik - Zielorientierung, Wirkungen, Effizienz, in: Rolf Caesar (Hrsg.): Zur Reform der Finanzverfassung und Strukturpolitik der EU, BadenBaden, S. 193-207.

Stähling, Karl-Heinz (1994): Indikatoren ausgewählter Infrastrukturbereiche für die Länder der Europäischen Gemeinschaften, Köln.

Streinz, Rudolf (1992): Europarecht, Heidelberg.

Streit, Manfred E.(1991): Theorie der Wirtschaftspolitik, 4. Aufl., Düsseldorf.

Taube, Reginbert (1990): Ein Vorschlag zur Reform des Länderfinanzausgleichs, in: Wirtschaftsdienst, Heft 7, S. 372-380.

Teutemann, Manfred (1992): Rationale Kompetenzverteilung im Rahmen der europäischen Integration - ein Beitrag zur finanzwirtschaftlichen Ordnungspolitik, Berlin.

Thiel, Elke (1997): Die Europäische Union - Aktualisierung: Die EU nach dem Europäischen Rat von Amsterdam (Neue Vertragsgrundlage), München.

Thomas, Ingo P. (1994): Finanzausgleich und Kohäsion in der Europäischen Union, in: Die Weltwirtschaft, Heft 4, S. 472-491.

Thomas, Ingo P. (1997): Ein Finanzausgleich für die Europäische Union? Eine allokationstheoretische und fiskalföderalistische Analyse, Kieler Studien, Nr. 285, Tübingen.

Thöni, Erich (1986): Politökonomische Theorie des Föderalismus - Eine kritsche Bestandsaufnahme, Schriften des Vereins zur öffentlichen Verwaltung und öffentlichen Wirtschaft, Nr. 84, Baden-Baden.

Thurow, Lester C. (1966): The Theory of Grants-In-Aid, in: National Tax Journal, Vol. 19, S. 373-377.

Thurow, Lester C. (1996): Die Zukunft des Kapitalismus, Düsseldorf/ München.

Tichy, Gunther (1993): Gibt es ein optimales europäisches Integrationsgebiet?, in: Wirtschaftswissenschaftliches Studium (WiSt), Heft 5, S. 229-234.

Tietzel, Manfred (1988): Zur Theorie der Präferenzen, in: Erik Boettcher/ Philipp HerderDorneich/ Karl-Ernst Schenk (Hrsg.): Jahrbuch für Neue Politische Ökonomie, 7. Bd., Interdisziplinarität - Voraussetzungen und Notwendigkeiten, Tübingen, S. 38-71.

Tinbergen, Jan (1954): International Economic Integration, Amsterdam.

Tinbergen, Jan (1972): Wirtschaftspolitik, 2. Aufl., Freiburg. 
Tuchtfeldt, Egon (1977): Wirtschaftspolitik, in: Willi Albers (Hrsg.): Handwörterbuch der Wirtschaftswissenschaft (HdWW), Bd. 9, Stuttgart u.a., S. 178-206.

Tullock, Gordon (1967): The Welfare Costs of Tariffs, Monopolies, and Theft, in: Western Economic Journal, Vol. 5, S. 224-232.

Unger, Brigitte (1995): Europa zwischen Integration und Desintegration - Zum Spannungsfeld zwischen ökonomischer und politischer Integration, in: Karl S. Althaler u.a. (Hrsg.): Sozioökonomische Forschungsansätze - Historische Genese, Methoden, Anwendungsgebiete, Marburg, S. 243-264.

Vanberg, Victor/ Buchanan, James M. (1988): Rational Choice and Moral Order, in: Analyse \& Kritik, Bd. 10, S. 138-160.

Vaubel, Roland (1992): Die politische Ökonomie der wirtschaftspolitischen Zentralisierung in der Europäischen Gemeinschaft in: Philipp Herder-Dorneich u.a. (Hrsg.): Jahrbuch für Neue Politische Ökonomie, 11. Bd., Ökonomische Systeme und ihre Dynamik, S. 30-65.

Vaubel, Roland (1994): The Political Economy of Centralization and the European Community, in: Public Choice, Vol. 81, S. 151-190.

Wagner, Helmut (1993): Wachstum und Entwicklung - Theorie der Entwicklungspolitik, München/ Wien.

Wagner, Helmut (1995): Europäische Wirtschaftspolitik - Perspektiven einer Europäischen Wirtschafts- und Währungsunion (EWWU), Berlin u.a.

Waldauer, Charles (1973): Grant Structures and Their Effects on Aided Government Expenditures - An Indifference Curve Analysis, in: Public Finance, Vol. 28, S. 212-226.

Wallace, William (1990): Introduction - The Dynamics of European Integration, in: William Wallace (Hrsg.): The Dynamics of European Integration, London.

Walsh, Cliff (1993): Fiscal Federalism - An Overview of Issues and a Discussion of their Relevance to the European Community, in: Europäische Kommission (Hrsg.): The Economics of Community Public Finance, European Economy, Reports and Studies, No 5, Brussels/ Luxembourg, S. 25-62.

Walthes, Frank (1996): Europäischer Finanzausgleich, Berlin.

Waniek, Roland W. (1994): Die EG-Regionalpolitik für die Jahre 1994 bis 1999, in: Wirtschaftsdienst, Heft 1, S. 43-49.

Waniek, Roland W. (1995): Sektoraler und Raumstruktureller Wandel in Europa, in: Helmut Karl/ Wilhelm Henrichsmeyer (Hrsg.): Regionalentwicklung im Prozess der Europäischen Integration, Bonn, S. 15-51.

Wasmayr, Bernhard (1997): Kohäsionspolitik der EU in der Europäischen Wirtschafts- und Währungsunion, Ausgestaltung - Kritik - Reformvorschlag, Frankfurt am Main u.a.

Weidenfeld, Werner (Hrsg.) (1995): Reform der Europäischen Union - Materialien zur Revision des Maastrichter Vertrages 1996, Gütersloh. 
Weindl, Josef (1996): Europäische Gemeinschaft - Institutionelles System, Binnenmarkt sowie Wirtschafts- und Währungsunion auf der Grundlage des Maastrichter Vertrages (EU), 3. Aufl., München/ Wien.

Welfens, Paul J.J. (1996): Koordinationserfordernisse der EU-Infrastrukturpolitik, in: Helmut Karl (Hrsg.): Die Koordination der Finanz-, Währungs- und Strukturpolitik in der EU, Bonn, S. 145-184.

Werner, Gabriele (1996): Die europäische Regionalpolitik im Spannungsfeld zwischen Wachstums- und Ausgleichspolitik - die Rolle der Regionalpolitik im Integrationsprozeß der Europäischen Gemeinschaft, Baden-Baden.

Wessels, Wolfgang (1992): Maastricht - Ergebnisse, Bewertung und Langzeittrends, in: Integration, Beilage zur Europäischen Zeitung, Jg. 15, Nr. 1, S. 2-16.

Wessels, Wolfgang (1996): Europäische Union - Entwicklung eines politischen Systems, in: Renate Ohr (Hrsg.): Europäische Integration, Stuttgart/ Berlin/ Köln, S. 19-45.

Wicksell, Knut (1896): Finanztheoretische Untersuchungen, Jena.

Wieland, Beate (1991): Verfassungspolitische Probleme der „Staatswerdung Europas“, in: Rudolf Wildenmann (Hrsg.): Staatswerdung Europas? Optionen für eine Europäische Union, Baden-Baden, S. 429-459.

Wilde, James A. (1968): The Expenditure Effects of Grants-In-Aid Programs, in: National Tax Journal, Vol. 21, S. 340-348.

Wilde, James A. (1971): Grants-In-Aid - The Analytics of Design and Response, in: National Tax Journal, Vol. 24, S. 143-155.

Williamson, Oliver E. (1975): Markets and Hierarchies, New York.

Willms, Manfed (1998): Die Europäische Währungsunion im Lichte der Theorie optimaler Währungsräume, in: Hans-Herrmann Francke/ Eberhard Ketzel/ Hans-Hermann Kotz (Hrsg.): Europäische Währungsunion von der Konzeption zur Gestaltung, Berlin, S. 41-58.

Wilming, Claudia (1995): Institutionelle Konsequenzen einer Erweiterung der Europäischen Union - Eine ökonomische Analyse der Entscheidungsverfahren im Ministerrat, BadenBaden.

Wirtschafts- und Sozialausschuß (1970): Anhörung des Wirtschafts- und Sozialausschusses vom 26.11.1969 zu den beiden Mitteilungen der Kommission an den Rat betreffend die Ersetzung der Finanzbeiträge der Mitgliedstaaten durch eigene Mittel sowie die Stärkung der Haushaltsbefugnisse des Europäischen Parlaments vorgeschlagenen Texten, in: Amtsblatt der Europäischen Gemeinschaften, Nr. C 19 vom 13.2.1970, S. 23-28.

Wisdorff, Eberhard (1997): In Amsterdam können keine Jubelgesänge intoniert werden, in: Handelsblatt, Donnerstag, 2. Oktober 1997, S. 3.

Wissenschaftlicher Beirat (1992): Gutachten zum Länderfinanzausgleich in der Bundesrepublik Deutschland - erstattet vom Wissenschaftlichen Beirat beim Bundesministerium der Finanzen, Schriftenreihe des BMF, Heft 47, Dezember, Bonn. 
Wissenschaftlicher Beirat (1994): Ordnungspolitische Orientierung für die Europäische Union, Gutachten des Wissenschaftlichen Beirats beim Bundesministerium für Wirtschaft, BMWi-Dokumentation, Nr. 356, Oktober, Bonn.

Wohlers, Eckhardt (1997): Relevanz von Schocks in der Europäischen Union - empirischer Befund, in: Otto G. Mayer/ Hans-Eckart Scharrer (Hrsg.): Schocks und Schockverarbeitung in der Europäischen Währungsunion, Baden-Baden, S. 79-113.

Wolter, Achim/ Hasse, Rolf H. (1997): Gemeinsame Beschäftigungspolitik - Überfällig oder überflüssig?, in: Wirtschaftsdienst, Heft 7, S. 386-389.

Zeitel, Gerhard (1970): Kommunale Finanzstruktur und gemeindliche Selbstverwaltung, in: Archiv für Kommunalwissenschaften, 9. Jg., S. 1-20.

Zimmermann, Horst (1977): Instrumente der Finanzpolitik, in: Fritz Neumark (Hrsg.): Handbuch der Finanzwissenschaft, Bd. I, 3. Aufl., Tübingen, S. 165-192.

Zimmermann, Horst (1983): Allgemeine Probleme und Methoden des Finanzausgleichs, in: Fritz Neumark (Hrsg.): Handbuch der Finanzwissenschaft, Bd. IV, 3. Aufl., Tübingen, S. 3-52.

Zimmermann, Horst (1996): Wohlfahrtsstaat zwischen Wachstum und Verteilung, München.

Zimmermann, Horst/ Henke, Klaus-Dirk (1994): Finanzwissenschaft - eine Einfuihrung in die Lehre von der öffentlichen Finanzwirtschaft, 7. Aufl., München. 


\section{FINANZWISSENSCHAFTLICHE SCHRIFTEN}

Band 1 Werner Steden: Finanzpolitik und Einkommensverteilung. Ein Wachstums- und Konjunkturmodell der Bundesrepublik Deutschland. 1979.

Band 2 Rainer Hagemann: Kommunale Finanzplanung im föderativen Staat. 1976.

Band 3 Klaus Scherer: Maßstäbe zur Beurteilung von konjunkturellen Wirkungen des öffentlichen Haushalts. 1977.

Band 4 Brita Steinbach: "Formula Flexibility" - Kritische Analyse und Vergleich mit diskretionärer Konjunkturpolitik. 1977.

Band 5 Hans-Georg Petersen: Personelle Einkommensbesteuerung und Inflation. Eine theoretisch-empirische Analyse der Lohn- und veranlagten Einkommensteuer in der Bundesrepublik Deutschland. 1977.

Band 6 Friedemann Tetsch: Raumwirkungen des Finanzsystems der Bundesrepublik Deutschland. Eine Untersuchung der Auswirkungen der Finanzreform von 1969 auf die Einnahmenposition der untergeordneten Gebietskörperschaften und ihrer regionalpolitischen Zieladäquanz. 1978.

Band 7 Wilhelm Pfähler: Normative Theorie der fiskalischen Besteuerung. Ein methodologischer und theoretischer Beitrag zur Integration der normativen Besteuerungstheorie in der Wohlfahrtstheorie. 1978.

Band 8 Wolfgang Wiegard: Optimale Schattenpreise und Produktionsprogramme für öffentliche Unternehmen. Second-Best Modelle im finanzwirtschaftlichen Staatsbereich. 1978.

Band 9 Hans P. Fischer: Die Finanzierung des Umweltschutzes im Rahmen einer rationalen Umweltpolitik. 1978.

Band 10 Rainer Paulenz: Der Einsatz finanzpolitischer Instrumente in der Forschungs- und Entwicklungspolitik. 1978.

Band 11 Hans-Joachim Hauser: Verteilungswirkungen der Staatsverschuldung. Eine kreislauftheoretische Inzidenzbetrachtung. 1979.

Band 12 Gunnar Schwarting: Kommunale Investitionen. Theoretische und empirische Untersuchungen der Bestimmungsgründe kommunaler Investitionstätigkeit in NordrheinWestfalen 1965-1972. 1979.

Band 13 Hans-Joachim Conrad: Stadt-Umland-Wanderung und Finanzwirtschaft der Kernstädte. Amerikanische Erfahrungen, grundsätzliche Zusammenhänge und eine Fallstudie für das Ballungsgebiet Frankfurt am Main. 1980.

Band 14 Cay Folkers: Vermögensverteilung und staatliche Aktivität. Zur Theorie distributiver Prozesse im Interventionsstaat. 1981.

Band 15 Helmut Fischer: US-amerikanische Exportförderung durch die DISC-Gesetzgebung. 1981.

Band 16 Günter Ott: Einkommensumverteilungen in der gesetzlichen Krankenversicherung. Eine quantitative Analyse. 1981.

Band 17 Johann Hermann von Oehsen: Optimale Besteuerung. (Optimal Taxation). 1982.

Band 18 Richard Kössler: Sozialversicherungsprinzip und Staatszuschüsse in der gesetzlichen Rentenversicherung. 1982.

Band 19 Hinrich Steffen: Zum Handlungs- und Entscheidungsspielraum der kommunalen Investitionspolitik in der Bundesrepublik Deutschland. 1983.

Band 20 Manfred Scheuer: Wirkungen einer Auslandsverschuldung des Staates bei flexiblen Wechselkursen. 1983. 
Band 21 Christian Schiller: Staatsausgaben und crowding-out-Effekte. Zur Effizienz einer Finanzpolitik keynesianischer Provenienz. 1983.

Band 22 Hannelore Weck: Schattenwirtschaft: Eine Möglichkeit zur Einschränkung der öffentlichen Verwaltung? Eine ökonomische Analyse. 1983.

Band 23 Wolfgang Schmitt: Steuern als Mittel der Einkommenspolitik. Eine Ergänzung der Stabilitätspolitik? 1984.

Band 24 Wolfgang Laux: Erhöhung staatswirtschaftlicher Effizienz durch budgetäre Selbstbeschränkung? Zur Idee einer verfassungsmäßig verankerten Ausgabengrenze. 1984.

Band 25 Brita Steinbach-van der Veen: Steuerinzidenz. Methodologische Grundlagen und empirisch-statistische Probleme von Länderstudien. 1985.

Band 26 Albert Peters: Ökonomische Kriterien für eine Aufgabenverteilung in der Marktwirtschaft. Eine deskriptive und normative Betrachtung für den Allokationsbereich. 1985.

Band 27 Achim Zeidler: Möglichkeiten zur Fortsetzung der Gemeindefinanzreform. Eine theoretische und empirische Analyse. 1985.

Band 28 Peter Bartsch: Zur Theorie der längerfristigen Wirkungen 'expansiver' Fiskalpolitik. Eine dynamische Analyse unter besonderer Berücksichtigung der staatlichen Budgetbeschränkung und ausgewählter Möglichkeiten der öffentlichen Defizitfinanzierung. 1986.

Band 29 Konrad Beiwinkel: Wehrgerechtigkeit als finanzpolitisches Verteilungsproblem. Möglichkeiten einer Kompensation von Wehrungerechtigkeit durch monetäre Transfers. 1986.

Band 30 Wolfgang Kitterer: Effizienz- und Verteilungswirkungen des Steuersystems. 1986.

Band 31 Heinz Dieter Hessler: Theorie und Politik der Personalsteuern. Eine Kritik ihrer Einkommens- und Vermögensbegriffe mit Blick auf die Leistungsfähigkeitstheorie. 1994.

Band 32 Wolfgang Scherf: Die beschäftigungspolitische und fiskalische Problematik der Arbeitgeberbeiträge zur Rentenversicherung. Eine Auseinandersetzung mit der Kritik an der lohnbezogenen Beitragsbemessung. 1987.

Band 33 Andreas Mästle: Die Steuerunion. Probleme der Harmonisierung spezifischer Gütersteuern. 1987.

Band 34 Günter Ott: Internationale Verteilungswirkungen im Finanzausgleich der Europäischen Gemeinschaften. 1987.

Band 35 Heinz Haller: Zur Frage der zweckmäßigen Gestalt gemeindlicher Steuern. Ein Diskussionsbeitrag zur Gemeindesteuerreform. 1987.

Band 36 Thomas Kuhn: Schlüsselzuweisungen und fiskalische Ungleichheit. Eine theoretische Analyse der Verteilung von Schlüsselzuweisungen an Kommunen. 1988.

Band 37 Walter Hahn: Steuerpolitische Willensbildungsprozesse in der Europäischen Gemeinschaft. Das Beispiel der Umsatzssteuer-Harmonisierung. 1988.

Band 38 Ulrike Hardt: Kommunale Finanzkraft. Die Problematik einer objektiven Bestimmung kommunaler Einnahmemöglichkeiten in der gemeindlichen Haushaltsplanung und im kommunalen Finanzausgleich. 1988.

Band 39 Jochen Michaelis: Optimale Finanzpolitik im Modell überlappender Generationen. 1989.

Band 40 Bernd Raffelhüschen: Anreizwirkungen der sozialen Alterssicherung. Eine dynamische Simulationsanalyse. 1989.

Band 41 Berend Diekmann: Die Anleihe- und Darlehenstransaktionen der Europäischen Gemeinschaften. 1990.

Band 42 Helmut Kaiser: Konsumnachfrage, Arbeitsangebot und optimale Haushaltsbesteuerung. Theoretische Ergebnisse und mikroökonometrische Simulation für die Bundesrepublik Deutschland. 1990. 
Band 43 Rüdiger von Kleist: Das Gramm-Rudman-Hollings-Gesetz. Ein gescheiterter Versuch der Haushaltskonsolidierung. 1991.

Band 44 Rolf Hagedorn: Steuerhinterziehung und Finanzpolitik. Ein theoretischer Beitrag unter besonderer Berücksichtigung der Hinterziehung von Zinserträgen. 1991.

Band 45 Cornelia S. Behrens: Intertemporale Verteilungswirkungen in der gesetzlichen Krankenversicherung der Bundesrepublik Deutschland. 1991.

Band 46 Peter Saile: Ein ökonomischer Ansatz der Theorie der intermediären Finanzgewalten Die Kirchen als Parafisci. 1992.

Band 47 Peter Gottfried: Die verdeckten Effizienzwirkungen der Umsatzsteuer. Eine empirische allgemeine Gleichgewichtsanalyse. 1992.

Band 48 Andreas Burger: Umweltorientierte Beschäftigungsprogramme. Eine Effizienzanalyse am Beispiel des "Sondervermögens Arbeit und Umwelt". 1992.

Band 49 Jeanette Malchow: Die Zuordnung verteilungspolitischer Kompetenzen in der Europäischen Gemeinschaft. Eine Untersuchung aufgrund einer Fortentwicklung der ökonomischen Theorie des Föderalismus. 1992.

Band 50 Barbara Seidel: Die Einbindung der Bundesrepublik Deutschland in die Europäischen Gemeinschaften als Problem des Finanzausgleichs. 1992.

Band 51 Ralph Wiechers: Markt und Macht im Rundfunk. Zur Stellung der öffentlich-rechtlichen Rundfunkanstalten im dualen Rundfunksystem der Bundesrepublik Deutschland. 1992.

Band 52 Klaus Eckhardt: Probleme einer Umweltpolitik mit Abgaben. 1993.

Band 53 Oliver Schwarzkopt: Die Problematik unterschiedlicher Körperschaftsteuersysteme innerhalb der EG. 1993.

Band 54 Thorsten Giersch: Bergson-Wohlfahrtsfunktion und normative Ökonomie. 1993.

Band 55 Li-Fang Chou: Selbstbeteiligung bei Arzneimitteln aus ordnungspolitischer Sicht. Das Beispiel der Bundesrepublik Deutschland. 1993.

Band 56 Harald Schlee: Einkommensteuerliche Behandlung von Transferzahlungen. Zur Neuordnung der Familienbesteuerung sowie der Besteuerung von Versicherungsleistungen und Sozialtransfers. 1994.

Band 57 Alexander Spermann: Kommunales Krisenmanagement. Reaktionen baden-württembergischer Stadtkreise auf steigende Sozialhilfekosten und Einnahmenausfälle (198092). 1993.

Band 58 Otto Roloff / Sibylle Brander / Ingo Barens / Claudia Wesselbaum: Direktinvestitionen und internationale Steuerkonkurrenz. 1994.

Band 59 Claudia Wesselbaum-Neugebauer: Internationale Steuerbelastungsvergleiche. 1994.

Band 60 Stephanie Miera: Kommunales Finanzsystem und Bevölkerungsentwicklung. Eine Analyse des kommunalen Finanzsystems vor dem Hintergrund der sich abzeichnenden Bevölkerungsentwicklung am Beispiel Niedersachsens unter besonderer Berücksichtigung des Landkreises Wolfenbüttel und seiner Gemeinden. 1994.

Band 61 Wolfgang Scherf: Die Bedeutung des kaldorianischen Verteilungsmechanismus für die gesamtwirtschaftlichen Wirkungen der staatlichen Neuverschuldung. 1994.

Band 62 Rainer Volk: Vergleich der Vergünstigungseffekte der verschiedenen investitionsfördernden Maßnahmen. 1994.

Band 63 Hans-Georg Napp: Kommunale Finanzautonomie und ihre Bedeutung für eine effiziente lokale Finanzwirtschaft. 1994. 2., unveränderte Auflage 1994.

Band 64 Bernd Rahmann / Uwe Steinborn / Günter Vornholz: Empirische Analyse der Autonomie lokaler Finanzwirtschaften in der Europäischen Gemeinschaft. 1994. 
Band 65 Carsten Kühl: Strategien zur Finanzierung der Altlastensanierung. 1994.

Band 66 Stephan Boll: Intergenerationale Umverteilungswirkungen der Fiskalpolitik in der Bundesrepublik Deutschland. Ein Ansatz mit Hilfe des Generational Accounting. 1994.

Band 67 Karl Justus Bernhard Neumärker: Finanzverfassung und Staatsgewalt in der Demokratie. Ein Beitrag zur konstitutionellen Finanztheorie. 1995.

Band 68 Christian Haslbeck: Zentrale versus dezentrale Internalisierung externer Effekte bei unvollständiger Information. 1995.

Band 69 Regina Müller: Horizontale oder vertikale Transfers zur Durchsetzung eines horizontalen Finanzausgleichs. 1995.

Band 70 Christian Hockenjos: Öffentliche Sportförderung in der Bundesrepublik Deutschland. Darstellung und finanztheoretische Analyse. 1995.

Band 71 Manfred Rosenstock: Die Kontrolle und Harmonisierung nationaler Beihilfen durch die Kommission der Europäischen Gemeinschaften. 1995.

Band 72 Christian Rüsch: Wohnungsbau- und Wohneigentumspolitik im Rahmen der Einkommensteuer. Eine Analyse unter steuersystematischen, verteilungspolitischen und fiskalischen Aspekten. 1996.

Band 73 Stephan Winters: Die kollektive Vorsorge für den Pflegefall im Alter. Eine Untersuchung am Beispiel der gesetzlichen Pflegeversicherung in den Niederlanden. 1996.

Band 74 Knut Blind: Allokationsineffizienzen auf Sicherheitsmärkten: Ursachen und Lösungsmöglichkeiten. Fallstudie: Informationssicherheit in Kommunikationssystemen. 1996.

Band 75 Barbara Petrick-Rump: Ökonomische Wirkungen von Steueramnestien. Untersuchung konkreter Erfahrungen ausgewählter Länder mit dem Einsatz von Steueramnestien anhand eines effizienten Steueramnestieprogramms. 1996.

Band 76 Georg Hirte: Effizienzwirkungen von Finanzausgleichsregelungen. Eine Empirische Allgemeine Gleichgewichtsanalyse für die Bundesrepublik Deutschland. 1996.

Band 77 Ulrike Kirchhoff: Die rheinland-pfälzischen Gemeinden im System des Finanzausgleichs. 1996.

Band 78 Kerstin Keil: Der soziale Mietwohnungsbau: Mängel und Alternativen. 1996.

Band 79 Bernhard Manzke: Kinderlastenausgleich versus verstärkte Einwanderung. Alternative Ansätze zur langfristigen Sicherung der Gesetzlichen Rentenversicherung. 1997.

Band 80 Hariolf M. Wenzler: Institutionenökonomik und öffentliche Finanzkontrolle. Eine Analyse am Beispiel der Europäischen Union. 1997.

Band 81 Joachim Nagel: Supply-Side Policy in den USA. Eine theoretische und empirische Analyse der angebotsorientierten Wirtschaftspolitik Reagans unter besonderer Berücksichtigung steuerlicher Aspekte. 1997.

Band 82 Heinz Lampert: Krise und Reform des Sozialstaates. 1997.

Band 83 Monika Hanswillemenke / Bernd Rahmann: Zwischen Reformen und Verantwortung für Vollbeschäftigung. Die Finanz- und Haushaltspolitik der sozial-liberalen Koalition von 1969 bis 1982.1997.

Band 84 Berthold Fürst: Die Maastrichter Budgetkriterien im Konflikt mit der Verschuldungsautonomie der deutschen Gebietskörperschaften. 1997.

Band 85 Burkhard Pahnke: Einkommensorientierte Förderung des sozialen Mietwohnungsbaues. Bestandsaufnahme und Kritik. 1998.

Band 86 Judith Safford: Staatsverschuldung im Vereinigten Königreich. Die öffentliche Verschuldung unter der Konservativen Regierung von 1979-1994. Ursachen und Auswirkungen. 1998. 
Band 87 Ralf Oberheide: Die Bekämpfung der Steuerumgehung. 1998.

Band 88 Achim Truger: Die neue Finanzwissenschaft zwischen Realitätsferne und Irrelevanz der Annahmen. Eine methodologische Analyse potentieller Verteidigungsstrategien der neuen Finanzwissenschaft gegen den Vorwurf der Realitätsferne ihres entscheidungstheoretischen Fundamentes. 1998.

Band 89 Karin Bickel: Familienbezogene Elemente im System der gesetzlichen Rentenversicherung. Unter besonderer Berücksichtigung von Ein-Eltern-Familien. 1999.

Band 90 Wolfgang Scherf: Schlüsselzuweisungen und Kreisumlage. Die Problematik der Finanzierung der Landkreise am Beispiel des kommunalen Finanzausgleichs von RheinlandPfalz. 1998.

Band 91 Sandra Ehmann: Familienpolitik in Frankreich und Deutschland - ein Vergleich. 1999.

Band 92 Hendrik Suermann: Einkommensteuerliche Behandlung von Währungsgewinnen und -verlusten. Eine finanzwissenschaftliche Analyse des Steuerrechts in den USA und in Deutschland. 1999.

Band 93 Rolf Bösinger: Die Neuordnung des bundesstaatlichen Finanzausgleichs 1995. Eine theoretische und empirische Analyse unter Berücksichtigung von allokationstheoretischen und polit-ökonomischen Gesichtspunkten. 1999.

Band 94 Ulrich Ermschel: Finanzwirtschaftliche Konsequenzen beim Übergang auf das Ursprungslandprinzip im Europäischen Binnenmarkt. Eine Untersuchung am Beispiel des unvollkommenen oligopolistischen Neufahrzeugmarktes. 1999.

Band 95 Ute Hansen: Überwälzte Leistungen der Administration. Eine empirische und theoretische Analyse. 2000.

Band 96 Hans-Werner Seiler: Zur Durchsetzung der Einmalbesteuerung deutscher Körperschaftsgewinne. Strategien zur Vermeidung der im deutschen Körperschaftsteuersystem angelegten Benachteiligung ausländischer Anteilseigner. Eine finanzwissenschaftliche Analyse. 2000.

Band 97 Steffen Meyer: Zwischenstaatliche Finanzzuweisungen im zusammenwachsenden Europa. Zur Gestaltung eines Finanzausgleichs für die Europäische Union. 2000. 
Steffen Meyer - 978-3-631-75269-2

Downloaded from PubFactory at 01/11/2019 06:28:10AM

via free access 


\section{Der Euro und die Folgen}

\section{Probleme und Perspektiven}

\section{Konzeption und Koordination: Alfons Lemper}

Frankfurt/M., Berlin, Bern, New York, Paris, Wien, 1998. 215 S. ISBN 3-631-34021-4 · br. DM 38.-*

Die Einführung des Euro zum 1.1.1999 bringt nicht nur eine Fülle schwieriger und kostspieliger technischer Probleme mit sich, an deren Bewältigung allseits gearbeitet wird, sondern auch eine Reihe von Konsequenzen, die auf den ersten Blick nicht in Erscheinung treten, die gleichwohl für die Beurteilung des Gesamtprojektes „Europäische Währungsunion" (EWU) äußerst wichtig sind. Sie betreffen neben der prospektiven Stabilität der künftigen Währung und den Konsequenzen für die Kapitalanleger etwa Fragen nach den verbleibenden wirtschaftlichen Gestaltungsspielräumen für nationale Regierungen oder Tarifpartner, die Wahrscheinlichkeit eines innergemeinschaftlichen Finanzausgleichs oder Folgen für die Sozialstandards. Tiefgreifende Probleme ergeben sich auch für künftige Unternehmensmärkte. Die Lösung dieser - großenteils politischen - Probleme auf längere Sicht dürften für den Erfolg des Projektes EWU entscheidender werden als die bank- und bilanztechnischen Probleme, die derzeit meist im Vordergrund stehen.

Aus dem Inhalt: Prospektive Stabilität des Euro und seine internationale Position - Eingeschränkte Spielräume nationaler Wirtschaftspolitik - Finanzausgleich und Sozialstandards · Konsequenzen für Unternehmensmärkte

Frankfurt/M - Berlin - Bern - New York - Paris - Wien

Auslieferung: Verlag Peter Lang AG

Jupiterstr. 15, CH-3000 Bern 15

Telefax (004131) 9402131

*inklusive Mehrwertsteuer

Preisänderungen vorbehalten 
Steffen Meyer - 978-3-631-75269-2

Downloaded from PubFactory at 01/11/2019 06:28:10AM

via free access 